Bianca-Jeanette Schröder

Bildung und Briefe im 6. Jahrhundert 


\section{Millennium-Studien}

zu Kultur und Geschichte des ersten Jahrtausends n. Chr.

\section{Millennium Studies}

in the culture and history of the first millennium C.E.

Herausgegeben von / Edited by

Wolfram Brandes, Alexander Demandt, Helmut Krasser,

Hartmut Leppin, Peter von Möllendorff

Band 15

Walter de Gruyter · Berlin · New York 


\title{
Bildung und Briefe im 6. Jahrhundert
}

Studien zum Mailänder Diakon

Magnus Felix Ennodius

\author{
von \\ Bianca-Jeanette Schröder
}

Walter de Gruyter · Berlin · New York 
Diese Publikation wurde im Rahmen des Fördervorhabens 16TOA021 - Reihentransformation für die Altertumswissenschaften („Millennium-Studien“) mit Mitteln des Bundesministeriums für Bildung und Forschung im Open Access bereitgestellt. Das Fördervorhaben wird in Kooperation mit dem DFG-geförderten Fachinformationsdienst Altertumswissenschaften Propylaeum an der Bayerischen Staatsbibliothek durchgeführt.

\section{(cc) BY-NC-ND}

Dieses Werk ist lizenziert unter der Creative Commons Attribution-NonCommercial-NoDerivatives 4.0 International Lizenz. Weitere Informationen finden Sie unter http://creativecommons.org/licenses/by-nc-nd/4.0/.

Die Bedingungen der Creative-Commons-Lizenz gelten nur für Originalmaterial. Die Wiederverwenung von Material aus anderen Quellen (gekennzeichnet mit Quellenangabe) wie z.B. Schaubilder, Abbildungen, Fotos und Textauszüge erfordert ggf. weitere Nutzungsgenehmigungen durch den jeweiligen Rechteinhaber.

(0) Gedruckt auf säurefreiem Papier, das die US-ANSI-Norm über Haltbarkeit erfüllt.

ISBN 978-3-11-019955-0

ISSN 1862-1139

Bibliografische Information der Deutschen Nationalbibliothek

Die Deutsche Nationalbibliothek verzeichnet diese Publikation in der Deutschen Nationalbibliografie; detaillierte bibliografische Daten sind im Internet über http://dnb.d-nb.de abrufbar.

(C) Copyright 2007 by Walter de Gruyter GmbH \& Co. KG, 10785 Berlin

Dieses Werk einschließlich aller seiner Teile ist urheberrechtlich geschützt. Jede Verwertung außerhalb der engen Grenzen des Urheberrechtsgesetzes ist ohne Zustimmung des Verlages unzulässig und strafbar. Das gilt insbesondere für Vervielfältigungen, Übersetzungen, Mikroverfilmungen und die Einspeicherung und Verarbeitung in elektronischen Systemen.

\section{Printed in Germany}

Umschlaggestaltung: Christopher Schneider, Berlin 
Catharinae et Marco

Collegis Optimis 



\section{Vorbemerkung}

Für vielfältige Unterstützung bei der Beschäftigung mit Ennodius möchte ich auch an dieser Stelle von Herzen danken:

In Gesprächen mit Mitarbeitern am Thesaurus linguae Latinae entstand die Idee zu einem Buch über Ennodius. Joachim Dingel hat die Studie von Beginn an mit zuverlässigem Interesse begleitet und immer wieder guten Rat gegeben. Wilfried Stroh gab ungeachtet seiner Skepsis gegenüber einem so unciceronianischen Autor viele Anregungen durch scharfsinnige philologische Beobachtungen und kritische Fragen. Claudia Wiener, Hartmut Leppin und Rudolf Schieffer haben in ihren Gutachten zu der Habilitationsschrift hilfreiche Kommentare und Hinweise beigesteuert.

Die Vorträge auf den drei Ennodius-Konferenzen bisher und besonders die sich anschließenden Diskussionen mit anderen hochmotivierten »Ennodiani« gaben der Arbeit wertvolle Impulse.

Constanze Piacentini hat das Manuskript der Habilitationsschrift geduldig und sorgfältig korrigiert. - Die Kommunikation mit den Herausgebern der Reihe und mit den Mitarbeiterinnen des Verlags war angenehm unkompliziert.

Ohne die - nicht nur epistolographischen - Gespräche mit Jennifer Ebbeler, Foteini Kolovou, Katharina Luchner und Markus Dubischar hätte mir die Arbeit nur halb so viel Freude bereitet. Meinem Mann Jens-Peter Schröder verdanke ich nicht nur die Vorbereitung des Buches für den Druck. 



\section{Inhalt}

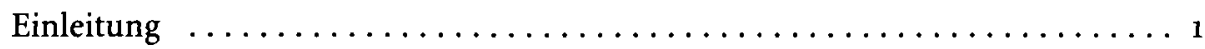

Teil I: Cultura sermonis $\ldots \ldots \ldots \ldots \ldots \ldots \ldots \ldots \ldots \ldots \ldots \ldots \ldots$

1. Krankheit und Gelübde des Diakons: Das »Eucharisticum» $(438) \ldots \ldots \ldots \ldots 11$

2. Einführung zu Leben und Werk $\ldots \ldots \ldots \ldots \ldots \ldots \ldots \ldots \ldots \ldots \ldots$

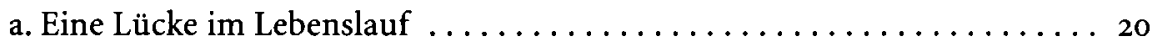

b. Die erhaltenen Werke $\ldots \ldots \ldots \ldots \ldots \ldots \ldots \ldots \ldots \ldots \ldots \ldots$

"Dictiones Sacrae« 36 - Prosa-Praefatio mit Gedicht 39-»Dictiones

Scholasticae« 40 - Briefe 41 - $»$ Praeceptum de cellulanis $«, »$ Dictio de

haereticis et synodo" 43 - Benedictiones cerei 43 - "Carmina minora" 44

- "Libellus de synodo" 45 - Vitae sanctorum 46 - „Dictiones Ethicae"

und "Controversiae" 47-Reisegedichte 48-Panegyricus dictus

clementissimo regi Theoderico 49 - Hymnen 50 - Epithalamium dictum

Maximo v.s. 50 - "Paraenesis didascalica" 52

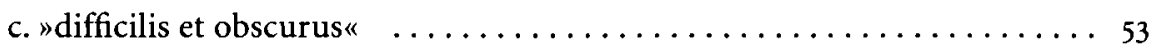

Mixtura verborum 56 -Ambiguitas 58 -Copiosa loquacitas 59

- Brevitas 60

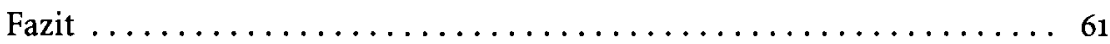

3. Der Diakon und sein >Vorleben « als Redner und Dichter (und Lehrer ?) . . . 63

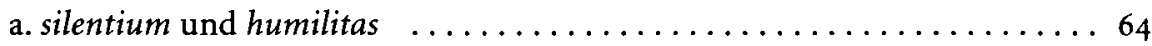

b.1 Hinweise in Briefen . . . . . . . . . . . . . . . . . . . . . . 68

b. 2 Hinweise in den $"$ Dictiones Scholasticae» $\ldots \ldots \ldots \ldots \ldots \ldots \ldots 71$

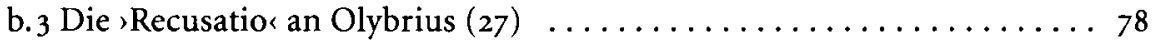

c. Fazit: Die Probleme des Diakons $\ldots \ldots \ldots \ldots \ldots \ldots \ldots \ldots \ldots$

4. Der Diakon und die studia liberalia $\ldots \ldots \ldots \ldots \ldots \ldots \ldots \ldots \ldots \ldots$

a. Weltliche und christliche Bildung $\ldots \ldots \ldots \ldots \ldots \ldots \ldots \ldots$

b. Bedeutung der Bildung für den Adel $\ldots \ldots \ldots \ldots \ldots \ldots \ldots \ldots$

b. 1 sorigo et studiar $\ldots \ldots \ldots \ldots \ldots \ldots \ldots \ldots \ldots \ldots \ldots \ldots \ldots \ldots \ldots$

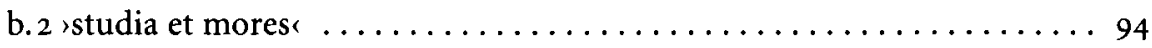

c. Die Macht der Sprache - Sprache und Macht $\ldots \ldots \ldots \ldots \ldots \ldots$ 
c. 1 Die Ars rhetorica in der $»$ Paraenesis $* \ldots \ldots \ldots \ldots \ldots \ldots \ldots \ldots . \ldots 9$

c. 2 Die Macht des Redners $\ldots \ldots \ldots \ldots \ldots \ldots \ldots \ldots \ldots \ldots \ldots \ldots \ldots \ldots$

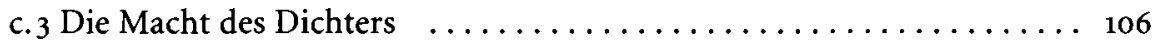

d. Ennodius' Rolle(n) gegenüber den jungen Adligen $\ldots \ldots \ldots \ldots \ldots \ldots 111$

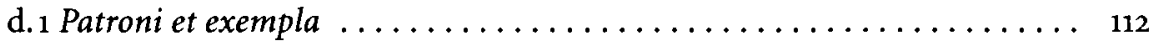

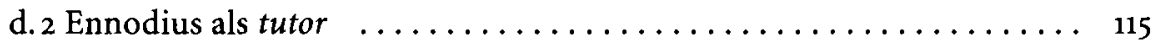

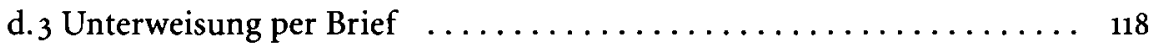

Strenge Mahnungen 119 - Lob aus Rücksicht 121 - Ermahnungen und Lob

für Avienus 122 - Briefe an Parthenius 124

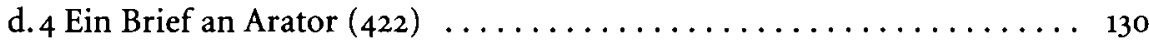

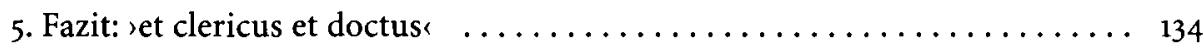

Teil II: Testimonium diligentiae $\ldots \ldots \ldots \ldots \ldots \ldots \ldots \ldots \ldots \ldots \ldots \ldots \ldots \ldots$

1. Allgemein zur Gattung $\gg$ Brief، $\ldots \ldots \ldots \ldots \ldots \ldots \ldots \ldots \ldots \ldots \ldots \ldots$

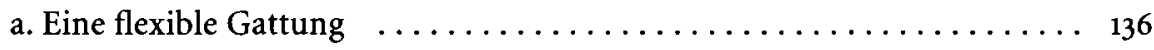

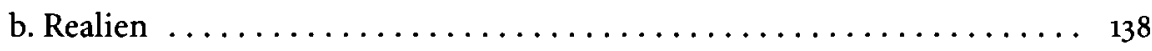

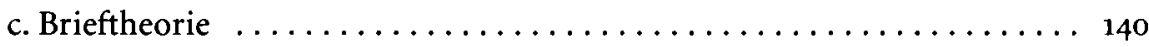

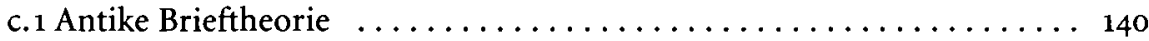

c. 2 Forschungsstand zur Epistolographie $\ldots \ldots \ldots \ldots \ldots \ldots \ldots \ldots \ldots$

c. 3 Zur Kategorisierung von Briefen $\ldots \ldots \ldots \ldots \ldots \ldots \ldots \ldots \ldots \ldots \ldots$

d. Die gesellschaftliche Funktion von Briefen: Amicitia und Performance . 150

e. Die zu vergleichenden Epistolographen . . . . . . . . . . . . 157

Symmachus 158 - Hieronymus, Ambrosius, Augustin, Paulinus von Nola 160

- Sidonius Apollinaris 162 - Ruricius von Limoges 165 -Cassiodor 165

2. Charakteristika der Briefe des Ennodius $\ldots \ldots \ldots \ldots \ldots \ldots \ldots \ldots \ldots$

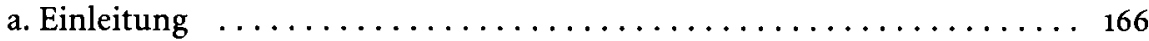

Eine Entschuldigung (24) 167 - Eine Bitte (139) 170

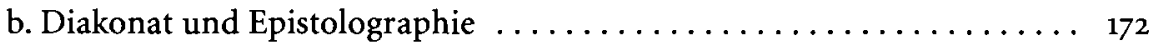

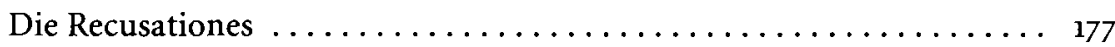

Olybrius (13) 178 - Mascator (95) 181 - Florianus (20; 21) 184

- Pomerius (39) 189 - Hormisda (317) 195 - Fazit 196

c. Eine Nebenrolle: Der freundliche Diakon . . . . . . . . . . . . . . 197

d. Die Hauptrolle: Der unzufriedene, fordernde Freund (und Verwandte) 202

d. $1>$ Korrespondenz und Freundschaft $<\ldots \ldots \ldots \ldots \ldots \ldots \ldots \ldots \ldots 2$

d. 1.1 Funktionen und Inhalte von Briefen . . . . . . . . . . . . . . . 204

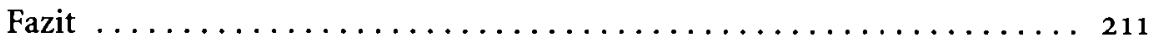


d.1.2 Grundsätze des Verhaltens im Vergleich mit Symmachus

indulgentia / urbanitas - querellae / inportunitas 213 - >Briefe und Freund-

schaft bei Symmachus 214 - BBriefe und Freundschaft bei Ennodius 217

- Ärger verschweigen - beneficium querellarum 222 - inpudentia -

inportunitas 224-urbanitas - sinceritas 226 - modestia-fiducia sui 231

- Freud und Leid 234-Zur Symmachus-Rezeption bei Ennodius 245

d.1.3 Die 'Topoi-Cluster

Prooemien in Briefen 254 - Sentenzen in Briefen 255 - Der Kanzleistil 256

- Die Funktion der Praefatio bei Ennodius 258 - Verwendung von Konnektoren

259 - Begründung des eigenen Verhaltens 260 - Erwartungen an den Adressaten

262 - Kritik am Adressaten und Aufforderung zur Besserung 263-Fazit 264

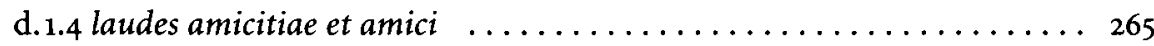

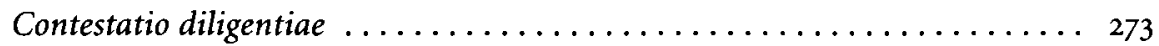

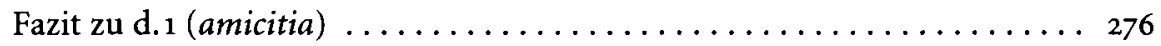

d.2 Propositum .......................... 277

Fazit: Bedeutung von Briefen $\ldots \ldots \ldots \ldots \ldots \ldots \ldots \ldots \ldots \ldots \ldots \ldots \ldots \ldots \ldots$

3. Gestaltung bestimmter Briefe:

`Kontaktpflege`, Glückwünsche, Empfehlungen $\ldots \ldots \ldots \ldots \ldots \ldots \ldots \ldots$

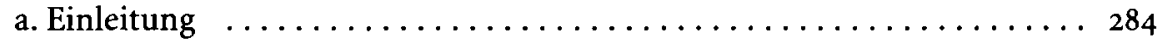

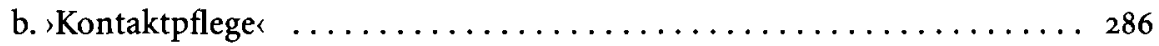

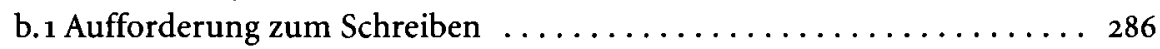

b. 2 Dank für erhaltene Briefe . . . . . . . . . . . . . . . . 294

Dank für Briefe von Geistlichen 295-Dank an weltliche Adressaten 299

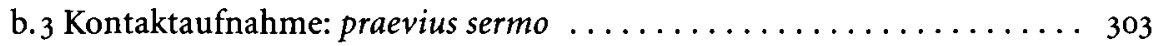

,Erster Brief^ohne vorherige Bekanntschaft 305- $>$ Erster Brief $\triangleleft$ nach

vorangehendem Kontakt $310-$, Erster Brief`auf Anforderung 314

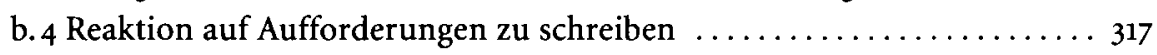

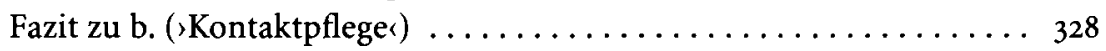

c. Glückwunschschreiben . . . . . . . . . . . . . . . . . . . . 329

c. 1 Vorwurfsvolle Glückwunschschreiben $\ldots \ldots \ldots \ldots \ldots \ldots \ldots \ldots \ldots \ldots$

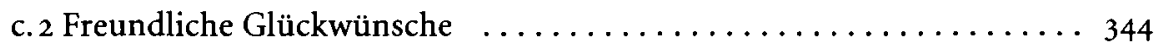

Fazit zu c. (Glückwunschschreiben) $\ldots \ldots \ldots \ldots \ldots \ldots \ldots \ldots \ldots \ldots \ldots \ldots \ldots \ldots$

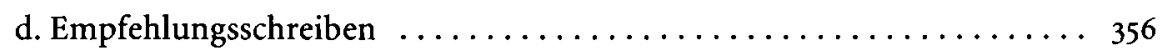

d. 1 Zeugnis für das Verhältnis zwischen Empfehlendem und Adressat . . . 361

d. 2 Empfehlung nach langem Schweigen $\ldots \ldots \ldots \ldots \ldots \ldots \ldots \ldots \ldots$

Fazit zu d. (Empfehlungsschreiben) $\ldots \ldots \ldots \ldots \ldots \ldots \ldots \ldots \ldots \ldots \ldots \ldots \ldots \ldots \ldots$

Zusammenfassung: Ars mihi regna dedit $\ldots \ldots \ldots \ldots \ldots \ldots \ldots \ldots \ldots \ldots$

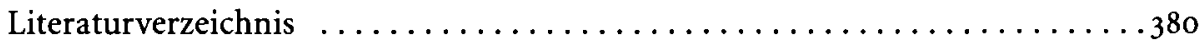

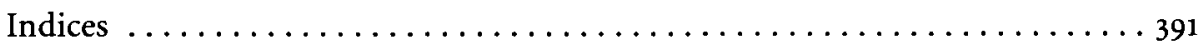





\section{Einleitung}

Ennodius, ein etwas älterer Zeitgenosse des Boethius und des Cassiodor, wurde 473/474 in Gallien geboren; zur Zeit der Kämpfe zwischen Odoaker und Theoderich und danach lebte er in Norditalien. Ein Großteil seines Lebens fiel also in die Zeit der Herrschaft des Ostgoten Theoderich, eine Epoche, die wegen des kulturellen Aufblühens, das sich an den (Wiederauf-) Bauprojekten von öffentlichen Gebäuden ebenso ablesen lässt wie an den literarischen Werken des Boethius, Cassiodor, und - in deren Schatten - des Ennodius, ein »Goldenes Zeitalter« genannt wird (z.B. ENssLIN 1959, 237; O'DONNELl 1979, 8; MARKus 1997, 34), in dem sich aufgrund der vielversprechenden Ruhe "Optimismus « verbreiten konnte (O'Donnell 1979, 5, 54, 84f.). Allerdings wird sich im Folgenden zeigen, dass Ennodius, anders als Cassiodor, keineswegs durchweg den Eindruck verbreitet, dass er in einem »Goldenen Zeitalter « lebte.

Ennodius erhielt eine profunde traditionelle rhetorische Ausbildung und betätigte sich, was bisher nicht erkannt wurde, zunächst als (Gelegenheits-) Redner und Dichter, vielleicht auch als Lehrer (Kapitel I 3). Spätestens 494 gehörte er zum Klerus des Bischofs Epiphanius in Ticinum (Pavia). Dann (nach 495, auf jeden Fall vor 499) wechselte er in den Klerus des Bischofs Laurentius in Mailand, zu dessen Diakon er 501/502 geweiht wurde. Spätestens 513 wurde Ennodius Bischof von Pavia. Zweimal, 515 und 517, ging er als Gesandter des Bischofs von Rom Hormisda nach Konstantinopel. Ennodius starb 521; sein Epitaph befindet sich (etwas versteckt) in S. Michele in Pavia. Im Mittelalter wurde er als Heiliger verehrt und als Autorität zitiert. Kirchenhistorikern ist Ennodius ein Begriff als einer der Verfechter des Primates des Papstes, Historiker der Epoche kennen ihn als Verfasser eines Panegyricus für Theoderich, des wohl bekanntesten Werkes des insgesamt unbekannten, weder sprachlich noch gedanklich leicht zugänglichen, noch wenig erschlossenen und allgemein wenig geschätzten Autors. ' (Die Biographie wird in Kapitel I 2.a genauer ausgeführt.)

Diese Untersuchung widmet sich insbesondere den Briefen des Ennodius (Teil II) und Details seiner Biographie (Teil I), soweit diese helfen können, sich einem Verständnis des Inhalts seiner Schriften zu nähern. Zwar entwerfen die Briefe nicht im

Siehe etwa Funrmann $\left({ }^{2} 1995,334\right):$ " [... er stellt sich dem heutigen Betrachter als ein ebenso seichter wie eitler Literat dar, der den Dünkel seines Berufsstandes mit dem Dünkel seiner Schicht verband. Er war Modeschriftsteller, Autor eines bunten Vielerlei; seine Werke bekunden zum Teil nichts als inhaltslose Aufgedunsenheit und zum Teil eine dünne Mischung von Gedanken, die auf Bekenntnisse zu einem klischeehaften Bildungsideal hinauslaufen sowie auf ein Christentum, das zu einigen wenigen Phrasen verkümmert ist.« 
entferntesten ein anschauliches Bild der Zeit, sie entsprechen nicht einem Tagebuch, aber sie sind auch nicht inhaltsleer, wie dies vielfach in der Forschungsliteratur zu lesen ist. Sie sind ein interessantes Dokument für den Stand der Bildung und für die Bedeutung von brieflicher Kommunikation am Anfang des 6.Jh., indem sie zeigen, wie sich Ennodius als Diakon - und dieses Amt nimmt entgegen der communis opinio entscheidenden Einfluss auf die Briefe - in seiner Korrespondenz gegenüber verschiedenen Adressaten präsentiert, zu denen nicht nur Verwandte wie Schwestern und Neffen, sondern auch eine große Anzahl wichtiger Persönlichkeiten in Kirche und Staat wie Papst, Bischöfe und Konsuln oder der Praefectus Praetorio gehören. Wenn sich auch die Frage danach, 'was in einem Brief mitgeteilt wird, zumeist knapp beantworten lässt, so verdient die Frage nach dem >wie` um so mehr Aufmerksamkeit. Der ehemalige Redner und Dichter zeigt sich in seiner Korrespondenz sehr wandlungsfähig, je nach Situation und seinem Verhältnis zum Adressaten bzw. zur Adressatin: von demütig-fromm über gütig-freundlich und klagend-vorwurfsvoll bis hin $\mathrm{zu}$ anspruchsvoll-selbstbewusst und fordernd (Kap. II 2. $\mathrm{c}$ und d).

Dass sich durch eine gründliche Lektüre der Texte etliche pauschale (Vor-) Urteile revidieren lassen, haben Ennodius' Werke mit der Mehrzahl der Werke der Spätantike gemeinsam, die erst allmählich einer Neubetrachtung - und das heißt oft: einer ersten gründlichen wissenschaftlichen Untersuchung - unterzogen werden. $\mathrm{Zu}$ vielen negativen Urteilen über Ennodius hat außer den allgemeinen Vorurteilen gegenüber Inhalt, Sprache und Stil spätantiker lateinischer Texte häufig offenbar nicht zuletzt die Tatsache geführt, dass nur einzelne Werke betrachtet oder einzelne Stellen überinterpretiert und überbewertet wurden und viele Teile des relativ umfangreichen Werkes überhaupt nicht in den Blick kamen. Die wenigen Ausschnitte aus seinem Werk, die beachtet wurden, sind oft nicht richtig gedeutet worden; neben vielen kleineren lassen sich auch manche erhebliche Missverständnisse der Forschung aufzeigen, so z.B. hinsichtlich des »Eucharisticum «, in dem Ennodius über einige Ereignisse in seinem Leben berichtet (siehe Kapitel I 1), hinsichtlich seines Briefes an Caesarius von Arles nach dessen >Begegnung $>$ mit Theoderich (siehe unten 352) oder auch hinsichtlich seines Briefes an Pomerius, der als Lehrer des Caesarius von Arles bekannt ist (siehe unten 189). Nicht zuletzt mögen auch Vorurteile über den Inhalt, d.h. über die vermeintliche Inhaltslosigkeit seiner Briefe, dazu geführt haben, dass eine Aussage gar nicht erst gesucht und daher auch nicht wahrgenommen wurde; folgende Zitate mögen die communis opinio illustrieren: "Kunst, unaufhörlich zu reden, ohne etwas zu sagen " (FonTAINE 1962, 416), "l'ornatus prevale sulla res" (NAVARRA, 1972, 465), "Seine Werke sind stilistisch hochgeschraubt und manieriert, inhaltlich aber aussagearm und matt" (RoHR 1995, 15).

Die überlieferten Werke, die sämtlich aus der Zeit seines Diakonats stammen, also bevor er Bischof wurde, füllen einen Band des Corpus Scriptorum Ecclesiasticorum Latinorum (Bd. 6, Hartel 1882) bzw. der Monumenta Germaniae Historica (Auct. Ant. 7, Vogel 1885). Die ca. 300 Briefe machen vom Umfang her etwas weniger als 
die Hälfte des äußerst vielseitigen Werkes aus, das so verschiedene Gattungen wie Brief, Epigramm, christlicher Hymnus, Heiligenvita, Streitschrift, traditionelle Schuldeklamation, neckisches Epithalamium, Reisegedicht, Panegyricus u.a. umfasst. (Die Werke werden in Kapitel I 2 b vorgestellt.)

Sprache und Stil der Werke haben häufig (durchaus berechtigt) Anlass zu Klagen über die Schwierigkeit gegeben; stets zitiert wird in diesem Zusammenhang eine Äußerung Arnulfs von Lisieux (12.Jh.) über den »sermo tenebrosus «. Ausgehend von Quintilians Bemerkungen zur obscuritas lässt sich zeigen, dass Ennodius offenbar ganz gezielt so formuliert, dass ein sermo obscurus entsteht. Daher ist der bisherigen Forschungsmeinung zu widersprechen, dass Ennodius im Stil des Sidonius Apollinaris schreibe (Kapitel I 2c).

Die Werke des Ennodius insgesamt werden bisher ganz überwiegend als historische Quellen genutzt, nicht nur für die Biographie des Ennodius selbst, sondern besonders der Panegyricus für Theoderich und die Vita des Bischofs von Pavia Epiphanius für die Geschichte der Ostgotenzeit, beide Heiligenviten für Aspekte des Mönchtums und kirchlicher Ämter, der Libellus pro synodo für die Kirchengeschichte (speziell für die Frage der Herausbildung des Primates des Bischofs von Rom). Die Briefe sind angesichts des zahlreichen und prominenten Adressatenkreises, zu dem u.a. Boethius, Papst Symmachus, der Diakon und nachmalige Papst Hormisda und Caesarius von Arles gehören, besonders für die Prosopographie wichtig (für manche Adressaten ist Ennodius die einzige Quelle oder die zweite außer Cassiodor); von den 32 namentlich bekannten Inhabern der höchsten Ämter (Praefectus praetorio, Praefectus urbi, Quaestor sacri palatii, Magister officiorum, Comes rerum privatarum, Comes sacrarum largitionum) zwischen 500 und 525 hat Ennodius mit 22 korrespondiert (BARTLETT 2001, 205).

Nach der umfangreichen dreibändigen Biographie von MAGANI (1886) ${ }^{2}$ brachten Untersuchungen zur Chronologie der Werke, besonders von Hasensta B (1890), Vogel (1898) und Sundwall (1919), große Fortschritte. Die erste neuere grundlegende Arbeit war der RAC-Artikel von Fontaine (1962). Nachdem aus Anlass des 1500. Geburtstages in den 1970er Jahren einige Publikationen erschienen waren, steigerte sich in den letzten Jahren das Interesse an Ennodius zusehends. Das erste "Ereignis« war die Monographie zum Panegyricus für Theoderich mit grundlegender Einleitung, Neuedition, deutscher Übersetzung und Erläuterungen von Christian Rонr (1995). Fünf Jahre später erschien die Monographie »Magnus Felix Ennodius. A gentleman of the Church « von Stefanie Kennell (2000); sie stellt viele Werke vor unter Hauptthemen wie Leben, Bildung/Literatur, Umwelt (Natur, Kultur, Kunst),

2 Da die Ausgabe von Vogel kurz vor Beendigung von MAGanis Arbeiten erschien, konnte er sich nicht darauf stützen, sie aber im letzten Moment vor der Drucklegung noch kommentieren (siehe besonders seine Bemerkungen zu VoGEL in Bd. 1,126; 183-194). 
Familie/Freunde, religiöse Inhalte; sie beobachtet besonders, welche Gedanken und Motive innerhalb verschiedener Gattungen und Situationen erscheinen. In den letzten Jahren entstanden außerdem gründliche philologische Einzelkommentare: kommentiert und jeweils mit einer Einleitung und einer italienischen Übersetzung versehen sind nun der Panegyricus (Simona Rota 2002), die Carmina 1,7 und 1,8 (Gianluca VANDONE 2004, unter dem Titel "Appunti su una poetica tardoantica«), das zweite Buch der Carmina (Daniele DI RIENzo 2005). Hinzuweisen ist außerdem auf die Forschungsberichte von CARINI (1987, zum Zeitraum 1960-1983) und Di Rienzo (2004, für 1983-2003). Das wachsende Interesse spiegelt sich auch in den sehr kommunikativen und arbeitsintensiven "Giornate Ennodiane«, die im März 2000 in Pavia, im Oktober 2001 in Neapel und im November 2004 wiederum in Pavia stattgefunden haben und deren Erträge in den Kongressbänden greifbar sind (hrgg. GASTI 2001, D'ANGELO 2003, GASTI 2006).

MAGANI (1886) hat in seiner Biographie die Briefe ausführlich berücksichtigt; allerdings lässt er die Texte, von denen er weite Passagen übersetzt, überwiegend selbst sprechen oder schmückt sie mit Kommentaren wie z.B. "Anima bella d'Ennodio e cuor generoso! pieno del dolce e nobile sentimento della gratitudine" (Bd. 1,106). Sundwall (1919) erwähnt in seiner Studie fast alle einzelnen Briefe unter der Perspektive, ob sie Hinweise zur Chronologie bieten. Auch Kennell (2000) illustriert ihre Monographie mit vielen Zitaten aus den Briefen. Allerdings neigt Kennell (wie zuvor auch MaGANI) sehr dazu, vom Werk auf das Leben zu schließen, z.B.: »Two principles ultimately governed the way Ennodius composed his works and conducted his life. The first is the preeminence of friendship [...]. The other principle $[\ldots]$ is that appropriateness is paramount, governing both diction and behavior «; "this reading will represent an attempt to discover the condition and evolution of his mind $[\ldots]$ « $(2000,20 ; 22)$. Wie die folgende Studie zeigen wird, entdeckt meine Lektüre allenfalls einen Autor, der Freude an der Sprache und am Schreiben hat und seine rhetorische Wendigkeit dazu nutzt, »the condition of his mind « in möglichst wenigen Aspekten preiszugeben, und der im Gegenteil besonders darin brilliert, zu verschiedenen Adressaten in verschiedenen Situationen in verschiedenen Rollen zu sprechen.

Nur wenige Forschungsbeiträge widmen sich speziell den Briefen; zu nennen sind hier Gioanni (2001) und Kennell (2003). Da die Briefe bisher durch keinen Kommentar erschlossen sind und lediglich 54 Briefe (d.h. die ersten beiden Briefbücher nach der Einteilung von SiRmond und HARTEL) in einer französischen Ubersetzung (LÉGLISE 1906; an einer neuen französischen Übersetzung arbeitet Stéphane Gioanni, der erste Band mit den ersten beiden Briefbüchern ist soeben erschienen) und Teile von Briefen innerhalb von Maganis Abhandlung in italienischer Übersetzung vorliegen, erschien es als vordringliche Aufgabe, zunächst durch eine Monographie den Zugang zu den Briefen zu erleichtern, indem Fragen der Biographie (Teil I) und der Gestaltung der Briefe in Hinsicht auf die Gattung (Teil II) behandelt werden. 
Im Zusammenhang mit der Biographie des Ennodius war das Problem der Chronologie der überlieferten Werke bisher einer der zentralen Aspekte der Forschung; dabei ergab sich, dass die Werke bis auf ganz wenige Ausnahmen in chronologischer Ordnung, in der Reihenfolge ihres Entstehens bzw. so, wie sie Ennodius nacheinander in sein Kopialbuch eingetragen hat, überliefert sind. Nun gehören die erhaltenen Werke nicht nur ganz verschiedenen Gattungen an und zeigen entsprechend diesen verschiedenen Gattungen auch bald profanen, bald religiösen, bald »neutralen « Charakter, sondern sie sind außerdem noch in buntem Neben- bzw. Durcheinander und nicht nach Gattungen geordnet überliefert. Die ältere Forschung, die dem Nachweis, dass der "Unordnung « der Gattungen in den Handschriften eine weitgehend chronologische Ordnung entspricht, vorausging, gab daher die Werke nach Gattungen geordnet heraus und neigte dazu, die Werke profanen Inhalts der Lebensphase vor dem Eintritt in den Klerikerstand zuzuordnen (besonders deutlich bei MAGANI).

Durch die Erkenntnis, dass die Werke in chronologischer Anordnung überliefert sind, ist die kanonische Heiligkeit des Ennodius fast völlig in Vergessenheit geraten. Das zeitliche Nebeneinander von Profanem und Religiösem, »die Leichtigkeit, mit der sich hier Profanes mit Religiösem vermischt « (FonTaINe 1962, 400), trifft in der Forschung ganz überwiegend auf Verwunderung. Die Existenz heidnisch-antiker Elemente, z.B. der Epigramme über Pasiphae und den Stier oder über die Kuh des Myron, hat erstaunte Aufmerksamkeit gefunden und wiederholt zu der Bemerkung geführt, dass die Werke des Ennodius es sich bis auf wenige Ausnahmen nicht anmerken ließen, dass sie von einem Diakon verfasst worden seien; Zweifel an der Tiefe seines christlichen Glaubens wurden laut. Offenbar erwartet die Forschung von einem Kleriker nur Werke eines bestimmten Inhalts und Charakters - man fühlt sich erinnert an die Enttäuschung moderner Leser über den Heiden Symmachus, der es "versäumt « habe, in seinen Briefen über den »letzten Kampf des Heidentums« zu berichten. Die Erwartungshaltung heutiger Leser, die Vorstellung, was die Autoren hätten schreiben können, worüber sie in ihren Briefen hätten berichten sollen - weil es die modernen Leser interessiert -, bestimmt denn auch das Urteil über die Briefe, wenn sie diese Erwartung nicht erfüllen.

Zwar sollte man wohl lieber darauf verzichten, anhand der Schriften die Tiefe von Ennodius' Glauben auszuloten. Dennoch kann die Beachtung der Tatsache, dass die Werke in ihrer Vielfalt von einem Diakon stammen, zu wichtigen Ergebnissen führen. Denn aus eindeutigen, von der Forschung aber bisher übersehenen Bemerkungen in Briefen und in den "Dictiones Scholasticae (Reden bei schulischen Anlässen wie z.B. der Einführung neuer Schüler) geht hervor, dass Ennodius sich eine Zeitlang intensiv mit Redekunst und Dichtung beschäftigt und sein Können wahrscheinlich auch in der einen oder anderen Weise an Jüngere weitergegeben, als Diakon aber seine literarische Tätigkeit zum großen Teil aufgegeben hat (Kapitel I 3). Mit diesem ,Vorleben c lässt sich erklären, dass Ennodius sich als Diakon häufig über die Bedeutung der traditionellen sprachlichen Bildung für den ordo amplissimus, die 
senatorische Oberschicht ${ }^{3}$, äußert (Kapitel I $4 \mathrm{a}-\mathrm{c}$ ) und sich um die Bildung junger Adliger kümmert (wenn auch sicher nicht in der institutionalisierten Weise als Lehrer; Kapitel I 4d). Eine Betrachtung seiner frühen beruflichen Laufbahn (vor dem Zeitpunkt, zu dem die erhaltenen Werke einsetzen), die er an einigen Stellen erwähnt, zeigt, dass in der Biographie des Ennodius eine wichtige Phase ergänzt werden muss, die in den Abrissen seines Lebens und seiner Laufbahn bisher fehlt. Wie viele andere - erinnert sei nur an Cyprian, Laktanz, Ambrosius, Augustin, Marius Victorinus, Ennodius' Zeitgenossen und Empfänger eines Briefes Pomerius oder seinen jüngeren Korrespondenten Arator - gab Ennodius seine weltliche Karriere auf, um seine Fähigkeiten in den Dienst der Kirche zu stellen bzw. um so seinen Lebensunterhalt zu sichern. Auf die Tatsache, dass er dem geistlichen Stand angehört, verweist Ennodius an vielen Stellen innerhalb seiner Werke, was in der Forschung bisher ebenfalls übersehen wurde. Die Spannung zwischen Ennodius' Überzeugung von der Bedeutung der cultura sermonis, ${ }^{4}$ der traditionellen sprachlich-rhetorischen Bildung, und seiner Freude am Verfassen von Dichtung und Prosa auf hohem sprachlich-stilistischem Niveau einerseits und den Anforderungen des Amtes als Diakon und des angestrebten Bischofsamtes andererseits durchzieht das ganze Werk und wird in dieser Untersuchung eine große Rolle spielen (besonders Kap. I 5, II 2.b). Die communis opinio über die Auswirkungen von Ennodius' Diakonat: "Ennodius wurde Geistlicher, ein Ereignis, dem, soviel ersichtlich, ein Wandel des Denkens weder vorausging noch folgte " (FUHRMANN ${ }^{2}$ 1995, 334), ist zu revidieren.

Die Briefe zeichnen sich durch eine bisher in keiner Weise gewürdigte Besonderheit aus: die Authentizität. Es handelt sich um sechte Briefe in dem Sinne, dass man recht sicher sein kann, dass Ennodius sie so an die Adressaten versandt hat, wie sie

3 Zur Verwendung der Begriffe "senatorisch, Senatoren, Adel, Amtsadel, Aristokratie, Elite, Klasse, ordo, Oberschicht, Stand, Status« u.ä., die keine eindeutig umrissene Personengruppe, sondern je nach Ort und Zeit unterschiedlich definierte (auch unterschiedlich klar definierte) Personengruppen bezeichnen, siehe NäF (Senatorisches Standesbewusstsein in spätrömischer Zeit, 1995), 5-8 (»Zur Begrifflichkeit«). Für Ennodius können folgende "Bestandteile einer Definition senatorischen Adels" (8) gelten, wie sie NäF aufzählt und erläutert (8-11 "Senatorisches Standesbewusstsein und die Definition senatorischen Adels «): Voraussetzung sind die Existenz des Kaisertums, die rechtliche Neukonstituierung des Standes im 4.Jh. und die zahlreichen Ordnungen für Ämterlaufbahnen; einerseits handelt es sich um Amtsadel, andererseits ist der Adel wesentlich auch durch die Geburt definiert; Kennzeichen sind erheblicher Besitz, Ausübung von öffentlichen Ämtern, Euergetismus und Patrozinium (damit verbunden ist die Abgrenzung von anderen Ständen); das Selbstbewusstsein zeigt sich an dem Stolz auf die Verkörperung von Tugendkatalogen und Bildung, an einem bestimmten Auftreten und einer besonderen Lebensart. - In diesem Sinn sind die Begriffe »Adel «, »Oberschicht « etc. auch in dieser Untersuchung verwendet. - Siehe auch Anm. 62.

4 Siehe z.B.: $(10,2)$ cultura sermonum; $(15,6)$ scriptionis cultura; $(411,2)$ sermonis $[\ldots]$ cultura. 
uns überliefert sind. Dies zeigt sich zum einen daran, dass er die Briefe nicht in eine kunstvolle bzw. vorgeblich kunstlose Reihenfolge gebracht hat, sondern dass sie zwischen den anderen Werken überliefert sind, zum anderen daran, dass sie keine Spuren einer Überarbeitung zeigen, die sie auch für ein breiteres Publikum, das den ursprünglichen Zusammenhang der Kommunikation nicht kennt, verständlich machen sollte. Wie sich im Folgenden zeigen wird, ist es auch nicht wahrscheinlich, dass er seine Briefe oder auch nur eine Auswahl später einmal veröffentlichen wollte. Besonders angesichts dieser Authentizität in dem Sinne, dass die Briefe in der Form erhalten sind, wie sie abgeschickt wurden, und nicht als überarbeitete und gestaltete Sammlung, ist es erstaunlich, dass sie in der Forschung so geringe Aufmerksamkeit erfahren haben. War doch bis in allerjüngste Zeit eine zentrale Frage fast jeder Beschäftigung mit antiken und spätantiken Briefen die nach der Authentizität - wobei "authentische « ungleich positiver gewertet wurden als solche, deren Verfasser seinen Blick auf die Publikation und ein weiteres Publikum richtete. (Allgemein zum Forschungsstand zur Epistolographie siehe Kap. II 1. c und d.)

Die Briefe sind also, selbst wenn Ennodius sie später hätte überarbeiten und herausgeben wollen, mit Blick auf den ersten Adressaten und - außer wenn es sich um vertrauliche Angelegenheiten handelte - diejenigen verfasst, denen dieser den Brief vorlesen oder weitergeben würde (zu derartigen "Realien « des Briefwesens siehe Kap. II 1.b). Sie weisen durch diesen Adressatenbezug den in vielen antiken und spätantiken Briefen beschworenen und in der Forschungsliteratur als brieftypisch bezeichneten "dialogischen « Charakter auf, der zuweilen in den von den Verfassern selbst herausgegebenen Sammlungen von Briefen, die mit Beschreibungen, Berichten oder Essays auf eine größere Öffentlichkeit zielen, recht äußerlich bleibt. Ähnlich wie Ciceros Briefe, die nicht für solche Leser konzipiert wurden, die den Kommunikationszusammenhang nicht kannten oder in Erfahrung bringen konnten, sind Ennodius' Briefe daher häufig nur für den ersten konkreten Adressaten verständlich und zwangsläufig für den heutigen Leser erklärungsbedürftig.

Bei der Analyse von Briefen, zumal von authentischen im erläuterten Sinne, spielt die Frage nach Details der Biographie des Verfassers eine wesentlich andere Rolle als bei epischen, dramatischen oder auch lyrischen Texten. Das Brief-Ich ist mit dem Verfasser der Briefe in größerem Maße identisch als z.B. ein lyrisches Ich, da der Verfasser eines Briefes in der Regel mit dem Adressaten eine Kommunikation aufbauen möchte, die funktionieren soll. Daher lassen sich auch Briefe (ebenso wie Reden) als "genres para-littéraires« bezeichnen, die »auf der Grenze zwischen Literatur und Leben " existieren (MARTIN/GAILlARD 1981, 2,169). Wenn sich Verfasser und Adressat bereits kennen, sei es aus persönlicher Bekanntschaft, vorangegangener Korrespondenz oder aus Darstellungen Dritter, dann können im konkreten Brief manche Informationen als bekannt vorausgesetzt werden. Da für den heutigen Leser der Briefe die meisten dieser Vorinformationen unwiederbringlich verloren sind, ist es umso wichtiger, die wenigen Informationen über den Verfasser, die die Briefe und andere Werke 
dann doch enthalten, auch wahrzunehmen. Hinzu kommt die weitere Erschwernis, dass, wie bei fast allen antiken und spätantiken Briefen, sowieso lediglich eine »Hälfte des Gesprächs«, d.h. eine einzige Seite der ehemals (überwiegend) wechselseitigen Korrespondenz erhalten ist. Besonders bei Briefen, die offensichtlich eine Antwort darstellen, muss man versuchen, den jeweiligen Handlungszusammenhang zu erkennen; häufig, wenn auch nicht immer, lässt sich die Situation grob - und hoffentlich plausibel - erahnen. Es ist wichtig, bei der Bewertung des Stils, des Inhalts und der Schwierigkeiten beim Lesen zu beachten, dass der heutige Leser einen viel komplizierteren Weg zum Verständnis geht als der ursprüngliche Adressat. Da der ehemalige Kontext verloren ist, bedürfen die Briefe heute mehrmaliger Lektüre und erschließen sich nicht linear, sondern häufig von hinten nach vorn oder im Zickzack. Die Erläuterung mancher wiederkehrender inhaltlicher Details, die Aufdeckung bestimmter Strukturen der Argumentation, die Betrachtung von Traditionslinien innerhalb der Epistolographie (Kap. II 2.d; II 3) und von Besonderheiten des Stils (Kap. I 2.c) soll die Lektüre der Briefe erleichtern.

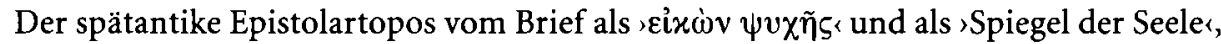
d.h. die Vorstellung, dass der Brief ein Abbild - und gemeint war ursprünglich: das ideale Abbild - der Seele des Adressaten sei, führte zu der lange weit verbreiteten Annahme, dass die Verfasser in ihren Briefen naiv ihr stiefstes Inneres zeigen $<$ bzw. dass man von den Briefen unmittelbar auf den `wahren`Charakter der Verfasser schließen könne. Daher war es in der früheren Forschung üblich, Briefe nicht nur als Quelle für historische Fakten, sondern auch als Quelle zur Analyse des Charakters des Verfassers zu nutzen und dessen Persönlichkeit moralisch zu beurteilen. Neuere Forschung hingegen rechnet weniger mit Unmittelbarkeit, Offenheit und Ehrlichkeit als vielmehr - wie bei anderen Arten von Literatur - mit kalkulierter Wirkung auf den Adressaten und beschäftigt sich mit Briefen als einer Möglichkeit der Selbstdarstellung, Selbststilisierung, Präsentation (Kap. II 1.d).

Zwar handelt es sich bei den Briefen des Ennodius anders als z.B. bei denen des Plinius nicht um eine `Performance` für ein breiteres zeitgenössisches Publikum und für die Nachwelt mittels einer überarbeiteten Briefsammlung; denn während die Sammlung des Plinius von anderen Lesern als den ursprünglichen Adressaten (wenn es diese denn überhaupt gegeben hat) gelesen werden soll, sind die des Ennodius als rechte Gebrauchsbriefe، für konkrete Adressaten bestimmt. Doch auch in diesen präsentiert sich der Verfasser, wenn auch lediglich in den einzelnen Briefen für den jeweiligen Adressaten (bzw. für dessen näheren Umkreis); er will auf den konkreten Adressaten in einer bestimmten Situation in bestimmter Weise wirken.

Die Briefe des Ennodius werden in der Forschungsliteratur überwiegend im Vergleich mit anderen Epistolographen, besonders mit Symmachus und Sidonius Apollinaris, bewertet. Dabei finden sich durchgängig abwertende Urteile über Ennodius, z.B.: 
"< die Briefe $>$ haben nicht mehr den Schwung des Gedankens und der Empfindung, der noch in der vorherigen Generation den Reiz der Briefe des Sidonius Apollinaris ausmachte [...]; sie sind verknöcherte Nachfahren jener Briefe voll gesellschaftlicher Floskeln, die der jüngere Plinius bisweilen abfaßte« (Fontaine 1962, 40of.). Besonders häufig wird erwähnt, dass Ennodius Symmachus bewundert habe, doch genauer untersucht wurde dieses Verhältnis bisher nur hinsichtlich des Panegyricus (RoHR 1998). In Bezug auf die Briefe finden sich lediglich pauschale Urteile wie z.B.: "Die [...] Briefe sind [...] ebenso inhaltsarm wie die Freundschaftsbriefe seines Vorbildes Symmachus" (Zelzer 1997, 348). Da bei den vergleichenden Wertungen sehr subjektive Vergleichskriterien wie etwa »Schwung des Gedankens« angewandt werden, und zwar ohne dass die Briefe des Ennodius je gründlich untersucht worden wären, soll in dieser Arbeit der Vergleich auf eine solidere Basis gestellt werden (Teil II); dabei soll das Ziel nicht sein, eine Wertung vorzunehmen, sondern die Besonderheiten der verglichenen Autoren deutlicher zu sehen. Zum Vergleich herangezogen werden besonders Symmachus, Sidonius Apollinaris und Cassiodor, gelegentlich auch Ambrosius, Hieronymus, Paulinus von Nola, Augustin und Ruricius von Limoges (in Kap. II 1.e werden sie kurz vorgestellt). Als zu vergleichende Aspekte bieten sich zum einen aufgrund ihrer weiten Verbreitung und der entsprechend großen Materialmenge die $>$ Brieftopoi` an, besonders die $>$ Höflichkeitsfloskeln $\prec$ und insgesamt der für die Korrespondenz etablierte Verhaltenskodex (Kapitel II 2.d), zum anderen die besondere Gestaltung verschiedener Brief-Gattungen wie z.B. Glückwunsch- und Empfehlungsschreiben (Kapitel II 3).

Bei diesem Vergleich stellt sich heraus, dass Ennodius entgegen der communis opinio ganz anders schreibt als sein vermeintliches Vorbild Symmachus. Im Gegensatz zum immer freundlichen und nachgiebigen Symmachus ist Ennodius häufig gereizt, voller Klagen und Vorwürfe. Er ahmt die grundlegende indulgentia des Symmachus keineswegs nach, sondern nimmt als importunus, der häufig querellae vorbringt, eine gegensätzliche Haltung ein. Er orientiert sich zwar an Symmachus, doch in dem Sinne, dass er häufig Gedanken, die bei Symmachus vereinzelt und als Ausnahme aufscheinen, verwendet, um sie sozusagen radikal durchzuführen (Kap. II 2.d.2). Anders als vermutlich >im wirklichen Leben` ist für Ennodius in den Briefen die Rolle des frommen Diakons nur eine Nebenrolle, die er insbesondere in Briefen an Frauen einnimmt (Kap. II 2.c), die literarische Rolle des unzufriedenen Freundes hingegen die Hauptrolle (Kap. II 2.d). In etlichen Briefen beweist Ennodius, dass er der Konvention voll zu entsprechen versteht, doch häufiger zeigen sich seine Wandlungsfähigkeit, seine Lust am Spiel mit der Konvention, seine oft sehr scharfsinnige Gedankenführung und sein Hang zum Klagen: So z.B. wenn er in Briefen, die der Beziehungspflege dienen, dem Adressaten unterstellt, dieser schreibe ihm deshalb nicht, weil er Karriere gemacht habe und hochmütig geworden sei (Kap. II 3.b), oder wenn er in Situationen, in denen ein Glückwunsch erwartet wird, dem Adressaten ausführlich vorwirft, dass dieser ihn nicht selbst von dem freudigen Anlass unterrichtet habe 
(Kap. II 3.c), oder wenn er in Empfehlungsschreiben an Bekannte, zu denen er lange keinen Kontakt hatte, diesen zunächst mit scharfen Worten ihre Schreibfaulheit vorwirft, anstatt wegen der folgenden Bitte freundlich zu beginnen (II 3. d).

Wenn Fuhrmann die Briefsammlung des Ennodius als »ein Dokument par excellence der spätrömischen Adelskultur “ $\left({ }^{2} 1995,335\right)$ bezeichnet, so stimmt dies nur zum Teil bzw. in einem speziellen Sinn: Einerseits ermahnt er junge Adlige, durch ihre Bildung ihren Adel und durch Briefe ihre Bildung bzw. ihr sprachliches Können zu zeigen, und er ist sehr bemüht, brieflich den Kontakt zu einer Reihe von Adligen zu halten. Andererseits spricht Ennodius in seinen Briefen häufig davon, wie sich sein kirchlicher Stand einschränkend auf seine literarische Produktion, auch auf die Gestalt seiner Briefe, auswirke und dass er nicht mehr so schreiben könne bzw. dürfe wie früher (Teil II 2.b). Aufgrund seines kirchlichen Amtes ist er gezwungen, seine literarische Tätigkeit stark einzuschränken (Kap. I 3); doch Briefe, nicht zuletzt dienstliche, geben ihm eine Möglichkeit, seine Fähigkeiten nicht völlig aufzugeben. Ennodius selbst schreibt davon, dass er nach der Übernahme des Diakonats nicht sofort bzw. nur äußerlich die damit verbundenen Forderungen an Veränderungen seiner Lebensweise, d.h. auch seiner literarischen Tätigkeit, erfüllt habe; er stellt dies im "Eucharisticum» dar, das als erstes zu untersuchen ist (Teil I 1).

Diese Studien sollen ergänzt werden durch eine zweisprachige Ausgabe der Briefe in der Reihe »Fontes Christiani«. Da Ennodius wenig bekannt ist, wird in dieser Arbeit relativ viel zitiert (nach der Ausgabe von VoGEL), übersetzt und paraphrasiert; an einigen Stellen deutet der Hinweis: <?> an, dass sich mir der Sinn des lateinischen Textes nicht vollends erschlossen hat. Der lateinische Text wird im Haupttext zitiert, wenn die Begriffe selbst für die Diskussion wichtig sind, ansonsten steht er in der Fußnote. Bei der Darstellung wird Charakteristisches exemplarisch aufgezeigt, wobei einerseits lieber zu viele als zu wenige Beispiele angeführt werden, um möglichst viele Briefe zu berücksichtigen, andererseits Vollständigkeit in Anbetracht des Umfangs des überlieferten Werkes nicht angestrebt ist. Je nach Themenstellung werden einzelne Stellen aus Briefen betrachtet, wobei dann der Kontext kurz skizziert ist, oder ganze Briefe vorgeführt (letzteres besonders in Teil II 3).

Zitate und Nummerierung folgen der Ausgabe von Vogel (1885). An einigen Stellen erschien es jedoch sinnvoll, die Interpunktion gegenüber VoGEL zu verändern, siehe z.B.: $(1,4)$ unten $67 ;(18,3)$ u. $333,(71,2)$ u. $297,(110,1)$ u. 293.

Abkürzungen von Autoren und Werken folgen überwiegend dem Thesaurus linguae Latinae (doch für Symmachus steht nur Sy.); auf die Nennung von Werktiteln wird verzichtet, wenn es sich um Briefsammlungen handelt; es steht also statt Symm. epist. 1,1,1 nur: Sy. 1,1,1, entsprechend bei Cic., Plin., Hier., Ambr., Aug., Paul. Nol., Ruric., Cassiod. 


\section{Teil I: Cultura sermonis}

\section{Krankheit und Gelübde des Diakons: Das »Eucharisticum« (438)}

Die von SIRMOND unter dem Titel "Eucharisticum de vita sua " edierte Schrift spielt in der biographischen Forschung zu Ennodius eine ebenso große Rolle wie bei ihrer Interpretation erhebliche Missverständnisse aufgetreten sind, die die Urteile über Ennodius stark beeinflusst haben. Wurde bisher angenommen, im sogenannten $>\mathrm{Eu}-$ charisticum ' gehe es überwiegend um die Jugend des Ennodius, so ist zu zeigen, dass von der Jugend nur innerhalb einer rückblickenden Passage gesprochen wird; im Mittelpunkt stehen vielmehr die Krankheit und das Gelübde des Diakons. Anders als bisher angenommen berichtet Ennodius in diesem Text nicht davon, dass er in seiner Jugend als Dichter und Redner aufgetreten ist, sondern die betreffenden Passagen beziehen sich auf seine Zeit als Diakon.

Im `Eucharisticum berichtet ein Ich-Erzähler über einige Stationen seines Lebensweges, über seine Erfolge, über eine schwere Krankheit und seine schließliche Hinwendung zu Gott. Auf den ersten Blick ist zu erkennen, dass dieses Werk im Stil und Ton von Augustins Confessiones gehalten ist; jedoch muss allein der ebenfalls ins Auge springende erhebliche Unterschied im Umfang vor einem vorschnellen inhaltlichen Vergleich der beiden Werke abraten, denn das "Eucharisticum« umfasst lediglich ca. dreieinhalb Seiten in der Ausgabe von Vogel. Dennoch wird es, ausgehend von Parallelstellen, als Imitation von Augustins Confessiones überwiegend abschätzig bewertet, z.B.: "pastiche assez médiocre«, »superficiel« (CouRCElle 1958, 453), "eher eine unbeholfene Nachahmung" (Wermelinger 1982, 655). Für eine vergleichende Bewertung ist jedoch die Sammlung von Parallelstellen (siehe bei CourCELLE 1958 und Pizzino 1978) keine ausreichende Grundlage; eine genauere vergleichende Untersuchung von Sprache, Stil und Erzähltechnik dürfte zeigen, wie intensiv Ennodius sich mit den Confessiones beschäftigt, Charakteristisches erkannt und verarbeitet hat. ${ }^{5}$

5 Anders Kennell (2000, 24-29), nach deren Ansicht der Text mehr formale Ähnlichkeiten mit den gleichzeitig überlieferten Briefen des Ennodius habe als mit Augustins Confessiones (25); sie versucht anhand einiger Details zu zeigen, dass der Text wie ein Brief (an Gott) strukturiert sei ("like a letter to the Almighty«, "fundamentally epistolary nature « 24 ; u.ö.). Dabei übersieht sie allerdings z.B., dass gerade keine brieftypische Grußformel voransteht, sondern der Text überschrieben ist In nomine patris et filii et spiritus sancti, und dass das erste angeredete "Du « die eigene Schwachheit ist ( $\$ 2$ ergo tibi post 
Allerdings wird dieser Text in der Forschung als willkommene Fundgrube für historisch-biographische Details über Ennodius betrachtet, besonders da aus anderen Werken recht wenig über seine äußeren Lebensumstände hervorgeht. Jedoch ist es dabei wichtig zu beachten, dass es sich ebensowenig wie bei Augustins Confessiones um eine Biographie im Sinne einer Zusammenstellung möglichst vieler entscheidender Ereignisse, Daten und Umstände handelt und dass Ennodius nicht nur den sprachlichen Ductus Augustins nachahmt, sondern auch seine Erzähltechnik, die nicht durch lineares Erzählen, sondern durch Auswahl und Weglassen, Ausmalen einzelner Details, Einschübe, Rückblicke und Ausblicke charakterisiert ist. ${ }^{6}$ Jede Darstellung der Biographie des Ennodius stützt sich mangels Alternativen auf diesen Text, ${ }^{7}$ auch angesichts der dabei aufkommenden Probleme, die ihrerseits an die Probleme erinnern, die eine biographische Auswertung von Augustins Confessiones mit sich bringt. Eine deutsche Übersetzung findet sich bei FerTIG (1855, 7-10); eine moderne Übersetzung und ein Kommentar sind ein Desiderat. - VANDONE (2001) analysiert speziell den Abschnitt über die Dichtung (\$5-7) im Vergleich mit Passagen aus anderen Werken des Ennodius; er kommt zu dem richtigen Ergebnis, dass Ennodius das kirchliche Amt als unvereinbar mit literarischer Aktivität betrachtet, und zwar weniger wegen der Inhalte letzterer als wegen der Tatsache, dass sie zu Hochmut und Ehrgeiz führen könne. VANDONE spricht allerdings allgemein von "status ecclesiastico" und äußert sich nicht zur Chronologie und zu der Frage, welches Amt das dichtende Ich des »Eucharisticum» innehat.

Zunächst eine knappe Analyse zu Inhalt und Aufbau, wobei Erläuterungen zu Inhalt und Struktur in spitzen Klammern < > eingefügt sind:

$<$ Ein Vorwort (\$1-4) führt in das Thema ein, für das ab \$5 ein konkretes Beispiel gegeben wird:> Nach der Ausführung des paulinischen Gedankens, dass Schwäche des Körpers zur Stärke des Geistes bzw. zur Gnade Gottes führe, ${ }^{8}$ berichtet der Er-

deum debetur, inbecillitas nostra, quod [...]); außerdem sind im weiteren Verlauf mehrere Leser angesprochen: expendite legentes $(\$ 12)$. Aus dem Briefcharakter schließt KENNELL dann weiter auf die völlige Aufrichtigkeit des Verfassers: "Unless he was more foolish and depraved than the most hostile critics could imagine, he should be at his most candid in addressing God, the omniscient Supreme Being " (2000, 23; 25).

6 Die Kurzcharakteristiken in der Forschungsliteratur können andere Erwartungen wecken, z.B. BARDENHEWER (1932, 243): »als Ennodius, von einer schweren Krankheit [...] genesen, zur Feder griff, um [...] einen prüfenden Rückblick auf sein bisheriges Leben zu werfen und für die Zukunft Besserung zu versprechen «. RoHR (1995, 7): „Der kurze Lebensbericht in Form eines Gebetes«; DöpP $(1999,190)$ : „worin Ennodius im Rückblick auf sein Leben von der Nichtigkeit des Irdischen spricht. «

7 Siehe z.B.: Magani (1886, passim), Vogel (1885, Praef. passim), Rohr (1995, 3f.), KenNELL (2000, besonders 5f.; 23-29).

8 (\$1) Oraculum est scientissimi doctoris gentium, quod pariat infirmitas nostra potentiam [...]. ad divitem dei gratiam pervenitur ieiuna et sterili paupertate membrorum: »Ein wei- 
zähler, dass ihn eine Krankheit ( $\$ 2$ inbecillitas; febris; exustio) zur Gottesfurcht und die folgende Genesung zur Freude an Gott gebracht habe (\$2); das Ergebnis seiner körperlichen Krankheit sei die Gesundheit seines Geistes ( $\$ 2$ mentis sanitas procurata languoribus). Erst die körperliche Krankheit habe ihm bewusst gemacht, dass der Geist vorher krank gewesen sei; denn dass es sich bei der körperlichen Gesundheit um ein Geschenk Gottes gehandelt habe, sei im gesunden Zustand voller Hochmut (\$3 superbia, supercilium) nicht gesehen worden <vom Hochmut wird in diesem Text noch häufiger gesprochen werden>; diese Einsicht und mit ihr die Reue seien während der Krankheit gekommen $\left(\$_{3}\right)$. Gott wird dafür gedankt $\left(\$_{4}\right)$, dass er die Menschen auf verborgenen Wegen und durch Qualen zur Vollkommenheit führe; ohne Wunden könne man die Medizin Gottes nicht erlangen, d.h. die irdische Nichtigkeit überwinden. <Mit diesem Vorwort $\left(\$_{1-4}\right)$ ist der Leser vorbereitet auf eine Geschichte, in der jemand durch eine Krankheit zur Einsicht, d.h. zu Gott kommt, nachdem er zuvor in glücklichen Umständen nicht erkannt hat, dass diese ein Geschenk Gottes sind.>

$<$ Mit ecce setzt der erste Hauptteil $\left(\$_{5}-18\right)$ ein $>$. Ennodius berichtet, er habe es genossen, dass es ihm gutging, so als ob dieser Zustand kein Ende haben könnte $(\$ 5)$. Durch Erfolge verleitet hatte er sich unter die Dichter begeben ( $\$ 5$ poetarum me gregi [...] indideram), ${ }^{9}$ und zwar ohne Gedanken an die veneranda professio. $<$ Es ist wichtig zu sehen, dass die veneranda professio das Amt des Diakons ist, zu dem die Dichtertätigkeit nicht passt, wie später im Text deutlich wird $>.{ }^{10} \mathrm{Er}$ habe große Freude an kunstvoll gestalteten Gedichten gehabt ( $\$ 5$ delectabant carmina quadratis fabricata particulis). Wenn ihm ein Gedicht gut gelungen sei, habe er sich den Engelschören zugehörig gefühlt ( $\$ 6$ angelorum choris me [...] poema miscebat). Häufig habe er sein Haupt, das aus religiösen Gründen entblößt war ( $\$ 6$ propter religionem vertex nudatus) < das heißt, dass er Tonsur trug $>$, bei den Beifallsstürmen vor Stolz erhoben. ${ }^{11}$

ses Wort des weisesten Lehrers der Heiden besagt, dass unsere Schwäche Stärke hervorbringt [...]. Zur reichen Gnade Gottes gelangt man durch die dürftige und karge Armut der Glieder «; vgl. II Cor. 12,10: cum enim infirmor tunc potens sum.

9 Vgl. auch $(\$ 7)$ : in rhetoricis et poeticis campis.

10 Polara $(1993,224)$ hat veneranda professio auf die Kunst der Dichter bezogen, was aber von VANDONE $(2001,90)$ korrigiert und richtig auf den geistlichen Stand bezogen wird. Richtig zuvor schon MAGANI, (1886, Bd. 3,54): "immemore del venerando stato di vita", (id. Bd. 1,22): »dimentico della mia veneranda condizione «. - ignarus in diesem Sinne ebenfalls z.B. 3,$5 ; 14,1$.

11 Den Ausdruck propter religionem vertex nudatus bezieht schon Magani auf die Tonsur (1886, Bd. 3, 53-60, bes. 54f.). So auch VAndone (2001, 90). - Zur Tonsur siehe: Louis TRICHET, La tonsure. Vie et mort d'une pratique ecclésiastique, Paris 1990, besonders das Kapitel: L'élaboration du rite, $54 \mathrm{ff}$.); diese Stelle bei Ennodius, aus der hervorgeht, dass der Diakon Tonsur trägt, ist dort nicht erwähnt. 
Er berichtet weiter, als Redner und Dichter habe er nach Lob gestrebt: nihil aliud cupiens nisi auris vanae laudationis adsurgere $\left(\S_{7}\right.$ »mit keinem anderen Wunsch als dem, mich durch die günstige Brise eitlen Lobes emportragen zu lassen $\ll$ ) <das Streben nach Lob war dem Diakon nicht erlaubt, wie er an anderen Stellen deutlich sagt, siehe z.B. unten 66; 70>; nach der wahren sapientia habe er nicht gesucht $(\$ 7)$. Doch Rettung (für seine Seele) sei genaht in Form einer (körperlichen) Krankheit (\$7) $<$ von der als Hauptthema in der Einleitung schon die Rede war >. Die Krankheit, die letztlich zur Vertreibung seines Hochmuts gegenüber Gott geführt habe ( $\$ 8 \mathrm{dum} e$ latebris suis pelleretur adrogantia), habe ihn Furcht gelehrt. $<$ Dass der Diakon jeden Eindruck von Hochmut, superbia/ adrogantia/ iactantia, vermeiden musste, ist auch in anderen Werken Thema, siehe z.B. unten 74.> Er habe aber gewusst, dass Gott ihn heilen könne ( $\$ 8$ ). Alle (die ganze civitas) hätten angenommen, dass er nicht mehr lange leben würde (\$9); Heilungsversuche hätten es nur schlimmer gemacht, die Kunst der Ärzte habe versagt (\$10), so dass er schon an Selbstmord gedacht habe, trotz der damit verbundenen großen Sünde $(\$ 11)$. Er habe sich in den Tod stürzen wollen; doch Gott habe ihm geholfen $(\$ 12)$. Als einer derer, die ihn heilen wollten, die Hoffnung aufgegeben habe, habe er selbst neue Hoffnung geschöpft (\$13). Er habe sich an den heiligen Victor ${ }^{12}$ gewandt, der Gott seine Bitten vorbringen sollte: Wenn Gott bedenke, woraus der Mensch geschaffen sei, müsse er verstehen, dass es schwierig sei, die Aufträge Gottes zu erfüllen $(\$ 14)$. Trotz der Reinigung durch die Taufe bringe der Teufel durch seine Verlockungen den Tod; Rettung könne nur der bringen, der den verlorenen Sohn wieder aufgenommen habe $(\$ 15)$. Er fährt fort, er habe Gott um seine Unterstützung gebeten, um künftig auf eine bessere Art zu leben (\$16-17); er habe Gott um den richtigen Verstand gebeten und versprochen, ihm den besten Teil seines Talents als Opfer zu geben und es nicht mehr in den Dienst weltlicher Dinge zu stellen: [...] de muneribus ipsius ingenioli mei eidem adipem litarem, ut numquam stili cura de saecularium rerum ventosa executione lassaretur ( $\$ 17$ "[...] dann würde ich ihm von den Gaben meines kleinen Talentes den fettesten Teil opfern, dass ich nämlich beim Schreiben nie <mehr> meine Kraft für die nichtige Behandlung weltlicher Dinge vergeuden würde«). Er habe Gott gebeten, ihn nicht zu verlassen, nachdem er ihm doch schon so viel Gutes getan habe: Gott habe ihn, der keine Eltern mehr hatte <dies wird in \$2of. wieder aufgenommen>, unterstützt ( $\$ 18$ quem genuini praesidii tutela destitutum fovisset) und ihn anderen, die noch Eltern hatten, vorgezogen ( $\$ 18$ et illis, qui parentum laetabantur defensione, praetulisset). <Diese Wohltaten werden ausführlicher beschrieben in $\$ 21-23>$. Weiter sagt er <in einem Vorausblick>, dass Gott bei der Erfüllung seiner Wünsche gezeigt habe, wie viel der Sünder der Gnade Gottes zu verdanken habe. <Noch wird aber nicht gesagt, in welcher konkreten Weise Gott ihm geholfen hat $>$.

12 In einer Kapelle der Basilika S. Ambrogio in Mailand ist ein Kuppelmosaik mit einer Darstellung Victors aus dem 5. Jh. erhalten. 
$<$ Dann setzt der zweite Hauptteil ein $(\$ 19-26)$, der von Ereignissen erzählt, die vor den im ersten Hauptteil erzählten liegen:> Ennodius ruft aus, dass ihm viele Wohltaten Gottes in den Sinn kämen; er berichte nun lediglich von einer Wohltat, wobei er die anderen übergehe $(\$ 19)<$ er hat schon zuvor in \$18 erwähnt, wie er während der Krankheit Gott an frühere Wohltaten für ihn als Waisenkind erinnert habe; dies wird nun weiter ausgeführt $>$.

Er berichtet, er habe, als Theoderich Italien eroberte, mit ca. 16 Jahren seine Tante, bei der er aufwuchs, verloren $(\$ 20)$. Gott habe ihn Aufnahme in einem reichen und frommen Haus finden lassen $(\$ 21)$; er habe sich mit der jungen Tochter verlobt; mit dieser gottgefälligen Familie habe er in materiellem Überfluss gelebt $(\$ 22)$. Er habe sich wie ein König gefühlt und den Urheber von Glück und Unglück nicht gesehen: adflictorum orditus sum mala deridere et quasi debita mihi fuisset prosperitas, sic illorum neglegere auctorem $(\$ 23$ "Ich fing an, über das Unglück in Not Geratener zu lachen und nicht an den Urheber des Unglücks zu denken, so als stände mir mein Glück zu “). Nach langer Zeit habe Gott die Geduld verloren und ihm seinen Schutz entzogen $(\$ 24)<$ Es ist zu vermuten (VoGel, Praef. VI), dass es sich konkret um materielle Bedrängnis gehandelt haben könnte, weil die Familie seiner Verlobten, vielleicht wegen der Kriegshandlungen in Norditalien, ihr Vermögen verloren hat; an anderer Stelle spricht Ennodius davon, dass »der Sturm seiner unermesslichen Sünden ihn in einem Unwetter dazu gebracht habe, das Amt anzutreten « (11,2; dazu unten 68) >. Und er habe die Frage gehört: «Adam, wo bist du? « (cf. Gn. 3,9). Erst jetzt habe er die - nun vergangenen - Gaben Gottes erkannt und geweint: rerum a te conlatarum aestimatio tunc concessa est, cum mihi perirent ( $\$ 25$ "Ich lernte die Dinge, die du mir geschenkt hattest, erst in dem Moment schätzen, als ich sie verlor «). Sofort sei Gott zu Hilfe gekommen durch den Auftrag, dass er durch das Amt des Diakons geheilt werden solle: ordinasti, ut per officium levitarum coactus sanarer et inpacti honoris sarcina quod premebat a me pondus amoveret $(\$ 25 » \mathrm{Du}$ hast angeordnet, dass ich durch das Amt des Diakons zwangsläufig geheilt werden sollte und dass die Last der auferlegten Ehre mich von der Last, die auf mir lag, befreien sollte«). Doch er habe zwar Glanz aufgrund des Titels, nicht aber das entsprechende Gewissen aufgrund glänzender Taten gehabt ( $\$ 26$ habui de titulo genium, non de actionis nitore conscientiam). ${ }^{13}$

$<$ Im Schlussteil $(\$ 27-29)$ führt der Bericht die Bitte an Victor weiter $(\$ 27$ haec et alia plura, sicut praefatus sum [...], cf. \$14).> Die Bitte um Genesung sei erfüllt worden. Außerdem sei etwas eingetreten, was über seine Wünsche hinausgegangen sei, denn auch seine ehemalige Verlobte habe einen Entschluss gefasst: $(\$ 27)$ ut illa [...] religiosae mecum habitudinis decora partiretur [...]. Dies dürfte bedeuten, dass die ehemalige Verlobte nun - und damit später als Ennodius, der ja auch offenbar älter

13 genius im Sinne von ‘wahrer Glanz ist eines von Ennodius' Lieblingswörtern, cf. den Wortindex s.v. bei VoGEL. 
war als sie (vgl. \$22 parvulam filiolam) - ebenfalls dem weltlichen Leben entsagt hat.> Daraufhin (\$28-29) wird die christliche Tugend der ehemaligen Verlobten hervorgehoben $(\$ 28)$, und den Abschluss bilden eine Anrede und eine Bitte an Gott (\$29).

Es ist wichtig, sich den Aufbau des Textes zu vergegenwärtigen, um einige Missverständnisse in der Forschung ausräumen zu können: Im zweiten Teil (\$19-26) erfahren wir, dass der Ich-Erzähler als Waise bei seiner Tante aufwuchs, bis diese zur Zeit der Kämpfe Theoderichs in Norditalien starb, dass er dann Aufnahme in einem reichen und christlichen Haus fand und sich mit der Tochter verlobte, dass er in eine Notlage geriet und dass er schließlich Diakon wurde, aber sein Verhalten dem glanzvollen Amt nicht entsprach. All dies ist Teil des Rückblicks auf früher erfahrene gute Taten Gottes, und dieser Rückblick wiederum ist Teil der Worte, die an den heiligen Victor gerichtet sind. Die Bitte an Victor wird also gesprochen von einem Diakon, der Hilfe in der Krankheit sucht. Im ersten Teil (\$5-18) erfahren wir die Geschichte des Diakons bis zu der Krankheit: Er betätigt sich als Redner und Dichter, er ist ignarus venerandae professionis (\$5): eben dies sagt er mit anderen Worten am Ende des Rückblicks innerhalb des Gebets $(\$ 26)$ : habui de titulo genium, non de actionis nitore conscientiam. - Berichtet wird also von einem Diakon, der zwar das Amt hat, sich aber nicht entsprechend verhält und durch eine Krankheit zur Reue und zu einem Gelübde kommt. Der Text reiht sich damit unter viele Bekehrungsberichte, in denen ein Gelübde oder eine Konversion nach einer Krankheit bzw. einer anderen Notlage keine Seltenheit ist.

Noch einmal übersichtlicher:

\$1-4: Hinführung zum Thema: geistige Gesundheit erst nach körperlicher Krankheit.

\$5-18: Der Diakon betätigt sich als Redner und Dichter, er ist hochmütig und strebt nach Lob; er wird krank und betet zum heiligen Victor; er verspricht, künftig sein Talent nicht mehr für Weltliches einzusetzen.

\$19-26 Rückblick: Im Gebet an Victor erinnert er Gott an früher schon empfangene Wohltaten: Nach dem Tod seiner Tante ließ Gott ihn in seiner Notlage Aufnahme in einem reichen Haus finden; der Überfluss machte ihn übermütig, und er geriet wiederum in Not; aus dieser Notlage befreite ihn die Übertragung des Diakonats; dieses Amt hat er allerdings nicht angemessen ausgefüllt (was zu der Krankheit führt, die in \$5-18 Thema ist).

\$27-29: Victor hat das Gebet Gott überbracht, und Ennodius' Wunsch wird erfüllt; seine Wünsche werden noch dadurch übertroffen, dass nun auch seine ehemalige Verlobte Gelübde ablegt. 
Wenn man den Aufbau der Erzählung, besonders den Rückblick innerhalb des Gebets, beachtet, lässt sich zunächst ein oft wiederholtes Missverständnis ausräumen: In der Forschung wurde bisher übersehen, dass es in dem Text um die Krankheit eines Diakons und dessen Reue über seine Lebensweise geht, so dass man fälschlicherweise annahm, es werde von der Bekehrung in der Jugend berichtet, die zum Eintritt in den Klerikerstand führte: MaGaNi z.B. vermutet, Ennodius habe zur Zeit der dargestellten Krankheit zu den Lektoren gehört (1886, Bd. 1,243ff.; 247). Ebenso heißt es etwa im Artikel »Ennodius « in PCBE 2.1 (1999, 621; 625), die Krankheit, in der Ennodius um die Hilfe des Heiligen Victor gebeten habe, habe zu dem Entschluss geführt, Kleriker zu werden; bei dem Text handle es sich um den Anfang einer Biographie, die von den Jugendjahren berichte und vor der Übernahme des Diakonats abbreche. Kennell schreibt, Victor habe Ennodius' Eintritt in den Klerus unterstützt, Ennodius und seine ehemalige Verlobte hätten sich gleichzeitig für ein religiöses Leben entschieden (2000, 7; 148). Die Begeisterung für das Dichten von profanen Versen $(\$ 6)$ wird daher auf die Jugend bezogen, auf die Zeit vor dem Tod der Tante, z.B.: »appassionamento giovanile per la poesia« (NAVARRA 1974, 22), »in jungen Jahren fühlt er sich zur Poesie hingezogen«(WERm ELINGer 1982, 654). Doch dies muss korrigiert werden: Derjenige, der sich in diesem Text begeistert der Dichtung hingibt, ist Diakon und trägt Tonsur; ob Ennodius auch vor der Übernahme des Diakonats als Redner und Dichter aufgetreten ist, wird in diesem Text mit keinem Wort erwähnt (dass er dies durchaus getan hat, ergibt sich aus anderen Texten, siehe dazu unten Kap. I 3 ).

Nach dieser inhaltlichen Richtigstellung sind weiter die missfälligen Urteile über den Text bzw. über Ennodius selbst zu betrachten, die sich mit den Erfolgen der historisch-biographischen Forschung zu Ennodius erklären lassen. Denn diese Wertungen des Textes lassen sich größtenteils auf die Tatsache zurückführen, dass das »Eucharisticum « nicht für sich allein überliefert ist, auch nicht innerhalb einer von Ennodius hergestellten Anordnung, sondern inmitten der anderen Werke in chronologischer Ordnung (siehe unten 28). Nun sind in der Nähe zum "Eucharisticum "Briefe des Jahres 511 überliefert, in denen Ennodius von einer Krankheit und wundersamen Genesung spricht (393f., 396, 399, 401-404, 407). Daher wird die Krankheit, von der in den Briefen die Rede ist, biographisch mit der Krankheit gleichgesetzt, über die das »Eucharisticum « berichtet, was letztlich auch richtig sein dürfte. Doch das Missverständnis, dass von einer Bekehrung vor dem Eintritt in den Klerikerstand berichtet werde, führt in der Forschung zu zwei Vorwürfen: Der erste besteht darin, dass Ennodius sein Leben nicht wahrheitsgemäß darstelle: »Das Ganze erweckt den Eindruck und will ihn erwecken, als handle es sich um die Jugendgeschichte des Schriftstellers. Leider hat Vogels eingehende Kritik <sc. seine Ergebnisse zur Chronologie> ein dem Ennodius keineswegs günstiges Resultat ergeben [...]. Es ist aus den Briefen [...] völlig sicher zu erweisen, dass die kritische Krankheit in den Sommer 511 gefallen 
ist. [...] so ergibt sich, dass Ennodius hier aus schriftstellerischen Rücksichten, die gewiß zum Teil in dem Bestreben wurzeln, seinem Lebenslauf einen dramatischen und gleichsam durch Gott ganz persönlich beeinflußten Verlauf zu geben, die Tatsachen auf das ärgste verschoben hat “ (BENJAMIN 1905, 2633); "Was soll man jedoch über die wahrscheinlich von Ennodius selbst herbeigeführte Vermengung seines Eintritts in den Klerikerstand vJ. 493 mit seiner auf eine wunderbare Heilung durch den hl. Victor folgenden Bekehrung vJ. 511 denken [...]? Hier wird offenbar versucht, das eigene Leben bei der Rückschau zu stilisieren« (Fontaine 1962, 402). Ebenso, allerdings etwas zurückhaltender RoHR (1995, 7): "Allerdings vermengt Ennodius - bewußt (?) - seine schwere Krankheit, die erst ins Jahr 511 fällt, mit seiner Bekehrung und der seiner Verlobten in jungen Jahren «. - Zwar beruhen diese Äußerungen auf einem inhaltlichen Missverständnis, das sich nun ausräumen ließ; dennoch ist grundsätzlich $\mathrm{zu}$ bedenken, dass viele weitere spätantike Darstellungen von Bekehrungserlebnissen zeigen, dass "schriftstellerische Rücksichten « und »Stilisierung « auch dieser Art von Texten durchaus nicht fremd sind und dass es unberechtigt ist, >Authentizität zu erwarten. Weder in den Briefen noch im "Eucharisticum « hat Ennodius die Absicht, einen möglichst authentischen Erlebnisbericht zu geben, was schon ein Detail zeigen kann: In der Forschung wird zwar hervorgehoben, dass manche Motive und Formulierungen im "Eucharisticum " an solche in den Briefen erinnern, die in zeitlicher Nähe zum »Eucharisticum « überliefert sind und auf die Krankheit hinweisen; doch auffälliger sind eigentlich die Unterschiede: In drei Briefen, nicht aber im »Eucharisticum«, vergleicht sich Ennodius mit Lazarus (siehe 393,1f.; 394,1; 407,1); nur in einem Brief berichtet er von der erfolgreichen Anwendung eines wundertätigen Ols $(401,2)$. Dagegen findet sich in den Briefen nur ein verborgener Hinweis auf das Gelübde (ut melioraretur): (402,1) Mox ubi me gratia superna respexit et animam de iudicii caelestis vicinitate trepidantem concesso, ut melioraretur, vivendi laxavit spatio [...]: "Sobald die himmlische Güte auf mich blickte und meine Seele, die wegen der Nähe des himmlischen Urteils zitterte, beruhigte, indem sie ihr weitere Lebenszeit zur Besserung zugestand [...].«

Der zweite Vorwurf, der auf der chronologischen Anordnung der Werke beruht, ist, dass Ennodius nach dem Gelübde noch mindestens zwei Jahre lang ohne merkliche Veränderung geschrieben habe, so z.B. Fontaine $(1962,399 f$.): »Der überlieferte Bestand bricht mit dem Jahr 513, dem vermutlichen Zeitpunkt seiner Erhebung zum Bischofsamt, ab. Muss man annehmen, dass Ennodius seine literarische Tätigkeit freiwillig einstellte, weil er im Anschluss an eine schwere Krankheit eine »Bekehrung « erlebte? Dagegen spricht, dass zwischen dieser vielleicht entscheidenden Erfahrung seines Lebens und der Abfassung der letzten erhaltenen Werke noch zwei Jahre verstreichen." Es überrascht, dass an diesem Gelübde in der Forschung in dem Maße gezweifelt wird, wie dem "Eucharisticum« andere Details des Lebenslaufs (Alter beim Tod der Tante; Verlobung bzw. Heirat etc.) gern entnommen werden. Doch wenn man das Gelübde des kranken Diakons näher betrachtet, so spricht Ennodius 
ja keineswegs davon, gar nicht mehr schreiben zu wollen, sondern, seine Mühe nicht mehr auf res saeculares zu verwenden: ut numquam stili cura de saecularium rerum ventosa executione lassaretur.

Um das Gelübde einzuschätzen, muss man unterscheiden zwischen der für Ennodius absehbaren zeitgenössischen Rezeption des "Eucharisticum « - der Imperativ expendite legentes $(\$ 12)$ zeigt, dass er mit Lesern rechnete - und der modernen Rezeption, die es nicht als einzelnes Werk liest, sondern als Teil der Gesamtausgaben. Ennodius baut diesen Text so auf, dass sich die Chronologie nicht auf den ersten Blick erfassen lässt, indem er ihm eine komplizierte Struktur mit Voraus- und Rückblicken gibt und indem er auf genaue Angaben über die zwischen den einzelnen Ereignissen verstrichenen Monate und Jahre verzichtet. Er wollte offenbar nicht, dass ein Leser das Gelübde auf einen bestimmten Moment seines Lebens festlegen konnte, denn der Leser sollte keine exakte Biographie bekommen, sondern einen Bericht über einen Diakon, der erst eine gewisse Zeit nach der äußerlichen Übernahme des Amtes durch eine Krankheit zum sechten`, d.h. sinnerlichen` Gelübde kommt.

Weiter ist zu überlegen, welche seiner Texte die von Ennodius erwarteten Leser des »Eucharisticum « noch kannten: Die Briefe waren nur seinem engsten Umfeld und den einzelnen Briefadressaten bzw. deren engstem Umfeld bekannt. Auch die Epigramme oder das witzige Epithalamium für Maximus waren sicher nicht für einen weiten Leserkreis bestimmt. Für ein breiteres Publikum waren nur Werke wie die Hymnen, die Heiligenviten oder auch der Panegyricus gedacht. Die Leser, die das "Eucharisticum« als Text ihres Diakons oder (später) Bischofs lasen und die ihn auch nur in der Rolle des Diakons oder Bischofs kannten, waren mit dieser >Bekehrungsgeschichte< sicher zufrieden: Sie konnten z.B. den Panegyricus als ein weltliches Werk ansehen, wie Ennodius es nach dem Gelübde nicht mehr schreiben wollte; sie sahen, dass Ennodius nicht als weltlicher Redner auftrat, und sie kannten keine weltlichen Gedichte von ihm. Dahe mögen die zeitgenössischen Leser wohl mit dieser "Confessio“ eines Diakons bzw. später eines Bischofs und ehemaligen Diakons zufrieden gewesen sein.

Die besondere Überlieferungslage ermöglicht uns einen anderen Blick, den Ennodius sicher nicht gewollt hätte, denn die prüfende Lektüre im überlieferten chronologischen Zusammenhang hat er nicht vorausgesehen. Aufgrund des Vergleichs mit den übrigen Werken kommt Vogel zur Einschätzung: "facta et ficta permiscentur « (1885, Praef. XXII). Doch dagegen ist zu sagen, dass Ennodius im »Eucharisticum « weniger erfindet als vielmehr manches verschweigt, was er an anderer Stelle sagt, bzw. manche Details, die die Forschung interessieren, übergeht, weil sie nicht zu seiner Intention passen. Dennoch lassen sich dem »Eucharisticum « manche Informationen über Ennodius entnehmen, die der Forschung bisher entgangen sind.

Im Folgenden wird deutlich werden, dass Ennodius im "Eucharisticum " zentrale Probleme seines Diakonats darstellt, die ihn auch in anderen Texten beschäftigen (siehe unten Kapitel I 3, bes. 82): die geforderte humilitas bzw. verbotene adrogantia, 
das untersagte Streben nach Lob (laus), die (eigentlich) aufgegebene Tätigkeit als Redner und Dichter und seine Freude an literarischer Tätigkeit, insgesamt also das Problem, dass das propositum des Diakons zunächst recht äußerlich war und er damit nicht immer so ernsthaft umging, wie er es - nicht zuletzt hinsichtlich der angestrebten Karriere - wohl sollte. Im »Eucharisticum« stellt Ennodius es so dar, dass erst die Krankheit zu einem Gelübde geführt hat, das den zunächst nur äußerlichen Wandel zum Diakon `vervollständigte «. Das zentrale Thema des »Eucharisticum «, die Spannung zwischen dem propositum des Diakons und der Freude am Schreiben, ist allerdings von der ersten Seite der überlieferten Werke an zu beobachten. Daher ist nicht zu entscheiden, ob Ennodius tatsächlich durch die Krankheit, von der er auch in Briefen spricht, zu dem im "Eucharisticum " genannten Gelübde gekommen ist oder ob er seinen allmählichen Weg vom Dichter-Redner, bei dessen Verstößen gegen die veneranda professio und expliziter Auseinandersetzung mit dem propositum der Leser oft Zeuge ist, zum überzeugten Diakon in eine gängige literarische Form bringen wollte.

Bei der Betrachtung von Leben und Werk wird auch deutlich werden, dass Ennodius im »Eucharisticum " speziell sein Diakonat im Blick hat und andere Details seines Lebens, die die Darstellung seines Verhaltens im "Eucharisticum « sogar hätten "mildern “ können, hier bewusst auslässt, um die Probleme des Diakonats möglichst schonungslos herauszustellen. So übergeht er im "Eucharisticum « ebenso, dass er vor dem Diakonat bereits ein anderes kirchliches Amt hatte, wie auch die Tatsache, dass er nicht erst als Diakon zum Redner und Dichter wurde - seine traditionelle literarische Bildung und seine Freude am Reden und Dichten werden erst für den Diakon zum Problem, und nur darum geht es in diesem Text.

\section{Einführung zu Leben und Werk}

\section{a. Eine Lücke im Lebenslauf}

An vielen Stellen in seinen Texten setzt Ennodius beim Leser das Wissen voraus, dass er auf eine Phase seines Lebens zurückblickt, in der er nicht Diakon war. Diese Information erhalten wir in etlichen Passagen, was allerdings von der Forschung bisher völlig übersehen wurde. Ennodius spricht in einigen Briefen davon, dass er sich früher mit Redekunst und Dichtung beschäftigt habe - und zwar offenbar mit einigem Erfolg (er erwähnt z.B. die ieiunia oris olim probati, die »<jetzige $>$ Dürftigkeit meiner einst anerkannten Rede «, 219,1) -, dies aber nun wegen seines Amtes, das Schweigen und Demut fordere, nicht mehr dürfe; auch in den »Dictiones Scholasticae « thematisiert er diese Veränderung. Die betreffenden Passagen durchziehen das ganze Werk vom ersten der überlieferten Texte an, stehen also im Zusammenhang 
mit der Übernahme des Diakonats, nicht mit dem im »Eucharisticum« erwähnten späteren Gelübde (siehe dazu oben 11 ff.). Wenn man diese Äußerungen über »früher" und "jetzt" als für christliche Autoren typische >Topoi` abtut und nicht weiter beachtet, geht die Grundlage für das Verständnis vieler Stellen verloren. So fehlt denn auch bisher in den Abrissen über das Leben und die Laufbahn des Ennodius die Information, dass er sich eine Zeitlang - dem überlieferten Werk zeitlich vorangehend - intensiv, d.h. über die übliche Ausbildung hinausgehend, mit den weltlichen studia beschäftigt hat, indem er sich als Dichter und Redner betätigte.

Doch zunächst kurz zu einigen bekannten Fakten der Biographie. Gute und knappe Einführungen geben vor allem Vogel (1885, Praef.), Cesa (1988, 8-17) und RoHR (1995, 1-4), ausführlicher aber zuweilen etwas spekulativ ist KenNeLl (2000, 4-42). Ennodius gibt nur spärliche Informationen, zumeist unsystematisch und zufällig, d.h. an Stellen, wo eigentlich von etwas ganz anderem die Rede ist. Z.B. erfahren wir nur indirekt vom Tod des Mailänder Bischofs Laurentius, bei dem Ennodius einen Großteil des Zeitraumes, aus dem die überlieferten Werke stammen, Diakon war und dessen Tod für einen so engen Mitarbeiter nicht ohne Auswirkungen geblieben sein kann: Es fällt lediglich einmal der Name von Laurentius' Nachfolger Eustorgius in einem Epigramm für ein Baptisterium (379,8); da Ennodius außerdem in einem Brief (314, siehe unten 123) darüber klagt (ohne irgendeinen Hinweis auf den Zusammenhang zu geben), dass jemand anders ihm selbst vorgezogen worden sei und ihm nun keine Hoffnung im Leben mehr verbleibe, wird daraus geschlossen (SUNDWALL 1919, 51f.), dass Ennodius sich Hoffnungen auf die Nachfolge des Laurentius gemacht habe, aber nicht zum Zuge gekommen sei. Zu dieser Spärlichkeit an eindeutigen Realien kommt erschwerend hinzu, dass Ennodius, wie bereits zu sehen war (siehe Kap. I 1), im »Eucharisticum « (438), in dem er in der ersten Person über bestimmte Erlebnisse und Erfahrungen berichtet, in der gleichen Weise wie Augustin in den Confessiones Biographisches mitteilt oder auch gerade nicht mitteilt.

Der Name Ennodius ist an etlichen Stellen im Werk überliefert (siehe VoGeL, Praef. I). Das -o- ist lang, wie zwei Hexameter zeigen, sowohl ein Vers von Ennodius (210: Divitibus pretium est Ennodi forma metallis; zu dem Vers unten 65) als auch ein Vers von Faustus' Sohn Messala, der unter den Werken des Ennodius überliefert ist (371,1: Suscipe versiculos, Ennodi proxime, nostros); für den Hexameter des Epitaphs (incipit: Ennodius vatis [...]) muss also entweder Synizese angenommen oder eine weitere prosodische Unsicherheit neben anderen festgestellt werden.

Ennodius wurde 473 oder 474 in Gallien geboren, möglicherweise in Arles. ${ }^{14} \mathrm{Er}$ stammte aus konsularischer Familie, und er war mit vielen seiner Korrespondenten

14 Die Argumente für 473 oder 474, zu Gallien und Arles bei Vogel (1885, Praef. II f.) und Rohr (1995, 2 Anm. 8). 
verwandt, u.a. mit Boethius und der Familie des Konsulars Faustus Niger ${ }^{15}$ (an Mitglieder dieser Familie, an Faustus selbst, an seine Söhne Avienus und Messala und an Faustus' Schwester Stephania, geht ein großer Teil der Briefe), wobei wir die genauen Grade der Verwandtschaft selten kennen. ${ }^{16}$ Nach dem frühen Tod seiner Eltern (Genaueres ist nicht bekannt; siehe die betreffende Passage: 438,18 ) wuchs er in Ligurien bei einer Tante auf; diese starb 489/490, zur Zeit der Kämpfe Theoderichs gegen Odoaker in Norditalien, als Ennodius etwa sechzehn Jahre alt war $(438,20){ }^{17}$ Er fand dann Aufnahme in einem reichen und christlichen Haus und verlobte sich mit der jungen Tochter $(438,22)$; ob er sie geheiratet hat, ist aufgrund des Überlieferungszustands der betreffenden Textstelle umstritten, und auch ihre Identität, d.h. die Frage, ob sie sich irgendwo unter den Adressatinnen der Briefe verbirgt, lässt sich nicht klären. ${ }^{18}$

Ennodius hat eine fundierte weltlich-traditionelle, d.h. auf sprachliche Fähigkeiten ausgerichtete Bildung erhalten, und er hat sich, wie unten (Kap. I 3.b) darzustellen ist, eine Zeitlang - bis zum Diakonat und darüber hinaus -, als Dichter und Redner betätigt. Aus einem Brief an einen Servilio (236) geht hervor, dass dieser an Ennodius' geistlicher Ausbildung beteiligt war, ${ }^{19} \mathrm{cf}$. )damit Du nicht glaubst, die kirchliche Saat einem entarteten Sohn übergeben zu haben « $(\$ 2[\ldots]$ ne degeneri te credas ecclesiasticum germen filio commisisse); "Durch dein Pflügen ist der frucht-

15 Fl. Anicius Probus Faustus iunior Niger; er war Consul (i.J. 490), Magister officiorum (?492-494), Quaestor palatii (503-505/6), Praefectus praetorio in Italien (509-512); siehe im Detail PLRE II, 454-456.

16 Cf. im Epitaph v.3 (abgedruckt bei Voges, Praef. LVIII): clarus prole quidem, generosior ipse propinquis; in einem Brief schreibt einer seiner Patensöhne über Ennodius (ebenfalls abgedruckt bei VoGEL, Praef. LIX, Z.17f.) qui generosi sanguinis nobilitatem humilitate praevexit ad gloriam. - Zu prosopographischen Fragen, anderen Ennodii und Verwandten unseres Ennodius siehe neben PLRE auch Vogel (1885, Praef. III f.), Stroheker (1948, 166f., 238), Mathisen (1981), Pietri (1981), Cesa (1986; 1988, 8f. Anm. 5f.), Bureau (1998), Artikel "Ennodius« in PCBE $(1999,621)$.

17 Einführend zur Zeit z.B.: L. Cracco RugGini, Nobiltà romana e potere nell'età di Boezio, 73-96 in: L. Obertello (ed.), Atti del Congresso internazionale di studi Boeziani, Rom 1981. - B. Luiselli, La società dell'Italia romano-gotica, 49-116 in: Atti del $7^{\circ}$ congresso internazionale di studi sull'alto medioevo, vol. I, Spoleto 1982. - MEYER-FLÜGEL 1992. - J. Moorhead, Theoderic in Italy, Oxford 1992. - P. Amory, People and Identity in Ostrogothic Italy (489-554), Cambridge 1997. - F. M. AusBütTEL, Theoderich der Große, Darmstadt 2003.

18 Gegen die Heirat z.B. Vogel (1885, Praef. VI) und Rohr (1995, 3 Anm. 11); für die Heirat zuletzt Kennell $(2000,7)$. Zu einer erwogenen Kandidatin unter den Adressatinnen siehe unten Anm. 646.

19 Wie Kennell (2000, 173f.) dies als Fehlinterpretation von Léglise $(1906,1,303)$ abtun und vermuten kann, dass es in diesem Brief um Arator als Schüler des Servilio gehe, ist mir unerklärlich. 
bare kirchliche Pflänzling so stark geworden [...]« (\$3 ita vomeribus tuis ecclesiasticae fecunditatis planta convaluit $[. .]$.$) .$

Über die kirchliche Laufbahn des Ennodius ist dank einer Formulierung in der Vita Epiphani bekannt, dass Bischof Epiphanius von Pavia ihn in den Klerikerstand versetzt hat: quem [sc. me, Ennodium] religionis titulis insignisti [sc. tu, Epiphani] $(80,199)$. Warum und wann er in den Klerikerstand eingetreten ist, erfahren wir nicht; im "Eucharisticum " geht es, wie oben dargelegt wurde (siehe $11 \mathrm{ff}$.), nicht um den Eintritt in den Klerikerstand, sondern um die spätere Übernahme des Diakonats (als Grund für die Übernahme dieses Amtes werden materielle Sorgen angedeutet) und die Probleme, diesem Amt zu entsprechen. Mitte der 49oer Jahre begleitete er Bischof Epiphanius auf einer diplomatischen Gesandtschaft zum König der Burgunder Gundobad, die zum Ziel hatte, Gefangene freizukaufen; ${ }^{20}$ Ennodius scheint dabei eine Art Sekretär gewesen zu sein. ${ }^{21}$ Insgesamt lässt sich nicht klären, welche kirchlichen Ämter Ennodius wann innegehabt hat und ob er die vorgeschriebene Reihenfolge der Ämter im jeweils festgelegten Alter durchlaufen hat. Denn einerseits gab es Vorschriften sowohl für die Anforderungen an Moral und Bildung der Kandidaten für ein Amt als auch für das jeweilige Mindestalter und die Zeiträume, die zwischen dem Antritt eines Amtes und der Erlangung des nächsten liegen sollten (siehe den Brief des Papstes Siricius aus dem Jahr 385, epist. pontif. 255); andererseits aber führten sowohl die konkreten Umstände als auch regionale Unterschiede zu vielen Ausnahmen. ${ }^{22}$ In schwierigen Zeiten, wenn aufgrund von Kriegen und anderen Katastrophen der Bedarf an Personen, die wichtige Funktionen und Verantwortung übernehmen konnten, besonders groß war, spielten das Alter und der zwischen der Erlangung verschiedener Grade erforderliche Zeitabstand keine Rolle, wie aus einem Brief des Bischofs von Rom Gelasius hervorgeht. ${ }^{23}$ Dieser Brief wird auf das Jahr 494 datiert, und

20 Zum Freikaufen von Gefangenen aus sowohl religiösen als auch politischen Motiven, als eine Verbindung des Ausdrucks christlicher Caritas mit der Möglichkeit für den Bischof, seinen Einfluss zu stärken und seine Autorität als Patron der Stadt zu zeigen, siehe KLINGSHiRn (1985).

21 Die Gesandtschaft wird unterschiedlich datiert, auf 496 von CESA $(1988,10$ mit Kommen$\operatorname{tar} z u \$ 123$ und \$139), hingegen auf 494 von RoHR $(1995,4)$. Die Gesandtschaft ist dargestellt in der Vita Epiphani (80, 136-177), ebenso die Tätigkeit des Ennodius (80,171); vgl. insgesamt den Kommentar von CESA (1988).

$22 \mathrm{Zu}$ den überlieferten Vorschriften für das Mindestalter zur Erlangung von kirchlichen Ämtern und zu Ausnahmen siehe Gaudemet (1958, 124-127).

23 Gelasius epist. pontif. 636 Jaffé (anno 494) [...] quo nec in totum formam veterum videamur excedere regularum, et reparandis militiae clericalis officiis, quae per diversas Italiae partes ita belli famisque consumpsit incursio, ut in multis ecclesiis, sicut fratris et coepiscopi nostri Johannis Ravennatis ecclesiae sacerdotis frequenti relatione comperimus, usquequaque deficiente servitio ministrorum, nisi remittendo paulisper ecclesiasticis promotionibus antiquitus intervalla praefixa, remaneant, sine quibus administrari nequeunt, sacris ordinibus ecclesiae funditus destitutae [...]. 
wir sehen Ennodius um die Mitte der 490er Jahre im Umfeld des Epiphanius. Gerade deswegen ist Vorsicht geboten bei Vermutungen über die kirchliche Laufbahn des Ennodius. KenNEll z.B. versucht (2000, 7-11), anhand der Laufbahn des Epiphanius Vermutungen über die des Ennodius anzustellen, obwohl sie andererseits zu Recht auf die erwähnte fehlende Einheitlichkeit hinweist. Die Tatsache, dass Epiphanius die Laufbahn bis hin zum Bischof schon durchlaufen hatte, bevor Ennodius überhaupt geboren wurde bzw. bevor die katastrophalen Ereignisse in Norditalien begannen, muss vor Übertragungen von Epiphanius auf Ennodius warnen.

Später sehen wir Ennodius im Klerus des Bischofs von Mailand Laurentius, ${ }^{24} \mathrm{mit}$ dem auch einige seiner Werke in engem Zusammenhang stehen. Der erste Text in der chronologischen Reihenfolge der Werke in den Handschriften (dazu unten 28) ist die Rede zu einem Jahrestag der Ordination des Bischofs Laurentius von Mailand. Unter anderem werden (1,20-24) Laurentius' Erfolge bei einer Synode in Rom (501/502) erwähnt, auf der versucht wurde, das Schisma zwischen Symmachus und Laurentius (nicht identisch mit dem Mailänder Bischof) beizulegen; beide waren i.J. 498 fast gleichzeitig zum Bischof von Rom gewählt worden. Im Zusammenhang mit dem Schisma und dem Ergebnis der sog. Palmensynode steht die von Ennodius später verfasste Streitschrift zur Verteidigung der Synode und des Siegers Symmachus, Libellus adversus eos, qui contra synodum scribere praesumpserunt (49), die auf eine Schrift der Anhänger des Laurentius reagiert, mit der diese das Ergebnis der Synode angegriffen hatten.

Ennodius spricht von sich als diaconus oder clericus und von seinem officium, ministerium o.ä., ${ }^{25}$ und auch der sehr häufig fallende Begriff propositum bezieht sich auf seine Stellung als Diakon (dazu ausführlich unten 277). Gleich in der Überschrift zum ersten überlieferten Text ist Ennodius als diaconus bezeichnet, und er erwähnt darin sein venerandum propositum $(\$ 5)$, d.h. sein Amt und die damit verbundenen Vorsätze. Im nächsten Werk wird die Freude über die Rückkehr nach Rom thematisiert; auch hier findet sich im Titel die Bezeichnung diaconus, und im Text werden die mit dem propositum verbundenen Gelübde erwähnt: coepti conpleantur honesta vota propositi $(2,7)$; die Formulierungen dürften darauf hindeuten, dass das Amt des Diakons für Ennodius zu dieser Zeit noch neu ist, denn die Rede ist von »Kindheit « und »Beginn «: [...] ego in ordinis et meriti constitutus infantia $(2,3)$; coepti $[\ldots]$ propositi $(2,7)$. Im »Eucharisticum« stellt Ennodius dar, dass er Diakon wurde, als er sich gerade in einer Notlage befand (siehe oben 15, dasselbe deutet er auch in 11,2 an, siehe unten 68), und es spricht nichts dagegen, dass er die höheren Weihen

24 Ob Ennodius mit Laurentius verwandt war, ist umstritten; siehe VoGel (1885, Praef. IX), der aus einer Stelle in einem Brief $(19,4)$ auf Verwandtschaft schließt, und dagegen LumPE $(1966,202)$. - Der Tod des Bischofs von Pavia Epiphanius, mit dem der Wechsel des Ennodius nach Mailand in Verbindung stehen könnte, wird unterschiedlich datiert, auf 496/ 497/ 498, vgl. Cesa (1988, $211 \mathrm{zu} \$ 195)$.

25 Z.B: diaconus $(334,2)$; clericus $(315,1)$; officium $(2,2 ; 11,2 ; 21,4)$; ministerium $(17,5)$. 
empfing (er hatte zuvor schon ein Amt bei Bischof Epiphanius), um von materiellen Sorgen befreit zu sein. Die Annahme, dass sein Verwandter und wichtigster Korrespondent Faustus ihn zur Übernahme des Diakonats gedrängt habe, beruht auf einem Missverständnis (siehe unten 68).

Der Diakon (diaconus/levita) ${ }^{26}$ war eng dem Bischof zugeordnet bzw. stand im Dienst des Bischofs; zusammen mit dem episcopus und dem presbyterus gehört der diaconus zu den ordines maiores. Der Diakon hatte neben liturgischen Pflichten bei Eucharistie und Taufe karitative Aufgaben wie die Sorge für Waisen, Kranke und Alte, außerdem administrative Aufgaben, besonders die Verwaltung des kirchlichen Vermögens; der Diakon war "geradezu der Geschäftsführer der Gemeinde« (KLAUser 1957, 899). Ennodius schreibt nirgends ausführlich über seine Aufgaben, aber manche Briefe geben immerhin eine Ahnung: Einige Empfehlungs- und Bittbriefe für Dritte enthalten Andeutungen über Probleme wie geraubte oder entlaufene Sklaven (z.B. 11, siehe unten $68 ; 66$, u. 263; 86, u. 371; 275), unleistbare Steuerforderungen (457) oder gewaltsame Übergriffe auf Ländereien und Auseinandersetzungen mit den barbari (281). In einigen Briefen werden Gerichtsverfahren erwähnt, an denen Ennodius beteiligt war (z.B. in 64, unten 233; 71, u. 298), in manchen anderen geht es um finanzielle Angelegenheiten (z.B. 139, siehe unten 170). An einigen Stellen spricht Ennodius davon, dass er im Auftrag des Bischofs Reisen unternahm (z.B. 245, unten 48; 305, u. 299); von den konkreten Zielen der Reisen erfahren wir nichts, aber Ennodius wird in der einen oder anderen Weise (materielle oder ideelle) Interessen seines Bischofs vertreten haben. GionNni (2001; 2003) bezieht alle Reisen und sonstigen Tätigkeiten, die in den Briefen angedeutet werden, auf Ennodius' Einsatz für die Macht des Papstes, d.h. für die Unterstützung des Symmachus. Doch ist zu bedenken, dass Ennodius als Diakon viele Aufgaben hatte und dass er sicher nicht hauptsächlich damit beschäftigt war, die Macht des Symmachus zu erhalten. Wenn er für Symmachus tätig war, dann sicher im Einverständnis mit seinem Bischof bzw. nach aller Wahrscheinlichkeit in dessen Auftrag.

Im Verhältnis zu der großen Menge an Briefen erfahren wir sehr wenig Konkretes über Ennodius und seine Zeit, da die Briefe fast gar nicht dem Bericht bzw. Informationsaustausch dienen, sondern überwiegend andere Funktionen haben (siehe unten II.3). Nur selten lassen die Briefe einen Blick auf Ennodius' Tätigkeiten oder die Zeitumstände zu. So ahnt man z.B. bei der Lektüre einiger Briefe im Zusammenhang mit der Bischofswahl in Aquileia, was für >Verhandlungen` einer solchen Wahl vorausgingen (siehe unten 103, 270; cf. Vogel 1885, Praef. XV). - Über das langjährige Schisma, das zu schweren Tumulten in Rom führte und in dessen Zusammenhang

26 Die Identität von Diakon und levita (siehe KLAUSER 1957, 897) wird zuweilen übersehen, was zu Fehlern bezüglich der Biographie des Ennodius führen kann (z.B. bei HaSENStab 1890, 18). - Zum Amt des Diakons siehe Klauser (1957), Gaudemet (1958, 101-104), FAIVRE (1977). 
Ennodius den "Libellus pro synodo« verfasste, wird in den Briefen nicht explizit gesprochen. Es finden sich nur Andeutungen wie »das Übel, dem Rom unterliegt« $(6,7$ malum cui Roma subcumbit), die sich vielleicht darauf beziehen, und später auch Hinweise auf die Beilegung der Probleme (301,2 reducta in ecclesia Romana concordia; 297,2 quietis tempore); die deutlichste Äußerung ist wohl folgende in einem Brief an den römischen Diakon Hormisda: "Als uns vor einiger Zeit die Angst bedrohte, als wir unsere Verdienste abschätzten und uns daher der Milde des gütigen Königs nicht sicher waren und zweifelten, haben wir Eurer Erhabenheit eine Anzahl von Pferden für den Papst unter der Bedingung übergeben [...] « (235,2). ${ }^{27}$ Man sollte jedoch vorsichtig sein, solche Andeutungen bestimmten Ereignissen zuzuordnen. Sehr zuversichtlich in dieser Hinsicht scheint hingegen GIOANNI (2003, 42), der sogar so weit geht, den Streit um den Primat des Papstes als »l'un des thèmes majeurs de la Correspondance zu bezeichnen $(2004,534)$; damit weckt er die Erwartung, Ennodius behandle dieses Thema in seinen Briefen, was aber keineswegs der Fall ist.

Ähnlich spärlich äußert sich Ennodius in seinen Briefen $\mathrm{zu}$ außenpolitischen Problemen. In einem Brief an den Praefectus Galliae Liberius (447; zum Brief siehe unten 269) erwähnt er lobend, dass Gallien nun endlich zu Italien gehöre. Dass es vorher beim Kontakt zwischen Italien und Gallien Schwierigkeiten gegeben haben könnte, lassen nur Andeutungen in Briefen an die Schwester Euprepia ahnen, z.B.: "Der Notwendigkeit schuldet man zwar Schweigen, doch der Liebe Briefe. Die Furcht fordert, nicht zu schreiben, doch manchmal weicht sie der Liebe [...] « $(293,1){ }^{28}$

Persönliche Themen sind selten, abgesehen davon, dass Krankheiten erwähnt werden, vor allem eine besonders schwere (siehe oben 17). In einigen Briefen spricht Ennodius von seinem dringenden Wunsch nach einem eigenen Haus; mit diesem Wunsch wendet er sich zunächst ohne Erfolg an Boethius (in 370, siehe unten 350); er wird ihm schließlich von Faustus und Liberius erfüllt (siehe unten 266;269;351). Häufiger als konkrete Äußerungen sind vage Andeutungen, z.B. der Dank für nicht näher bezeichnete beneficia des Faustus in $(275,1)$ und $(276,2)$.

Ennodius hat keine theologischen Abhandlungen geschrieben. Es findet sich nur ein Brief mit Ausführungen über den freien Willen (56), der in Hinsicht auf das Fortleben des Semipelagianismus sehr interessant ist, da Ennodius hier offensichtlich von

$27(235,2)$ dudum dum nobis metus instaret et de clementia pii regis dubio meritorum aestimatione penderemus incerto, caballos nostros tot dandos domno papae tali reverentiae vestrae condicione tradidimus [...]. - Ob und inwiefern Geld, das von Ennodius' Bischof in Ravenna für den Papst ausgelegt wurde und um dessen Rückzahlung Ennodius sich in mehreren Briefen bemüht (siehe in $77,283,300$ ), mit dem Schisma in Zusammenhang steht (und ob eigentlich in den Briefen von nur einem oder mehreren Vorgängen die Rede ist), bleibt mit einiger Spekulation verbunden; siehe zuletzt KENNEL.. (2000, 40-42).

28 (293,1) Debentur quidem necessitati silentia, sed scripta diligentiae: exigit metus abstinentiam tabellarum, sed interdum cedit affectui $[\ldots]$. Siehe auch $(84,3$, unten 282$)$ und $(252,2)$. 
diesem beeinflusst ist. ${ }^{29}$ Auch bemerkt Fontaine $(1962,416)$ richtig, dass Ennodius »das Walten Gottes in einer Weise auf[faßt], die sich kaum von den heidnischen oder jüdischen Ideen über die immanente Gerechtigkeit der Gottheit unterscheidet. ${ }^{30}$ Es wäre interessant, diese Aspekte genau zu untersuchen; erforderlich wäre eine unvoreingenommene Untersuchung von theologischer Seite, die nicht unbedingt die Orthodoxie des Heiligen Ennodius aufweisen will.

Im Jahr 515 ist Ennodius erstmals als Bischof von Pavia bezeugt. ${ }^{31} \mathrm{Zu}$ welchem Anlass er die Dictio incipientis episcopi (336; siehe dazu unten 38) verfasst hat - ob er sie für einen anderen (siehe unten 33 ) oder sozusagen für sich selbst »auf Vorrat « schrieb bzw. weil er sich in einer konkreten Situation Chancen auf das Amt ausmalte - muss wohl ungeklärt bleiben. Immerhin lässt sich anhand dieser Dictio ahnen, wie Ennodius die weitere Entwicklung eines gerade zum Bischof Gewählten sah: "Den Glanz des Bischofs sollen seine Taten, nicht seine Zunge bezeugen. Der Glanz dieses Amtes leuchtet mehr durch das Zeugnis der Wirklichkeit als durch das der Beredsamkeit [...]. Wenn mein Reden nicht die Seelen heilt, ist es nichts wert « $(336,4){ }^{32}$ Vielleicht ist es nicht nur Zufall, dass aus seiner Zeit als Bischof keine Werke von ihm überliefert sind.

Aus Papstbriefen geht hervor, dass Ennodius 515 und 517 als einer der Gesandten des Papstes Hormisda nach Konstantinopel ging, um Verhandlungen wegen des Acacianischen Schismas zu führen. ${ }^{33}$ Das Epitaph, das in S. Michele in Pavia noch zu sehen ist, nennt den 17. Juli 521 als Tag seiner Bestattung. ${ }^{34}$

Ein Patensohn des Ennodius, Florianus, erwähnt Ennodius nach dessen Tod in einem Brief ${ }^{35}$ als einen seiner himmlischen Fürsprecher; er erwähnt Ennodius' Redekunst und seinen erfolgreichen Einsatz in dogmatischen Auseinandersetzungen. Paulus Diakonus schöpft direkt oder indirekt aus der Vita Epiphani. ${ }^{36}$ Im 9. Jahrhundert

29 Siehe dazu: Lumpe (1969, 31 ff.); Navarra (1974, 38-42); Kennell (2000, 171f.).

30 Siehe z.B.: $(382,1)$ »die Krankheit, die ich wegen meiner Sünden erlitten habe« (inaequalitatem, quam pro peccatis sum passus); $(459,3)$ »Gibt es noch irgendeinen Menschen $<$ sc. außer mir>, der wegen seiner Sündenlast so leiden muss? « (aliquis hominum pro peccati sui onere sic laborat?); siehe auch $(463,2)$.

31 Die Argumente für die Annahme, dass er bis Ende 513 noch nicht zum Bischof geweiht war, bei VoGel (1885, Praef. XXIV f.).

$32(336,4)$ splendorem pontificis res, non lingua testetur. plus lucet claritas huius officii veritatis indicio quam loquelae [...]. sermo noster, nisi animae medetur, abiectus est.

33 Die Stellen bei Vogel (1885, Praef. XXV f.).

34 CIL V,2, 6464; ILS (Dessau) 2952. Siehe dazu: C. Merkel, L'epitafio di Ennodio, Atti della Accademia nazionale dei Lincei, Classe di scienze morali, Memorie, ser. 5,3, 1895, 83-219; M. Heinzelmann, Bischofsherrschaft in Gallien, München 1976, cf. das Personenregister s.v. Ennodius.

35 Überliefert im Codex Vat. Pal. 869, abgedruckt bei Vogel (1885, Praef. LIX). Siehe dazu JUSSEN 1991, 156f.

36 Siehe Vogel (1885, Praef. XXVI f.). 
erwähnen die Päpste Nicolaus I und Johannes VIII Ennodius als Autorität mit Zitaten aus dem "Libellus pro Synodo ${ }^{37}{ }^{37} \mathrm{Im}$ Jahr 1160 äußert sich Arnulf von Lisieux in einem Brief ${ }^{38}$ über den Stil des Ennodius, da er einen Band mit Werken des Ennodius an seinen Adressaten sendet (dazu unten Kap. I 2.c). Interesse für den Stil führte auch dazu, dass Auszüge aus Ennodius' Werken im 12. und 13. Jh. in Florilegien eingingen (z.B. in das um die Mitte des 12. Jh.s entstandene Forilegium Anglicanum), die zum Unterricht in der Ars dictaminis dienten; gesammelt wurden Beispiele für den Briefstil und besonders Sentenzen, die beim Verfassen eigener Briefe verwendet werden konnten. ${ }^{39}$ In den Acta Sanctorum findet sich die Lebensgeschichte des heiligen Ennodius unter dem 17. Juli. ${ }^{40}$

Die handschrifliche Überlieferung ist gut erforscht. ${ }^{41}$ Historisch-biographische Studien haben ergeben, dass die Werke in den Handschriften weitgehend chronologisch angeordnet sind, ${ }^{42}$ also in der Reihenfolge ihres Entstehens bzw. korrekter gesagt, ihrer Fertigstellung und Eintragung in das Kopialbuch (z.B. erwähnt Ennodius in Brief 405, dass er die »Paraenesis « jemandem zur Korrektur zugesandt habe, und das Werk ist als Nr. 452 überliefert). Werke verschiedenster Gattungen sind daher bunt nebeneinander überliefert. Einige wenige Stücke lassen sich datieren ( 9 Avieno consule i.J. 502/1; 140 Messala consule i.J. 506; Panegyricus i.J. 507; 461 i.J. 513), und diese sind bis auf eine eventuelle Ausnahme (Nr. 43) in chronologischer Reihenfolge überliefert. Ein Problem für die Chronologie bereitet die Rede anlässlich des Jubiläums des Epiphanius (43), das auf die Mitte der 490er Jahre zu datieren ist; die Datierung der Schrift ist aber umstritten. Auch wenn Sundwalls Datierungen der Texte auf bestimmte Jahre und Jahreszeiten noch in Einzelheiten zu korrigieren sein mögen, scheint doch nichts grundsätzlich gegen die chronologische Anordnung zu sprechen. - Sequenzen von Briefen zum gleichen Thema lassen sich in der überlie-

37 Siehe Migne PL 119, 942 D und PL 126, 944 C.

38 Der Brief ist abgedruckt bei Vogel (1885, Praef. LX f.)

39 Siehe Rouse und Rouse $(1989,104-106)$ mit Beispielen auch der weiteren Verwendung von Passagen aus den Florilegien.

40 Acta Sanctorum, Iulii V (dies XV-XIX).

41 Siehe besonders: Rouse/Rouse (1989); Di Rienzo (2004); außerdem: Vogel (1885), HaRTEL (1882), RoHR (1995; 1997), FINI (2000); ausführlich zu den verschiedenen Prinzipien der Ausgaben Kennell (2000, 13-15; 2000a), cf. BARTLETt (2003, 55).

42 Siehe die Studien zur Chronologie von: Vogel (1898), Hasensta b (1890), Sundwall (1919).

Einwände, d.h. Beispiele, die gegen die Chronologie sprechen, hat jüngst BARTLETT (2003) vorgebracht, allerdings kaum stichhaltig (siehe z.B. unten 378). - Im Artikel "Ennodius« in PCBE $2.1(1999,621)$ werden ohne jeglichen Hinweis auf die Abweichung von der communis opinio etliche Datierungen vorgenommen, die diese Chronologie sprengen; z.B. werden zwei Briefe an Avienus (65 und 111) als Glückwunschschreiben anlässlich seines Konsulats bezeichnet (im Zusammenhang mit Brief 9); alle drei Texte seien geschrieben, bevor Ennodius Diakon wurde. 
ferten Reihenfolge verstehen. Allerdings sollte man nicht annehmen, dass Ennodius alle Briefe eingetragen hat (siehe z.B. unten 228); wahrscheinlicher ist, dass er nur die besonders ausgefeilten aufbewahrte; Vermutungen darüber, dass Ennodius auf manche Briefe "offenbar « keine Antwort erhielt und der Adressat den Kontakt nicht wünschte (siehe z.B. unten 312f.), sind außerdem schon deshalb reine Spekulation, weil ja auch die Möglichkeit des persönlichen Treffens bestand.

Frühere Ausgaben haben die "Unordnung« der Handschriften bereinigt, indem sie die Werke nach Gattungen ordneten, und zwar in 9 Bücher Epistulae, 10 Opuscula miscella (darunter der Panegyricus auf Theoderich und das »Eucharisticum«), 28 Dictiones, 2 Bücher Carmina (Buch 1 mit den längeren Gedichten, u.a. den Hymnen, Buch 2 mit den Epigrammen); SiRMond (Paris 1611) ging darin voran, andere Herausgeber bis hin zu Hartels Ausgabe im CSEL (1882) sind ihm gefolgt. ${ }^{43}$ In Vogels Ausgabe in den MGH (1885), nach der in dieser Untersuchung (so wie ganz überwiegend in der Forschung zu Ennodius) zitiert wird, ist die Reihenfolge der Handschriften wiedergegeben. Von SIRMOND stammen auch einige Titel, z.B. "Eucharisticum«, »Paraenesis didascalica «, »Dictiones Sacrae«, »Dictiones Scholasticae», "Controversiae «; diese nicht überlieferten Titel werden im folgenden in Anführungsstriche gesetzt. Die meisten Werktitel und Überschriften sind handschriftlich überliefert und es spricht einiges dafür, dass sie im großen und ganzen von Ennodius selbst stammen. ${ }^{44}$

Doch nun zu einigen schon angedeuteten Details in Ennodius' Biographie, die bisher in der Forschungsliteratur undeutlich oder nicht erkannt sind: Kein klares Bild ergeben die Forschungsbeiträge zur Zeit vor Ennodius' Eintritt in den Klerikerstand, d.h. über seine Ausbildung, und über seine Zugehörigkeit zum Klerus vor dem Diakonat. Zwar lassen Sprache, Stil, Verwendung der Gattungen, die offenbare Kenntnis vieler weltlicher und christlicher Autoren ${ }^{45}$ überhaupt keinen Zweifel daran zu, dass Enno-

43 WeRmeLINGER $(1982,654)$ »Der Zugang zum vielfältigen Werk wird wesentlich erleichtert durch die seit Sirmond traditionelle und auch von Hartel übernommene Einteilung der Schriften nach Sachgruppen «. Gegen diese Ansicht wendet sich KenneLL, die allerdings den Eindruck erweckt, als seien die Vorteile von Vogels Ausgabe der Forschung bisher entgangen (2000a; 2000, 2; 13-16).

44 Siehe Verf., Titel und Text: Zur Entwicklung lateinischer Gedichtüberschriften. Mit Untersuchungen zu lateinischen Buchtiteln, Inhaltsverzeichnissen und anderen Gliederungsmitteln, Berlin / New York 1999, 206-209.

$45 \mathrm{Zu}$ den vielfältigen literarischen Anspielungen siehe die den betreffenden Indices der Ausgaben von Vogel und Hartel; außerdem: Vogel (1885, Praef. VIII), Dubois (1903, 51-85), Alfonsi (1976, zu Ambrosius) Fini (1982-1984) Rota (2001, 2001a). 
dius eine fundierte traditionelle sprachlich-rhetorische Ausbildung erhalten hat, aber dennoch sind manche Äußerungen dazu sehr zögerlich und übervorsichtig. ${ }^{46}$

Im Folgenden soll eine Frage wieder aufgenommen werden, auf die man in älteren Untersuchungen stößt: ob Ennodius als Diakon selbst in einer traditionellen weltlichen Schule unterrichtet bzw. einer Schule vorgestanden habe. FerTig $(1855,12)$ etwa legt dar, dass ihm bei der Betrachtung der Werke der Gedanke gekommen sei, Ennodius könnte selbst Unterricht gehalten haben, und er hält dies nur deswegen für unwahrscheinlich, weil es sich mit Ennodius' Wohlstand und Adel nicht vereinbaren lasse. Vogel (1885, Praef. XI) lehnt angesichts einiger Äußerungen des Ennodius den Gedanken, dass er unterrichtet habe, nicht völlig ab; er nimmt jedoch nicht an, dass Ennodius einer Schule vorgestanden habe, sondern er bezeichnet ihn als curator et fautor (ohne diese Begriffe zu erläutern) des Mailänder Lehrers Deuterius und vermutet, dass er einzelne Schüler in privatem Rahmen, überwiegend durch sein eigenes Beispiel, unterrichtet habe. ${ }^{47}$

Ausführlicher widmen sich Magani und Léglise dieser Frage: Nach Magani (1886, Bd. 1, 285; 289; 299) zwingt die Existenz der traditionellen Deklamationen wie z.B. der Antwort auf die Ps.-Quintilianische Declamatio maior 5 Aeger redemptus (siehe unten 47) unter den Werken des Ennodius zu der Schlussfolgerung, dass der Verfasser zur Zeit ihrer Niederschrift Lehrer war; er nimmt an, dass Ennodius gleichzeitig seine Aufgaben als Diakon wahrgenommen, Kleriker ausgebildet und auch, eventuell nicht so regelmäßig, Laien unterrichtet habe. LÉGLISE (1890, bes. 212-218; $587 \mathrm{ff}$.) folgt MaGANI in der Annahme, Ennodius sei Lehrer in einer Schule gewesen: Ennodius habe trotz seiner vielfältigen Aufgaben als Diakon eine Schule eröffnet, die mit dem Bischofssitz verbunden gewesen sei; er räumt zwar ein, dass die Korrespondenz des Ennodius hinsichtlich dieses Themas sehr diskret sei, aber man lerne aus ihr doch einige seiner Schüler kennen; in vielen Briefen könne man sehen, wie Ennodius die Erziehung auch aus der Ferne brieflich weiterführe. Diese Ausführungen von MAGANI und LÉGLISE über eine eventuelle Lehrtätigkeit des Ennodius werden in der Forschung fast völlig vernachlässigt; ${ }^{48}$ doch sie haben eine wichtige

46 Im Artikel "Ennodius " in PCBE (1999, 621 mit Anm. 24) wird die Information, dass Ennodius als junger Mann klassische literarische Studien betrieben habe, lediglich mit dem Hinweis auf eine Stelle belegt, an der Ennodius ein Zitat (aus Senecas Medea, was Ennodius aber nicht sagt) mit der Bemerkung einführt, dass er es adulescentiae meae [...] temporibus gelesen habe $(49,38)$.

47 So ebenfalls z.B. bei Benjamin (1905, 2630). Auch ReydelLet $(1993,693)$ erwähnt Ennodius' Rolle als Berater oder Repetitor neben dem Mailänder Lehrer Deuterius.

48 Kein Hinweis z.B. in der Monographie von Kennell (2000) oder bei Navarra (1974, vgl. besonders 16), der immerhin dem Thema ,Schuler ein ganzes Kapitel widmet, wobei er Ennodius' Äußerungen zur Pädagogik auf Erinnerungen an dessen eigene Schulzeit zurückführt. - Nur selten wird das Thema berührt: CESA (1988) vermeidet diese Frage bei der Behandlung des Lebenslaufes, widmet ihr aber immerhin eine Anmerkung in der all- 
Frage gestellt, wenn auch ihre Antworten zu modifizieren sind: Die Frage, warum Ennodius sich um die Bildung junger Adliger gekümmert und im Zusammenhang damit u.a. Deklamationen geschrieben hat. Daran anschließen lassen sich die verwandten Fragen, warum Ennodius dichtete bzw. warum er überhaupt dichten konnte, warum er einen Panegyricus für Theoderich und eine Verteidigungsschrift für eine Synode schrieb, warum er Aufträge für Heiligenviten bekam. Im Folgenden ist zu zeigen, dass man für die Beantwortung dieser Fragen nicht nur die Zeit des Diakonats, d.h. die Entstehungszeit der überlieferten Werke, in Betracht ziehen muss, sondern auch die Zeit vor dem Diakonat. Denn es geht aus den Texten zum einen hervor, dass Ennodius zur Zeit des Entstehens der überlieferten Werke, d.h. während des Diakonats, nicht Lehrer war, sondern sich um die Bildung junger Adliger in unterschiedlicher, jedenfalls in nicht schulisch-institutionalisierter Weise gekümmert hat; zum anderen lässt sich den Texten entnehmen, dass Ennodius sich in früherer Zeit intensiv - und zwar wesentlich intensiver als während des Diakonats - mit Redekunst und Dichtung beschäftigt und vielleicht auch unterrichtet hat; dies wird weiter unten zu entwickeln sein.

Nach einem kurzen Überblick über die erhaltenen Werke vor dem Hintergrund, dass sie von einem Diakon verfasst wurden, sollen die Äußerungen des Diakons zu seinem ,Vorleben', zu seinem jetzigen Stand und zum Gegensatz zwischen den beiden Phasen untersucht werden; diese Äußerungen sind dann mit der Darstellung im »Eucharisticum« zu vergleichen.

\section{b. Die erhaltenen Werke}

Auf den ersten Blick wird die Vielfalt der Gattungen deutlich, in denen sich Ennodius bewegt hat: Brief, Epigramm, Heiligenvita, Panegyricus, Pamphlet, Gelegenheitsgedichte und -reden zu weltlichen und kirchlichen Anlässen. Er zeigt Kenntnisse der verschiedensten paganen und christlichen Autoren, z.B. Vergil, Lucan, Statius, Claudian, Ambrosius, Symmachus, Augustin, Sidonius Apollinaris, um nur einige zu nennen, auf die er sich häufiger bezieht, sei es mit wörtlichen Zitaten, sei es mit Anspielungen auf bestimmte Passagen. Er dichtet nicht nur in Hexametern und Distichen, sondern er verwendet auch u.a. sapphische Strophen, Septenare, stichische Adonier. ${ }^{49}$ Seinen Umgang mit der Tradition beschreibt Consolino (1999, 76f.): "Per

gemeineren Betrachtung des kulturellen Hintergrundes (16, Anm. 23): "[...] Non è chiara la veste in cui Ennodio svolse la sua attività didattica."

49 Zu metrischen Fragen siehe z.B.: D. SCHALLER, Der alkäische Hendekasyllabus im frühen Mittelalter, MlatJb 19, 1984, 73-90. - S. ConDORELLI, L'esametro di Ennodio: alcune osservazioni prosodiche e metriche, in: D'ANGELo (hrg. 2003, 75-89). 
questo tardo erede dello sperimentalismo di Ausonio, tutta la produzione precedente è come un enorme repertorio da utilizzare per performances che sembrano avere a loro scopo primario una dimostrazione di versatilità, sia nel saper trattare qualsiasi genere $o$ argumento $[\ldots]$, sia nel saper variare rispetto agli schemi più consueti del genere letterario e/o della tradizione espressiva cui egli si rifâ «. Polara $(1993,221)$ benennt als einen Grund für diese oft überraschenden Variationen die Furcht vor der Banalität: "Ennodio [...] si sforza di trovare materiale sempre nuovo, di disporlo in maniere provocatorie ed inusitate, forse anche per superare con la meraviglia creata dalla novitas dell'elocuzione il possibile fastidio per la banalità e la ripetitività dei contenuti«. »Versatilità « und »Angst vor der Banalität«, wie sie Consolino und PoLARA bei Ennodius' Umgang mit den Texten früherer Autoren beobachten, werden besonders in Teil II bei der Untersuchung, wie Ennodius seine Briefe gestaltet, auf Schritt und Tritt begegnen.

Das überlieferte Gesamtwerk des Ennodius erinnert mit seiner Vielfalt an das des Sidonius Apollinaris: Dieser hatte vor seiner Wahl zum Bischof 3 hexametrische Panegyrici (mit distichischen Praefationes) und eine Reihe weiterer Gelegenheitsgedichte (Epithalamien, Dankbriefe an Gastfreunde) veröffentlicht. Als Bischof veröffentlichte er Briefe ( 9 Bücher mit insgesamt 147 Briefen), in die einige kleinere Gedichte eingelegt sind (Grabgedichte, Inschriften für Kirchen). Sidonius verwendet außer Hexametern und Distichen auch u.a. Hendekasyllaben, sapphische Strophen, Asklepiadeen und Anakreonteen. Aus seinen Briefen geht hervor, dass die Vielfalt in dem Kreis der amici, die beim persönlichen Treffen oder per Brief »ingénieuses bagatelles « austauschten, hoch geschätzt wurde (LoYeN 1943, 101; 103). In den Briefen erzählt er von Bekannten, die durch ihre Dichtkunst das Publikum begeisterten, er äußert sich schriftlich zu Gedichten, die er erhalten hat, und insgesamt spielen die Themen "Literatur« und "gebildeter Austausch« eine große Rolle in seinen Briefen.

Auch Ennodius ist in seinem Umfeld nicht der einzige, der literarisch tätig ist: In einer "Dictio Scholastica " lobt er den Lehrer Deuterius für dessen Rede- und Dichtkunst $(85,6$, siehe unten 75$)$. Er bedankt sich bei Faustus für Werke, indem er ihm seinerseits welche schickt (10, siehe unten 106; 26,2 gratias [...] refero de suscepto carmine); er erwähnt die "von der ganzen Welt gepriesenen dictiones « des Faustus $(45,4$ illas mundi ore celebratas dictiones vestras, cf. auch 7); er schreibt ein Gedicht die über Epigramme, die Faustus für seine Bücherschränke verfasst hat (70); ein Epigramm von Faustus über Ligurischen Wein ist überliefert (367). Die jungen Adligen senden Ennodius nicht nur zuweilen dictiones, sondern sie versuchen sich auch im Dichten: Ein Epigramm von Faustus' Sohn Messala ist überliefert (371), und in einem Brief wird erwähnt, dass Ennodius' Neffe Parthenius Verse verfasst hat $(258,4)$. Wir erfahren davon, dass Fehler bei den Quantitäten der Silben Kritik und Spott hervorrufen: einmal verweist Ennodius in einem Gedicht auf betreffende Schwächen des Messa- 
la (373); in einem anderen Fall muss sich Ennodius selbst verteidigen (398,2f.; 407,2, cf. 362 ).

Doch im Vergleich mit Sidonius fällt rasch auf, dass die »ingénieuses bagatelles« und der "gebildete Austausch «, wie ihn Sidonius so anschaulich macht, angesichts der Menge der Briefe des Ennodius in diesen eine ganz untergeordnete Rolle spielen. Zwar erhält Ennodius zuweilen dictiones seiner jüngeren Korrespondenten, die er dann lobt oder kritisiert; doch hierbei handelt es sich weniger um Austausch als um das Vorzeigen der Fortschritte in der Ausbildung. Er spricht in den Briefen sehr selten davon, dass gedichtet wird oder dass Werke versandt werden. In einem Brief mit einem beigefügten Gedicht bittet er den Adressaten, dieses nur selbst zu lesen und nicht zu verbreiten (siehe unten 335). Es ist auch nur einmal in einem Brief an den Presbyter Adeodatus davon die Rede, dass Bücher ausgetauscht werden $(460,4) ; ;^{50}$ der Ton der Briefe an Adeodatus insgesamt lässt vermuten, dass es sich dabei nicht um pagane Texte oder gar eigene Dichtungen gehandelt haben dürfte. Wenn nur die Briefe überliefert wären mit den wenigen in sie eingelegten Gedichten, würde man nicht ahnen, dass die Dichtung für Ennodius eine so große Rolle gespielt hat, wie es die neben den Briefen überlieferten Dichtungen zeigen.

Eine Besonderheit an der Produktion des Ennodius ist bisher in der Forschung noch kaum betont worden: Er hat nicht nur einige Werke im Auftrag, sondern auch einige im Namen anderer verfasst. Dies geht weit hinaus über die >Auftragsarbeiten im üblichen Sinne wie die Vita Epiphani $(80,1)$, die Vita Antoni $(240,4$ tu autem, venerabilis abba Leonti, qui id mihi operis iniunxisti [...]) und eventuell auch der Panegyricus (263,77 nunc ecclesia dirigit laudatorem).$^{51}$ Auch der »Libellus pro synodo « (49) ist eine Auftragsarbeit; hier formuliert Ennodius eine Antwort der angegriffenen Anhänger des Symmachus, spricht aber im eigenen Namen und verweist darauf, für wen er spricht: »Ich widme also, so gut ich kann, den Dienst meiner Stimme den Bischöfen, gegen die die Gifte der zischenden Zungen ausgegossen wurden $[\ldots]$ « $(49,4) .{ }^{52}$ Aus einigen anderen Werken jedoch geht nicht hervor, dass Ennodius sie verfasst hat: Das "Praeceptum de cellulanis" (8) ist im Namen eines Bischofs (wohl des Laurentius von Mailand) formuliert, ebenso der Brief an Christen in Afrika (51). Auch in einigen "Dictiones Sacrae" ist Ennodius nicht selbst das sprechende Ich: Einmal spricht Bischof Honoratus (98 Dictio missa Honorato episcopo Novariensi in dedicatione basilicae [...]), einmal der Vicarius Stefanius (214 Dictio data Stefanio v.s. vicario dicenda Maximo episcopo); in zwei weiteren Fällen ist nicht zu entscheiden, wer das spre-

$50(460,4)[\ldots]$ codicem recipientes meum cum illo, qui a vobis promissus est, destinate.

51 Es ist allerdings strittig, ob sich diese Formulierung konkret auf den Panegyricus oder allgemein auf den Zustand der Redekunst bezieht; gegen einen konkreten Bezug RoH R $(1995,252)$, Rota $(2002,405)$.

$52(49,4)$ oris ergo ministerium pro ingenii valitudine sacerdotibus dedo, adversus quos sibilantium effusa sunt venena linguarum [...]. 
chende Ich ist (277; 336, siehe unten 37 f.). Ein Gedicht, in dem ein Wunsch des Lehrers Deuterius an Eugenes formuliert ist und die Redekunst des Eugenes gepriesen wird, sollte Deuterius in eigenem Namen an Eugenes senden (213 Dictio data Deuterio v.s. grammatico nomine ipsius Eugeneti v.i. mittenda). Ennodius hat also zuweilen als `Sprachrohr und auch als `Ghostwriter bzw. logographos fungiert, und zwar nicht nur für seinen eigenen Bischof.

In der Forschungsliteratur wird immer wieder vermerkt, dass man es den Werken des Ennodius, bis auf Ausnahmen, nicht anmerke, dass sie von einem Kleriker bzw. Diakon stammen, z.B.: »Briefe, in denen sich die geistliche Würde des Ennodius durch eine verstohlene Anspielung auf eine Bibelstelle verrät, sind selten" (FonTAINE 1962, 401), oder: "Zweifellos würde man bei der Lektüre der Werke des Ennodius nicht vermuten, daß sie von einem Diakon verfaßt wurden, sieht man vom Libellus pro synodo, den Viten, den Benedictiones cerei und den Hymnen ab (RонR 1995, 14). Abgesehen davon, dass schon die von RoHr hier genannten Werke einen beträchtlichen Umfang haben, ist zunächst anzumerken, dass eine Anspielung oder ein Zitat einer Bibelstelle einen Autor nicht automatisch als Kleriker ausweist, sondern - wenn überhaupt - zunächst einmal als Christen; auch um einen christlichen Hymnus oder eine Heiligenvita zu verfassen, ist ein kirchliches Amt keine unabdingbare Voraussetzung. Es stellt sich die Frage, ob man erwarten darf, dass ein Christ oder auch ein Kleriker immer nur von Themen spricht, die ihn sofort als Christen oder Kleriker identifizieren.

Verschiedentlich ist von den Werken auf den Glauben des Ennodius geschlossen worden, allerdings mit entgegengesetzten Ergebnissen: So bemerkt Peter (1901, 162), dass "seine Briefe, obwohl mit den Prunkstücken heidnischer Bildung ausstaffiert, meist einen christlichen Geist atmen «, ähnlich Döpp (1999, 191): „In Ennodius' Werk gibt sich nicht nur tiefe Frömmigkeit zu erkennen, sondern allenthalben auch Aufgeschlossenheit für das Bildungserbe der paganen Antike«; FunRmann $\left({ }^{2} 1995,334\right)$ hingegen spricht von einem »Christentum, das zu einigen wenigen Phrasen verkümmert ist«, ähnlich GRUBER $(1997,1047)$ : "Hinter diese Bildungsgläubigkeit tritt seine christliche Überzeugung zurück".

Dass sowohl die negativen als auch die positiven Urteile über die christliche Haltung des Ennodius weniger über diesen aussagen als über die Erwartungen ihrer jeweiligen Vertreter, zeigt sich nicht zuletzt, wenn man einen Blick auf vergleichbare Ansichten über andere spätantike Autoren wirft: Anders als Ennodius, dem die paganen Elemente in seinen Texten nicht selten zum Vorwurf gemacht werden, ist Ambrosius ein mangelndes Verständnis für die weltliche Bildung vorgehalten worden (z.B. KLEIN 1971, 134). Dagegen zeigt Zelzer (1993), dass und in welcher Form Ambrosius klassische Texte verarbeitet; bei seinen Anspielungen auf klassische Texte handle es sich nicht um ein bloßes Schmuckelement, sondern vielmehr habe sich Ambrosius im Stil seinen Adressaten angepasst und so der Angst der Heiden entge- 
gengewirkt, mit der paganen Religion werde gleichzeitig auch das geistige und literarische Erbe getilgt; ZELZER macht deutlich, dass Ambrosius, als dem römischen Adel entstammender Kirchenpolitiker, eine Brückenfunktion übernimmt und einen wichtigen Beitrag leistet $\mathrm{zu}$ einem neuen Umgang mit dem kulturellen Erbe. - Auch die Werke des Hieronymus werden inzwischen positiv als "Schnittstelle von paganer und christlicher Literatur “ (CoNRING 2001, 1) gesehen; zwar haben die Traumvision, von der Hieronymus in Brief 22 berichtet ("Ciceronianus es, non Christianus «), und ihre eingetretenen oder ausgebliebenen Konsequenzen seit Rufin zu viel Kritik und Diskussion Anlass gegeben; inzwischen aber wurde erkannt, dass die Äußerungen des Hieronymus zur traditionellen Bildung immer im Zusammenhang mit ihrem jeweiligen Adressaten gesehen werden müssen (siehe z.B. ReBenICH 1992, 167). - Noch anders die Einschätzung des Sidonius Apollinaris: Er gab nach seiner Ernennung zum Bischof das Dichten zugunsten der Epistolographie auf und »die schon zu Lebzeiten viel bewunderten Briefe übten große Wirkung auf Spätere aus und sind eine wertvolle Quelle für das gesellschaftliche und geistige Leben seiner Zeit“ (ZeLzer 1997, 348). ${ }^{53}$ Erstaunlich ist im Vergleich zum Umgang mit dem Diakon Ennodius, dass dem Bischof Sidonius Apollinaris, der sich im Vorwort zum ersten Buch ausdrücklich auf Symmachus und Plinius als Vorbilder beruft, der streckenweise sehr weltliche Inhalt seiner Briefe nicht zum Vorwurf gemacht wird.

Anstatt in der angedeuteten Weise zu werten, sollte man sich daher darauf beschränken, zu beobachten, welche Art von Werken ein Diakon am Anfang des 6. Jh. geschrieben hat; dass er höchstwahrscheinlich nicht alle Werke, und dass er sie sicher nicht in der Weise, wie sie uns vorliegen, selbst veröffentlicht hat, kann das Interesse an ihrer Gesamtheit nur verstärken: Wo haben wir sonst Texte eines nachmaligen Bischofs, die er zum Teil selbst nicht veröffentlicht hat und vielleicht gar nicht veröffentlichen wollte?

Im Folgenden sollen die Werke kurz vorgestellt werden ${ }^{54}$, damit für die innerhalb der folgenden Untersuchung der >Vorgeschichte des Diakons anzuführenden Zitate der jeweilige Zusammenhang deutlich ist. Werke, die in der Forschung noch kaum Beachtung gefunden haben (z.B. die »Dictiones Sacrae«, das Epithalamium), werden dabei vergleichsweise ausführlicher dargestellt als die bekannteren (wie z.B. die Vita Epiphani, der Panegyricus). Die Werke werden in einer Reihenfolge präsentiert, die Chronologie (das Prinzip der Handschriften, dem Vogels Edition folgt) und Gattungen (das Prinzip, das Srrmond eingeführt hat und dem Hartels Edition folgt) verbindet: Damit in gewissem Maße die Vielfalt und Buntheit der Werke deutlich

53 Siehe auch z.B. die Darstellung bei Funrmann ( $\left.{ }^{2} 1995,274-281\right)$.

54 Die Literaturangaben zu den einzelnen Werken beschränken sich auf einführende und grundlegende Arbeiten; ergänzend hinzuzuziehen sind jeweils die Angaben bei RoHr (1995, 5-11) und die Bibliographie von Di Rienzo (2004). 
wird, werden die verschiedenen Gattungen in der Reihenfolge vorgestellt, wie sie in den Handschriften nacheinander erstmals erscheinen; im Zusammenhang mit dem jeweils zuerst überlieferten Text einer Gattung werden alle zugehörigen Texte, die zumeist über das Gesamtwerk verstreut sind, erwähnt. So kann deutlich werden, dass über den gesamten Zeitraum verteilt Werke unterschiedlichen Charakters entstanden sind: solche mit eindeutig christlichem Inhalt, die in unterschiedlicher Weise das kirchliche Leben betreffen; solche, die eindeutig in der paganen Tradition ihrer Gattungen stehen, aber dennoch deutlich erkennen lassen, dass sie von einem Christen verfasst wurden; außerdem solche Werke, die gar keinen Hinweis darauf enthalten, dass sie von einem Christen verfasst wurden; schließlich auch solche, in denen aus Aspekten des Christentums witzige Pointen formuliert werden. Warum Ennodius ein so vielfältiges Werk hinterlassen konnte, wird im Laufe von Teil I verständlich werden.

\section{"Dictiones Sacrae«}

Zuerst überliefert ist eine der sechs sogenannten "Dictiones Sacrae« $(1 ; 98 ; 214 ; 277$; 336; 464); hierbei handelt es sich um Prosatexte, die Anlässen im kirchlichen Bereich (im weitesten Sinne) gewidmet sind. In einigen ist nicht Ennodius selbst das sprechende Ich, sondern sie sind für andere Sprecher verfasst worden (siehe oben 33). Außer kurzen Erwähnungen bei Magani (1886), NaVarRa $(1972,474-478)$ und KeNNELL (2000, 100; 175; 182; 211) sind diese Beispiele für Texte zu kirchlichen Anlässen, die keine Predigten sind, noch kaum beachtet worden.

(1) »Zum Jahrestag der Ordination des Mailänder Bischofs Laurentius«: Auf eine Vorrede in eigener Sache, d.h. zur Problematik des Redens (\$1-6; dazu unten 65), folgt eine Beschreibung der aktuellen Jahreszeit, des Frühlings (\$7-8); den Hauptteil bildet ein Abriss von Laurentius' Zeit als Bischof, über seine Wahl (\$9-11), seinen Einsatz für seine Gemeinde in Kriegszeiten (\$12-19) und über seine Leistung während einer Synode in Rom (\$20-24); abschließend $(\$ 25)$ wird die Hoffnung auf ein langes Leben des Laurentius ausgesprochen.

(98) »Bei der Weihung der Basilika der Apostel an der Stelle, wo vorher ein heidnischer Tempel war; für Honoratus, den Bischof von Novara«: Dieser Text gehört zur Reihe derer, in denen andere als Sprecher gedacht sind, hier ist Honoratus das sprechende Ich (cf. \$2). Betont wird die Tatsache, dass zwar das Gebäude geblieben, aber der alte Kult der christlichen Religion gewichen ist $(\$ 1)$; Victor, Honoratus' Amtsvorgänger, der diese Umwidmung initiiert hat, wird gelobt (\$2f.) und als Beispiel gerühmt (\$4). Ausführlich herausgearbeitet wird der Gegensatz zwischen dem ehemaligen paganen Tempel mit den entsprechenden Riten einerseits ( $\$ 9$ templa turpi hactenus dedicata patrocinio) und der Kirche mit dem christlichen Glauben andererseits (\$5-9); abschließend wird der anwesende Mailänder Bischof Laurentius gelobt (\$gf.). 
(214) Auch die folgende Dictio ist für einen anderen Sprecher bestimmt: Ennodius hat sie für Stefanius ${ }^{55}$ geschrieben, der sie dem Bischof Maximus vortragen (oder vielleicht auch nur vorlegen?) sollte (Dictio data Stefanio [...] dicenda Maximo episcopo). Der Sprecher hat das Ziel, mit dieser knappen (cf. \$9 strictim) Würdigung der Persönlichkeit und der Qualitäten des Adressaten seine rhetorischen Fähigkeiten zu empfehlen ( $\$ 9$ pro linguae meae commendatione), um dann später einmal dessen Taten ausführlicher darzustellen, damit die Erinnerung daran nicht verlorengeht $(\$ 9$ gestorum tuorum plena me relatione consecrabo, ut quae universis nota sunt, mansuris in posterum litteris [...] serventur). Es ist vielleicht kein Zufall, dass der angesprochene Bischof, dem hier die spätere schriftliche Verewigung seiner Taten angeboten wird, zuvor eine weltliche Karriere durchlaufen hat ( $\$ 4$ te olim saecularibus inhaerentem titulis $[. .]$.$) .$

(277) Bischof Maximus erhält ein Schreiben anlässlich der Weihung eines Johannes dem Täufer, Antoninus und Cassianus geweihten Kirchenraumes ${ }^{56}$ (Dictio in dedicatione missa Maximo episcopo). Der Sprecher wendet sich am Ende an denjenigen, der die Weihung der Kirche initiiert hat $(\$ 7)$; es ist schwer zu entscheiden, ob Ennodius als Sprecher sich an Maximus, oder ob Maximus sich an einen anderen wendet (und damit auch dieser Text zu denen gehört, die Ennodius für jemand anders verfasst hat); die Bezeichnung frater scheint allerdings darauf hinweisen, dass hier von gleich zu gleich, also von Bischof $\mathrm{zu}$ Bischof gesprochen wird $(277,7 \mathrm{tu}$ autem, frater sanctissime, huius oblator aedificii [...]). - Zunächst beschäftigt sich der Sprecher mit dem Problem, dass er bei diesem Anlass sprechen soll: Der an den Anfang gestellte >Topos`, dass ein mageres Talent kein Grund zur Furcht sein müsse, wenn der Anlass für die Rede ein bedeutender sei, wird weitergeführt mit dem Hinweis darauf, dass Gott in der Lage sei, die Fähigkeiten des Redners zu vergrößern $(\$ 1)$; Gott habe auch Mose geholfen, von einem Moment auf den anderen gut sprechen zu können (\$2); aufgrund der weltlichen Bildung sei weder zu große Selbstsicherheit angebracht noch Furcht $\left(\$_{3}\right)$, zumal Johannes schon durch seine Geburt und deren Wirkung auf die Sprache des Zacharias gezeigt habe, dass er der Schlüssel der Worte sei ( $\$ 5$ clavis [...] verborum). Weiter wird hervorgehoben, dass das Gebäude zwar vergänglich sei, aber durch Christus an Stärke gewinne $(\$ 6)$; der Initiator der Weihe solle sich an der Frucht seiner Tat freuen $\left(\$_{7}\right)$. - Es spricht manches dafür, dass der in der Überschrift genannte Maximus mit dem Adressaten der letztgenannten Dictio (214) identisch ist. Dort wird erwähnt, dass der neu ernannte Bischof Maximus zunächst eine Karriere am Hof des Kaisers durchlaufen hat $(214,4$, siehe oben

55 In PLRE II, p.1031, "Stephanus [sic] 18 " wird vermutet, dass Stefanius Vicarius Italiae gewesen sei und Maximus der Bischof von Pavia.

56 cf. $\$ 3$ dedicationis festa celebrantes; $\$ 6$ consecrantis nobilitate; $\$ 4$ beati Iohannis prophetae et apostoli, cuius templum hoc sanctificavit ingressus; $\$ 5$ in huius comitatu Antoninus [...] et beatissimi Cassiani iuncta claritudo [...]. 
37); darauf kann sich hier der Vergleich mit Mose beziehen, der in einem einzigen Augenblick eine Veränderung erlebte hin zu: perfectam magistri eloquentiam, fortissimi monitoris tubam und officium ducis (\$2). Mose ist verändert worden, und auch Maximus (ebenso wie Ennodius) muss sich im kirchlichen Amt nun anders verhalten als früher, er muss mit der früher erworbenen Redekunst jetzt anders umgehen. Auch der Hinweis auf Zacharias hat für Maximus mit seinem »weltlichen Vorleben" eine spezielle Bedeutung: Für ihn muss nicht aus Stummheit Redekunst, sondern aus weltlicher Redekunst ( $\$ 4$ pristina linguae inperitia) die eines Bischofs werden.

(336) In der Dictio incipientis episcopi wird nicht gesagt, wer der Bischof ist, auf dessen Amtsantritt sich dieser Text bezieht; Sundwall $(1919,54)$ vermutet, dass die Dictio für den neuen Bischof von Mailand Eustorgius, den Nachfolger des Laurentius, verfasst sei. Doch da, anders als bei den gerade vorgestellten Dictiones für Honoratus und Maximus, weder die Überschrift noch der Text einen Hinweis auf die Identität des sprechenden Ichs enthält, ist diese Zuweisung völlig hypothetisch - es könnte ebensogut sein, dass Ennodius in der Hoffnung, selbst Nachfolger des Laurentius zu werden, den Text im Voraus - und, zumindest für diesen Zeitpunkt, vergeblich - für sich selbst geschrieben hat; auf jeden Fall passt die Auseinandersetzung mit den Themen "Lob" und "Demut " fraglos gut zu Ennodius selbst (siehe unten Kap. I 3.a). - Der Text beginnt mit dem Gedanken, dass ein Bischof zu Beginn seiner Amtszeit noch kein Lob verdiene; echtes Lob sei solches, das mit vielen Mühen erarbeitet sei (\$1f.). Für den Sprecher bestehe das besondere Problem, dass er einerseits ein lobenswertes Leben führen müsse, andererseits aber nicht auf Lob von Menschen aus sein dürfe $\left(\$_{3}\right)$. Den Glanz eines Bischofs müssten seine Taten, nicht Worte (darüber) bezeugen; seine Rede sei nur gut, wenn sie die Seelen heile (\$4). Die Gemeinde müsse dem guten Beispiel des Bischofs folgen, auch wenn er gar nicht rede. Außerdem gebe die neue verantwortungsvolle Position Grund zur Sorge ( $\$ 5)$, und gefordert sei größte Demut $(\$ 6)$. Der zweite Abschnitt $(\$ 7-9)$ ist ein Gebet (unter der Überschrift Precatio missarum) an Gott den Schöpfer, das sich bei der Übernahme des neuen Amtes an den Gott der Anfänge richtet ( $\$ 7$ ut inter exordia dignitatis tibi principiorum domino supplicemus); Gottes Wirken bei der Schöpfung wird beschrieben $(\$ 7 \mathrm{f}$.), und Gott wird um entsprechende Unterstützung des Sprechers gebeten (\$9). Der abschließende Teil (\$1of.) unter der Überschrift Oratio ante missam zeigt am Beispiel des Mose, was Gott bewirken kann, und bittet um die Gnade Gottes und um die entsprechenden Qualitäten, die die Wahl des Sprechers zum Bischofs rechtfertigen.

$\mathrm{Zu}$ den Dictiones Sacrae zählt SIRMOND auch (464), doch da der Text einen von den gerade vorgestellten Dictiones verschiedenen Charakter und einige Ähnlichkeiten $\mathrm{zu}$ anderen Texten aufweist, soll er in anderem Zusammenhang vorgestellt werden (unten 43).

Die Schrift (43) zum 30. Jahrestag der Ordination des Bischofs von Pavia Epiphanius wird seit SIRMONDs Einteilung zwar zu den Carmina gerechnet, gehört aber aufgrund des Themas eher zu den Dictiones Sacrae; anders als die bereits vorgestellte 
ganz in Prosa gehaltene Dictio zum Jahrestag des Bischofs Laurentius (1) besteht sie aus einer Prosa-Vorrede und einem Hauptteil in Hexametern. Die Prosa-Einleitung thematisiert die Situation des Sprechers, und das Gedicht beginnt mit der Darlegung der Unterschiede den zwischen früheren - heidnischen - und den vom Heiligen Geist und Christus inspirierten Dichtern. Der Hauptteil setzt ein (v.44) mit der Darstellung der Umstände bei Epiphanius' Wahl zum Bischof, es folgt (v.88) ein Rückblick auf ein Wunder bzw. Zeichen in seiner Kindheit, das zu seiner frühen Weihung für die Kirche führte. Angedeutet wird Epiphanius' Einsatz für den Freikauf von Gefangenen in Gallien (v.126 ff.), und sein Wirken als Bischof wird im allgemeinen gelobt (134 ff.). Den Abschluss bildet eine Anrede an den Adressaten mit dem Hinweis darauf, dass der Verfasser sich Mühe gegeben habe, die Quantitäten der Silben zu beachten (mit Akrostichon En-no-di-us in den letzten vier Versen). - Umstritten ist, warum dieses Werk zwischen den anderen überliefert ist, d.h., ob Ennodius es erst Jahre nach dem Anlass (das Jubiläum des Epiphanius wird auf 495, 496 oder 497 datiert) verfasst oder ob er es wieder hervorgeholt hat, als er begann, die Vita des Epiphanius zu schreiben (siehe dazu Hasensta $1890,15-18$; Vogel 1898, 54f.). - Zu vergleichen ist neben der Dictio auf Laurentius besonders die Vita Epiphani (80, dazu unten 46).

\section{Prosa-Praefatio mit Gedicht}

Das an zweiter Stelle überlieferte Werk Dictio Ennodi diaconi quando de Roma rediit (bei SIRMOND carmen 1,6) besteht aus zwei Teilen, einem in Prosa und einem in elegischen Versen. ${ }^{57}$ Ennodius thematisiert zunächst im Prosateil seine Freude bei der Rückkehr ( $§$ If.); für das Verfassen von Versen beruft er sich auf das Beispiel der Propheten $(\$ 2 f$.). Er erwähnt, er habe bereits gelernt, mit welcher Wucht man für den Glauben kämpfen müsse, und er habe dabei schon Erfolge erzielt (\$3); er sieht Angriffe von Neidern voraus $(\$ 4 \mathrm{f}$.). Letzteres könnte sich darauf beziehen, dass er das Amt des Diakons erst kürzlich übernommen hat, und auch das Weitere spricht für diese Annahme. Er betont, dass die traditionelle weltliche, d.h. rhetorische Bildung der geeignete Ausgangspunkt sei, um sich mit der richtigen Grundlage den Studien der Heiligen Schrift zu widmen (\$5f.; siehe dazu unten 84 ). Man müsse jeden Teil der Gemeinde ansprechen können, die Gebildeten mit anspruchsvoller Sprache, die Ungebildeten in ihrer Sprache $(\$ 6)$. Das direkt anschließende Gedicht (siehe dazu unten 49) fasst die Themen >Reise`, >Ankunft‘ und >Freude` in Bilder.

Zwei längere Gedichte $(26 ; 27),{ }^{58}$ die jeweils durch eine Prosa-Praefatio eingeleitet sind (26 ist überschrieben mit praefatio Fausto, 27 zunächst nur mit praefatio, der

57 Siehe dazu MaUrach (1984, Úbersetzung und Interpretation der Verse) und LebeK (1993). LEBEK möchte u.a. zeigen, dass der Prosateil und das Gedicht nicht zusammengehören.

58 Siehe Einleitung, Übersetzung und Kommentar von VANDONE (2004). 
Adressat Olybrius ist dann vor dem Gedicht genannt), werden zuweilen als panegyrische Dichtungen auf die Adressaten bezeichnet. ${ }^{59}$ Doch da der Terminus spanegyrisch،, zumal in spätantikem Kontext, an öffentliche Anlässe und speziell an Kaiserlob denken lässt, erscheint er wenig passend. Darauf, dass an ein weiteres Publikum als an den direkten Umkreis des jeweiligen Adressaten gedacht wäre, gibt es keinen Hinweis. Zudem betrifft das Lob für die Adressaten ganz überwiegend ihre Dichtung, es geht in nicht geringem Maße um Dichtung allgemein und auch um die des Verfassers. Deshalb wäre es passender, von ,Gelegenheitsgedichten über Dichter und Dichtung zu sprechen, und daher trägt auch VANDONEs Untersuchung der beiden Gedichte den passenden Titel "Appunti su una poetica tardoantica."

Faustus, der Adressat von (26), hat Ennodius ein Werk zugesandt, für das dieser sich mit der Prosa-Praefatio und dem polymetrischen Gedicht (Distichen, Hexameter, sapphische Strophen, Adoneen) bedankt; die dichterischen Fähigkeiten des Faustus werden gepriesen, ihnen werden die geringeren Fähigkeiten des Verfassers gegenübergestellt (siehe dazu unten 107).

Olybrius hat Ennodius offenbar aufgefordert, ihm zu schreiben; in der Praefatio und im distichischen Gedicht (27) legt Ennodius in verschiedenen Bildern die Gründe dar, die dagegen sprechen (dazu ausführlich unten 78). Hauptthema ist Ennodius' eigene Dichtung, wobei sich das Lob auf die betreffenden Fähigkeiten des Olybrius im Kontrast ergibt, doch keineswegs im Mittelpunkt steht. Ennodius kleidet seine "Recusatio« (so treffend Polara 1993, 227; Vandone 2004, 101) im Prosateil in bukolische Bilder ein, im Gedicht in einen Vergleich seiner Situation mit der des Phaethon.

\section{"Dictiones Scholasticae«}

Die sog. "Dictiones Scholasticae" dienen zuweilen als Dokument für das Bestehen einer Schule in Mailand, sind aber noch wenig untersucht; einige werden vorgestellt von NavarRa (1972, 466-470) und Kennell (2000, 59f., 138f.). Es handelt sich dabei um Prosatexte zu verschiedenen schulischen Anlässen: eine Rede bei der Verlegung einer "Schule", d.h. des Unterrichtsraumes eines Lehrers, an einen anderen Ort (3), vier Reden zur Einführung von neuen Schülern bei einem Lehrer $(69,85,124,451)$ und zwei Reden anlässlich des Erfolgs von Schülern $(94,320)$. Hinzuzählen sollte man auch das an einen Lehrer gerichtete distichische Gedicht zur Einführung zweier Schüler (262, cf. v.19: stirpem Proculi [...] suscipe doctor; bei SIRMOND carm. 1,3). In einem Teil dieser Texte ist als Lehrer namentlich Deuterius angesprochen, und auch in den übrigen könnte er der Adressat sein..$^{60}$ Deuterius scheint gleichzeitig sowohl Grammatik als auch Rhetorik unterrichtet zu haben, denn auf den Unterricht beim

59 Zusammen mit der Dictio zum dreißigjährigen Jahrestag der Ordination des Bischofs Epiphanius (43); siehe z.B. Rohr (1995, 9f.).

$60 \mathrm{Zu}$ Deuterius siehe besonders Kaster (1988, 267-269); PLRE II,356f. („Deuterius 3"). 
Rhetor beziehen sich die Texte (3), (69) und (85), auf den Grammaticus hingegen weisen (94), (124) und (451). Entsprechend erwähnt ihn Ennodius als Dichter und auch als Redner. Ob Ennodius diese Texte tatsächlich bei entsprechenden Feierlichkeiten vorgetragen hat, wie groß das Publikum war, ob er sie hat von anderen vortragen lassen, ob es vielleicht Schreiben nur an den Lehrer bzw. an den oder die Schüler waren, oder ob vielleicht gar nicht alle dem gleichen Zweck gedient haben, ist eine offene Frage. An zwei Stellen in den Texten finden sich immerhin Hinweise auf ein größeres Publikum (94,9 coram multis; 124,3 auditorum benignitate). Die letzten $\mathrm{Pa}-$ ragraphen der Eingangsrede für Arator (85,14 ff.), die besser nicht als Teil der Rede, sondern als nachträgliche Bemerkungen gelesen werden (darauf weist außer dem Inhalt die Tatsache, dass alle Handschriften mit $\$ 14$ einen neuen Abschnitt beginnen lassen, vgl. den Apparat bei VogeL), scheinen allerdings darauf hinzuweisen, dass Ennodius die Rede $(\$ 1-13)$ nicht persönlich bei dem Anlass vorgetragen, sondern den Text schriftlich übersandt hat. - In welcher Funktion und warum Ennodius diese Texte verfasst hat, wird weiter unten untersucht (siehe Kapitel I 3.b.2).

\section{Briefe}

Der vierte überlieferte Text eröffnet die Reihe der ca. 300 Briefe. ${ }^{61}$ Da Teil II dieser Arbeit den Briefen gewidmet ist, können hier kurze Hinweise genügen, soweit sie als Hintergrund für Zitate aus Briefen in Teil I wichtig sind. Die Briefe richten sich an einen großen Kreis von Adressaten, an Verwandte und an kirchliche und weltliche Amtsträger ${ }^{62}$ (siehe den Index der Adressaten bei VoGEL, 327-329, zusammen mit dem Index nominum, 348-363). Die Anzahl der Briefe, die die einzelnen Adressaten erhalten, ist ganz verschieden; die meisten Briefe ( 54 nach dem Index bei VoGEL) erhält Faustus, mit dessen Frau Ennodius verwandt ist; an zweiter Stelle folgt deren Sohn Avienus (24 Briefe) ${ }^{63}$ etliche Adressaten erhalten aber auch nur einen einzigen Brief.

Ennodius nimmt seine Korrespondenz anders als etwa Ambrosius oder Hieronymus nicht zum Anlass für theologische Traktate. Viele Briefe danken ihr Entstehen einem erkennbaren konkreten Anlass, z.B. Glückwunschschreiben, Bittbriefe für ihn selbst oder für andere, oder auch die große Anzahl von Empfehlungsschreiben. Der

61 Sirmond hat 297 Texte als Briefe klassifiziert, Vogels Index der Adressaten hingegen ergibt 311 Briefe, siehe dazu Kennell (2003, 112f.).

62 Anreden in den Briefen wie magnitudo, culmen, sublimitas, amplitudo u.a. werden im Folgenden i.d.R. mit »Hoheit « übersetzt - in Ermangelung einer befriedigenderen Lösung, da sich in jedem Fall ungewollte Assoziationen ergeben.

63 Wie in vielen der bei den Briefen aufkommenden prosopographischen Fragen ist auch hier letztlich keine Sicherheit zu erlangen, doch es spricht zumindest nichts dagegen, dass es sich um einen einzigen Adressaten dieses Namens handelt; in PLRE II, 192f., sind die Briefe 65 und 75 einem anderen Avienus als dem Sohn des Faustus zugeschrieben, wofür ich jedoch keinen zwingenden Grund erkennen kann. 
Inhalt vieler Briefe dient der Kontaktpflege, z.B. mit der Frage nach der Gesundheit des Adressaten und einer Mitteilung über die eigene, mit dem Dank für einen erhaltenen Brief bzw. der Aufforderung zu schreiben, mit der Nachricht über die gute Heimkehr nach einer Reise u.ä. Wichtige Themen sind `Freundschaft` und `Korrespondenz` (siehe unten Kap. II 2.d.1, 2), besonders gegenüber jüngeren Adressaten spricht Ennodius über Bildung und den Zusammenhang zwischen Bildung und Korrespondenz (siehe unten Kap. I 4). Es besteht immer die Möglichkeit, dass der Briefbote konkretere Nachrichten ausgerichtet hat, und zuweilen wird im Brief darauf verwiesen. Nur wenige Briefe haben gemäß ihrem Anlass ein Thema, das den Glauben berührt, z.B. ein Trostbrief (34) an jemanden, der seinen Sohn verloren hat, oder ein Brief (56), in dem sich Ennodius zum Problem der Willensfreiheit äußert. Viele Briefe enthalten gar kein Bibelzitat oder ein speziell christlich zu verstehendes Wort. In der großen Menge von Briefen stehen christliche Gedanken bzw. Formulierungen weder im Mittelpunkt noch werden sie ausgeklammert; häufig sind kurze Bemerkungen wie "Ich habe Gott um sein reiches Erbarmen gebeten $[\ldots]$ « $(9,1$ abundantem dei misericordiam precatus $[\ldots]),{ }^{64}$ aber auch Bitten um Fürbitte oder Dank für erfolgreiche Gebete, z.B. „Dank Eurer unterstützenden Gebete - denn Eure Unschuld und Demut lässt Euch unserem Gott angenehm sein -, fühle ich mich schon besser" $(403) .65$

Zum "Einlesen " in die Briefe allgemein können z.B. die 24 Briefe an Faustus' Sohn Avienus dienen, da man in ihnen einen Großteil der Themen vorfindet, ${ }^{66}$ mit denen sich Ennodius in seinen Briefen beschäftigt (besonders `Brieftopik« und Ermahnungen zur Bildung, aber auch die Krankheit und der Wunsch nach einem Haus); vergleichbar sind in dieser Hinsicht nur die (mehr als doppelt so vielen) Briefe an Faustus. Anders als bei der großen Zahl der Glückwunsch- und Empfehlungsschreiben an verschiedene Adressaten, die durch bestimmte Anlässe hervorgerufene >Einzelbriefer bleiben, lassen sich in der Korrespondenz mit Avienus (wie auch besonders in der mit Faustus) zuweilen Themen über mehrere Briefe verfolgen. Auch zeigt sich, dass Ennodius nicht immer im gleichen Tonfall spricht: Avienus gegenüber gibt er sich manchmal freundschaftlich mahnend, häufiger streng mahnend, zuweilen ironisch und selten rartig freundlich', phasenweise auch klagend. An diesen Briefen lässt sich weiterhin gut beobachten, wie Ennodius seinem Prinzip folgt, sei-

64 Häufig nur wenige Worte, kurze Hinweise wie z.B.: $(6,4)$ deo gratias, qui ea quae dura aestimantur clementia bene vertit $[\ldots] ;(12,4)$ sic apicem vestrum $[\ldots]$ divinus favor adtollat; $(18,3)[\ldots]$ si miseretur divinitas $[\ldots] ;(22,2)[\ldots]$ deo supplicans $u t[\ldots] ;(36,1)$ quanto deprimuntur peccatores suorum fasce factorum.

65 (403, an Avienus) [...] iuxta orationum vestrarum suffragia, quos innocentia et devotio deo nostro facit adceptos, meliorem me esse iam sentio [...]. Siehe auch z.B. unten 114, 124, 198f., 202, 233, 241, 301.

66 Viele dieser Briefe werden in dieser Arbeit angesprochen, vgl. den Index s.v. Avienus. 
ne Adressaten nicht direkt, sondern lieber gegenüber Dritten zu loben (siehe unten $119,122)$.

Besonders hinzuweisen ist auf einen Brief (51), den Ennodius im Namen des Bischofs verfasst hat (cf. \$5 quod [...] directis ad filium nostrum diaconum litteris sperastis [...]). Dieser Brief richtet sich an Christen in Afrika, die unter der Verfolgung durch die Vandalen leiden und die wohl um die Übersendung von Reliquien Mailänder Märtyrer gebeten haben ( $\$ 5$ beatorum martyrum Nazari et Romani benedictionem poscentes).

"Praeceptum de cellulanis" (8); "Dictio de haereticis et synodo" (464)

Das ,Praeceptum de cellulanis ${ }^{67}$ (so die in der Forschung verwendete Kurzform; als Überschrift ist überliefert: praeceptum quando iussi sunt omnes episcopi cellulanos habere) gehört zu den Texten, die Ennodius im Namen anderer verfasst hat (siehe oben 33). In diesem Text wird im Namen eines Bischofs, ${ }^{68}$ wohl des Laurentius, vorgeschrieben, dass alle Bischöfe und Diakone unter den Augen von Zeugen leben sollen, d.h. dass entweder jemand (ein cellulanus, >Mitbewohner') mit in ihrem Haushalt leben soll, um ihren Lebenswandel zu sehen, oder dass sie, wenn ihre Mittel dafür nicht reichen, selbst cellulanus eines anderen werden sollen. Diese Vorschrift steht im Zusammenhang mit den Vorwürfen unerlaubten Umgangs mit Frauen, wie sie während des Schismas gegen Symmachus erhoben wurden.

Um eine vergleichbare Auftragsarbeit, diesmal für den Bischof von Rom, handelt es sich bei dem Text unter der überlieferten Überschrift In Christi nomine (464), der enge Parallelen mit einem Brief des Papstes Symmachus vom 8. Oktober 512 (epist. pontif. 762 Jaffé) über dogmatische Fragen aufweist (vgl. den Apparat bei VoGEL).

\section{Benedictiones cerei}

Für den Gottesdienst verfasst wurden zwei Benedictiones cerei, Prosa-Reden zur Weihe der Kerze in der Osternacht. ${ }^{69}$ Es war eine der Aufgaben des Diakons, am Vorabend der Auferstehung das Lob des Lichtes zu singen und die Osterkerze zu weihen (Klauser 1957, 902). An den Anfang beider benedictiones stellt Ennodius ausführliche Gedanken über die Bedeutung der Sprache und der Sprachfähigkeit der Menschen. Zwar ist etwa die Aussage, dass sich die Menschen von den Tieren wesentlich durch die Sprache unterscheiden (14,1f.; 81,2), häufig zu lesen, ${ }^{70}$ doch innerhalb dieser

67 Siehe dazu Lumpe (1969).

68 Cf. $(8,6)$ nos $[\ldots]$, quos pastoralis cura constringit, quibus tuendarum commissa est animarum diligentia.

69 Siehe dazu Fontaine (1979, von Prud. cath. 5 Hymnus ad incensum lucernae bis Isidor), der die in der Tradition der Gattung konstanten Elemente herausstellt.

70 Siehe $2 . B$. Cic. inv. 1,4,5; de orat. 1,32f. 
Gattung ist sie nicht selbstverständlich; in Prudentius' Hymnus ad incensum lucernae (cath. 5) z.B. findet sich dieses Thema nicht (nur der Unsagbarkeitstopos, v.81f.).

Die wesentlichen Aspekte der ersten Benedictio (14) sind die Schöpfung Gottes, der die Erde und die wechselnden Jahreszeiten mit den Gegensätzen von Feuer und Wasser bzw. Hitze und Eis, von Tag und Nacht geschaffen hat $(\$ 3-5)$, dann die Bedeutung des Lichts nach dem Dunkel $(\$ 5)$, die Bestandteile der Kerze ( $\$ 6 ; c f .81,8)$, der Gegensatz zwischen den alten paganen und den jüdischen Opfern und dem Opfer des Kerzenwachses $(\$ 7)$ und der typologische Zusammenhang zwischen dem Osterfeuer, das zum Wasser der Taufe führt, mit der Feuersäule, die die Israeliten durch die Wüste zum Wasser und durch das Meer führte ( $\$ 8)$. Gott wird um vergleichbare Unterstützung der Christen gebeten ( $\$ 8)$. Die Kerze wird Gott geweiht (\$gf.), damit verbunden ist die Bitte um Gottes Beistand für die Gläubigen (\$10) und um seinen Segen für die Ernte und für den Bischof und seinen Klerus (\$11).

Schwerpunkte der zweiten Benedictio cerei (81) sind die Erschaffung des Menschen, der Sündenfall und die Erlösung durch die Taufe. Zunächst wird die Besonderheit betont, dass in der Osternacht die Flamme der Kerze auf die Nähe des heilsamen Taufwassers vorausweise $(\$ 1)$. Gott selbst segne, was er geschaffen habe, und Gott könne gelobt werden dank der Sprache, die er den Menschen geschenkt habe (\$2). Er selbst habe den Menschen als seinen Tempel geschaffen und ihm den Weg des Heils gezeigt $\left(\$_{3}\right)$. Gott habe den Menschen aus Erde geschaffen und ihm als höchste Gabe den richtigen Weg des Handelns gezeigt (\$4). Doch die folgende Gnade sei noch größer: Die ersten Menschen hätten die höchste Gabe wieder verloren (\$5), doch dank der zweiten Geburt durch die Taufe hätten die Menschen den Trost, dass das Wasser die irdischen Sünden abwasche (\$6). Es sei Zeit, Körper und Seelen Christus zu weihen, und zwar nicht mit blutigen Opfern, sondern durch die Taufe $(\$ 7)$. In der Osternacht werde daher die Kerze geweiht, die aus dem Docht bestehe, der im Flusswasser entstanden sei, aus dem vom Himmel kommenden Feuer und aus dem Wachs, das die Bienen erschaffen, ohne Schaden an ihrer Jungfräulichkeit zu nehmen $(\$ 8)$. Christus liebe die Unversehrtheit, wie er durch seine Geburt gezeigt habe und wie schon am Beispiel des brennenden Dornbusches deutlich werde ( $\$ 9)$. AbschlieBend wird um den Segen Gottes gebeten $(\$ 10)$.

\section{"Carmina minora"}

SIRMOND fasste 151 Epigramme bzw. `Carmina minora‘, die teils in Gruppen, teils ganz verstreut zwischen anderen Werken überliefert sind, zum 2. Buch der "Carmina " zusammen. ${ }^{71}$ Darunter findet sich eine Reihe von Epitaphien ( $46 ; 50 ; 215 ; 230$; $325 ; 333 ; 354 ; 375 ; 462 ; 465)$, zu denen weitere hinzukommen, die in Briefe eingelegt sind $(219 ; 362)$ und daher von SIRMOND nicht unter die "Carmina« aufgenommen

71 Kommentar zum gesamten 2. Buch von Di Rienzo (2005); zu einzelnen Epigrammen: Polara (1993); D'ANGelo (1993). 
wurden; die Epitaphien zeigen großen Einfluss der langen Tradition der Gattung, indem sowohl speziell christliches Gedankengut verwendet ist als auch traditionelles, z.B. die Klage über den frühen Tod eines Jungen, der den Fortbestand einer Familie in Gefahr bringt (siehe 46,3), oder der Gedanke, dass die merita über den Tod hinaus lebendig sind $(50,1)$.

13 Epigramme sind den Bischöfen von Mailand gewidmet, von Ambrosius bis Laurentius (195-207; vielleicht ist auch in 102 Laurentius gemeint, der in 207 nur einen einzigen Vers erhält). Eine Reihe von Epigrammen beschreibt verschiedene Kirchenbauten, z.B. die von Laurentius errichtete Basilica des hl. Syxtus (96), die nach einem Brand wiedererrichtete Basilica Sanctorum (97), die restaurierte Basilica des hl. Calemerus (183), das Baptisterium in Mailand (181). Von den Distichen für einzelne Teile eines Hauses (z. B. "An der Treppe«, »Vor der Küche«, 162-162f) weist nicht nur dasjenige »Vor dem Oratorium» (162) christliche Gedanken auf.

Der Großteil der Epigramme steht in der paganen Epigramm-Tradition und weist keinerlei christlich-religiöse Gedanken auf: Es handelt sich dabei um Beschreibungen von kunstvollen Gegenständen, z.B. "Auf einen marmornen Löwen, aus dessen Maul Wasser fließt « (127) oder die Variationen »Über ein Gefäß, auf dem Pasiphae und der Stier zu sehen sind « $(133,136-136 \mathrm{~b})$, außerdem um Spottepigramme, z.B. »Über einen, der der Sohn einer Dirne und eines Esels sein soll (132), „Über einen, der nur beim Begräbnis seines Sohnes zum Essen einlud“ (134), "Über einen Dummkopf, der Virgilius hieß « (326-326d). Auch Epigramme über Dichter, Bücher und Literatur fehlen nicht, z.B.: "Über die Epigramme, die Faustus (sc. als Inschriften) für seine Bücherschränke gedichtet hat « (70), überliefert ist auch ein Epigramm von Faustus' Sohn Messala, in dem dieser Ennodius um ein Buch bittet, und dazu zwei Antwortgedichte von Ennodius (371-373). Zwei »Einleitungsgedichte« finden sich mitten zwischen anderen Gedichten: »Vorwort zu seinem gesamten dichterischen Werk « (187 Praefatio totius operis poetici quod fecit; siehe dazu unten 110) und "Darüber, dass er während der Weinlese dichtete ( 188 De eo quod vindemiarum tempore scripsit).

\section{"Libellus de synodo"}

Im Zusammenhang mit dem von 498 bis 507/508 währenden Schisma zwischen Symmachus und Laurentius (vgl. oben 24) steht der Libellus adversus eos qui contra synodum scribere praesumpserunt, ${ }^{72}$ den Ennodius im Namen der Symmachus unterstützenden Bischöfe verfasst hat $(49,4$ oris [...] ministerium [...] sacerdotibus dedo). Der Libellus ist die Antwort der Anhänger des Symmachus auf die von den Anhängern des Laurentius verfasste Schrift Adversus synodum absolutionis incongruae $(49,7)$, mit der diese das für Symmachus positive Ergebnis der Synode von 502 angegriffen hatten; der Inhalt der verlorenen Streitschrift der Laurentianer lässt sich anhand von Ennodius' Replik im groben nachvollziehen. Ennodius wendet sich gegen die Vor-

72 Siehe dazu Wirbelauer (1993, 147ff.); Kennell (2000, 186-201; 2001). 
würfe (z.B. dass die auf der Synode versammelten Bischöfe aufgrund ihres Alters unfähig gewesen seien) mit allen Mitteln der Rhetorik, besonders mit allen Registern der Invektive. Den Abschluss des Werkes bilden drei Reden des Petrus, des Paulus und der personifizierten Roma.

Da sich diese Schrift bei der Verteidigung des Symmachus nicht zuletzt auf die Begründung stützt, dass die Synode über keinen Höhergestellten urteilen könne, hat sie für die Entwicklung des Primates des Papstes eine wichtige Rolle gespielt; entsprechende Zitate daraus (siehe oben 27) zeigen die Autorität des Ennodius in späteren Jahrhunderten. Diese kirchenhistorisch wichtige Schrift, die sich auf hohem literarischem Niveau bewegt, hätte von philologischer Seite mehr Aufmerksamkeit verdient. Lohnend wäre eine Untersuchung im Rahmen der Tradition der paganen und christlichen Invektive. ${ }^{73}$

\section{Vitae sanctorum}

Zwei Heiligenviten berichten zum einen über den Bischof von Pavia Epiphanius $(80),{ }^{74}$ in dessen Klerus Ennodius zunächst tätig gewesen war und der im Mittelpunkt eines weiteren größeren Werks des Ennodius steht (43; siehe oben 38), und zum anderen über den Mönch in Lérins Antonius (240). ${ }^{75}$ Während beide Viten innerhalb der Gattung dadurch hervorstechen, dass der Bericht über Wundertaten auf ein Minimum reduziert ist, ${ }^{76}$ weisen die Lebensläufe des Epiphanius und des Antonius große Unterschiede auf bzw. werden zwei unterschiedliche Konzepte von Heiligkeit präsentiert: Antonius ist bestrebt, den Kontakt mit anderen Menschen zu meiden und ein Leben in der Einsamkeit zu führen; auf der Suche nach immer einsameren Orten hat er weniger mit Versuchungen des Teufels zu kämpfen als mit seinem un-

73 Z.B. dürfte folgende Einschätzung von $\operatorname{KenNELL}(2001,67)$ zu modifizieren sein: "a new asthetic founded on Christian truth, non traditional, likelihood-based persuasion «, "the substantive moral rightness of his cause permitted him to transcend polite civilities."

74 Die erste Biographie eines Bischofs in Italien seit der von Paulinus verfassten Vita des Ambrosius (CESA 1988, 7). - Einleitung, Text, italienische Übersetzung und Kommentar von Cesa (1988); Pietrella (1984, 214-218; mit ausführlicher Inhaltsangabe); Sotinel (1995; mit tabellarischer Inhaltsübersicht). Siehe auch G. M. Cook, The Life of Saint Epiphanius by Ennodius. A Translation with an introduction and commentary, Diss. Washington 1942. Vgl. auch F. LotTer, Severinus von Noricum, Stuttgart 1976, bes. 42-45, 223-227, 230-233.

75 Marotta Mannino (1989) stellt das Werk vor und ordnet es einerseits in den Kontext der Gattung der Heiligenvita ein und zeigt andererseits Einflüsse der klassischen Tradition auf. - In einigen Punkten recht spekulativ: Daniela Russo, La Vita Antoni di Ennodio e il riferimento alla Tellina vallis, in GASTI (hrg. 2001, 79-88).

76 Was oft hervorgehoben wurde, siehe z.B. Navarra $(1974,327-330)$, Marotta ManniNo (1989, bes. 337; 351f.), NÄF (1990, 121), Sotinel (1995, 588-591). Zuvor hatte Fontaine $(1962,401)$ beide Viten in die "Tradition des wunderreichen orientalischen Heiligenlebens « eingereiht. 
gewollten Ruhm als Asket, der sich verbreitet und immer wieder Menschen zu ihm führt, die dafür die schwierigsten Wege auf sich nehmen; schließlich lernt er die Vorteile des Klosterlebens schätzen und verbringt seine beiden letzten Lebensjahre im Kloster von Lérins.

Die Leistungen des Bischofs Epiphanius (80) werden in erster Linie im Bereich der Kirchenpolitik bzw. -diplomatie gesehen; geschildert werden u.a. seine Reisen als Gesandter zum Burgunderkönig Gundobad und als erfolgreicher Vermittler zwischen Ostkaisern und Machthabern im Westen. ${ }^{77}$ Epiphanius' diplomatische und rhetorische Fähigkeiten im Umgang mit den weltlichen Herrschern werden auffällig betont; seine Erfolge werden weniger als das Ergebnis der Macht von Glauben und Gebet als vielmehr der Macht des Wortes dargestellt (CESA 1988, 24f., 34). Epiphanius' 'Heiligkeit` ist nicht durch kontemplative Zurückgezogenheit charakterisiert, sondern er ist aktiv, um das Wohl der Bürger seiner Stadt und der Region zu verbessern (Sotinel 593-595): "La volonté de célébrer la sainteté d'Epiphane s'efface devant celle de présenter un modèle idéal de gouvernement de l'Eglise “ (Sotinel 585). Die Vita fällt einerseits (wie auch die des Antonius) durch die im Vergleich mit anderen Heiligenviten ins Auge stechende Reduzierung von Wundergeschichten auf, andererseits (auch im Vergleich mit der Antonius-Vita) durch Elemente der Panegyrik und der Historiographie. Sowohl aufgrund des Inhalts als auch der für eine Heiligenvita singulären sprachlich-literarischen Form ist kaum an die versammelte Gemeinde als Rezipienten zu denken, sondern an einen kleinen Kreis der intellektuellen Elite (Pietrella 1984, 226). Aufgrund vieler historischer Nachrichten wird die Vita einerseits als Quelle für die Zeitgeschichte und die Haltung des Ennodius zu Theoderich geschätzt, ${ }^{78}$ wobei andererseits darauf verwiesen wird, dass aufgrund der panegyrischen Elemente bzw. mancher Ungenauigkeiten und Auslassungen die Verwendung als Quelle nicht unproblematisch ist. ${ }^{79}$

\section{"Dictiones Ethicae« und »Controversiae ${ }^{80}$}

Ganz in der Tradition der Schule stehen 15 Übungs- oder Musterreden: ${ }^{81}$ Fünf "Dictiones Ethicae", z.B. "Worte des Diomedes, als er vom Ehebruch seiner Frau erfuhr" (208), "Worte der Thetis, als sie erkennen musste, dass Achill verloren war" (220),

77 Reydellet $(1981,148,158)$; Cesa $(1988,23)$.

78 NaVARRA (1974, 326-333). Die Vita wird unter historischen Fragestellungen ausgewertet wie der Libellus und der Panegyricus, z.B. von Näf (1990), Delle Donne (2001). - Zu Ennodius' positiver Haltung gegenüber Theoderich, wie sie in der Vita zum Ausdruck kommt, siehe CeSA (1988, 21-23), Rota (2002, 36-43).

79 Siehe Pietrella (1984, 219); Cesa (1988, 30-32).

80 Zur Frage, inwieweit die von Sirmond gewählten Bezeichungen treffend sind, siehe SCHRÖDER (2003, 267, 269f.).

81 Siehe dazu Navarra (1972), Schetter (1977), Fini (1982-1984), Kennell (1992), WinTERBOTTOM (2003), SCHRÖDER (2003). 
"Worte des Menelaos, als er das von den Flammen zerstörte Troja sah" (414), und zehn »Controversiae«, z.B. »Gegen den Legaten, der das Land an die Feinde verraten hat « (221), "Gegen den, der als Belohnung eine Vestalin als Ehefrau gefordert hat « (223), »Gegen einen Spieler, der das Stück Land, auf dem seine Eltern begraben lagen, beim Spiel einsetzte (261), „Gegen einen, der im Bordell eine Statue der Minerva aufstellte" (278) und die Antwort auf Ps. Quint. decl. mai. 5 (Aeger redemptus) ${ }^{82}$ (363). Die dem traditionellen paganen Gedankenkreis entstammenden Themen werden in einem Rahmen behandelt, der sich durch Hinweise auf den Polytheismus eindeutig als nicht-christlich identifizieren lässt, ${ }^{83}$ und Möglichkeiten, speziell christliche Gedanken oder Ideale zu vertreten, werden nicht genutzt.

\section{Reisegedichte}

Zwar bezeichnet Reydellet $(1993,694)$ diese beiden Texte als »due poemi autobiografici«, doch wir erfahren aus ihnen wenig Konkretes. RoтA $(2004,357)$ konstatiert in ihrer Untersuchung der Itineraria (mit nützlichen Inhaltsübersichten), dass sie "mit üblichen Reiseerzählungen wenig gemein haben, da die Beschreibung der Reise in ihnen nur einen sehr geringen Raum einnimmt und die carmina fast ausschließlich aus Naturbeschreibungen bestehen; " "tatsächlich ist die Reise nicht mehr als ein Anlass, die wortreichen Naturbeschreibungen zu rechtfertigen, welche die tragende Struktur der Gedichte bilden« (362). Rota (357) arbeitet heraus, dass die Natur, die Ennodius in den Reisegedichten darstellt, "verquer und verdreht $<$ ist $>,[\ldots]$ sich im Aufruhr befindet, zumindest ihr normales Maß überschritten hat. « Sie zeigt auf, dass hingegen außerhalb der Itineraria die Natur generell »als gehorsam und dem Menschen untertan dargestellt« wird (385). Sie formuliert den Verdacht, Ennodius deute auf diese Weise Risse in der Stabilität der Welt an - sozusagen in einem Gegenbild zu soffiziellen Schriften ' wie dem Panegyricus (387-389).

Das Itinerarium Brigantonis Castelli (245; bei SIRMOND carm. 1,1), ${ }^{84}$ ein Gedicht in elegischen Distichen, berichtet über verschiedene Stationen bzw. Erlebnisse einer Reise, die Ennodius in der Hitze des Hochsommers, wobei aber auch eisige Berge zu überschreiten waren, nach Gallien geführt hat; über den Anlass der Reise erfahren wir nichts, außer dass er sie im Auftrag seines Bischofs unternommen hat (vgl. v.6 iussus; v.8 obsequio; v.16 edocuit vates [= episcopus, siehe den Index bei Vogel, 416]

82 Siehe dazu die Übersetzung mit Kommentar von Winter Botтom (2003).

83 Gegen die zuletzt von KeNNELL (1992; 2000, 72-79; 152-163) favorisierte christlich-allegorische Deutung siehe Winterbottom (2003, 287, Anm. 10) und SChröder (2003, 255261).

84 CARINI $(1987,1988)$ diskutiert besonders verschiedene Vorschläge zum Anlass der Reise. Navar Ra (1979) vergleicht recht allgemein einige Passagen der Reisebeschreibungen bei Venantius Fortunatus mit Ennodius (2; 245; 423) und Ausonius' Mosella, wobei er bei Venantius mehr Gemeinsamkeiten mit Ennodius als mit Ausonius beobachtet; allerdings erscheinen die dabei herangezogenen wörtlichen Anklänge wenig überzeugend. 
fervidus imperio). Ennodius beschäftigen nicht die konkreten Orte und Zeiten, sondern z.B. Paradoxa wie die Überquerung vereister Berge mitten im Hochsommer.

Aus dem zweiten, hexametrischen Itinerarium (423; bei SIRmond carm. 1,5 »Itinerarium Padi «) erfahren wir konkret nur, dass die Reise privater Natur war: Ennodius wollte eine Schwester besuchen, um sie nach dem Verlust eines Kindes zu trösten (cf. v.22-25). Thema ist der Fluss, den Ennodius bei der Reise überschreiten musste: Er beschreibt, wie der Po über die Ufer getreten war und wie er ihn letztlich doch noch überquert hat.

Auffällig ist, dass beide Reisegedichte am Anfang pagane Elemente aufweisen (245,9 Quid [...] renovas mihi, Musa [...]?; 423,2 Umor Castalius veniat [...]), dass dann aber das eine mit Bitten an Heilige schließt $(245,49-52)$ und das andere mit der Feststellung, dass das Ziel mit Christi Hilfe erreicht worden sei (423,52). "Die Reise trägt gleichsam das Kennzeichen eines Weges zum Glauben«(Rota 2004, 370).

Als "Reisegedicht « ist der Versteil der Dictio Ennodi diaconi quando de Roma rediit (2; siehe oben 39) zu vergleichen (siehe auch dazu Rota 2004); auch hier fällt auf, dass zunächst eine pagane Gottheit erwähnt wird (zwar wird keine Muse angerufen, aber es heißt von den Seeleuten: permulcent pelagi numen, v.15), das Gedicht im Folgenden (ab v.21) jedoch von christlichen Gedanken geprägt ist.

\section{Panegyricus dictus clementissimo regi Theoderico}

Der Panegyricus ist das Werk, dem aufgrund des Adressaten und des entsprechenden Zeitbezugs mit Neuedition, zwei Übersetzungen (italienisch und deutsch), Kommentaren und sowohl historischen als auch philologischen Spezialuntersuchungen bisher die meiste Aufmerksamkeit zuteil geworden ist. ${ }^{85}$ Der Panegyricus lässt sich auf 507 datieren, wenn auch der Anlass, aus dem er verfasst wurde, bisher nicht befriedigend geklärt ist. Berichtet wird in einzelnen Episoden über den Werdegang des Theoderich, über seine innen- und außenpolitischen Leistungen und über einige Schlachten. - In historischen Untersuchungen steht außer historischen Details die Haltung des Ennodius zur Herrschaft des Ostgotenkönigs Theoderich bzw. zur Vergangenheit Roms im Zentrum. ${ }^{86}$ Dabei ist deutlich geworden, dass Ennodius hier (wie auch in der Vita Epiphani) - entsprechend der Gattung - die Rolle Theoderichs positiv darstellt, wobei er besonders die Bewahrung der Rolle bzw. der Rechte der römischen Senatoren und die "Erneuerung " Roms und Italiens nach den Kriegen gegen Odoaker hervorhebt. Wie Cassiodor ist Ennodius bestrebt, die Kontinuität der Herrschaft in bzw. über Italien herauszustellen. Der christliche Glaube Theoderichs wird häufig

85 Neue Ausgabe mit Einleitung, deutscher Úbersetzung und Anmerkungen von RoHr (1995); ausführliche Einleitung, italienische Übersetzung, ausführlicher Kommentar von RoTa (2002).

86 Siehe dazu Näf (1990), Delle Donne (1998; 2001). Siehe auch Amory (1997, 112-120) zum Begriff civilitas. 
erwähnt (z.B. \$80), doch konkretere Aspekte der Religion und Religionspolitik bleiben ausgespart, wohl angesichts von Theoderichs Arianismus. Allgemeine Verweise auf Gott finden sich verstreut in dem Werk: Wie in der Vita Epiphani $(80,109)$ wird z.B. die Macht des Herrschers auf Gottes Willen zurückgeführt.

\section{Hymnen}

Zwölf Hymnen ${ }^{87}$ bestehend aus jeweils acht vierzeiligen Strophen, davon 11 in jambischen Dimetern, einer in stichischen alkäischen Elfsilblern (348), widmen sich den folgenden Anlässen bzw. Heiligen: "Am Abend «, "In trauriger Zeit «, "Zu Pfingsten«, "Zu Christi Himmelfahrt «; die übrigen besingen acht Heilige, die in der Mailänder Kirche besonders verehrt wurden: Cyprian, Stephanus, Ambrosius, Euphemia, Nazarius, Maria, Martin, Dionysius. Vielleicht sind es diese Hymnen, die im Epitaph eigens erwähnt werden: templa deo faciens ymnis decoravit et auro / et paries functi dogmata nunc loquitur (v. 17f.).

\section{Epithalamium dictum Maximo v.s.}

Das polymetrische Epithalamium steht zwar in der heidnischen Tradition des Genus, ${ }^{88}$ allerdings spielt das Aufeinandertreffen von antikem Mythos und christlicher Religion eine besondere Rolle: In der Praefatio (1-24) folgt nach einer Beschreibung des blühenden Frühlings, der allenthalben Zeichen von Vermählung und Fruchtbarkeit gibt (v. 1-15), eine Anrede an den Bräutigam mit lobenden Worten für ihn und die Braut, besonders für beider virginitas (15-24). Nach vier Versen, in denen um den Beistand des Phoebus beim Dichten gebeten wird, beginnt die eigentliche Geschichte (29-122): Zu Venus, die sich nackt und schön auf einer Blumenwiese vergnügt (2948), kommt Cupido, um darüber zu klagen, dass sie beide ihre Macht verloren hätten: Es gäbe kaum noch Hochzeiten, nicht mehr genug Kinder, nur noch Alte, denn die virginitas habe mit nie dagewesener Leidenschaft alle in Besitz genommen, erhabene Gelübde würden das Fleisch bändigen; von Hochzeit zu reden, werde schon als Schuld angesehen; Venus solle etwas unternehmen, damit man nicht denke, auch sie werde von den iura pudicitiae gefangen gehalten. Venus kleidet sich an, überlegt, an wem sie ein Exempel statuieren soll, und ihr Blick fällt auf Maximus (74-94). Cupido fliegt los und trifft mit seinem Pfeil zunächst Maximus (95-111) und dann die Braut (112-117). Auf Cupidos gute Wünsche für das Paar (118-122) folgt eine abschließende Bemerkung des Sprechers (123-128).

87 Dazu: J. Szövérffy, Annalen der latein. Hymnendichtung, 1964, 1, 119-122; M. MuzzicA, Gli Inni di Ennodio di Pavia, Neapel 2003; D. Di Rienzo, L'Hymnus vespertinus di Ennodio tra ascendenze classiche e tradizione ambrosiana, Boll. Stud. Lat. 34, 2005, 626-644.

88 Siehe Z. PAvlovskis, Statius and the Late Latin Epithalamia, CPh 60, 1965, 164-177. Wenig mehr als eine Zusammenfassung bei Horst manN 2004, 318f. 
Dieses amüsante Gedicht bereitet der Forschung einige Probleme: "[...] selbst wenn das Gedicht des Ennodius als das beurteilt wird, was es ist, als eine geistreiche Tändelei, als Hochzeitsgabe für einen Freund, als Schöpfung eines Diakons bleibt es verwunderlich « (Fontaine 1962, 414f.). Die Pointe, dass durch die christlichen Keuschheitsgelübde Venus und Cupido in Bedrohung geraten, wird zuweilen unterdrückt. ${ }^{89}$ Andere versuchen eine Erklärung: RoTA $(1999,128)$ kommt in ihrer Untersuchung der Elemente des paganen Mythos bei Ennodius zu dem Schluss, der mythologische Apparat diene zur Verlebendigung des christlichen Lobes für das Sakrament der Ehe. Kennell (2000, 94) kommentiert die Rede des Cupido: „Ennodius himself could obviously not have uttered the sentiment Cupido voices here"; diese Bemerkung, die wohl den Kleriker entlasten soll, erklärt allerdings nicht die Tatsache, dass Ennodius diese Worte überhaupt formuliert und sie Cupido in den Mund legt. Denn Ennodius hätte ja auch einen Glückwunschbrief senden können (vgl. den in seiner Art ebenfalls bemerkenswerten Glückwunsch für Avienus in Brief 459, unten 343), oder er hätte ein Hochzeitslied wie Paulinus von Nola für Julianus und Titia (carm. 25) verfassen können, das sich nicht an das Schema der traditionellen Epithalamien anlehnt, in dem die paganen Hochzeitsbräuche abgelehnt werden und die christliche Feier beschrieben ist. Anders Kennell (2000, 92):»[...] only through metaphors of vernal fecundity and mythological situations could he articulate the physical nature of marriage positively and with apposite candor. Of necessity, his poem minimizes the Christian background to the impending nuptials «; sie legt die kirchliche Lehre zugrunde, dass Enthaltsamkeit besser ist als Ehe (96): "he had to employ his rhetorical skill to promote a way of life diametrically opposed to what the church officially approved «. Dazu ist zu sagen, dass der Ehestand zwar an Ansehen dem der Virgines nachstand, aber dennoch keineswegs grundsätzlich missbilligt wurde (Rota 1999, 128). KenNell versucht offenbar, Ennodius zu entlasten, indem sie betont, dass die Aufgabe anders nicht zu lösen war (»of necessity «, »had to «). Doch schlägt die versuchte Entlastung ins Gegenteil um, wenn der Kleriker zum paganen Mythos greifen muss, um dem für seine Jungfräulichkeit bekannten Bräutigam die von der Kirche missbilligte Ehe schmackhaft zu machen. Sicher wird niemand ihn gezwungen haben, ein Epithalamium zu schreiben, in dem Venus und Cupido auftreten und sich über die Auswirkungen des Christentums beschweren.

In die Interpretation des Epithalamium müssten fünf Briefe an Maximus einbezogen werden $(334 f ., 337,356,386)$, in denen dessen Hochzeit das zentrale Thema

89 Rонr (1995, 9 Anm. 30) lässt sie unerwähnt und sagt lediglich, dass Amor und Venus um den besonders keuschen Maximus kämpfen. - Im Artikel »Hymenaios« (DNP, Bd. 5, 1998, Sp. 787) wird lediglich erwähnt, dass christliche Schriftsteller (Ennodius u.a.) in Epithalamien "die Bildersprache und Myth. der früheren Dichter" verwenden. - PAvlovskis $(1965,172 f$.) verweist auf Parallelen in Details der Handlung im Vergleich mit Stat. silv. 1,2; sie hebt hervor, dass das Frühlingsbild als Eröffnung eine Neuheit bei Ennodius sei; die Bedrohung der Venus durch das Christentum wird nicht erwähnt. 
ist (sehr knapp bei KenNell 2000, 71). In diesen Briefen spielt Ennodius z.T. in ironischem und stichelndem Ton auf die bevorstehende Hochzeit an - offenbar hatte Maximus früher angekündigt, niemals zu heiraten. Im Zusammenhang damit mag es zwar immer noch verwundern, dass Ennodius im Epithalamium nicht nur mit dem paganen Mythos spielt, sondern auch mit dem christlichen. Aber es muss akzeptiert werden, dass er nicht eine Hochzeitspredigt über die christliche Ehe schreibt, sondern dem Adressaten ein Geschenk »in paganer Tradition « macht, mit dem er ihn ebenso wie in einigen Passagen der genannten Briefe wegen seiner Meinungsänderung aufzieht.

Zum »Eucharisticum» (438) siehe oben $11 \mathrm{ff}$.

\section{"Paraenesis didascalica"}

Diese prosimetrische ${ }^{90}$ Schrift, die in den Handschriften keinen speziellen Titel hat, sondern als Brief Ennodius Ambrosio et Beato überschrieben ist (von SiRmond stammt der Titel »Paraenesis didascalica ad Ambrosium et Beatum«), behandelt in allgemeiner Weise die von Adligen anzustrebende Bildung, indem sie die Darstellung von christlichen Grundtugenden und weltlicher Sprachkunst verbindet. ${ }^{91}$ Gewöhnlich wird die "Paraenesis " als "Studienplan " (FonTAINE 1962, 402) bezeichnet, ${ }^{92}$ was aber leicht $\mathrm{zu}$ falschen Vorstellungen führen kann, denn es handelt sich keineswegs um konkrete Vorgaben, was die Adressaten im einzelnen studieren sollen. Voran steht eine dreiteilige Einleitung, zunächst in Prosa eine Anrede an die Adressaten, dann in Versen eine laus versuum und wieder in Prosa einige Worte zur eigenen Situation des Verfassers. Den Hauptteil bilden die Vorstellung bzw. Charakterisierung, jeweils sowohl in Prosa als auch in Versen, zunächst der nötigen christlichen Tugenden Verecundia, Castitas und Fides, dann der zu erlernenden Artes Grammatica und Rhetorica. Auch der Abschluss ist dreiteilig: Zunächst eine weitere Anrede in Prosa an die Adressaten, in der ihnen die Vorbilder, an denen sie sich in Rom orientieren sollen, vor Augen geführt werden; es folgt eine kurze Wendung in Versen an Symmachus, der zu den genannten Vorbildern gehört, und eine weitere Anrede, ebenfalls in Versen, an die Adressaten.

Der Ars Rhetorica sind u.a. folgende Worte über sich selbst in den Mund gelegt: "Wer mich <sc. die Rhetorik> intensiv studiert, kann bald die Welt beherrschen" $(452,17$ qui nostris servit studiis, mox imperat orbi). Daher wird diese Schrift nicht besonders geschätzt: »[...] diese seichte Programmschrift versteht sich dazu, die Macht

90 Sie markiert aufgrund einiger Auffälligkeiten "eine bedeutende Etappe in der Geschichte der prosimetrischen Literatur", siehe PABST $(1994,149)$.

91 Siehe dazu: Rallo Freni (1971); Pabst (1994, 149-158).

92 NavarRa (1974, 13): "vademecum negli studi. Re Reydellet (1993, 693): "un' introduzione agli studi.« RoHR (1995, 8): »Anleitung zum Erwerb höherer Bildung." GrUBER (1997, Sp. 1046): »ein rhetorischer Studienplan in prosimetrischer Form. "Besser PABst $(1994,149)$ : »eine kurze Anweisung zur richtigen Lebensführung und geistigen Betätigung.« 
der Rhetorik in einer sittlicher Schranken weithin überhobenen Weise zu preisen, in einer Weise, die radikalen Sophisten vom Schlage des Platonischen Thrasymachos alle Ehre gemacht hätte« (FunRmann ${ }^{2} 1995,336$ ). - Die Worte der Rhetorik, »das

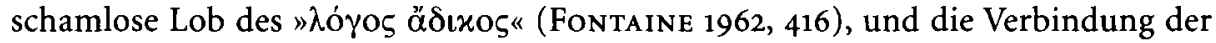
christlichen und weltlichen Tugenden bzw. Fähigkeiten insgesamt sollen weiter unten näher untersucht werden (unten 86 und 97).

\section{c. »difficilis et obscurus«}

Arnulf von Lisieux ${ }^{93}$ (Bischof 1141-1182) versendet i.J. 1160 einen Ennodius-Text und schreibt dazu in seinem Brief:

[...] Prima siquidem facie difficilis et obscurus [sc. Ennodius] incedit et, cum rerum difficultatem stilus lucidior debeat aperire, intelligentiam potius sermo tenebrosus obtundit. Cumque multum habeat laboris inspectio, nihil habet assecutio voluptatis, quia nec absolutione sententia complacet nec oratio venustate. Summa enim eius intentio est aliter omnia dixisse quam caeteri, ideoque totum quod loquitur exquisita quadam intricatione complicat et innodat, ut rectius INNODIUS quam ENNODIUS debeat appellari. (epist. 27 Barlow)

Dies ist in der Ennodius-Forschung oft zitiert worden, und moderne Urteile schließen sich nahtlos an, z.B.: "[sc. Arnulfus,] quo viro perdocto haud scio an nemo umquam acerbius et rectius de Ennodi operibus iudicaverit" (Vogel 1885, Praef. XXVII); »Ennodius ermuntert zwar seine Freunde zu einem einfachen Stil, ist aber selbst an rhetorischem Wortgeklingel nicht mehr zu übertreffen « (RoHr 1995, 15). Abweichend äußert sich lediglich Kennelu, die Ennodius' Stil an vielen Stellen als »elegant « (z.B. 200o, 20, 64, 80) oder »graceful« (64) bezeichnet; allerdings macht sie ihre Bemerkungen zum Stil (z.B. 62: »his fondness for the well-turned phrase«; 5: »tantalizingly allusive style $)$ nicht konkret am Text fest. Sie sieht die Probleme mehr im 'was` als im `wie und weist darauf hin, dass unsere Auffassung nicht die der Zeitgenossen gewesen sein muss: "Ennodius' topicality is often our obscurity; I doubt his correspondents experienced the difficulties we do " $(2003,115, \mathrm{cf} .2000,84 \mathrm{f}$.).

In diesem Kapitel wird die Frage gestellt, warum die Lektüre des Ennodius so schwierig ist, denn bisher hat sich die Forschung damit begnügt, dies zu konstatieren bzw. zu beklagen. Hier sollen als Ausgangspunkt für weitere Studien zwei Aspekte hervorgehoben werden. Zum einen zeigt sich, dass Arnulfs Charakteristik obscurus für den Stil sehr treffend ist; denn ausgehend von Quintilians Ausführungen zur obscuritas lässt sich beobachten, dass Ennodius bestimmte syntaktische und stilistische

93 The Letters of Arnulf of Lisieux, ed. F. Barlow, Camden Society, Third Series, vol. 61, London 1939, 1-217; epist. 27: pp. 36-38. - Opera omnia, ed. J. P. Migne, PL 201, Paris 1903. - Zu den Briefen siehe: Carolyn Poling Schriber, The Letter Collections of Arnulf of Lisieux, Lewiston u.a. 1997 (Texts and Studies in Religion 72). 
Mittel offenbar gezielt einsetzt, um den Eindruck von obscuritas hervorzurufen. Zum anderen ist zu zeigen, dass Ennodius' Stil entgegen der communis opinio keineswegs dem des Sidonius Apollinaris entspricht. - Ziel dieser knappen Ausführungen ist es, durch die Beschreibung einiger häufig vorkommender stilistischer Auffälligkeiten, die in der Forschung bisher nicht erwähnt wurden, den Zugang zu Ennodius zu erleichtern. Eine gründliche sprachwissenschaftliche Darstellung ist ein Desiderat; ein lohnendes Feld sind u.a. die vielen ausführlichen und oft gewagten Vergleiche und Bilder, siehe z.B. unten $85,112,127 \mathrm{f} ., 283$.

$\mathrm{Zu}$ verschiedenen Aspekten von Sprache und Stil des Ennodius liegen Untersuchungen vor: Besonderheiten der Lexik (wozu selbstredend inzwischen, soweit vorhanden, der ThlL zu vergleichen ist) verzeichnen Vogel (1884; "Index rerum et vocabulorum « der Ausgabe 1885), Dubois 1903 und Trahey 1904, der außerdem das Wortmaterial des Ennodius mit dem des Hieronymus vergleicht. Die Studien von DuвоIs sind breiter angelegt: Er verzeichnet zum einen sprachliche Besonderheiten des Ennodius, zum anderen verweist er auf auch bei Ennodius zu beobachtende allgemein spätantike Tendenzen wie z.B. die Vertauschung von Simplex und Kompositum und von Positiv und Komparativ, Besonderheiten des Kasusgebrauchs (z.B. partitives de statt Gen. part.; Komparativ neben $a b$ oder de statt bloßem Abl. comp.) und der Syntax (z.b. dicere quod; indirekte Fragesätze im Indikativ). Duвois gibt außerdem Beispiele für Tropen und Figuren, die sich bei Ennodius finden. Die Prosodie untersucht Fougnies (1951) ${ }^{94}$, siehe dazu die Zusammenfassung bei Rota (2002, 116f.).

Einige Besonderheiten von Sprache und Stil im Panegyricus vermerkt RoHr in der Einleitung (1995, 27-38). Äußerst instruktiv ist das Kapitel zu Sprache und Stil von Simona Rota (2002, 99-117), die den Leser, der vom klassischen Latein geprägt ist, in viele Neuerungen der spätantiken Sprache und auch in Besonderheiten des Ennodius einführt. Sie verweist präzise und übersichtlich u.a. auf Auffälligkeiten in Konjugation, Deklination, Gebrauch der Kasus und Präpositionen, Besonderheiten der Syntax. Wichtig sind auch die semantischen Hinweise, sowohl zu allgemein spätantiken Entwicklungen, z.B. zu tamen (neben dem üblichen adversativen Sinn sehr häufig als Überleitungspartikel: »also« o.ä.) und vel (im Sinne von $e t$ ) und allgemein zur spätantiken Neigung zur Abstraktion (z.B. antiquitas statt antiqui, generalitas statt homines, hostilitas statt hostes), als auch zu besonderen Wortbedeutungen bei Ennodius (z.B. populus im Sinne von multitudo). Als besonderes Charakteristikum der Darstellungsweise des Ennodius stellt sie eindrücklich die abudantia sermonis heraus: Er stellt oft einen Gedanken in einem zweiten Anlauf ausführlicher und vor

94 A. Fougnies, Een studie over de clausulen bij Ennodius, Verhandelingen van de koninklijke Vlaamse academie voor wetenschappen, letteren en schone kunsten van Belgie, Klasse der letteren 13,12, Brüssel 1951. 
allem konkreter dar, d.h. er wiederholt einen Gedanken, indem er ihn anders formuliert (RotA, 113f.; etliche Beispiele in ihrem Kommentar, z.B. 235, 287, 290).

Eine Schwierigkeit der Briefe für die heutigen Leser, die Ennodius nicht selbst zu verantworten hat, rührt daher, dass er seine Briefe nicht für das Verständnis eines breiteren Publikums, das den unmittelbaren Kontext der Kommunikation nicht kennt, überarbeitet hat, da er sie nicht selbst herausgegeben hat. Das zeigt sich besonders deutlich an den Briefanfängen, die vom ersten Wort an die Lektüre nicht leicht machen. Denn die Möglichkeiten, einen Briefanfang zu gestalten, um (auch) für den nicht-eingeweihten Leser verständlich zu sein, ${ }^{95}$ werden nicht genutzt. So kann man, wie es in anderen Sammlungen häufig zu beobachten ist, am Anfang auf das Thema des vom Adressaten erhaltenen Briefes verweisen, auf den nun geantwortet wird, wie z.B. (Plin. 1,8,1) [...] litterae tuae, quibus flagitabas [...]; (Plin. 1,18,1) Scribis [...]; (Plin. 1,23,1) Consulis, an [...]; (Plin. 2,17,1) Miraris, cur [...]; (Plin. 2,19,1) Hortaris, ut [...]; (Sy. 1,59) Mones, ut [...]; (Sy. 1,65) Scire postulas, quid [...]; (Sy. 5,36) [...] lectione cognovi [...]; (Sy. 5,78) Quaeris, [...]. Oder der erste Satz kann direkt zum Thema hinführen, z.B.: (Plin. 1,5,1) Vidistine quemquam M. Regulo timidiorem [...]; (Plin. 1,12,1): Iacturam gravissimam feci, si iactura dicenda est tanti viri amissio; decessit Corellius Rufus [...].

Ein weiteres Problem heutiger Leser, für das Ennodius nicht verantwortlich zeichnet, sind die Besonderheiten der spätantiken Sprache. Manche Missverständnisse lassen sich leicht ausräumen. Z.B. ist das Wort conversatio ein ,false friend des Übersetzers. conversatio bedeutet bei Ennodius nicht etwa »Konversation«, sondern "Lebensweise« (siehe im Index bei Vogel, s.v. conversatio = vita, mores).$^{96}$

Ungewohnt für >klassische Leser` ist auch die Neigung zur Verwendung von Abstrakta: Statt des Substantivs mit Attribut im gleichen Kasus steht sehr häufig das Substantiv im Genetiv abhängig von der "substantivierten Eigenschaft", also z.B. statt eloquentia exilis: $(1,4)$ eloquentiae exilitas, statt uber patrimonium: $(270,2)$ patrimonii ubertas; $(1,4)$ verborum abundantiam; $(1,5)$ oneris inmensitate; $(1,6)$ silentii foeditate; $(4,4)$ novitatem sensuum monstras serenitate sermonum; $(40,4)$ macies studii; $(119,3)$ precum [...] adsiduitate [...] ubertate culparum; $(125,1)$ votorum maciem beneficii ubertate; $(455,1)$ pertinacia amoris; $(457,1)$ verborum ubertate.

Doch in manch anderer Hinsicht hat Ennodius sich offenbar selbst geradezu bemüht, es dem Leser schwer zu machen. Die epistolographische Theorie verlangt vom Brief perspicuitas (Eindeutigkeit, Klarheit), da man den Brief im Zweifelsfall nicht fragen

95 Siehe zu Plinius: F. Gamberini, Stylistic Theory and Practice in the Younger Pliny, Hildesheim etc. 1983, 153-161 (»Opening Phrases and Unity of Theme «).

96 Dies wird zuweilen übersehen, siehe z.B. die Übersetzung von GIOANNI (2001, 176; 2004, 522) Oder KenNeLl $(2000,148)$. 
könne, was gemeint sei: Ceterum, cum abscondito nihil opus est, cavenda obscuritas magis quam in oratione aut in sermocinando: potes enim parum plane loquentem rogare, ut id planius dicat, quod in absentium epistolis non datur [...] (Iulius Victor p.105, 28-31 Giomini / Celentano). Worin obscuritas besteht und wie man sie vermeiden kann, legt Quintilian im 8.Buch dar. Es zeigt sich, dass die vitia, die laut Quintilian zur obscuritas führen, geradezu charakteristisch für Ennodius sind. Einige vitia, wie sie durchaus sprachüblich sind und sich auch bei den klassischen Autoren finden, setzt Ennodius auffällig gehäuft und offenbar bewusst ein; zudem erscheinen häufig mehrere der vitia gleichzeitig.

\section{Mixtura verborum}

Quintilian spricht zunächst über obscuritas aufgrund der Verwendung bestimmter einzelner Wörter und wendet sich dann Wortverbindungen und Sätzen zu: Ein Satz solle nicht zu lang sein, man solle nicht zu weite Hyperbata bauen, und man solle eine mixtura verborum vermeiden (wie z.B. saxa vocant Itali mediis quae in fluctibus aras). ${ }^{97}$ Dass Ennodius weder lange Sätze noch weite Hyperbata scheut, wurde bereits beobachtet (siehe die Beispiele bei Dubors 1903, 509f.). Darauf, dass er die mixtura verborum besonders zu schätzen scheint, ist hier aufmerksam zu machen.

Die künstliche Wortstellung führt häufig dazu, dass aufgrund mehrdeutiger Kasusendungen die Bezüge nicht auf den ersten Blick deutlich werden, z.B.: (Zusammengehöriges ist durch gleiche Auszeichnung, Kursive bzw. KaPITÄLCHEN, markiert.)

- $(1,3)$ dicat forsitan aliquis $[\ldots]$ quod operis PRESSA magnitudine exhausti MACIEs ariscat ingenii et destituta dicendi valitudine garrulitas defectum mercetur ex copia ("Jemand [...] mag sagen, dass mein mageres Talent von der Größe der Aufgabe erdrückt, erschöpft und aufgezehrt wird und dass meine Redseligkeit, der die Kraft zum Reden fehlt, sich durch die Fülle < des Stoffes $>$ Mangel einhandelt. «)

- $(107,1)$ gemina $[\ldots]$ luce Fulgentia SCRIPTA suscepi dum quod pectus sanctum repperit, dextera serena signavit (»Ich habe [...] einen Brief erhalten, der in doppeltem Licht glänzt, indem die ungetrübt heitere Rechte schrieb, was das verehrungswürdige Herz dachte «); anders Sundwall (1919, 24): "Avienus [...] hat dem Ennodius zwei Schreiben zukommen lassen [...], wohl um seine guten Vorsätze zu zeigen".

- (2,v.23) Im Versteil der Dictio Ennodi diaconi quando de Roma rediit heißt es über Christus u.a.: Qui latices vinxit fundens in pocula saxum,/ qui lapides sol-

97 (Quint. inst. 8,2,14): Plus tamen est obscuritatis in contextu et continuatione sermonis, et plures modi. Quare nec sit tam longus ut eum prosequi non possit intentio, nec +transiectio intra modum hyperbato + finis eius differatur. Quibus adhuc peior est mixtura verborum, qualis in illo versu: »saxa vocant Itali mediis quae in fluctibus aras« (Verg. Aen. 1,109). [...] 
vit, qui solidavit aquas (2, v.23). MAURACH (1984, 37 mit Anm. 26) gesteht, dass er zu v.23 keinen überzeugenden Bibelbezug feststellen und keine befriedigende Deutung vorschlagen könne (»der die Wasser band, als er den Stein in den Becher tauchte«, mit Anm. 26). Lebek (1993, 289f.) vermutet einen Bezug auf die Verwandlung von Wasser in Wein und verändert das letzte Wort zu »bacc(h)um «. - Doch wenn man in v.23 die Objekte anders bezieht: latices als Objekt zu fundens und saxum als Objekt zu vinxit, ergibt sich: "indem er Flüssiges <sc. den Wein beim Abendmahl> in Becher goss, hemmte er die Macht des Steins <sc. des Grabsteins>«. Derselbe Stein ist wieder erwähnt in v.24 (qui lapides solvit); hingegen ist das in v.24 erwähnte Wasser (qui solidavit aquas) nicht identisch mit den latices aus v.23, sondern bezieht sich darauf, dass Christus über das Wasser geht.

Häufig entsteht die Unklarheit aber auch ohne doppeldeutige Endungen, allein durch die Wortfolge, so dass die Bezüge nicht auf Anhieb klar werden, z.B.:

- $(360,1)$ ego in amplitudine vestra tot coacervata epistolari sermone bona non venerer? "epistolari sermone " ist Abl. zu venerer, nicht zum rahmenden acervata bona, also: "Ich sollte die vielen in Eurer Hoheit angesammelten Leistungen nicht in einem Brief würdigen? «; anders $\operatorname{KenNELL}(2003,122)$ : »may I not venerate in your amplitude so many good things piled up by epistolary discourse? "

- $(94,12)$ ecce iam ex hiemali pectore et corde algido dictionum flosculi vernant et ridentia verborum germina depingunt calathos exhibentes: "flosculi« ist Sujekt sowohl zu vernant als auch zu depingunt, und germina ist nicht Subjekt, sondern Objekt, also: "Schau, schon erblühen aus seiner <= Parthenius'> winterlichen Brust und dem eisigen Herzen Blüten von dictiones, sie malen lächelnde Sprosse von Worten und bieten Blütenkelche dar«; anders KeNNelL (2000, 57) »behold, already from wintry breast and chilly heart little flowers of dictiones blossom forth and the smiling sprouts of words adorn the calyxes as they unfold."

$-(226,4)[\ldots]$ precor, ut perlator praesentium famulus vester felici sorte peregrini apud vos nomen excipiat, quia quod adtributum fuerit precibus meis, vestrum supra dotes suas ornat officium. peregrini ist Genetiv zu nomen, nicht zu sorte: "[...] und ich bitte, dass der Überbringer dieses Briefes als Euer Diener ein gutes Schicksal haben und bei Euch als >Fremder < < und damit als Objekt christlicher caritas $>$ gelten möge; denn was meinen Bitten gewährt wird, das schmückt Euer Amt über seinen <bereits vorhandenen> Schmuck hinaus«; anders KENNELL $(2000,45)$ : "that his nephew [...] may acquire a good name among you by a stranger's happy lot, because what will have been bestowed by my prayers, your office embellishes above its own endowments«. 


\section{Ambiguitas}

Quintilian schreibt weiter vor, Zweideutigkeit (ambiguitas) zu vermeiden, und zwar nicht nur wirkliche wie "Chremetem audivi percussisse Demean", sondern auch rein grammatische Zweideutigkeit, die beim Hinsehen inhaltlich eindeutig ist wie "si quis dicat visum a se hominem librum scribentem $« ; 9$ auch wenn der Inhalt letztlich eindeutig feststehe, sei es doch »schlecht geschrieben«. Ennodius hat eindeutig einen Hang zur ambiguitas (wie auch gerade bei der mixtura verborum schon zu sehen war). So gibt es z.B. nicht selten außer dem vom Sinn erforderten richtigen Bezugswort für ein Relativpronomen (mindestens) ein weiteres grammatisch mögliches Bezugswort, das näher beim Relativpronomen steht als das richtige Bezugswort (das richtige ist hier in Kapitälchen gesetzt):

- $(1,1)$ DISPENDIA opinionis, quae vitat, incurrit.

- $(7,3)$ FURTo Iacob primogeniti fratris vicit aetatem, cuius beneficio principatum obtinuit, "Mit einer List besiegte Jakob das Alter des erstgeborenen Bruders, dank derer er den Vorrang erlangte«.

- $(7,4)$ contra legis vetita, quae minores habet aculeos, ESURIEM corporis effugavit, "er vertrieb gegen die gesetzlichen Verbote den körperlichen Hunger, der geringere Stacheln hat « <sc. als der Hunger des Geistes, wie im Folgenden deutlich wird $>$.

- $(12,3)$ solent $[\ldots]$ DIGNos venia iudicare perfecti, quos inter epistulares vias nutantia deseruere vestigia [= quorum vestigia deseruere vias], "Dennoch verzeihen die Vollkommenen gewöhnlich denen, die ihre schwankenden Schritte auf den brieflichen Wegen im Stich gelassen haben «.

- $(40,1)[\ldots]$ ut per loquellae audaciam quae ornare poterat pereat SPES TACENDI, "[...] dass waghalsiges Reden das vielversprechende Schweigen beendet, das als Schmuck hätte dienen können «.

- $(30,2)[\ldots]$ ut nullas per tanta temporum spatia, quae bonam valitudinem vestram significarent, LITTERAs suscepissem?, "[...] dass ich über so einen langen Zeitraum keinen Brief erhalten habe, der Eure gute Gesundheit anzeigte? «

- (242,1) venit optatus dies et ille, quem numquam de meritis meis sed semper de superna pietate postulavi, magnitudini tuae SPLENDOR accessit, "Gekommen ist der gewünschte und ersehnte Tag, und Deine Hoheit hat jenen Glanz erhalten, den ich nie aufgrund meiner Verdienste, sondern immer von der himmlischen Liebe erbeten habe.«

98 (Quint. inst. 8,2,16) Vitanda in primis ambiguitas, non haec solum, de cuius genere supra dictum est, quae incertum intellectum facit, ut "Chremetem audivi percussisse Demean", sed illa quoque, quae etiam si turbare non potest sensum in idem tamen verborum vitium incidit, ut si quis dicat visum a se hominem librum scribentem. Nam etiam si librum ab homine scribi patet, male tamen composuerit, feceritque ambiguum quantum in ipso fuit. 


\section{Copiosa loquacitas}

Quintilian wendet sich auch gegen eine copiosa loquacitas, die dadurch entstehe, dass man die gewöhnliche Redeweise vermeide und alles mit vielen Worten umschreibe, bis es unverständlich werde..$^{99}$ Arnulf von Lisieux schreibt Ennodius gerade diese Eigentümlichkeit zu (aliter omnia dixisse quam caeteri, siehe oben). Hierher gehören z.B. die vielen Synonyme für »Brief « und »Briefschreiben«, z.B. apices; officium; $(255,2)$ conloquia praestare; $(268,6)$ epistularis concinnatio; $(276,1)$ epistularis cura; $(442,1)$ epistolare commercium; $(448,2 ; 461,1)$ (epistularis) promulgatio conloquii; $(459,5)$ exhibere colloquia; $(456,4)$ epistolaris commercii munera; $(449,1)$ litterarum munera promulgare; $(228,3)$ paginas destinare; $(273,1)$ litterarum munus inpertire. Auch bei der Formulierung des Grußes ist Ennodius darum bemüht, es immer wieder etwas anders zu sagen, z.B. $(226,4)[\ldots]$ salutationis reverentiam obsequiorum devotione restituens precor, ut [...]; $(271,3)[\ldots]$ salutationis uberrimae servitia dependens quaeso, ut...; $(273,2)[\ldots]$ saluto plurimum reverentia consueta et imploro, ut $[\ldots] ;(274,2)[\ldots]$ praelato debitae salutationis obsequio precor, ut $[\ldots] ;(276,2)[\ldots]$ salutem uberrimam dicens precor, ut $[\ldots] ;(279,2)[\ldots]$ plenum reddo salutationis obsequium deprecatus, $u t$ $[\ldots] ;(280,2)$ nunc salutationis meae dicens obsequia $[\ldots] ;(281,2)[\ldots]$ salutati reverentiam dicens precor $[\ldots] ;(282,2)[\ldots]$ servitia salutationis accipientes facite, ut [...]; etc. etc. - Cf. bei Symmachus: (Sy. 4,23,2) [...] quibus <sc. verbis> tibi salutationis officium de more persolvens [...]; (Sy. 7,72) [...] honorificentiam vobis debitae salutationis exhibeo; (Sy 7,67) celebro igitur honorem tuum salute dicenda [...]; derart ausführliche und förmliche Grüße sind bei Symmachus allerdings eher die Ausnahme.

Auffällig ist auch der häufige Gebrauch des Gen. identicus, der lediglich eine Doppelung von Synonymen ergibt, z.B.: $(9,1)$ beneficiorum eius muneribus, $(459,4)$ coniunctionis tuae copulam, $(448,1)$ sollicitudinis cura, $(457,1)$ oneris sarcinas.

Besonders ist hier die von Rota (2002, 114f.) dargestellte abundantia sermonis zu nennen. Dafür ein Beispiel aus den Briefen: $(468,1)$ Solent inauspicata felicitate superbarum mentium colla mollescere et rigidioris propositi novo gaudio supercilia temperari. nam benignitatem seminat quicquid votis obsequitur, nec plus aliquid humiliat potissimos quam optata sublimitas. indictio communionis et obsequii est ad apicem pervenisse. - (2) Tu postquam ad cupita provectus es, ignorato hactenus tumore me despicis [...]. ("Üblicherweise werden die Nacken erhabener Seelen durch unerwartetes Glück weicher, und die Erhabenheit strenger Vorsätze wird durch die neue Freude gemäßigt. Denn was auch immer den Wünschen entspricht, sät Güte, und nichts de-

99 (Quint. inst. 8,2,17) Est etiam in quibusdam turba inanium verborum, qui, dum communem loquendi morem reformidant, ducti specie nitoris circumeunt omnia copiosa loquacitate, eo quod dicere nolunt ipsa: deinde illam seriem cum alia simili iungentes miscentesque ultra quam ullus spiritus durare possit extendunt. (18) In hoc malum a quibusdam etiam laboratur: neque id novum vitium est, cum iam apud Titum Livium inveniam fuisse praeceptorem aliquem qui discipulos obscurare quae dicerent iuberet, Graeco verbo utens oxótıov. Unde illa scilicet egregia laudatio: »tanto melior: ne ego quidem intellexi». 
mütigt die Mächtigsten so sehr wie die erwünschte Erhabenheit. Zum Gipfel gelangt zu sein, ist gleichbedeutend mit der Ankündigung, dass man Gemeinschaft suchen und dass man gefällig sein wird. - <Doch> Seitdem Du zur Erfüllung Deiner Wünsche gelangt bist, verachtest Du mich mit bisher unbekanntem Hochmut [...] «). In diesem Satz korrespondieren zum einen folgende Formulierungen, die ausdrücken, dass es um die Freude darüber geht, dass ein Wunsch erfüllt und eine hohe Stellung erreicht wurde: inauspicata felicitate / novo gaudio / quicquid votis obsequitur / optata sublimitas / ad apicem pervenisse / ad cupita provectus. Außerdem korrespondieren Ausdrücke mit dem Sinn, dass Hochmut vergehen sollte: superbarum mentium colla mollescere / rigidioris propositi supercilia temperari / benignitatem seminat / humiliat potissimos / indictio communionis et obsequii / ignorato hactenus tumore me despicis.

\section{Brevitas}

Laut Quintilian ist jedoch nicht nur die copiosa loquacitas, sondern auch das andere Extrem, die übermäßige brevitas, zu meiden; ${ }^{100}$ Quintilian hält es für schlecht, wenn man das Gesagte nur aufgrund seines eigenen Scharfsinns verstehen kann: at ego vitiosum sermonem dixerim quem auditor suo ingenio intellegit (inst. 8,2,19).

Ein von Ennodius häufig verwendetes Stilmittel, das dem Leser einen gewissen Scharfsinn abfordert, ist die Syllepse, z.B.:

- $(6,2)$ concessum est precum adsiduitati quod negabatur examini, "gewährt wurde der Stetigkeit der Bitten, was der Prüfung < der Bitten $>$ verweigert wurde $<$ d.h. die Bitten wurden erfüllt, weil sie häufig vorgebracht wurden, nicht, weil sie bei der Prüfung gebilligt wurden.«

- $(9,7)$ peccatorum magnitudo munus caeleste, quod non potuit desideriis, denegaret aspectibus, "die Menge meiner Sünden verweigerte meinem Anblick das himmlische Geschenk, das sie meinen Wünschen nicht <verweigern> konnte." - $(323,2)$ didicistis causam maeroris, [...] date remedii, "Ihr habt den Grund für meinen Kummer erfahren, gebt [...] mir einen <Grund> zur Abhilfe."

- $(446,1)$ ecce vix fero brevem, absentia longa fatigandus, "So also ertrage ich kaum eine kurze Abwesenheit, wo ich doch durch eine lange < Abwesenheit $>$ gequält werden muss."

- $(449,2)$ bene fecisti, domna Agnella, mundi istius blandimenta respuere, et dum celsiora sequeris, etiam quae potuerunt venire a legitimis remediis non habere, $" \mathrm{Du}$ hast gut daran getan, verehrte Agnella, die Annehmlichkeiten dieser Welt zu verschmähen und bei Deinem Streben nach Erhabenerem < auch> die < Annehmlichkeiten $>$ nicht zu haben, die von erlaubtem Trost kommen könnten.«

100 (Quint. inst. 8,2,19) Alii brevitatem aemulati necessaria quoque orationi subtrahunt verba, et, velut satis sit scire ipsos quid dicere velint, quantum ad alios pertineat nihili putant. 
- $(456,1)[. .$.$] quia quod ratione non possumus, temporum prolixitate sepelimus,$ »[...] weil wir das durch die Länge der Zeit begraben, was wir mit dem Verstand nicht <begraben> können. «

- $(457,4)$ generis mei patronus quod in Italia positis praestitit, non neget in Gallia, ut [...], »Was der Patron meiner Familie denen, die sich in Italien befinden, gewährt hat, möge er < denen> in Gallien nicht verweigern.«

Fazit

Quintilian fasst zusammen: Nobis prima sit virtus perspicuitas, propria verba, rectus ordo, non in longum dilata conclusio, nihil neque desit neque superfluat (inst. 8,2,22). Ennodius hingegen bemüht sich in keiner Weise um perspicuitas: Er bevorzugt die ungewöhnliche Reihenfolge, und sein Stil ist eine mixtura aus abundantia und brevitas. Man muss daher Stefanie Kennell, die die Forderung des Iulius Victor nach Klarheit (wie auch seine übrigen Vorschriften, siehe unten 285) bei Ennodius rundum erfüllt sieht $(2003,115)$, entschieden widersprechen. Lohnend wäre die Untersuchung, an welche Adressaten und in welchen Situationen Ennodius mehr oder weniger dunkel schreibt.

An einer Stelle beschreibt Ennodius selbst einen Stil, der dem Empfänger eines Briefs nicht gefallen kann, u.a. mit den Worten nebulosus, ambiguus und caecitas: »[...] wo eine rauhe Sprache die Begrenztheit einer armen Begabung erkennen lässt und dadurch, dass sie ihre Gedanken nicht richtig anordnet, in die eifrige Rede Dunkel bringt und aufgrund der Unklarheit der nebelhaften Erzählung durch die Darlegung selbst eine gewisse Dunkelheit erzeugt $[\ldots] \ll(12,2) .{ }^{101}$ Wenn er hier davon ausgeht, dass undurchsichtige und verworrene Sprache darauf schließen lasse, dass der Verfasser nicht begabt sei, ist sein absichtlicher Einsatz solcher Dunkelheit offenbar ein Mittel, seine an einigen Stellen explizit vorgebrachten Äußerungen, dass ihm rhetorische bzw. literarische Fähigkeiten abgingen (siehe unten 233), zu illustrieren. Dass natürlich gerade die offensichtlich gezielt erzeugte Dunkelheit gerade das Gegenteil beweist, werden auch die Adressaten so gut wie er selbst gewusst haben.

Dieser sermo tenebrosus entspricht nicht dem Stil des Sidonius Apollinaris; ${ }^{102}$ man mag sowohl den Stil des Sidonius als auch den des Ennodius als manieristisch be-

$101(12,2)[\ldots]$ ubi scaber sermo angustiam pauperis signat ingenii nec conceptum suum in ordinem digerendo noctem studio elocutionis interserit et nebulosae narrationis ambiguo quandam generat de ipsa explanatione caecitatem.

102 Zu Sidonius Apollinaris siehe Gualandri (1979) und Amherdt (2001, 52-55). Charakteristisch sind: Parallelismen, dreifach-Konstruktionen, wachsende Tricola, Anaphern, Chiasmen, Alliterationen, Homoioteleuta und Reime, Polyptota, Wortspiele und Paronomasien, Antithesen, Häufungen von Synonymen (AMHERDT 52). 
zeichnen, doch dahinter verbirgt sich jeweils etwas grundlegend anderes. Bei der Lektüre der Briefe des Sidonius fällt als Charakteristikum die Reihung gleicher syntaktischer Einheiten auf, die zumeist parallel, zuweilen aber auch chiastisch gestellt sind. Dafür nur einige kürzere und längere Beispiele: (Sidon. 3,5,3) [...] quicquid meus aetate frater / professione filius / loco civis / fide amicus acceperit. - Über ein Buch des Claudianus Mamertus heißt es: (Sidon. 4,3,6) sentit ut Pythagoras / dividit ut Socrates / explicat ut Platon / implicat ut Aristoteles / ut Aeschines blanditur / ut Demosthenes irascitur / vernat ut Hortensius / aestuat ut Cethegus / incitat ut Curio / moratur ut Fabius / simulat ut Crassus / dissimulat ut Caesar / suadet ut Cato / dissuadet ut Appius / persuadet ut Tullius [...]. - Über einen parasitus heißt es: (Sidon. $3,13,2$ ) est enim hic gurges de sutoribus fabularum / de concinnatoribus criminum / de sinistrarum opinionum duplicatoribus / loquax ipse nec dicax / ridiculusque nec laetus / arrogansque nec constans / curiosusque nec perspicax / atque indecenter adfectato lepore plus rusticus; / tempora praesentia colens / praeterita carpens / futura fastidiens;/ beneficii, si rogaturus est, importunus petendi / derogator negati / aemulator accepti / callidus reformandi / querulus flagitati / garrulus restituti; at si rogandus, simulator parati / dissimulator petiti / venditor praestiti / publicator occulti / calumniator morati / infitiator soluti. [...] - Die Beispiele lassen sich beliebig vermehren. Auch wenn die Sätze lang sind, hat man bei Sidonius keinerlei Mühe, den Satzbau oder die Bezüge zu durchschauen. ${ }^{103}$

Bei Ennodius finden sich keine solchen Reihungen, wie sie eines der »Markenzeichen « des Sidonius sind. ${ }^{104}$ Die wenigen und daher besonders auffälligen Parallelismen bei Ennodius sind z.B.: $(4,2)$ saevit ut bestia, currit ut fluvius, fluctuat ut profundum; $(246,1)$ sitientem fons, aestuantem aura [...] lassum requies. Ungleich häufiger ist die Inkonzinnität, zumindest der Wechsel von Singular und Plural, von Parallelismus und Chiasmus, z.B.: $(3,1)$ campus militem, mare navitas, fora causidicum $[\ldots]$, incerta raptorem, $[. .$.$] linguas auditoria [\ldots] ;(40,3)$ ubertas linguae, castiga-

103 Gualandri $(1979,143)$ : "Pur se tortuoso ed elaborato il periodare sinodiano non riflette una struttura sintattica complessa, mirante a sfumare e graduare i concetti con rigorose concatenazioni di cola e sapienti giochi di coordinazione e subordinazione. [...] Si caratterizza invece $[\ldots]$ in prevalenza per l'agglutinarsi di brevi cola coordinati che vengono a organizzarsi secondo schemi d'accumulo, ove parallelismi e chiasmi s'intersecano in mille combinazioni [...].« AMHERDT $(2001,52) » L a$ structure syntaxique de la phrase sidonienne est généralement assez simple, ce qui n'empêche celle-ci d'être très élaborée."

104 Auch Ruricius hat eine Vorliebe für solche Reihungen, siehe z.B. in Briefen an den Rhetor Hesperius: (Ruric. 1,3,1) [...] pietas, per quam flectuntur rigida, saxea molliuntur, sedantur tumida, leniuntur aspera, tumescunt lenia, mitescunt saeva, saeviunt mitia, accenduntur placida, acuuntur bruta, dominantur barbara, immania placantur [...]. (Ruric. 1,5,4) $\{\ldots\}$ quod deliciis suave, quod esui dulce, quod usui utile, quod victui necessarium, quod visui iucundum, quod olfactui gratum, quod tactui blandum [...]. 
tus sermo; $(268,1)$ rerum omnium cursus obsequiis corporis, animarum constat imperio; aliud nobilitat caelestis adfinitas, aliud abiectio terrena summittit.

Arnulf von Lisieux hat mit seinem Urteil über den sermo tenebrosus also nicht Unrecht. Doch folgendes ist zu bedenken, wenn Arnulf fordert, dass ein klarer Stil dafür sorgen müsse, dass man die schwierigen Dinge gut verstehen könne (cum rerum difficultatem stilus lucidior debeat aperire [...]): In den Briefen des Ennodius gibt es sehr häufig keine rerum difficultas, da sie häufig einzig der Kontaktpflege dienen (siehe unten II 3.b) und Themen wie »Warum schreibst Du nicht? «, »Wie geht es Dir, mir geht es gut « variiert werden müssen. Da der Inhalt also häufig keine Schwierigkeiten macht, sorgt Ennodius auf andere Weise dafür, dass der Leser nachdenken muss. Der Scharfsinn des Lesers ist auch gefordert, wenn Ennodius häufig darauf verzichtet, den Gedankengang durch Konnektoren zu verdeutlichen; dies wird unten in anderem Zusammenhang ausführlich dargestellt (Kap. II 2 d.1.3). Warum er sich so sehr bemüht, die von Quintilian bezeichneten vitia aufzuweisen, ist weiter unten zu überlegen (siehe unten 176).

\section{Der Diakon und sein /Vorleben als Redner und Dichter (und Lehrer?)}

Dass Ennodius im »Eucharisticum» von der Unvereinbarkeit seines kirchlichen Amtes mit literarischer Aktivität spricht, u.a. da diese zu Hochmut und Ehrgeiz führen könne, hat VANDONE (2001) treffend herausgearbeitet. Im Folgenden soll gezeigt werden, dass diese Problematik nicht nur im »Eucharisticum« eine Rolle spielt, und es soll erklärt werden, warum sich Ennodius überhaupt mit diesem Problem konfrontiert sieht (a. silentium und humilitas). Dafür soll nun die erwähnte "Lücke im Lebenslauf « untersucht werden, d.h. die Zeit, in der Ennodius noch nicht Diakon war und sich intensiv mit den studia liberalia beschäftigt hat. Hier sind die Hinweise auf die Zeit vor dem Diakonat zu betrachten und die Passagen, in denen Ennodius auf Unterschiede zwischen seiner Vergangenheit und der Gegenwart hinweist: An einigen Stellen in Briefen (b.1), deren Bedeutung der Forschung bisher entgangen ist, stellt Ennodius seine jetzige Situation als Diakon seiner früheren im erfolgreichen Dienst der studia liberalia, d.h. der eloquentia (zu dieser Gleichsetzung unten 83), gegenüber. Bei der Betrachtung der »Dictiones Scholasticae« (b.2) bestätigt und konkretisiert sich dieses Ergebnis: Aus ihnen geht ebenfalls hervor, dass der Sprecher ein Kleriker ist; dieser verweist auch hier auf seine (vorgeblich) vergangene eloquentia; auBerdem lässt sich vermuten, dass er früher nicht nur Prosa und Dichtung verfasst hat, sondern auch Lehrer gewesen sein könnte. In den betreffenden Passagen, in denen Ennodius die zwei Phasen einander gegenüberstellt, wird ganz deutlich, mit welchen 
Begriffen er seinen Stand als Diakon charakterisiert: "Gelübde / Vorsatz" (professio / propositum), "Schweigen « (silentium), "Demut « (abiectio / humilitas), »Gebet « (preces / oratio). Es zeigt sich, dass er in Briefen und "Dictiones Scholasticae « mit diesen Begriffen auf die gleiche Problematik weist wie im »Eucharisticum«: die Mühen des Diakons, seinem Amt nicht nur äußerlich zu entsprechen.

\section{a. silentium und humilitas}

Wenn Ennodius über den Gegensatz zwischen seiner früheren und seiner jetzigen Tätigkeit bzw. über die Anforderungen seines Standes als Diakon spricht, spielen, wie gleich vorzuführen ist, die Begriffe humilitas und silentium eine entscheidende Rolle. Dabei handelt es sich allerdings nicht etwa um Verhaltensweisen, die speziell mit dem Amt des Diakons in Verbindung stünden, sondern um allgemein christliche Tugenden. Demut ist "die christliche Tugend schlechthin, in der alle anderen wurzeln« (Dinle 1957, 761). Geschwätzigkeit zählt ebenso zu den von Christen zu bekämpfenden Lastern wie etwa Gefräßigkeit oder Trunksucht. ${ }^{105}$

"Demut « und "Schweigen « sind nicht nur in Mönchsregeln zentrale Begriffe (dort kommt noch »Gehorsam « hinzu, der bei Ennodius auch zuweilen erwähnt wird, aber nicht zentral ist). ${ }^{106}$ In der Auseinandersetzung mit den Forderungen nach humilitas und silentium sehen wir auch den Bischof von Mailand Ambrosius in seinem Werk De officiis. Gleich zu Beginn wehrt er sich gegen den möglichen Vorwurf, er sei anmaßend, wenn er sich vornehme zu lehren, wo er doch selbst noch lerne; kurz danach und in engem Zusammenhang damit kommt das Problem des Redens und Schweigens auf, das dann ausführlich behandelt wird: Das erste, was er selbst lernen müsse, sei das Schweigen, denn: »Aufgrund deiner Worte wirst du verurteilt werden ${ }^{107}$

Ennodius thematisiert also statt der speziellen Anforderungen oder Charakteristika seines Amtes als Diakon zwei Verhaltensweisen, die zum einen von al-

$105 \mathrm{Zu}$ "silentium « siehe die christlichen `Tugendkataloge`, z.B. 1 Tim 3,2-11; 1 Petr 3,8 [...] qui enim vult vitam diligere et videre dies bonos, coerceat linguam suam a malo et labia eius ne loquantur dolum eqs.; Mt 5,37 sit autem sermo vester "est est, non non «, quod autem his abundantius est a malo est; vgl. z.B. (Hier. epist. $75,2,1$ ) in proelio peccatorum, vitiis sordidamur; $[\ldots]$ de otioso verbo reddituri sumus rationem.

106 Siehe in der Regula magistri: Kap. 7 De oboedientia..., Kap. 8 De taciturnitate...; Kap. 10 De humilitate...; Regula Benedicti: Kap. 5 De oboedientia, Kap. 6 De taciturnitate, Kap. 7 De humilitate.

107 (Ambr. off. 1,1,1) Non adrogans videri arbitror si inter filios suscipiam adfectum docendi $[\ldots] ; 1,1,4[\ldots]$ docere vos coepi quod ipse non didici. 1,2,5 Quid autem prae ceteris debemus discere quam tacere, ut possimus loqui, ne prius me vox condemnet mea quam absolvat aliena? Scriptum est enim: "Ex verbis tuis condemnaberis« (Mt 12,37). 
len Christen erwartet werden, deren Ausübung zum anderen aber auch schon prominenten Christen wie Ambrosius Probleme bereitet hat. Ennodius setzt sich nun wohl weniger in der Absicht literarischer imitatio und aemulatio mit diesen Problemen auseinander, sondern weil sie seinen Lebensalltag - ebenso wie den des Ambrosius - entscheidend betreffen. Die Lebensläufe der beiden lassen sich immerhin insoweit miteinander vergleichen, dass beide zunächst eine traditionelle sprachlichrhetorische Bildung erhielten und dann in den Dienst der Kirche traten, allerdings von unterschiedlichen Stufen der weltlichen Karrieren auf unterschiedliche Stufen der Kirchenhierarchie. Dass für einen ehemaligen Adepten der studia liberalia das silentium eine große Herausforderung sein kann, ist nicht weiter verwunderlich. Ebensowenig muss überraschen, dass für jemanden, der sich in adligen Kreisen bewegt hat und in bestimmtem Ausmaß auch weiterhin bewegt, die besonders bei der Sorge um Kranke, Waisen und Arme geforderte humilitas keine selbstverständliche Verhaltensweise ist. Es kommt hinzu, dass Ennodius - zumindest in seinen literarischen Erzeugnissen - häufig wenig dazu neigt, sein Licht unter den Scheffel zu stellen (dazu besonders unten 231). Als kurzes und prägnantes Beispiel für sein Selbstbewusstsein kann die einzeilige Aufschrift für eine Schale mit einem Porträt des Ennodius dienen (210, überschrieben: In missorio ubi imago ipsius est): Divitibus pretium est Ennodi forma metallis: "Das Bild des Ennodius gibt dem wertvollen Metall seinen wahren Wert ${ }^{108}$

Vorgestellt sei zunächst eine typische Argumentation zum Thema "Reden und Schweigen«, die sich in der Einleitung zum ersten überlieferten Werk findet, der »Rede zum Jahrestag der Ordination des Mailänder Bischofs Laurentius« (1, siehe die Einführung oben 36). An dieser Einleitung wird deutlich, dass der Redner allen Scharfsinn aufwendet, um den Eindruck zu vermeiden, er verstoße mit der dictio gegen sein venerandum propositum, das ihn zu silentium und humilitas verpflichtet; es war offenbar keineswegs selbstverständlich, dass ein Diakon eine solche dictio verfasste (ob er sie auch vorgetragen hat, entzieht sich unserer Kenntnis). Die Rede beginnt, als würde zunächst ein gewöhnlicher Bescheidenheitstopos angeführt: „Wie lange noch soll meine träge Unsicherheit zulassen, dass ich beengt im Verborgenen bleibe? « $(\$ 1) .{ }^{109}$ Diese diffidentia wird nun nicht mit Zweifeln an den eigenen Fähigkeiten begründet; der Sprecher hat offenbar Sorge um seinen Ruf: "Wie lange noch soll meine übergroße Vorsicht, die die Grenzen der geziemenden Furcht überschreitet, meinem guten Ruf Schaden bringen - was sie doch gerade zu vermeiden sucht? « $(1,1) .{ }^{110} \mathrm{Er}$

108 Anders übersetzt Di Rienzo (2005, 123): „Vale la pena forgiare l'immagine di Ennodio in ricco metallo"; ganz anders verstanden von KenNELL $(2000,118)$ : "Ennodius' reward is his form in rich metals."

$109(1,1)$ Quousque me iners diffidentia intra angustum patitur penetrale delitiscere?

$110(1,1)$ quousque nimia cautio terminos honesti timoris exsuperans dispendia opinionis, quae vitat, incurrit? 
steht vor dem Problem, dass der gute Ruf auf verschiedene Weise Schaden nehmen kann: »Denn es ist bei den Menschen gewöhnlich so: Ebenso wie der gute Ruf durch Kühnheit Schaden nehmen kann, so kann er durch unnötige Furcht zugrunde gehen " $(\$ 1) .{ }^{111}$ Der Sprecher muss sich also entscheiden, ob er seinen Ruf (opinio, fama) lieber durch timor oder durch audacia aufs Spiel setzen möchte. ${ }^{112}$ Er sagt nun, in welcher Hinsicht er seinen Ruf gefährdet sieht, dass er nämlich Angst hat, als ruhmsüchtig zu gelten: »Denn wenn jemand eine Verpflichtung erfüllt, deren Ursache und Ansporn, sie zu erfüllen, im richtigen Benehmen liegt, dann darf man nicht tadelnd sagen, dass dieser gierig auf Lob aus sei, und dann darf das nicht gierige Zurschaustellung von künstlicher Ergebenheit genannt werden« $(\$ 2) .{ }^{113}$ Weiter begründet der Sprecher, warum er kein avarae laudis adsumptor sei: »Denn ebenso wie auf den guten Ruf ein Schatten fällt, wenn man durch Reden Ruhm erlangen möchte, so wird der gute Ruf fast völlig verdunkelt, wenn man eine Verpflichtung, derer man sich bewusst ist, nicht erfüllt" ( $(\$ 2) .{ }^{114}$ Es schadet also dem Ruf des Sprechers, wenn es so aussieht, als wenn er auf Ruhm aus sei (und damit gegen die gebotene humilitas verstoße); allerdings sieht der Sprecher noch größeren Schaden für seinen Ruf, wenn er eine bestimmmte Verpflichtung nicht erfüllt. Dass er es als Verpflichtung ansieht, diese Rede zu verfassen, zeigt sich im Folgenden: "Überflüssiges zu schreiben ist Wichtigtuerei, Notwendiges zu verschweigen hingegen zeigt Verachtung " $(\$ 2) .{ }^{115}$

Diese Gedankengänge sind typisch für Ennodius: Es besteht ein Anlass, eine Rede bzw. einen Text zu verfassen, und Ennodius weiß, dass er dies gut kann, doch er muss erst eine (und sei es nur scheinbar) überzeugende Argumentation vorbringen, um es - gegen die Forderungen von humilitas und silentium - zu ,dürfen $\measuredangle$. Die größte Gefahr, die er beim Rednen sieht, ist keineswegs die, zu versagen. Die Alternative, vor der er hier steht, ist nicht dieselbe, vor der sich z.B. der Verfasser einer Dankrede sieht, der entweder als undankbar dasteht, wenn er nicht spricht, oder aber als unfähig, sobald er den Mund auftut: (paneg. lat. $3(11), 1,2$ ) aut indiserti aut ingrati [...] fama. Ennodius befürchtet den Vorwurf der Ruhmsucht und damit den Vorwurf, er habe gegen die humilitas verstoßen, wenn er spricht; er kann also keine großen Zweifel an seinen Fähigkeiten haben. Die zweite Alternative (aut ingrati $[\ldots]$ fama) ist ver-

$111(1,1)$ usu enim rerum venit inter homines, ut quantum famae decerpitur per audaciam, superfluum non minus pereat per timorem.

112 Vor vergleichbaren Alternativen sehen sich Redner bzw. Autoren zuweilen: z.B. (Cic. orat. 2) malo enim, cum studio tuo sim obsecutus, desiderari a te prudentiam meam quam, si id non fecerim, benevolentiam.

$113(1,2)$ non enim debet notari velut avarae laudis adsumptor, non adscribi cupido affectatae devotionis ostentui, apud quem res obnoxia pudoris stimulis adacta conpletur [...]. - VoGELs Ergänzung "ei« vor adscribi erscheint verzichtbar.

$114(1,2)$ quia sicut in umbram cogit gloriae appetitus, oratione dum quaeritur, ita non reddere quod deberi noveris proximitatem noctis indicit.

$115(1,2)$ superflua scribere res iactantiae est: necessaria reticere contemptus. 
gleichbar: Der zitierte Verfasser der Dankrede möchte nicht als undankbar erscheinen, und auch Ennodius fühlt sich verpflichtet (pudor; reddere quod deberi noveris; necessaria). Ennodius hat eine ähnliche Verpflichtung, aber er steht vor einer anderen Alternative als der Verfasser des Panegyricus.

Nachdem der Redner damit begründet hat, warum er sprechen sollte, geht es im folgenden dann doch auch noch um die Frage, ob sein Talent ausreichend ist; auffälligerweise legt er aber die Zweifel an seinen Fähigkeiten einer anderen Person in den Mund: "Jemand, der einen guten Rat geben möchte, mag sagen, dass mein mageres Talent von der Größe der Aufgabe erdrückt, erschöpft und aufgezehrt wird und dass meine Redseligkeit, der die Kraft zum Reden fehlt, sich durch die Fülle <des Stoffes> Erschöpfung einhandelt [...] « $(\$ 3) .{ }^{116}$ Doch diesem Einwand kann der Sprecher begegnen: ${ }^{117}$ Auch ein geringes Talent wachse bei einem großen Thema oft über sich hinaus $(\$ 4)$, und die Liebe zu dem Gefeierten, d.h. zu Laurentius, bringe hervor, was das Talent eigentlich verweigere. Mit der Erwähnung von amor ergibt sich ein weiterer Grund, der gegen die Ablehnung der Aufgabe spricht, wobei Ennodius sich hier auf neutestamentliche Autorität stützen kann: die Furcht passt nicht zur Liebe (I Ioh 4,18 ) und damit nicht zum propositum des Sprechers ( $\$ 5$ facessat ergo formido venerando inimica proposito!).

Mit dem Ergebnis der Einleitung scheint der Redner zufrieden zu sein ( $\$ 6$ his ita se habentibus eqs.), und er folgert, dass Schweigen nicht das Richtige sei: "Warum soll ich durch hässliches Schweigen dem Beginn des glänzenden Jubiläumstages die Ehre verweigern?« $(\$ 6) .{ }^{118} \mathrm{Er}$ folgen nun Gedanken über den engen Zusammenhang von Freude und Sprache: "Freude ohne Sprache ist matt, und wenn man seine Freude verbirgt, sieht es so aus, als wäre man traurig, und es sieht aus wie Kummer, wenn man in der Freude keine Stimme hat " $(\$ 6) .{ }^{119}$ Solche altbekannten und z.B. für Symmachus völlig unproblematischen $>$ Topoi ${ }^{120}$ kann der Redner erst jetzt anbringen, nachdem er bis hierher Argumente dafür finden musste, dass seine Worte angebracht

$116(1,3)$ dicat forsitan aliquis animo consulendi, quod operis pressa magnitudine exhausti macies ariscat ingenii et destituta dicendi valitudine garrulitas defectum mercetur ex copia $[\ldots]$.

117 Gegenüber Vogel geänderte Interpunktion: statt »dicantur ad pretium [...] « Neueinsatz nach Doppelpunkt vor ad, also "[...] dicantur: ad pretium [...] «.

$118(1,6)$ cur lucidi natalis exordium silentii foeditate dehonestem?

$119(1,6)$ marcida est sine sermone hilaritas et simulacrum maeroris occultare quod gaudeas et adflictionis imitatio vocem in laetitia non habere.

120 Siehe z.B. (Sy. epist. 1,13,1) Solet facunda esse laetitia et angustias clausi pectoris aspernata gestire. $(1,37,1)[\ldots]$ quippe laetitia loquax res est atque ostentatrix sui. $(1,38)[\ldots]$ siquidem difficilis est patientia gaudiorum; siehe auch: (paneg. 2 [12], 2,2) dum in eundem hominem non puto convenire gaudium et silentium; $z$.T. innerhalb des "Bescheidenheitstopos «, d.h. bei angeblichen Zweifeln an der eigenen Fähigkeit zu reden, z.B.: (paneg. 2,2,1) impia taciturnitate; (paneg. 3 [11], 1,1f.). 
sind. Er hat sich bemüht zu verschleiern, dass solche Allgemeinplätze für ihn, der sich zu humilitas und silentium verpflichtet hat, strenggenommen nicht mehr gelten. (Eine ähnliche Verschleierungstaktik ist z.B. in $94 \mathrm{zu}$ beobachten, siehe unten 75.

Ennodius beschäftigt sich häufiger mit dem Problemkomplex >Reden und Schweigen`, d.h. mit dem geforderten silentium, das eng verbunden ist mit der geforderten humilitas. Warum er zuweilen in so auffälliger Weise beträchtlichen Aufwand betreibt, um sein Reden zu rechtfertigen, erklärt sich mit seinem »Vorleben « und seinen in früherer Zeit offenbar gern ausgeübten Fähigkeiten im Schreiben und Reden. In seinen Werken enthaltene Hinweise auf dieses "Vorleben « sollen nun betrachtet werden.

\section{b. 1 Hinweise in Briefen}

In zwei Briefen verweist Ennodius ganz allgemein auf einen Gegensatz zu seiner früheren Lebensweise: In einem Brief (71) an einen Abt bedankt Ennodius sich für einen Brief von diesem und beklagt sich: "Weshalb habe ich, solange mich die unreine, ausschweifende Welt festhielt, niemals Briefe von einem so hohen Mann verdient und auch hinterher lange Zeit niemals solches Gut erhalten? « ${ }^{121}$

In einem Brief an Faustus (11) wehrt er sich gegen den Vorwurf, er halte fremde Sklaven fest; er legt dar, dass die betreffenden Sklaven sich an die Kirche um Hilfe gewandt hätten und dass er von dem Vorfall nur so viel wisse, dass diese aufgefordert worden seien, zu ihrem Herrn zurückzukehren. ${ }^{122} \mathrm{Er}$ beschwert sich über den Vorwurf, der bedeute, dass man offenbar einem Kleriker eine solche Tat zutraue; er habe den Eindruck einer verkehrten Welt: »Man nimmt an, dass ich das, was ich <sogar> vor dem Antritt des kirchlichen Amtes nicht machen durfte, ohne Gedanken an das Rechte begehe, nachdem ich durch das kirchliche Amt den Sünden abgeschworen habe. In welchem Unwetter, du Sturm meiner unermesslichen Sünden, hast du mich dazu gebracht, dieses mir Tadel einbringende Amt anzutreten? ${ }^{123}$ Und zwar das Amt,

$121(71,2)$ quare dum me saecularis licentia inmunda possedit, numquam tanti viri apices $<=$ litteras $>$ merui, post etiam per longa intervalla numquam huiusmodi bona suscepi?

122 Pietri $(1981,431)$ nennt u.a. diese Stelle im Zusammenhang damit, dass Papst Gelasius (492-496) sowohl Respekt für den Besitz der Kirche gefordert als auch den Besitz der Laien respektiert hat; z.B. schickte er Sklaven, die ihren Herren entlaufen waren und in der Kirche Zuflucht gesucht hatten, zu diesen zurück, wenn den Sklaven Straffreiheit zugesichert wurde.

123 Auf dieser Stelle beruht die häufig zu lesende Annahme, Ennodius' Eintritt in den Klerikerstand gehe auf Faustus' Einfluss zurück. Dies geht zurück auf ein Missverständnis von Vogel (1885 Praef. VII), der conpulisti nicht auf die procella, sondern auf den Adressaten des Briefs bezieht. Schon Magani $(1886$, Bd. 1,251) und Lumpe $(1966,201)$ haben dem mit Recht widersprochen, was allerdings erstaunlicherweise in der Forschung kaum 
in dem üblicherweise alle Zweige möglichen Fehlverhaltens von der Sichel <sc. der Vorschriften>, die die Lebensweise lehrt, abgehauen werden ${ }^{124}(\$ 2)$. Diese Worte zeigen deutlich, dass mit dem Amt des Diakons eine Änderung der Lebensweise verbunden ist.

Andere Briefe enthalten Informationen über den Inhalt der vergangenen Phase, dass sich Ennodius nämlich früher den studia liberalia, d.h. der eloquentia, gewidmet hat. Gegenüber seiner Schwester Euprepia macht er nur eine leichte Andeutung, dass er auf ehemaliges Lob für seine Sprachkunst zurückblicken könne: »die <jetzige > Dürftigkeit meiner einst anerkannten Rede « $(219,1$ ieiunia oris olim probati). Doch in Briefen an Florianus, Pomerius und Mascator ist er deutlicher; in diesen Briefen, die sich durchaus als recusationes bezeichnen lassen, begründet Ennodius, warum er mit den Adressaten keinen Briefwechsel führen könne, wie sie ihn wünschten. Hier sollen nur die Hinweise auf die Vergangenheit herausgegriffen werden, die Briefe im ganzen werden unten interpretiert (Teil II.2.b); dort ist dann auch zu zeigen, dass Ennodius nicht zuletzt in diesen Briefen, in denen er betont, seine sprachlichen Fähigkeiten aufgegeben zu haben, diese in besonderem Maße einsetzt.

Florianus erhält zwei Briefe (20; 21), in denen Ennodius deutlich auf sein jetziges kirchliches Amt hinweist, das ihm die früher ausgeübte Redekunst verbiete: Schon seit langem habe das vielversprechende Schweigen (spes tacendi) die Lust am Schreiben verdrängt; ${ }^{125}$ er habe schon lange die weltliche Rhetorik aufgegeben zugunsten von Gebeten (oratio); ;26 er könne sich nicht mit schönen bunten Worten beschäftigen, da ihn sein Amt (officium) laut zu Klagen und Gebeten (gemitus et preces) rufe. ${ }^{127}$ (Ausführlicher zu den Briefen unten 184).

Auch im Brief an Pomerius (39) setzt Ennodius einer früheren Zeit, in der er sich der Redekunst gewidmet hat, eine Gegenwart entgegen, die durch andere Inhalte bestimmt ist. Er führt aus, er habe von einem Dritten erfahren, dass Pomerius Briefe

beachtet wurde, so dass man das Missverständnis auch in neueren Publikationen wiederholt findet. Außerdem ist darauf hinzuweisen, dass es an dieser Stelle nicht allgemein um den Eintritt in den Klerikerstand geht, sondern um das Amt des Diakons.

$124(11,2)[\ldots]$ quod ante religiosam professionem admisisse non decuit, hoc postquam per titulum ecclesiasticum culpis renuntiavimus, sine honesti credimur consideratione peragere. qua me tempestate, procella inmanium peccatorum, ire ad famosum officium conpulisti? in quo omnes errorum rami magistra vivendi solent falce truncari. - Das Bild der falx praeceptorum ausführlicher in 8,1 .

$125(20,2)$ cum diu esset quod antiquaverat apud me scribendi studium spes tacendi [...].

$126(21,4)$ cum diu sit quod oratorium schema $<$ o. s. ist Objekt $>$ affectus $<$ Subjekt $>$ a me orationis absciderit: "da mir schon seit langem die Neigung zum Gebet die Redephrasen genommen hat." - Das Wortspiel mit den beiden Bedeutungen von oratio ("Gebet" und "Rede") auch: 95,3 (unten Anm. 132); 452,26.

$127(21,4)$ cum $[. .$.$] nequeam occupari verborum floribus, quem ad gemitus et preces evocat cla-$ mor officii. 
des Ennodius gelesen und ihre literarische Qualität kritisiert habe (\$3). Auf die ihm hinterbrachten Vorwürfe des Pomerius antwortet Ennodius, dass er keinen Wettkampf in der Redekunst eingehen dürfe, ${ }^{128}$ da seine professio sich mit einer einfachen Lehre begnüge. ${ }^{129}$ Wenn ihn allerdings früher, als er noch seine Freude hatte an den Freien Studien und sie neu für ihn waren, jemand so gereizt hätte wie jetzt Pomerius, dann hätte er entweder mit einer geeigneten Entschuldigung geantwortet oder mit einer Entgegnung, derer er sich nicht zu schämen bräuchte. ${ }^{130}$ Abschließend bittet Ennodius Pomerius, sich in der Korrespondenz mit ihm doch lieber kirchlichen bzw. religiösen Fragen zuzuwenden; die weltliche Redekunst müsse man verachten $(39,6$ ista quae sunt saecularium schemata respuantur). (Ausführlicher dazu unten 189).

In einem Brief an Mascator (95) spricht Ennodius davon, dass er sich früher einmal erfolgreich mit den Freien Künsten beschäftigt, die Ergebnisse dieser Studien aber aufgegeben habe; er, der früher über einige Redekunst verfügt habe, könne nun kaum noch reden. Für diese Veränderung wird ein Grund angegeben: Seine Zunge, die aufgrund von stetem Gebrauch und Übung beweglich gewesen sei, sei durch einen anderen Gebrauch nun stumpf. An die Stelle der Redekunst sei das Schweigen (silentium) getreten, statt prunkender Rede schätze er nun die Demut (abiectio). ${ }^{131}$ Die Begriffe silentium und abiectio verweisen eindeutig auf eine religiöse Begründung für die Aufgabe der Redekunst, was im selben Brief zudem explizit ausgesprochen wird: Er habe in seiner von der Kirche geforderten Demut solchen literarischen Erzeugnissen abgeschworen, die gefallen könnten; wer das Gebet liebe, strebe nicht nach prunkender Rede; ${ }^{132}$ in Anbetracht seines propositum vermeide er alles, was ihm Ruhm bringen und ihn emporheben könne. ${ }^{133}$ - In diesem Brief betont

$128(39,4)$ periclum facere de eloquentiae pompa non debeo [...].

$129(39,5)[\ldots]$ cum professionem meam simplici sufficiat studere doctrinae.

$130(39.5)$ si me $[\ldots]$ quondam studiorum liberalium adhuc novitate gaudentem aliquis tali dente tetigisset, parassem vel quod ad excusationem esset idoneum vel quod non puderet obiectum.

131 (95,4f.) [...] replico, quod illud, quicquid studiorum dederat cura liberalium, iam reliqui, quod alveo quondam copiosi fluminis vix arentis gutta fundatur eloquii. taceo, quod linguam, quam usus mobilem fecerat, alter usus hebetavit: esse pro facundia silentium, abiectionem a nobis diligi pro coturno: "ich wiederhole, dass ich, was auch immer die Bemühung um die freien Studien mir gebracht hatte, längst hinter mir gelassen habe und dass im Bett des einst reichen Stromes kaum noch ein Tropfen einer vertrockneten Rede fließt. Ich verschweige (weil meine Zunge, die durch die Praxis beweglich geworden war, durch eine andere Praxis abgestumpft ist), dass an die Stelle der Redekunst das Schweigen getreten ist, dass ich die Demut schätze an Stelle des Prunks."

$132(95,3)$ taceo [...] ecclesiasticam humilitatem quod placere poterat abiurasse, orationum pompam qui orationem diligit non secutum.

$133(95,3)$ taceo [...] propositi consideratione et illud me fugere quod ducit ad gloriam, quasi vitium declinare quicquid attollit, culpam putare quod erigit aut sublimat: »ich will nicht erwähnen $[\ldots]$, dass ich aufgrund meines Amtes auch das vermeide, was zu Ruhm führen 
Ennodius, dass zwischen seiner ecclesiastica humilitas, seinem propositum und dem alter usus einerseits und den früher betriebenen Studien und beherrschten Fähigkeiten andererseits ein unvereinbarer Gegensatz bestehe. (Ausführlicher zu diesem Brief unten 181).

Diese Aussagen über die früher vorhandene eloquentia, die nun aufgrund eines kirchlichen Amtes verboten sei, sind nicht 'topisch ‘ im Sinne von 'bedeutungslos`, wohl aber in dem Sinne, dass der Gedanke in vielen ähnlichen Situationen aktuell ist. Auch wenn schon viele christliche Autoren vor Ennodius immer wieder den Konflikt thematisiert haben, der für Christen bzw. Kleriker durch die weltliche Bildung entsteht, ${ }^{134}$ so heißt das nicht, dass dieses Problem für Ennodius bedeutungslos ist. Die Gleichgültigkeit der Forschung gegenüber diesen ,Topoi`, die die ehemalige Beschäftigung mit den studia liberalia zum Thema haben, führte im Fall des Ennodius dazu, dass man als Argument für seine traditionelle Ausbildung lediglich die Vielfalt der in seinen Werken zitierten klassischen Autoren heranzog und kaum sichere Schlüsse über seine Ausbildung zu ziehen wagte (siehe oben 29). - Eine interessante Frage ist allerdings, warum Ennodius diese stopischen، Gedanken nur wenigen Adressaten gegenüber vorbringt, um die Korrespondenz mit ihnen entweder ganz einzustellen oder in andere Bahnen zu lenken, und warum hingegen in der Korrespondenz mit anderen Adressaten entweder dieses Problem völlig ausgeblendet ist oder der Gedanke an den kirchlichen Stand in gänzlich anderer Weise eine Rolle spielt (siehe unten $277 \mathrm{ff}$.).

\section{b. 2 Hinweise in den "Dictiones Scholasticae»}

In weiten Teilen der „Dictiones Scholasticae» (vgl. oben 40 spricht Ennodius von der Bedeutung von Bildung für die Adligen und betont, wieviel Anstrengung bei der Ausbildung nötig sei; er hebt die wichtige Aufgabe des Lehrers hervor und lobt diesen. Nava Rra $(1972,465)$ beobachtet an diesen Dictiones richtig die Mischung aus unterschiedlichen Elementen, dass sich nämlich in ihnen zuweilen neben den Lobre-

könnte, dass ich wie einem Laster allem ausweiche, was mich <sc. aus meiner humilitas> erheben würde, dass ich für tadelnswert halte, was mich aufrichten oder emporheben könnte.《

134 Siehe aus der reichen Literatur zu diesem Thema z.B.: H. HagendaHL, Latin Fathers and the Classics, Göteborg 1958. - Ders. Von Tertullian zu Cassiodor. Die profane literarische Tradition in dem lateinischen christlichen Schrifttum, Göteborg 1983. - Siehe insgesamt die von C. Gnilka begonnene und herausgegebene Reihe X@̃̃oı / Chrêsis: Die Methode der Kirchenväter im Umgang mit der antiken Kultur, Basel. - W. Evenepoes, The Place of Poetry in Latin Christianity, in: J. den Boeft, A. Hilhorst (Hgg.), Early Christian Poetry. A collection of Essays, Leiden u.a. 1993, 35-60. 
den auf die klassische Bildung auch (allerdings sehr knappe) religiöse Gedanken bzw. christliche Worte finden. ${ }^{135}$ Navarra nimmt an, dass solche christlichen Formulierungen neben Lobreden auf die klassische Bildung für die ersten Hörer »un strano effetto di contrasto $(1972,467)$ bedeutet haben müssen. Doch wie bereits aus den gerade betrachteten Briefen hervorging und wie sich im Folgenden an den "Dictiones Scholasticae « bestätigt, ist Ennodius in einer früheren Zeit als Redner und Dichter in Erscheinung getreten, nun aber ist er Diakon; daher werden sich die Zeitgenossen, die den neuen und den alten Stand des Ennodius sicherlich kannten, im Gegensatz zu modernen Interpreten nicht sehr darüber gewundert haben, wenn eine Dictio mit einer Bitte an Gott schloss; ebensowenig werden sie gestaunt haben, wenn der Sprecher darauf verwies, dass für die Angesprochenen und für ihn selbst jeweils verschiedene Autoren maßgeblich sind: Maro vester $[. .$.$] Hieronymus noster (69,14)$.

Die ehemalige Tätigkeit birgt den Grund dafür in sich, dass Ennodius diese Dictiones überhaupt verfasste; denn die von NavarRA $(1972,466-468)$ vorgebrachte Erklärung für die Existenz dieser Dictiones, dass nämlich der Autor jede sich ergebende Gelegenheit nutzen wolle, die klassische Bildung zu loben, dürfte nicht ausreichen. Denn wie sollte es sich konkret ergeben haben, dass ein Diakon ohne weitere Begründung anlässlich einer Schulfeier die klassische Bildung loben wollte und konnte? Auf jeden Fall lässt sich nachvollziehen, dass Ennodius als ehemaliger Adept der Studia liberalia - offensichtlich gern - das Wort (falls denn die Texte wirklich zum Vortrag bestimmt waren) bzw. zumindest den Stilus ergriff.

In diesen "Schulreden" finden sich viele bisher unbeachtete Aussagen über die frühere Tätigkeit des Ennodius. Aus ihnen geht eindeutig hervor, dass sich die bereits (oben 30) erwähnte Annahme von MAGaNI und LégLISE, Ennodius sei gleichzeitig Diakon und Lehrer in einer Schule gewesen, nicht halten lässt. Die Reden ergeben eindeutig, dass Ennodius zur Zeit ihrer Abfassung nicht Lehrer war. Er weist selbst explizit auf die schwierige Situation hin, dass er als Kleriker solche Reden halte bzw. schreibe und er deutet an, dass er dies eigentlich nicht dürfe und könne; daher führt er jeweils Gründe dafür an, warum er dennoch bei solchen schulischen Anlässen als Redner auftrete. Wenn diese Reden mit einer eigenen Tätigkeit als Lehrer in Verbindung stünden, wie sie MaGani und LégLise vermuten, müsste er sein Auftreten nicht jeweils - und zwar unterschiedlich - begründen. Auch fragt sich, ob der ,Zwang zum Einsatz von `Bescheidenheitstopoi` so weit gehen konnte, dass ein Lehrer vor Schülern und eventuell einem weiteren Schulpublikum die eigenen Fähigkeiten stellenweise so herabspielen ${ }^{136}$ oder die Gründe dafür, dass er nicht gut sprechen könne, so ausführlich darlegen würde. Vielmehr zeigt sich, dass Ennodius die ehemalige Tätigkeit als Redner und Dichter (eigentlich) aufgegeben hat.

135 Z.B. $(3,10)$ deus $[\ldots]$ votis se comitem iungat; $(69,15)$ deum precor, ut [...].

136 z.B.: (85,5) meus sermo quod scaber est et nullo splendescens dictionis adtritu [...]: »Dass meine Rede so schäbig ist und nicht mit gefeiltem Ausdruck glänzt [...].« 
Dass diese "Schulreden « nicht von einem Lehrer gesprochen wurden, geht aus den Stellen hervor, an denen der Sprecher darlegt, in welcher Funktion er spricht bzw. in welchem Verhältnis er zu dem jeweiligen neuen Schüler steht: Einmal (69) hebt er hervor, als Verwandter bringe er seinen jungen Verwandten, gleichzeitig als Kleriker einen Waisenjungen zu dem Lehrer; ${ }^{137}$ aus diesen beiden Gründen sei er mit dem Jungen verbunden, und deshalb stelle er ihn dem Lehrer vor. Ein anderes Mal (85) dient als Rechtfertigung dafür, dass er als Redner auftrete, seine Liebe zu Arator; ${ }^{138}$ diese Liebe halte ihn davon ab zu beachten, was sich eigentlich für ihn gehöre. ${ }^{139}$ In einer weiteren Rede (124) kommt er zu dem Schluss, für seine Sorge, aufgrund fehlender Übung nicht mehr reden zu können, bestehe kein Grund, da sein geistliches Amt verlange, dass er in diesem Fall eine Rede halte, da er nämlich einen Waisenjungen bringe $^{140}$ (dem Diakon oblag die Waisenfürsorge), den ihm dessen Vater anvertraut habe. Ein anderes Mal führt er als Grund an (451), dass er als Pate ein zweiter Vater sei und damit eine besondere Verpflichtung habe. ${ }^{141}$

Ein Lehrer, der als Grammaticus dem Rhetor einen ehemaligen Schüler übergibt oder als Rhetor einen Jungen beim Grammaticus einführt, würde sein Auftreten wohl nicht in dieser Weise begründen. In einer solchen Situation wären zwar die Hinweise auf Verwandtschaft und Zuneigung als Begründungen, die das berufliche Interesse ergänzen, möglich. Die Erwähnungen des religiosum officium, das (u.a.) zur Fürsorge für Waisen verpflichte, weisen jedoch deutlich auf einen Diakon als Sprecher.

Aus weiteren Passagen geht ebenfalls hervor - was für die ersten Rezipienten offensichtlich war -, dass ein Kleriker spricht, und es wird außerdem deutlich, dass es nicht selbstverständlich war, dass ein Diakon Reden für solche schulischen Anlässe verfasste. Wie in den im letzten Kapitel betrachteten Briefen verweist er auch hier auf die für ihn geltenden Forderungen nach silentium und humilitas: Die am Anfang der ersten überlieferten "Schulrede" (3) gestellte Frage, welchen Grund es geben könnte, am gegenwärtigen Ort, auf dem forum (wo sich offenbar der neue Unterrichtsort des angesprochenen Lehrers befindet), zu schweigen, und die folgenden Begründungen für das Reden wären aus dem Munde eines Lehrers und Redners wenig sinnvoll. Wa-

$137(69,13)$ propinquum ad te consanguineus, orbum parentibus religiosus exhibui.

$138 \mathrm{Zu}$ Arator, dem nachmaligen Verfasser des Bibelepos über die Apostelgeschichte, einem der bekannteren Adressaten des Ennodius, siehe unten 130.

$139(85,9)[\ldots]$ imperiis amoris excusor. [...] dum caris prospicimus, quid nos deceat non videmus.

$140(124,4)$ insinuandum orbitatis miseratio, orationem religiosum commendat officium.

141 (451,11) ego in animae eius secunda nativitate aut recreatione sum genitor. ergo peculiaris eruditionis eius me provisio respicit, cuius pater et inter caelestia sum vocatus. Dies ist eine wichtige Stelle für die Geschichte der Patenschaft, da aus ihr hervorgeht, dass, anders als zuvor, die Taufe nicht mehr unbedingt nur verwandte Personen verband; außerdem zeigt sich die Verantwortung als "pater «, nämlich die soziale Funktion und die Erziehungsfunktion, die sich aus der Patenschaft ergab; siehe dazu Jussen 1991, 1566 . 
rum sollte jemand, der sich berufsmäßig mit Sprache und Rede beschäftigt, fast am Anfang einer Rede ausrufen: »Denn ach, welcher Grund kann zum Schweigen raten an einem Ort, wo Belohnungen für Worte ausgesetzt sind? « ${ }^{142}$ Dass allerdings jemand, zu dessen kirchlichem Stand grundsätzlich das silentium gehört, zunächst das Schweigen zum Thema macht und darlegt, aus welchen Gründen das Forum zum Reden aufrufe, lässt sich nachvollziehen. Einigermaßen erstaunlich ist allerdings, wie schnell und mit welchen Worten (quae, malum, ratio [...]) er sich über das von ihm geforderte silentium hinwegsetzt und den Eindruck erweckt, als könne es auf diese Frage keine sinnvolle Antwort geben. Indem er die Frage formuliert, welchen Grund es geben könnte, an diesem Ort zu schweigen, versucht er, vergessen zu lassen, dass es für den Diakon eigentlich keinen Grund dafür geben kann, in dieser Situation eine Rede zu halten.

Vergleichbar sind die Eingangsworte in der Rede für Ennodius' Neffen Parthenius (94), in der er sich beim Lehrer für Parthenius' Fortschritte bedankt: Hier ist nicht das vom Diakon geforderte silentium Thema, sondern die ebenfalls geforderte humilitas bzw. das untersagte Gegenteil, adrogantia / iactantia. Der Sprecher legt ausführlich dar, warum er überhaupt das Wort ergreife (bis zu \$4: sed iam omissis thematis commendationibus), und er beginnt mit dem Gedanken, dass es sich, wenn man sich für einen erwiesenen Dienst bedanke, nicht um iactantia handle, da man ja lediglich der Notwendigkeit gehorche. ${ }^{143}$ Es überrascht, dass sich der Sprecher, der sich bedanken möchte, dafür offenbar rechtfertigen muss. Warum kann es problematisch sein, dass er sich bei dem Lehrer dafür bedanken möchte, dass sein Neffe bei ihm große Fortschritte gemacht hat (siehe \$9-12)? Warum beendet er zudem die Dictio mit dem Gedanken, was es bedeuten würde, wenn er sie nicht verfasst hätte, ${ }^{144}$ statt mit dem Hinweis auf die erworbene Fähigkeit des Schülers zu schließen? ${ }^{145}$ Auch dies wird aus der Situation des Ennodius verständlich: Er nimmt an, dass man ihm, wenn er diese Rede verfasst, iactantia / adrogantia vorwerfen werde, d.h. dass er seine Fä-

$142(3,1)$ nam quae, malum, ratio suadebit silentium in loco, in quo sunt praemia constituta verborum?

$143(94,1)$ Quando debitas beneficiis reddimus gratias, credo quod abiuramus iactantiam necessariis obsequendo.

$144(94,13)$ his ergo muneribus tuis nisi reddam vicissitudinem, praestitisse te aestimes non merenti. quisquis enim feriata lingua successus meliores suscipit, ostendit se quod attulit prosperitas non amare: "Denn wenn ich dir für deine Leistungen <sc. den erfolgreichen Unterricht des Neffen> nicht den entsprechenden Dank ausspräche, würdest du denken, dass du sie jemandem erwiesen hast, der sie nicht verdient hat. Denn wer einen schönen Erfolg hinnimmt, ohne etwas dazu zu sagen, zeigt dadurch, dass ihm nicht gefällt, was das Glück ihm gebracht hat.«

$145(94,12)$ ecce post gentile murmur de ore eius, quae humanitatem significent, verba funduntur: »Da! Aus seinem Mund, aus dem vorher barbarische Laute kamen, ergießen sich nun Worte, die einen Menschen zu erkennen geben.« Hierauf folgt direkt der in der letzten Anm. zitierte Gedanke. 
higkeiten zur Schau stellen wolle und dass er auf Lob und Ruhm für seine Redekunst aus sei, was sich aber für ihn als Diakon verbietet. Er betont daher, dass seine Worte nicht dem Ruhm dienen, sondern dem Verwandten, und dass es eine Sache sei, in der Hoffnung auf Lob und Ruhm zu sprechen, eine andere aber, zu sprechen, um nicht getadelt zu werden. ${ }^{146}$

Wie im vorangehenden Beispiel (3), so argumentiert der Sprecher auch hier letztlich nicht wirklich überzeugend: Die iactantia ist ihm zwar aufgrund seines kirchlichen Amtes verboten, aber die Begründung dafür, dass es sich nicht um iactantia handle, entstammt der weltlichen Sphäre. Ebenso wie völlig unbestritten ist, welche ratio dem Diakon in der ersten Rede zum Schweigen raten müsste $(3,1)$, so ist hier klar, dass es ein Grund wäre, den Diakon zu tadeln, wenn er dem Lehrer mit einer Dictio dankt. Er will sich rechtfertigen durch die spitzfindige Unterscheidung, dass er nicht rede, um gelobt zu werden, sondern um Tadel zu vermeiden - und er versucht so zu verschleiern, dass sein Ziel darin besteht, sich gegenüber dem Lehrer richtig zu verhalten, und nicht darin, den Ansprüchen des kirchlichen Amtes zu genügen. Es ist auffällig, wie Ennodius einerseits die Charakteristika seines geistlichen Standes benennt, andererseits aber mit weltlichen Begründungen und innerhalb der weltlichen Wertewelt argumentiert (siehe auch oben $68 \mathrm{zu}$ 1).

Wenn der diese Reden verfassende Diakon an einigen Stellen Gründe dafür vorbringt, warum er nicht gut reden könne, macht er dabei gleichzeitig deutlich, dass er es früher einmal konnte oder unter anderen Umständen auch jetzt noch könnte. Er spricht nämlich nicht nur von einer (vorgeblichen) grundlegenden Unfähigkeit mangels Begabung, sondern er bringt andere, plausiblere Gründe vor: In einer Schulrede (124) führt er aus, dass er nicht deshalb Sorge habe zu reden, weil es neu für ihn sei, sondern weil er es nicht mehr gewohnt sei (124,1 intermissa; dicendi usu pereunte): An verschiedenen Beispielen zeigt er, dass Gewohnheit Sicherheit bringe, fehlende Übung hingegen dazu führe, dass alles je Gelernte vergessen werde $(\$ 1-3)$; dass dies auf ihn selbst zu beziehen sei, sagt er ausdrücklich. ${ }^{147}$ Er verweist eindeutig darauf, dass er die besagte Fähigkeit einmal besessen hat; er sagt nicht, dass er etwa aufgrund mangelnder Begabung nicht sprechen könne, sondern er sagt deutlich, dass er es verlernt habe.

In der Rede zur Einführung des Arator (85) wird eingangs ausführlich dargestellt, dass (gute) Reden nur halten könne, wer Zeit und Muße habe, sie gründlich auszuarbeiten, und nicht von anderen Beschäftigungen und Sorgen davon abgehalten werde; ${ }^{148}$ wer von vielen Aufgaben zerrissen werde, könne sich nicht intensiv einer Sache

$146(94,1)$ aliud est enim ut lauderis dicere, aliud dicere ne carparis.

$147(124,3)$ talis est nostrae, quam post temporum intervalla producimus, condicio dictionis: "Das ist die Situation meiner Rede, die ich nach längerer Unterbrechung verfasse."

$148(85,1)[\ldots]$ eliminatis curarum procellis orationum serena plus rutilent: $»[\ldots]$ ohne die Stürme von Sorgen können Reden besser in Heiterkeit erstrahlen; « cf. Ov. trist. 1,1,39 carmina proveniunt animo deducta sereno. 
widmen. Ennodius weist ausdrücklich darauf hin, dass diese Vorrede ihn selbst betreffe, denn er habe zu viel anderes zu tun ( 85,5 occupationes variae; non datur duris solvere colla laboribus). Daraus geht hervor, dass er sich wohl zutrauen würde, eine gute Rede zu verfassen, wenn er nur die nötige Muße hätte. Er vergleicht sich und seine Situation mit dem angesprochenen Lehrer Deuterius: Deuterius bemühe sich um Erfolge im Reden und gehöre zum Volk der Dichter - während er, Ennodius, von Delos vergessen sei; ${ }^{149}$ Deuterius gehöre der Castalische Quell, während Ennodius seine Lippen nur mit spärlichen Tropfen eines mageren Nasses netze; Deuterius sei die rettende Hand, die ausgestreckt werde, um den Verfall der Redekunst abzuwehren (zum Lehrer als Retter gegen den Verfall siehe unten 92), Ennodius hingegen, der an der jetzigen Welt nicht nur das Schlechte, sondern sogar das Gute fürchten müsse, sei in der engen Kirche eingeschlossen. ${ }^{150}$ Deuterius ist also Redner, Dichter und Lehrer. Ennodius kann sich hier auf diese Weise mit Deuterius vergleichen, weil auch er bereits als Redner und Dichter in Erscheinung getreten ist: Von seiner Erfahrung im Reden war bereits zu hören (eben in Reden, dem Anlass entsprechend), und dass Ennodius nicht nur als Diakon dichtet (wie das überlieferte Werk zeigt), sondern dies auch früher getan hat, sagt er ebenfalls explizit (siehe unten 78 ). Ob auch die dritte Gegenüberstellung, dass Deuterius als Lehrer den Verfall aufhalte, Ennodius hingegen der Kirche gehöre, auf eine ehemalige Lehrertätigkeit des Ennodius verweist (ein Indiz dafür findet sich in der ersten überlieferten Schulrede, siehe gleich unten) oder vielleicht nur auf einen unerfüllten Wunsch, ist nicht mit Sicherheit zu klären; eine sichere Tatsache ist immerhin, dass er sich als Diakon häufig über die Bildung von jungen Adligen äußert (siehe unten Kapitel I 4).

Ennodius fährt dann fort mit der Frage, warum Deuterius ausgerechnet ihn zum Sprechen aufgefordert habe; ihn habe eine andere Lebensweise doch schon niedergebeugt: [...] animos, quos alter iam sibi vitae ordo subdiderat $(85,8)$. Daraus ist zu schließen, dass Ennodius früher einmal der geeignete Ansprechpartner war und bei vergleichbaren Anlässen aufgetreten ist.

Einige Unterschiede zu den bisher erwähnten »Schulreden" weist die erste auf (3), und es wäre durchaus möglich, dass wir hier Ennodius als Redner vor seinen ehemaligen Schülern sehen. Ein Indiz dafür ist seine Aufforderung an die Adressaten, ihn nicht zu vergessen $(3,8$ mei meminisse dignamini). Dieser Wunsch wäre zwar auch aus dem Mund eines eingeladenen >Festredners` möglich, der ansonsten keine Be-

$149(85,6)$ te inter palestra tua originaria linguae palma sollicitat, te inter cives, mei inmemor, superba Delus adnumerat [... ]: "Dich reizt auf deinem Übungsplatz dein angestammter Siegespreis im Reden, dich zählt das stolze Delos zu seinen Bürgern, während es mich vergessen hat $[. .$.$] .« - Ennodius verwendet palestra als Neutrum Plural, cf. 13,1;39,4.$

$150(85,6)$ tu Castalii gurgitis lautus possessor incedis, at ego vix arentibus labiis stillantem guttam marcidi liquoris infundo [...]. tu in sustentationem ruiturae libertatis felix dextera subrogaris - me ecclesiae angulus etiam bona metuentem saeculi praesentis includit. 
ziehung zu den Angesprochenen hat, näherliegend ist es aber, an einen ehemaligen Lehrer zu denken.

Diese "Schulrede» hebt sich zunächst dadurch von den anderen $a b$, dass sich der Redner an eine Gruppe von Schülern wendet, nicht wie in den anderen an einen oder zwei mit Namen angesprochene. In den anderen Schulreden rechtfertigt er sein Auftreten jeweils mit seiner Rolle als Pate, Verwandter oder Kleriker, was er hier auffälligerweise gar nicht tut. Vielmehr schreibt er sich hier anders als in allen anderen Schulreden explizit eine Rolle als hortator $(\$ 8)$ und monitor $(\$ 9) \mathrm{zu}$; er verwendet für seine eigene Rolle die Begriffe, die auf einen Lehrer verweisen, aber auch allgemeiner verwendet werden können: institutor virtutis $(\$ 9)$, praeceptor $(\$ 10)$, praecepta daturus $(\$ 9)$; die Rede selbst nennt er vox commonentis (\$5) und exhortatio (\$9). Auch in den anderen Reden spricht er zwar Ermahnungen an die einzelnen Schüler aus, aber er schreibt sich nicht explizit eine solche Rolle zu. Auffällig ist, dass er von sich auch in der ersten Rede nicht als doctor oder magister spricht: ${ }^{151}$ Als doctor bezeichnet er den angesprochenen Lehrer Deuterius: doctorum optime $\left(\$_{3}\right)$, außerdem in der Wendung an die Schüler: habetis praevium eloquentiae morumque doctorem ( $\$ 8)$.

Ennodius beginnt die an die Schüler gerichteten Worte mit dem Hinweis, dass er ihnen aufgrund väterlicher Zuneigung Ermahnungen schulde. ${ }^{152}$ Die paterna affectio spricht weder eindeutig für noch gegen die ehemalige Lehrerrolle. Auf welche Art von Beziehung sie weist, ist für uns anders als für die ersten Adressaten schwer zu entscheiden. Es könnte sich um die Beziehung zwischen Lehrer und Schülern handeln, denn der häufiger zu lesende Gedanke, dass der Lehrer die Stelle der Eltern übernimmt, ist Ennodius nicht fremd. ${ }^{153}$ Diese Worte könnte also ein Lehrer, auch ein ehemaliger Lehrer sprechen. Aber auch in Empfehlungsschreiben für seinen Neffen Parthenius an Persönlichkeiten in Rom, die keine Lehrer waren, bittet er um suffragia paterna (225,2) und: patrem reddite $(227,3)$. Auch hinsichtlich der Beziehung von Bischof Laurentius zu seiner Gemeinde spricht Ennodius von der paterna pietas $(1,14)$. Es weist allerdings nichts darauf hin, dass Ennodius als Diakon allgemein die Fürsorge für die in dieser Schulrede Angesprochenen hätte (anders als in 69 und 124), denn

151 Wenn er allgemein über Lehrer oder über den konkret angesprochenen spricht, wechseln die Begriffe, wobei doctor oder magister in der Regel darunter ist; vgl. in den anderen Dict. Schol.: (69) allgemein über Lehrer: $\$ 8, \$ 13$ doctor, $\$ 9$, \$14 praeceptor, $\$ 8, \$ 14$ institutor, $\$ 15$ magister, der konkret angesprochene: $\$ 12$ doctor, $\$ 13$ magister. (85) konkret: $\$ 5$ magister; (94) konkret: $\$ 4$ magister, $\$ 8$ doctor; (124) konkret: $\$ 7$ doctor; (262) konkret: v.19 doctor; (451) konkret: $\$ 9$ doctor.

$152(3,5)$ quibus paterna conventus affectione vocem debeo commonentis.

153 Siehe Kaster $(1988,68$ f.). Ennodius zitiert Juvenal (luv. 7,209 f.) qui praeceptorem sancti voluere parentis / esse loco $(452,4)$ und erläutert dann den Gedanken. Die Ars grammatica sagt von sich: $(452,13)$ nos parentes dixit aetas illa maior optimos. Siehe auch: $(425,4)$ paterna, sicut praeceptores vocavit antiquitas, pietate. 
Der Diakon und sein >Vorleben

es ist von ihren Eltern, besonders ihren Müttern die Rede, ${ }^{154}$ und es findet sich kein Hinweis darauf, dass sie Waisen wären.

Wenn Ennodius hier tatsächlich als ehemaliger Lehrer spricht, ohne dies unmissverständlich zu sagen, ließe sich dies wohl zum einen damit erklären, dass die Adressaten es sowieso wussten, außerdem aber damit, dass der ehemalige Beruf wohl kein unbestreitbarer Grund für den Diakon gewesen wäre, in dieser Situation das Wort zu ergreifen. Er wählt solche Formulierungen (paterna pietas, hortator, monitor, institutor virtutis), die sowohl zum ehemaligen Lehrer passen als auch allgemeiner verwendet (und verstanden) werden können.

\section{b. 3 Die $>$ Recusatio an Olybrius (27)}

Olybrius erhält eine doppelte, Recusatio ( siehe oben 39). Im distichischen zweiten Teil wird die Geschichte des Phaethon ausgeführt (v.1-2o), wobei in Bezug auf die Kunst der Dichter und Redner Ennodius die Rolle des Phaethon und Olybrius die des Phoebus zugeschrieben wird (v.21 ff.). Dabei spricht Ennodius zunächst davon, dass er die Dichtkunst nicht beherrsche (v.31-34). Dann aber wird deutlich, dass er früher einmal solche Fähigkeiten besessen hat; die Verse können für sich sprechen: "Was immer ich mit dem Plektron des Apoll sagte, ich habe damit aufgehört und / die Sprache vergessen, die mir die Saiten gaben./ Meine bäuerische Rechte irrt über die zarten Saiten,/ und die barbarischen Plektra zerbrechen die süßen Weisen./ Oh, wie oft floss für mich der Helikon durch grüne Wiesen - das Wasser, das den Lippen zulächelt und Durst macht./ Oh wie oft führte ich, die Schläfen mit Efeu umwunden,/ die Aonische Schar, sie mit einem Lied erfreuend « (v.35-42). ${ }^{155}$ Doch nun sei er mit anderen Dingen beschäftigt, die von ihm auch einen anderen Umgang mit seinen sprachlichen Fähigkeiten erforderten; dabei vergleicht er den Dienst in der Kirche mit der Arbeit des Bauern (v.44 agrestem [...] militiam): »Jetzt aber bin ich entschlossen, in den Wäldern, in den Höhlen der Tiere / den ländlichen Dienst zu leisten;/ ich übergebe starken Furchen große Samen,/ damit das Unkraut den Spross des Lebens verlässt [...]«. Er dürfe durch seine Schriften weder den Eindruck von Verweichlichung noch den von Stolz erwecken (cf. mollis und tumidus): »[...], damit nicht zarte Worte meinen Sinn als schlaff bloßstellen / und ich weichlich in Worten und Talent genannt werde./ Meine Zunge soll nicht durch weite Felder hin- und

$154(3,5)$ parentum titulos; $(3,7)$ matres optimae.

155 (27, v.35-42) Quidquid Apollineo loquebamur pectine, cessi / Oblitus linguae, quam mihi fila dabant./ Rustica per teneras errat mihi dextera cordas,/ Confringunt dulces barbara plectra modos./ A quotiens vitreis Helicon mihi fluxit in herbis / Adridens labiis quae facit unda sitim./ A quotiens hederis redimitus tempora duxi / Aonium mulcens carmine concilium! - Ist der metrische Fehler in v.35, das kurze se in loquebamur, in diesem Zusammenhang ein Zufall? - Cf. im Einzelnen den Kommentar von Vandone (2004). 
herlaufen / und ich will nicht mit starken Signalhörnern kraftvolle Worte ausstoBen,/ damit mein Herz nicht vom großtönenden Kothurn entflammt wird / und man glaubt, von meinen aufgeblasenen Schriften auf meinen Charakter schließen zu können « (v.43-52). ${ }^{156}$ Denn wenn man so von ihm denke, habe er keine Zuflucht mehr; Olybrius könne Ruhm suchen, er selbst hingegen müsse schweigen, um sich richtig zu benehmen: „Wo finde ich dann einen rettenden Hafen? Mein Leser <sc. Olybrius> erstrebt von allen Seiten Ruhm./ Doch mein eigenes Gewissen bleibt unerschüttert, wenn ich schweige «. Darauf schließt Ennodius: „Du magst den Himmel besitzen, lass mich in Ruhe auf der Erde,/ der ich nur das eine weiß, dass ich nichts gut gelernt habe" (v.55f.). ${ }^{157}$ Mit der letzten Bemerkung meint er sicher nicht, dass er wenig gelernt habe, sondern das Falsche.

Im vorangehenden Prosateil der Recusatio mit einem bukolischen Bild ist die agrestis militia des Klerikers, die im Versteil der Phaeton-Thematik untergeordnet ist, das Hauptthema. Hier vergleicht Ennodius seine Situation als rusticus, d.h. Kleriker (in dieser Hinsicht sehr vorsichtig VANDONE 2004, 101), mit der des urbanus Olybrius (hier sind gleichzeitig beide Bedeutungen von urbanus aktuell: Olybrius ist fein gebildet und lebt in einer städtischen, weltlichen Umgebung). Dem Hirten wird von einem urbanus eine Lyra dargeboten, doch der Hirt lehnt aufgrund seiner rusticitas ab. Zunächst wird ausgemalt, wie der Hirt in der Natur seine Flöte spielt und welche Sorgen die Hirten haben (\$1f.). Wenn man diesem Hirten nun eine Lyra anbietet, wird er verunsichert, da der Klang der Lyra die Seele rührt: »Wenn einem, der mit solchen Dingen beschäftigt ist, ein Gebildeter eine mit ihren Saiten sprechende Kithara gibt und - ein feiner städtischer Spötter - redende Saiten bringt, schwankt die einfache Schlichtheit, was sie wählen soll; denn die Berührung der Lyra bringt ja - und sei es mit unsicheren Fingern - einen süßen Klang hervor, der die Seele erweichen kann « $\left(\$_{3}\right) .{ }^{158}$ Doch der Hirt weiß, warum er die ihm angebotene Lyra ablehnen muss; wenn er nach Höherem strebt und die ihm gesetzten Grenzen überschreitet, wird er auch das Wenige einbüßen, was er hat: »Dennoch hält er es für frevelhaft, sich durch die Anmut einer anderen Lebensweise <sc. durch die Anmut der Lyra, die zu einer anderen Lebensweise gehört> dazu verleiten zu lassen, seine ererbten Kennt-

156 (27, v.43-52) At nunc per silvas, inter spelaea ferarum / Agrestem certus ducere militiam,/ Grandia per validos commendo semina sulcos, / Ut germen vitae destituant lolia,/ Lactea ne mentem denudent verba solutam,/ Et dictis mollis dicar et ingenio./ Non mihi per campos discurrat lingua patentes / Mascula nec lituis dicta feram gravibus,/ Ne mea grandisono flammentur corda coturno / Et tumidus scriptis moribus esse puter.

157 (27, v.53-56) Qui mihi tunc portus? famam petit undique lector./ Sed stabilis pudor est, si taceam, proprius./ Tu caelum teneas, me terris linque quietum, / Qui solum novi, quod bene nil didici.

$158(27,3)$ cui talia agenti si quis sermocinantem fidibus citharam doctus admoveat et loquacia fila inrisor urbanus adportet, in ancipiti est quid eligat nuda simplicitas, dum lyrae tactus licet errantibus digitis dulcem et qui animam frangat crepitum reddit. 
nisse nicht <mehr > zu lieben; er erkennt, dass er durch das Streben nach Höherem, indem das ungezügelte Streben die Grenzen der einfachen Lehre nicht beachtet, auch das (ihm) Mögliche verlieren werde $[\ldots] \ll\left(\$_{4}\right) .{ }^{159}$ Dann folgt die Auflösung des Bildes, die Gleichsetzung des Hirten und des doctus mit Ennodius und Olybrius, dem groBen Redner ( $\$ 5$ ). Olybrius wird gebeten, Ennodius nicht weiter zu bedrängen und durch rhetorische Kniffe überreden zu wollen: $» B i t t e$ entferne die verführende ausgefeilte Rede, die Du verwendest, um mich aufzufordern. Fern seien die rhetorischen Zwangsmittel, die Du auch bei Könnern anwendest. Zügle die Finger Deiner Worte, mit denen Ihr die Seelen von Widerstrebenden zur Erfüllung Eurer Wünsche zu treiben pflegt. Mir sei es entweder erlaubt, mein Unwissen mit Schweigen zu bedecken oder mit meiner Rohrpfeife anderen ein gewöhnliches Lied zu bringen $\ll(\$ 6) .{ }^{160}$ Es folgt der Übergang zum Gedicht, in dem Ennodius darauf verweist, dass die Korrespondenz mit Olybrius seinen alten Qualitäten, d.h. seinen »ehemaligen« sprachlichen Fähigkeiten, zu verdanken und etwas Neues sei; offenbar kennt er Olybrius noch nicht lange $(\$ 6) .{ }^{161}$ - Im ersten Teil dieser $>$ Recusatio räumt Ennodius ein, dass die Lyra ihn verlockt, aber er macht deutlich, dass er fest bei seinem Vorsatz bleiben wolle: Er muss die ihm gesetzten Grenzen einhalten, um so immerhin das ihm Mögliche zu erreichen. Anders als im darauf folgenden Versteil (z.B. v.39 und 41 A quotiens ...!) und ebenso wie im "Eucharisticum " gibt er im ersten Teil keinen Hinweis auf sein >Vorleben`; im Gegenteil, an dem Hirten wird betont, dass er seiner Herkunft treu bleiben müsse ( $\$ 4$ avita scientia; paternae institutionis mediocritas).

\section{c. Fazit: Die Probleme des Diakons}

Die Briefe an Florianus, Pomerius und Mascator, die "Schulreden « und die "Recusatio « an Olybrius zeigen deutlich, dass der Diakon Ennodius auf ein /Vorleben` als Redner und Dichter (und vielleicht auch als Lehrer) zurückblickt - ein Vorleben, in dem er die literarischen Fähigkeiten erworben und ausgeübt hat, die sich in den vielfältigen erhaltenen Werken des Diakons zeigen. Wenn es in der »Rede zum Jahrestag der Ordination des Mailänder Bischofs Laurentius« heißt: „Dir also, Bischof, soll ich jetzt nicht darbringen, was ich anderen darzubringen schon gelernt habe [...]?»

$159(27,4)$ nefas tamen putat, si alieni tractus lepore propositi avitam discat scientiam non ama$r e$, ut dum infrenis ambitus rusticantis doctrinae terminum non metitur, superiorum affectu et ipsa se possibilia intellegat perditurum $[\ldots]$.

$160(27,6)$ amove, quaeso, quam adhibes ad invitandum me elucubrati sermonis inlecebram. absint, quibus etiam apud peritos uteris, vincla conloquii. conpesce verborum digitos, quibus soletis renitentum animas ad desideria vestra conpellere. liceat me aut silentio inscitiam tegere aut per stridentem stipulam aliis triviale carmen adferre.

$161(27,6)$ vobiscum fabulari res est meriti veteris et novae felicitatis. 
$(1,9),{ }^{162}$ so lässt sich dies mühelos auf die frühere Tätigkeit als Redner beziehen; ${ }^{163} \mathrm{er}$ ist sicher häufig bei schulischen Anlässen, bei Geburtstagen, Hochzeiten o.ä. aufgetreten. ${ }^{164}$ Es erklären sich auch weitere Stellen, wenn er etwa in einem Empfehlungsschreiben sagt: "Verehrter Faustus, Ihr wisst, mit welcher vorgefassten Meinung <sc. dass sie erfolgreich sein werden $>$ diejenigen, die nach den Freien Studien streben, mich belasten, wenn sie von mir ein Empfehlungsschreiben fordern wie etwas, das ihnen zusteht « $(292,1) .{ }^{165}$ - Auch das Wort culpa, das in dem Gedicht über Faustus' und seine eigene Dichtung (26) im distichischen Teil wie nebenbei fällt, erhält Sinn: Ennodius hat zunächst dargestellt, dass das Gedicht von Faustus auf ihn wirke wie ein Fluss, dessen Wasser nur immer noch mehr Durst wecke; dann beschreibt er Faustus' Sprachkunst, die die Welt verändere (siehe dazu unten Kap. I 4 c.3) und z.B. hungrigen Löwen ihre Beute wieder aus dem Maul nehmen könne. Dieser Teil des Gedichts schließt mit den Worten: "Ich weiß schon, wohin ihr mich gezogen habt, Castalische Liebhabereien: Zu meinen Sünden kommen eure Geschenke hinzu « $(26,31 f$. $) .{ }^{166}$ Faustus hat Ennodius ein Gedicht zugesandt, das ihn zu dieser polymetrischen Antwort inspiriert hat; doch für den Diakon bedeutet es eine culpa, ein solches Gedicht zu verfassen.

Die in diesem Kapitel betrachteten Passagen zeigen deutlich, dass Ennodius sich von den Inhalten seiner früheren Lebensphase noch nicht völlig getrennt hat: Die Forderungen seines jetzigen Standes nach silentium und humilitas thematisiert er häufig, doch gegen mögliche Vorwürfe, dass er gegen diese Forderungen verstoße, wendet er sich z.T. mit weltlichen Argumenten. Er verfasst Reden für schulische Anlässe und vermeidet es tunlichst zu sagen, dass er aus dem Grunde spricht, weil er ehemals Redner, Dichter und (wahrscheinlich) Lehrer war - und offensichtlich weiterhin Freude am Reden bzw. an literarischer Betätigung hat. Nur gegenüber wenigen Adressaten seiner Briefe verweist er darauf, dass sein Verhalten von silentium und humilitas geprägt sein müsse, während dieser Aspekt in der großen Masse seiner Briefe keine Erwähnung findet; auf welche andere Weise der Gedanke an seinen Stand auch in vielen Briefen an andere Adressaten deutlich einfließt, wird weiter unten zu betrachten sein (Teil II, 277).

$162(1,9)$ tibi ergo, antistes, nunc non reddam quod aliis iam praestare didici $[\ldots]$ ?

163 Gegen Hasensta $(1890,6)$, der annimmt, die Eingangsworte Quousque ... per timorem etc. hätten "nur einen entsprechenden Sinn unter der Annahme, dass Ennodius mit dieser Rede das erstemal als Schriftsteller an die Öffentlichkeit getreten ist."

164 Zur Bedeutung von "Gelegenheitsgedichten « für die Eliten siehe A. CAMEron, Wandering Poets: A Literary Movement in Byzantine Egypt, Historia 14, 1965, 470-509.

$165(292,1)$ Scit magnitudo vestra, quo me onerent praeiudicio studiorum liberalium sectatores tamquam rem sibi debitam commendationis meae scripta poscentes.

$166(26,31 \mathrm{f}$.) Iam scio Castalii quo me traxistis amores:/ Accedunt culpis munera vestra meis. 
Aufträge für `offizielle Werke wie den »Libellus pro synodo«, die Heiligenviten und den Panegyricus für Theoderich oder auch kleinere Aufträge wird Ennodius aufgrund seines $>$ Vorlebens und seiner auch weiterhin lebendigen Freude am Schreiben gern übernommen haben. Verständlich wird auch, warum er seine Korrespondenten so eindringlich zum Schreiben auffordert - Briefeschreiben war offenbar weniger 'problematisch، als Dichten, wenngleich sich in Teil II zeigen wird, dass auch dies differenzierter gesehen werden muss. Ob er aber die nicht-offiziellen Werke für ein breiteres oder überhaupt für ein Publikum gedacht hat, ist im Einzelfall gründlich zu überlegen.

Wenn man nun diese Ergebnisse mit dem zuvor untersuchten »Eucharisticum« vergleicht, so wird deutlich, dass Ennodius sich entgegen seiner Darstellung im »Eucharisticum « auch vor der Krankheit durchaus der für ihn problematischen Anforderungen seines Amtes als Diakon bewusst war und darüber nicht nur nachgedacht, sondern auch geschrieben hat. Seine Probleme als Diakon, von denen er im "Eucharisticum " berichtet (sein Hochmut, sein Streben nach Lob mit Reden und Dichten), rühren daher, dass er sich schon vor dem Diakonat intensiv mit Literatur und literarischer Produktion beschäftigt hat; er ist nicht als Diakon zum Dichter/ Redner geworden - wie man es dem »Eucharisticum« entnehmen könnte -, sondern er ist es trotz des neuen Amtes (in gewissem Umfang) geblieben. Dass Ennodius seine Vorgeschichte mit der traditionellen sprachlichen Bildung im »Eucharisticum« nicht erwähnt, hängt damit zusammen, dass er sich dort ja nicht rechtfertigen, sondern im Gegenteil sein falsches Verhalten während des Diakonats besonders herausstellen will. Er verschweigt dort ja auch, dass er schon vor dem Diakonat im Dienst des Bischofs Epiphanius stand.

Im folgenden soll gezeigt werden, dass Ennodius sich auch als Diakon immer noch mit den Themen "Bildung" und "Redekunst « beschäftigt, um den literarischen Fortschritt junger Männer (z.T. vielleicht ehemaliger Zöglinge) besorgt ist und immer noch einen Bezugspunkt für die Ausbildung besonders von jungen Verwandten darstellt.

\section{Der Diakon und die studia liberalia}

Dass Ennodius, der ehemalige Dichter, Redner und vielleicht auch Lehrer, sich als Diakon von seiner >literarisch-rhetorischen Vergangenheit‘ nicht völlig verabschiedet hat, beweist bereits die Existenz der Schulreden, die im letzten Kapitel heranzuziehen waren. Dass er als Diakon weiterhin vielfältige Prosa und Dichtung schreibt, zeigt das überlieferte Werk insgesamt. Es wurde bereits erwähnt, dass dem Diakon 
in der Forschung lange seine Haltung gegenüber der traditionellen weltlichen Bildung vorgeworfen wurde, wobei manche Elemente im Werk zu ungünstigen Urteilen der Interpreten über seine christliche Überzeugung geführt haben (dagegen deutlich Rota 1999, 132). Im Folgenden wird nun genauer betrachtet, wie sich der Diakon zu den weltlichen Studien äußert, ohne dass man daraus Wertungen über seinen christlichen Glauben ableiten sollte. Dargestellt werden seine Aussagen über (a) das Verhältnis von weltlicher und christlicher Bildung, (b) die Bedeutung von Bildung für den Adel und (c) die Macht der Ars Rhetorica. Außerdem wird überlegt (d), wie sich Ennodius' Rolle gegenüber den jungen Adligen, um deren Bildung er sich kümmert, beschreiben lässt.

Ennodius hat selbst die traditionelle weltliche Ausbildung erhalten und ist mit selbst verfassten Reden und Gedichten aufgetreten; vielleicht hat er eine Zeitlang seinerseits diese Bildung vermittelt. "Bildung « bedeutet für Ennodius fast ausschließlich »literarische Bildung « und »Redekunst«, wie ja überhaupt in der antiken und spätantiken Schule das oberste Ziel des Unterrichts bei Grammaticus und Rhetor die korrekte Sprachbeherrschung und die Fähigkeit zu reden war. Eloquentia war das Fundament für eine Karriere als Anwalt oder in der Zivilverwaltung bzw. für die Aufnahme in das Netz von Beziehungen und Patronage; ${ }^{167}$ die sprachlich-rhetorische Bildung verschaffte den Zugang zur Macht, zum Prestige, zur Elite, die sich von der armen, anonymen, ungebildeten Masse absetzte. Die Inhalte und Methoden dieser Bildung und Ausbildung blieben konstant, als sich das Christentum durchsetzte; zwar kamen im Unterricht christliche Texte (Bibelepen) hinzu, dadurch wurden aber die paganen Texte nicht verdrängt.

\section{a. Weltliche und christliche Bildung}

Ennodius äußert sich zur Bedeutung sowohl einer traditionellen rhetorischen als auch einer christlichen Bildung für Kleriker und auch für Angehörige des Adels. Bemerkenswert an seinen Aussagen zur Bildung ist, dass er klassische Literatur und Bildung nicht generell als Wert empfiehlt oder als Übel ablehnt, sondern die Beschäftigung damit je nach der Person bzw. deren Stand in Welt oder Kirche bewertet - was allerdings bisher in der Forschung unbeachtet geblieben ist. ${ }^{168}$ Wenn MARKus über die Zeit Gregors des Großen schreibt $(1997,39$, zum Thema "value of secular disci-

167 Siehe dazu z.B. Kaster $(1988,28 f$.); grundlegend, mit Beispielen besonders für den Ostteil des Reiches: Peter Brown, Macht und Rhetorik in der Spätantike, München 1995 (engl. Orig. 1992). Zu diesem Aspekt bei Cassiodor siehe: MeXER-Flügel 1992, 394-396.

168 Vgl. die pauschale opinio communis etwa bei GRUBER (1997, Sp. 1047): "Die Artes liberales hält er für die Bildung der jungen Kleriker für unabdingbar und betont daher nicht nur ihren intellektuellen, sondern auch ethischen Wert. Beherrschung der Redekunst ist auch für ihn der Nachweis für die Befähigung zu öffentlichen Ämtern, ja sie verleiht un- 
plines (): "a gulf had opened between the religious and the secular culture which Augustine and Cassiodorus could never have envisaged ", so lässt sich auch bei Ennodius beobachten, wie sich die Kluft auftut; andererseits ist aber noch das Bemühen erkennbar, für die Angehörigen der weltlichen und der kirchlichen Sphäre möglichst viel von der jeweils anderen Sphäre auch gelten bzw. möglich sein zu lassen.

In diesem Zusammenhang ist zu betonen, dass Ennodius bestimmte ,topische Probleme nur selten hat. Es ist oft darauf hingewiesen worden, dass die Literatur der Ostgotenzeit eine enge Mischung von paganen und christlichen Elementen aufweise (siehe z.B. Rota 1999, 125, mit weiterer Literatur), und Ennodius' Werk mit den vielen Anspielungen auf verschiedenste pagane und christliche Autoren ist ein gutes Beispiel dafür. Dass er auf pagane Autoren anspielt, ja sogar Elemente des paganen Mythos verwendet, wird keinen Zeitgenossen auf den Gedanken gebracht haben, er sei kein Christ (endlich deutlich: RoTA 1999, 132). Wenn er sich dennoch an einigen wenigen Stellen (die in den Handbüchern gern zitiert und angesichts seiner vielen Zitate antiker Autoren als "Lügen« entlarvt werden) gegen die Lügen der alten Dichter $(43$, v.1-18, dazu Rota 1999, 129$)$ oder gegen die anilium commenta poetarum $(13,4)$ wendet, so bedeutet das keineswegs seine momentan aufblitzende Ablehnung der traditionellen Literatur, sondern er hat jeweils ganz spezielle inhaltliche Aspekte im Blick (siehe z.B. zu 13 unten 178). Insgesamt sagt er jedoch auffällig selten, dass die Inhalte der paganen Literatur für ihn als Christen problematisch sein können. Seine persönlichen Probleme bestehen, wie oben ausgeführt wurde, darin, dass er wegen der geforderten humilitas auf seine Dichtkunst bzw. insgesamt auf seine sprachlichen Fähigkeiten nicht stolz sein darf und dass er wegen des geforderten silentium mit seinen literarischen Erzeugnissen nicht vor die Öffentlichkeit treten darf.

Zum Thema »weltliche und christliche Bildung« sollen zunächst zwei Texte betrachtet werden, in denen Ennodius die Auffassung vertritt, dass die studia liberalia der Übernahme eines kirchlichen Amtes vorangehen sollten $(2 ; 431)$, die umgekehrte Reihenfolge hingegen nicht gut möglich ist (431), und dass die Verbindung von beidem besonders gute Früchte bringt (2). Dies ist die Sicht auf das Problem, wie sie sich in hartem Ringen allmählich allgemein durchgesetzt hatte. ${ }^{169}$ Im Prosateil der Dictio Ennodi diaconi quando de Roma rediit (2, dazu oben 39) thematisiert Ennodius seine eigene Situation und betont, dass jemand, der in den studia liberalia unterrichtet ist, die Geheimnisse der heiligen Schrift umso besser verstehen und andere da-

sterblichen Ruhm. Hinter dieser Bildungsgläubigkeit tritt seine christliche Überzeugung zurück."

169 Siehe z.B. Laktanz (inst. 1,1,10): Multum tamen nobis exercitatio illa fictarum litium contulit, ut nunc maiore copia et facultate dicendi causam veritatis peroremus. Quae licet possit sine eloquentia defendi, ut est a multis saepe defensa, tamen claritate ac nitore sermonis illustranda et quodammodo disserenda est, ut potentius in animos influat, et vi sua et instructa religione et luce orationis ornata. 
rin unterrichten kann. Das Verhältnis zwischen christlicher und weltlicher Bildung wird bildreich beschrieben: "Ebenso wie feuchte Zweiglein, wenn sie mit fremden Ästen vermählt werden, den Ästen edle Früchte bringen, wie sie den Pflanzen vorher unbekannt waren, so erhebt ein Mann, der Bildung als Mitgift mitbringt, die Seele, die mit einem guten Bestreben schwanger geht, zur Hoffnung auf einen besseren Sproß. [...] Denen, die von diesen studia zu Größerem aufbrechen, eröffnen sich die Geheimnisse der göttlichen Bücher; wenn einer deren Tür öffnet, indem er mit dem Verstand anklopft, kann er als Anführer für die Völker den unbekannten Weg gangbar machen, indem er die Vornehmen mit glanzvoller Rede, die Ungebildeten mit einem auf sie <sc. entsprechend ihrem Bildungsstand> zugeschnittenen Latein und mit, wie man sagt, künstlicher Einfachheit führt « $(2,5 f.) .{ }^{170}$

Dieselbe Ansicht liegt einem Brief (431) zugrunde, in dem sich Ennodius über einen Jungen äußert, der seine Ausbildung gerade beginnen soll. Aus dem Brief an Ennodius' Verwandte Camella geht hervor, dass die Adressatin ihren kleinen Sohn ( $\$ 1$ parvulum) zu Ennodius geschickt hat, um ihn in den studia liberalia ausbilden zu lassen; d.h. Ennodius sollte sich darum kümmern, dass er unterrichtet wurde, er muss ihn nicht selbst unterrichtet haben, siehe unten Kap. I $4 \mathrm{~d}$. Nun hat aber Camella die (über den Diakon Patricius mit Ennodius erfolgte, vgl. \$2) Absprache in der Weise durchkreuzt, dass sie den Jungen zuvor der Kirche geweiht hat ( $\$ 1$ religionis titulis insignisti); vielleicht war er Lektor, das Amt konnten Knaben mit ca. 8 Jahren antreten. Ennodius ist verstimmt darüber, dass ein der Kirche geweihter Junge in den weltlichen Künsten unterrichtet werden soll: »Der Dienst in der Kirche ist zwar ehrenvoll, doch er lässt dem Geist nicht die Möglichkeit, sich in zwei verschiedene Richtungen zu bewegen. Der Weg zu Christus ist ein einziger und schwierig, und der enge Weg nimmt niemals diejenigen auf, die mit verschiedenen Dingen beschäftigt sind. Wenn man von den weltlichen Künsten zum Bringer des Heils kommt, dann weist er einen nicht $\mathrm{ab}$, aber er lässt nicht $\mathrm{zu}$, dass jemand von seinem Glanz her zu jenen geht.« $(431,2)$ - Allerdings hat Ennodius den Knaben trotz dieser Bedenken aufgenommen $\left(\$ 3\right.$ suscepi)..$^{171}$

$170(2,5$ f.) velut uda praesegmina peregrinis maritata fomitibus nobilitatem fructuum ramis tribuunt, quam parturientia diu nesciere plantaria, ita dotatus liberalibus institutis bona mentem cura gravidam ad spem germinis melioris adtollit. [...] (\$6) hinc ad clariora digredientibus divinorum patescunt secreta librorum, quorum ianuam sensu pulsante dum reserat, populis se duce pervium facit iter ignoratum, dum fastidiosos eloquii splendore, parum doctos fabricata <infabricata coni. W. Stroh> latinitate et, ut aiunt, artifici rusticitate perducit.

171 (431,1) veneranda quidem ecclesiastici forma servitii, sed quae ad duas partes animum non relaxet. unum et difficile iter est quo itur ad Christum, nec occupatos multipliciter aliquando via arta suscepit. properantes ad se de disciplinis saecularibus salutis opifex non refutat, sed ire ad illas quemquam de suo nitore non patitur. - (431,1f.) intercepisti nostrum nescio quem secuta consilium. [...] (\$2) vere animum meum de quietis statione ad cogita- 
Eine andere Gewichtung von christlicher und weltlicher Bildung findet sich in der "Paraenesis« (452), die von den Passagen, wo sich Ennodius über Bildung äußert, in der Forschung bisher am meisten bzw. fast ausschließlich beachtet wurde (siehe die Einführung oben 52 . Im ersten Teil dieses Werkes werden die christlichen Tugenden Verecundia, Castitas und Fides vorgestellt, und es folgen dann Grammatica und Rhetorica. Als Übergang von der Darstellung der christlichen Tugenden zu den beiden die schulische Ausbildung bestimmenden Artes dient der Satz: "Den genannten Tugenden [sc. verecundia, castitas, fides] darf auf keinen Fall die Bemühung um die Freien Künste fehlen, damit das Gut, das Glaube und Religion darstellen, wie durch den Glanz eines kostbaren Schmuckstückes erhöht wird « $(\$ 10) .{ }^{172}$ Die divinarum bona rerum sollen also durch die studia liberalia geschmückt werden. Hieran ist zweierlei auffällig:

(1.) Ungewöhnlich ist zunächst im Vergleich mit den gerade betrachteten ÄuBerungen in der Dictio (2) und in dem Brief an Camella (431) die Reihenfolge, dass nämlich christliche Tugenden den weltlichen Artes vorangehen. Genau daran, dass die Rhetorica den Endpunkt der personifizierten Tugenden und Künste darstellt, scheinen sich die Interpreten besonders zu stoßen ${ }^{173}$ (neben der Präsentation der Rhetorica an sich, siehe dazu ausführlich unten 97). Doch der vermeintliche Widerspruch zwischen den verschiedenen Aussagen über das Verhältnis von christlicher und weltlicher Bildung in (2) und (431) einerseits und in der "Paraenesis " andererseits löst sich auf, wenn man die Verschiedenheit der Adressaten und die jeweiligen Inhalte der weltlichen bzw. christlichen Bildung in Betracht zieht; Ennodius vertritt nicht eine grundsätzliche Meinung zur Bedeutung von Bildung, sondern je nach Person bzw. Stand lässt er unterschiedliche Ansprüche und Maßstäbe gelten: Für die Jungen, die eine weltliche Karriere vor sich haben, geht es darum, über christliche Grundtugenden zu verfügen; für den Kleriker hingegen bedeutet »christliche Bildung «, die divinorum $[. .$.$] secreta librorum (2,6)$ zu durchdringen. Die "Paraenesis « richtet sich an die jungen Adligen Ambrosius und Beatus, die sich zur Fortführung ihrer Studien in Rom aufhalten und Ratschläge für eine weltliche Karriere erhalten; divinarum bona rerum $(\$ 10)$ sind in diesem Fall die unverzichtbaren christlichen Grundtugenden für Angehörige des weltlichen Standes; sie sind nicht der Rhetorik "unterstellt« (so Fontaine 1962, 418), sondern sie sind ihr unverzichtbares Funda-

tionum pelagus expulisti: "Du hast meinen Ratschlag zunichte gemacht und bist dem eines anderen gefolgt. [...] In der Tat, du hast meine Seele aus ruhiger Lage in ein Meer von Überlegungen getrieben."

$172(452,10)$ De praefatis virtutibus facessat studiorum liberalium deesse diligentiam, per quam divinarum bona terum quasi pretiosi monilis luce sublimentur.

173 Siehe z.B. das Urteil Fontaines $(1962,418)$ : »seltsam $[\ldots]$ zu sehen, daß in diesem Werk christliche Tugenden mit den Artes liberales vermengt werden und diesen, insbesondere der Rhetorik, sozusagen unterstellt sind «; (400): »<sc. die Paraenesis ist $>$ in ihrer Schilderung der literarischen Bildung so bewußt weltlich.« 
ment. In dem Brief an Camella (431) hingegen ist die Rede von einem kleinen Jungen, der bereits der Kirche geweiht ist, und in der Dictio (2) spricht Ennodius von sich selbst, der früher Dichter und Redner (und vielleicht Lehrer) war und nun Diakon ist. Wären in der "Paraenesis « die Virtutes und Artes in der umgekehrten Reihenfolge dargestellt - also zunächst Grammatica und Rhetorica, erst dann die christlichen Tugenden -, hätte dies eventuell zur Folge gehabt, dass die eine Karriere in der Welt anstrebenden Adressaten denken könnten, sie hätten ja lediglich das Ziel, die Rhetorik zu beherrschen und müssten daher die weiteren Schritte nicht beachten. So erklärt sich diese auf den ersten Blick vielleicht befremdliche Reihenfolge mit der Rhetorik als Abschluss als geschicktes Eingehen auf die Adressaten. Ennodius weiß, dass sie sich auf eine weltliche Karriere vorbereiten; er versucht nicht, sie für den geistlichen Stand zu gewinnen oder ihnen jedenfalls deutlich zu machen, dass der von ihm selbst gewählte Stand der bessere sei - was beides bei den Adressaten wahrscheinlich keine große Begeisterung hervorgerufen hätte -, sondern er verweist auf die christlichen Tugenden in der Weise und in dem Ausmaß, wie es von sweltlichen، Christen akzeptiert werden konnte. Übrigens spricht Ennodius auch in einem Brief (405) an Beatus (einen der beiden Adressaten der »Paraenesis «), in dem er die »Paraenesis « erwähnt (als epistola admonitionis \$2), von christlicher und weltlicher Bildung in derselben Reihenfolge: "Dass du gläubig bist, ist ein Geschenk Gottes für Dich; die Bildung wird mit Gottes Hilfe als zweites hinzukommen " $(405,1) .{ }^{174}$

(2.) Auffällig ist an der "Paraenesis« außer der Reihenfolge der auftretenden christlichen Tugenden und weltlichen Künste auch die bereits zitierte ausdrückliche Ermahnung, dass es auf keinen Fall unterbleiben dürfe, die genannten Tugenden mit den studia liberalia zu schmücken ( $\$ 10$, siehe oben 86 ). Auffällig deshalb, weil die Adressaten Ennodius um eine concinnatio didascalica, eine Schrift zur Anleitung für ihre Studien, gebeten hatten $\left(\$_{1}\right)$, wobei sie kaum an moralische Ermahnungen gedacht, sondern eher mit Ausführungen über Grammatik und Rhetorik, wahrscheinlich mit einem 'Studienplan', gerechnet haben werden. Erwartet hätten sie wohl eher die umgekehrte Ermahnung in dem Sinne, ,vergesst über den Studia liberalia bitte nicht die christlichen Tugenden`. Indem Ennodius die Ermahnung umkehrt, sagt er implizit, dass die Orientierung an den betreffenden christlichen Tugenden selbstverständlich ist - so selbstverständlich, dass er die Adressaten dazu nicht extra auffordern muss. Er ermahnt hingegen zu den studia liberalia, als stünde die Beschäftigung mit ihnen zur Diskussion - dabei sind doch die Adressaten in Rom, um ihre Studien weiterzuführen -, und verweist so indirekt darauf, dass das Streben nach den Idealen verecundia, castitas und fides völlig selbstverständlich ist. - Vielleicht erhofft er sich von dieser indirekten Ermahnung eine größere Wirkung seiner Ausführungen über die Tugenden als von der gewohnten und von den Adressaten sicher erwarteten direkten.

$174(405,1)$ quod fidelis es, divini est muneris in natura: eruditio per deum veniet res secunda. 
Nur kurz sei darauf hingewiesen, dass sich die verschiedenen bei Ennodius zu erkennenden sModelle` dafür, welcher Personenkreis welche Art der Bildung anstreben soll, sowohl vom Konzept Augustins in De doctrina christiana als auch von dem des späten Cassiodor, wie er es im Psalmenkommentar und in den Institutiones vertritt, unterscheiden. Beide stellen dar, wie und warum man die Kenntnisse und Fähigkeiten der weltlichen Artes für den christlichen Gebrauch, d.h. für das Verständnis der Heiligen Schrift, nutzbar machen kann und soll. Die «Paraenesis« hat eine andere Absicht und andere Adressaten, so dass ein bloßer Vergleich des Inhalts zu kurz greifen muss. ${ }^{175}$

b. Bedeutung der Bildung für den Adel

Dass Ennodius in der (sprachlich-literarischen) Bildung ein wichtiges Charakteristikum des Adels sieht, hat NäF (1995) deutlich formuliert: »Primär war für Ennodius Adel mit Bildung assoziiert « (199). NÄF hat herausgearbeitet, dass Ennodius der Bildung des Adels im Vergleich mit anderen Autoren eine besonders wichtige Rolle zuschreibt (204). Im Folgenden ist die Aufmerksamkeit auf einige bisher vernachlässigte Aspekte des Komplexes 'Adel und Bildung`zu richten, besonders zunächst (b.1) darauf, dass aus Ennodius' steten Ermahnungen, sich um die Bildung zu bemühen, eine gewisse Sorge um die tatsächliche Bedeutung der Bildung für den Adel zu sprechen scheint, und dann (b.2) darauf, welchen Einfluss auf den Adel Ennodius der Bildung zuschreibt.

\section{b. 1 rorigo et studias}

Den Kontakt zu adligen Kreisen pflegt Ennodius während des Diakonats intensiv, wie an einem Großteil der Korrespondenz mit Adligen zu erkennen ist, die auf verschiedenen Stufen weltlicher Karrieren stehen; z.T. handelt es sich um rein private Kontakte, vielfach aber auch um dienstliche. ${ }^{176}$ Seine Werke, besonders der Panegyricus, werden von Seiten historischer Forschung genutzt, um sein Konzept von >Adel (vgl. oben 5 mit Anm. 3) herauszuarbeiten. ${ }^{177}$ So stellt Delle Donne (1998) die Bedeutung von Herkunft bzw. von Vererbung von >Adel im Panegyricus dar. Er zeigt, dass

175 Vgl. Fontaine $(1962,419)$ : "Der durchaus weltliche Bildungsbegriff des Ennodius hat mit dem des Cassiodor nichts gemein; " Ennodius scheine "von der klugen Weite des Lehrplans, den Cassiodor [...] aufzustellen sich anschickte, unberührt."

$176 \mathrm{Zu}$ Kontakten zwischen Adel und Kirche siehe: Ch. PIETRI, Aristocratie et société cléricale dans l'Italie chrétienne au temps d'Odoacre et de Théoderic, MEFRA 93, 1981, 417467.

177 Siehe Delle Donne (1998; 2001); NäF (1990). 
Ennodius zwar an der traditionell in einem Panegyricus dafür vorgesehenen Stelle konkrete Informationen über die Eltern bzw. die Abstammung des Theoderich übergeht (ibid. 78f.), ansonsten aber an vielen Stellen deutlich macht, dass Theoderich nicht nur aufgrund seiner Qualitäten, sondern besonders aufgrund seiner Herkunft zum Herrscher bestimmt sei (ibid. 79f.; cf. z.B. \$13 rex genitus). Das Konzept des ererbten Adels liegt auch der am Ende des Panegyricus (\$93) ausgesprochenen Hoffnung auf die Geburt eines Sohnes Theoderichs zugrunde (ibid. 80). Mehrfach wird darauf hingewiesen, dass auf demselben Prinzip der römische Adel beruht. Delue Donne weist darauf hin, dass die von Ennodius vorgebrachten Gedanken über die Privilegien der Herkunft in der Literatur isoliert dastehen und sich in paganer philosophischer wie in christlicher Tradition viele gegenteilige Ausführungen finden, die die ursprüngliche und letztliche Gleichheit der Menschen hervorheben (ibid. 81f.). Delle Donne nimmt wohl zu Recht an (1998, 83; 2001, 12-15), dass Ennodius diese ungewöhnliche Auffassung von den Privilegien der Herkunft in der Absicht vorgebracht hat, den römischen Adligen dazu zu verhelfen, auch unter Theoderich ihre ererbten Rechte und Funktionen (wieder bzw. weiterhin) ausüben zu können, und um die traditionelle Bedeutung Roms zu betonen.

An einigen Stellen im Panegyricus werden allerdings Herkunft und eigene Qualität eng miteinander verbunden, und zwar in dem Sinne, dass die Qualitäten des Theoderich seine Herkunft bestätigen; z.B. werden Theoderich folgende Worte in den Mund gelegt: "Ich muss mit Waffen dafür sorgen, dass nicht durch mich das Ansehen meiner Vorfahren zunichte wird. Wir haben keinen Grund, uns auf das Ansehen der Vorfahren zu stützen, wenn uns nicht auch das eigene < Ansehen> unterstützt «. ${ }^{178}$ Es findet sich keine Formulierung des Sinnes, dass eine ererbte Stellung allein ausreiche.

Ein Blick auf andere Werke des Ennodius zeigt, dass er gegenüber römischen Adligen ganz ähnlich argumentiert. Auch ihnen gegenüber hebt er die Bedeutung von Familie und Abstammung hervor, und er malt dies in vielen ausführlichen Bildern aus. Eine wichtige Rolle spielen dabei Vorbilder, besonders das des Vaters, das erreicht oder übertroffen werden soll; als entscheidende Qualität der Adligen wird die Bildung, also sprachliche Fähigkeiten, bezeichnet, z.B.: »Wenn ich einen Brief von Dir erhalte, in dem Du die Vollkommenheit Deines Vaters nachahmst $[\ldots]$ « $(17,4)$; »Werde hinsichtlich der Bildung wie Dein Vater, so wie Du hinsichtlich des Namens wie Dein Großvater bist « $(23,5) .{ }^{179}$

$178(263,43)$ telis agendum est, ut avorum per me decora non pereant. sine causa parentum titulis nitimur, nisi propriis adiuvemur. Siehe auch $(263,88)$ origo te quidem dedit dominum, sed virtus adseruit: "Deine Herkunft hat dich zwar zum Herrscher gemacht, aber deine Qualitäten haben dich als Herrscher bestätigt.«

$179(17,4)$ si epistulas tuas aemulas paternae perfectionis accepero; $(23,5)$ ut avum nomine, ita patrem redde doctrina. 
Immer wieder, in vielen Briefen und in ausführlichen Passagen der "Dictiones Scholasticae «, weist Ennodius darauf hin, dass es nicht ausreiche, als Adliger geboren zu werden, sondern dass man sich adliger Abstammung würdig erweisen solle bzw. dass man sie krönen müsse durch Bildung (doctrina), womit zu allererst die Redekunst gemeint ist, z.B. in einer »Dictio Scholastica«: »Der Glanz eurer Rede möge das Licht eurer Geburt aufzeigen; vermehrt die Ehrentitel eurer Eltern, indem ihr Wissen hinzufügt; schmückt das Ansehen der Vorfahren mit Bildung « $(3,5) .{ }^{180}$ Ennodius betont, dass Bildung hilfreich sei, den Adel unter Beweis zu stellen: "die römische Bildung <in diesem Fall konkret auch: die in Rom erworbene Bildung>, die nützlich sein wird, um den Adel zu bezeugen « (409,1 profutura ad testimonium ingenuitatis studia Romana). Er sieht es als Pflicht und Aufgabe eines adlig Geborenen, diesen Adel durch Bildung sich entfalten zu lassen und ihn zu zeigen, vgl. z.B.: »Entspricht etwa Deine Zunge nicht Deiner Herkunft? Oder willst Du nicht mit blühenden Reden ein Zeugnis Deiner Abstammung geben? « $(335,2)$. Adel ist ohne Bildung nicht erkennbar: »Man verfügt über kein Zeugnis für seinen Adel, wenn nicht die Bildung die Herkunft zeigt « $(94,4) .{ }^{181}$

Auffällig ist in diesem Zusammenhang die Verwendung des Wortes libertas und die enge Verbindung, die Ennodius zwischen Bildung und Freiheit herstellt. Wie bereits etliche Herrscher vor ihm wird auch Theoderich verschiedentlich als Garant der $l i$ bertas $^{182}$ bezeichnet: Eine Inschrift nennt ihn custos libertatis et propagator Romani nominis (CIL X,1, 6850 f.; ILS (Dessau) 827); bei Cassiodor ist er libertatis dominus (var. 3,11,1), libertatis defensor (var. 3,43,2). Moor heAd $(1987,167)$, der die Verwendung der Begriffe libertas und nomen Romanum in Bezug auf die Herrschaft der Ostgoten untersucht, kommt zu dem Ergebnis, dass Cassiodor und Ennodius zu den Autoren gehörten, die die althergebrachten Wertbegriffe verwenden, um die Kontinuität der Herrschaft auszudrücken. So nennt Ennodius in zeitgeschichtlichen $\mathrm{Zu}$ sammenhängen Freiheit in einem Atem mit Theoderich, im Panegyricus heißt es: »die Freiheit, die deinen Waffen zu verdanken ist « (263,1 armis tuis libertas obnoxia); »während du das Schwert, den Beschützer der Freiheit, um deine Seite gürtetest«

$180(3,5)$ naturae lucem iubar dictionis ostendat. multiplicate suffectu scientiae parentum titulos, ornate eruditione decora maiorum $[\ldots]$. Siehe auch z.B. $(4,4)$ veteris decora prosapiae novelli vincis nitore conloquii: "Du übertriffst den Glanz deiner alten Familie mit dem Leuchten deiner neuartigen Rede."

$181(335,2)$ numquid tibi inpar est lingua natalibus? aut non testimonium generis adnuntias flore sermonis? $(94,4)$ nullo enim teste nobilitatis utitur cuius sanguinem non prodit instructio.

182 Libertas " is not an innate faculty or right of man, but the sum of civic rights granted by the laws of Rome" (WIRSzUBSKI 1950, 7); im Prinzipat galt libertas als speziell römisches Gut, gleichbedeutend mit Bürgerrecht (id., 3-6). - Zum Kaiser als vindex libertatis siehe z.B. (mit weiterführender Literatur): B. Müller-Rettig, Der Panegyricus des Jahres 310 auf Konstantin den Großen, Stuttgart 1990, 152f. 
(263,42 dum lateri tuo vindex libertatis gladius aptaretur); in einem Brief bezeichnet auch er Theoderich als dominus libertatis $(159,1)$. Nach der Eroberung der Provence und der Narbonensis (a. 508-510) schreibt Ennodius mit einiger Übertreibung an Liberius, den Praefectus Galliae: "[...] denen <gemeint sind die Bewohner der Provinz $>$ Du nach vielen Jahren die civilitas $^{183}$ gebracht hast und denen es vor Dir nicht zuteil wurde, den Geschmack der römischen Freiheit zu schmecken [...] « $(447,6) .{ }^{184}$ Was die Bedrohung der libertas konkret bedeuten kann, zeigt die Vita Epiphani, wo berichtet wird, dass Theoderich nach seinem Sieg überlegte, wie er mit den Anhängern seines Gegners Odoaker verfahren sollte: »Da kam Theoderich, dem ausgezeichneten König, plötzlich die Überlegung in den Sinn, nur denjenigen das Recht der römischen Freiheit (Romanae libertatis ius) zu erteilen, die sich in bewährter Treue mit seiner Seite verbunden hatten; diejenigen aber, die aus irgendwelchen Gründen nicht auf: seiner Seite gestanden hatten, ließ er von den Rechten, als Zeuge aufzutreten, über ihr Vermögen zu verfügen und in Testamenten bedacht zu werden, ausnehmen « $(80,122) .{ }^{185}$ In dieser Situation wird Epiphanius zu Theoderich gesandt, um Gnade zu erbitten, was ihm auch gelingt.

Auffällig ist nun, dass Ennodius in den Passagen, wo er nicht über Theoderich, sondern über Bildung spricht, ${ }^{186}$ deutlich macht, dass es nicht ausreicht, aufgrund seiner Geburt an der libertas zu partizipieren: "Von der Herkunft bekommt man die Freiheit geschenkt, ihrer würdig wird man durch den Lehrer« $(69,9)$, Die Freiheit wird immer durch die ehrenhaften Studien offenbart, wohingegen ungebildeter Adel im Dunkel verborgen bleibt « (105,3-4); über eine Büchersammlung heißt es u.a.: "Wer sich mit diesem Riemen gebunden hat, ist frei; diese Hacke verschönert die Ader der glänzenden Herkunft « $\left(327,4 \mathrm{f}\right.$.). ${ }^{187}$ Angesichts dieser Überlagerung von libertas und Bildung bzw. eloquentia drängt sich der Gedanke auf, dass letztlich die Formulierung des Tacitus: pari eloquentia ac libertate (hist. 1,1,1) dahintersteht, auch wenn für Ennodius die Begriffe anders gefüllt sind.

183 Siehe dazu Ratti, Évolution et signification de la civilitas ..., d'Ennode à Cassiodore (2002).

$184(447,6)[\ldots]$ quibus civilitatem post multos annorum circulos intulisti, quos ante te non contigit saporem de Romana libertate gustare [...].

$185(80,122)$ Interea subita animum praestantissimi regis Theoderici deliberatio occupavit, ut illis tantum Romanae libertatis ius tribueret, quos partibus ipsius fides examinata iunxisset; illos vero, quos aliqua necessitas diviserat, ab omni iussit et testandi et ordinationum suarum ac voluntatum licentia submoveri. - Cf. den Kommentar von CESA $(1988,189)$.

186 Moorhead (1987) zieht bei der Untersuchung der Begriffe ausschließlich die Passagen heran, in denen sich Ennodius über Theoderich äußert.

$187(69,9)$ libertatem origo tribuit, dignum libertate monitor facit. $(85,5)$ venerabilis magister, libertatis index. (105,3-4) Libertas semper studiis reseratur honestis, / Infabricata latet nobilitas tenebris. $(327,4 \mathrm{f}$.) liber extat, hoc quicumque colla loro vinxerit./ Sanguinis venam nitentis comit iste sarculus. 
Wird im Panegyricus das Schwert Theoderichs als vindex libertatis bezeichnet $(263,42)$, so ist der Lehrer index libertatis, "Anzeichen für die Freiheit « $(85,5)$ - in diesem Sinne betont Ennodius im Panegyricus, dass der Herrscher die Voraussetzungen dafür schaffe, dass die Künste sich entfalten können (263,1f., siehe unten 101). Dass Ennodius die libertas in Gefahr sieht, ergibt sich aus den Worten, die an den Lehrer gerichtet sind: »Du wirst als die glückliche rechte Hand eingesetzt, die die fast einstürzende Freiheit aufhalten soll « $(85,6)$; "durch dessen Hand die schon fast einstürzende Freiheit gestützt wird « $(94,8) ;{ }^{188}$ einmal nennt er sogar den Lehrer custos imperii (208, v.1 im Anschluss an die dictio [=carm. 2,90]).

Dass Ennodius eine Gefährdung der sprachlichen Kultur sieht, wird so sehr deutlich. Daher erscheint NäFs Deutung in diesem Zusammenhang zu optimistisch, wenn er schreibt $(1990,122):{ }^{189} »$ Ennodius glaubte an einen Neuanfang, der dem Römisch-Katholischen, der römischen Bildung, der römischen Aristokratie, dem Klerus und der näheren Heimat einen sicheren Platz gewährleisten würde. "Gerade die Häufigkeit und Eindringlichkeit der Äußerungen, dass es nicht ausreiche, als Adliger geboren zu sein, oder die Formulierung, dass der Lehrer den Verfall aufhalte, könnte darauf hinweisen, dass ein rein auf die Geburt gestützter Dünkel oder auch die Zufriedenheit mit der Situation unter Theoderich und eine Vernachlässigung der Bildung recht verbreitet waren. Immerhin findet sich bei Cassiodor die Aussage: (var. $3,6,1$ ) origo ipsa iam gloria est: laus nobilitati connascitur: "Die Herkunft selbst bedeutet schon Ruhm: Anerkennung wird mit dem Adel zugleich geboren. " Das heißt allerdings nicht, dass Cassiodor dem Adel nicht auch bestimmte Charakteristika zuweisen bzw. abverlangen würde. NÄF, der regelrecht von »Tugendkatalogen« spricht (1995, 8), schreibt zusammenfassend über Cassiodor (ibid., 222): "Zentral ist die Aktivierung des Stolzes auf Herkunft, auf Adel und Ämter sowie hauptsächlich einer Reihe von [...] Wertvorstellungen [...]: Integrität, Gerechtigkeit, Grosszügigkeit, Ausgeglichenheit, Bildung, korrekter Lebenswandel und korrektes Auftreten, Bescheidenheit [...]. « ${ }^{190}$ Ennodius hingegen hebt sehr einseitig die Bedeutung der Bildung bei der Entfaltung des Adels hervor. So ist auch Rom für Ennodius die urbs amica liberalibus

$188(85,6) t u$ (sc. magister) in sustentationem ruiturae libertatis felix dextera subrogaris. $(94,8)$ per cuius dexteram libertas iam iamque ruitura relevatur; siehe auch $(452,12)$ rhetorum dextera et libertas illa. - Cf. Ambr. (epist. 2,7,9) non igitur natura servum facit, sed insipientia, nec manumissio liberum, sed disciplina.

189 Diese Deutung beruht allerdings auf der Betrachtung anderer Texte; NäF (1990) untersucht unter der Fragestellung, inwieweit das Ende Roms bzw. das Jahr 476 thematisiert wird, Werke mit jeweils speziellem Adressaten(kreis) und Inhalt (Brief 370: Gratulation zum Konsulat des Boethius, besonders die Erwähnung der Roma [mit carm. 2,132]; Panegyricus und Libellus (Bild der Roma), Vita Epiphani, Vita Antoni, Dictio zum 30. Jahrestag des Laurentius).

$190 \mathrm{Zu}$ den bei Cassiodor geforderten Merkmalen eines nobilis siehe auch MEYER-FLÜGEL $(1992,325-344)$. 
studiis $(290,1)$, für Cassiodor umfassender illa eloquentiae fecunda mater, illa virtutum omnium latissimum templum (var. 4,6,3). Ennodius' auffällige Konzentration auf die Bildung dürfte sich damit erklären lassen, dass hier noch der ehemalige Adept der Studia liberalia spricht - sein neuer Stand als Diakon hat ihn seine Vergangenheit nicht ganz ablegen lassen. Die Bewahrung der Sprachkultur ist dem ehemaligen Redner und Dichter ein zentrales Anliegen. Ennodius sieht, dass die Sprachkultur und der Adel als Träger dieser Kultur untrennbar miteinander verbunden sind; wenn es ihm in erster Linie nicht um das Überleben der Sprachkultur, sondern um den Fortbestand des Adels ginge, könnte er auch andere Merkmale des Adels betonen, wie es bei Cassiodor zu beobachten ist.

Auch Sidonius Apollinaris spricht in seinen Briefen häufig von Bildung: Er klagt zuweilen über den Verfall der Bildung bzw. lobt die wenigen, die sich noch darum bemühen, ${ }^{191}$ wobei Percival betont, dass Sidonius weniger auf den Verfall hinweise als auf die Tatsache, dass das hohe Niveau der Kultur immer noch von einigen gehalten werde, "as if Sidonius [...] were anxious to assure himself and his correspondents that all is well, and that in spite of appearances to the contrary the world, fundamentally, has not changed « $(1997,291)$. AMHERDT $(2001,16)$ sieht in diesem aussichtslosen Kampf des Sidonius um den Erhalt der Sprache und Kultur Realitätsflucht. Dieses Verhältnis des Sidonius zur Bildung wird mit der politischen Situation erklärt, z.B. GUALANDRI (1979, 184): »l'esigenza [...] di mantenere una continuità culturale che si va spezzando.« Ähnlich sieht man in Ennodius einen »Vertreter einer nach rückwärts gewandten rhetorischen Bildung « (NÄF 1990, 104), »die Flucht in die Literatur, in eine manieristisch übersteigerte eigene Welt « (RoHR 1995, 15). Sollte man jedoch die Sorge um den Zustand der Bildung und die vielen Aufforderungen an junge Adlige, sich um Bildung zu bemühen, nicht vielmehr als zukunftsorientiert bezeichnen? Auf jeden Fall war sie gegenwartsorientiert, denn zu Ennodius' Zeit hatte die traditionelle rhetorische Ausbildung in der Schule ihren Zweck für die Karriere der jungen Männer, und auch die Werke und Vorträge von Rednern und Dichtern gehörten zum gesellschaftlichen Leben der herrschenden Schicht. Dass das Reich Theoderichs nur eine Episode sein würde, konnte er nicht wissen.

Hatten sich frühere christliche Autoren mit einer heidnischen Umwelt auseinanderzusetzen, so hat sich zur Zeit des Ennodius der Konflikt längst verlagert: ${ }^{192}$ Er war sowohl mit seiner christlichen Umwelt konfrontiert, die sich in Laien, Kleriker und Mönche bzw. Nonnen gliederte, als auch mit der Bedrohung, die andere Völker

191 Siehe z.B. Sidon. epist. 4,17,2 laetor saltim in inlustri pectore tuo vanescentium litterarum remansisse vestigia; siehe auch $2,9,4 ; 2,10,1 ; 3,14,2 ; 5,10,1 ; 5,10,4 ; 8,2,1 ; 8,4,3 ; 8,16,2$.

192 Wie schon für Sidonius, vgl. Harries $(1994,3) »$ For Sidonius, the conflict was not between Christianity and pagan classicism but between Roman culture, which he identified with the classical tradition, and barbarism." 
für die eigene Kultur darstellten. Wurde früher die Beschäftigung mit der paganen Literatur von vielen Christen als problematisch betrachtet, aber als unverzichtbar für die Schule hingenommen, so wird bei Ennodius (wie in anderer Weise auch bei Sidonius Apollinaris) deutlich, dass man sich inzwischen um den Erhalt der tradierten Bildung ausdrücklich bemühte und bemühen musste - unter fremden Herrschern war die traditionelle Bildung ein deutliches Zeichen römischer libertas.

\section{b. 2 sstudia et mores}

Ebenso wie im Vergleich mit Cassiodor auffällt, dass bei Ennodius Tugendkataloge für den Adel fehlen zugunsten der einseitigen Betonung der Bildung, überrascht bei Ennodius die Seltenheit des Gedankens, dass sprachlich-literarische Bildung und Charakterbildung untrennbar verflochten sind. Denn traditionell zählen zu den Aufgaben des Grammaticus nicht nur recte loquendi scientia et poetarum enarratio (Quint. inst. 1,4,2), sondern es sollten anhand der in der Dichtung dargestellten Personen und Taten auch die vorbildlichen mores erläutert und verinnerlicht werden. ${ }^{193}$ Der Unterricht beim Grammaticus (und der häufig anschließende beim Rhetor) verhalf so nicht nur zu der Sprachbeherrschung, die für eine Position innerhalb der Elite vonnöten war, sondern auch zur Aneignung der von dieser Elite anerkannten Werte. In dem Panegyricus, mit dem i.J. 298 der Redner den Statthalter um die Wiedererrichtung der Schule bat, heißt es: »dass die Literatur das Fundament aller Tugenden ist, da sie die Lehrmeisterin der Enthaltsamkeit, der Mäßigung, der Sorgfalt und der Geduld ist [...] « (paneg. 9 [4] 8,2). ${ }^{194}$ Cassiodor hebt den Aspekt der charakterbildenden studia litterarum häufig hervor, ${ }^{195}$ z.B.: "die sprachlich-literarische Bildung $[\ldots]$ ist ruhmreich, weil sie - was das Wichtigste am Menschen ist -, den Charakter reinigt " (var. 3,33,3); "[...] die sprachlich-literarische Bildung, wo du alles gelernt hast, was sich gehört, und durch die Unterweisung der Lehrer den Geist gebildet hast, um ein ruhmreiches Leben führen zu können. Die Bildung möge also das Vergehen meiden. Nur ein ungebildeter Geist lässt sich zum Vergehen verleiten. Wer durch Bücher gebildet ist, gibt Unrecht keinen Raum, da in zarten Jahren erworben wird, was im reifen Alter bewahrt werden soll" (var. 3,11,4f.). ${ }^{196}$

193 Siehe Kaster (1988, 12 mit Anm. 2). Cf. z.B. Ovid (Pont. 2,9,47f.) adde quod ingenuas didicisse fideliter artes / emollit mores nec sinit esse feros; siehe dazu unten Anm. 373 .

194 (paneg. $9[4], 8,2)[\ldots]$ litteras omnium fundamenta esse virtutum, utpote continentiae modestiae vigilantiae patientiae magistras [...].

195 Siehe dazu MeYer-FüUGel (1992, 366-369) im Kapitel »Bildung und Charakter.«

196 (Cassiod. var. 3,33,3) gloriosa est [...] scientia litterarum, quia quod primum est in homine, mores purgat. - (var. 3,11,4f.) [...] studia litterarum, ubi cognovisti omne quod deceat et ad usum vitae gloriosae animum, doctorum nimirum institutione, formasti. (5) Fugiat ergo doctrina delictum. indocilis est animi ad vitia trahi: aedificatus libris locum non relinquit 
Den Zusammenhang zwischen studia und mores stellt Ennodius nur einmal dar, dort allerdings umfassend, nämlich in der Dictio data Aratori quando ad laudem provectus est (320), die mit Thema: Laus litterarum überschrieben ist. Zu beachten ist, dass Ennodius diesen Text zwar verfasst hat, darin aber Arator das sprechende Ich ist, das die ausführliche laus litterarum vorbringt. Über die litterae heißt es hier u.a.: "Ihr bietet den Weg, die Gerechtigkeit zu erforschen « (\$6); »Ihr seid die Urheber der Frömmigkeit, ihr seid die Feinde des Verbrechens « $(\$ 8)$; »fern sei den litterae, entweder das Würdige zu verändern oder das Schädliche nicht zu verändern« (\$9). Die Dictio endet mit den Worten: "Lebt wohl, die ihr der Schmuck eines besseren Zeitalters seid; seid die Besitzer der Welt, die ihr unterrichtet habt, ihr, die ihr von Gott gegeben seid als Heilmittel für schwierige Zeiten « $(\$ 12) .{ }^{197}$

Ansonsten enthält sich Ennodius der Aussage, dass literarische Bildung den Charakter veredele, obwohl er doch so häufig über Bildung spricht. Der Charakter soll sich an Vorbildern orientieren (siehe auch oben 89 und unten 115); so schließt der Brief an den jungen Marcianus, dieser solle so werden wie sein Vater, »[...] indem Du Deine Sprache mit der Hacke der Lektüre und Deinen Charakter durch die Nachahmung der Guten läuterst « $(\mathbf{1 7 5}, 4)$. Im Lehrer der Schüler, die in einer dictio angesprochen sind, ist beides vereinigt: "ihr habt einen Lehrer für Redekunst und Charakter, der euch auf dem richtigen Weg vorangeht “ $(3,8) .{ }^{198}$ In einem Empfehlungsbrief für seinen Neffen Parthenius an Papst Symmachus schreibt er immerhin, dass man durch die studia zunächst schlechte Eigenschaften ablege: ${ }^{199}(226,3)$ sancta sunt studia litterarum, in quibus ante incrementa peritiae vitia dediscuntur. Diese Stelle wird zuweilen zitiert und kommentiert, z.B.: »[...] célèbre avec un excès d'enthousiasme surprenant chez un clerc, le mérite des studia liberalia" (PIETRI 1981, 438). Das Auffälligste an diesen Worten ist jedoch, dass Ennodius nur hier, ausgerechnet dem Papst gegenüber, die studia als sancta ${ }^{200}$ bezeichnet und ihre Bedeutung für die Charakterbildung hervorhebt - anderen Adressaten gegenüber verzichtet er offenbar

iniuriis, ubi in teneris annis adquiritur quod matura aetate servetur. - Siehe auch z.B.: var. $5,21,1 ; 9,21,8 ; 10,3,4$.

$197(320,6)$ ad investigandam iter iustitiam vos praebetis (KenNell $[2000,60]$ bezieht dies nicht auf die litterae, sondern auf Arator: $»$ He is praised especially for affording a way to pursue justicer [...]."). $(320,8)$ vos religionis auctores, vos hostes criminum. (\$9) facessat a litteris vel mutare quod dignum est vel non mutare quod noxium. (\$12) valete, ornamenta melioris saeculi, et mundum, quem eruderastis, concessae a deo in temporum remedio possidete.

$198(175,4)[$ [...] linguam lectionis sarculo, mores bonorum imitatione purgando. $(3,8)$ habetis praevium eloquentiae morumque doctorem.

199 Auch dieser Gedanke wurde vor ihm häufig ausgesprochen, siehe KaSTER $(1988,17)$.

200 Siehe zu der Vorstellung von den sacrarum studia litterarum (mit weiteren Belegen) $\operatorname{KASTER}(1988,15 f$.): "Such voices spoke with the knowledge that they possessed something set apart and enduring, something fundamental to the scheme of right order $[\ldots] . .4$ 
ebenso bewusst auf diesen Aspekt wie er ihn hier gezielt erwähnt. In einem weiteren Empfehlungsschreiben für denselben Parthenius an einen anderen Adressaten dreht Ennodius den Gedanken, dass die Redekunst zur Veredelung des Charakters führe, sogar um: $(225,1)$ ad eloquentiae ornamenta non tendunt nisi moribus instituti. Sonst werden höchstens sehr vereinzelt in Empfehlungsbriefen knapp die mores des Empfohlenen erwähnt (z.B. 410,$1 ; 416,1)$, oder es wird die Hoffnung ausgesprochen, dass sich die mores des Empfohlenen durch die Fürsorge des Adressaten gut entwickeln mögen $(424,1),{ }^{201}$ aber ohne dass gleichzeitig die Bildung erwähnt würde.

Festzuhalten ist, dass Ennodius, obwohl er die moralische Begründung für die Bildung kennt, wie Cassiodor sie häufig und ausführlich formuliert, stattdessen immer wieder nur davon spricht, dass seine Adressaten dadurch ihren Adel zeigen können bzw. sollen. ${ }^{202}$ Dass dies wohl kein Zufall ist, zeigen die im folgenden Kapitel zu untersuchenden Passagen, in denen er sehr offen und unbarmherzig von den möglichen Ergebnissen der Bildung, von den Möglichkeiten der Ars Rhetorica spricht.

c. Die Macht der Sprache - Sprache und Macht

Sowohl in der "Paraenesis« als auch in anderen Zusammenhängen, wo nicht Bildung und Rhetorik das eigentliche Thema sind, erwähnt Ennodius die Möglichkeiten der Ars Rhetorica, dass nämlich ein Redner Dinge und Taten besser oder schlechter darstellen könne, als sie wirklich seien, oder dass er sie durch das Reden überhaupt erschaffen oder im Gegenteil auch totschweigen könne. Auffällig an den Worten der Ars Rhetorica in der "Paraenesis « wie auch an den übrigen Stellen ist, dass Ennodius die Möglichkeiten der Rhetorik so offen ausspricht. Die betreffenden Passagen bedeuten weniger ein Loblied auf die Rhetorik als vielmehr eine provokante Offenlegung eines Machtmittels - allerdings immer im engen Kreis derer, die es schon wissen sollten. Hat Ennodius Angst, dass sie es vergessen könnten?

Zunächst sind die Worte der Ars Rhetorica in der »Paraenesis« zu untersuchen (c.1), dann einige Passagen (c.2), in denen auf unerwartete Weise deutlich wird, dass die angesprochenen Adligen bzw. Herrschenden die Sprachkunst benötigen, sei es, indem sie sie selbst einsetzen, sei es, indem andere über sie sprechen. Weitere Passagen (c.3) zeigen, dass auch die Dichtung mächtig ist.

$201(416,1)$ est enim qui gratiam vestram et natalibus mereatur et moribus. $(424,1)[\ldots]$ sperans ut vestra $<$ sc. sollicitudine $>$ adulescens ad maturos deo auspice mores erigatur.

202 In der Gewichtung nicht zutreffend Gruber (1997, Sp. 1047): „Die Artes liberales hält er für die Bildung der jungen Kleriker für unabdingbar und betont daher nicht nur ihren intellektuellen, sondern auch ethischen Wert.« 


\section{c. 1 Die Ars Rhetorica in der »Paraenesis«}

Der Ars Rhetorica sind unter anderem folgende Worte über sich selbst in den Mund gelegt (cf. oben 52): „Wer mich <sc. die Rhetorik> intensiv studiert, kann bald die Welt beherrschen « (qui nostris servit studiis, mox imperat orbi, 452,17), was in der Forschung mehrfach erwähnt und als Aussage von einem Kleriker kritisiert wurde. Dabei handelt es sich bei diesen Worten nur um einen kleinen Ausschnitt aus einer längeren (Selbst-)Vorstellung der Rhetorik; diese soll hier zwar nicht ganz, aber doch etwas ausführlicher zitiert werden: "Nach der hohen Gottheit bin ich diejenige, die entweder das, was geschehen ist, verändert oder es überhaupt geschehen lässt. Es ist gleichgültig, in wie schwere dunkle Taten jemand verwickelt ist - ihm reicht der Glanz, den ich ihm durch mein Reden bringe. Ich bin es, von der die Menschen einen Schuldspruch erwarten, wenn ich missmutig bin, und einen Freispruch, wenn ich heiter bin. Durch mich wird ein dunkles Gewissen mit Glanz überzogen, und ein von sich aus strahlendes Gewissen mit ihm fremdem Dunkel, auch wenn es kein Dunkel kennt. Es besteht weder für die Reinheit Grund zur Zuversicht noch für die Schuld zum Seufzen [...]. Von den Taten tapferer Männer wird geglaubt, was ich will; niemand denkt, dass etwas geschehen ist, wenn ich es verschweige [...] « $(\$ 15 f.){ }^{203}$

Diese Beschreibung der Macht der Rhetorik erinnert zweifellos an z.B. die u.a. bei Quintilian $(1,12,18)$ zitierten Tragikerworte omnium regina rerum oratio (Pacuv. trag. 177) ${ }^{204}$ Ebenso kommen die Sophisten in den Sinn, aber auch die häufig zu lesenden Ermahnungen zum rechten Gebrauch der Rhetorik, vom Auctor ad Herennium und Cicero über Quintilian ${ }^{205}$ bis zu den christlichen Autoren, die sich intensiv mit diesem Problem auseinandersetzen, siehe z.B. eine der prominentesten Stellen bei Augustin: "[...] Da also die Kraft der Redekunst neutral ist und sowohl zum Schlechten als auch zum Richtigen kraftvoll raten kann - warum sollen die Guten

203 (452,15f.) Post apicem divinitatis ego illa sum, quae vel commuto si sunt facta vel facio. quantisvis actionum tenebris involuto lux sufficit, quam loquendo contulero. ego sum per quam expectant homines reatum de turbida et innocentiam de serena. per me fusca splendore conscientia, per me luce sua radians adventicia nocte tegitur, vel si sit ignara tenebrarum: est quod nec confidit puritas nec culpa suspirat. [...] de virorum fortium factis quod volumus creditur; actum nemo aestimat quod silemus [...].

204 Siehe auch: Cicero de orat. 2,187; vgl. die Worte der Hekabe, Euripides Hec. 816-819, 816:

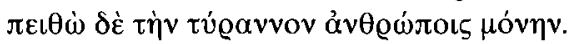

205 Siehe z.B.: Rhet. Her. 1,1 non enim parum in se habet fructus copia dicendi et commoditas orationis, si recta intellegentia et definita moderatione animi gubernatur. Cic. inv. 1,1 Saepe et multum hoc mecum cogitavi bonine an mali plus attulerit hominibus et civitatibus copia dicendi ...; ut existimem sapientiam sine eloquentia parum prodesse civitatibus, eloquentiam vero sine sapientia nimium obesse plerumque, prodesse numquam; quare si quis, omissis rectissimis atque honestissimis studiis rationis et officii, consumit omnem operam in exercitatione dicendi, is inutilis sibi, perniciosus patriae civis alitur eqs. Siehe auch z.B. Quint. inst. 1,12,16-18. 
sie sich nicht in der Absicht aneignen, für die Wahrheit zu kämpfen, wenn doch die Bösen sie für Ungerechtigkeit und Irrtum einsetzen, um schlechte und eitle Dinge durchzusetzen? « (doctr. christ. 4,2,3). ${ }^{206}$ Dass diese Gedanken auch zur Ostgotenzeit nicht vergessen sind, zeigt Cassiodor, z.B.: "Es ist allgemein anerkannt, wie nützlich eine mit gutem Charakter ausgerüstete Redekunst ist. Denn ebenso wie es gefährlich ist, wenn ein Gebildeter zum Schlechten rät, so dient es dem Wohl, wenn die Redekunst die Grenzen der Wahrheit nicht überschreitet « (var. 8,12,2). ${ }^{207}$

Dass der breit belesene Ennodius ausgerechnet von dieser in der antiken und spätantiken Literatur so häufig behandelten Problematik nichts wusste, ist wenig wahrscheinlich, ${ }^{208}$ zumal er einmal nebenbei von der $»$ Redekunst, der Helferin der Bosheit« spricht (54,1 adiutricem malitiae facundiam); auf das Problem verweist er auch in folgender Passage in einer dictio: "mit dem gleichen Mund werden Tyrannen und gute Herrscher gelobt, und es gibt keinen Unterschied zwischen einem, der Lob verdient und einem, der es sich anmaßt.« $(94,2) .{ }^{209}$ Ebenso unwahrscheinlich ist, dass er sich nicht im Klaren darüber war, was die Worte der Ars Rhetorica bedeuteten; warum sollten gerade die ungewöhnlichen, sprovokanten Passagen Ennodius nur so sherausgerutscht ‘ sein, wie seine 'Verteidiger c es sehen? ${ }^{210}$ Zumal darauf hinzuweisen ist, dass er an weiteren Stellen vergleichbare Gedanken äußert (siehe unten c.2). Einfacher und naheliegender wäre es sicher gewesen, die üblichen Warnungen zu wiederholen. Man sollte also vielmehr davon ausgehen, dass Ennodius in der »Paraenesis« bewusst auf die doch sehr naheliegenden Ausführungen über die Gefahren der Rhetorik verzichtet.

Warum also will Ennodius die Gefahren nicht formulieren? Warum spricht er in der "Paraenesis" nicht von den moralischen Anforderungen, die dem Gebrauch der Rhetorik Grenzen setzen, wie sie sich bei ihren Befürwortern finden? Ruft er zum be-

206 Aug. (doctr. christ. 4,2,3) cum ergo sit in medio posita facultas eloquii, quae ad persuadenda seu prava seu recta valet plurimum, cur non bonorum studio comparatur, ut militet veritati, si eam mali ad obtinendas perversas vanasque causas in usus iniquitatis et erroris usurpant? eqs. - Weitere Stellen bei EvenePoel (1993).

207 (Cassiod. var. 8,12,2) probatum est, quid utilitatis habeat moribus armata facundia. nam sicut perniciosum est doctos prava suadere, sic salutare munus est, cum veritatis terminos disertitudo nescit excedere.

208 Anders Rallo Freni (1971, 121), die anmerkt, dass Augustins Definition der Rhetorik (doctr. christ. 4,2,3) offenbar vergessen sei.

$209(94,2)$ uno quidem tyranni laudationes et bonorum principum ore celebrantur, nec est aliqua inter eius qui meretur praeconia diversitas et illius qui usurpat.

210 NAVArRa (1974, 15f.) weist zwar darauf hin, wie groß die Entfernung vom christlichen Ethos sei, wenn die Rhetorica ausführe, dass das Urteil über Schuld und Unschuld lediglich von der rhetorischen Fähigkeit, nicht aber von der wirklichen Schuld oder Unschuld abhänge; er vermutet aber, dass Ennodius sicher nicht beabsichtigt habe, so weit zu gehen: »Preso dai suoi antichi amori di retore, indulse a un bel motto." 
denken- und schrankenlosen Gebrauch der Macht der Rhetorik auf ? Letztere Vermutung liegt offenbar den negativen Urteilen der Interpreten zugrunde. ${ }^{211}$

Indem Ennodius die Möglichkeiten der Rhetorik benennt, ohne ihre Gefahren zu erwähnen bzw. ohne moralische Anweisungen für den rechten Gebrauch zu geben, kann er vielleicht besser auf die Gefahren aufmerksam machen, als wenn er ausdrücklich auf sie hinweisen würde: Vorwürfe gegen die Rhetorik bzw. gegen ihren falschen Gebrauch und Verteidigungen bzw. Ermahnungen zu ihrem rechten Gebrauch hatte man zu Ennodius' Zeiten oft gelesen, wahrscheinlich zu oft, als dass sich davon noch jemand hätte beeindrucken lassen. Eine nüchterne Beschreibung der Fähigkeiten der Rhetorik war etwas Anderes und konnte die Leser vielleicht provozieren, über den rechten und falschen Gebrauch selbst nachzudenken, anstatt über die gewohnten Phrasen hinwegzulesen - immerhin gegenüber den modernen Interpreten ist die Provokation eindeutig gelungen.

Außerdem ist zu beobachten, dass in der »Paraenesis« keineswegs eine Wertung der Möglichkeiten und Mittel der Rhetorik ausgesprochen wird. Lobende Ausdrücke finden sich so wenig wie tadelnde, sondern Ennodius legt der Rhetorik sselbst $<$ die Worte in den Mund, mit denen sie sich beschreibt - genauso wie vorher die christlichen Grundtugenden und auch die Grammatik. Es gibt jedoch einen wichtigen Unterschied in der Darstellung der Tugenden und der Grammatik gegenüber der Rhetorik: Verecundia, Castitas, Fides und Grammatica sprechen im eigenen Namen nur die Verse (die jeweils mit dem Hinweis auf die Sprecherin eingeleitet werden, \$5; \$7; \$9; $\$_{13}$ ), während die jeweils vorangehenden Beschreibungen und Aufforderungen, sich ihr zuzuwenden, in Prosa vom Sprecher formuliert werden: $\$ 5$ matrem bonorum operum amate verecundiam; $\$ 6$ pudori [...] cognatam semper sociate pudicitiam; $\$ 8$ hanc (sc. castitatem) admittentes fidei ornate consortio; zur Beschäftigung mit der Grammatik findet sich auffälligerweise keine so direkte Aufforderung. Die Rhetorik wird zunächst beschrieben, spricht dann aber auch schon in Prosa für bzw. über sich selbst (eingeleitet in \$15): Einerseits bekommt die Rhetorik sselbst c so mehr Raum als die anderen Personifikationen, andererseits nimmt es nicht der Sprecher auf sich, die Rhetorik so darzustellen, und distanziert sich auf diese Weise von ihr. Ob die von der Rhetorica vermittelten Fähigkeiten und Möglichkeiten lobens- oder tadelswert sind, bleibt dem Urteil des Lesers ihrer Worte überlassen. ${ }^{212}$

211 Auch Kennell scheint dies zu vermuten, ohne es allerdings negativ zu werten: „Ennodius never disguises the basic amorality of the techne that serves him and his superiors so well. His religious profession may require him to insist rhetoric be used only for good ends; his refusal to condemn it outright shows a soundly teleological pragmatism " (2000, 52).

212 Anders z.B.: Fontaine $(1962,402)$ : "begeistert wird die universelle Macht der Rhetorik gefeiert [...] «; Rohr $(1995,8)$ : »Rhetorik [...], die [...] über alle Maßen gelobt wird «; CesA $(1988,16)$ »'aperta esaltazione dell'abilità retorica«. 
Auf jeden Fall müsste der Leser in der Lage sein, ein eigenes Urteil darüber zu fällen; denn er hat zuvor die Anweisungen von Verecundia, Castitas und Fides erhalten, und ihm ist zudem in der ersten Verspartie der »Paraenesis « vorgeführt worden, dass man als Christ nicht bedenkenlos alle zur Verfügung stehenden Fertigkeiten nutzt: In dem mit Laus versuum überschriebenen Gedicht $(\$ 3)$ werden die Gefahren der Dichtkunst genannt, und es wird ausgeführt, in welcher Form ein miles Christi sich mit Dichtung beschäftigen kann: "[...] Wir aber sind besonnen und verwenden die Musenrede nur so weit, wie der Glanz und die Kraft des Wahren es zulassen; wir erdulden es, dass sich die dem Soldaten Christi eingepflanzte Härte vor Weichlichkeit hütet « (452,3, v. 8-12; cf. dazu auch unten 174). ${ }^{213}$ Hinsichtlich der Rhetorik müssen die Adressaten dann selbst beurteilen, inwieweit sie die Möglichkeiten der Rhetorik einsetzen sollen. Die der Rhetorica in den Mund gelegten Worte rufen so indirekt auf zum Nachdenken über die Macht der Rhetorik, sie müssen anhand der vorangehenden Worte von verecundia, castitas und fides bewertet werden, ohne dass dazu nochmals eigens aufgerufen würde.

\section{c. 2 Die Macht des Redners}

Ennodius lässt die Ars Rhetorica u.a. von sich sagen: "Wenn ich Ämter, Reichtum und Ehrenstellungen nicht mit Schmuck versehe, sind sie nichts wert«; »Niemand denkt, dass etwas geschehen ist, wenn ich es verschweige «. ${ }^{214}$ Über die derartigen Fähigkeiten der Ars Rhetorica spricht er allerdings nicht nur in der "Paraenesis«, sondern auch in einigen anderen Texten, wo es um ihre konkrete Anwendung geht. So erwähnt er in zwei enkomiastischen Texten $(9 ; 263)$ das Phänomen, dass erst schriftliche Fixierung und Überlieferung den Ruhm sichern können. In zwei Briefen $(48 ; 174)$ hebt er die Fähigkeit der Adressaten hervor, alles so darzustellen, wie sie wollen, und unwiderstehlich Einfluss auf ihre Zuhörer zu nehmen (auch in dem Gedicht 213). In zwei weiteren Briefen $(376 ; 387)$ wird auf den möglichen Unterschied zwischen Gesagtem und Wahrheit hingewiesen.

In dem Glückwunschschreiben (9) an Faustus anlässlich des Konsulats von dessen Sohn Avienus betont Ennodius die Fähigkeit des Redners, Personen und Taten gröBer und bedeutender erscheinen zu lassen, als sie wirklich waren (siehe auch unten 267): "Zurücktreten mögen vor ihm <sc. Avienus> die Lobreden für die Alten, denen

213 (452,3, v.8-12) At nos Pieriae modum loquelae / In tantum sequimur monente cura,/ Quantum dat genius vigorque veri./ Christi militis insitum rigorem / Elumbem patimur cavere ductum.

$214(452,16)$ fasces divitias honores si non ornamus, abiecta sunt. $[\ldots]$ actum nemo aestimat quod silemus. 
<erst> die Einfälle der Gebildeten zu ihrem Ansehen verholfen haben $[\ldots]$ « $(9,5) .{ }^{215}$ Hier handelt es sich um einen verbreiteten Topos der Panegyrik, dass nämlich der momentan zu Lobende das Lob wirklich verdiene im Gegensatz zu den früheren Empfängern von Lobesworten. ${ }^{216} \mathrm{Obwohl}$ der oft gelesene Gedanke unmissverständlich klar ist, erklärt Ennodius ihn noch: »Denn ein mageres Thema muss durch die Möglichkeiten des Redners vergrößert werden, damit der Wert, den der Stoff nicht bietet, durch die Steigerungen des Griffels eingefügt wird ". ${ }^{217}$ Warum setzt Ennodius diese unnötige Erklärung hinzu und weist so unüberhörbar auf die Notwendigkeit hin, ein unbedeutendes Thema durch die Kunst der Rede zu erhöhen? Hier erzeugt er ein zwiespältiges Gefühl, indem er den Gedanken zwar nicht selbst ausspricht, aber beim Leser unweigerlich aufkommen lässt, inwieweit eigentlich der hier Gelobte - der sehr junge Konsul Avienus - das Lob wirklich verdient hat. (Siehe zu dem Brief auch unten 347.)

Auch im Panegyricus für Theoderich (263) wird die Macht der Sprache betont, Taten vor dem Vergessen zu bewahren: Theoderich wird gebeten, er möge die literarische Gabe des Panegyricus annehmen, denn Sprache sorge dafür, dass glänzende Taten nicht vergessen würden (263,2 ne senescat claritudo operum, advocanda sunt linguarum exercitia). Diese Tatsache, dass Theoderich den Redner benötige, wird weiter ausgeführt: Die Berichtenden hielten wie mit einer Kette das fest, was Theoderich geleistet habe und was sonst mit der Zeit vergessen würde. ${ }^{218}$ Theoderich gewährleiste die nötige Ruhe und Sicherheit für die Ausübung solcher Künste, durch die er selbst Ewigkeit erlangen könne (263,2 disciplinarum enim quietem vos tribuitis, per quas vobis continget aeternitas). Der Redner weiß also, was er Theoderich verdankt, stellt aber gleichzeitig mit deutlichen Worten heraus, dass auch Theoderich Grund zur Dankbarkeit ihm gegenüber habe. Dieser Gedanke, dass literarische Werke zur Ewigkeit verhelfen können, ist in anderen Zusammenhängen bzw. Gattungen weit verbreitet, doch ob Theoderich sich in diesem Zusammenhang über diese Feststellung gefreut hat, ist fraglich. Denn in Panegyrici findet man üblicherweise Beteuerungen, dass der Redner unfähig sei und dass die Aufgabe seine Kräfte übersteige, ${ }^{219}$

$215(9,5)$ cedant huic priscorum laudes, quibus nobilitatem doctorum commenta pepererunt [...].

216 Siehe z.B. paneg. lat. 2 [12], 8,5 amplificatrix veri vetustas; 2,2,3; 2,17,1f.; 3 [11], 8,1; 4 [10], 15,5 .

$217(9,5)$ necesse enim est exilitatem thematis narrantis opibus ampliari, ut dos, quae in materia non invenitur, stili processionibus inseratur.

$218(263,2)$ quid egeris, ne vetustas sibi vindicet, obliget catena referentum. Cf. $(240,1)$ linguarum catena.

219 Siehe z.B. paneg. $(3[11], 1,1)$ ingenii cuius me poenitet conscius etiam nunc tacere voluissem. $(3,1,2)$ aut indiserti aut ingrati esset fama subeunda. Siehe auch paneg. $(2[12], 1,1),(2,1,4 \mathrm{f})$, $(4[10], 2,8)$. 
nicht aber den Gedanken, dass erst der Redner bzw. Verfasser die dargestellten Taten bzw. die Person unvergesslich machen könne.

Eine andere Fähigkeit der Ars Rhetorica besteht darin, dass sie ihre Zuhörer dazu bringen kann, ihr zu folgen und zu glauben; in der "Paraenesis" sagt sie von sich: „Wenn ich spreche, wird die Urteilskraft (der Hörer) wie eine Gefangene geführt «. ${ }^{20}$ Dass dies nicht etwa 'unmoralisch ist, wie modernes Urteil schließen könnte, sondern ein anerkanntes Ziel des Redners, zeigt z.B. ein kurzer Blick auf einen Ratschlag, den Ambrosius einem neu ernannten Bischof gibt: "Deine Predigten sollen also hervorströmen, sie sollen gut verständlich und klar sein, so dass du den Ohren der Gemeinde beim Sprechen über die rechte Lebensweise süßen Wohlklang einflößt und durch die Anmut der Worte die Gemeinde für dich einnimmst, so dass sie willig folgt, wohin du führst «. ${ }^{221}$ (Cf. auch in der Dictio ... quando de Roma rediit, oben 85.

Diese Fähigkeit, die Ansichten der Zuhörer bzw. Leser widerstandslos beeinflussen zu können, schreibt Ennodius Olybrius und Liberius in Briefen an diese zu. In einem Brief an Olybrius (48; dazu auch unten 245) beschreibt Ennodius zunächst ausführlich die sprachlichen Fähigkeiten des Adressaten und lässt dies in der Aussage gipfeln, durch sein Reden veränderten sich die Dinge (mutatur natura causarum) und wahr sei, was er als wahr vortrage (veritas est quodcumque pro veritate narratis): "Diese Gaben sind Gott zu verdanken, der $<$ Euch $>$ einen wissensliebenden Sinn gewährte und auch die Feile der Studien zur Gestaltung der Rede nicht verweigerte. (\$4) Nicht durchreißt so ein von Sehnen getriebener flinker Pfeil den Himmel, wie Eure Rede die Einfälle Eures Geistes darstellt: sie wird durch kein Hindernis träge, durch keine Hürden langsam; jede Schwierigkeit, die sich ihr entgegenstellt, bietet Durchlass, und auf wundersame Weise verwandelt sich durch das Können des Sprechenden die Natur der Dinge $(\$ 3 f$.). Dann macht Ennodius noch deutlicher, dass er einen Unterschied sieht zwischen >eigentlicher Wahrheit ‘ und rerzählter/ formulierter Wahrheit<. "Du lässt eine Sache so erscheinen, wie Du es willst <? $>$. Wahrheit ist, was immer Ihr als Wahrheit darstellt. Daher steht es <sogar> vorsichtigen Richtern nicht frei, zu widersprechen. $<$ Auch $>$ die kleinlichsten Prüfer ihrer Meinung betrachten es als Gewinn, als Gefangene dorthin folgen zu können, wohin die mächtige Rede sie zieht $\ll(\$ 4) .222$

220 (452,17) Dum loquimur, captum ducitur arbitrium. Cf. $(48,4)[\ldots]$ si sequantur quo pertrahit oratio inperiosa captivos, unten 103.

221 (Ambr. epist. 7,36 [Maur.2],5) sint ergo sermones tui proflui, sint puri et dilucidi, ut morali disputatione suavitatem infundas populorum auribus et gratia verborum tuorum plebem demulceas, ut volens quo ducis sequatur. - Cf. Cic. de orat. 1,30; Cassiod. var. 6,5,3.

$222(48,3 \mathrm{f}$.) deo debentur haec munera, qui et amatorem scientiae sensum contulit et limam studiorum ad oris fabricam non negavit. $(\$ 4)$ non sic pernix aether acta nervis arundo proscindit, quemadmodum inventa ingenii vestri sermo describit. nulla languiscit obice, nullis tardatur obstaculis, fit pervia quaecumque se illi difficultas obtulerit, et mirum in modum 
Für solche rhetorischen Fähigkeiten lobt Ennodius auch Liberius (174). Dieser hat nach Theoderichs Sieg über Odoaker als Praefectus Praetorio die Landverteilung an die Goten geleitet (von Ennodius lobend erwähnt in 447,5) und steht seit 500 im Rang eines patricius; ${ }^{223}$ er erhält fünf weitere Briefe (zu 63 siehe unten 313; zu 447 unten 269 ). - Liberius hat sich offenbar schriftlich ( $\$ 1$ verba dirigitis) für seinen Favoriten bei der Bischofswahl in Aquileia (siehe dazu auch unten 270) eingesetzt und dadurch auch Ennodius für diesen überzeugt, wie er in seiner Antwort (174) mitteilt. Allerdings macht Ennodius sehr deutlich, dass er sich zwar dem rhetorisch brillant vorgebrachten Urteil des Liberius anschließt, selbst aber von den Qualitäten des ihm unbekannten Kandidaten noch nicht überzeugt ist; Ennodius lobt zwar Liberius, lässt aber doch Skepsis am Kandidaten durchklingen. Der Brief geht ohne Praefatio in medias res; wo Liberius lobe, könne niemand widersprechen: "Während Ihr wegen der Wahl des Bischofs von Aquileia einen Eurem frommen und verehrungswürdigen Herzen entsprechenden Brief geschrieben habt und Eure in die christlichen Bräuche eingeweihte Zunge der <sc. künftigen> Weihe diente, hielten uns die Fesseln Eurer Rede in der Zuneigung zu einem Unbekannten fest; denn es bleibt nichts zu entscheiden, wenn ein Anerkannter <sc. wie Liberius> etwas lobt. Denn was bleibt Folgsamen zu entscheiden, wenn derjenige der Gerechtigkeit gehorcht, dessen Aussage nicht geprüft werden muss? Ihr erreicht durch Euer gutes Herz das, was man Eurem Befehl kaum verweigern könnte « (\$1f.). ${ }^{224}$ Dann beschreibt Ennodius die Taktik des Liberius bei der Präsentation des Kandidaten, nämlich sich selbst zurückzunehmen und den Kandidaten umso mehr zu loben, um nicht durch seine Autorität das Ergebnis zu erzwingen, sondern sozusagen den Kandidaten selbst siegen zu lassen: »Der höchste unter den Menschen <sc. Liberius>, durch seine Demut erhöht, erwies sich unter denen, die den verehrungswürdigen Marcellinus beurteilen, als Kollege <sc. und nicht als übergeordnet>; und damit böse Zungen die Zustimmung nicht seiner <sc. des Liberius> Machtposition zuschrieben, verminderte er seinen eigenen Glanz um soviel, wie er dem Gelobten an Wert hinzufügte. Ihr habt Euren eigenen Rang herabgespielt, damit nicht das Lob eines sehr Hochgestellten Grund zu Argwohn geben konnte <sc. dass der Bischof nur gewählt würde, weil Liberius ihn unterstützt hat, und nicht, weil er für das Amt geeignet ist $>$. Damit die Aussagen der Höchsten

per allegantis peritiam mutatur natura causarum. hoc facis in merito negotium habuisse quod cupias. veritas est quodcumque pro veritate narratis. hinc cautis iudicibus non licet repugnare. minutissimi discussores opinionis lucrum aestimant, si sequantur quo pertrahit oratio inperiosa captivos.

223 Details bei: SCHÄFER 1991, 79-83; O'DONNELL 1981.

224 (174,1f.) Dum pro venerandae religione conscientiae verba dirigitis in Aquileiensis electione pontificis et divinis initiata cultibus lingua militat consecrando, in ignoti nos diligentia sermonum vincla tenuerunt, quia nihil superat iudiciis, quotiens aliquid probatus extulerit. quid enim sententiae sequacium derelinquat, quando iustitiae obsequitur, cuius in examen definitio non vocatur? (\$2) agitis bono conscientiae, quod vestro vix negaretur imperio. 
Kraft haben, muss die höchste Macht gezügelt werden « $(\$ 2) .{ }^{225}$ Der Kandidat habe großes Glück, einen solchen Fürsprecher zu haben $(\$ 3)$. Schließlich signalisiert Ennodius seine Zustimmung zu diesem Kandidaten, wobei er nochmals den Einfluss des Liberius hervorhebt: »Auch ich, Höchster, gebe Eurer Seite - gemäß meiner eigenen Wenigkeit - meine Zustimmung, da <auch> der Himmel Euch Folge leistet, und lasse mich - was unter den Menschen als erstaunlich gilt - durch den Gedanken an Euch zur Zuneigung <zu dem Kandidaten> hinziehen. Ich entschließe mich zu einer Zuneigung, die mir durch einen anderen eingegeben wurde $[\ldots]$ « $(\$ 4){ }^{226}$ Ennodius schließt mit dem Wunsch, dass der Kandidat entweder geeignet sein oder werden möge, und mit einer Bitte um Briefe (\$5).--In diesem Brief macht Ennodius sehr deutlich, welchen Einfluss Liberius auf ihn selbst hat, und er schreibt dies der Macht von dessen Worten zu.

Auch in dem Gedicht (213), das Ennodius für den Lehrer Deuterius verfasst hat (siehe oben 33), das dieser an den Quaestor Eugenes (zu ihm unten 346) senden sollte und das Deuterius' Bitte um einen Gefallen vorbringt, wird die Macht der Rhetorik beschrieben. Der Redekunst des Eugenes 227 - er ist Vox iusti quaestor (v.5) und wird angeredet als tuba causarum (v.12) - wird die Macht zugesprochen, wilde Tiere zu zähmen: "Mit deiner Rede unterwirfst du Luchse, mit deiner Stimme Löwen./ Aufgrund deiner süßen Sprache unterdrückt die Schlange die Waffen ihres Halses./ Tigerweibchen, denen die Jungen geraubt wurden, würden dir Geschenke bringen [...] « $(213,15-17) .{ }^{228}$ Damit wird auch Eugenes konkret die Macht der Rhetorik zugeschrieben, die in der »Paraenesis« von sich sagt: Dum loquimur, captum ducitur arbitrium $(452,17)$.

In zwei Briefen an junge Adressaten $(376 ; 387)$ weist Ennodius darauf hin, dass es wichtig ist, Gelegenheiten zum Verfassen von `brieflichen Schaustücken` wahrzuneh-

$225(174,2)$ exhibuit inter arbitros Marcellini venerabilis collegam maximus hominum humilitate sublimior, et ne potestati favor per obliquos adscriberetur interpretes, quod de proprio decerpsit genio, laudati iunxit ad pretium. egistis mediocrem, ne praecelsi esset suspecta praedicatio. clarissimorum testimonia ut vires accipiant, culmina castigantur. - exhibuit [...] collegam nicht richtig aufgefasst von O'Donnell (1981, 41 mit Anm.39): »He named a colleague for himself in supervising the election «; "Ennodius may exaggerate Liberius' restraint and fairness. «Ennodius spricht eindeutig auch im Folgenden von Liberius’ persönlichem Eintreten für den Kandidaten.

$226(174,4)$ iungo et ego, amplissimi, partibus vestris pro modulo exiguitatis propriae caelo vobis obsequente consensum et, quod mirabile inter homines habetur, consideratione vestri adtrahor ad amorem. inspirata mihi per alterum placet affectio [...].

227 Nicht richtig verstanden von KenNell $(2000,123)$, die annimmt, das Gedicht preise Deuterius; infolgedessen nimmt sie auch an, Deuterius sei nach Rom berufen worden (cf. v.13).

$228(213,15-17)$ Eloquio lyncem, tu subdis voce leonem./ Melle tuo serpens gutturis arma premit./ Fetibus orbatae ferrent tibi munera tigres, [...]. 
men, um seine Fähigkeiten aufzuzeigen und dadurch sein Ansehen zu steigern; er deutet an, dass das bei solchen Anlässen Gesagte nicht den tatsächlichen Ansichten des Verfassers entsprechen muss.

Ennodius fordert Faustus' Sohn Avienus (376) zu mehr Eifer in der Korrespondenz auf, denn dadurch könne Avienus selbst profitieren, indem er sowohl seine Sprachkunst als auch seine Zuneigung zum Adressaten zeige. Ennodius wirft Avienus vor, einen (ungenannten) Anlass zum Schreiben nicht wahrgenommen zu haben: »Eure Hoheit, Ihr hättet dem Vorbild Eures ehrwürdigen Vaters folgen und den Reichtum Eures Talents hervorholen und die mit viel Mühe erworbene Bildung zum Zeugnis der Freundschaft herumschwenken müssen. Durch das genannte Schreiben wäre Euch doppeltes Lob zuteil geworden, da die Verehrung von Euren Schutzbefohlenen zugenommen hätte und Euch gleichzeitig die Siegespalme der Rede dargeboten worden wäre. Das, was uns Eure Freundschaft zeigt, hebt Euch empor. Durch eine einzige Handlung würde der Prunk sowohl der Rede als auch der Treue vervielfacht. Man nimmt an, dass diejenigen, die an der Spitze stehen, ihren Untergebenen die Zuneigung erweisen, von der sie sprechen. $[. ..] \ll(376,1) .{ }^{229}$ Letztere Bemerkung hinterlässt aufgrund ihrer Formulierung - putantur - ein zwiespältiges Gefühl, da zwar gesagt wird, dass man Mächtigen das glaube, was sie sagen, dennoch aber der Hinweis auf die mögliche Diskrepanz zwischen Worten und Wahrheit nicht zu überhören ist.

Im Brief an Arator (387) wird explizit deutlich, dass der Verfasser eines >brieflichen Schaustückes، in diesem nicht seine eigene Meinung vertreten muss. Arator wird getadelt, weil er ihm, Ennodius, nichts über die Hochzeit des Maximus geschrieben habe: "auch wenn Dir das alles <sc. das Verhalten des Maximus> nicht gefällt, solltest Du es dennoch loben, um Dein Talent zu zeigen « $(387,3$ haec etsi non diligis, debes tamen pro ingenii tui ostentatione laudare). Arator wird also aufgefordert, die Situation zu nutzen, um seine Fähigkeiten zur Schau zu stellen; das bedeutet, dass er sich der Situation entsprechend verhalten und formulieren soll, was die Beteiligten hören möchten - nicht das, was er selbst denkt.

Ennodius weist in den hier betrachteten Passagen darauf hin, dass die Adligen von der Ars Rhetorica abhängig sind, sowohl um ihre Macht zu erhalten als auch, um Ruhm über das Leben hinaus zu erlangen. Doch nicht nur diese Ars bietet solche Möglichkeiten, auch die Dichtung verfügt über große Macht, wie die folgenden Stellen zeigen.

$229(376,1)$ par erat magnitudinem vestram ingenii sui opulentiam, dum sancti patris sectatur instituta, depromere et multo adquisitam sudore doctrinam pro diligentiae testimonio ventilare. gemina vobis contingeret ex antefata concinnatione laudatio, quando crescente susceptorum devotione ferretur in medium palma sermonis. res, quae nobis amorem vestrum reserat, vos extollit. uno eodemque usu et oris pompa multiplicaretur et fidei. in apice constituti illam subiectis adfectionem putantur inpendere, quam locuntur. [...]. Abschließend folgt ein weiterer Hinweis auf das Vorbild des Vaters. 


\section{c. 3 Die Macht des Dichters}

In der "Paraenesis« wird dem Redner, sei es im genus iudiciale vor Gericht als Ankläger oder Verteidiger, sei es im genus demonstrativum als Lobredner, die Fähigkeit zugeschrieben, Dinge und Taten zu verändern, d.h. besser oder schlechter erscheinen zu lassen. Doch auch der Dichter hat laut Ennodius die Fähigkeit, die Dinge besser erscheinen zu lassen, als sie in Wirklichkeit sind. Auf verschiedene Weise werden so der Rhetorik und der Dichtung die gleichen Möglichkeiten zugeschrieben. Dies ist nur ein Aspekt der stetig zunehmenden Tendenz, dass die Trennung zwischen Prosa und Dichtung und zwischen den Gattungen immer unschärfer wird; machmal ist den Formulierungen gar nicht zu entnehmen, ob über Prosa oder über Dichtung gesprochen wird (so ist es z.B. nicht ungewöhnlich, dass das carmen eines disertus gepriesen wird, siehe unten 108). Allerdings sagt Ennodius von der Dichtung nie, dass sie die Dinge schlechter darstelle als sie seien. Der Dichter kann in seinem Werk die Welt verschönern, und für den Dichter selbst hat seine Dichtung besonders zwei Vorteile: er kann Ruhm erlangen, und er kann sich von der Wirklichkeit ablenken.

Den Gedanken, dass die Sprachkunst die Welt zum Besseren verändert, steigert Ennodius noch weiter dadurch, dass dies mit der Schöpferkraft Gottes vergleichbar sei. In der Eingangspassage seiner (paradoxen) Beschreibung des Comersees (10) $)^{230}$ lobt er zunächst die Kunst des Faustus, die dieser in seinem Werk über den Comersee gezeigt hat - allerdings bleibt offen, ob Faustus in Prosa oder in Versen geschrieben hat: »Mit welchen Gaben werden Orte geschmückt, die jemand erblickt hat, der eine reiche Sprache und Erfahrung im Reden hat [...]. Gott, der Schöpfer der Welt, hat den verschiedenen Gegenden manche Qualitäten zugeteilt, einige ließ er mehr, andere besseren Wein hervorbringen [...]. Doch diejenigen Gegenden, denen die widerstrebenden Eigenschaften ihrer Natur solches nicht gaben, machte er durch den Redner erhaben. [...] Durch den Glanz der Sprache werden den Ländern Vorzüge zugeteilt, und je nachdem, wie jemand reden kann, so hebt er das empor, worüber er spricht. Länder, ihr wachst durch die Sprachkultur! « $(10,1 \mathrm{f}.) .^{231}$

An anderer Stelle ist es eindeutig die Dichtkunst des Faustus (26, siehe einführend dazu oben 39), die nicht nur mit Myron, sondern mit Gott verglichen wird: "Die alte Zeit berichtet, dass Myron das Werk, das er mit belebender Hand schuf,

230 Siehe dazu SCHRÖDER (2003a).

$231(10,1 \mathrm{f}$ ) quibus ornantur dotibus loca, quae lingua dives et dicendi peritus aspexerit [...]! quasdam mundi artifex deus provinciis felicitates [...] concessit, alias uberius, melius alias vinum iussit effundere [...]. (2) quibus haec tamen ipsius naturae repugnantia merita non dederunt, fecit eas relatore sublimes. [...] linguarum genio <zu genius siehe oben Anm. 13> terris merita tribuuntur et qualiter quis loqui potuerit, taliter rem, de qua fuerit locutus, adtollit. crescitis, provinciae, cultura sermonum. [...]. - Mit cultura sermonum sind nicht konkret "Briefe" gemeint, wie GioanNi $(2001,175)$ annimmt, sondern die sprachlichen Fähigkeiten des Lobredners. 
mit seinen Fingern beseelt habe. Du [sc. Faustus] gibst durch die Worte ein Gesicht, durch die Verskunst die Glieder. Was Gott seine Natur gibt, das geben dir deine Studien « $(26, v .17-20) .{ }^{232}$ Weiter wird in einer Reihe von Adynata die verändernde Kraft von Faustus' Dichtung beschrieben, wobei das erste Adynaton wiederum Assoziationen an Gott und Christus hervorruft: „Wenn du dein Plektron heilbringend einem alten Leichnam zuwendest,/ machst du ihn mit deiner aufrichtenden Lyra zu einem (lebenden) Jüngling. Wenn du Blumen in den kalten nördlichen Regionen darstellst, dann durchpfeift bald die Luft mit Frühlingsweisen den Norden [...] « (26, v. 21-24).233

Diese Passage über die Ähnlichkeit zwischen der Schöpferkraft Gottes und des Dichters ist der Forschung besonders deshalb aufgefallen, weil sie ein Mann der Kirche formuliert hat (siehe z.B. Polara 1993, 229). Doch auch ohne Blick auf den geistlichen Stand des Verfassers sind diese Worte interessant genug, was die bloße Einordnung als "hyberbolisch « (so Polara ibid.) eher verschleiert. Die Macht der Rhetorik über Wahrheit und Erfindung und die damit verbundenen Gefahren mögen oft benannt worden sein, aber nach solchen Äußerungen über die Macht der Dichtung muss man länger suchen. VANDONE (2004, 30) weist sehr kurz darauf hin, dass der Vergleich zwischen Dichter und Gott einen Vorläufer bei Macrobius (Sat. 5,1,18-5,2,1) habe, ohne dem aber weiter nachzugehen. Dort stellt einer der Gesprächsteilnehmer zunächst dar, dass Vergil in der Aeneis seine Beherrschung aller vier genera dicendi offenbare, und vergleicht dann die Welt, das opus divinum, mit dem Dichtwerk: So wie die eloquentia Vergils - mal knapp, mal wortreich etc. - für alle Charaktere geeignet sei, so zeige sich die Erde teils mit Wiesen fruchtbar, teils mit Felsen rau etc. (Sat. 5,1,19) ${ }^{234}$ Hier wird das opus poeticum Vergils mit dem opus divinum verglichen und gleichgesetzt, doch von einer Veränderung der Wirklichkeit durch die Dichtung wie bei Ennodius ist nicht die Rede. Außerdem befürchtet der Sprecher, er könne bei dem Vergleich zwischen Vergil und der natura rerum übertrieben haben, und bittet um Nachsicht: ignoscite nec nimium me vocetis, qui naturae rerum Vergilium comparavi (Sat. 5,1,20).

Die Adynata und ganze Adynata-Reihen in der lateinischen Literatur sind Legion. Doch Ennodius setzt die Adynata in dieser Beschreibung von Faustus' Kunst in ganz neuer Weise ein. Adynata werden sonst formuliert, um zu verdeutlichen, wie unwahrscheinlich eine Handlung ist bzw. eingeschätzt wird, z.B.: Eher werden Hirsche im

232 (26, v.17-20) Aetas cana refert digitis animasse Myronem / Quod fingebat opus vivificante manu./ Tu verbis faciem tribuis, modulamine membra./ Quod natura deo, hoc tibi dant studia.

233 (26, v.21-24f.) In vetulum dexter si vertas plectra cadaver, / Primaevum facias aedificante lyra./ Si flores simules gelidi per plaustra Bootis,/ Mox Helicem vernis sibilat aura modis.

234 Zur Bezeichnung der Aeneis als opus divinum bzw. sacrum poema in den Saturnalia insgesamt siehe: B. W. SinclaIr, Vergil's sacrum poema in Macrobius' Saturnalia, Maia 34, $1982,261-263$. 
Himmel weiden, die Meere austrocknen und die Germanen am Tigris leben, als dass Tityrus seinen Wohltäter vergisst; oder: Der verbannte Dichter rechnet damit, dass nun die Meere in die Quellen der Flüsse zurückfließen werden und überhaupt alles den Naturgesetzen widersprechen wird, da sein Freund ihm nicht geholfen hat. ${ }^{235}$

Bisher fiel der Forschung nicht auf, dass der Gedanke, die Dichtkunst könne Adynata bewirken, ungewöhnlich ist. Denn Ennodius bringt mit den Adynata nicht zum Ausdruck, dass eine Handlung völlig unwahrscheinlich ist, sondern er stellt dar, dass durch die Dichtung völlig Unwahrscheinliches bewirkt wird bzw. eintritt.

Der Gedanke der Schöpferkraft der Dichtung in Verbindung mit Adynata findet sich außerdem noch in dem Gedicht "Am Eingang des Gartens" (163): "Beachte folgendes, der du deine Schritte durch liebliches Grün lenkst, damit du lernst, das Licht eines Redekünstlers einem schönen Garten vorzuziehen: Es lächelt der Spross, der mit dem Purpur der Sprache gemalt wird; wer im Gedicht Blumen erzeugt, kann im Winter Frühling haben; mitten im Eis können Worte milde Zephyrn verströmen. Die Worte sind trunken und berauscht vom glänzenden Purpur. In allen Dingen herrscht der Purpur der Rede $[\ldots]$ « $(163,1-7) .^{236}$

Dieser Einsatz von Adynata in dem Sinne, dass sich durch eine sprachliche Handlung die Natur in völlig unwahrscheinlicher Weise verändert, hat einen Vorläufer in den Vorstellungen von der Epiphanie einer Gottheit, von den Reaktionen der Natur bei der Geburt oder bei der Manifestation einer Gottheit. ${ }^{237}$ Diese Idee wurde dann übertragen auf große Persönlichkeiten. Claudian, dessen Kenntnis Ennodius an einigen Stellen zeigt (siehe bei Vogel 1885, 332 und Duвois 1903, 77f.), beschreibt Adynata, die bei der Geburt und in der Kindheit der Serena, der Tochter des Honorius (der späteren Adoptivtochter Theodosius' I. und Gattin des Stilicho), geschehen sind: ${ }^{238}$ »[...] Galizien lachte voller Blumen, und an den rosenbedeckten Ufern des Duria bekamen alle Schafe purpurnes Fell «, »wo immer du durch das Gras gekrochen bist, erglänzten Rosen und wuchsen strahlende Lilien« (Laus Serenae, carm. min. 30, 71-

235 Verg. buc. 1,59-63; 8,52-56; Ov. trist. 1,8,1-10. Siehe dazu: H.-J. Scheuer, Art. »Adynaton«, HWRh Bd. 1, Sp. 139-141, Tübingen 1992.

236 (163,1-7) Respice, qui gressum sinuas per amoena virecta,/ Ut discas cultis lucem praeferre diserti./ Adridet germen quod linguae pingitur ostro,/ Ver habet in bruma qui flores carmine gignit,/ Per glaciem zephyros exhalant verba tepentes./ Ebria fulgenti maduerunt murice dicta./ Omnibus in rebus sermonum purpura regnat [...].

237 Siehe die Freude der Natur bei Apolls Geburt im Homer. Apollon-Hymnos; die Reaktion auf die Anwesenheit des Bacchus (Eur. Bakch. 141f., 707-711; auch Ov. met. 3,664-669); die Freude der Insel Kos bei der Geburt des Ptolemaios (Theokrit Id. 17,64ff.); vgl. Menan-

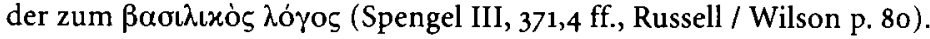

238 Siehe den Kommentar von F. E. Consolino, Elogio di Serena, Venedig 1986. 
73; 89f.). ${ }^{239}$ Bei Ennodius findet sich dieses Motiv, dass die Anwesenheit einer Person solche Adynata bewirkt, in dem Gedicht De horto regis (264); hier führt die Anwesenheit Theoderichs zum Aufblühen des Gartens, z.B.: „Was der Princeps berührt hat, erlebt mitten im Winter Frühling (v.14 quod tetigit princeps, ver habet in glacie; cf. den Kommentar von Di Rienzo 2005).

LiEBerg kommt in seiner Untersuchung "Poeta creator. Studien zu einer Figur der antiken Dichtung" (1982) zu dem Ergebnis (164): "Man muss bis zu Iulius Caesar Scaligerus und dessen Poetices libri septem aus dem Jahre 1561 gehen, um den schöpferischen Charakter der Poesie klar ausgesprochen zu finden. [...] Die anderen Künste sind also gleichsam die Schauspieler der Werke Gottes. Sie bringen diese gewissermaßen zur Aufführung. Im Unterschied dazu besitzt der Dichter die Fähigkeit, das, was ist, schöner zu machen und den Schein dessen zu schaffen, was nicht ist. Er erzählt nicht wie ein Schauspieler von den Dingen, d.h. er ahmt nicht Handlungen im Wort nach, sondern er scheint die Dinge wie ein zweiter Gott zu begründen, zu schaffen. [...] « Doch es ist festzuhaiten, dass nicht erst bei Scaliger, sondern auch schon mehr als 1000 Jahre zuvor bei Ennodius sich mehrfach der Gedanke findet, dass der Dichter (und der Redner) die Fähigkeit hat, die Dinge schöner und besser erscheinen zu lassen, als sie in Wirklichkeit sind. Dieses Konzept von Dichtung steht zwischen >Mimesis Welt nach, noch erfindet er eine völlig neue Phantasiewelt. Das Dargestellte steht in engem Bezug zur Wirklichkeit, aus der im Gedicht etwas nicht völlig Anderes, aber doch Schöneres und Besseres > wird،.

Verbessert und verschönert werden so nicht nur Gegenden und Pflanzen, sondern auch die Sprache des Zuhörers bzw. Lesers: In der Prosa-Vorrede zu dem eben betrachteten Gedicht über die Sprachkunst des Faustus (26) beschreibt Ennodius, welchen Einfluss diese auf seine eigene gehabt habe. Er beklagt sich darüber, dass Faustus so lange damit gewartet habe, ihn in den Genuss seiner sprachlichen Kunst kommen zu lassen. ${ }^{240}$ Denn aufgrund der reichen Sprachkunst des Faustus habe Ennodius seine eigene bereichern können. „Guter Gott, was für Fähigkeiten meiner Sprache kann ich erkennen, die mir früher fremd waren und die ich aufgrund von Euren sprachlichen Reichtümern erlangt habe! Es ist, wie ich merken kann, Aufgabe derer, die sich durch ihre Redekunst auszeichnen, diejenigen mit der Feile des Könnens zu verbessern, deren Zunge rostig und deren Sinn abgestumpft ist. Ihr habt etwas mit dem Schöpfer der Menschen gemeinsam: Er erschuf aus dem Nichts, Ihr verändert zum

239 (Claud. carm. min. 30, 71-73) [...] Callaecia risit / floribus et roseis formosus Duria ripis / vellere purpureo passim mutavit ovile; [...]. (ibid. 89f.) [...] quacumque per herbam / reptares, fulgere rosae, candentia nasci lilia $[\ldots]$.

$240(26,1)$ suspendistis hactenus ab ingenioli mei ariditate imbrem fructuum nutritorem: "Ihr habt bisher von meinem trockenen Talent den Regen, den Ernährer der Früchte, ferngehalten.« 
Besseren. Ich danke also für das erhaltene Gedicht, wenn ich auch traurig bin, dass die Wohltat so spät eintraf.« $(26,2){ }^{241}$ So wie der Redner verödete Landschaften »verschönern« kann, so kann er auch die sprachlichen Fähigkeiten des Ennodius verbessern. Allerdings nimmt er diesen Gedanken sofort wieder etwas zurück, wenn er auf die folgenden Verse u.a. mit den Worten hinweist, dass sie eine Schande für die $\mathrm{Mu}$ sen seien (26,3 ad Camenalem [...] ignominiam).

Eine weitere Qualität von Dichtung wird in dem Gedicht (187) erwähnt, das laut Überschrift als Vorrede zum dichterischen Werk fungieren sollte bzw. konnte: „Wenn mein sorgenvoller Geist vielfache Stürme ertragen muss und ich zum Spielball des glänzenden Meeres werde [...] - die Dichterleidenschaft überkommt mich [...], schon habe ich vom sanften Nass der Castalischen Süße getrunken. Sofort werden die Sorgen in der Brust schwächer und können abgelegt werden; ich heiße Lob, Gedichte und Freude willkommen «. ${ }^{242}$ Di Rienzo (2005, 2of.), dessen Kommentar für Detailfragen heranzuziehen ist, interpretiert die aestus der ersten vier Zeilen als Aussage des Ich über seine Unfähigkeit angesichts der schweren Aufgabe, zu dichten. In der Tat finden sich das Bild des Meeres und des zu kleinen Bootes auch bei Ennodius in Zusammenhängen, wo er sich über seine Dichtung bzw. über sein Schreiben allgemein äußert. ${ }^{243}$ Doch das stürmische Meer ist nicht nur ein Bild in poetologischen Zusammenhängen, sondern häufig auch ein Bild für das menschliche Leben, ${ }^{244}$ und letzteres dürfte hier gemeint sein: Wenn Ennodius von den Sorgen des Lebens bedrängt wird, schafft ihm die Tätigkeit des Dichtens Freude und verhilft ihm zu Ruhm - dass er als Diakon solchen Ruhm nicht erstreben dürfte, war bereits mehrfach zu sehen. Auch dieser Gedanke, dass der Dichter selbst durch das Dichten die ihn bedrängenden Sorgen vergisst, ist näherer Betrachtung wert: Verbreitet ist das Motiv, dass der Dichter andere tröstet, indem er sie auf andere Gedanken bringt, mit anderen

$241(26,2)$ deus bone, quam peregrinas in me et ex vestri oris divitiis adquisitas dicendi opes intellego! adiacet dictis locupletibus, quantum sentio, rubiginosos lingua et sensu hebetes peritiae lima conponere. est vobis quoddam cum hominum factore collegium. ille finxit ex nihilo, vos reparatis in melius. gratias ergo refero de suscepto carmine, cum de dilato maeream benificio.

242 Praefatio totius operis poetici quod fecit (187): (1) Dum mea multiplices mens anxia sustinet aestus / Et reddor vitrei mancipium pelagi, $[\ldots]: /(5)$ Pierius menti calor incidit $[\ldots], /(8)$ Castalii mellis murmura blanda bibi./ Continuo ponens marcentes pectore curas / Conplector laudem carmina laetitiam. Die Rezeption von Stat. Theb. 1,3 in v. 5 ist lange erkannt.

243 Z.B.: $(105,10)$ ad portum cumbam flecte Thalia meam; $(26,33-48) ;(40,5)$ committo tamen cumbam tenuem placido mari, quia parum ab ingratitudine differt muta gratulatio. $\mathrm{Zu}$ dem häufigen Bild siehe z.B.: G. LIEBERG, Seefahrt und Werk: Untersuchungen zu einer Metapher der antiken, besonders der lateinischen Literatur, GIF 21, 1969, 209-240.

244 Aus der Fülle von Stellen siehe z.B.: Ambr. epist. 7,36,1 saeculi [...] procellae. Paul. Pell. euch. 1of. inter et adversas iactatus saepe procellas / instabilis mundi. 
Themen von den Sorgen ablenkt (STroH 1981, 2648). ${ }^{245}$ Doch "tröstende Dichtung ist noch lange nicht Dichtung, mit der sich ein Dichter selbst tröstet « (ibid. 2647), und das Motiv der Selbsttröstung und Selbstbefreiung des Dichters hat nach zwei ungleichen Vorläufern, nämlich dem singenden Kyklopen bei Theokrit und Cicero, der nach dem Tod seiner Tochter eine Trostschrift für sich selbst verfasste (siehe Cic. Att. 12,14,3), erst Ovid mit den Verbannungselegien in die Literatur eingeführt. ${ }^{246}$ Anders als der verbannte Ovid und seine Nachfolger tröstet sich Ennodius jedoch damit, dass er nicht über seine Situation und seine Sorgen schreibt, sondern ganz andere Themen wählt und sich selbst beim Schreiben und sorgfältigen Formulieren auf andere Gedanken bringt ${ }^{247}$ und ganz einfach Freude am Schreiben hat (und sich zudem verbotenerweise über oder auf Lob freut).

Ennodius thematisiert also die Macht der Rhetorik und die entsprechende Macht der Dichtung (die nicht immer deutlich voneinander getrennt werden) häufig, wobei der Hinweis auf den möglichen Unterschied zwischen dem Gesagten und der Realität bzw. der Wahrheit unüberhörbar ist. Das Besondere ist, dass Ennodius nicht nur selbst über diese Macht verfügt und sie ununterbrochen einsetzt, sondern dass er seine Leser auch darauf aufmerksam macht.

\section{d. Ennodius' Rolle(n) gegenüber den jungen Adligen}

Als letzter Aspekt in diesem Abschnitt über Ennodius' Haltung zu den studia liberalia soll nun dargestellt werden, in welchen Rollen er junge Adlige, die eine weltliche Karriere als Anwalt oder in der Verwaltung anstreben, zur Bildung anhält. Aus den Schulreden geht hervor, dass der Diakon Ennodius sicher nicht (mehr) offiziell als Lehrer literarische Fähigkeiten vermittelt, aber doch den Kontakt zur Schule oder zumindest zu dem Lehrer Deuterius aufrechterhält. Die Briefe zeigen, dass der ehe-

245 Siehe auch: M. L. Ricci, Il »topos« della poesia consolatrice, Inv. Luc. 1, 1979, 143-170. W.-L. Liebermann, Trost der Dichtung und Trost der Philosophie, Ovid und Cicero, in: Ovid. Werk und Wirkung, FS M. von Albrecht, 1999, 2, 685-700.

246 Отвон $(1981,2653 ; 2645)$, siehe z.B. (Ov. trist. 1,11,7-12): quod facerem versus inter fera murmura ponti,/ Cycladas Aegaeas obstipuisse puto./ ipse ego nunc miror tantis animique marisque / fluctibus ingenium non cecidisse meum./ seu stupor huic studio sive est insania nomen,/ omnis ab hac cura cura levata mea est. Weitere Stellen, auch bei späteren Autoren (ohne Ennodius), bei StroH.

247 Am ehesten damit vergleichbar sind die Bemerkungen des Livius, dass er sich von der Beschäftigung mit der Geschichte verspreche, vom Anblick der gegenwärtigen Übel abgelenkt zu werden: (Liv. 1 praef. 5) [...] hoc quoque laboris praemium petam, ut me a conspectu malorum quae nostra tot per annos vidit aetas, tantisper certe dum prisca tota illa mente repeto, avertam [...]. 
malige Redner, Dichter und vielleicht auch Lehrer als offenbar weiterhin geachtete Kapazität junge Adlige ermahnt, ihre weltlichen literarischen Studien eifrig zu betreiben. In seinen Briefen tritt er nicht als Lehrer in religiösen Fragen auf, denn seine mahnenden Worte gegenüber den Jungen betreffen nicht die religiöse Sphäre, sondern sprachliche Fähigkeiten, deren gesellschaftliche Funktion und das mit ihnen verbundene Prestige. Wenn er direkt zu den jungen Adligen von den studia spricht, ist sein Ton in der Regel sehr streng, und er verschweigt nicht, dass die Ausbildung von sprachlichen Fähigkeiten harte Arbeit ist, z.B.: "bereite dich mit viel Schweiß auf die Kultur des Schreibens vor “ $(15,6)$; »[...], was ununterbrochene Arbeit und unermüdlicher Schweiß erreichen « (175,1); häufig werden dabei Parallelen zum Ackerbau gezogen, z.T. in ausführlichen Bildern (siehe z.B. 428,1 unten 120, 175,4 u. 122, in etwas anderem Zusammenhang in 290,2 u. 127, 369,4 U. 128)..$^{248}$

In welcher Form Ennodius konkret zur Bildung der einzelnen jungen Adligen beigetragen hat, lässt sich nicht pauschal beantworten. Er hat offensichtlich nicht zu allen, denen wir innerhalb seiner Werke begegnen, im gleichen Verhältnis gestanden, vielmehr hat er sich um ihre Bildung in unterschiedlicher Weise und Intensität gekümmert. So hat er zu Parthenius, dem Sohn seiner Schwester (zu ihm unten 124), als dessen parens et nutritor er sich bezeichnet $(369,2)$, sicher ein anderes Verhältnis gehabt als etwa zu Messala, dem Sohn des Konsulars Faustus.

\section{d. 1 Patroni et exempla}

Nicht jeder, der einen Beitrag zur Ausbildung junger Adliger leistete, musste Lehrer sein. Aus Briefen, besonders aus manchen Empfehlungsschreiben, und aus der "Paraenesis" ist zu erfahren, dass die jungen Männer nicht nur im Unterricht bei einem Lehrer, sondern auch in einer Art sTirocinium fori، anhand von Vorbildern lernen sollten, wobei es weniger um einzelne wissenswerte Details verschiedener Disziplinen ging als allgemein um das Auftreten, die Umgangsformen und die Sprache der vorbildlichen Persönlichkeiten (zum Vater als Vorbild siehe oben 89). Zur Beschreibung von deren Rolle lassen sich den entsprechenden Textstellen, besonders in Empfehlungsschreiben, Begriffe wie patronus, tutor, suffragia paterna oder exempla ent-

$248(15,6)$ ad scriptionis culturam multo sudore te praepara; $(175,1)[\ldots]$ quod labor continuus et indefessus sudor adipiscitur. - Auf die Häufigkeit von Metaphern aus dem Bereich >Naturs und besonders >Agrikultur in den Werken des Ennodius verweist Rallo Freni (1972), indem sie eine Reihe der Stellen vorführt; dort auch kurze Hinweise zur Geschichte des Motivs. - Auch Kennell (2000, 57-60) präsentiert eine Reihe der betreffenden Passagen. - Zu Metaphern aus dem Bereich >Natur für Aspekte der Rhetorik insgesamt siehe auch: C. ConNors, Field and Forum: culture and agriculture in Roman rhetoric, 71-89 in: W. J. Dominı (ed.), Roman Eloquence, Rhetoric in Society and Literature, London/New York 1997. 
nehmen. In den Empfehlungsschreiben werden - je nach Adressat und dessen besonderer Situation bzw. Stellung - verschiedene Wünsche und Erwartungen formuliert, wobei allgemein um Aufnahme und Unterstützung gebeten wird, um materielle Hilfe, um die Übernahme der Funktion als gutes Beispiel, um die Ausübung ihrer Autorität gegenüber den Empfohlenen.

Allgemein um Aufnahme und Fürsorge aus christlicher Caritas heraus wird besonders der Bischof von Rom gebeten: Jeweils zwei Schreiben an Symmachus und an dessen Diakon Hormisda verfasste Ennodius für einen nicht namentlich genannten adligen Waisenjungen (409 und 410) und für Beatus (416 und 417). Um den Waisenjungen solle Symmachus sich als Waisen und Fremden kümmern $(409,1)$; der Wunsch nach Gastfreundschaft wird auch für Beatus ausgesprochen $(416,1) .{ }^{249}$ In den beiden Briefen an den Diakon Hormisda wird darauf angespielt, dass er der nächste Bischof von Rom sein wird: Er wird gebeten, Beatus' besonderer tutor zu sein, da er es bald für alle Menschen sein werde (417,2 esto specialis tutor, omnium mox futurus).

Die vier Adressaten der Empfehlungsschreiben für Ennodius' Neffen Parthenius (225-228) sollen ihre Fürsorge auf unterschiedliche Weise zeigen: Ennodius schreibt an Faustus, er habe Parthenius dessen väterliche Unterstützung versprochen (225,2 suffragia paterna). Der Bischof von Rom Symmachus wird gebeten, Parthenius zu unterstützen (226,4 fovete); wie bei den im letzten Absatz genannten Empfehlungen bezieht sich die Bitte, dass Parthenius bei ihm als peregrinus gelten solle, auf das Gebot der christlichen caritas, sich um Fremde zu kümmern. ${ }^{250}$ Faustus iunior wird gebeten, Parthenius aufzunehmen (228,3 suscipiat) und dafür zu sorgen, dass es ihm auch in der Ferne gutgehe; auch die Hoffnung auf materielle Unterstützung wird angedeutet. ${ }^{251} \mathrm{Im}$ Brief an Luminosus (227) zeigt sich besonders gut die Dynamik des Beziehungsnetzes: Dieser sei zum patronus $(\$ 1)$ des Parthenius prädestiniert; da auch Luminosus früher nach Rom in die Fremde gegangen sei und dort Erfolg gehabt habe, sei er aufgrund dieser vergleichbaren Situation für Parthenius ein besonders instruktives Beispiel. ${ }^{252}$ Ennodius fordert ihn auf: »Sei bitte zu ihm wie ein Vater [...], damit ich das, was ich einmal für dich, Erhabener, an Mühe aufgewandt

$249(409,1)$ rem necessariam providet, qui parenti omnium orbatos et peregrinos insinuat: "wenn man dem Vater aller <sc. dem Papst> Waisen und Fremde empfiehlt, kümmert man sich um etwas Nötiges. " $(416,1)[\ldots]$ qui parenti omnium peregrinos insinuat. - Zur Gastfreundschaft als Ausdruck christlicher Caritas siehe z.B. Röm 12,13; 1 Petr 4,9; Hebr $13,2$.

$250(226,4)$ ut $[\ldots]$ peregrini apud vos nomen excipiat [...]. Cf. die vorangehende Anm.

$251(228,2)$ optat, ni fallor, peculii vestri habere testimonium.

$252(227,1)$ exemplis hortatur ex peregrino potens, ex incipiente perfectus: "Durch sein gutes Beispiel kann derjenige ermahnen, der aus einem Fremden zu einem Mächtigen geworden ist und aus einem Anfänger zum Vollkommenen. " $(227,1)$ vos patronos meruit causa communis. $(227,2)[\ldots]$ quem similis retineas fuisse fortunae. 
habe, durch einen anderen zurückbekomme« $(227,3) .{ }^{253}$ Parthenius werde Luminosus vor Augen haben und mehr durch das, was er beobachten könne, als durch Ermahnungen auf den richtigen Weg gebracht werden. ${ }^{254}$ - Später, als Parthenius in Rom Anlass zur Klage gibt, bittet Ennodius erneut Faustus um Hilfe (368): Der Brief beginnt mit dem allgemeinen Gedanken, dass junge Leute gute Aussichten haben, wenn sich große Persönlichkeiten um sie kümmern; doch wenn die Sorge (curatio) nachlasse, werde der Weizen von Unkraut überwuchert. Denn aufgrund der Abwesenheit des Faustus habe Parthenius in seinem Eifer bei den Studien nachgelassen. Parthenius' Vater habe berichtet, dass dieser sich bisher aus Angst (metus; lege formidinis) vor Faustus gut benommen habe. ${ }^{255}$ Faustus solle also bitte eingreifen, er solle mit Bekannten und mit dem Lehrer besprechen, was zu unternehmen sei. ${ }^{256}$

Für den jungen Ambrosius verfasst Ennodius Schreiben an Faustus, Meribaudus und Probinus (424-426). Faustus wird gebeten: "Schreibt Ihr ihm bitte vor, was er tun und was er lassen soll; gebt ihm Empfehlungsschreiben an andere mit, soweit Ihr es für nötig haltet« $(424,1)$; er solle für ihn beten, dass ihn die Laster Roms nicht berühren und dass ihn keine Krankheiten befallen (424,3). ${ }^{257}$ Probinus wird um allgemeine Unterstützung des Ambrosius gebeten (426,3 foveatis). Auffällig ist, dass auch der Brief an Meribaudus (425), der Ambrosius wohl in Rom unterrichten soll, nicht sehr konkret über die Ausbildung des jungen Mannes spricht. Erst am Ende ist zu erahnen, dass Meribaudus Lehrer ist: "Antwortet auf meine Bitte mit väterlicher - wie die alte Zeit die Lehrer nannte - Fürsorge« $(425,4) .^{258} \mathrm{Im}$ vorangehenden Satz hat er die Hoffnung ausgesprochen, dass mit Gottes Hilfe durch Meribaudus die in Ligurien gelegten ersten Fundamente (der Bildung des Ambrosius) gefestigt werden mö-

$253(227,3)$ circa memoratum patrem reddite $(. .)$, ut quicquid in magnitudine tua dudum laboris exhibui, mihi per alterum reformetur.

$254(227,2)[\ldots]$ sublimitatem tuam gerens ante oculos rebus ad virtutem potius quam monitis excitatur.

255 (368,1) Parthenium [...] diu circa diligentiam litterarum, quantum patris ipsius reseravit allegatio, culminis vestri metus adtraxerat. sed nunc per absentiam vestram venerandae solutus lege formidinis molitur obscena: "Soweit sein Vater sagte, hatte die Furcht vor Euch, erhabener Faustus, Parthenius lange Zeit dazu gebracht, seine Studien eifrig zu betreiben; aber da er nun durch Eure Abwesenheit vom Gesetz der Furcht und des Respekts befreit ist, betreibt er Schändliches."

$256(368,3)$ vos medicam manum, vos opem praestate consuetam [...]. commendate amicis quae agantur, insinuate doctori $[\ldots]$ : "Bietet Ihr Eure helfende Hand und die übliche Hilfe; ratet den Freunden, was zu tun ist, empfehlt es dem Lehrer [...].«

257 Z.B. (424,1) vos detis praecepta, quid sequi debeat, quid cavere; vos apud quos necessarium credideritis scriptione prosequamini. (\$2) [...] et orate pro ipso, ut adulescentem Roma nec vitiis possit nec morbis extinguere.

$258(425,4)[\ldots]$ et petitioni meae paterna, sicut praeceptores vocavit antiquitas, pietate respondete. Zum Lehrer / Vater siehe oben Anm. 153. 
gen $(425,3){ }^{259}$ Bis dahin beschäftigt sich der Brief nicht, wie man es von Ennodius vielleicht erwarten würde, mit Fragen von Unterricht und Bildung, sondern mit Bemerkungen darüber, wie bedeutend, reich und klug der Vater des Empfohlenen ist.

Die jungen Männer, um die sich nach dem Wunsch der Empfehlungsschreiben die bekannten Persönlichkeiten kümmern sollen, werden entsprechend aufgefordert, diesen nachzueifern. In der "Paraenesis « wird den Adressaten Ambrosius und Beatus die Frage in den Mund gelegt: „Welche Lehrer haben wir in diesen Dingen, wer soll uns unterrichten, wessen Beispiel sollen wir nachstreben $[\ldots]$ ? $(452,18) .{ }^{260}$ Darauf werden ihnen einige Männer genannt, die Wissen verkörpern, deren bloßer Anblick Unterricht genug sei, deren Gespräche würdigen Themen gewidmet seien: »Diese zu sehen bedeutet, gebildet zu werden; bei ihnen gibt es keine Gespräche über Unanständiges, keine fast unverzeihliche Erwähnung von Pantomimen; sie haschen nicht nach der Gunst des Volkes, indem sie ihren Anstand opfern, denn sie wollen lieber den Guten gefallen als den Vielen [... « ${ }^{261}$ Auch Verhalten und Sprache einiger Frauen werden als vorbildhaft erwähnt, z.B.: "Barbara, eine Blüte des wahren römischen Glanzes, da sie den Glanz ihrer Abstammung und ihrer Feinheit durch das Zeugnis ihres Antlitzes offenbart, an der ihr eine zurückhaltende Zuversicht findet und eine Zurückhaltung, die auf ihre guten Handlungen vertraut, außerdem eine Redeweise, die mit natürlicher und kunstvoller Einfachheit gewürzt ist $[\ldots]$ «. ${ }^{262}$

Die Ausbildung der jungen Adligen bestand also nicht nur im Unterricht bei einem speziellen Lehrer, der ihre sprachlichen Fähigkeiten steigern sollte; die zweite Hälfte der Ausbildung bestand darin, sich an einer Reihe von exempla / tutores / patroni zu orientieren, um insgesamt die Persönlichkeit zu entwickeln.

\section{d. 2 Ennodius als tutor}

Ennodius als patronus bzw. tutor konnte sowohl aufgrund seiner Erfahrung als Dichter, Redner und vielleicht auch Lehrer umso konkretere Hinweise zur sprachlichen Bildung geben als auch insgesamt durch sein Verhalten und seine Sprache als Vor-

$259(425,3)[\ldots]$, ut per vos principia eius hic bene locata solidentur.

$260(452,18)$ quibus ad ista magistris, quibus utamur institutoribus, quorum erigamur exemplis $[\ldots]$ ?

$261(452,19)[\ldots]$ quos vidisse erudiri est. non apud eos sermo de ludicris nec pantomimorum vix ignoscenda commemoratio. illi auram popularem per pudoris detrimenta non capiunt, contenti rectis magis placere quam plurimis $[\ldots] .-(452,19)$ omnium disciplinarum materia et constantis forma sapientiae: "er verkörpert den Stoff aller Wissenszweige und ist ein Beispiel beständiger Weisheit.«

$262(452,23)[\ldots]$ domnam Barbaram, Romani flos genii, quae testimonio vultus patefaciat lucem sanguinis et saporis, in qua invenietis et verecundam securitatem et de bono actionis confidentem verecundiam, sermonem naturali et artifici simplicitate conditum [...]. 
bild dienen. Dass sein Lebensalltag als Diakon sich von dem anderer patroni / tutores unterschied, die eine Stellung innehatten, wie sie die jungen Adligen anstrebten, steht dem nicht entgegen. Denn im Zusammenhang mit dem jungen Arator, der die traditionelle sprachliche Ausbildung erhielt und auch zunächst eine weltliche Karriere einschlug, beschreibt Ennodius die Vorbildfunktion des Bischofs Laurentius von Mailand, der den Waisenjungen aufnahm und ihm die traditionelle Schulbildung zukommen ließ. In der Praefatio quando Arator auditorium ingressus est (85) spricht er davon, wie sich das ingenium des Laurentius, der sich um die Nöte aller kümmere, in der Sorge um diesen Jungen zeige: "[...] jenes ingenium des Laurentius, das den Nöten der Welt zu Hilfe kommen muss, wird zugunsten dieses kleinen Jungen eingesetzt. [...] Er, dessen Autorität mild und dessen Milde streng ist, der in der Kirche Lehrer ist, Lehrer zu Hause, Lehrer beim gemeinsamen Essen, Lehrer beim Scherz, der niemals etwas tut, das man nicht nachahmen soll, dessen bis in die letzte Kleinigkeit ausgefeilte Lebensweise seinen Schülern den Weg zum Himmel zeigt, indem er ihn geht « $(85,18 \mathrm{f}.){ }^{263}$

Die Schwierigkeit, bezüglich der einzelnen Jungen konkrete Schlüsse auf Ennodius' Rolle in deren Ausbildung zu ziehen, beruht darauf, dass es sich bei den vorhandenen Quellen überwiegend um Briefe handelt: Waren die Jungen mit Ennodius am gleichen Ort, wurden keine Briefe geschrieben, so dass uns als Quelle in diesen Fällen nur die Schulreden zur Verfügung stehen und außerdem seltene Briefe, in denen sich Ennodius gegenüber Dritten über sie äußert. So erfahren wir z.B. über Ennodius' Verhältnis zu seinem Neffen Lupicinus, der ihm offenbar anvertraut ist, aus den Briefen an dessen Mutter Euprepia wenig mehr, als dass er sich darum kümmert, dass Lupicinus unterrichtet wird; immerhin wissen wir, dass Ennodius nicht sein Lehrer war, da er ihn zu einem Lehrer schickte und für ihn ein Empfehlungsschreiben an diesen verfasste. ${ }^{264}$ Über Parthenius, einen weiteren Neffen, von dem wir zunächst nur in einer Dictio hören, mit der sich Ennodius bei dessen Lehrer für den erkennbaren Fortschritt bedankt (94, siehe dazu oben 74 ), erfahren wir etwas mehr, seit durch dessen Aufbruch zu Studien nach Rom brieflicher Austausch nötig wird (siehe unten 124). Dass Ennodius sich um die Ausbildung des Sohnes seiner Verwandten

$263(85,18 \mathrm{f}$.) [...] illud domni Laurenti quod mundi necessitatibus succurrit ingenium in ministerio huius exercetur infantuli. [...] (19) ipse est, cuius est dulcis auctoritas aut horrida dulcedo, qui magistrum in ecclesia, magistrum in domo, magistrum in convivio, magistrum inplet in iocis, qui numquam facit quod sequentes nolit imitari, cuius ad unguem polita conversatio caeleste iter discipulis, dum incedit, ostendit.

264 Siehe in einem Brief an Ennodius' Schwester Euprepia: $(84,6)$ inbuendus liberalibus disciplinis limen nobilitatis ingressus est. ipsam quoque ad te dictionem, qua commendatus est, destinavi [...]: »Als Schüler der disciplinae liberales hat er die Schwelle zum Adel betreten; ich schicke dir auch das Schreiben, mit dem ich ihn (dem Lehrer an-) empfohlen habe." 
Camella kümmert, erfahren wir nur aus dem einen Brief an Camella (431), mit dem er auf die Ankunft des Jungen bei sich reagiert (siehe oben 85); auch dieser wird, ebenso wie Parthenius und Lupicinus, nicht von Ennodius in den Artes unterrichtet worden sein, sondern den regulären Unterricht eines Lehrers besucht haben. Auch über Ambrosius, einen der Adressaten der »Paraenesis « und Empfänger einer Dictio (261), dem Ennodius drei Empfehlungsschreiben (424-426) mitgibt, als er nach Rom geht, erfahren wir wenig: Im Schreiben an Faustus betont Ennodius, dass Faustus wisse, wieviel Faustinus, der Vater des Ambrosius, von ihm, Ennodius, erwarten könne $(424,1$ quid [...] debeamus). In allen drei Briefen spricht er davon, wie bedeutend Faustinus ist; gegenüber Probinus bezeichnet er Ambrosius als seinen Verwandten, gegenüber Meribaudus als "meinen Ambrosius « ${ }^{265}$ Außerhalb dieser fünf Texte erfahren wir allerdings nichts über Ambrosius, so dass sich über Ennodius' Einsatz für dessen Bildung nichts Konkretes erschließen lässt.

Deutlich ist, dass Ennodius dafür gesorgt hat, dass diese Jungen zu einem Lehrer in den Unterricht gingen. Nicht zu sagen ist, inwieweit er weiter aktiv wurde, etwa ihre Hausaufgaben überwacht oder nachgeholfen hat. Immerhin zeigen einige Überschriften der "Dictiones Ethicae" und "Controversiae", dass Ennodius diese weder für sich allein noch für eine ganze Gruppe von Schülern verfasst hat; denn bei einigen ist angegeben, für wen sie bestimmt waren, nämlich für Ambrosius bzw. für Arator. ${ }^{266}$ Einer dieser Dictiones (380) geht eine Vorrede voraus, in der Ennodius sagt, dass er mit seiner Bearbeitung des Themas auf eine Bearbeitung durch Arator reagiere, um so den Weg zu zeigen, dem Arator folgen solle, »in dem Wissen, dass unser Triumph umso glänzender ist, wenn der Junge mir vorgezogen wird, da er von mir hat (de nostro hausit), was er, reich an Möglichkeiten, mit Gottes Unterstützung aus seinem Können verströmt hat « $(380,1){ }^{267} \mathrm{Ob}$ sich die Worte de nostro hausit auf gelegentliche Ratschläge, auf die zur Verfügung gestellten Musterlösungen oder auf intensiven Privatunterricht beziehen, lässt sich nicht klären. Auf jeden Fall schreibt Ennodius einen nicht unerheblichen Anteil zumindest an Arators Fähigkeiten zur Ausarbeitung einer Dictio seinem Einfluss, zu (mehr zu Arator unten 130).

Von einem weiteren Jungen, um dessen Ausbildung sich Ennodius kümmern soll, erfahren wir in einem Brief an Victor (430). Victor hat dem Sohn des Paulus, der in den studia liberalia ausgebildet werden sollte, ein Empfehlungsschreiben an Ennodius mitgegeben, auf das Ennodius antwortet. Er sieht zwar aufgrund der Qualität des Empfehlungsschreibens keine Notwendigkeit, dass der Junge in der Fremde

$265(424,2)$ tanti viri; $(425,1)$ fortis; $(425,2)$ sanguis eius, $[\ldots]$ prudentia, $[\ldots]$ census; $(426,3)[\ldots]$ vitae auctoritas armat et generis. - $(425,2)$ Ambrosium nostrum; $(426,2)$ propinquos insinuo.

266 (239) In eum qui seni patri cibos subtraxit, data Aratori. (243) In tyrannum qui [...], data Aratori v. c. (261) Dictio data Ambrosio, in aleatorem qui [...].

$267(380,1)[\ldots]$ sed quem verborum callem sequi debeat demonstrantes, scimus in illo nobis clarius, si eum praeferri contigerit, triumphandum, qui de nostro hausit quicquid deo amplificante de scientia opum largus effuderit. 
unterrichtet wird: "Wenn derjenige, der einen Jungen zum Lehrer schickt, lobenswert spricht, braucht es (eigentlich) keine weit entfernten Lehrer. Es ist mir peinlich, dass der Junge weniger vorgefunden hat, als er mitbrachte [... «. Doch Ennodius verspricht, sein Möglichstes zu tun (430,1f.). ${ }^{268}$ Angesichts der in diesem Kapitel betrachteten Passagen muss man das verwendete Vokabular (magistris; docentem) nicht so verstehen, dass Ennodius selbst regelrecht als Lehrer des Jungen fungieren sollte. Wahrscheinlich hat Victor Ennodius gebeten, sich als patronus bzw. als einer von mehreren patroni um den Jungen zu kümmern und ihn durch sein gutes Vorbild zum Eifer bei den Studien zu ermahnen.

\section{d. 3 Unterweisung per Brief}

In diesem Bildungsbetrieb, der nicht nur durch Lehrer, die zu bestimmten Zeiten ihren Unterricht abhalten, sondern auch durch das allgegenwärtige Beispiel von patroni bestimmt ist, spielen auch Briefe eine wichtige Rolle. Die Korrespondenz mit Ennodius ist für die Heranwachsenden nicht nur das Mittel, Kontakt zu halten, sondern gibt ihnen insbesondere die Möglichkeit, ihre Fortschritte im sprachlichen Ausdruck zu zeigen. Daher verbindet Ennodius seine häufigen Forderungen nach reger Korrespondenz (dazu ausführlich unten in Teil II) eng mit dem Aspekt der Bildung seiner jungen Korrespondenten. So fordert er den jungen Avienus auf, ihm zu schreiben, "seine Bildung zu schwingen, um seine Freundschaft zu zeigen" $(376,1$ doctrinam pro diligentiae testimonio ventilare); Arator soll etwas über die Hochzeit des Maximus schreiben, "sie preisen, um Dein Talent zur Schau zu stellen " $(387,3$ pro ingenii tui ostentatione laudare). Es geht also nicht nur um den Inhalt der Briefe (siehe auch oben 105), sondern auch, wenn nicht gar in erster Linie, um die sprachliche Gestaltung. Auch sind die Briefe nicht immer nur für den ersten Adressaten bestimmt: In einem Brief an Johannes (15), in dem er dessen Stil lobt und kritisiert (siehe unten 119), erwähnt er, dass er die Briefe des Johannes auch anderen zeigen werde, damit diese anmerken könnten, was er, Ennodius, übersehen habe. ${ }^{269}$ Die jungen Adressaten werden sich über Ennodius' Briefe nicht immer nur gefreut haben, denn er ist sehr streng und kritisch, und Lob setzt er äußerst sparsam und sehr gezielt ein.

$268(430,1 \mathrm{f}$.) nihil longe degentibus magistris opus est, quando digna laude loquitur qui dirigit ad docentem. erubesco insinuatum minus invenisse quam detulit [...].

$269(15,6)$ scito epistulas tuas nulli doctorum a me esse denegandas, ut quod me per inscitiam fugerit per eos, qui ad unguem docti sunt, emendetur: "Du kannst sicher sein, dass ich Deine Briefe keinem Gebildeten vorenthalten werde, so dass das, was mir aus Unkenntnis entgangen ist, von denen, die in höchstem Grade gebildet sind, korrigiert wird.» 


\section{Strenge Mahnungen}

Gegenüber seinen jungen Korrespondenten lässt Ennodius ganz überwiegend Strenge walten und geht mit Lob sehr sparsam um. Seine Neigung zu Ermahnungen bzw. Tadel erwähnt Ennodius selbst: In einer Schulrede thematisiert er seine Strenge: „Erwartet von mir nicht süße Worte, sondern die nötigen, nicht liebliche, sondern kraftvolle. [...] Die Rede eines Mahners muss mit Gewicht versehen sein; wer möchte, dass man auf seine Ermahnungen hört, der muss eine Waage verwenden <sc. und gewichtige Worte wählen>« $(3,9) .{ }^{270}$ Ennodius weist mehrfach explizit darauf hin, dass er lieber gegenüber Dritten lobe als direkt ins Angesicht, z.B. in (15,2) siehe unten 119 , in $(173,2)$ u. 307 , in $(249,2)$ u. 270 . Ganz überwiegend hält sich Ennodius an diese Regel, zumindest gegenüber jüngeren Adressaten. (Wie und in welchen Zusammenhängen er andere lobt, die nicht mehr in der Ausbildung stehen, ist weiter unten zu betrachten, siehe 265). Selbst wenn die jungen Adligen Ennodius etwas zu lesen senden, lobt er selten. Seine Strenge zeigt er besonders dadurch, dass er kritisiert, wo andere loben; in einem Brief an seinen Neffen Parthenius (290) findet Ennodius viele freundliche Worte (besonders im Vergleich mit dem vorangehenden Brief an ihn, 258), die aber bald in Kritik übergehen (siehe unten 126). In dem seltenen Fall eines Lobes wird daran unweigerlich eine weitergehende Erwartung geknüpft und deutlich gemacht, dass das Ende der Bemühungen noch lange nicht erreicht sei. Häufig weist Ennodius darauf hin, dass es sich bei dem erfreulichen Fortschritt erst um den Anfang handle, so als hätte er Angst, dass der Gelobte aufhören werde sich anzustrengen, z.B. zu Johannes: »Auch wenn Du in der vollen Blüte der Redekunst Großes versprichst, so werde ich mich doch erst über die Ernte freuen « $(15,4){ }^{271}$

Seine Strenge und Zurückhaltung mit Lob zeigt sich z.B. in folgenden Beispielen aus Briefen an Johannes (15), Messala (377; 434) und Beatus (428). Johannes gegenüber bezeichnet er es gar als »Übel der Zeit " (vitia temporis), überschäumendes Lob $\mathrm{zu}$ verteilen (laudes inexhausta praedicatione reserare, 15,2). In diesem Brief an einen Johannes (15), der zuvor ihn gelobt hatte, lehnt er es ausdrücklich ab, seinerseits mit einem Lob zu antworten: Wechselseitig gespendetes Lob gehe zu Lasten der Freundschaft, denn leicht könne der Eindruck aufkommen, man schmeichle, um seinerseits gelobt zu werden. Seine Gedanken über den Fortschritt des Johannes müsse er taktvoll für sich behalten. ${ }^{272}$ Einem Freund schulde er keine einschmeichelnde Rede $\left(\$_{3}\right.$ delenificam orationem), keine Täuschung durch kunstvolle Worte (non tibi pictis verborum inludens artificiis), vielmehr korrigierende Worte (vocem [...] castigantis). In

$270(3,9)$ quaerite apud me non blanda sed necessaria, non deliciosa sed fortia. [...] ponderibus ornetur dictio castigantis, lancem in exhortatione teneat qui gestit audiri.

$271(15,4)$ sint licet grandia, quae in cano eloquentiae flore polliceris, ego tamen nisi de messe non gratulor. - Siehe auch $(4,6)$ deum precor, ut adulescentia in te, quae perfectionem primordiis monstrant, bonae frugis germina convalescant. $(331,1)$ adulescentiae tuae rudimenta solidentur [...]. Siehe auch in 242 , unten 346.

$272(15,2)$ in his, quae de profectu tuo sentio, religiosam tibi tantum debeo taciturnitatem. 
einer Praeteritio folgt zwar ein mögliches Lob (possem dicere [...]), das aber tatsächlich in Ermahnungen übergeht $\left(\$_{4}-6\right.$, z.B. 5 pulchra sunt quae scribis, sed ego amo plus fortia). Seine wahre Freundschaft könne Johannes an der aufrichtigen Ermahnung erkennen (\$5 amorem meum in admonitionis fide perpende).

Faustus' Sohn Messala wird zum Schreiben aufgefordert; Ennodius erinnert daran, dass Messala ihm zuvor einmal geschrieben und ihm dictiones gesandt habe, »in denen zwar die wünschenswerte Erhabenheit fehlte, doch immerhin fand sich auch nichts Unwürdiges und Verächtliches « $(377,2) .{ }^{273}$ Ennodius habe sich von weiteren Schreiben Fortschritte versprochen, doch Messala habe die Korrespondenz gleichzeitig begonnen und beendet; Messala solle täglich bedenken, wessen Sohn er sei (sc. des Faustus); doch er wolle nicht harte Worte in die Länge ziehen; Messala solle durch häufiges Schreiben zeigen, dass die Worte des Ennodius ihn auf den Weg der Besserung geführt hätten $(377,2 f$.). Nach einer weiteren Aufforderung (385) schreibt Messala zunächst einen Brief an den kranken Ennodius (worauf dieser mit 421 antwortet) und dann einen weiteren mit einer dictio, worauf Ennodius mit (434) reagiert: Wenn Messala seine seltenen Briefe mit glänzenden dictiones verbinde, könne Ennodius über die Seltenheit hinwegsehen. Er habe sie nicht ohne Freudentränen lesen können $(434,1)$, doch er wolle nicht mit aufdringlichen Worten ausführen, was er über Messala denke. Statt eines Lobes folgen weitere Ermahnungen: "Bemühe Dich, das, was Du - denn Du hast die Fähigkeit dazu geerbt - an Gedanken findest, mit der Redekunst gut darzustellen«. Messala stehe seinem Vater Faustus und seinem Bruder Avienus in nichts nach, außer wenn er sich selbst schade $(\$ 2) .{ }^{274}$

Beatus, für den Ennodius bei dessen Aufbruch nach Rom zwei Empfehlungsschreiben verfasst hat (416f.), erhält einen Brief voller Vorwürfe und Ermahnungen, weil er nicht schreibt: "Wenn Du von der Ernte Deiner Bildung im Speicher Deines Herzens etwas gespeichert hättest, um zuweilen etwas hervorzuholen, würden die Hände der Reisenden nicht ohne Briefe von Dir ankommen. Doch da Dein NichtSchreiben Deine Nachlässigkeit und Deine Unfähigkeit zeigt, muss ich mich notwendigerweise wieder daran machen, mich um Ermahnungen zu kümmern, Samen zu streuen und den unfruchtbaren Boden durch erneutes Pfügen zur Fülle zu bringen $[\ldots] \ll(428,1) .{ }^{275}$ Der Brief endet mit dem Hinweis, dass auch der Vater des Adressaten informiert worden ist.

$273(377,2)$ destinasti mihi dictiones tuas, in quibus etsi non fuit optanda sublimitas, non tamen deprehensa est quae sorderet abiectio.

$274(434,2)$ labora ut, quod suggerente in sensibus vena invenis, conponas eloquentia.

$275(428,1)$ Si proferenda temporibus de eruditionis messe pectoris horreo condidisses, ieiunae ab epistolis tuis commeantium dexterae non venirent. sed quia neglegentiam et sterilitatem tuam sermonis prodit abstinentia, nos necesse est iterum ad culturam admonitionis adsurgere et terga iactis infecunda seminibus recidivis ad ubertatem sulcis urguere. 


\section{Lob aus Rücksicht}

Nur selten überwiegen die lobenden Töne, wenn Ennodius sich über die Briefe oder dictiones seiner jungen Korrespondenten äußert; manchmal ist erkennbar, dass seine Freundlichkeit mit seiner Rücksicht auf andere Leser als den angesprochenen Adressaten zu erklären ist: Im Brief an einen Johannes ${ }^{276}$ (4) ist deutlich zu spüren, dass Ennodius ihn nicht nur für den ausdrücklichen Adressaten schreibt: Zunächst wird die Sprachkunst des Johannes beschrieben (\$1f.). Ennodius bedankt sich dafür, dass Johannes ihn gelobt habe, wenn er sich auch in dessen lobenden Worten nicht wiedererkenne $(\$ 3)$. Johannes habe mit dem Glanz seiner Sprache den Glanz seiner Familie übertroffen $(\$ 4)$. Ennodius führt diesen Erfolg des Johannes auf dessen Schwiegervater Olybrius zurück (\$5); er habe nie geglaubt, dass jemand an die Fähigkeiten des Olybrius werde heranreichen können, doch Johannes sei kurz davor (\$5). Er bitte Gott, dass er die guten Anfänge, die Johannes zeige, zu einem guten Ergebnis führen möge. Johannes habe gute Vorbilder zu Hause, und zwar seinen Vater hinsichtlich des ruhigen Charakters, Olybrius hinsichtlich der Redekunst (\$6). Johannes solle Ennodius nicht vergessen und Olybrius, dessen Sprachkunst er nachahme, nicht auch hinsichtlich des Vergessens nachahmen, das dieser gegenüber Ennodius zeige. - In diesem Brief überwiegen in auffälliger Weise neben Ermahnungen die freundlichen Töne. Es geht wohl nicht zu weit, wenn man Ennodius die Erwartung unterstellt, dass nicht nur Johannes, sondern auch dessen Schwiegervater Olybrius diesen Brief lesen werde. Denn das Lob für Johannes bedeutet ein umso größeres Lob für seinen Schwiegervater: Olybrius, dessen eloquentia unübertrefflich scheint, hat guten Einfluss auf Johannes. Johannes soll Olybrius in allem nachahmen - nur nicht in seinem brieflichen Schweigen gegenüber Ennodius. Olybrius scheint diese indirekte Aufforderung zum Schreiben verstanden zu haben, denn mit (13) kann Ennodius auf einen Brief von diesem antworten.

Sehr freundlich ist z.B. auch der einzige Brief an Marcianus (175); dieser ist der Sohn der Stefania, einer Schwester des Faustus (die später auch selbst drei Briefe erhält), und des bereits verstorbenen Asterius (cf. \$2; 394,3). Ennodius lobt einen Brief, den er von Marcianus erhalten hat und in dem dieser seine Fortschritte gezeigt habe (175,1 solida profectus tui indicia conloquii melle reserasti); er betont ausführlich, dass Marcianus ein würdiger Erbe seines Vaters sei (z.B. \$1 fidelis doctrinae heres). Der

276 Dieser scheint nicht mit dem gleichnamigen Adressaten des Briefes (15) mit einem ganz ähnlichen Thema (siehe oben 119) identisch zu sein, denn in (15) wird nur der Vater erwähnt $(15,6)$, in (4) hingegen sind Vater und Schwiegervater genannt, wobei das Gewicht auf dem Schwiegervater Olybrius liegt. Nur in (15) weist Ennodius auf eine relativ enge Bezehung zum Adressaten hin: $(15,1)$ inter familiares paginas; $(15,4)$ ore te parentis stimulo. Außerdem erscheinen das Thema und dessen Behandlung (Reaktion auf ein Lob) in beiden Briefen zu ähnlich, um an denselben Adressaten gerichtet zu sein; wenn (15) an denselben Adressaten gerichtet wäre, hieße dies, dass dieser nach dem Erhalt von (4) erneut ein Lob auf Ennodius geschrieben hätte. 
Brief wird so ebenso zu einem Nachruf auf den Vater wie zu einem Lob für den Sohn. Ennodius will hier offenbar weniger die Fähigkeiten des Marcianus kommentieren als vielmehr an den verstorbenen Vater erinnern; er rechnet daher sicher damit, dass auch Stefania diesen Brief lesen wird. Die Aufforderungen zu weiteren Studien fallen sanft und recht kurz aus: »[...] widme Dich intensiv diesen edlen Dingen; mögen Dich die Studien ganz aufnehmen; beeile dich, eine Ernte wie Dein Vater zu erlangen, indem Du Deine Sprache mit der Hacke der Lektüre und Dein Wesen und Benehmen durch die Nachahmung der Guten reinigst « $(\$ 4){ }^{277}$

\section{Ermahnungen und Lob für Avienus}

Wie Ennodius sein Lob verteilt, lässt sich gut daran beobachten, wem gegenüber und in welchen Situationen er sich über Faustus' Sohn Avienus äußert: Er lobt ihn sehr gegenüber Dritten (z.B. in dem an Faustus gerichteten Glückwunschschreiben anlässlich von Avienus' Konsulat, siehe unten 349), aber nur selten direkt; direktes Lob findet sich zumeist in Verbindung mit Ermahnungen oder nachträglich.

Mit dem Brief (23) antwortet Ennodius auf einen Brief von Avienus, den er zuvor in Brief (17) zum Schreiben aufgefordert hat. Wie in den gerade dargestellten Briefen an Johannes und Marcianus scheint das Lob für den Adressaten hier letztlich auf dessen Vater zu zielen. In diesem Brief mit vielen Bildern und literarischen Anspielungen lobt Ennodius einerseits den erhaltenen Brief, andererseits formuliert er weitere Ermahnungen und legt seinen schon im vorigen Brief benannten Standpunkt noch einmal dar. Dabei wird das Thema der edlen Abstammung besonders ausgemalt. - Zunächst lobt Ennodius den Brief des Avienus, indem er hervorhebt, dass dessen Worte, mit denen er über seine vermeintlich unzureichenden Fähigkeiten spreche und das Vorbild des Vaters als unerreichbar bezeichne, ihrem Inhalt widersprechen und vielmehr Avienus' Können zeigen (\$1). Avienus solle sich nicht vor den hohen Erwartungen, die wegen seines Vaters an ihn gerichtet werden, fürchten, denn er profitiere ja von der Kunst seines Vaters. Als Parallelen zu der Weitergabe von Fähigkeiten vom Vater auf den Sohn bringt Ennodius verschiedene Beispiele aus der Natur ${ }^{278}$, und er bezieht sich auf Aeneas, der seinen Sohn auffordert, von ihm zu lernen. Es fällt auf, dass Ennodius zwar im vorangehenden Brief ausgemalt hat, welche dulcedo $(17,3)$ ein Brief von Avienus für ihn bedeuten würde, er jetzt aber, anstatt die Süße des schließlich erhaltenen Briefes zu beschreiben, viel stärker in der Rolle des Mahners spricht als in dem ersten Brief, mit dem er zum Schreiben auffordern wollte.

$277(175,4)[\ldots]$ ad haec decora multus incumbe, totum te studia honesta suscipiant, festina ut ad messem patriam venias, linguam lectionis sarculo, mores bonorum imitatione purgando.

278 Über das Verhalten von Adlern gegenüber ihrem Nachwuchs $(\$ 4)$ könnte Ennodius bei Lukan oder bei Claudian gelesen haben, cf. Lucan. 9,902 ff. und Claudian in einer Praefatio zu einem Panegyricus (carm. 6 Hall, 52 ff.). Das Adler-Thema verwendet Ennodius noch einmal in 451. 
Faustus gegenüber (44) lobt Ennodius voller Begeisterung eine von Avienus verfasste dictio, allerdings auf eine Weise, dass nicht zuletzt Faustus gelobt wird: »Ich sage die Wahrheit mit der göttlichen Milde als Zeugin: wenn es in Ligurien Menschen gibt, die über echten Glanz in der Sprachkunst urteilen können: sie haben geglaubt, Ihr hättet an dieser dictio gearbeitet, die der in dem Jungen schon reife Verstand ohne Rücksicht auf sein Alter ausgearbeitet hat « $\left(\$_{3}\right){ }^{279}$

Avienus gegenüber lobt Ennodius dessen Briefe im Rückblick: »Lange haben Briefe von Eurer Hoheit meine Seele genährt und Nahrung geboten, die zu Fröhlichkeit passte. Deren jetziges Ausbleiben macht mich nicht traurig, sondern bringt mich fast um. Denn das, was früher der Freundschaft diente, hätte jetzt meinem Wohlergehen helfen können. Die treue Pflege der Freundschaft wird abgelehnt, wenn Worte, die meinem Wohlergehen nützen würden, verweigert werden « $(299,2) .{ }^{280}$ - So hat Ennodius früher mit Faustus gesprochen (siehe z.B. 6,7: mihi non tam delicias verba vestra pariunt quam salutem); in solchen klagenden Briefen entsteht zunehmend der Eindruck, dass Avienus nicht mehr der zu erziehende ist, sondern allmählich ernst genommen und als gleichberechtigt betrachtet wird.

Einmal äußert Ennodius seine Dankbarkeit für einen erhaltenen Brief sofort in seiner Antwort (314). Avienus hat einen Trostbrief geschickt, und der Antwort darauf lässt sich entnehmen, dass Ennodius verzweifelt ist, weil ihm jemand anders vorgezogen wurde. Dies wird in der Forschung auf die Bischofswahl nach dem Tod des Laurentius und die Wahl seines Nachfolgers Eustorgius bezogen (SundWalL 1919, 51f.), was plausibel scheint. Konkreter als in diesem Brief wird Ennodius nie; dass es einen Bischof namens Eustorgius gibt, geht lediglich aus einem Epigramm hervor (379). Zunächst äußert sich Ennodius kurz zum Stil des erhaltenen Briefes, was er recht selten tut; Avienus' Briefstil, der dem seiner declamationes entspreche, zeuge von seiner Begabung und seinem Fleiß: »[...] und Eure Sprache bewahrt genau die Besonderheiten Eurer Deklamationen. Das habt Ihr von Natur aus, das habt Ihr von der Mutter der Erfahrung, d.h. der unermüdlichen Lektüre« $(\$ 1) .{ }^{281}$ Aber Avienus’ Brief könne sein Ziel nicht erreichen, da sich Ennodius in dieser Situation nicht trösten lässt: "Doch für mein Unglück kann es keinen Trost geben, da ich vor Augen habe, was ich verdient hätte; und je unverdienter jemand vorgezogen wurde, umso deutlicher

$279(44,3)$ verum dico teste divina clementia: si sunt aliqui in Liguria, qui de litterarum possint genio et splendore iudicare, vos crediderunt in illa dictione laborasse, quam aetati praeiudicans canus iam in puero sensus excoluit.

$280(299,2)$ Paverunt diu animum meum a magnitudine vestra destinata colloquia et hilaritati congrua pabula praestiterunt. quorum nunc abstinentia non adfert tristitiam, sed cogit ad exitium. potuit enim saluti opem tribuere, quod ante militavit affectui. abiurata est caritatis religio, quando profutura meae valitudini verba denegantur.

$281(314,1)[\ldots]$ nec aliud est loqui vestrum nisi declamationum insignia custodire: hoc in vobis natura, hoc peritiae mater indeficiens lectionis cura congessit. 
zeigen sich die Schwächen des Übergangenen « $(\$ 1){ }^{282}$ Ungewöhnlich wie der lobende Anfang ist der Abschluss, in dem sich Ennodius für die durch den Brief gezeigte Freundschaft bedankt, während er sonst häufig über das Fehlen von Freundschaftsbeweisen klagt: "Ich kann Euch also nur ungenügend danken, dass Ihr die Freundschaft zu mir bewahrt, wie Ihr sie auch den Würdigsten nicht reicher erweisen würdet. Mein Herr, ich grüße herzlich und hoffe, dass Ihr nicht aufhört, für mich zu beten und zum Trost für mein Unglück hilfebringende Briefe schickt« $(\$ 2){ }^{283}$

Als gutes Beispiel nennt Ennodius Avienus in einem Brief an dessen Bruder Messala (434, siehe oben 120). - Auch gegenüber dem Presbyter Adeodatus (460) ist Ennodius wieder voller Lob für Avienus: Den einzigen Trost dafür, dass Avienus nun in Rom sei, finde er darin, dass Avienus zwar aus Rom stamme, aber in Ligurien - d.h. nicht zuletzt unter dem Einfluss des Ennodius - seine ausgezeichnete Bildung erhalten habe, wofür der Dank Gott gebühre: "Rom kann sich seiner Herkunft rühmen, Ligurien seines Fortschritts; dort ist er Domnus Faustus durch das Gesetz der Natur als Sohn gegeben worden, hier hat er sich durch seine Bildung als sein Sohn gezeigt. Es war weniger, wie alle als ein Mensch geboren zu werden, als - was unnachahmbar schien - als Sohn des Faustus bestätigt zu werden. [...]« $(460,3) .{ }^{284}$ (Zum Schreiben anlässlich von Avienus' Hochzeit, 459, siehe unten 343).

\section{Briefe an Parthenius}

Ennodius' Neffe Parthenius, ${ }^{285}$ für dessen Fortschritte sich Ennodius mit einer dictio beim Lehrer bedankt hat (94, siehe oben 74 ), hält sich später zu Studienzwecken in Rom auf; Ennodius hat ihn dafür mit Empfehlungsbriefen ausgestattet (siehe oben 113). Die vier Briefe an Parthenius in Rom $(247,258,290,369)$ sind gute Beispiele sowohl für die Strenge von Ennodius' Ermahnungen (wobei er erwähnt, dass er bekannt sei wegen seiner lex parcendi, 258,4) als auch für seine Freude über die Fortschritte des Neffen. Ennodius spricht auch hier über die Funktion von Briefen: Parthenius solle durch die sprachliche Gestaltung seiner Briefe zeigen, dass bzw. wie er sich entwickelt. Andere 'praktische` Ratschläge nehmen geringen Raum ein: Einmal wird Parthenius ermahnt, die richtige Gesellschaft zu suchen und schlechten Umgang zu meiden (290,3, siehe unten).

$282(314,1)$ sed miseriis meis evenire nulla consolatio potest, quando ante oculos sunt locata quae merui, et quantum praelatus indignior extiterit, tantum in aperto fiunt peccata superati. [...]

$283(314,2)$ vobis tamen insufficientes refero gratias, qui illam circa me servatis diligentiam, qua potiorem nec dignissimis praestaretis. domine mi, salutationis reverentiam solvens spero, $u t$ orare pro me minime desistatis et ad calamitatum solacia ferentia opem scripta mittantur.

$284(460,3)$ habet de origine eius Roma iactantiam, Liguria de profectu: ibi domno Fausto filius naturae lege concessus est, hic eruditione patefactus. minus fuit cum generalitate hominem nasci quam, quod inimitabile videbatur, Fausti subolem conprobari.

$285 \mathrm{Zu}$ Parthenius siehe: Bureau 1998. 
Im ersten, sehr kurzen Brief (247) beklagt sich Ennodius, dass Parthenius nicht schreibe. Hier wird sehr deutlich, dass es in den Briefen des Parthenius nicht nur um den Inhalt geht (etwa, ob es ihm gutgehe und ob es ihm in Rom gefalle), sondern ganz besonders um die sprachliche Gestaltung, durch die er zeigen soll, dass er Fortschritte macht. Ennodius beginnt mit strengen Vorwürfen: "Ich wundere mich nicht, dass Du nicht schreibst; denn wer nur einen winzigen Vorrat angelegt hat, kann nichts hervorholen. Glaubst $\mathrm{Du}$, dass auf diese Weise der wahre Zustand Deines Fortschritts verborgen bleiben könne? Schweigen verrät Unfähigkeit, ebenso wie ungeformtes Reden Sprachlosigkeit offenbart «. Immerhin habe sich Parthenius früher besser verhalten, aber nur so lange, bis es ihm erlaubt worden sei, nach Rom zu gehen $(\$ 1)$. "Zum Schluss: Leb wohl, nimm die Worte des Mahners an und zeige durch häufiges Schreiben, dass Du Dich gebessert hast« $(\$ 2){ }^{286}$

Dass Parthenius auf diesen Brief mit Bitten um Verzeihung geantwortet hat, geht aus dem nächsten Brief an ihn hervor (258), denn Ennodius hält ihm seine übertriebene Unterwürfigkeit vor (zu seiner Ablehnung von übermäßiger humilitas siehe auch unten 187): Parthenius solle seine Situation bedenken und einsehen, dass es ihm gar nicht freistehe, Ennodius nicht zu gehorchen. Nachdem Parthenius also endlich geschrieben hat, ist sein Brief Grund für neue Vorhaltungen. Ennodius betont eingangs, dass nur seine Liebe zu Parthenius ihn davon abhalte, sich über dessen geheuchelte Demut - eine Haltung, die er ablehne - aufzuregen: "Wenn ich Dich nicht von Herzen lieben würde und die Beständigkeit meiner treuen Liebe nicht unabänderlich fest verwurzelt wäre, könnte ich mich über den Kummer wegen des Unrechts aufregen und mich darüber ärgern, wenn Du entweder in kindischer Weise zornig bist oder in anmaßender Weise bittest. ${ }^{287}$ Denn ich kann mir nichts denken, das hochmütiger wäre als künstliche Demut. Ich ziehe Kränkungen dem Gehorsam einer verstellten Miene vor: geheuchelte Süße ist das denkbar Bitterste« $(\$ 1){ }^{288}$ Mit unerbittlich harten Worten macht Ennodius deutlich, dass Parthenius von ihm ab-

$286(247,1)$ Non in te admiror sermonis abstinentiam, quia qui exigua condiderit nil producit. credis sub hac occasione profectus tui latere substantiam? et taciturnitas inperitiam prodit et infabricata confabulatio manifestat infantiam. [...] (\$2) quod restat, vale et accipiens monitoris verba melioratum te scriptionis adsiduitate divulga.

287 Sundwall (42) nimmt an, dass Parthenius sich über den Brief des Ennodius aufgebracht gezeigt habe (irasci); doch im folgenden geht es um die zweite Alternative (supplicas); auch später spricht Ennodius von Parthenius' humilitas: $(369,2)[\ldots]$ primoribus litteris veniam fabricata humilitate poposceras, siehe unten zu 369. Vielleicht hat Parthenius auch in zwei Teilen seines Schreibens unterschiedlich reagiert, siehe unten zum Abschluss des Briefes.

$288(258,1)$ nisi te efflictim diligerem et pii amoris soliditas indemutabili radice constaret, possem iniuriarum dolore provocatus, vel cum pueriliter irasceris vel cum adroganter supplicas, commoveri. nihil enim invenio, quod sit fabricata humilitate superbius. praefero contumelias fucatae frontis obsequiis: transit amaritudinem dulcedo simulata. 
hängig ist: "Bitten sind unnötig, wenn Du weißt, welche Kette Dich bindet. Diejenigen mögen für ihre Vergehen um Verzeihung bitten, denen es freisteht, nicht zu gehorchen. Die strahlende Entscheidung des Himmels hat uns Sklaven zugeteilt, damit sie sich zwangsläufig dahin wenden, wohin immer unser Sinn sich richtet. [...] Die mir von Gott erteilte Gewalt wird nicht dulden, dass Du weit von dieser Ordnung abweichst« (\$2). ${ }^{289}$ Parthenius solle sich also vorsehen und sich so verhalten, dass er eine Strafe vermeiden könne: "Du musst hoffen, dass nicht berechtigte Gedanken an Deine Taten die Milde, die Du an mir lobst, entstellen und dass nicht die Menge Deiner Fehler den Weg der Milde entwertet." $(\$ 3) .{ }^{290}$ Die einzige Möglichkeit, einer Strafe zu entgehen, besteht darin, zu arbeiten und die erworbenen Fähigkeiten zu zeigen: »Nun kannst Du auf eine Weise die durch die ungemäßigten Reden zugefügten Wunden verheilen lassen: wenn Deine Bildung Dich auf den Gipfeln der studia liberalia als adlig aufweist. Ohne die Unterstützung von Wissen wirst Du keine Verzeihung erlangen. Einem Faulen gegenüber werde ich den Grundsatz der Schonung, für den ich bekannt bin, aufgeben und ewig Strenge bewahren.« Im letzten Satz liest man dann unerwartet fast ein Lob, denn Parthenius hat offenbar Verse gesandt, die zu einiger Hoffung berechtigen: "Abschließend bitte ich Gott, dass es Dir gutgeht und dass Du mit begleitender Hilfe des Himmels die Erwartungen, die Du mit Deinen Versen geweckt hast, vermehren mögest " $(\$ 4){ }^{291}$ Vielleicht hat sich Parthenius zweifach geäußert hat, zum einen demütig bittend im Brief und zum anderen aufgebracht (cf. \$1 cum pueriliter irasceris) in den Versen, doch man kommt über Vermutungen nicht hinaus.

Zusammen mit seinem nächsten Brief schickt Parthenius eine dictio, und er erhält darauf eine freundlichere Antwort (290). Ennodius ist zwar noch nicht ganz zufrieden, doch er beginnt den Brief zunächst voller Lob, um es dann allerdings wieder einzuschränken. Zunächst das für Ennodius' Verhältnisse große Lob: »Mein Lieber, mögen sich mit Gottes Hilfe Deine ersten Erfolge fortsetzen! Möge derjenige unsere gemeinsamen Wünsche unterstützen, der den studia Kraft gibt. Du hast durch Dein glänzendes Schreiben gezeigt, dass Du die Stadt, die die Freundin der freien Studien ist, schon gut kennst. Du hast am Beginn das vorausgeschickt, was die gierigen

$289(258,2)$ non opus est deprecationibus, si quae te catena nectat intelligis. poscant pro excessibus veniam, quibus est liberum non parere. ita famulos nobis iudicii caelestis claritudo deputavit, ut in quacumque mens parte deflexerit, illorum necessitas inclinetur. [...] haud procul te ab hoc ordine evagari potestas mihi a deo adtributa patietur.

$290(258,3)$ optare te convenit, ne mansuetudinem, quam in me praedicas, meritorum tuorum consideratio iusta devenustet et pietatis tramitem culparum multitudo depretiet. [...]

$291(258,4)$ nunc uno modo in cicatricem cogere vulnera intemperatis sermonibus ingesta praevalebis, si te per culmina liberalis studii ingenuum doctrina monstraverit. veniam nisi peritia suffragante non exiges. mutata, qua notus sum, lege parcendi circa desidem saevitiam sub perennitate servabo. quod restat, deum precor, ut valeas et de versibus tuis caelesti favore comitatus spem augeas quam dedisti. 
Wünsche der Eltern übertrifft « $(\$ 1) .{ }^{292}$ Dann schränkt Ennodius dieses Lob ein, indem er sich dafür >rechtfertigt : Da Parthenius noch am Anfang stehe, urteile er nicht streng und er hoffe zuversichtlich auf weitere Fortschritte; zur Begründung dieses Verhaltens bringt er ein Bild aus der Landwirtschaft: »Ich bin kein strenger Richter Deines Textes, und ich finde es nicht schlimm, dass er noch nicht sehr stark ist, denn das, was darauf folgen wird, gefällt mir. Sooft man mit Pflügen die Erde zeichnet, erhebt sich die Seele in der Hoffnung auf die künftige Frucht [...].« (\$1f.). ${ }^{293}$ Ennodius ist noch nicht zufrieden: "Wenn auch Deine kleine Rede nicht ganz mit glänzender Redekunst durchgestaltet ist, so schimmerte in ihr doch die Feinheit lateinischer Beredsamkeit durch; der Redefluss war nicht ungefällig, muss aber durch Lektürefrüchte bereichert werden « $(\$ 2) .{ }^{294}$ Lässt sich schon hier vermuten, dass Parthenius über diese Reaktion nicht sehr erfreut gewesen sein wird, so kann man dessen sicher sein, wenn aus dem Folgenden hervorgeht, dass er in Rom für seine dictio bereits von einem (für uns namenlosen) iudex gelobt worden ist: "Doch was habe ich da nach einem solchen Richter, dessen Ohren, wie Du sagst, die Gestaltung Deines Werkes gefallen hat, gezetert - wie eine Gans nach einem Schwan? Wer bei ihm Gefallen gefunden hat, kann sich gefahrlos einer Prüfung stellen. Beredsamkeit, die er gelobt hat, kann sogar von Gegnern Anerkennung einfordern « $(\$ 3) .{ }^{295} \mathrm{Ganz}$ überdecken kann Ennodius seine vorangehende Kritik so allerdings nicht. Ermahnungen, sich in der richtigen Gesellschaft zu bewegen und fleißig zu schreiben, schließen den Brief ab: »Bemühe Dich also, dass ein guter Fortgang das Begonnene steigert; widme Dich unablässig dem Umgang mit ehrenhaften Leuten; diejenigen, deren Gesellschaft Verderben bringt, - und Du schuldest meinen Mahnungen Respekt - meide wie einen Giftbecher. Berichte in Briefen immer demjenigen von Deinen Fortschritten, der es wissen möchte. Abschließend: Leb wohl, und entsprich in der Ernte der Bildung mit aller Hilfe der himmlischen Gunst Deiner Familie» $(\$ 3 f.) .{ }^{296}$

$292(290,1)$ deo auspice dilectionis tuae primordia convalescant. adsit desideriis communibus, per quem vires studia sortiuntur. declarasti te scriptionis luce urbem amicam liberalibus studiis iam tenere: praemisisti in foribus, quod avara parentum vota superaret.

293 (290,1f.) non sum dictionis tuae rigidus aestimator nec respuo tenuitatem praesentium, cui secutura blandiuntur. (\$2) quotiens vomeribus terram scribimus, animus de spe venturae frugis elevatur. [...]

$294(290,2)$ ductus mihi oratiunculae tuae etsi eloquentiae nitore non subsistit, Latiaris tamen venae sapore radiavit. fluxit sermo non absonus, lectionis tamen opibus ampliandus.

$295(290,3)$ sed quid ego post tantum iudicem, cuius auribus operis tui concinnationem placere signasti, quasi post olores anser strepui? illi quicumque placuit, examen securus ingreditur; facundia ab illo praedicata praevalet favorem etiam ab inimicis exigere.

$296(290,3$ f.) labora ergo, ut felix bene coepta eventus extollat, honestorum te obsequiis indesinenter inpende: eos qui consortio [VoGELs Ergänzung "se« scheint mir überflüssig] suo polluunt, debens monitis nostris reverentiam velut veneni poculum fuge: profectum tuum paginis scire cupido semper adnuntia. quod superest, vale et omnibus superni favoris iutus auxiliis familiae tuae de peritiae messe responde. 
Später gibt Parthenius wieder Anlass zu Klagen. Da Faustus eine Weile nicht vor Ort war, hat er in seinen Studien nachgelassen; Ennodius bittet Faustus (368), mit all seiner Autorität einzugreifen (siehe oben 114), und er schreibt auch an Parthenius selbst (369). Der Ton in diesem Brief schwankt zwischen strengen Worten und der Zusicherung von Zuneigung und Unterstützung. Eigentlich habe Ennodius mit Schweigen auf das Schweigen des Parthenius antworten müssen: »Es wäre zwar richtiger gewesen, Deinem missratenen Schweigen ebenfalls Schweigen entgegenzusetzen und die Rache auf dem gleichen Weg gehen zu lassen, auf dem der Fehler kam. [...]" Schon Ennodius' bisheriges Schweigen hätte zu einer Reaktion des Parthenius führen müssen: "Dich hätte schon lange mein zurückgehaltener Ärger treffen müssen, jedenfalls wenn Du nicht alle Menschlichkeit abgelegt hast « $\left(\$_{1}\right),{ }^{297}$ Sein Versprechen, sich zu bessern, habe Parthenius nicht gehalten: „Was hatte ich verbrochen, nachdem $\mathrm{Du}$ in Deinem ersten Brief mit künstlicher Demut um Verzeihung gebeten hattest? Ist das ein treues Versprechen, Dich zu bessern, dass Du Dich, nachdem Du mit besänftigender Rede <im zweiten Brief (der die oratiuncula begleitete), auf den Ennodius mit 290 geantwortet hat (?)> den entstandenen Zorn vertrieben hast, dafür schämst, nur geringe Vergehen begangen zu haben? Soweit ich sehe, vermeidest Du nach der Bekundung Deines Respekts nur eine enge Begrenzung Deiner Fehler« $(\$ 2) .{ }^{298}$ Ennodius erkennt also keine Besserung, sondern wirft ihm vielmehr vor, sich nun viel schlechter zu verhalten. Mit den folgenden Gedanken darüber, dass Eltern sich immer über ihre Kinder freuen, auch wenn sie Fehler machen, könnte Ennodius auf seinen letzten Brief anspielen; vielleicht befürchtet er, dass Parthenius seine Kritik zu schwer genommen hat; er beteuert, dass er Parthenius immer weiter ermahnen werde: »[...] Oder freuen sich die Eltern nicht auch über das Unrecht der krabbelnden Kleinen? Sie finden nichts bitter, wenn ihnen unter Erwünschtem etwas auftaucht, was den Wünschen zum Teil widerspricht. Auf einem Weizenfeld finden wir auch Dornen und Unkraut, und wenn wir das fruchtbringende Getreide pflücken, bekommen wir auch Unfruchtbares. Muss man etwa deshalb die sorgfältige Bebauung aufgeben oder mit dem Pflügen aufhören, wenn die Erde den Bauern nicht völlig zufriedengestellt hat? Ich bitte Gott, von Dir fernzuhalten, was ich verabscheue. Ich also werde, das kannst Du mir glauben, das Amt des Mahners niemals aufgeben « $(\$ 4 f.){ }^{299}$ Dann kommt Enno-

297 (369,1) par quidem fuerat silentio degeneri vicem taciturnitatis opponi et per ipsum callem vindictam, per quem venerat error, exire. [...] te per longum [per longum cf. 414,3 ] ferire debuit inclusa commotio, si tamen non ex toto ab humanitate discessisti.

$298(369,2)$ quid deliqueram, postquam primoribus litteris veniam fabricata humilitate poposceras? haec est correctionis fida promissio, ut postquam delenifica oratione conceptam iram extorseris, erubescas te minora peccasse? quantum video, post contestatam verecundiam solas errorum vitas angustias [...].

$299(369,3 f).[$...] aut creatores reptantium parvulorum non et mulcentur iniuriis? nihil amarum putant, quibus inter desideria quod votis pro parte adversetur efferbuit. $(\$ 4)$ invenimus inter triticeas segetes spinas et lolium, et dum frugiferam herbam carpimus, infecunda suggeruntur. 
dius zum aktuellen Anlass seines Briefes und seiner Vorwürfe: "Ich habe den Bericht Deines Vaters gehört, dass $\mathrm{Du}$ im Lernen schon nachlässt und, als ob Du den Gipfel des Wissens erreicht hättest, Dich nicht um bildende Lektüre bemühst. Du weißt, mein Sohn, dass man hierin den Gipfel nur mit größter Ausdauer halten kann. Es nützt nichts, sich darin irgendwann bemüht zu haben, wenn der bemühte Eifer nachlässt. Das Wissen flieht mit schnellen Flügeln vor den Nachlässigen, und was man mit Zeit und Schweiß erreicht hat, vergeht schnell. Sei gegrüßt und wachsam, dass Du die Ernte Deiner Fortschritte mit der Kette der täglichen Lektüre festhältst.« AbschlieBend versichert er Parthenius noch kurz seiner Unterstützung: "Schreib mir wenigstens jetzt - wenn Du bedenkst, was sich gehört -; denn, das kannst Du mir glauben, Du wirst niemals irgendwo auf der Welt einen vergleichbaren Unterstützer Deiner dictiones finden « (\$5f.). ${ }^{300}$ Auch dieser versöhnliche Abschluss, der das strenge Urteil des vorigen Briefes wieder einschränkt, lässt vermuten, dass Ennodius im Nachhinein seine Strenge bereut, was er weiter vorn mit deliqueram (\$2) angedeutet hat. Was Parthenius macht, anstatt zu studieren, wird hier noch weniger konkret benannt als im vorangehenden Brief an Faustus (368,1 molitur obscena; errata; $\$ 3$ vitiorum profectus).

Die Briefe an Parthenius vereinen beispielhaft alle Aspekte, die in diesem Kapitel behandelt wurden: Ennodius erwartet, dass Parthenius schreibt, um in den Briefen seine sprachlichen Fortschritte zu zeigen; durch seine Bildung soll er beweisen, dass er zum Adel gehört. Ennodius formuliert seine Erwartungen sehr deutlich und mit strengen Worten; auch wenn Parthenius von anderen bereits gelobt wurde, ist Ennodius noch nicht völlig zufrieden; mit Lob ist er äußerst sparsam. Er betont jedoch auch seine Liebe zu Parthenius und seinen Entschluss, ihn immer zu unterstützen. Ennodius gibt sich nicht als sanfter, nachgiebiger Onkel, sondern als anspruchsvoller und strenger Erzieher.

numquid ideo culturae respuenda diligentia est aut cessandum est a vomeribus, si non in toto satisfecerit terra cultori? deum precor, ut a te quod detestor excludat. ego tamen numquam, si credis, deseram monitoris officium. - si credis verstehe ich als "Formel der Versicherung«, siehe KüHNER/STEGMANN (II 2, p. 430) zu si quaeris.

$300(369,5$ f.) audivi te patris tui relatione circa studia iam remissum et, quasi arcem scientiae adeptus sis, ita nullatenus esse de lectionis instructione sollicitum. nosti, fili, istius rei summam nisi adsiduitate nimia non teneri. non profuit in hoc opere laborasse aliquando hominem, qui a laboris intentione destiterit. pernicibus alis neglegentes fugit scientia, et quidquid mora et sudore partum est sub celeritate transfertur. (\$6) te salutatum et vigilem volo, ut profectus tui messem cotidianae catenis lectionis adstringas. ad me vel nunc, si quid te deceat cogitas, rescribe, quia, si credis [siehe die vorige Anm. a.E.], numquam similem dictionum tuarum invenies in qualibet orbis parte fautorem. 


\section{d. 4 Ein Brief an Arator (422)}

Der letzte der drei Briefe an Arator enthält unerwartete Aussagen über die Bedeutung der studia liberalia. In diesem Brief wird noch einmal ganz deutlich, dass Ennodius nicht eine feste Meinung zur Bedeutung der studia vertritt, sondern dass sich die Aussagen je nach Adressat bzw. Situation des Adressaten unterscheiden (siehe oben Kap. I 4.a zum Verhältnis weltlicher und christlicher Bildung). In diesem Fall sieht man, wie er einem Adressaten gegenüber in Bedrängnis gerät, da er ihn nun mit anderen Ratschlägen konfrontiert als früher. Deutlich wird auch, dass die Bedeutung von Familie und Abstammung einerseits und von Bildung andererseits sich nicht immer nur ergänzten (siehe oben Kap. I 4.b.1), sondern dass die beiden Aspekte auch in Konflikt geraten konnten. Doch zunächst eine Vorbemerkung zu Arator:

Das heute bekannteste Detail aus Arators ${ }^{301}$ Leben ist, dass er als Subdiakon im Jahr 544 in Rom sein Bibelepos über die Apostelgeschichte öffentlich vortrug und die große Zuhörerschaft so begeistert Beifall spendete und um Wiederholungen bat, dass der Vortrag auf vier Tage verteilt werden musste - ein wichtiges Zeugnis für den öffentlichen Vortrag neuer Werke im 6. Jh. ${ }^{302}$ Zwar fehlen die genauen Lebensdaten des Magnus Arator, ${ }^{303}$ doch ist aus seinen Widmungsepisteln für das Bibelepos, aus einem Brief im Namen Athalarichs, in dem Arator zum comes domesticorum ("Haushofmeister «) ernannt wird (Cassiod. var. 8,12), ${ }^{304}$ und aus einigen Werken des Ennodius einiges über seinen Werdegang zu erschließen.

Als Eckpunkte bekannt sind der frühe Tod seines Vaters, die Förderung durch den Bischof von Mailand Laurentius und durch Ennodius, seine Advokatenlaufbahn am ostgotischen Hof und sein schließlicher Übergang zum Klerus in Rom und die gerade erwähnte Rezitation seines Werkes. Im weiteren Zusammenhang des Bildungsbetriebs am Anfang des 6.Jh. ist interessant, aber bisher nirgends als auffällig bezeichnet, dass Arator, dessen pater seit dem Tod seiner Eltern Bischof Laurentius war, ${ }^{305}$ eine traditionelle weltliche Ausbildung erhielt mit dem schließlich auch erreichten Ziel, eine weltliche Laufbahn einzuschlagen. So wie sich der Diakon Enno-

301 Siehe PLRE II,126f. - SChwind 1990, 9f.; K. Thraede, Art. »Arator «, RAC Suppl. I, 2001, 553-573; BUREAU 1998.

302 Zu den Handschriften, die diese Nachricht in der Praefatio oder Subscriptio überliefern, siehe SCHWIND 1990, 10 Anm. 10.

303 Der Name "Magnus" ergibt sich m.E. unzweifelhaft aus (85,12): et cum te gravidis scientiae culmis ornaveris, tunc te Magnum dici conveniet Aratorem.

304 Cassiodor (var. 8,12) lobt Arator im Namen Athalarichs als den Tullius Liguriens, der seinem Vater in Bildung und Redekunst nacheifere.

305 Aus der Rede für Arator ( 85 ) geht hervor, dass er verwaist war ( $\$ 17$ orbo parentibus; orbum parentibus) und dass Bischof Laurentius ihn aufgenommen hatte ( $\$ 17 \mathrm{cui}[\ldots] \mathrm{com}$ munis pater et episcopus factus est proprius; $\$ 20$ huius viri, sc. Laurenti, suscepto adulescenti). Zu Laurentius' Fürsorge für Arator siehe oben 116. 
dius um die Bildung einer Reihe von Heranwachsenden kümmert, so scheint auch Laurentius den Wert der herkömmlichen Bildung für junge Adlige geschätzt zu haben. Er hat nicht zuletzt auch selbst bei diplomatischen Aufgaben von seiner eigenen Redekunst profitiert (siehe oben 75) und den ehemaligen Dichter und Redner Ennodius in seine Dienste genommen.

Bei Ennodius finden sich einige Hinweise auf die frühen Jahre Arators: Zuerst liest man von ihm in der bereits betrachteten Rede (85, oben 75) anlässlich seines Eintritts in die Schülerschaft des Deuterius. ${ }^{306}$ Ein Distichon (237) zum Geburtstag enthält ein Wortspiel mit dem Namen "Arator", drei Distichen (267, a, b) variieren Gedanken zu einer goldenen Peitsche, die Arator gehörte. Eine weitere Rede (320) behandelt das bereits betrachtete Lob auf die Literatur (oben 95). Einige in den Bereich der Schule gehörende Texte sind für Arator geschrieben: "Gegen den, der seinem alten Vater nichts zu essen gab« (239), »Gegen den Tyrannen, der einem Vatermörder als Belohnung eine Statue unter denen der mutigen Männer zuerkannte« (243). Eine in denselben Komplex gehörende Ausführung zum Thema: "Aus einer eroberten feindlichen Stadt sollen die Priester und die Vestalischen Jungfrauen freigelassen werden " (380), ist, wie aus der Praefatio hervorgeht, eine Gegendarstellung zu einer Bearbeitung desselben Themas durch Arator (siehe oben 117). Außerdem sind drei Briefe an Arator überliefert; einmal wird er aufgefordert, zu schreiben (378), ${ }^{307}$ dann wird er getadelt, weil er sich nicht zur Hochzeit des Maximus äußert (387); im dritten Brief (422), der hier betrachtet werden soll, rät Ennodius ihm in Fragen der Lebenswahl.

Im letzten Brief an Arator (422) ist dieser offenbar im heiratsfähigen Alter. Allerdings scheint er nicht eben heiratswillig zu sein, denn Ennodius muss ihm zuraten. Ziel dieses Briefes ist es, Arator dazu zu bringen, seine völlige Konzentration auf die Studien aufzugeben und eine Familie zu gründen. Arator solle überlegen, ob er wirklich enthaltsam leben könne oder ob nicht eine Eheschließung der richtige Weg sei. Er solle also das Lager der Musen verlassen und sich der Gründung einer Familie zuwenden. Offenbar bedeutet der Schritt zur Ehe auch gleichzeitig den Schritt zu einem aufgabenreichen, verantwortungsvollen Leben, ${ }^{308}$ das nicht mehr nur durch Dichtung bestimmt sein kann. Arator scheute also wahrscheinlich nicht deshalb die Ehe, weil er eine kirchliche Laufbahn einschlagen wollte, sondern weil er sein sJunggesellenleben ‘ nicht aufgeben wollte, um die Verantwortung eines Familienvaters auf

306 Zum Alter des Arator: $(85,9)$ adulescentulus, $(85,10+20)$ adulescens, $(85,18)$ infantulus, (237 tit.) infans, (267 tit.) infans.

307 In diesem Brief (378) beklagt sich Ennodius, dass Arator, der die Stadt verlassen habe und aufs Land gereist sei, nicht schreibe. Woraus man schließen könnte, Arator sei in Ravenna, um zu studieren (so im Art. »Ennodius« in PCBE 2.1, 1999, 623), ist mir nicht klar.

308 Gründe für den Abbruch der Studien: Kaster 1988, 26 Anm. 60. 
sich zu nehmen. ${ }^{309}$ In der Tat hat Arator ja auch, wie aus dem Brief Athalarichs bzw. Cassiodors hervorgeht, zunächst eine weltliche Karriere eingeschlagen. Auch einer Bemerkung in einem früheren Brief an ihn kann man nicht entnehmen, dass Arator aus religiösen Gründen nicht heiraten wollte: Als Ennodius ihn dazu auffordert, sich zur Hochzeit des Maximus zu äußern, schreibt er, Arator solle die Gelegenheit nutzen, sein Talent zu zeigen, auch wenn ihm die Hochzeit nicht gefalle $(387,3$ haec etsi non diligis, debes tamen pro ingenii tui ostentatione laudare); ob Arator whaec non diligit", weil er weiß, dass Maximus selbst nicht heiraten wollte (siehe oben 50 zum Epithalamium), oder ob Ennodius hier auf Arators eigene Abneigung gegen das Heiraten anspielt, lässt sich nicht entscheiden. ${ }^{310} \mathrm{Im}$ Brief über Arators eigene Hochzeit (422) ist jedenfalls von religiösen Gründen Arators dafür, nicht heiraten zu wollen, keine Rede.

Dass auch schon Arator sich über eine Aufforderung von Ennodius, den Musen den Rücken zu kehren, wundern würde, hat dieser geahnt und gleich im ersten Satz um Nachsicht gebeten (veniam praestes) - allerdings für sein mangelndes Talent; ${ }^{311}$ bei den Studien müsse man auch denjenigen loben, der einem guten Redner nicht gleichkomme. ${ }^{312}$ Ennodius hebt hervor, dass man entweder auf Freunde oder auf Gebildete hören müsse ( $\$ 1$ inter benignos et eruditos $[\ldots]),{ }^{313}$ und er betont, dass er selbst hier als Freund spreche ( $\$ 2$ ergo crede diligenti), d.h. implizit: nicht in der Rolle des Tutors in der Ausbildung. Ennodius hat in diesen ersten Sätzen eine Entschuldigung vorgebracht, die sich allerdings nicht auf sein eigentliches $>$ Vergehen $\measuredangle$ bezieht, sondern nur damit zusammenhängt: es besteht eigentlich darin, dass er sich im Folgenden nicht in der Rolle des Verfechters der Bildung an Arator wendet.

Ennodius rät Arator dazu, die Musen zu verlassen und nun eine Familie zu gründen: "Mach bitte das Verlangen, durch das die Natur das Menschengeschlecht hervorbringt, nicht zum Grund von Kummer « $(\$ 2)$, „Wende dich also nach dem Lager der Musen und den zu unserer Zeit unnützen Gesängen nun der Sorge um Nachwuchs zu " $\left(\$_{3}\right) .{ }^{314} \mathrm{Er}$ bezeichnet also die Dichtung als in der Gegenwart unnütze Gesänge ( $\$ 3$ inanes aetate nostra cantilenas) dann führt er aus: "Meide das, was nichts

309 Die Zusammenfassung in PCBE 2.1 trifft nicht den Kern, da sie an einen religiösen Hintergrund denken lässt $(1999,623)$ : »le conseille au moment où il hésite entre le mariage et le célibat."

310 Es wird allerdings sonst davon ausgegangen, dass Maximus und Arator die gleichen Gründe hatten, sich gegen eine Hochzeit zu sträuben, siehe Kennell 200o, 71, BarTletT 2001, 208.

$311(422,1)$ velim ita labori meo faveas, ut ieiuno veniam praestes ingenio $[\ldots]$.

$312(422,1)$ laudandus est in studis vel qui facundum aequare non putatur eloquio.

$313 \mathrm{vgl}$. $(405,1)$ eligo benignis plus credere quam peritis [...].

$314(422,2 \mathrm{f}$.$) nolo [\ldots]$ desideria, quibus humanum genus natura peperit, digeras in maerorem. [...] (\$3) ergo post Musarum castra et inanes aetate nostra cantilenas ad curam te serendae subolis muta. - Der Verfasser des Artikels »Ennodius« in PCBE $2.1(1999,623)$ hat offen- 
mehr wert ist; denn es ist verrückt, unter Heerscharen von Unkundigen nicht <auch selbst> unkundig sein zu wollen; der Kluge ist froh, wenn er sich nicht von der Masse unterscheidet « ${ }^{315}$ Und nach den Grußworten folgt noch einmal ausdrücklich die eigene Ansicht, dass er »schon die Worte sfreie Künste nunmehr verachte«: ego ipsa studiorum liberalium nomina iam detestor $\left(\$_{4}\right)$.

Das sind Gedanken, wie man sie nach dem bisher Dargestellten von Ennodius nicht ohne weiteres erwartet hätte, und es ist nicht verwunderlich, dass in der Forschungsliteratur gerade der letzte Satz zuweilen zitiert wird. Fontaine $(1962,407)$ bemerkt dazu, man müsse diese »feierliche Erklärung« »aus dem Zusammenhang des Briefes verstehen, in welchem Ennodius seinem Schüler Arator eine strenge Moralpredigt hält «, wobei er aber nicht ausführt, wie man die Worte verstehen soll. Das Verständnis des Briefes wird weiter erschwert, wenn man dem Gedanken iuvat sapientem hoc esse quod plurimos die Worte entgegenhält, mit denen der Teil der "Schulrede « zur Einführung bei Deuterius (85), in dem sich Ennodius an Arator wendet, endet: "Möge daher die Hoffnung auf den Lohn das Streben nach Lob in Dir nähren. Ich habe gelesen, dass es kein Spiel des Zufalls ist, wenn einmal ein Gebildeter unter den schmutzigen Herden von Ungebildeten Erfolg hat. [...] Einen Gebildeten kann sein Bewusstsein aufrichten, und wenn er einmal in unsichere Stürme in schlechter Zeit gerät, kann er das Übel ertragen, das mehr den Umständen zuzuschreiben ist als seiner eigenen Qualität « $\left(85,12 \mathrm{f}\right.$.). ${ }^{316}$ Was bringt Ennodius zu solch widersprüchlichen Aussagen gegenüber ein und demselben Adressaten? Hat er vergessen, was er Arator früher geraten hat, oder nimmt er an, dass Arator seine Worte vergessen habe?

Ennodius macht im Briefeingang deutlich, dass er als Freund spricht, nicht als Gebildeter, und entsprechend bittet er eingangs um Nachsicht für sein angeblich mangelndes Talent. Da gerade Arator das Ausmaß von Ennodius' Talent kennt, bekommt er hier implizit den Hinweis, dass Ennodius diesen Brief nicht in der Rolle des Tutors in den studia liberalia schreibt (einen solchen Brief vom sTutor h hat Arator zuvor erhalten, als Ennodius ihn tadelte, weil er ihm nichts über die Hochzeit des Maximus geschrieben hat, siehe 387 ). Dieses wechselnde >Rollenverhalten ‘ erklärt sich nicht mit mangelnder Beständigkeit oder plötzlichem Sinneswandel, sondern es hat einen Grund in einer Forderung an den Epistolographen, beim Verfassen loca

bar aetate nostra auf das Alter des Arator bezogen, »lui recommande enfin d'abandonner la poésie, art pour lequel il le trouve trop âgé."

315 (422,3f.) vita quod viluit, quia inter imperitorum exercitus furor est nolle rusticari; iuvat sapientem hoc esse quod plurimos. LuMPE $(1966,206)$ verweist dazu auf das Sprichwort necesse est cum insanientibus furere, cf. A. Oтто, Die Sprichwörter und sprichwörtlichen Redensarten der Römer, Leipzig 1890, 151.

$316(85,12 \mathrm{f}$.) quocirca spes in te praemii nutriat laudis ardorem. legi quia non est fortunae lusus, si quando inter feculentos $[\ldots]$ inperitorum greges profecerit litteratus. $[\ldots]$ erigit doctos conscientia sua, et si quando incertis temporum flatibus opponuntur, sustinent mala, quae saeculis magis sunt adscribenda quam meritis. 
tempora personas zu beachten; es gibt hingegen keine Forderung an Epistolographen, immer die gleiche Meinung zu vertreten. ${ }^{317}$ Arator muss in dieser neuen Situation andere Ratschläge bekommen als früher. Ein weiterer Grund liegt in der Person des Ennodius, der an verschiedenen `Sphären` - Adel, Bildung, Kirche - partizipiert, die oft in Widerspruch miteinander treten. Und vielleicht liegt der wichtigste Grund für die unterschiedlichen Ratschläge für Arator darin, dass Ennodius in der dictio das Ideal beschreibt, in dem Brief hingegen die Realität.

\section{Fazit: set clericus et doctus}

Die Untersuchungen zum ,Vorleben über die studia liberalia und zu seiner Darstellung seiner eigenen Bekehrung im »Eucharisticum« zeigen, wie sehr Ennodius zur Zeit der Entstehung der überlieferten Texte noch seinen literarischen Interessen verhaftet ist. Er selbst sieht das Problem, dass er sich in zwei Sphären bewegt, sehr deutlich. Das im "Eucharisticum « (Kap. I 1) gezeichnete Bild eines Mannes, der während des Diakonats (Gelegenheits-) Reden und -Gedichte schreibt und vorträgt, der dem Hochmut verfällt und aufgrund einer Krise gelobt, bestimmte Arten von Texten nicht mehr zu verfassen, lässt sich durchaus vereinen mit dem Gesamtbild der Werke des Ennodius, wie sie eingangs vorgestellt wurden (I 2): In der Tat hat ja der Diakon verschiedenste Werke in Prosa und Versen geschrieben und in diesen zwar seine Vorsätze silentium und humilitas wieder und wieder thematisiert, doch zumindest hinsichtlich seiner literarischen Tätigkeit nicht konsequent befolgt. Er formuliert z.B. in der >Recusatio $<$ an Olybrius (I 3.b.3), dass er sich als Mann der Kirche nicht wie ein doctus, d.h. wie z.B. Olybrius, betätigen dürfe, doch ebenso wie gerade in dieser «Recusatio tut er dies in seinen Werken immer wieder. Die Kernaussage des "Eucharisticum «: der Konflikt zwischen Amt und literarischer Tätigkeit aufgrund der Vorsätze silentium und humilitas bestätigt sich also anhand der übrigen Werke.

Der Konflikt zwischen Kirchenamt und Freude an literarischer Tätigkeit, zwischen clericus und doctus, von dem u.a. das "Eucharisticum « berichtet, hat seine Wurzeln nicht in der Zeit des Diakonats, sondern in einer früheren Phase. Dass Ennodius sich früher, vor der Übernahme des Diakonats, intensiv literarisch betätigt hat und z.B. mit Gelegenheitsgedichten aufgetreten ist, verschweigt er zwar im "Eucharisticum «, nicht aber in einigen Briefen und Schulreden (I 3.b).

Die Briefe zeigen sehr deutlich, dass Ennodius die sprachliche Bildung, sowohl seine eigene als auch die seiner Adressaten, immer noch sehr am Herzen liegt (I 4). Immer wieder fordert er seine jüngeren Adressaten mit strengen Worten dazu auf,

317 Dies nicht getan zu haben, wirft Ennodius Asturius vor $(47,5)$. Vgl. (Sidon. epist. 1,1,1) prout eas <sc. epistulas> causa persona tempus elicuit. 
sich um ihre Bildung, d.h. eloquentia, zu bemühen und so zu beweisen, dass sie zum Adel gehören. Ennodius hat also mit der Übernahme des Diakonats seine Überzeugung von der Bedeutung der cultura sermonis und seine eigene Freude am Schreiben nicht aufgegeben, obwohl er sich zu silentium und humilitas verpflichtet hat. Auffällig ist, dass er einerseits ungewohnt offen über die Macht der Rhetorik, nicht zuletzt über ihre Macht zur Manipulation der Wahrheit, spricht (I 4.c), andererseits aber die Überzeugung, dass die Beschäftigung mit den studia liberalia den Charakter verbessere, kaum je äußert (I 4.b.2). Da aus der Zeit vor dem Diakonat keine Werke überliefert sind, bleibt leider offen, ob er sich vorher auch schon in dieser Weise geäußert hat oder ob diese Ansichten auf sein neues Amt zurückzuführen sind.

Nachdem in Teil I den Briefen und anderen Werken überwiegend Informationen über ihren Verfasser und sein Verhältnis zur Bildung entnommen wurden, sollen nun in Teil II die Briefe innerhalb ihrer Gattung untersucht werden. Es soll betrachtet werden, was für Briefe Ennodius schreibt, der sich der Macht der Rhetorik derart bewusst ist und der offen schreibt, dass die ars rhetorica alles zum Besseren oder Schlechteren verwandeln könne. Wie sehen die Briefe des vielfältigen Autors im Einzelnen aus, der ja einerseits als Diakon die Gemeinde verwaltet und besonders für die Armenfürsorge zuständig ist, andererseits als ehemaliger Redner und Dichter sich weiter um die Aus-Bildung junger Adliger kümmert und der sich auch literarisch betätigt? Bei näherer Betrachtung der Briefe erscheint Ennodius auch dort in verschiedenen Rollen: Er schreibt zuweilen als freundlicher, gütiger Mann der Kirche, viel häufiger aber als nörgelnder, unzufriedener Freund oder als strenger Mahner (wie er schon in Teil I gegenüber jüngeren Adligen zu beobachten war). 


\section{Teil II: Testimonium diligentiae}

\section{Allgemein zur Gattung >Brief}

Bevor in diesem II. Teil einige Charakteristika von Ennodius' Briefen (II. 2) und seine Gestaltung bestimmter Arten von Briefen (Briefe zur Kontaktpflege, Glückwunsch- und Empfehlungsschreiben, II.3) im Vergleich mit Briefen anderer Epistolographen dargestellt werden können, sind zunächst einige Vorbemerkungen erforderlich: 1. a-d) zur >Gattung Brief: zu den Realien, zur Brieftheorie, zum Problem der Kategorisierung von Briefen und zu besonderen Phänomenen der Epistolographie der Spätantike (Korrespondenz als Zeichen der amicitia, Selbstdarstellung des Verfassers) und 1.e) zu den spätantiken Epistolographen, mit deren Corpora die Briefe des Ennodius verglichen werden sollen. Die genannten Aspekte können in diesem Rahmen allerdings lediglich angedeutet und nur so weit kommentiert werden, wie es für die folgende Untersuchung als Grundlage unerlässlich ist, denn eine ausführliche Aufarbeitung ergäbe eine eigene Monographie.

\section{a. Eine flexible Gattung}

Die Verschiedenheit der Texte, die sich als $>$ Briefe $<$ bezeichnen lassen, scheint geradezu eines der Merkmale der Gattung zu sein: Die Kriterien, anhand derer sich die äußerst verschiedenen Sammlungen oder zunächst die einzelnen Briefe beschreiben lassen, sind vielfältig - man denke nur an die Briefe von Cicero, Ovid, Seneca, Plinius oder Hieronymus, wo schon die einzelnen Corpora ganz unterschiedliche Briefe enthalten. Die Weite der Gattung zeigt sich zum einen an der thematischen Vielfalt, die von einem kurzen Gruß über eine wichtige Nachricht oder Anfrage bis zur Behandlung von philosophischen oder theologischen Fragen reicht. Hinzu kommt die Vielfalt der Beziehungen, in denen Verfasser und Empfänger zueinander stehen können und die erheblichen Einfluss auf Inhalt, Ton und Stil von Briefen haben: es korrespondieren Verwandte, Freunde und Feinde, Privatleute, Geschäftsleute oder Amtsträger. Briefe können ganz verschiedenen Anlässen dienen: Glückwunsch, Dank, Einladung, Bitte, Empfehlung, Trost. Es gibt Briefe, die ausschließlich für die Veröffentlichung verfasst wurden und wo die Anrede an den Adressaten eine Würdigung ist. Es finden sich Briefe sowohl in Prosa als auch in metrisch gebundener Sprache, wobei letztere ebenfalls der Kommunikation dienen können, wie Paulinus von Nola 
und Ausonius zeigen. Es gibt Briefe innerhalb anderer Gattungen, wie Vorworte in Briefform (z.B. bei Martial vor den Büchern 2, 8, 12; bei Statius vor Buch 1-4 und vor 5,1 der Silvae) und in Geschichtswerke oder Romane eingelegte Briefe. Manche Briefe geben sich als von berühmten Persönlichkeiten verfasst, wobei die Frage des wirklichen Verfassers, der `Echtheit`, zuweilen schwierig ist (das bekannteste Beispiel sind wohl die Platon-Briefe), andere Briefe sind eindeutig fiktional (z.B. Ovids $\mathrm{He}$ roides); Briefe sind handschriftlich tradiert oder im Original auf Papyrus zufällig erhalten, usw.

Angesichts dieser Vielfalt von möglichen Formen, Inhalten und Funktionen von Briefen dient in der Forschung zumeist eine minimalistische Definition der Gattung insgesamt als Ausweg: Die Zugehörigkeit zur Gattung Brief wird rein anhand der äußeren Form, nämlich durch die Existenz von Eingangs- und Schlussformeln, bestimmt; ${ }^{318}$ so verfährt übrigens auch schon Augustin: [...] epistula est; habet quippe in capite quis ad quem scribat (retract. 2,20,1). Da durch diese formale Definition alles, was zwischen Begrüßungs- und Abschiedsformel steht, völlig unberücksichtigt bleibt, lassen sich etwa Ovids Heroides und Senecas epistulae morales problemlos der gleichen Gattung zuordnen. Zu eng für das Miteinander von Ovids Heroides und Senecas epistulae morales oder auch für die Plinius-Briefe ist etwa folgende Definition: "eine schriftliche Mitteilung von einer realen, historischen Person an eine andere reale, historische Person, die in der Regel zu einer schriftlichen Gegenäußerung auffordert, was den Ansatzpunkt für einen Briefwechsel (Korrespondenz) bildet « (MüLleR 1994, 61).

Als Einführung in die lateinische Epistolographie muss - und kann durchaus - immer noch Peters Monographie von 1901 über lateinische Briefe von Cicero bis in die Spätantike dienen, wenn auch viele Details und besonders die Wertungen inzwischen revidiert worden sind. Wesentliche Gründe dafür, dass PETER bisher nicht ersetzt worden ist, dürften sowohl in dem sehr unterschiedlichen Forschungsstand zu den einzelnen Autoren als auch in der von einem einzelnen Bearbeiter nicht zu überblickenden Quantität der überlieferten Briefe liegen. Auch für die neueren Philologien stellt die Gattung Brief, die mit zunehmender Entfernung von der Antike immer noch vielfältiger geworden ist, ein komplexes Phänomen dar (einen informativen Überblick gibt NıскISCH 1991. Doch da sich Vieles mit der Zeit grundlegend verändert hat (z.B. Boten- und Postwesen, Briefgeheimnis, gesellschaftlich-soziale Funktion von Briefen), lassen sich die Ansätze zur Untersuchung jüngerer Epistolographen nicht ohne Weiteres auf die antiken Epistolographen übertragen.

Zur Zeit stehen außer der Monographie von Peter zur Einführung in die antike und/oder spätantike griechische und/oder lateinische Epistolographie überwiegend Lexikonartikel, Kapitel in Literaturgeschichten oder Aufsätze in Sammelbänden zur 
Verfügung (siehe unten c.2), die sich in unterschiedlichem Maße den speziellen Bereichen der Forschung widmen:

- Realien des Briefschreibens (siehe unten b),

- Brieftheorie und >Brieftopoi< (c),

- gesellschaftliche Funktionen des Briefschreibens (d),

- einzelne Epistolographen, die außerhalb des Rahmens der Epistolographie insgesamt jeder für sich Gegenstand der Forschung sind (e).

Es bleibt zu hoffen, dass mit der Zeit möglichst viele Einzeluntersuchungen eine Grundlage für ein Handbuch der Epistolographie bilden werden (in diesem Sinne äußert sich auch schon SykUTRIS 1931, 188).

\section{b. Realien}

Recht gut erschlossen sind die brieftechnischen Realien:

- Beschreibstoffe, Tinte, Schrift und rein materielle Gestalt von Briefen,

- Schreiben, Diktieren und Sekretäre,

- Beförderungsmöglichkeiten, Boten, ergänzende mündliche Nachrichten,

- Archivierung bei Verfasser und/oder Empfänger, Entstehung von Sammlungen,

- Weitergabe von Briefen an einen weiteren Leserkreis, Rezitation von Briefen,

- die formelhaften Elemente wie Anrede, Grüße von Dritten und an Dritte.

Diese Themen werden sowohl in allgemeinen Untersuchungen der Gattung als auch in Arbeiten zu einzelnen Corpora häufig besprochen, außerdem gibt es Einzelstudien zu bestimmten Realien, ${ }^{319}$ so dass sich hier eine Darstellung der Einzelheiten erübrigt. Es fehlen jedoch systematische Untersuchungen unter dem Gesichtspunkt, welche Details sich bis in die Spätantike verändert haben oder auch gleich geblieben sind. Zumeist wird stillschweigend angenommen, ein bei Cicero erwähntes Phänomen gelte ebenso auch für die Kirchenväter.

Die Briefe des Ennodius enthalten hinsichtlich der brieftechnischen Realien einige Hinweise auf das Botenwesen: zuweilen weist Ennodius explizit darauf hin, dass der Bote außerdem mündlich etwas auszurichten habe (z.B. 138,2 significo me ad ali-

319 In allgemeinen Untersuchungen z.B.: Dziatzko 1897, 836-840; Peter 1901, 29-37; KLAUCK 1998, 55-70; Zelzer 1997, 328-332, 337-340; Scarpat 1972, 483-485. - Zu einzelnen Autoren, z.B. zu Cicero: R. Y. Tyrrell/L. C. Purser, Dublin ${ }^{3} 1904$, Vol. I., 54-60; zu Hieronymus: Conring 2001, 5-7; zu Paulinus von Nola: White 1992, 6 ff. - Zu Transport und Boten siehe z.B.: Peter 1901, 29 ff.; Mratschek 2002, 302. O. Nikitinski, Die (mündliche) Rolle von Briefboten bei Cicero, S. 229-247 in: L. Benz (Hrg.), Die römische Literatur zwischen Mündlichkeit und Schriftlichkeit, Tübingen 2001. J. Nicholson, The Delivery and Confidentiality of Cicero's Letters, CJ 90, 1994, 33-63. A. KoLB, Transport und Nachrichtentransfer im Römischen Reich, Berlin 2000. - Zu Anredeformen siehe z.B. H. ZiLliacus, JbAC 7, 1964, 167-182. 
qua suggerenda perlatorem praesentium destinasse). Von den Gefahren, dass Briefe unterwegs abgefangen werden oder verlorengehen könnten, spricht Ennodius selten. ${ }^{320}$ Wenn er von der portitorum neglegentia spricht, scheint er im einen Fall dahinter einen Vorwurf für den Adressaten zu verbergen $(40,6)$, im anderen $(58,1)$ schiebt er dies vielleicht nur als Ausrede vor.

Gionnni $(2001,169)$ nimmt an, dass Ennodius seine Briefe diktiert habe, doch eine pauschale Aussage darüber lässt sich nicht wirklich machen; GioANNIs Beleg $(17,3$ [...] legenda dictavi. visa est mihi, dum loquor, pagina mea te reddidisse) ist nicht treffend, da Ennodius für »Brief « häufig colloquium sagt (entsprechend hier loquor), er also den Brief als Ersatz für das Gespräch auffasst, und dictare »schreiben, verfassen« bedeuten kann (ThlL s.v., Sp. 1011,62). Doch es gibt immerhin eine Stelle, an der Ennodius von »diktieren « spricht: "[...] und schätze mich nicht nach diesem Brief ein, den ich - Gott ist mein Zeuge - auf dem Weg diktiert habe, als ich von der Kirche zurückkam« $(387,3) .{ }^{321}$ Da er sich hier für den schnell verfassten Brief entschuldigt, scheint er davon auszugehen, dass der Adressat üblicherweise mit sorgfältiger gestalteten Briefen rechnet; dies aber lässt für den 'Normalfall eher auf eigenes Schreiben als auf Diktieren schließen.

Die Frage, ob die Briefe nur für den einzelnen Adressaten (und sein engstes Umfeld) gedacht waren oder ob sie weitergegeben werden sollten bzw. durften, ist sicher ebenfalls nicht pauschal zu beantworten: In einem lobenden Brief an Liberius spricht Ennodius immerhin davon, dass dieses Schreiben "der Welt zu Ohren kommen werde“ (447,2 in aures mundi itura formantur; zu dem Brief unten 269). Einmal weist er darauf hin, dass er die Briefe seines jüngeren Korrespondenten auch anderen zu lesen gebe $(15,6)$. Auch Ennodius' Korrespondenten geben Briefe, die sie von ihm erhalten haben, Dritten zu lesen, wie aus dem Brief an Pomerius hervorgeht $(39,3$, siehe dazu unten 192).

Ein augenfälliges Problem in den Briefen des Ennodius wie überhaupt in spätantiken Briefen ist das "unlogische vos«, d.h. die oft beliebig wirkende Anrede mit $t u$ oder vos, besonders wenn, wie es bei Ennodius äußerst häufig vorkommt, derselbe Adressat innerhalb eines Briefes abwechselnd mit $t u$ oder vos angesprochen wird. Weder lässt sich in diesen Fällen das vos immer als »sociativer Plural« erklären, d.h. dass außer dem Adressaten auch dessen Familie mitgedacht ist, noch als "Plur. reverentiae», der in in der Spätantike aufkommt (siehe HofmanN-SzantYR 1965, \$30

320 GioANNI $(2001,169)$ führt als Beispiel dafür, dass Briefe verlorengingen, an: $(41,1)$ non est incuriae quod raro a me scripta prorogantur: similia frequenter, ut nunc repperi, bona se subtrahunt ("C'est ne pas à cause de mon incurie si mes lettres sont rares: il arrive souvent, à ce que je viens juste d'apprendre, que des biens semblables se perdent $«$ ). Doch mit bona se subtrahunt ist gemeint, dass sich nur selten Boten für Briefe von Ennodius anbieten, also »es bieten sich keine guten Gelegenheiten«, siehe unten 361.

$321(387,3)[\ldots]$ et non me de epistola mea aestimes, quam, deus testis est, dum de basilica remearem, transcursione dictavi. 
und 30B). Gerd Haverling (1995, 353), die sich diesem Phänomen besonders bei Symmachus widmet, macht zurecht darauf aufmerksam, dass es im Zusammenhang mit dem häufigen Gebrauch des "unlogischen nos" der Epistolographen untersucht werden sollte.

In diesem Rahmen lassen sich dazu nur kleine Beobachtungen festhalten, die zeigen, dass eine besondere Untersuchung lohnen könnte: In manchen Briefen verwendet Ennodius konsequent entweder nur $t u$ (und die 2. Person Singular) oder nur vos (und die 2. Person Plural). Nur tu steht z.B. in einigen Briefen an Adressaten, die nur einen Brief erhalten, z.B. 24 an Deuterius, 39 an Pomerius, 431 an Camella, 432 an Celsus. In den fünf Briefen an den jungen Beatus steht immer $t u$, bis auf zwei Fälle des eindeutig sociativen vos in 405,2 (iuxta petitionem vestram epistolam ad vos admonitionis), wo Ambrosius, der zweite Adressat der "Paraenesis", mitgemeint ist. - In den zwei Briefen an Florianus $(20,21)$ steht $t u$ und 2. Sing., nur einmal vos in dem Sinne "Leute wie Du« im Gegensatz zu Ennodius selbst (21,3 [...] laudem, quam multo sudore vos petitis, formidarem). - In den vielen Briefen an Faustus steht fast ausschließlich vos und 2. Person Plural, mit nur wenigen Ausnahmen (z.B. 6,9; 9,5; 145,2).

\section{c. Brieftheorie}

\section{c. 1 Antike Brieftheorie}

Ein weiterer Einzelaspekt der Forschung sind die Reste der antiken Brieftheorie, d.h. sowohl die theoretischen Abhandlungen als auch die verstreuten Bemerkungen innerhalb von Briefen selbst. An Brieftheorie außerhalb von Briefen sind in grie-

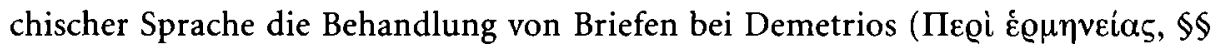
223-235) und Traktate mit Definitionen und Musterbriefen, sog. Briefsteller, erhalten

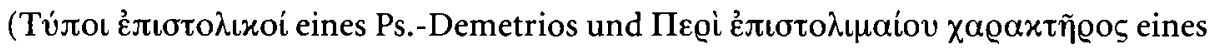
Ps.-Libanios bzw. Proklos), die bei Malherbe (1988) leicht zugänglich sind. Auf lateinischer Seite gibt es neben einem im Cod. Parisin. 7530 erhaltenen Fragment (Exc. rhet. p.589 Halm, Rhet. lat. min.) ein Kapitel de epistolis innerhalb der Ars rhetorica des Iulius Victor, auf das im Folgenden häufiger zu verweisen sein wird. ${ }^{322}$ Iulius Victor (Ende 4. Jh.) behandelt am Ende seiner Ars rhetorica ${ }^{323}$ Briefe im Anschluss an die

322 Hinweise auf Verlorenes bei Cugusi $(1983,43)$. - Zu Ovids Ratschlägen für das Verfassen von Liebesbriefen siehe W. STroh, Rhetorik und Erotik: Eine Studie zu Ovids liebesdidaktischen Gedichten, WJA 5, 1979, 117-132. - Erst im Mittelalter fließen die Texte mit praecepta für das Verfassen von Briefen reichlicher, siehe dazu: M. CAMARgo, "Ars dictandi / dictaminis", HWRh 1, Sp. 1040-1046, Tübingen 1992; R. M. G. NICKISCH, "Briefsteller«, HWRh 2, Sp. 76-86, Tübingen 1994.

323 C. Iulius Victor, Ars rhetorica, ed. R. Giomini, M. S. Celentano, Leipzig (1980), 105,9106,20; siehe die Einführungen dazu: M. S. Celentano, La codificazione retorica della 
Konversation (sermo) und unter ausdrücklichem Verweis auf die Ähnlichkeiten mit dieser. Er gibt konkrete Vorschriften für das Verfassen von Briefen, indem er z.B. über die richtige Länge bzw. Kürze von Briefen spricht, über den richtigen Ton je nach Situation und Adressat, über das Niveau der Sprache und über den angemessenen sprachlichen Schmuck. - Hinzu kommen Äußerungen der Epistolographen selbst, die innerhalb ihrer Briefe immer wieder über das Schreiben von Briefen bzw. über Charakteristika von Briefen reflektieren, besonders über Wesen und Aufgabe(n), Anlässe, Themen, Sprache und Stil von Briefen. Außerdem ergeben sich bestimmte Themen fast zwangsläufig aus der Briefsituation, z.B.: die (häufig unbefriedigende) Frequenz des Briefwechsels, die Sorge um das Wohlergehen des Korrespondenten, die möglichen Inhalte bzw. die Inhaltslosigkeit von Briefen. Nicht zuletzt gehört dazu das Thema der amicitia zwischen den Korrespondenten, wobei dieses Thema zum einen eng mit einem Aspekt der Brieftheorie zusammenhängt, nämlich der wichtigen Aufgabe des Briefes, die Korrespondenten zu verbinden, und zum anderen übergeht in die weiterreichende ,Freundschafts-Topik‘. Diese Themen und Gedanken kehren in einem Großteil der Briefe - von Cicero bis in die Spätantike (und darüber hinaus) - so häufig wieder, dass sie als `gattungsimmanent ‘ bzw. ‘Brieftopik` gelten; THRAEDE (1970) spricht auch von »briefeigener Thematik und Phraseologie« (8) bzw. »briefspezifischen Äußerungen« (10).

Die betreffenden Texte bzw. Passagen sind recht gut zugänglich: Immer noch unverzichtbar ist der materialreiche Band "Epistolographi graeci« von HERCHER (1873), der sowohl die theoretischen Texte als auch viele vollständige Briefsammlungen enthält. Eine nützliche Auswahl wichtiger griechischer und lateinischer Texte, sowohl theoretische Traktate als auch entsprechende Passagen bei Epistolographen, hat MalHerbe (1988) erstellt (mit englischer Übersetzung). Wichtig sind die Ausführungen zu den einschlägigen Passagen bei Cugusi (1983, Äußerungen innerhalb von Briefen: 27-41) und Thraede (1970, zur Theorie besonders 17-27, zu Passagen innerhalb von Briefen passim). ${ }^{324}$

Die >Brieftopoi` sind Gegenstand verschiedener Untersuchungen, von denen hier die wichtigsten genannt seien: KoskenNiEMI (1956) betrachtet griechische Briefe (vorwiegend Papyrusbriefe) bis 400 n.Chr., besonders die Phraseologie, die den Brief selbst und die Briefsituation betrifft. - Thraede (1970) untersucht eine Reihe griechischer und lateinischer antiker und spätantiker, paganer wie christlicher Autoren (nicht Ennodius), wobei er besonders auf die Gemeinsamkeiten zwischen griechischen und lateinischen, paganen und christlichen Briefen, d.h. auf die fortlaufenden Traditionen von Thematik und Phraseologie verweist. Thraede betont

comunicazione epistolare nell'Ars rhetorica di Giulio Vittore, RFIC 122, 1994, 422-435; Un galateo della conversazione nell' ars rhetorica di G. Vittore, Vichiana 3. ser. 1, 1990, 245-253.

324 Kurze Einführungen bzw. Zusammenfassungen finden sich z.B. bei: KLAUCK 1998, bes. 148-164; Zelzer 1997, 327f.; Peter 1901, 22-24 (Cicero), 27 (Iulius Victor). 
die Notwendigkeit, auf dem Hintergrund der Tradition nach dem Eigenbeitrag der einzelnen Autoren und nach den speziell christlichen Elementen zu fragen (8); er macht deutlich, dass sich die "persönlich gefärbte Konvention und gesellschaftlich stilisierte Individualität« (3) einer Briefsammlung, d.h. die Frage, inwieweit ein Autor einen bestimmten Schatz an Motiven, Themen und Phraseologie in gewohnter oder in besonderer Weise verwendet, nur im Vergleich erkennen lässt ( $8 ; 10$, Anm. 18). Cugusi (1983, 73-104) bespricht "topica di idee« und »topica di lingua« von der vorciceronianischen bis zur augusteischen Epistolographie. - Eine große Sammlung von Brieftopoi von Cicero bis Alkuin, untergliedert nach den Themen Anwesenheit vs. Abwesenheit, Schreiber vs. Leser, Reden vs. Schweigen, Schreiben vs. Sprechen, findet sich bei Suzanne AвRAM (1994). ${ }^{325}$

Fraglich ist, inwieweit die Äußerungen der Epistolographen innerhalb ihrer Briefe oder die Anweisungen des Demetrios oder Iulius Victor dazu dienen können, eine moderne Definition der Gattung oder eine Beschreibung der erhaltenen Texte, die sich als Briefe bezeichnen lassen, zu erarbeiten. Denn weder die Äußerungen der Epistolographen noch die Anweisungen oder die "Typoi« sind systematisch oder erschöpfend, abgesehen von der Unsicherheit der Chronologie der griechischen Traktate. Auf einen großen Unterschied zwischen Theorie und Praxis weist Peter hin (1901, 19): "während in der thatsächlichen Entwickelung die Vorstellungen der Alten ihm <sc. dem Brief> einen sehr weiten Spielraum gelassen hatten, <beschränkte sich> die Theorie auf den eigentlichen Brief, der zum Ersatz mündlicher Mitteilung dienen sollte. "In diesem Zusammenhang fällt z.B. auf, dass die Theorie wissenschaftliche Abhandlungen in Briefen verbietet (Demetr. eloc. \$231), was in der Praxis häufig missachtet wird. Für eine moderne Beschreibung der Gattung sollten daher die antiken Selbstäußerungen und Vorschriften zunächst beiseite bleiben und nur die Briefe an sich im Mittelpunkt stehen.

In der Forschungsliteratur wird allerdings bisher in der Regel zwischen den antiken Äußerungen bzw. Anweisungen und der modernen Beschreibung von Briefen nicht deutlich getrennt; zumeist werden bei der modernen Definition von Briefen Kriterien verwendet, die den antiken Texten entnommen sind. Dabei wird nicht beachtet bzw. nicht darauf hingewiesen, dass viele erhaltene Briefe in etlichen Punkten gegen die in ihnen formulierten Regeln verstoßen. Wichtig ist die Beobachtung von Thraede (1970, z.B. 30), dass sich die brieftheoretischen Reflexionen der Epistolographen häufig gerade an solchen Stellen finden, wo gegen das Übliche verstoßen wird. Z.B. wird die auch in modernen Darstellungen oft erwähnte Vorschrift, dass ein Brief kurz sein solle, oft nicht befolgt ${ }^{326}$ bzw. gerade dann erwähnt, wenn ein Brief

325 Zur >Brieftopik bei einzelnen Autoren siehe z.B.: Conring, Hieronymus, 2001 (Kapitel 3); ZELZER zu Ambrosius, 1987, 219-223.

326 Die Grenze zwischen Brief und libellus ist oft nicht zu ziehen; siehe einige Beispiele bei ZELZER (1997, 322 und 325); siehe auch Aug. retract. 2,25,1; 2,33,2. 
im Begriff ist länger zu werden - abgesehen von der Frage, was genau unter ’kurz` zu verstehen ist.

\section{c. 2 Forschungsstand zur Epistolographie}

Die wichtigsten allgemeineren Arbeiten zur lateinischen Epistolographie sollen kurz vorgestellt werden, ${ }^{327}$ wobei der Schwerpunkt der Darstellung auf den jeweiligen expliziten oder impliziten Ansätzen zur Kategorisierung von Briefen liegt:

Seit Bentleys Arbeiten zu den Phalaris-Briefen beherrschen die Kategorien 'Authentizität ‘ versus ,Fiktion ‘ die Diskussion über viele Briefcorpora. Bentley verband mit dieser Unterscheidung, die in erster Linie die Auswertbarkeit von Briefen für historische Fragen betraf und literarische Fragestellungen ausklammerte, eine Abwertung der nicht als Quelle nutzbaren >fiktiven« Briefe. Bentleys Einfluss war enorm: "Die Auswirkungen der Phalariskontroverse sind noch heute spürbar. Bentleys langfristig vernichtendes Urteil über die Phalarisbriefe und weitere Epistolographen hat die Gattung so sehr in Verruf gebracht, nichts weiter als geistlose, historisch unbrauchbare Machwerke zu sein, daß sie viele Gelehrte von der Beschäftigung mit diesen abgehalten haben " (HINZ 2001, 424). Bis heute finden sich weitaus weniger literarische Untersuchungen als historische, die Briefe als Quellenmaterial verwenden. ${ }^{328}$ - Die Kategorie >fiktive< Briefe wird in der Forschung allerdings nicht einheitlich verwendet: zum einen werden so spseudonymer Briefe wie die Phalaris-Briefe bezeichnet, die nicht von ihrem angeblichen Verfasser stammen, zum anderen aber häufig auch solche, die nicht sauthentisch ‘ sind in dem Sinne, dass sie nie so versandt wurden, wie sie überliefert sind (die Frage der >Authentizität`vs. >Überarbeitung

327 Siehe auch folgende Artikel in DNP: P. L. SchмiDT, "Brief", Bd. 2, 1997, 771-775; M. HeilmanN, "Brief, Briefliteratur", Bd. 13, 1999, 541-545; P. KoCH, "Briefkunst/Ars dictaminis«, Bd. 13, 1999, 545-551; H. GörgemanNs, M. Zelzer, »Epistel«, Bd. 3, 1997, 11611166; H. GörgemanNs, »Epistolographie«, Bd. 3, 1997, 1166-1169. - Siehe außerdem in Literaturgeschichten: Schanz/Hosius Bd. I,1, 471-474 (allgemeine Einleitung zu Briefen vor der Behandlung von Ciceros Briefen); M. von Albrecht, Geschichte der römischen Literatur Bd. I, 409-414 ("Der Brief in der römischen Literatur «); G. Mazzolı, La forma epistolare, 198-214, in: F. MonTANARI (ed.), La prosa latina, Rom 1991. - Siehe außerdem die Einführung in: M. Trapp, Greek and Latin Letters. An Anthology, with Translation, Cambridge 2003, 1-41.

328 Erst in jüngerer Zeit werden Ciceros Briefe ausdrücklich als 'Literatur betrachtet und auch bezeichnet, siehe G. O. Hutchinson, Ciceros Briefe als Literatur (ad Att. 1,16), Hermes 121, 1993, 441-451 und ders., Cicero's Correspondence. A Literary Study, Oxford 1998. B.-J. SChröDER, Ciceros Briefe als Briefe, ACD 40/41, 2004/5, 193-214. - Ein Beispiel aus der Spätantike: Zu den Briefen des Symmachus, des größten Redners seiner Zeit, entstehen erst in den letzten Jahren Kommentare, die sich ganz überwiegend historischen Fragen zuwenden. 
bzw. /Verfassen für die Publikation` spielt u.a. in der Forschung zu Horaz, Seneca, Plinius, Ambrosius eine entscheidende Rolle).

Deissmann (Bibelstudien 1895, 187ff [Prolegomena zu den biblischen Briefen und Episteln] und "Licht vom Osten «, 4. Aufl. 1923 [zuerst 1908], bes. 194-198), der die Briefe des Neuen Testaments vor dem Hintergrund von Papyrusbriefen und Ostraka untersuchte, gab einen entscheidenden Impuls für die Forschung zur Epistolographie. Er unterscheidet zwischen dem "(echten, natürlichen) Brief ", der nur für den einen Adressaten gedacht ist, mein Stück Leben" $(1923,195)$ bedeutet und von dem Beispiele auf Papyrus erhalten sind, auf der einen Seite und der "(literarischen, künstlichen) Epistel«, einem »Erzeugnis literarischer Kunst« (ibid.) in der äußeren Form eines Briefes, die für ein Publikum geschrieben ist, auf der anderen Seite. Zur "Mittelgattung « zwischen beiden rechnet er die »halb und halb auf die Öffentlichkeit berechneten Briefe", solche "angeblichen Briefe, deren Schreiber nicht naiv geblieben ist, bei jedem Worte, vielleicht weil er sich für einen berühmten Mann hielt, nach der Öffentlichkeit schielend [...] $(1923,196)$. DeissmanN untersucht dann mit dieser Begrifflichkeit die "Brieflichkeit« der neutestamentlichen Briefe mit der These, dass "sämtliche Paulusbriefe wirkliche, unliterarische Briefe sind. Der Apostel Paulus ist Briefschreiber, nicht Epistolograph" (1923, 203).

In der darauf folgenden heftigen Diskussion wurden die Bedingungen antiker Korrespondenz deutlicher erkannt, dass nämlich nur selten klar zu unterscheiden ist, welche Briefe nur von einem Adressaten gelesen werden sollten, welche hingegen auch für dessen näheren oder weiteren Umkreis bestimmt waren und welche von Anfang an für die Veröffentlichung vorgesehen waren. Viele langwierige und längst nicht abgeschlossene Diskussionen zeigen, dass bei vielen Briefen nicht zu klären ist, ob sie für eine Publikation geschrieben wurden oder zunächst so oder ähnlich versandt worden sind (siehe etwa die Diskussionen zu Seneca, Plinius, Ambrosius, aber auch zu Horazens Epistulae und Ovids Epistulae ex Ponto). Denn die Gattung hat sich verändert, vor allem ausgeweitet: "Während z.B. der Brief des Speusippos an Philippos einen echten brieflichen Anlaß hat, die Empfehlung des Antipatros von Magnesia, wird die Briefform bei den Römern und dann in der christlichen Literatur als eine fertige literarische Form der Publizistik ohne jeden Anlaß angewandt « (SYKUTRIS 1931, 200, zum "Brief als Einkleidungsform «).

Die Kategorien Derssmanns leben aber trotz der offensichtlichen Probleme bei ihrer Anwendung unterschwellig fort, wobei aus Deissmanns »Brief« der »Privatbrief im engsten Sinn «, »Papyrusbrief" oder der »nichtliterarische Brief « wird und die "Epistel « zum »literarischen Privatbrief" oder "literarischen Brief" (dabei tritt allerdings das Problem auf, dass literarisch in unterschiedlichem Sinn verwendet wird: als `stilisiert, ausgefeilt ‘ oder `veröffentlicht bzw. für die Veröffentlichung gedacht ).

Dzıатzко im RE-Artikel »Brief« (1897) stellt überwiegend die Realien des Briefwesens dar. Er unterteilt in »eigentliche Briefe, irgend einem Bedürfnis des wirk- 
lichen Lebens dienend ( (die sich wiederum in private und öffentliche gliedern) (840), und "uneigentliche Briefe, die eine besondere Gattung der Litteratur bilden, die litterarische Epistel, lehrhaft oder unterhaltend, in welcher der Autor nur die Form des Briefes entlehnt, um in ihr zwanglos vor dem größeren Publikum sein Thema behandeln zu können “ (842). Seine Darstellung beschränkt sich auf den "eigentlichen Brief «, d.h. den (entweder privaten oder öffentlichen) Brief als "Ersatz mündlicher Mitteilungen«, den anderen Teil übernimmt ausführlich SyкUTRIs im RE-Artikel »Epistolographie« (siehe gleich unten).

Peter in seiner Monographie (1901) schreibt zunächst über die Anfänge der Briefliteratur, die antike Theorie und die Realien. Er spricht von einer Entwicklung vom »Brief« ("persönlicher Brief«) zur »Epistel« ("Kunstbrief«) (1of. mit 11, Anm. 2). Er präsentiert dann Sammlungen von Prosa-»Briefen “ und »-Episteln", von Cicero über Plinius, Fronto und Symmachus bis zur spätantiken »Epistolographie im südlichen Gallien und im oberen Italien «, wobei mit chronologischem Fortschreiten die Ausführlichkeit abnimmt. Nach diesem chronologischen Durchgang geht er über zu einer systematischen Darstellung weiterer Briefsammlungen mit Kapiteln zur »Epistel unter fremdem Namen «, zum "poetischen Brief«, zum »amtlichen Brief« und zum $» B r i e f$ als Einkleidung für Flugschriften, wissenschaftliche und litterarische Erörterungen, Mahnungen, Widmungen."

Ebenso wie die Monographie von PETER ist immer noch grundlegend der RE-Artikel von SYKUTRIs (1931), der sich sowohl der griechischen als auch der lateinischen Epistolographie widmet. SYKUTRIS unterteilt insgesamt in "Privatbrief im engsten Sinne, wie wir ihn vor allem durch die Papyrusfunde kennengelernt haben" (186) und »literarischen Brief«, wobei er hervorhebt, dass die Grenzen zwischen beiden nicht klar gezogen werden können (187). Ansonsten übernimmt er Peters Kategorien und nennt unter Rubriken, die sich kaum von denen PeTers unterscheiden, jeweils knapp Beispiele.

Im RAC-Artikel »Brief" von SCHNEıder (1954) bilden die "griechisch/römischen "Briefe eine regionale Gruppe neben anderen; grundsätzlich unterteilt er Briefe zunächst in "nichtchristliche" und "christliche", dann weiter nach Regionen; unter den "griechisch/römischen" Briefen stellt SCHNeIder dann einzelne Sammlungen vor unter ähnlichen Rubriken wie Peter.

Grundlegend zur Epistolographie im Allgemeinen ist auch die Monographie "Grundzüge griechisch-römischer Brieftopik « von Thraede (1970); er stellt die besondere »brieftypische Thematik« dar und beobachtet die Spannung zwischen Stabilität und Entwicklung der Topik in griechischen und lateinischen, heidnischen und christlichen Briefen (dazu auch oben 141).

Das Kapitel "L'epistolografia " von SCARPAT (1972) in der »Introduzione allo studio della cultura classica" berücksichtigt griechische und lateinische Epistolographen. Einleitende Bemerkungen sind u.a. der Unterscheidung zwischen privaten und öffentlichen Briefen gewidmet. In einem zweiten Teil charakterisiert SCARPAT eine Rei- 
he von »nicht-privaten « Briefsammlungen, die er mit leichten Unterschieden zu PEter untergliedert. Scarpat folgt Peter zum Teil (»Briefe der politischen Propaganda «, »Lehrbriefe«, "poetische Briefe«), außerdem aber verwendet er zur Einteilung auf der obersten Ebene Begriffe, die bei Peter untergeordnet sind (z.B. »Trostbriefe«).

Umfangreiche Studien zur lateinischen (Prosa-) Epistolographie vom 2. Jh. vor Chr. bis hin zur Zeit Frontos verdanken sich Cugusi (Evoluzione 1983; Modelli 1989), der auch Papyrusbriefe in seine Untersuchungen einbezieht (bes. 1993, 400-405; auch 1983, 271-284); CugusI behandelt ausführlich sowohl die einzelnen Epistolographen als auch übergreifende Themen wie "antike Brieftheorie", "Struktur von Briefen «, »Brieftopik«, »Klassifizierung von Briefen«. Cugusı (1983) unterteilt zunächst in "private « und "öffentliche "Briefe, die "privaten « dann weiter in "scherzhafte«, »Glückwünsche«, »Trostbriefe«, »Liebesbriefe« u.a.; die »öffentlichen Briefe « untergliedert er in "amtliche«, "autobiographische«, "politische«, »gelehrte/wissenschaftliche«, »Versbriefe« u.a.

Der spätantiken griechischen und lateinischen Epistolographie widmet sich ein Aufsatz von GARZYA im Kongressband "Le trasformazioni della cultura nella tarda antichità " (1985); anders als die bisher genannten Forscher verzichtet er auf eine Betrachtung verschiedener Briefarten oder einzelner Epistolographen und betrachtet die »lettera dotta "bzw. »lettera privata letteraria« (348) als Kommunikationsmittel und zeigt deren gesellschaftliche, inhaltliche und formale Konventionen auf.

Ebenfalls der griechischen und lateinischen Epistolographie der Spätantike gilt eine Einführung von Michaela ZELzer im "Neuen Handbuch der Literaturwissenschaft (Bd. 4: Spätantike, 1997); sie bietet exemplarisch einen Eindruck von einzelnen Topoi, von Charakteristika der Gattung, den Realien, den Fragen der Theorie, Problemen der Herausgabe von Sammlungen, besonders von den vielen einzelnen Epistolographen und den verschiedenen möglichen Inhalten von Briefen. Zelzer spricht nicht ausdrücklich von einer Kategorisierung von Briefen (die sie jedoch im Anschluss an ihre Vorgänger verwendet) und betont mehr die verschiedenen Funktionen von Briefen (z.B. 324: "Vermittlung von Information und Pflege persönlicher Beziehungen ", "erbaulich-belehrende Briefe«).

KlaUCK (1998), „Die antike Briefliteratur und das Neue Testament", gibt vor der Betrachtung der Briefe des NT eine Einführung in verschiedene Bereiche der antiken Epistolographie: Struktur von Briefen, Brieftheorie, Realien, Klassifikation von Briefen; außerdem stellt er eine Reihe von griechischen und lateinischen Epistolographen (sehr) knapp vor. Er unterteilt Briefe in »nichtliterarische« Briefe (die zumeist mit Papyrusbriefen identisch sind), "diplomatische« Briefe (von Königen oder Kaisern) und »literarische« Briefe; dadurch finden sich z.B. »Empfehlungs-« und »Freundschaftsbriefe« sowohl unter den nichtliterarischen als auch unter den literarischen Briefen.

Im Gegensatz zu den bisher genannten Arbeiten, in denen die explizit oder implizit vorgenommene Kategorisierung von Briefen eine Selbstverständlichkeit zu sein 
scheint und die damit verbundenen Probleme höchstens einmal bei der Diskussion um die Trennung zwischen "echtem Privatbrief" und "kunstvoller Epistel " anklingen, spricht KLaUCK deutlich von den dabei auftretenden erheblichen Problemen bzw. von "Hilfskonstruktionen [...], die wir zur Bewältigung der erdrückenden Materialfülle benötigen" (73) und von der Notwendigkeit eines "pragmatischen Modells" (72).

\section{c. 3 Zur Kategorisierung von Briefen}

Die "Hilfskonstruktion « für die vorliegende Untersuchung verzichtet auf eine Reihe der Kriterien, die in den erwähnten Studien zur antiken Epistolographie fungieren: Es wird nicht unterschieden zwischen Papyrusbriefen und solchen, die durch Abschriften tradiert wurden, da die handschriftlich überlieferten ihr Überleben ihrer Stilhöhe verdanken, sich prinzipiell aber z.B. eine auf Papyrus erhaltene Nachricht über eine gesunde Rückkehr nicht von einem Brief gleichen Inhalts von z.B. Symmachus unterscheidet; denn ebenso wie bei Papyrusbriefen hängt das Stilniveau bei den sprachlich anspruchsvollen, >literarischen« Briefen von Schreiber und Adressat ab.

Die Unterscheidung zwischen Prosa und Vers spielt in diesem Modell nur eine untergeordnete Rolle; dies hat den Vorteil, dass die Versepisteln von Horaz, Ovid, Ausonius, Paulinus von Nola und Claudian weniger isoliert stehen und in einen weiteren Zusammenhang eingeordnet werden können. Während Thrafde bei der Untersuchung der Brieftopoi Versepisteln einbezieht und somit auf die Zusammengehörigkeit verweist, werden sie sonst zumeist ausgeblendet (explizit z.B. CuGUSI 1989, 400) bzw. als "Unterabteilung" ausgegliedert. Doch viele Fragen der Forschung sind dieselben, wobei die vergleichbaren Fälle aufgrund der Trennung von Prosa und Vers selten in den Blick geraten. So hat sich bei den Versepisteln die Forschung ebenso wie bei Prosa-Briefen intensiv mit der Frage beschäftigt, ob und inwieweit man die Briefe als biographische Quelle verwenden könne, inwieweit es sich um "echte ", "spontan geschriebene" oder um »vorgebliche« Briefe handle. Ein umfassenderer Blick könnte vielleicht zu einer klareren Einschätzung beitragen.

Auch die häufig vorgenommene Unterscheidung zwischen christlichen und nichtchristlichen Briefen führt dazu, dass Zusammenhänge übersehen werden. Die Briefe des Christen Sidonius Apollinaris etwa haben viel mehr Ähnlichkeit mit den PliniusBriefen als mit denen des Hieronymus oder Ambrosius. Auch erscheint es weniger erstaunlich, dass die Kirchenväter den Brief für theologische Erörterungen nutzen, wenn man etwa Senecas epistulae morales danebenhält. ${ }^{329}$

329 Anders Zelzer (1994/5, 547): »Somit hat Ambrosius das Genus des Freundschaftsbriefes einem neuen, exegetischen Zweck dienlich gemacht (vielleicht hatte er auch dafür ein alexandrinisches Vorbild).. 
Verzichtet wird weiter auf die Unterscheidung zwischen "privat" und "öffentlich « (wichtig etwa bei Scarpat 1972, 474; Cugusı 1983, 30 ff., 47); denn diese Kriterien werden zum einen in der Forschung nicht einheitlich verwendet und zum anderen mit der Frage vermengt, ob es sich um »echte« oder "zu veröffentlichende « Briefe handelt. Da sich aber häufig weder die Grenze zwischen "privat« und »öffentlich« eindeutig ziehen lässt noch erkennbar ist, welche Briefe in der überlieferten Gestalt auch versandt wurden, sollte man diese Unterscheidung lieber nicht zum übergeordneten Kriterium machen.

Bei der Einteilung von Briefen gehe ich übergeordnet von den Personen aus, die von dem Brief betroffen sind: Verfasser, Adressat und Dritte. Erst in zweiter Linie wird unterschieden zwischen: ich-orientiert, du-orientiert, beziehungs-orientiert, er-/sieorientiert, sach-orientiert. Dieser zweite Schritt erweitert das in den neueren Philologien gemeinhin verwendete Modell, wie es z.B. NickisCH $(1991,12)$ beschreibt: „Da der Brief als Redesubstitut zum Zwecke eines dialogischen Austauschs fungiert, weist er wie jeder kommunikative Akt ein diesem entsprechendes Merkmal als dominant auf: Er informiert (sach-orientiert), appelliert (partner-orientiert) oder manifestiert (selbst-orientiert). « Doch bei dieser Dreiteilung lassen sich zwei Arten von Briefen, die einen Großteil der Briefe des Ennodius ausmachen, nur schwer einordnen: Empfehlungsschreiben appellieren zwar, sind aber nicht auf den Briefpartner orientiert, sondern beziehen sich auf einen Dritten. Bei Vorwürfen wegen Schreibfaulheit ist schwer zu entscheiden, ob sie eher partner- oder eher selbst-orientiert sind. Angesichts der antiken und spätantiken Gegebenheiten im Briefwesen empfiehlt sich daher die Erweiterung, die sowohl das Phänomen des Boten einbezieht (er-/sie-orientiert) als auch die Tatsache, dass der Inhalt vieler Briefe ausschließlich der Kontaktpflege dient (beziehungs-orientiert). Es sei also für antike und spätantike Briefe folgendes >Modell skizziert und zur Diskussion gestellt:

Den Inhalt eines Briefes oder eines Briefteils bestimmt schwerpunktmäßig: ${ }^{330}$

1. die Situation bzw. der Kenntnisstand des Verfassers (der entweder eine Reaktion erwartet, die ihn selbst betrifft [a], oder nicht $[\mathrm{b}])$ :

a) Der Inhalt ist von Interesse/Nutzen für den Verfasser, denn vom Adressaten wird eine Reaktion/Handlung in Bezug auf den Verfasser erwartet: Bitten, Aufträge (ich-orientiert), Anfragen (sach-orientiert), Einladungen (beziehungs-orientiert). - Solche Briefe sind für einen breiteren Leserkreis kaum wegen des Inhalts, sondern nur wegen des Stils interessant.

330 Eine strikte Unterscheidung ist nur selten möglich, da in unterschiedlichem Maße zumeist Mehreres vorhanden ist; so sind Empfehlungsschreiben in erster Linie er-/sie-orientiert, handeln aber natürlich immer auch von der Beziehung zwischen Verfasser und Adressat. 
b) Der Inhalt ist von Interesse/Nutzen für den Adressaten; es wird nicht unbedingt eine Reaktion in Bezug auf den Verfasser erwartet, da das Ergebnis des Briefes eher den Adressaten betrifft: Nachrichten, Berichte, Mitteilungen, Auskünfte, Belehrungen (auch Edikte in Briefform); diese können, müssen aber nicht, eine Antwort auf eine Anfrage (die leicht fingiert werden kann) sein. Der Übergang von knapp mitgeteilten Nachrichten über den eigenen Gesundheitszustand (ichorientiert), sei es in einem auf Papyrus erhaltenen Brief eines nur mit Mühe schreibenden Soldaten oder in einem ausgefeilten Brief entsprechenden Inhalts z.B. von Fronto, über eine gründliche Darstellung der eigenen Lage bis zu ausgestalteten Berichten über die Lage des Staates, sei es aus persönlichem Interesse oder in Ausübung eines Amtes (sach-orientiert), ist fließend; ebenso gibt es keine klare Grenze zwischen gelegentlichen Ermahnungen und Belehrungen und dem Lehrbrief; ${ }^{331}$ schon bei Cicero ist der Übergang zum Essay / libellus angelegt. Diese Briefe können entweder eher ‘reale` Inhalte haben (etwa Berichte eines Feldherrn an den Senat) oder eher sintellektuelle` (etwa Senecas epistulae morales), wobei christliche Briefe über konkrete Angelegenheiten der Gemeinde in der Mitte stehen (z.B. Paulus; Cyprian). Die sach-orientierten Briefe dieser Gruppe können bei entsprechendem sprachlichem Niveau einem Bericht, einem Vortrag, einer Predigt nahekommen. - Die Briefe dieser Gruppe, besonders die sach-orientierten, sind aufgrund ihres Inhalts auch für andere Leser als den oder die ursprünglichen Adressaten interessant bzw. verwendbar, z.B. die PaulusBriefe, die zunächst aus aktuellem Anlass geschrieben wurden, dann aber in den Kanon des NT aufgenommen wurden.

2. die Situation des Adressaten (von der der Verfasser mündlich oder schriftlich informiert worden sein kann) (du-orientiert): Glückwunsch, Trost.

3. die Situation eines Dritten, häufig des Boten (er-/sie-orientiert): Empfehlungsschreiben, Bitten für Dritte.

4. die Beziehung zwischen Adressat und Verfasser (beziehungs-orientiert): Kontaktaufnahme, Kontaktpflege (Gruß, Dank für Briefe, Klagen wegen Schreibfaulheit, Entschuldigung eigenen Schweigens). Diese Briefe können entweder nur wegen ihrer sozialen Funktion entstanden und mit einem speziellen Boten geschickt worden sein, oder sie können geschrieben worden sein, weil sich zufällig ein Überbringer anbot, ohne dass schon vorher der aktuelle Wunsch zum Schreiben vorhanden war, denn: »Ein nicht zu unterschätzender Anlaß <zum Briefschreiben> ist der Zufall, daß gerade ein Briefbote, dem man einen Brief mitgeben kann, angekommen ist «. ${ }^{332}$ Eine weitere Möglichkeit ist, dass ein Brief eine Beigabe zu einer wichtigen mündlichen Nachricht war; denn die ursprüngliche

331 Vgl. Sy kUtris $(1931,202)$ zum "Lehrbrief«. Peter $(1901,16 f$.$) leitet im Anschluss an Hir-$ zEL (Dialog) den Lehrbrief aus den Philosophenschulen und vom Dialog her.

332 BÜCHNER 1939, 1207. 
Funktion von Briefen, mündliche Nachrichten zu ersetzen, hat sich in vielen Fällen dazu gewandelt, dass der Brief die mündliche Nachricht wie eine Visiten-

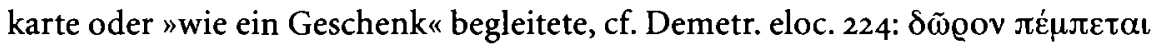

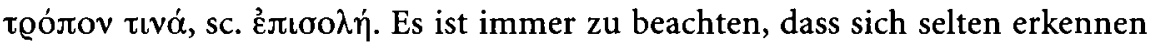
lässt, ob der Bote etwas Wichtiges ausgerichtet hat bzw. worum es sich dabei gehandelt haben könnte. Es ist möglich, dass viele der >topischen` Briefe, die scheinbar nur der ,Kontaktpflege dienen (,Wie geht es Dir? ‘,Warum schreibst Du nicht? (), eine wichtige mündliche Nachricht begleiteten.

Die meisten Briefe des Ennodius gehören zu den Gruppen 1a, 2 und 3, besonders aber zur Gruppe 4. Er schreibt keine Lehrschriften wie etwa Hieronymus oder Darstellungen in der Art eines Plinius oder Sidonius Apollinaris, sondern ganz überwiegend handelt es sich um Briefe in »Standardsituationen des Lebens«: Glückwünsche, Empfehlungen, Trostschreiben, Kontaktaufnahme, Kontaktpflege. Warum Ennodius gerade diese Art Briefe schreibt und sich nicht in die Tradition des Sidonius Apollinaris stellt, ist weiter unten zu betrachten. Zunächst soll die allgemeine Funktion der für Ennodius so wichtigen beziehungs-orientierten Briefe (Gruppe 4) genauer betrachtet werden.

d. Die gesellschaftliche Funktion von Briefen: Amicitia und Performance

In Teil I dieser Arbeit wurde die Bedeutung von sprachlich-rhetorischer Bildung für die Angehörigen des Adels dargestellt, besonders die Rolle von Korrespondenz während der Ausbildung als eines Mittels, die Fortschritte im sprachlichen Ausdruck zu zeigen. Auch für die horizontale Kommunikation zwischen mehr oder weniger gleichgestellten Persönlichkeiten haben Briefe eine wichtige Funktion, die durchaus nicht immer im gedanklichen Austausch über wichtige Themen bestehen muss, wie sich dieser z.B. in den Briefen von Hieronymus, Augustin, Paulinus von Nola beobachten lässt. Viele überlieferte Briefe haben ihren Zweck weniger in einem solchen Gedankenaustausch oder in der Übermittlung einer bestimmten Nachricht (was in der Regel dem Boten überlassen werden konnte) als vielmehr in der gegenseitigen Versicherung des Wohlwollens, dem Erhalt von Verbindungen, der Bestärkung des Zusammengehörigkeitsgefühls innerhalb der herrschenden Schicht bzw. innerhalb von bestimmten Kreisen (nicht zuletzt unter Christen, siehe WHITE 1992, 5), ${ }^{333}$ kurz

333 Zur Funktion von Briefen im Beziehungsgeflecht und zur Bedeutung des Adressatenkreises siehe: Stefan Rebenich, Hieronymus und sein Kreis. Prosopographische und sozialgeschichtliche Untersuchungen, Stuttgart 1992. - MratscheK (Paulinus von Nola, 2002), spricht von "literary networks (3). - Auch Ciceros Briefe haben eine vergleichbare Funktion, siehe W. C. SchNeIder, Vom Handeln der Römer. Kommunikation und Inter- 
gesagt: Briefe können als Zeichen der amicitia dienen. ${ }^{334}$ Bei Briefen, die zur Kontaktpflege geschrieben werden, ist - unabhängig vom Inhalt - das Schreiben an sich ein Zeichen der Freundschaft.

Nun ist amicitia nicht mit "Freundschaft" im heutigen Sinne gleichzusetzen, wenn es auch, wie mangels Alternativen allgemein üblich, mit "Freundschaft « übersetzt wird. Mit amicitia wird nicht immer eine positive emotionale Gestimmtheit oder besonders enge Vertrautheit bezeichnet, sondern häufig eine gesellschaftlichsoziale Konstellation, die weniger mit Gefühlen zu tun hat als vielmehr mit einem Netz von Kontakten, mit der Zugehörigkeit zu einem bestimmten Kreis, der sich u.a. durch die Partizipation am gleichen Bildungsgut definiert, und daher nicht zuletzt mit gesellschaftlicher Position und Macht. ${ }^{335}$ Es wird daher auch nicht erwartet, dass der Verfasser vor dem ১befreundeten ‘ Adressaten sein Herz ausschüttet und sein Innerstes offenlegt. Oft wird die amicitia an sich thematisiert oder bestimmte Verhaltensweisen, die das zwischen den Korrespondenten bestehende Verhältnis der amicitia aufzeigen können, oder es werden andere Themen in der Weise behandelt, dass dadurch die amicitia zwischen Verfasser und Adressat deutlich wird. - Eine wichtige Spielart der amicitia ist die Verbundenheit unter Christen, wie sie besonders Paulinus von Nola kultiviert und thematisiert (Mratsché 2002, $490 \mathrm{ff}$.), von der Ennodius aber nur selten spricht (siehe unten 202).

Zum Zeichen einer bestehenden amicitia werden reine Freundschaftsbriefer versandt (siehe dazu z.B. Zelzer, Sidonius, 1994/5,544), in denen die Mitteilungsfunktion des Briefes gegenüber der sozialen Funktion des Freundschaftsbeweises drastisch reduziert ist, bzw. in denen die Mitteilung ausschließlich das zwischen den Korrespondenten bestehende Verhältnis und die Kontaktaufnahme an sich betrifft (im oben skizzierten Modell Gruppe 4: beziehungs-orientierte Briefe). Die Funktion von Briefen hat sich im Laufe der Zeit also ins Gegenteil gewandelt, wenn man annimmt, dass Briefe ursprünglich *Aufträge und Nachrichten zum Ersatz mündlicher Mitteilungen durch Boten « enthielten und sich »in ältester Zeit natürlich auf Fälle < beschränkten>, wo die mündliche Botschaft nicht auszureichen schien “ (Dziatzko 1897, 836). Mit der Zeit war es offenbar häufig entweder sicherer, die eigentlichen Nachrichten dem Boten mündlich anzuvertrauen, damit die Nachricht nicht so leicht in falsche Hände geraten konnte, oder - im Gegenteil - die Nachricht an sich erschien für die schrift-

aktion der politischen Führungsschicht vor Ausbruch des Bürgerkriegs im Briefwechsel mit Cicero, Hildesheim u.a. 1998.

334 Bzw. bei Ennodius auch: affectio, affectus, amor, caritas, dilectio, diligentia, gratia.

335 Zum weiten Komplex der amicitia siehe z.B.: WHITE, Christian Friendship [...], 1992. BRUGGISSER, Symmaque ou le rituel épistolaire de l'amitié littéraire [...], 1993. - A. FürST, Streit unter Freunden. Ideal und Realität in der Freundschaftslehre der Antike, Stuttgart u.a. 1996 (BzA 85). - D. Konstan, Friendship in the Classical World, Cambridge 1997. - K. TreU, »Freundschaft «, RAC VIII, 1972, 418-434. - Weitere Literatur bei: O. HiLtbrunNER, Bibliographie zur lateinischen Wortforschung, Bd. 2, Bern u.a. 1984, $171 \mathrm{ff}$. 
liche Ausgestaltung nicht wichtig bzw. nicht interessant genug, um sie sorgfältig auszuformulieren. Symmachus z.B. hat zuweilen konkrete Mitteilungen in (nicht überlieferten) Anhängen beigegeben. ${ }^{336}$

So stellt Bruggisser seine Untersuchung des ersten Buchs der SymmachusBriefe (1993) unter den programmatischen Titel »Symmaque ou le rituel épistolaire de l'amitié littéraire « und beginnt mit dem Hinweis, dass es in den Briefen nicht darum gehe, Nachrichten zu übermitteln, sondern darum, "un rite social et culturel" auszuüben; die Botschaft steht nicht im Brief, sondern sie ist der Brief selbst (3): „La lettre de Symmaque n'est pas le support d'une information, mais l'accomplissement d'un rite social et culturel. Alors que très souvent l'information elle-même consiste en instructions confiées oralement au porteur de l'epistula ou consignées dans une pièce annexe, le message n'est pas contenu dans la lettre, il est la lettre elle-même.«

Die Funktion des Briefs, als ein Zeichen der Verbundenheit bzw. Zugehörigkeit zu einer bestimmten Gruppe zu dienen, steht in engem Zusammenhang damit, dass sich dem Verfasser in Briefen die Möglichkeit bietet, dem Adressaten (und dessen Umkreis) gezielt und unter Aufbietung aller sprachlich-stilistischen Fähigkeiten ein bestimmtes Bild von sich selbst zu vermitteln. Zu Symmachus, der seine Briefe nicht in erster Linie für die Veröffentlichung geschrieben hat, verweist BRUGGISSER (1993) eingangs kurz darauf, dass in einem Brief dem Adressaten der Status und die Bildung des Verfassers gezeigt werden; die Briefe, »souvent subordonnées à l'art du paraître«, illustrieren seine Situation, seine Verbindungen und Einflussmöglichkeiten. "La lettre est une manifestation de l'amitié et, à ce titre, elle peut être un instrument de carrière" (3). Im Brief zeigt man nicht nur seine amicitia, sondern auch die sprachlichen Fähigkeiten, die ja ein entscheidendes Kriterium für die Definition der herrschenden Schicht waren: "Ein entscheidender Bereich senatorischen Selbstverständnisses waren Pflege und Demonstration von Bildung" (NäF 1995, 47), und um die Bildung aufzuzeigen, waren Briefe neben dem persönlichen Auftreten ein unverzichtbares Medium.

"Die Gebildeten kannten aus Theorie und Praxis als Inbegriff der Epistolographie den Typus des kultivierten Freundschaftsbriefes, weder >rein literarische Form noch `rein` sprudelnde Natürlichkeit, sondern persönlich gefärbte Konvention und gesellschaftlich stilisierte Individualität« (ThRAEDE 1970, 3). Unter Gebildeten geschätzt und gepflegt wurde der "literarische Privatbrief « (GARZYA 1985, 348), d.h. ein stilistisch ausgefeilter Brief für den Adressaten (und dessen Umkreis, dem er ihn zu

336 Z.B.: "Doch die Einzelheiten kann Dir die Aufstellung in der Anlage zeigen oder auch Rufus berichten« (Sy. 1,68 singula autem tibi vel commonitorii series indicabit vel Rufus expediet ...). »Die Vorkommnisse in der Stadt könnt Ihr der beigefügten Aufstellung entnehmen « (Sy. 6,48 quae ad urbem pertinent, indiculi cohaerentis lectione noscetis); siehe auch Sy. 5,$21 ; 5,22 ; 5,26 ; 6,2 ; 6,40,2 ; 6,45 ; 6,55 ; 6,65,1 ; 7,82$. 
lesen geben konnte), der sich durchaus auch veröffentlichen ließ. Es war selbstverständlich, dass der Verfasser durch die Stilisierung des Briefs seine Bildung und damit seine Berechtigung, zum gleichen Kreis wie der Adressat zu gehören, zeigte, und es hätte grob gegen die Regeln verstoßen, wenn ein Gebildeter an einen ebenfalls Gebildeten sogenannte »eigentliche Briefe« geschrieben hätte, wie sie der Sand Ägyptens aufbewahrt hat.

Daher ist man von der Erwartung, dass sich der Schreiber eines Briefes unmittelbar >outet $<,{ }^{337}$ in der Forschung zur Epistolographie allgemein ${ }^{338}$ und auch in großen Teilen der Klassischen Philologie inzwischen abgerückt, wobei im Rahmen der lateinischen Epistolographie die Forschung zu Plinius in dieser Frage am weitesten ist. LuDOLPH (1997) untersucht unter dem programmatischen Titel "Epistolographie und Selbstdarstellung " besonders die "Paradebriefe « des Plinius (epist. 1,1-8). Dabei ist für LudoLPH vor allem die Tatsache, dass Plinius selbst die Sammlung hergestellt hat und sie deshalb ein literarisches Werk ist, der Ausgangspunkt dafür, den historischen Autor und das briefliche Ich zu trennen (16f.); er legt dar, dass, auf welche Weise und warum Plinius die Briefe als Mittel verwendet, "gezielt ein Bild von sich zu zeichnen, das, ohne mit der Realität übereinstimmen zu müssen, sein Nachleben würde sichern können« (19). LudolPH betont (20), "dass für die Selbstdarstellung in einem publizierten Briefcorpus ganz andere Bedingungen gelten als für die Selbstdarstellung in einem echten Gebrauchsbrief «; er zeigt, dass Plinius in den bewusst angeordneten Briefen gezielt ein stimmiges Bild von seiner Persönlichkeit in ihren vielen Facetten (Anwalt, pater familias, Gutsbesitzer, Freund, Dichter etc.) aufbauen kann.

Doch Selbstdarstellung ist keineswegs nur ein Phänomen von solchen Briefen, die vom Verfasser selbst für einen weiteren Leserkreis herausgegeben wurden, wie man dies nach LudoplPHs Untersuchungen annehmen könnte. So wie eine herausgegebene Sammlung auf die Wirkung bei der Mit- und Nachwelt zielte, so hatte zunächst jeder einzelne versandte Brief ein Ziel beim ersten Adressaten; auch in Briefen, die (zunächst) nur einen Adressaten (und dessen näheren Umkreis) im Auge haben, präsentiert der Verfasser ein bestimmtes Bild von sich.

Briefe hatten also für ihre jeweilige Gegenwart (und haben auch für die Nachwelt) eine soziale Funktion im Rahmen von "self presentation and social identification ". ${ }^{339}$

337 Siehe z.B. Peters Ansicht (1901, 12): »das Künsteln in der Form gilt uns als mit seinem $<$ sc. des Briefes $>$ Wesen unvereinbar, als erster Vorzug $<$ des Briefes $>$ wahre und echte Natürlichkeit.«

338 Siehe aus der Menge der Forschungsliteratur z.B.: A. C. ANTon, Authentizität als Fiktion, Briefkultur im 18. und 19. Jahrhundert, Stuttgart u.a. 1995. - T. VAN HoudT, J. PAPY u.a. (Hgg.), Self-Presentation and Social Identification. The Rhetoric and Pragmatics of Letter Writing in Early Modern Times, Leuven 2002.

339 Dieses Phänomen, dass Briefsammlungen als "Selbstporträt" dienen können und dass Epistolographen sich als "managers of their own reputation « betätigen, beschränkt sich 
Die Epistolographen haben für ihre Adressaten bewusst ein Bild (bzw. verschiedene Bilder) von sich entworfen. Dieses Bild musste, zumindest im Fall von »echten« Briefen, überzeugend und glaubhaft sein, damit die briefliche Kommunikation funktionieren konnte. Allerdings sprach man nicht von der Möglichkeit, Retuschen vorzunehmen, sondern im Gegenteil von der unmittelbaren Ersetzung der Person durch den Brief, "Zwar weist Deine Sprache höchsten Glanz auf, doch noch größerer leuchtet mir in Deiner Zuneigung; denn in Deinen Briefen sehe ich den Glanz Deiner Seele. [...] « (Ambr. 7,53). ${ }^{340}$ Die Bemühung um Glaubhaftigkeit wurde unterstützt durch den Topos vom "Brief als Spiegel der Seele ${ }^{341}$ Ennodius äußert diesen Gedanken in von ihm selbst unveröffentlichten Einzelbriefen): »[...] ich glaube, dass Briefe Spiegel des Herzens sind, durch die man aus der Entfernung sehr wohl Freundschaft erkennen kann " $(113,2){ }^{342}$ Allerdings verändert er in anderen Briefen das Motiv dahingehend, dass der Verfasser sich beim Schreiben ein Bild des Adressaten schafft, um mit ihm zu sprechen, $"[\ldots]$ die Sprache malt im Brief so wie in einer Art Spiegel ein ihr angenehmes Bild, mit dem sie wie lebendig spricht « (110,1); »Als Trost bleibt nur der Trost der Briefe; denn wenn ich Worte an Euch richte, schmeichelt meinen Wünschen ein Bild Eurer Anwesenheit “ $(276,1)$; "Ohne irgendeinen Trost müsste man die Abwesenheit von Freunden ertragen, wenn nicht heilende Briefe zu Hilfe kämen, die die hungernden Seelen der Sehnsüchtigen mit der Speise des Gesprächs ernähren. Denn die Freundschaft kann sich gut mit dem Griffel das Bild des Freundes malen, um mit ihm ohne große Mühe süße Gespräche zu wechseln« $(419,1) .{ }^{343}$

Doch: Diese Epistolographen treten nicht unvorbereitet vor den Spiegel, sondern sie machen sich gezielt und gründlich so zurecht, dass das Spiegelbild ihren Wünschen entspricht und auch anderen präsentiert werden kann. Briefe spiegeln also die Seele keineswegs unmittelbar, sondern so, wie die Verfasser sie gesehen wissen wollten. Daher ist es nicht überraschend, dass auch vom "(Brief-)Buch als Spiegel der Seele" gesprochen werden kann: So schreibt Sidonius Apollinaris an den Widmungsadressa-

nicht auf die Antike, wie immer wieder zu sehen ist, siehe van HoudT $(2002,3 ; 6 ; 10$ u.ö.) zu denselben Phänomenen in den Briefen von Mitgliedern der »Respublica litterarum " der frühen Neuzeit.

340 (Ambr. 7,53) Summus quidem splendor in sermone est tuo, sed magis in affectu elucet mihi; nam in epistulis mentis tuae aspicio fulgorem [...].

341 Zur Geschichte des Topos siehe Müller 1980.

$342(113,2)[\ldots]$ in paginis speculum puto esse conscientiae, per quas amicitiam discernere absentia vix praesumit.

$343(110,1)[\ldots]$ quasi in quodam speculo ita in paginis sermo sibi amicam pingit effigiem, cum qua viva vice conloquitur; $(276,1)[\ldots]$ sola in consolatione remanserunt solacia litterarum, quia dum sermo ad vos dirigitur, aliqua praesentiae vestrae desideriis meis imago blanditur. $(419,1)$ Insolabiliter amantum ferretur absentia, nisi opem darent remedia litterarum, quae ieiunas desiderantum animas pascunt esca conloquii. bene enim per stilum dilectio amicam sibi pingit effigiem, cum qua sine laboris patientia misceat mella sermonum. ad hoc magnitudo tua artifex, ne inpastam gratiam linqueres, scripsisti. 
ten eines Briefbuchs, das dieser vor der Verbreitung noch begutachten soll: »Ich übergebe also die verschiedenen Bewegungen meines Herzens Deinem Urteil, wohl wissend, dass die Seele in einem Buch so offenliegt wie das Gesicht im Spiegel (velut vultus in speculo). Denn in manchen Briefen habe ich ermahnt, in vielen gelobt und in einigen Rat gegeben, selten geklagt und manchmal gescherzt [...]« (Sidon. 7,18,2). ${ }^{344}$ Der Gedanke findet sich auch bei Cassiodor in der Praefatio zu den Variae, als er die Argumente derer nennt, die ihn bitten, seine Briefe nicht länger unter Verschluss zu halten: »Du verbirgst [...] den Spiegel Deiner Seele (speculum mentis tuae), in dem Dich die ganze Zukunft betrachten kann “ (Cassiod. var. praef. 10). ${ }^{345}$

Allerdings ist dieser Topos vom Brief als ,Urkunde des Herzens der Seele r lange zu wörtlich genommen worden. Briefe wurden lange Zeit fast ausschließlich als Quelle betrachtet, sei es für die Zeitgeschichte und die Biographie des Verfassers, sei es für ein Bild seines Charakters, das sich eben aus dem >Spiegel der Seele` ergeben soll. ${ }^{346}$, Authentizität` war das entscheidende Kriterium sowohl für den sunverstellten< Einblick in die Seele als auch für die ,Wahrheit ‘ der aus der Quelle hervorgehenden Informationen.

Zum Ritus des Briefeschreibens unter Freunden gehören ganz spezielle `Spielregeln`, die zum einen das Entstehen von Briefen überhaupt beeinflussen, wie etwa die Verpflichtung, auf einen erhaltenen Brief zu antworten (siehe z.B. zu Paulinus von Nola bei MratsCheK 2002, 39of.). Die 'Spielregeln (beziehen sich aber auch auf den Inhalt und auf das Verhalten des Verfassers gegenüber dem Adressaten: Loyen $(1943,98 f$.) erkennt bei Sidonius Apollinaris folgende Spielregeln ("usages courtois «), wobei er sich besonders auf epist. 4,17 bezieht: 1. caritas, die verlangt, dass man die Werke der Freunde lobe; 2. verecundia oder pudor, d.h. die Bescheidenheit, Zurückhaltung; 3. urbanitas ("le savoir-vivre"), die verlange, dass man seine eigenen Werke grundsätz-

344 (Sidon. 7,18,2) commendo igitur varios iudicio tuo nostri pectoris motus, minime ignarus, quod ita mens pateat in libro velut vultus in speculo. dictavi enim quaepiam hortando, laudando plurima et aliqua suadendo, maerendo pauca iocandoque nonnulla [...].

345 (Cassiod. var. praef. 10) celas [...] speculum mentis tuae, ubi te omnis aetas ventura possit inspicere.

346 In der Forschung wurden Briefe häufig als unmittelbarer 'Spiegel ^der Seele und des Charakters angesehen, siehe z.B. über Cicero: »moralische Schwächen treten ungeschminkt hervor $[\ldots]$. Es ist kein großartiger, kein fester, in sich geschlossener Charakter " (Schanz) Hosıus I,483). - Plinius: "dessen (freilich nicht schwerwiegende) charakterliche Schwächen selbst dem oberflächlichen Betrachter nicht verborgen bleiben konnten [...] « (H.-P. BüTler, Die geistige Welt des jüngeren Plinius, Heidelberg 1970, 7). - Ambrosius: „Wertvoll für die Zeitgeschichte sind seine Briefe, in denen sich seine Energie, seine Klugheit und seine Güte deutlich offenbaren " (W. WILBRAND, RAC 1, 1950, 368). - „Ennodius, matt als Mensch und Autor« (H. FunrmanN, Einladung ins Mittelalter, München 2000 [zuerst 1987], 158). 
lich abwerte. Zu Symmachus beobachtet BrUgGisser (1993, 19-24) Ähnliches: Das Verhalten des Symmachus und seiner Korrespondenten wird von fünf Normen bestimmt: 1. Wohlwollen, Nachsicht (»bienveillance«): das Interesse für den Adressaten; Nachsicht, wenn er einer Pflicht nicht nachkommt; Vertrauen auf die Treue des Adressaten; 2. das Bestreben, sich selbst herabzusetzen und den anderen zu loben (»bienséance «); 3. Anmut, Humor (»agrément»): das Bestreben, nicht mit zu vielen Details zu langweilen, keinen Verdruss hervorzurufen; 4. Vorsicht, weil Briefe abgefangen werden könnten ("prudence«); 5. Zurückhaltung ("retenue «): das Bestreben, seine Freunde nicht mit seinem Kummer zu behelligen und unnötig zu beunruhigen.

Im folgenden soll (nach einer Vorstellung der mit Ennodius zu vergleichenden Epistolographen) dargestellt werden, wie sich Ennodius präsentiert: inwieweit er in der Verwendung der entsprechenden $>$ Brieftopoi` mit anderen Epistolographen übereinstimmt, inwieweit bzw. in welcher Form es sich auch bei den Briefen des Ennodius, die ja sehr häufig dem Kontakt zwischen Verfasser und Adressat dienen, um eine "manifestation de l'amitié" handelt und inwieweit er vergleichbare Spielregeln befolgt wie Symmachus, Sidonius Apollinaris und andere. Bisher wird Ennodius durchweg in Übereinstimmung mit den Konventionen gesehen (zuletzt KenNell 2003). Das Ergebnis dieser Untersuchung dürfte daher auch angesichts der communis opinio über die Vorbildfunktion des Symmachus einigermaßen verblüffen. Denn es wird sich zeigen, dass Ennodius nicht nur besonders gegen die Spielregeln »Nachsicht" und ZZurückhaltung« verstößt, sondern häufig auch gegen die Forderung, selbst bescheiden zu sein und den anderen umso mehr zu loben (besonders letzteres Beobachtung widerspricht dem bisher gängigen Urteil von der "molesta modestia « des Ennodius, z.B. Vogel 1885, Praef. III). Dies steht insgesamt im Gegensatz zu der Annahme, Ennodius folge seinem Vorbild Symmachus, denn anders als der freundliche, nachgiebige und verständnisvolle Symmachus präsentiert sich Ennodius sehr häufig als streng, unnachgiebig und klagend. In anderen Briefen allerdings ist Ennodius ganz der freundliche und demütige Diakon. Diese verschiedenen Rollen sind aber keineswegs austauschbar, da sie von Ennodius' Beziehung zum Adressaten und von dessen Situation bestimmt sind; zu revidieren ist daher folgendes Urteil von PETER (1901, 167): "Die Anpassung des Tones des Briefes an die Person des Empfängers hat er <sc. Ennodius $>$ zwar gelehrt, aber selbst noch weniger durchgeführt als Symmachus ${ }^{347}$ In manchen Passagen wird allerdings deutlich, dass die strenge Haltung des Ennodius nur eine Pose ist, die sich der inventio für einen besonderen Brief ver-

347 KenNell (2000) verweist zwar mehrfach darauf, dass Ennodius situations- und publikumsbezogen schreibe (z.B.: »[...] every single composition - letters, epigrams, dictiones - was intended for a specific situation and audience at a specific moment in time«, 21), bleibt aber nachvollziehbare konkrete Belege schuldig. Siehe auch unten 285. 
dankt; andererseits schimmert auch in manchen freundlichen Briefen durch doppeldeutige Bemerkungen ein weniger freundlicher Verfasser durch. Ennodius tritt offenbar gezielt bald freundlich, bald unzufrieden auf. Neben manchen freundlichen Briefen steht eine ganz erhebliche Anzahl von Briefen, die sich geradezu als sexercise in polite rudeness or amicable hostility « bezeichnen lassen (in den Worten von E. OLIENSIS zu Horazens epist. 1,7). ${ }^{348}$

\section{e. Die zu vergleichenden Epistolographen}

Die Briefe des Ennodius sollen im Folgenden im Vergleich mit anderen Epistolographen analysiert werden, und zwar in einem ersten Schritt anhand einiger Aspekte, die die Briefe insgesamt betreffen (Teil II 2): Die Briefe als Möglichkeit zur Selbstdarstellung und, davon nicht zu trennen, als Zeichen der amicitia (vgl. oben 15off.); dazu gehört auch die Untersuchung, wie Ennodius manche brieftypische Topoi (vgl. oben 141) verwendet.

Zum Vergleich eignet sich ganz besonders das Corpus der Symmachus-Briefe, da Symmachus wie Ennodius sehr viele 'nicht inhalts-orientierte Briefer schreibt bzw. sich ebenfalls überwiegend der Kontaktpflege widmet; außerdem lässt sich sicher zeigen, dass Ennodius Symmachus-Briefe kannte. Die Variae Cassiodors sind interessant als zeitlich und räumlich nächste Briefe, wobei sich zwar der Inhalt kaum zum Vergleich anbietet - Cassiodor schreibt amtliche Briefe im Namen des Herrschers und nicht, um eigene Kontakte zu pflegen -, aber umso mehr die Briefstruktur. Bei der Betrachtung der Brieftopoi lassen sich neben Symmachus punktuell auch Briefe von Cicero, Plinius, Fronto, Ambrosius, Hieronymus, Paulinus von Nola und Augustin heranziehen; damit soll nicht gesagt sein, dass Ennodius exakt das jeweils Zitierte gekannt und als Quelle benutzt haben muss, sondern es soll auf analoge Fälle, auf die Tradition der Topoi hingewiesen werden, die Ennodius aus zahlreichen, auch uns nicht bekannten Briefen vertraut war. Bei der Betrachtung von in bestimmten Situationen entstandenen Briefen, wie z.B. Glückwunschbriefen, ist neben Symmachus auch Sidonius Apollinaris heranzuziehen, seltener ist auf Cicero oder Plinius zu verweisen. Nicht zum Vergleich mit den Ennodius-Briefen eignen sich rein exegetische, kirchenpolitische oder gemeindeorientierte Briefe der Kirchenväter oder rein darstellende Briefe von Plinius oder Sidonius Apollinaris, da sich aufgrund der zu großen Verschiedenheit kein Ansatzpunkt zum Vergleich bietet (also Briefe der Gruppe 1b, siehe oben 148). - Die im allgemeinen weniger bekannten spätantiken Epistolographen sollen zunächst kurz vorgestellt werden, wobei auf ihre jeweilige Bedeutung für die Ennodius-Briefe hingewiesen wird.

348 Ellen W. Oliensis, Horace and the Rhetoric of Authority, Cambridge 1998, 157. 
Zum Forschungsstand zu den verschiedenen Epistolographen, der in diesem Rahmen nicht im einzelnen dargestellt werden kann, ist vorab insgesamt zu sagen, dass gattungsspezifische oder überhaupt literaturwissenschaftliche Ansätze rar sind (zu allgemeinen Einführungen siehe oben 142). Ganz überwiegend widmen sich Untersuchungen zu einzelnen Briefen biographischen, (kirchen)historischen, prosopographischen Fragen, Problemen der Datierung der Briefe, der Frage nach der Überarbeitung bzw. der Entstehung der Briefe für die Publikation, häufig (nicht nur bei neu aufgefundenen Briefen) der Verfasserfrage; Untersuchungen zu Sprache und Stil beschränken sich zumeist auf die Anredeformen oder die Nachweise von Kenntnissen der klassischen Literatur.

\section{Symmachus}

Von Symmachus (um 340-402), dem berühmtesten Redner seiner Zeit, sind neben Fragmenten von acht Reden gut 900 Briefe an Verwandte, Freunde und Amtsträger überliefert, außerdem 49 amtliche Schreiben (sog. relationes) an den Kaiser, die in Symmachus' Zeit als Stadtpräfekt (384/5) entstanden sind. Lange Zeit hat sich die Forschung überwiegend mit Symmachus als einem der Anführer der Senatoren im letzten Kampf des Heidentums ‘ beschäftigt, d.h. mit der Kontroverse um den Erhalt traditioneller religiöser Institutionen und besonders des Victoria-Altars, die durch die 3. Relatio des Symmachus und die Entgegnung des Ambrosius (epist. 72 [17]; 73 [18]) dokumentiert ist. ${ }^{349}$

Die Sammlungen der Symmachus- und der Ennodiusbriefe ähneln sich rein äuBerlich in mancher Hinsicht. Beide Verfasser haben ihre Briefe zwar gesammelt, aber nicht selbst herausgegeben; wahrscheinlich ist der Sohn des Symmachus für die Edition verantwortlich (MATTHEws 1974, 67f.). Es gibt daher bei beiden, anders als z.B. bei Plinius, Sidonius Apollinaris oder Cassiodor, kein Vorwort. Beide schreiben sowohl an Verwandte und Freunde als auch an Amtsträger; viele Adressaten erhalten eine ganze Reihe von Briefen. Beide schreiben keine Abhandlungen in Briefform, keine längeren Erzählungen, sondern viele Briefe zur Kontaktpflege, Briefe zu bestimmten Anlässen wie Empfehlungs-, Glückwunsch-, Dank-, Trostbriefe, und auch Briefe mit konkreten Fragen, Problemen oder Informationen.

Eine gute Einführung in die Symmachus-Briefe und insgesamt zu Symmachus gibt Matthews (1974), der sich gegen viele der (anachronistischen Vor-) Urteile wendet und eine positive Perspektive auf die Briefe eröffnet. Er verteidigt Symmachus gegen den häufig vorgebrachten Vorwurf, in seinen Briefen nicht ausführlich über

349 Siehe z.B. R. KLEIN, Symmachus. Eine tragische Gestalt des ausgehenden Heidentums, Darmstadt 1971. - Gegen eine Überbewertung der heidnischen Reaktion wendet sich: Alan Cameron, Paganism and Literature in Late Fourth Century Rome, in: Christianisme et formes littéraires de l'antiquité tardive en occident, Entretiens Fondation Hardt 23, Genf 1977, 1-40. 
die aktuellen gesellschaftlichen und politischen Probleme zu berichten, und legt dar, welche Ziele Symmachus mit seiner Korrespondenz verfolgte (64). MatTHEws zeigt, auf welche Weise die Briefe Einblick geben in das Leben und die Umgangsformen der Oberschicht. Zelzers Wertung $(1987,226)$, dass die Briefe des Symmachus »Worte ohne Inhalt« seien, die »nur sein stilistisches Können zum Ausdruck bringen« sollten, greift zu kurz hinsichtlich deren gesellschaftlicher Bedeutung, wie sie MatTHEws im allgemeinen und RoDA (1986) hinsichtlich der Empfehlungsbriefe, die einen Großteil der Sammlung ausmachen, herausgearbeitet haben. - Allmählich wird den Briefen größere Aufmerksamkeit zuteil, zum einen durch die stetig wachsende Reihe von (historischen) Kommentaren, zum anderen durch einen ebenfalls überwiegend historisch orientierten Kongressband zu Symmachus (ed. PAschoud, Paris 1986).

Dass Ennodius sich beim Verfassen seiner Briefe Symmachus zum Vorbild genommen habe, ist häufig betont worden, siehe z.B.: "Noch mehr aber <sc. als der Wortschatz> zeigt der ganze Charakter seiner Briefe die Nachahmung " (PETER 1901, 167); "das bevorzugte Vorbild des Ennodius für seinen Briefstil« (FontaINE 1962, 401); "Briefe im Stil des Q. Aurelius Symmachus (RoHR 1995, 15); "correspondence of Symmachus, whose ethos and diction evidently inspired Ennodius (KENNELL 2000, 5). Wenn in diesem Zusammenhang eine Wertung ausgesprochen wird, fällt diese für beide Epistolographen wenig positiv aus, z.B.: »Die Anpassung des Tones des Briefes an die Person des Empfängers hat er <sc. Ennodius > zwar gelehrt, aber selbst noch weniger durchgeführt als Symmachus " (PETER 1901, 167); "Die 297 in gesuchter Sprache geschriebenen Briefe sind [...] ebenso inhaltsarm wie die Freundschaftsbriefe seines Vorbildes Symmachus [...] « (ZELzer 1997, 348).

Es sei vorab angedeutet, dass sich diese vergleichenden Wertungen auf die vor allem von Hartel $(1882,613)$, Vogel $(1885,332)$ und Dubois $(1903,80-83)$ gesammelten Parallelstellen, und zwar besonders auf eine bestimmte Textstelle stützen, an der Ennodius Symmachus erwähnt (ohne allerdings seinen Namen zu nennen) und aus einem seiner Briefe zitiert (ausführlich dazu unten 245): Ut tradit quaedam eloquentiae persona sublimis, lex est in epistulis neglegentia et auctorem genii artifex se praebet incuria (48,1 "Ein bestimmter Vertreter der hohen Redekunst hat gesagt, in Briefen gelte Nachlässigkeit als Gesetz, und eine künstliche Nachlässigkeit verhelfe ihnen zum wahren Glanz «), vgl. bei Symmachus: [...] ingeniorum varietas in familiaribus scriptis neglegentiam quandam debet imitari, in forensibus vero quatere arma facundiae (Sy. 7,9 »ein vielseitiges Talent muss in Briefen an Bekannte eine gewisse Nachlässigkeit nachahmen, in offiziellen hingegen die Waffen der Beredsamkeit schwingen«). Doch eine gründliche Untersuchung zur Bedeutung der Symmachus-Briefe für die des Ennodius, auf die sich die zitierten Wertungen stützen könnten, gibt es bisher nicht. Untersucht ist lediglich die Bedeutung der orationes des Symmachus für den Panegyricus des Ennodius: Rour (1998) stellt eine Reihe von wörtlichen und motivischen Parallelen aus Ennodius' Panegyricus und aus den orationes des Symmachus 
zusammen und weist Symmachus für die Deutung des Panegyricus die Schlüsselrolle zu (47): Aus der erkennbaren Symmachus-Rezeption schließt RoHr, dass Ennodius beabsichtige, seinen Panegyricus nationalrömisch auszurichten und "Theoderich als einen in der Tradition der weströmischen Kaiser stehenden Herrscher Italiens zu legitimieren« (45). Roн R betrachtet auch kurz die Anleihen aus den SymmachusBriefen in denen des Ennodius (43-45); er stützt sich dabei auf die von Vogel angeführten Parallelstellen und stellt die entsprechenden Passagen einander gegenüber mit der Frage, inwieweit es sich um wörtliche Übernahmen handelt. Er merkt an, dass in Anbetracht des Umfangs des Ennodianischen Briefcorpus die Anleihen bei Symmachus nicht wirklich zahlreich seien; außerdem vermutet er, dass es sich bei den Übereinstimmungen z.T. um allgemein verbreitete Wendungen handelt.

Im Folgenden ist gründlicher zu untersuchen, auf welche Weise die SymmachusBriefe auf die des Ennodius Einfluss nehmen bzw. wie Ennodius sich mit ihnen auseinandersetzt. Es wird sich zeigen, dass Ennodius zwar in der Tat intensiv auf Symmachus rekurriert (es finden sich weitaus mehr deutliche Anspielungen als bisher verzeichnet wurden), sich dies aber keineswegs als »Nachahmung eines Vorbilds« beschreiben lässt. Denn anders als Roнr es für das Verhältnis zwischen den orationes des Symmachus und Ennodius' Panegyricus erarbeitet hat, setzt sich Ennodius in seinen Briefen in vieler Hinsicht deutlich von Symmachus ab. Er setzt sich mit Symmachus auseinander, nutzt seine Briefe intensiv als Material für Sprache und Formulierungen, jedoch häufig in anderen Situationen oder mit gegensätzlichem Ziel; vielfach rezipiert er Gedanken von Symmachus, um sie eindringlicher, konsequenter und kompromissloser zu formulieren; in Vielem widerspricht er Symmachus so deutlich, dass er zu einem »Anti-Symmachus« wird.

\section{Hieronymus, Ambrosius, Augustin, Paulinus von Nola ${ }^{350}$}

Diese vier Epistolographen können hier knapper vorgestellt werden, denn sie werden im Folgenden nur eine Nebenrolle spielen, da sich im Großteil ihrer Briefe keine Anhaltspunkte zum Vergleich mit Ennodius ergeben. Sie schreiben überwiegend Briefe, die der Information oder Belehrung der Adressaten dienen (Briefe der Gruppe $1 \mathrm{~b}$, siehe oben 148), so dass sich in den Briefen ihr Wirken als Theologen, Exegeten, Seelsorger, Übersetzer, Kirchenpolitiker, Verbreiter von asketischen Ideen etc. spiegelt. Doch im >Rahmen mancher solcher Briefe, d.h. im Eingangs- oder Schlussteil, verwenden auch sie einige der `brieftypischen Gedanken $`$, die im Folgenden betrachtet werden sollen, und zuweilen schreiben sie auch Briefe zur Kontaktpflege, Glückwünsche, Empfehlungen oder Trostbriefe.

350 Zur ersten Einführung siehe: LeCLERCQ 1929, Lettres chrétiennes: 2683-2885. Lettres classiques: 2885-2942; Lettres des Papes: 2942-2982; zu Ambrosius: 2809-2821, Paulinus: 2824-2826, Hieronymus: 2826-2834, Augustin: 2834-2851; die Artikel sind nützlich, weil die Hauptthemen vieler einzelner Briefe genannt werden. 
Von Hieronymus ${ }^{351}$ sind knapp 150 Briefe erhalten, u.a. an Augustin, Paulinus von Nola, Papst Damasus und adlige Frauen in Rom wie z.B. Melania. Hieronymus behandelt exegetische Probleme, diskutiert über Auslegung und Übersetzung, schreibt über moralisch-asketische Fragen, gibt Anweisungen z.B. zum jungfräulichen Leben (epist. 2), darüber, wie ein Mädchen christlich zu erziehen sei (107) oder wie ein Kleriker leben solle (52), er bekämpft Häresien, schreibt Trostbriefe (z.B. 23f., 39, 66, 77). In einer ganzen Reihe von Briefen, überwiegend in solchen, die der Kontaktpflege dienen (z.B. 4, 7, 8, 9, 32), findet sich relativ viel briefspezifische Topik ‘. - Vielleicht hat Ennodius Briefe des Hieronymus gekannt, auf jeden Fall kommt er ihm in Formulierungen und Gedanken zuweilen sehr nahe (siehe z.B. unten 223, 225, 256, 376).

Von Ambrosius ${ }^{352}$ sind insgesamt 92 Briefe überliefert (darunter ein Brief an Kaiser Theodosius in zwei Fassungen). Es überwiegen Briefe zu exegetischen Fragen, manche widmen sich praktischen Themen, z.B.: ein Bischof erhält Ratschläge zur Amtsführung $(7,36)$, jemandem wird vorgehalten, die Taufe unnötig aufzuschieben $(2,9)$, Kleriker werden aufgefordert, ihren Ämtern treu zu bleiben $(4,17)$. Kirchenpolitisch wichtig sind besonders die beiden an Valentinian gerichteten Stellungnahmen gegen die dritte Relatio des Symmachus (vgl. oben 158); weiter sind die Trauerreden auf die Kaiser Theodosius und Valentinian unter den Briefen überliefert. Doch es finden sich auch kurze Briefe zur Kontaktpflege (z.B. 7,41 ff.; 7,53), Trostbriefe $(2,8 ; 5,25)$, ein Brief mit der Bitte um Unterstützung des Überbringers (49); in einer Reihe von Passagen reflektiert Ambrosius über die Funktion von Briefen. ${ }^{353}$

Die Briefe des Ambrosius sind insofern beachtenswert, als Ennodius zur Zeit der Entstehung seiner Werke als Diakon bei einem Nachfolger des Mailänder Bischofs Ambrosius tätig war. Insgesamt wäre es interessant, die Bedeutung des Ambrosius für Ennodius zu untersuchen, da er von Ennodius an verschiedenen Stellen genannt und auch unbezeichnet zitiert wird; wahrscheinlich ließe sich auch in diesem Fall Vogels Liste der Parallelen $(1885,332)$ ergänzen. Alfonsi (1976) stellt einige Stellen vor, an denen Ambrosius im Werk des Ennodius erscheint, doch das Thema wäre eine gründlichere Behandlung wert.

351 Zur Einführung siehe: Rebenich, Hieronymus und sein Kreis, 1992; Conring, Hieronymus als Briefschreiber, 2001.

352 Zur Einführung siehe: E. Dassmann, Ambrosius von Mailand. Leben und Werk, Stuttgart 2004. - K. und M. Zelzer, "Retractationes« zu Brief und Briefgenos bei Plinius, Ambrosius und Sidonius Apollinaris, 393-405 in: Alvarium (FS Gnilka), hrg. von W. Blümer, R. Henke, M. Mülke, Münster 2002.

353 Siehe: Thraede 1970, 183 ff.; Zelzer (Ambrosius, 1987, 219); Dies., Plinius Christianus, Ambrosius als Epistolograph, StudPatr 23, 1989, 203-208. Ob Ambrosius die Brieftopoi allerdings nur deshalb eingefügt hat, um seine Abhandlungen in Briefform veröffentlichen zu können (so Zelzer Praef. ed. CSEL 82/2, 1990, p. XXXVI f., 1987, 223), also sozusagen als Bemäntelung, mag dahingestellt bleiben. 
Von Augustin ${ }^{354}$ sind 254 Briefe erhalten, außerdem 54 Briefe, die an Augustin gerichtet sind. $\mathrm{Zu}$ den Adressaten zählen u.a. Hieronymus und Paulinus von Nola. Die meisten Briefe ergeben sich aus Augustins Amt als Bischof und widmen sich theologischen, exegetischen, glaubenspraktischen, kirchenpolitischen und rechtlichen Fragen (vgl. die Übersicht über die einzelnen Briefe bei DIvJAK 2001). Es handelt sich zumeist um Abhandlungen, die auf Anfragen antworten. Nur eine kleine Reihe von Briefen stammt aus der Zeit vor der Ernennung zum Bischof (1-20); besonders in diesen finden sich Passagen mit brieftypischer Thematik،. - Ennodius' Verhältnis zu Augustin insgesamt wäre eine eigene Untersuchung wert; im »Eucharisticum" rekurriert er offensichtlich auf Augustins Confessiones (vgl. oben 11), einmal spielt er auf den Obstraub an $(7,6$ doctorem Libycum ... sublata a se piri poma flevisse), in einem Brief fallen bei Ausführungen de arbitrii libertate (56, vgl. oben 26) die wohl auf Augustin zu beziehenden Worte toxica Libycae pestis $(56,16)$.

Von Paulinus von Nola ${ }^{355}$ sind vier Versepisteln (davon zwei an Ausonius zur Rechtfertigung seiner conversio) und ca. 50 Prosa-Briefe überliefert. Zu seinen Adressaten zählen u.a. Augustin und Sulpicius Severus. Seine Briefe dienen dem geistigen Austausch und behandeln Fragen des Glaubens und der Lebensführung, besonders solche, die mit seiner eigenen conversio verbunden sind: Askese, Vermögensverzicht, Ausrichtung des Lebens auf Christus, gegenseitige Bestärkung im Glauben. Je nach Adressat ist seine Absicht eher apologetisch oder werbend; mehr als Ambrosius, Hieronymus und Augustin, die sich auch in Briefen in großem Ausmaß der Exegese widmen, nutzt Paulinus seine Briefe zur Darstellung seiner eigenen Position und Situation: Walsh $(1966,14)$ spricht von »spiritual autobiography«, Mratschex (2002, 415) von einem »Selbstporträt«. >Brieftypische Thematik findet sich häufig; ${ }^{356}$ besonders charakteristisch für Paulinus' Briefe sind das Thema der ,Freundschaft unter Christen', einer Freundschaft aufgrund von geistiger Übereinstimmung, und die reiche der Bibel entnommene Bildlichkeit.

\section{Sidonius Apollinaris ${ }^{357}$}

Die erhaltenen Werke des Sidonius Apollinaris, der nach der Ausübung hoher politischer Ämter aufgrund der politischen Umstände in den geistlichen Stand eintrat, da öffentliche Wirksamkeit in Gallien nur noch Trägern eines kirchlichen Amtes

354 Zur Einführung siehe den äußerst informativen Artikel „Epistulae« von J. DivjaK 2001. Außerdem: T. Fuhrer, Augustinus, Darmstadt 2004.

355 Zur Einführung siehe: Walsh 1966; M. SKeb, Paulinus von Nola, Epistulae/Briefe I, Lateinisch-Deutsch, Freiburg u.a. 1998 (Fontes Christiani); Conybeare 2000; MratscheK 2002.

356 Beispiele bei SKeB 1998, 105f.

357 Zur Einführung siehe: Loyen 1943; Zelzer (1994/5); die Einleitungen zu den Kommentaren: zum 1. Buch von KöHLER 1995, zum 4. Buch von AMHERDT 2001. 
möglich war, ${ }^{358}$ und um 470 Bischof der Auvergne mit Amtssitz in Clermont wurde, teilen sich in Gedichte und Briefe (147 Briefe in neun Büchern). Innerhalb der Briefe findet sich die Aussage, dass er als Bischof die Gattung Brief pflege und dass die Art der früher betriebenen Dichtung für ihn nicht mehr in Frage komme (epist. 9,12; 9,16; vgl. unten 173).

Die Briefe des Sidonius sind mehrheitlich in seiner Zeit als Bischof entstanden, und er hat sie jedenfalls als Bischof selbst herausgegeben. ${ }^{359}$ Anders als Ennodius hat er also die Briefe selbst in eine bestimmte Reihenfolge gebracht und zu einigen Büchern Vorworte verfasst. Die Briefe stehen ersichtlich in der Tradition des Plinius, auf den Sidonius sich (wie auch auf Symmachus) ausdrücklich beruft (Sidon. 1,1,1);360 außerdem spricht er über seine Briefe in Worten, die an Plinius erinnern, vgl.: ego non historiam sed epistulam efficere curavi (Sidon. 1,2 a.E.) und: sed quid ego istaec iusto plusculum garrio, qui laborum tuorum non ex asse historiam texere sed pro parte memoriam facere praesumpsi etc. (Sidon. 3,3,9); dies erinnert deutlich an Plinius $(1,1)$ : collegi non servato temporis ordine (neque enim historiam componebam) [...].

Anders als bei Ennodius, der an seine Adressaten unterschiedlich viele Briefe richtet, z.B. an Faustus 54 und an dessen Sohn Avienus 24, an manche Adressaten hingegen wenige oder nur einen, erhalten die meisten Adressaten von Sidonius einen einzigen Brief (147 Briefe an 108 verschiedene Adressaten), und es ist nach Sido-

358 Siehe: Sidon. (epist. 2,1,4) si nullae a republica vires, nulla praesidia, si nullae [...] Anthemii principis opes, statuit te auctore nobilitas seu patriam dimittere seu capillos; siehe dazu z.B. Stroheker (1948, 72f.); N. Delhey, Apollinaris Sidonius, Carm. 22: Burgus Pontii Leontii, Berlin u.a. 1993, 4f. - Bartlet (2001) betont, dass die politischen Bedingungen in Gallien und Italien sich nicht so sehr unterschieden hätten, als dass sich allein mit den politischen Bedingungen in Gallien erklären ließe, dass dort so viele Mitglieder der Aristokratie Bischöfe wurden (ein Phänomen, das in Italien erst später auftrat); er sieht als entscheidend an, dass die aus dem Kloster Lérins hervorgegangenen Bischöfe beispielhaft zeigten, dass ein kirchliches Amt eine Alternative zum weltlichen sein kann.

359 Dies betont Rousseau $(1976,356)$, der darauf hinweist, dass man aus den Briefen nicht Sidonius als typischen Aristokraten herauslesen solle, da zu bedenken sei, dass er sie als Bischof herausgegeben habe; Rousseau untersucht, in welcher Weise das Bischofsamt auf Sidonius' Haltung als Adliger Einfluss genommen hat.

360 Sidon. $(1,1,1)$ [...] Quinti Symmachi rotunditatem, Gai Plinii disciplinam maturitatemque vestigiis praesumptuosis insecuturus. Was genau er damit meint, wäre noch zu untersuchen; eine pauschale Wertung wie "Sidonius, der in seinem Briefwechsel Symmachus nachfolgt " (vON ALBRECHT ${ }^{2} 1994$, Bd. 2, 1148) wird dem Phänomen offensichtlich ebensowenig gerecht wie die häufig benannte Vorbildfunktion des Symmachus für Ennodius (siehe oben 159). - Zelzer (1994/5, 550) vermutet Ambrosius als (von Sidonius nicht genanntes) Vorbild für die Gestaltung der Sammlung. 
nius' eigenen Worten ein Ehrenbeweis, als Adressat in die Sammlung einzugehen. ${ }^{361}$ Die Briefe beschränken sich jeweils auf ein einziges Thema (dazu AMHERDT 2001, 35), wie auch Sidonius selbst betont $(7,18,4)$. Es handelt sich dabei teils um Dank-, Trost-, Gratulations- und Empfehlungsschreiben und Briefe zur Kontaktpflege; teils enthalten die Briefe Erzählungen, Berichte über Angelegenheiten der Kirche (z.B. die Wahl eines Bischofs), Beschreibungen (von Personen, Anwesen, Bibliotheken), sie geben ein Bild von der literarischen Kultur der Aristokratie, und in vielen Briefen finden sich Hinweise auf die Zeitgeschichte und die problematische politische Lage in Gallien. NÄF (1995, 155-159) betont die große Bedeutung des Lobes in den Sidonius-Briefen, was an die insgesamt sehr positive Haltung des Plinius erinnert. ${ }^{362}$ AmherdT (2001, 39; 43) bezeichnet es als das Ziel von Sidonius' Korrespondenz, seine Kultur, seine soziale Klasse, die römische Macht zu verteidigen; Sidonius habe die Absicht, seinen Freunden Stolz einzuflößen, zu einer Elite zu gehören, und sie dazu zu bringen, nach Kräften die aristokratische Gesellschaft lebendig zu erhalten.

Ennodius spielt in Versen der Schrift zum 30. Jahrestag der Ordination des Epiphanius (43) auf zwei carmina des Sidonius Apollinaris an (auf carm. 2, den Panegyricus auf Anthemius, und carm. 16, das Dankgedicht für Bischof Faustus von Riez); ob er auch die Briefe gekannt hat, ist nicht sicher, denn es ist bisher keine eindeutige Bezugnahme bekannt. Daher ist nicht ersichtlich, warum GionNn ihn als wichtigstes Vorbild für Ennodius' Briefe bezeichnet ( Sidoine Apollinaire, son principal modèle épistolaire $[\ldots]$ «, 2001, 176). Doch auch so ist es interessant $\mathrm{zu}$ vergleichen, welche Art Briefe Sidonius als Bischof veröffentlicht (und z.T. auch als Bischof geschrieben hat), und welche Art Briefe Ennodius als Diakon geschrieben hat. Beide behandeln keine theologischen oder religiösen Themen, und dennoch sind die Briefe äußerst verschieden: Anders als Sidonius schreibt Ennodius nicht in der Tradition des Plinius und hat offensichtlich nicht die Absicht, in Briefform ein Gemälde seiner Zeit und Welt, ein Spiegelbild des intellektuellen und politischen Lebens seiner Zeit zu verfassen. Im II. Teil dieser Untersuchung wird Sidonius daher nicht so oft heranzuziehen sein wie Symmachus. Im Kapitel über Sprache und Stil (Kap. I.2.c) war bereits festzustellen, dass der Stil des Ennodius, anders als häufig behauptet wurde, viele Unterschiede zu dem des Sidonius aufweist.

361 Siehe Sidon. 8,5; 9,15,1; vgl. 4,2, wo sich Claudianus Mamertus (in dem einzigen an Sidonius gerichteten Brief innerhalb der Sammlung) beklagt, noch keines Schreibens gewürdigt worden zu sein.

$362 \mathrm{Zu}$ Plinius' Haltung siehe: E. Aubrion, Pline le Jeune et la rhétorique de l'affirmation, Latomus 34, 1975, 90-130. 


\section{Ruricius von Limoges ${ }^{363}$}

Ruricius (Bischof von Limoges ca. 485-ca. 507) hat 83 Briefe hinterlassen; außerdem sind 14 Briefe an ihn erhalten, darunter 8 von Faustus von Riez (Abt in Lérins, später Bischof von Riez). Die Sammlung enthält in nicht-chronologischer Ordnung sowohl Briefe, die er als Bischof geschrieben hat, als auch frühere. Fast alle Korrespondenten befinden sich innerhalb des Westgotenreiches; viele Briefe richten sich an Bischöfe benachbarter Städte. Die Briefe stehen in vieler Hinsicht in der Tradition des Sidonius (cf. Ruricius' Äußerungen über Sidonius in $2,26,3$ ). Inhaltlich sind sie recht vielfältig: Ruricius schreibt Trostbriefe, Empfehlungsschreiben, Bittbriefe für Dritte, er gibt Rat bei einer Bischofswahl, er gibt oder bittet selbst um Rat für ein gottgefälliges Leben, er spricht von Literatur und ausgetauschten Codices, er schreibt an den Rhetor, der seine Söhne unterrichtet, er bedankt sich für Geschenke und sendet selbst welche usw.; das Thema >Freundschaft ' und die ausgetauschten Grüße spielen eine große Rolle; im Vergleich zu Sidonius äußert er sich sehr wenig über zeitgeschichtliche Ereignisse und macht nur vage Andeutungen wie z.B. $(1,6,1)$ sollicitudines saeculi. Stilistisch erinnert manches an Sidonius (siehe oben 62).

Drei der Korrespondenten des Ruricius gehören auch zu denen des Ennodius (Julianus Pomerius, Parthenius, Caesarius von Arles). Möglicherweise war Ennodius' Neffe Parthenius ein Enkel des Ruricius (siehe Mathisen 1999, 26; Bureau 1998).

\section{Cassiodor}

Ennodius' etwas jüngerer Zeitgenosse Cassiodor ${ }^{364}$ (ca. 485-ca. 580) gab 537/538 eine 12 Bücher umfassende Sammlung von insgesamt 468 Briefen heraus, wobei er die Briefe für die Herausgabe überarbeitete und durch zwei Vorworte einleitete (siehe var. 1 praef;; 11 praef.). Der Titel Variae bezieht sich, wie im Vorwort erläutert wird, auf die Verschiedenheit des Stils in verschiedenen Briefen. Es handelt sich dabei um offizielle Schreiben, Erlasse und Urkunden in Briefform, die Cassiodor überwiegend nicht im eigenen Namen (nur Bücher 11 und 12 als Praefectus Praetorio), sondern im Namen von Theoderich (Bücher 1-5), Athalarich (Bücher 8 und 9), Amalaswintha, Theodahat und Witigis (Buch 10) verfasste. Die Bücher 6 und 7 enthalten Ernennungsformeln für verschiedene Ämter. - Die Forschung beschäftigt sich mit den Variae überwiegend als Quelle für die Prosopographie, für die Zeit- und Sozialge-

363 Siehe: Mathisen 1999. - D. Shanzer, Bishops, Letters, Fast, Food, and Feast in Later Roman Gaul, 217-236 in: R. W. Mathisen, D. Shanzer (edd.), Society and Culture in Late Antique Gaul, 2001. - R. W. Mathisen, The Letters of Ruricius of Limoges and the Passage from Roman to Frankish Gaul, 101-115, ibid.

364 Zur Einführung siehe: O'Donnell 1979. - S. J. B. BARnish, The Work of Cassiodorus after His Conversion, Latomus $48,1989,157-187$. 
schichte, mit der Präsentation des Verhältnisses zwischen Römern und Goten und mit der Frage, warum Cassiodor diese Sammlung veröffentlichte. ${ }^{365}$

Während oft erwähnt wird, dass die Briefe des Ennodius mit denen des Symmachus und des Sidonius Apollinaris vergleichbar seien, gehen die seltenen kurzen Hinweise, dass sie an Cassiodors offizielle Korrespondenz erinnern (FontaIne 1962, 401; LUISElli 1982, 72f.; PfersChy 1986), fast völlig unter. Im Folgenden wird u.a. darauf aufmerksam gemacht, dass bestimmte Strukturelemente bei Ennodius, besonders die Praefatio von Briefen, große Ähnlichkeit mit Cassiodor aufweisen.

\section{Charakteristika der Briefe des Ennodius}

\section{a. Einleitung}

Im Folgenden werden im Vergleich mit anderen Epistolographen, besonders mit Symmachus, zunächst (II.2) charakteristische Aspekte der Briefe des Ennodius herausgearbeitet (allgemein einleitend zu den Briefen oben 41), insbesondere: der Einfluss des Diakonats auf die Briefe; die verschiedenen Rollen des Brief-Ichs (`der freundliche Diakon` und `der unzufriedene Freund`); die Grundsätze des Verhaltens in der Korrespondenz; die Bedeutung der amicitia; Äußerungen über die Funktionen und Inhalte von Briefen; der charakteristische Beginn von Briefen mit einer Praefatio. Außerdem (II.3) werden ganze Briefe analysiert, und zwar unter der Fragestellung, wie Ennodius verschiedene Arten von Briefen (’Kontaktpflege`, Glückwunsch- und Empfehlungsschreiben) gestaltet.

Doch vor diesen Analysen ist zunächst an zwei Beispielen, einer Entschuldigung (24) und einer Bitte (139), zu zeigen, dass es sich tatsächlich lohnen kann, die Briefe genauer zu betrachten, als dies bisher für nötig gehalten wurde. Denn Ennodius fordert nicht nur seine jüngeren Korrespondenten auf, in Briefen ihr ingenium aufzuzeigen (z.B. 387,3 pro ingenii tui ostentatione, siehe oben 118), sondern er nutzt auch viele seiner eigenen Briefe dazu, seine Adressaten durch unerwartete Gedankengänge und Argumentationen zu verblüffen; einem seiner Briefe ist zu entnehmen, dass der Adressat von Ennodius' rhetorica versutia, "rhetorischer Wendigkeit “, gesprochen hat $(21,4$, siehe dazu unten 186$)$.

365 Siehe z.B.: ReYdellet 1981, 183-253. - F. Prinz, Cassiodor und das Problem christlicher Aufgeklärtheit in der Spätantike, HZ 254, 1992, 561-580. - J.-L. Jounaud, Pour qui Cassiodore a-t-il publié les Variae?, 721-741, in: AA.VV., Teoderico il Grande e i Goti d'Italia. Atti del XIII Congresso internazionale di studi sull'Alto Medioevo (Milano 2-6 novembre 1992), Bd. 2, Spoleto 1993. - A. Giardina, Cassiodoro politico e il progetto delle $\mathrm{Va}$ riae, 45-76, in: AA.VV., Teoderico il Grande [...], Bd. 1, Spoleto 1993. 


\section{Eine Entschuldigung (24)}

Ennodius Deuterio] Quam velim saepe officium visitationis omittere, si dulcem tribuit culpa mercedem, et caelestis mandati sententiam sciens prudensque neglegere, si desideriis copiam vindicanda conciliant! mihi uni contigit de offensionis merito evenisse quod gaudeam. didici nunc tali remuneratione errata sectari. (\$2) non sunt adversa, doctor optime, amicitiarum religioni quae profero coactus in medium, immo propter confessionem digna proposito. valitudinis tuae dubia numquam velut ingratus optavi; quin etiam, quantum in me fuit, contra ingruentes tibi inaequalitates precum manus opposui. (\$3) sed ecce quam alacer sensus est, non in prospera membrorum salute fundata ostendit pagina, in qua utraque luce fulsisti. tua, quaeso, lumina nube doloris hebetantur, cuius tam clara sunt carmina? et qui lucem loqueris, de visione causaris? quam timeo, ne parcus in meritis tuis laudator inveniar. tibi recte adscribitur cunctis dare oculos et obscura mentium peregrino splendore radiare. ergo putas tibi validum non esse quod tribuis? $\left(\$_{4}\right)$ pelle, quaeso, animo curas superflua forsitan sollicitudine aut cautione conceptas. dabit deus, ut quidquid corporalis adcessit incommodi, vice animae tuae per sudum rutilantis nitore mundetur.

»Wie gern möchte ich die Besuchspflicht oft vernachlässigen, wenn meine Schuld mir einen süßen Lohn schenkt, und den Willen des himmlischen Auftrags in vollstem Wissen missachten, wenn das Tadelnswerte meinen Wünschen ihre Erfüllung verschafft. Mir allein ist es widerfahren, dass dadurch, dass ich Anstoß erregt habe, etwas eingetreten ist, worüber ich mich freuen kann. Ich habe nun durch eine solche Belohnung gelernt, nach Verfehlungen zu streben. $(\$ 2)$ Bester Gelehrter: Es widerspricht nicht den Grundsätzen der Freundschaft, was ich gezwungenermaßen <d.h. auf Deine Vorwürfe hin> vortrage, vielmehr ist es wegen des ehrlichen Geständnisses meiner Vorsätze ${ }^{366}$ würdig. Niemals habe ich wie ein Nicht-Liebender Deinen misslichen Gesundheitszustand gewünscht, vielmehr habe ich, soweit ich konnte, den über Dich hereinbrechenden Krankheiten meine betenden Hände entgegengehalten. (\$3) Aber sieh doch: wie scharf Dein Gesichtssinn ist, zeigt das Schreiben, das nicht auf ein glückliches Wohlergehen Deiner Glieder gegründet ist, in dem Du mit beiden Lichtern geglänzt hast. Was, Deine Augen werden von einer Wolke des Schmerzes abgestumpft, wo Deine Gedichte so glänzend sind? Und der Du glänzend redest, klagst über das Sehen? Wie fürchte ich, als spärlicher Lobredner Deiner Verdienste befunden zu werden. Dir schreibt man mit Recht zu, allen <sc. Schülern> Augen zu verleihen und das Dunkel ihrer Sinne mit einem unbekannten Glanz zu erleuchten. Glaubst Du also, dass bei Dir selbst nicht wirkt, was Du anderen schenkst? $(\$ 4)$ Bitte vertreibe die Sorgen aus Deiner Seele, die vielleicht durch eine überflüssige Beunru-

366 propositum bezieht sich auf die Vorsätze, die mit dem Diakonat verbunden sind, siehe ausführlich unten 277 . 
higung oder Vorsicht entstanden sind. Gott wird geben, dass, was immer an körperlicher Beeinträchtigung eingetreten ist, durch Deine Seele, deren Glanz am wolkenlosen Himmel strahlt, geheilt wird.«

Nachdem man den Brief ganz gelesen hat, lässt sich der konkrete Anlass grob erschließen: Deuterius, der in Teil I mehrfach erwähnte Lehrer, Dichter und Redner, muss Ennodius Vorwürfe gemacht haben, denn dieser spricht in dem Brief von culpa, offensio und errata $\left(\$_{1}\right)$. Der Vorwurf bestand darin, dass Ennodius Deuterius nicht besucht hat ( $\$ 1$ officium visitationis omittere [...]). In $\$ 2$ ist unbestimmt von ingruentes [...] inaequalitates die Rede, und am Ende von corporale incommodum $(\$ 4)$; in $\$ 3$ wird deutlich, dass Deuterius an einer Augenkrankheit litt (lumina nube doloris hebetantur; de visione causaris). Deuterius zu besuchen, wäre Ennodius' Pflicht gewesen (officium visitationis), und zwar die speziell christliche Pflicht (cf. caelestis mandati sententiam sciens prudensque neglegere), Kranke zu besuchen. Da Epistolographen allerdings häufig »besuchen « und »Briefe schreiben « gleichsetzen, ${ }^{367}$ dürfte Deuterius wohl darüber geklagt haben, während seiner Krankheit keinen Brief erhalten zu haben. - Deuterius hat seine Klagen offenbar in einem metrisch gebundenen Brief vorgebracht, denn Ennodius spricht von pagina und carmina (\$3).

Nun ist es interessant zu beobachten, wie Ennodius auf den vorwurfsvollen Brief des Deuterius antwortet: Anders, als man vielleicht erwarten könnte, entschuldigt er sich nicht für sein Versäumnis, sondern `beweist`, dass er sich völlig richtig verhalten habe. Er antwortet also nicht der Etikette entsprechend, sondern mit einem gewissen Trotz: Er zeigt durch ein Paradoxon, wie er es gern verwendet, dass er nichts zu bereuen habe, und `beweist` durch Komplimente für Deuterius, dass dieser seine eigene Situation falsch einschätze und man sich um dessen Gesundheitszustand keine Sorgen machen müsse. Ennodius, der doch sonst mit direktem Lob sparsam ist (siehe oben 119, unten 268), bezeichnet sich hier als laudator $(\$ 3)$ - das Lob ist also gleichsam ein Ersatz für die Entschuldigung. Am Ende zeigt sich allerdings, dass diese Argumentation nicht ganz ernst gemeint ist.

Ennodius gestaltet den Brief folgendermaßen: Eingangs betont er seine Freude über die paradoxe Situation, dass ihm eine Freude zuteil wurde, weil er sich falsch verhalten habe, denn er habe deswegen einen Brief erhalten. Nur durch die Erwähnung der ihm vorgeworfenen culpa und seiner errata räumt er immerhin indirekt sein Versäumnis ein. Doch er zeigt sich als zweifelhafter Diakon, wenn er sagt, er verstoße gern gegen seine christlichen Pflichten, wenn ihm ein solches Verhalten Vorteile bringe $\left(\$_{1}\right.$ Quam velim saepe officium visitationis omittere $[\ldots]$. didici nunc $[\ldots]$ errata sectari.). In der Ahnung, dass solche Äußerungen auf Kritik stoßen könnten, stellt er

367 visitatio per Brief auch: $(411,1)$ ut me reverentia vestra alloquiis visitaret. Siehe auch bei Paulinus von Nola, z.B.: $(3,5)$ visita litteris tuis; $(11,3)[\ldots]$ adsiduis nos litteris adeas $[\ldots]$; $(13,2)[\ldots]$ ut te spiritali aditu visitarem. 
fest, dass sie im Gegenteil völlig seinen Vorsätzen in der Freundschaft und auch im Amt entsprechen ( $\$ 2$ non sunt adversa ... amicitiarum religioni quae profero coactus in medium, immo propter confessionem digna proposito). Es folgt ein neuer, ganz anderer (mit sed ecce angeschlossener) Gedanke: Der tadelnde Brief des Deuterius lasse erkennen, dass seine Augenkrankheit so besorgniserregend nicht sein könne; sowohl der im Brief bewiesene Glanz seiner carmina als auch die Tatsache, dass er allen (gemeint sind wohl seine Schüler) zu glanzvollem Stil verhelfe, zeigten, dass Klagen über den Zustand seines Augenlichts nicht angebracht seien ( $\$ 3$ sed ecce - quod tribuis?). Ennodius lobt die sprachlichen Fähigkeiten des Deuterius mittels eines Spiels mit Begriffen aus dem Wortfeld ,Licht (lux, lumina, oculi, splendor, radiare, clara), das sich aus der Erwähnung der Augenprobleme ergibt. Abschließend fordert er ihn auf, sich nicht zu sehr zu sorgen; an dieser Stelle lenkt Ennodius ein und geht in seinen abschließenden Worten doch noch mit einem ernstzunehmenden Wunsch auf die Krankheit des Deuterius ein $(\$ 4$ dabit deus - nitore mundetur).

Dieser Brief ist ein gutes Beispiel dafür, dass es häufig weniger um das tatsächlich Gesagte geht als vielmehr um die ostentatio ingenii: Sich bei dem Adressaten Deuterius, der Dichter, Redner und Lehrer war, einfach nur für das Versäumnis zu entschuldigen und ihm gute Besserung zu wünschen, hält Ennodius nicht für den angemessenen Ton und Stil. Daher konzipiert er einen Brief, der der Konvention nicht entspricht und den Deuterius gerade deshalb gewürdigt haben wird. Mit Hilfe des Wortspiels mit lux, oculi etc. kann Ennodius zu dem Trugschluss gelangen, dass die Qualität des erhaltenen Briefs dessen Inhalt konterkariere. Dass die Ausführungen über die übertriebenen Sorgen nicht ernst gemeint sind, zeigt sich am Ende, wo Ennodius doch noch mit Genesungswünschen auf die Krankheit eingeht. So weist dieser Brief einige Charakteristika auf, wie sie an den Briefen des Ennodius häufig zu beobachten sind:

- Die frappierende Behauptung, ihm bedeute ein Brief vom Adressaten mehr als die Erfüllung seiner christlichen Pflichten, ist ein Beispiel dafür, dass Ennodius sein kirchliches Amt und seine Briefe häufig in engen Bezug zueinander setzt und dass er Briefen eine hohe Bedeutung beimisst; vorab sei gesagt, dass dabei den Briefen nicht immer in dieser Weise der Vorrang gegeben wird.

- Den Konventionen innerhalb der Korrespondenz, dass man sich z.B. auf einen berechtigten Vorwurf hin eigentlich entschuldigen müsste (oder dass man zu einem freudigen Anlass gratuliert, ein Empfehlungsschreiben äußerst freundlich formuliert etc.), entspricht Ennodius zwar zuweilen, in vielen Fällen aber keineswegs; wenn er der Konvention widerspricht, lenkt er meistens (aber nicht immer) am Ende ein.

- Das Spiel mit den Konventionen beruht häufig auf einer geistreichen Argumentation, wie z.B. hier auf dem Paradoxon und einem Trugschluss. Manchmal formuliert Ennodius auch offenbar bewusst zweideutig, so dass der Adressat zu- 
nächst auf eine falsche Spur gelockt wird und erst am Ende merkt, dass der Anfang anders gemeint war.

- Die sorgfältige sprachliche Gestaltung zeigt sich auch an der oft reichen Bildlichkeit und Metaphorik, im Brief an Deuterius an den Formulierungen aus dem gleichen Wortfeld >Licht`sowohl für die Augenkrankheit als auch für die sprachlichen Fähigkeiten.

\section{Eine Bitte (139)}

Ennodius Luminoso] Qui amicam conscientiam manifestis pandit indiciis, tollit otium, quibus gratiae praestiterit dignitatem. vix enim feriata sunt ora eius, qui consuevit audiri; quia magnum dispendium pudoris est verborum retinere benificium, ut dum linguae parcimus, honestatis prodiga frons laboret. vos me garrulum fecistis, qui preces meas consuestis admittere. sed ne praestanda circumloquar et epistulae prolixitate inpetranda suspendam, ad rem redeo. sublimis vir Laurentius [...].

»Wer durch deutliche Zeichen die Freundschaft seines Herzens zeigt, nimmt denen ihre Muße, denen er die Ehre seiner Gunst erwiesen hat. Denn kaum kann der Mund derer geschlossen bleiben, die üblicherweise erhört werden; das gute Benehmen nimmt nämlich großen Schaden, wenn man die Wohltaten von Worten zurückhält, so dass, indem wir die Zunge schonen, unser Ansehen leidet, weil es die Anständigkeit aufgibt. - Ihr habt mich redselig gemacht, da Ihr meine Bitten üblicherweise erfüllt habt. Doch damit ich nicht um die Bitte herumrede und die Erfüllung durch die Länge des Briefes aufschiebe, komme ich zur Sache: Der Sublimis vir Laurentius [...].«

Zweck dieses Schreibens an Luminosus ist eine Bitte ( $\$ 1$ preces) für einen Dritten, nämlich für einen Laurentius, dessen von der römischen Kirche zugesagte Zinsen nicht eintreffen $(\$ 2$ sublimis vir Laurentius reditus sibi debitos $[\ldots]$ adserit $[\ldots]$ denegari). ${ }^{368}$ Doch bevor Ennodius konkret dazu kommt ( $\$ 1$ a.E. ad rem redeo), formuliert er eine ohne Weiteres nicht leicht verständliche Praefatio, die er dann abbricht mit dem Wunsch, Längen zu vermeiden (sed ne praestanda circumloquar et epistulae prolixitate inpetranda suspendam, [...]). Die Praefatio besteht aus einem ersten Teil mit allgemeinen Formulierungen und einem zweiten konkreten Teil über den Adressaten und das Brief-Ich (Vos me [...]). Im allgemeinen ersten Teil geht es zunächst darum, dass jemandem ein Gefallen getan wurde, um den er gebeten hatte (cf. gratiae prae-

368 Dass es sich hier, wie Kennell (2000, 40f.) annimmt, um die gleiche finanzielle Angelegenheit handelt wie im früheren Brief an Luminosus (77), erscheint fraglich (so auch Sundwall 1919, 27: "die Zinsen eines anderen «). Zum einen spricht Ennodius in 77 im Namen des Bischofs $(77,3$ sanctus pater vester domnus episcopus), in 139 hingegen von einem sublimis vir Laurentius $(\$ 2)$. In 77 geht es um die Rückzahlung von Auslagen, die der Bischof in Ravenna für den Papst getätigt und für die Ennodius gebürgt hat $(77,3)$, hier hingegen um die Zinsen des Laurentius (139,2 reditus sibi debitos). 
stiterit dignitatem; audiri); das Erfüllen dieser Bitte ist ein deutlicher Beweis für die Freundschaft (amicam conscientiam manifestis pandit indiciis). Derjenige, dem ein Gefallen erwiesen wurde, hat keine Muße mehr und muss sprechen (cf. tollit otium; vix feriata sunt ora). Denn man verhalte sich falsch, wenn [...]. - Nun folgt allerdings nicht, wie man vielleicht erwarten könnte, ein Dank für den erwiesenen Gefallen, sondern es geht anders weiter: Man verhalte sich falsch, wenn man wohltätige Worte (verborum benificium) zurückhalte. Der Briefschreiber will also nicht seinen Dank für einen erwiesenen Gefallen formulieren, sondern eine weitere Bitte, die ein benificium für einen Dritten bedeutet, für den der Adressat sich einsetzen soll.

Die Praefatio enthält eine Pointe: Der Adressat sei sozusagen selbst schuld, wenn er so häufig um Gefallen gebeten werde, da er ja die Wünsche immer erfülle (vos me garrulum fecistis, qui preces meas consuestis admittere.); Ennodius stellt es so dar, als bringe der Gebetene die Bittenden um ihre Muße; denn wenn man wisse, dass man erhört werde, sei man auch verpflichtet, Bitten für Dritte vorzubringen. Der erste Satz lässt sich dann so verstehen und erläutern: ,Wer <sc. wie der Adressat $>$ durch deutliche Zeichen die Freundschaft seines Herzens zeigt <sc. vorgebrachte Bitten erfüllt>, nimmt denen <sc. wie Ennodius> ihre Muße, denen er die Ehre seiner Gunst erwiesen hat.؛

Auch in diesem Brief spielt Ennodius mit der Konvention, indem er eine verblüffende Argumentation vorbringt: Der Bittende bedankt sich nicht für eine offenbar zuvor erfüllte Bitte, er entschuldigt sich auch nicht dafür, dass er die Muße des Gebetenen stört, sondern führt aus, dass seine eigene Muße gestört werde, weil der Gebetene seine Wünsche zu erfüllen pflege. Typisch für Ennodius sind außerdem:

- die allgemeine Praefatio, die auf den konkreten Inhalt vorbereitet;

- die geradezu kryptischen Formulierungen, die dazu führen, dass sich der Sinn kaum beim ersten linearen Lesen erschließen lässt; der Leser wird zum Nachund Mitdenken regelrecht gezwungen.

Dass Ennodius mit der Konvention lieber spielt, als ihr zu entsprechen, zeigt sich im Vergleich mit anderen Epistolographen sehr deutlich; besonders im Vergleich mit den Symmachus-Briefen setzt Ennodius viele eigene und überraschende Akzente. Allerdings findet sich nicht in jedem Brief ein Spiel mit der Konvention, eine scharfsinnige Argumentation und eine verblüffende Pointe, sondern unter den Briefen sind auch einige, die den Konventionen entsprechen. Es ist daher lohnend, Ennodius' Bandbreite vom 'ganz gewöhnlichen`zum 'ganz verblüffenden` Brief zu beobachten. An dieser Variatio lässt sich zeigen, dass das bereits oben 156 zitierte Urteil, Ennodius habe den Ton seiner Briefe nicht auf den jeweiligen Adressaten eingestellt, nicht die geringste Berechtigung hat. 


\section{b. Diakonat und Epistolographie}

Es wurde bereits erwähnt, dass Ennodius sich mit seinen Briefen weder in die Tradition des Plinius oder des Sidonius Apollinaris stellt noch in die der Kirchenväter, sondern dass seine Briefe inhaltlich insofern an die des Symmachus erinnern (siehe oben 158, 160), als er ganz überwiegend keine sachbezogenen Briefe schreibt, die auch für andere aufgrund ihres Inhalts interessant sein könnten, sondern zumeist beziehungsorientierte Briefe (Kontaktpflege), er-/sie-orientierte (Empfehlungs- und Bittschreiben) und Du-orientierte (z.B. Glückwünsche), siehe oben 150. Er betont, dass Briefe überhaupt nur für die Pflege der amicitia erfunden worden seien, wobei er die entsprechende >Brieftopikı erheblich verkürzt (siehe unten 204ff.). Seine eigenen Briefe jedenfalls stellt er durchweg in den Dienst der amicitia, und selbst Empfehlungs- und Glückwunschschreiben funktioniert er häufig um für diese Aufgabe (siehe unten Kap. II 3.c und d).

Es fragt sich, warum Ennodius so beharrlich und wenig abwechslungsreich immer wieder über die Themen 'Freundschaft` und `Korrespondenz`schreibt, und zwar auch bei Anlässen, zu denen man (auch) anderes erwarten würde, wie in vielen Empfehlungs- und Glückwunschschreiben. Erstaunlich ist dies besonders angesichts der Tatsache, dass die Briefe von einem ehemaligen Dichter und Redner stammen, der sich, wie die erhaltenen Werke zeigen, von dem Inhalt seiner früheren Lebensphase nicht völlig getrennt hat, sondern sich weiterhin gern literarisch betätigt und auch andere dazu auffordert. Dass er auch in der Lage ist, über andere Themen zu schreiben, zeigen das thematisch vielfältige Gesamtwerk und auch vereinzelte Briefe, die dann doch ganz anders sind und verblüffende Schaustücke darstellen: In einem Brief an Faustus (10) reagiert Ennodius auf eine Schrift von diesem über den Comersee, indem er den See in einer paradoxen Vituperatio als schreckliche Gegend darstellt (siehe dazu SCHRöDer 2003a). Mit einem weiteren Schreiben an Faustus (26, vgl. oben 39) schickt er ein längeres prosimetrisches Gedicht über die dichterischen Fähigkeiten des Faustus und seine eigenen. Auch die an Olybrius gerichtete bukolische Einleitung mit dem anschließenden Phaeton-Gedicht (27, vgl. oben 39) könnte in einer an Plinius und Sidonius erinnernden Briefsammlung stehen. In einem weiteren Brief an Faustus (381) spricht Ennodius über Maultiere, die der Bischof zu Faustus sendet, in solchen Worten, als handle es sich dabei um besonders christliche Frauen (siehe dazu SCHRÖDER 2006). Dass Ennodius nicht aus Ideen- oder Zeitmangel nur so wenige solche 'Kabinettstücke ( geschrieben hat, sondern weil er mehr nicht wollte oder durfte, ist nach einem kurzen Blick auf Sidonius Apollinaris zu zeigen.

Sidonius Apollinaris thematisiert an wenigen Stellen, dass sein neues Amt als Bischof auf seine literarische Tätigkeit Einfluss nehme; er betont, dass er sich bemühe, nun anders zu schreiben: »Denn während ich wegen des mir auferlegten Amtes allmählich eine neue Art zu schreiben anstrebe und die alte sprunghaft verlerne $[\ldots]$ « (Sidon. 4,3,9 nam dum inpactae professionis obtentu novum scribendi morem gradatim 
appeto et veterem saltuatim dedisco [...]). Er erwähnt einmal, dass er zugleich mit der Annahme dieses Amtes das Dichten aufgegeben habe: »[...] da er <sc. Dein Brief> zu wenig abwägt, welchem Stand ich angehöre, und nun von mir neue Gedichte erbittet. Gleich nach dem Antritt des kirchlichen Amtes habe ich ganz besonders diesen Übungen abgeschworen, da es ja als Leichtsinn ausgelegt werden könnte, wenn mich die Leichtigkeit von Versen vereinnahmt, wo mich doch jetzt der schwere Ernst der Taten betrifft « (Sidon. 9,12,1). ${ }^{369}$ Dies hält ihn allerdings nicht davon ab, einzelne Briefe mit beigelegten Gedichten innerhalb der Briefsammlung zu veröffentlichen (dabei handelt es sich nicht nur um thematisch >Angemessenes \&ie Epitaphien, z.B. in $2,8,3,12,4,11$, oder Inschriften für Kirchen wie in 2,10) ${ }^{370}$ In Versform nennt er den Grund, warum er keine Verse mehr schreibe: »[...] ich habe meine ganzen literarischen Studien auf die Pflege des Briefeschreibens übertragen, damit ich nicht, wegen des leichtfertigen Dichtens angeklagt, auch wegen meiner leichtfertigen Taten angeklagt würde; außerdem, damit man nicht denken kann, ich würde durch die lieblichen Worte verweichlicht, wenn ich rhetorische Figuren und Prunk in meine Schriften füge, so dass der Ruf des Dichters in keiner Weise die Strenge des Klerikers beflecken kann $\ll .{ }^{371}$ Nicht nur das Dichten lehnt Sidonius als Bischof ab, sondern an anderer Stelle weigert er sich unter anderem mit dem Hinweis auf seinen Stand (ordo; professio), Geschichte zu schreiben: »Doch meine Situation ist völlig anders, da mein neuerlicher Aufenthalt in der Fremde <sc. im Exil> mir Kummer verursacht und die alte Lektüre keinen Nutzen hat, ferner die Religion mein Beruf ist und Demut mein Ziel [...]. Geschichtsschreibung scheint zu meinem Stand sehr schlecht zu passen [...] « (Sidon. 4,22,4f.). ${ }^{372}$ Einmal schreibt er, dass er mit seinem Sohn Terenz gelesen habe, wobei ihm bewusst sei, dass sein neuer Stand dies eigentlich verbiete: "Ich saß bei seinen Studien neben ihm, wobei ich nur an meine Natur dachte und meinen Beruf vergaß (Sidon. 4,12,1 studenti assidebam naturae meminens et professionis oblitus). Hinsichtlich seiner Briefe, die er explizit in die Tradition des Plinius stellt und die er als Bischof veröffentlicht und auch überwiegend geschrieben hat, zeigt Sidonius keine Skrupel.

369 (Sidon. 9,12,1) [...] quippe qui parum metiens, quid ordinis agam, carmina a nobis nunc nova petat. primum ab exordio religiosae professionis huic principaliter exercitio renuntiavi, quia nimirum facilitati posset accommodari, si me occupasset levitas versuum, quem respicere coeperat gravitas actionum.

$370 \mathrm{Zu}$ den Ausnahmen siehe Gualandri $(1979,6 \mathrm{ff}$.).

371 (Sidon. 9,16, vv. 49-56) [...] ad epistularum / transtuli cultum genus omne curae,/ ne reus cantu petulantiore / sim reus actu;/ neu puter solvi per amoena dicta,/ schema si chartis phalerasque iungam,/ clerici ne quid maculet rigorem / fama poetae.

372 (Sidon. 4,22,4f.) nostra longe condicio dispar, quibus dolori peregrinatio nova nec usui lectio vetus, tum religio professioni est, humilitas appetitui [...]. (\$5) ilicet, scriptio historica videtur ordine a nostro multum abhorrere [...]; siehe dazu GUALANDRI $(1979,30-33)$ und besonders P. Cugusi, Un'epistola recusatoria di Sidonio, Boll. Stud. Lat. 20, 1990, 375-380. 
In Bezug auf das Verfassen von Versen sind die Aussagen des Sidonius mit denen des Ennodius vergleichbar: Bei Ennodius findet sich die ähnliche Sorge, dass die Süße der Dichtung den Christen verderben könnte. In der »Paraenesis« fordert er dazu auf, sich beim Dichten vorzusehen: "wir erdulden es, dass sich die dem Soldaten Christi eingepflanzte Härte vor Weichlichkeit hütet« (Paraenesis 452,3 v.11 f.: Christi militis insitum rigorem / elumbem patimur cavere ductum); vielleicht ist die Verwendung des Wortes pati hier ein Anzeichen dafür, dass es sich dabei um einen keineswegs leichten Verzicht handelt. In der »Recusatio « an Olybrius (27, vgl. oben 39 und 78) begründet Ennodius seinen Verzicht auf das Dichten so: "[...] damit nicht zarte Worte meinen Sinn als schlaff bloßstellen / und ich weich in Worten und Talent genannt werde. [...] damit man nicht aufgrund meiner Schriften annimmt, auch mein Charakter sei aufgeblasen « $(27$, v.47f., 52 [...] lactea ne mentem denudent verba solutam / et dictis mollis dicar et ingenio. [...] ne ... tumidus scriptis moribus esse puter). Die Parallelen zur Begründung des Sidonius in 9,16 sind nicht zu übersehen (solvi-mentem solutam; rigor; reus cantu, reus actu - et dictis mollis dicar et ingenio).$^{373}$

Allerdings sieht Ennodius nicht nur in der Dichtung Gefahren, sondern auch in bestimmten Aspekten von Briefen. In einigen Briefen, die sich als recusationes bezeichnen lassen (siehe ausführlich unten $177 \mathrm{ff}$.), wendet er sich gegen briefliche Wettkämpfe, certamina amicitiae und/oder litterarum. Der Gedanke, dass zur Freundschaft das Bestreben gehöre, einander an Freundlichkeit und im Erweisen von Gefälligkeiten und Unterstützung zu übertreffen, ist ein Element der Theorie der Freundschaft, vgl. z.B. Cic. Lael. 32: quam <sc. amicitiam> qui adpetiverunt, adplicant se et propius admovent, ut et usu eius quem diligere coeperunt, fruantur et moribus sintque pares in amore et aequales propensioresque ad bene merendum quam ad reposcendum atque haec inter eos sit honesta certatio. Plinius verwendet die Wörter certamen und vincere: (Plin. $7,7,2$ ) certat $[. .$.$] tecum honestissimo certamine mutuae caritatis; (Plin.$ $4,1,5)$ nam vinci in amore turpissimum est. Bei Symmachus erscheint das Motiv des Wettstreits häufig, wobei der Wettstreit in der Freundschaft eng verbunden ist mit dem, der sich auf Quantität und/oder Qualität der Korrespondenz richtet. Es gibt einen Wettstreit in der Häufigkeit von Briefen, z.B.: "Der briefliche Wettstreit unter Freunden ist eine schöne Sache, und daher haben wir uns zurecht beide vorgesehen, nicht im Austausch von Briefen besiegt zu werden; ich freue mich also, dass wir uns gleichkommen nicht nur an Zuneigung der Seelen, sondern auch im Austausch von Briefen; doch ich werde künftig dafür sorgen, dass die Waagschale meines Einsatzes sich weiter neigt; denn es soll nicht wie ein Wettkampf in Trägheit aussehen, dass wir immer als gleichschwer gewogen werden “ (Sy. 1,92); »eine Antwort auf meinen Brief

373 mollis ist hier eine Eigenschaft, die mit dem rigor des Christen unvereinbar ist; eine andere Perspektive bei Ovid (Pont. 2,9,47f.): adde quod ingenuas didicisse fideliter artes / emollit mores nec sinit esse feros. 
schenkt mir Freude - und die Verweigerung der Antwort den Sieg « (Sy. 7,25). ${ }^{374}$ Letztlich wichtig ist die Stärke der Freundschaft: "wenn ich auch an sprachlicher Eleganz unterlegen bin, versuche ich doch, an Beständigkeit der Freundschaft gleich zu sein “ (Sy. 4,26); "hinsichtlich der Briefe müssen wir uns geschlagen geben, aber hinsichtlich der Freundschaft können wir den Kampf aufnehmen « (Sy. 8,22) ${ }^{375}$ Symmachus kann auch eine Niederlage eingestehen: "Bisher kamen wir uns in unseren Freundschaftsdiensten gleich; nun muss ich ohne Zögern meine Unterlegenheit eingestehen. Ich glaube, dass Dir als Gegenleistung für Deine Freundschaft mein Eingeständnis, besiegt zu sein, ausreicht " (Sy. 3,29); "Ich weiche zurück [...] und muss beschämt anerkennen, dass ich nicht in vergleichbarer Weise antworten kann « (Sy. 4,72). ${ }^{376}$

Ennodius lehnt einen solchen Wettstreit aus mehreren Gründen ab, wobei er als den wichtigsten Grund die Sorge um seinen Ruf als Diakon nennt: Er befürchtet nicht nur, als Dichter mollis und tumidus zu erscheinen (siehe oben 174), sondern er hat auch beim Verfassen von Briefen Sorgen um seinen Ruf, und zwar die bereits in Teil I dargestellten: Er muss sich um humilitas und silentium bemühen. Seine humilitas verbietet ihm, einen Wettkampf aufzunehmen. Und da Ennodius weiß, dass er gut schreiben und damit Lob gewinnen kann, gerät er in eine Zwickmühle, wenn er einerseits Briefe schreiben und andererseits humilitas zeigen möchte. Er muss es vermeiden, in Antwortbriefen Lob zu lesen, wie man es in anderen Briefsammlungen findet. So lobt etwa Ruricius einen erhaltenen Brief: "Ich habe einen Brief von Dir, lieber Gleichgesinnter, erhalten, der ebenso mit Freundschaft wie mit Redekunst, ebenso mit Zuneigung wie mit Anmut, ebenso mit Witz wie mit Süße benetzt ist, in dem weder an Süße etwas fehlt noch an Würze. Während er in jeder Kunst der Rede und des Verstandes hervorsticht $[\ldots]$ « (Ruric. 1,4,1). ${ }^{377}$ Sidonius reagiert auf einen lobenden Brief: "Denn welche Flamme an Gedanken und welches Meer der Sprache Euer Schreiben begleitet, würde ich freier schreiben, wenn Du nicht, indem Du

374 (Sy. 1,92) Dulce certamen est familiaris officii, et ideo iure ambo cavimus, ne alternis epistulis vinceremur. gratulor igitur pares nos esse non solum adfectione mentium sed etiam vicissitudine litterarum. curabo tamen posthac, ut obsequii mei trutina et libra praeponderet, ne videatur inertiae quoddam esse conludium semper aequa lance censeri. $($ Sy. 7,25$)$ repensa [...] officia laetitiam mihi praestant, negata victoriam. Siehe auch z.B.: Sy. 3,15,1 vinci. 3,78 ne vincar. 3,80 certatio.

375 (Sy. 4,26) nos etsi elegantia sermonis inpares sumus, constantia religionis pares esse nitemur. (Sy. 8,22,1) litteris vincimur, amore certamus.

376 (Sy. 3,29) [...] stetimus officiis religionis hactenus pares; nunc tibi sine cunctatione cedimus. puto tibi sufficere ad vicem tantae gratiae victi confessionem. (Sy. 4,72) cedo [...] meque inparem referendae vicissitudini pudenter agnosco.

377 (Ruric. 1,4,1) Recepi apices unianimitatis tuae, tam gratia quam eloquentia, tam amore pariter quam lepore, tam sale quam melle respersas, in quibus nec dulcedini desset aliquid nec sapori. qui cum omni dictionis et rationis arte praemineant [...]. 
mich so eifrig lobst, es mir verbieten würdest, Dich zu loben. ${ }^{378}$ Und obwohl in Deinem Brief Deine Freundschaft beständig Deine Liebenswürdigkeit erkennen lässt, Deine Natur Deine Redekunst und Deine Erfahrung Deine Kenntnisse [...] « (Sidon. $8,10,1) .{ }^{379}$

Ennodius möchte offenbar solche lobenden Worte für seine Briefe gerade nicht lesen. ${ }^{380}$ Wie im nächsten Kapitel darzustellen ist, erklärt er einigen seiner Adressaten recht deutlich, dass er Briefe, in denen er seine Fähigkeiten zeigen und sich Lob für diese erwerben könnte, aufgrund seines Amtes nicht schreiben dürfe, z.B. »[...] vor Lob, wie Ihr es mit viel Mühe sucht, würde ich zurückschrecken« (21,4 [...] laudem, quam multo sudore vos petitis, formidarem).

Die Antwort (72) auf einen Brief, in dem er gelobt wurde, beginnt Ennodius damit, dass er vor Staunen den Mund nicht mehr zubekäme, wenn er nicht selbst seine Qualitäten einschätzen könnte. Maximus habe vor lauter Freundschaft seine Urteilskraft verloren: »Euch hat Eure Güte nicht an ein prüfendes Urteil denken lassen, mich zwingen meine Vorsätze, im ehrbaren Verborgenen zu leben. Ihr lobt meine Schriften so wie ein Freund, ich muss jene fürchten, die alles mit widerwärtiger Geringschätzung verachten und auch das wenige verurteilen, worauf ich mich schon reduziert habe« $(72,1){ }^{381}$ Dann wird deutlich, dass das Lob von dritter Seite kam: Maximus hat offenbar geschrieben, dass ein gewisser Patricius den Brief des Ennodius gelobt habe. Wenn daher Ennodius eingangs auf seine mangelnden Fähigkeiten bzw. auf sein propositum hinweist, sagt er damit implizit, dass es nicht sein könne und auch nicht sein dürfe, dass jemand Qualitäten eines Briefs von ihm lobe. Er beschreibt deshalb die Situation, wie sie auch gewesen sein könnte bzw. dürfte: Er bedankt sich dafür, dass Patricius ihn so beurteile, wie Maximus ihn empfohlen habe. Die Freundschaft des Patricius zu Ennodius werde also der Empfehlung durch Maximus verdankt, nicht einem Brief des Ennodius, der ja jeder Redegabe entbehre (scaber stilus sine eloquentiae dote, "der räudige Griffel ohne Redegabe«), d.h. entbehren

378 Es soll nicht so aussehen, als lobe man nur, weil man selbst zuvor gelobt worden ist, bzw. als habe der erste gelobt, um seinerseits gelobt zu werden; siehe bei Ennodius in 15,1, unten 268.

379 (Sidon. 8,10,1, an Ruricius) [...] nam stilum vestrum quanta comitetur vel flamma sensuum vel unda sermonum, liberius assererem, nisi, dum me laudare non parum studes, laudari plurimum te vetares. et quamquam in epistula tua servet caritas dulcedinem, natura facundiam, peritia disciplinam [...].

380 Wenn man die Urteile in der Forschungsliteratur betrachtet, ist es ihm zumindest hinsichtlich der Nachwelt gelungen, Lob für seine Briefe zu vermeiden; im 12. Jh. urteilt Arnulf von Lisieux, dass Ennodius jegliche venustas abgehe (cf. oben 53); oder: »die Lektüre seiner Schriften ist [...] nahezu eine Marter “ (Schanz/HosıUs/Krüger 4,2, 148).

$381(72,1)$ vos dignatio censurae fecit inmemores, me propositum intra verecundum degere penetrale conpellit. vos scripta mea tamquam amantes adtollitis, me necesse est illos metuere, qui rancido despicientes cuncta neglectu etiam edecumata condemnant. 
muss. Ennodius macht deutlich, dass er nicht für Leistungen gelobt werden dürfe, sondern gezwungen sei, rein auf Sympathie, favor, zu bauen.

Einem Diakon schreibt er, dass er sich beim Briefeschreiben vorsehe und sich nicht von seinen Vorsätzen abbringen lasse (317, siehe unten 195), und gegenüber einem anderen Diakon spricht er von dessen Vorsicht $(384,1$ cautellitas), die er als Grund für dessen Schweigen vermutet, allerdings sich selbst gegenüber als unnötig bezeichnet. Doch Ennodius ist keineswegs konsequent und zeigt auch an seinen Briefen, dass seine Änderung der Lebens- und Schreibweise noch nicht vollkommen, sondern äußerlich und partiell ist (vgl. besonders oben I 5 ). Wie schon oben $(68,75)$ an einigen dictiones zu beobachten war, ist auch im Folgenden an vielen Briefen zu sehen, dass Ennodius angesichts der Forderungen von silentium und humilitas mit spitzfindigen Argumentationen immer wieder Scheinlösungen findet: Sein Ausweg, um trotz allem in Briefen sein Talent zu zeigen, besteht darin, dass er sein ingeni$u m$ darauf richtet, gerade nicht lobenswert zu schreiben - nicht charmant, nicht liebenswürdig, nicht elegant, nicht über besondere Inhalte -, aber sich sein Lob gerade für sein ingenium sozusagen durch die Hintertür zu holen, als vorgeblich ungewollt. Nicht zu Unrecht hat ein Korrespondent (derselbe, dem Ennodius über sein Verhältnis zum Lob schreibt) ihm seine rhetorica versutia vorgehalten $(21,4$, siehe unten $186-$ 188). Dass seine ganze Strategie der Lob-Vermeidung eine Scheinlösung ist, zeigt sich schon an der Länge der Briefe, denn für wirklich `ängstliche` bzw. svorsichtige Briefe hätte er so knapp schreiben können wie Symmachus oder gar wie der noch wortkargere Dionysios von Antiochien (um 500 n. Chr., siehe bei HeRCHER p.260-274).

\section{Die Recusationes}

Hier sind nun diejenigen Briefe ausführlicher zu interpretieren, aus denen einige Passagen bereits oben (Kap. I 3.b) kurz herangezogen wurden, um Ennodius' frühere intensive Beschäftigung mit den studia liberalia zu beweisen und aufzuzeigen, dass er seinen jetzigen Stand durch die Schlüsselwörter silentium und humilitas, d.h. seine Vorsätze (propositum), charakterisiert. In diesen Briefen schreibt er, dass er aufgrund seines kirchlichen Amtes das literarische Schaffen bzw. diese »weltliche» Art der Kommunikation aufgegeben habe. Er weigert sich, in der Korrespondenz die literarischen Kräfte zu zeigen und zu messen, ${ }^{382}$ d.h. er will an dem brieflichen Wettstreit, wie man ihn in gebildeten Kreisen gern pflegte (siehe oben 174), nicht teilnehmen; einmal lehnt er sogar ausdrücklich den vom Adressaten gewünschten Briefwechsel ganz ab (siehe unten $184 \mathrm{zu}$ Florianus). Diese Briefe sollen hier ausführlich vorge-

382 (21,2f.) quid faceres, si certamina promisissem [...]? (\$3) [...] scribendi contentiones; $(39,4)$ periclum facere de eloquentiae pompa non debeo nec praesumo qualiter quis valeat experiri; $(317,2)$ concertatio. 
führt werden, da sie besonders deutlich machen, dass Ennodius mit seiner Absage an die anspruchsvolle Korrespondenz nicht konsequent ist: Denn er zeigt, wie in recusationes üblich, gerade in diesen Briefen sein Können. Es muss ihm durchaus daran gelegen gewesen sein, auf seine Adressaten Olybrius, Mascator, Florianus, Pomerius und Hormisda mit diesen >Absagen` Eindruck zu machen: Sie werden vielleicht nicht die Aussage der Briefe, d.h. seine Absage, gelobt haben, wohl aber Ennodius' ingenium, das er nicht nur im geschickten Aufbau des Gedankengangs zeigt, sondern auch in seinem Geschick darin, den Adressaten durch Doppeldeutiges zu täuschen und sich in seinen Aussagen letztlich nicht festzulegen, indem er Lob und Vorwurf mischt. In demselben Maße, wie er mel, dulcedo und lepos bewusst zu vermeiden scheint (vgl. oben Kap. I 2.c), spielt er seinen Scharfsinn und seine Fähigkeit zu spitzfindigen Argumentationen aus.

Weiter sind die unterschiedlich gestalteten recusationes deutliche Beispiele für den Adressatenbezug: Ennodius verhält sich gegenüber den weltlichen Adressaten Olybrius und Mascator eindeutig anders als gegenüber den Klerikern: In den Briefen an Olybrius und Mascator zeigt er, dass er sich über den Kontakt mit ihnen freut und diesen auch fortsetzen möchte, allerdings auf seine Weise; in diesen beiden Briefen legt er seine Weigerungsgründe ausführlich dar, und besonders gegenüber Olybrius zeigt er sein Bedauern darüber. Anders steht er zu den Klerikern (Pomerius und Hormisda sind sicher Kleriker, bei Florianus ist es zu vermuten). An Florianus und Pomerius schreibt er besonders ausführlich (der Brief an Pomerius ist recht lang, Florianus erhält zwei Briefe, da er den ersten offenbar nicht ernstgenommen hat), wobei die eigentliche recusatio den wenigsten Raum einnimmt, sondern Ennodius mehr Worte darauf verwendet, das Verhalten der Adressaten zu tadeln; wahrscheinlich kehrt Ennodius in diesen Briefen deshalb besonders seine Strenge hervor, da es sich bei diesen Adressaten anders als bei Olybrius und Mascator ebenfalls um Kleriker handelt. Den Diakon Hormisda tadelt Ennodius nicht explizit für sein Ansinnen, mit ihm ein certamen litterarum aufzunehmen, er macht aber dennoch deutlich, dass er selbst bei seinen Vorsätzen bleiben wolle.

\section{Olybrius (13)}

Olybrius (siehe zu ihm PLRE II, 795f., »Olybrius 5 (; SCHÄFER 1991, 87f.) war einer der führenden Männer des Senats (cf. 27, v.25f.), vermutlich war er Praefectus praetorio Italiae (cf. 48,3, zu 48 siehe oben 102); er galt als ein großer Redner (cf. 27,5, zu 27 siehe oben 78; Cassiod. 8,19,5). In dem Brief an seinen Schwiegersohn Iohannes werden Olybrius' Fähigkeiten sehr gelobt; allerdings deutet Ennodius dort auch an, dass Olybrius ihm nicht schreibe (4, siehe oben 121). Man nimmt an, dass sich der Brief an Eugenes (67) über den Tod von dessen Bruder, der im Brief nicht namentlich genannt wird, auf Olybrius bezieht; denn ein Brief ist an beide gemeinsam gerichtet (32), und die zunächst relativ dichte Korrespondenz mit Olybrius bricht ab (zu 42 siehe unten 301). 
Ennodius spricht in seinem ersten an Olybrius gerichteten Schreiben (nach dem Brief 4 an dessen Schwiegersohn, in dem er Olybrius erwähnt) über ihre Freundschaft, über die foederis certamina und über das Wiegen der wachsenden Freundschaft. Dabei äußert er sich besonders über den Inhalt von Briefen, bzw. konkret tadelt er ein Element des Briefes, den er von Olybrius erhalten hat. Olybrius hat offenbar in seinem Brief den Kampf des Herkules gegen Antaeus als Beispiel eines certamen erwähnt, doch er wird von Ennodius zurechtgewiesen: Ein solches certamen mit Sieg und völliger Niederlage sei der Freundschaft nicht angemessen; vielmehr müssten in der Freundschaft beide sowohl siegen als auch unterliegen wollen $\left(\$_{3}\right.$ et vinci ambo optemus et vincere). Außerdem dürften Christen nur die Wahrheit sagen und sollten daher in ihren Briefen auf pagane Mythen verzichten bzw. sie nur sehr eingeschränkt verwenden. Dieser Brief ist ein gutes Beispiel für Ennodius' Vorgehen, Lob und Kritik zu mischen: auf anfängliches Lob folgt die Kritik, und am Ende lenkt er wieder ein.

Ennodius beginnt mit einer der bei ihm seltenen Beschreibungen des erhaltenen Briefes (siehe dazu unten 265); nach einer Anspielung auf Vergil überträgt er Begriffe, die zum Kampf zwischen Herkules und Antaeus passen, auf die Sprachkunst des Olybrius: "Indem Du honigsüß redest und aus dem Nektar der Redekunst in Wachswaben flüssigen Honig herstellst, hast $\mathrm{Du}$ auf meine Lippen den fremden Geschmack eines reichen Mahles geträufelt, indem Du den Kampf des Herkules und die triumphbringenden Stürze des Antaeus erwähntest. So offenbaren sich die auf den Übungsplätzen der Studien trainierten Ringkünste, so bringen sie <sc. die Ringkünste> die mit dem Öl der Studien befeuchteten Glieder des Mundes durch Kunstgriffe der Rede zum Unterliegen « $(\$ 1) .{ }^{383}$ Doch dann wird deutlich, dass Ennodius den peregrinus sapor $(\$ 1)$ des Briefes gar nicht als angenehm empfunden hat: "Doch ehrlich gesagt, wäre ich lieber nicht, wie man so sagt, von der Erwähnung dieses Kampfes gepeinigt worden « $(\$ 2) .{ }^{384}$ Dieser Kampf des Herkules gegen Antaeus, den Ennodius z.B. aus Lukan gut kannte, wird in einem Satz zusammengefasst: "Das alte Geschichtchen sagt, Antaeus habe, damit er nicht durch den Fall auf den Boden <sc. neue Kraft erhalte und > gewönne, die Hilfe seiner Mutter $<=$ der Erde> verloren, als er begann nicht mehr zu fallen; er soll durch den Kunstgriff des schlauen Feindes im

$383(13,1)$ Dum favos loqueris et per domos cereas eloquentiae nectare liquentis elementi mella conponis, peregrinum labiis meis saporem epuli divitis infudisti, Herculei certaminis et triumphalium Anthei casuum faciens mentionem. sic se equidem exercita litterarum gymnasiis palestra dilucidant, sic madefacta studiorum oleo loquendi artificiis oris membra submittunt. - Zum Beginn vgl. Verg. Aen. 1,432f. liquentia mella / stipant et dulci distendunt nectare cellas. - palestra verwendet Ennodius als Neutrum Plural, siehe den Index bei VOGEL. - HARTEL ergänzt "se " nach loquendi, doch wenn man madefacta [...] membra als Akkusativ auffasst und palestra als Subjekt auch zu submittunt, ist diese Ergänzung unnötig.

$384(13,2)$ Sed noluissem fateor illius ut aiunt pugnae commemoratione morderi. 
Stehen besiegt worden sein und an der Brust des Gegners seinen Geist aufgegeben haben « (\$2). ${ }^{385}$ Es folgt die Erklärung, warum Ennodius im Brief des Olybrius lieber nicht davon gelesen hätte: »Diese List ist es sicher wert, nicht vergessen zu werden, aber der Vorsätze der Freundschaft nicht würdig. Ich erinnere mich natürlich, dass wir den Wettkampf des (Freundes-) Bundes aufgenommen haben, aber einen, bei dem wir im Erweisen unserer gegenseitigen Zuneigung siegen, so dass wir, während wir uns bei solchen Kämpfen anstrengen, beide sowohl zu unterliegen als zu siegen wünschen. Wir müssen aufgrund der gemeinsamen Geheimnisse unserer Herzen lieber leben als sterben, die wir durch die Macht der Mutter Kirche verbunden sind, die uns beiden, damit wir die Wahrheit sagen, die reichliche nährende Milch des Glaubens zu trinken gibt. Weichen sollen die Erfindungen der altweiberhaften Dichter, verschmäht werde das sagenreiche Altertum. Unser Zustand der Unschuld soll auf keine Weise mit dem Verderben eines anderen vermengt werden <sc. (?) wir unschuldigen Christen sollten nichts mit den verderblichen alten Geschichten zu tun haben> « $\left(\$ 2 \mathrm{f}\right.$.). ${ }^{386} \mathrm{Zum}$ "neuen Gebrauch « (in novellum usum) schlägt er andere Personen aus dem Mythos vor, allerdings auch dies mit einem Vorbehalt: "Wenn wir die Beispiele der Alten auf neue Weise nutzen wollen, schickt es sich besser, sich an die Freundschaft und Treue eines Pylades und Orestes, Nisus und Euryalus, Pollux und Castor zu erinnern, wenn nicht heimliche Schandtaten gegen sie sprechen. Diese Männer fesselte eine so einträchtige Gleichheit der Seelen aneinander, dass von ihnen zwei es anstrebten, zusammen mit dem Freund unterzugehen, und der eine dem Freund das Leben zum Preis seines eigenen Todes brachte $(\$ 4) .{ }^{387}$ Ennodius beendet den Brief mit einem anderen Bild der Freundschaft, das er der Natur - anstatt dem Mythos - entnimmt, und mit einer kurzen Bemerkung über seine Freundschaft mit Olybrius, aus der hervorgeht, dass die beiden sich noch nicht lange kennen (was sich auch im nächsten Brief bestätigt, siehe oben $80 \mathrm{zu}$ 27,6): "Solche Dinge sind der Erinnerung würdig, sooft in neuen Verbindungen der Eintracht durch den, um es so

$385(13,2)$ Antheum fabella senior, ne elisus vinceret, matris solacium, postquam coepit non cadere, loquitur perdidisse; qui per callidi hostis fabricam fertur stando esse superatus et in pectore animam posuisse certantis.

$386(13,2 f$.) Res scilicet daedala memoratu, sed amicitiarum indigna proposito. ( $\$ 3$ ) nos nempe memini foederis certamina suscepisse, sed per quae mutuae vincamus caritatis officiis, ut dum inter huiusmodi luctamina nitimur, et vinci ambo optemus et vincere. nobis per communia pectorum secreta vivendum potius quam obeundum est, matris ecclesiae ope sociatis, quae utrosque, ut vera loquamur, fidei ubere lacte pascit altrici. $(\$ 4)$ cessent anilium commenta poetarum, fabulosa repudietur antiquitas. status innocens ruinae nequaquam misceatur alterius.

$387(13,4)$ nobis, si placet in novellum usum maiorum exempla revocare, potius Pyladis et Orestis, Nisi et Euryali, Pollucis et Castoris, si nihil his clandestinorum actuum decerpit obscenitas, convenit gratiae meminisse vel fidei. quos inter se ita concors animorum devinxit aequalitas, ut horum, dum duos expetitus cum amicis iuvaret interitus, alter amico vitam pretio suae mortis adferret. 
zu sagen, feuchten Bast der Seelen eine edle Frucht mit kräftigen Ästen verbunden und gepaart wird. Jene Seelen versprechen Früchte der Eintracht, die erkennen, wieviel Mühe bei der Pflege < der Eintracht> nötig ist.« Abschließend lenkt Ennodius ein und zeigt so, dass die Kritik doch nicht so ernstgemeint war: "Ich freue mich also, dass uns unsere <sc. gleichartige> Gesinnung bereits in einer unauflösbaren Gemeinschaft verbindet und wir gleich am Tor der Freundschaft mit der prüfenden Waagschale das Anwachsen der Freundschaft abwiegen« $(\$ 5) .{ }^{388}$

Wahrscheinlich hat Olybrius, nachdem er Ennodius persönlich kennengelernt hatte, einen sersten Brief`( siehe unten 303) über die amicitia und besonders das certamen amicitiae geschrieben. Bemerkenswert ist, dass Ennodius auf den ersten Brief von Olybrius mit einer Zurechtweisung reagiert. Immerhin ist Olybrius kein Schüler, sondern ein bekannter Redner und ein wichtiges Mitglied des Senats, und Ennodius hatte sich bei dessen Schwiegersohn Johannes leise darüber beklagt, dass er nicht schrieb (siehe oben 121). Ennodius muss sich sicher gewesen sein, dass Olybrius seinen Ton zu schätzen wusste.

\section{Mascator (95)}

Eine ganz andere recusatio erhält Mascator, der derselbe sein könnte wie der Adressat eines wesentlich späteren Briefs (444), der als homo palatii bezeichnet wird (siehe PLRE II, 733). - In der Anfangspassage (die einen neuen Sinn erhält, sobald man den Brief ganz gelesen hat) schreibt Ennodius kurz von seiner Freude über die von Mascator gezeigte Freundschaft und betont dann das seltene Ereignis, dass ausnahmsweise er einmal zum Schreiben aufgefordert worden sei: "Mit neuem Glanz hat mich die unverstellte Freundschaft Eures Herzens geschmückt. Ich, der ich den Gebildeten außer durch Unwissen durch Geschwätzigkeit missfalle, habe nun einen Beweis dafür, dass mein Griffel aufgefordert wurde « $(\$ 1) .{ }^{389}$ Es folgt eine auffällig lange Reihe von allgemeinen Bemerkungen (siehe dazu unten 252ff.) zur Qualität von Schreiben, die aufgrund von Aufforderungen entstanden sind: "Ein eingeforderter Brief hat sich einen Wert, den er nicht aufgrund der Redekunst hat, durch den auferlegten Zwang angeeignet. Niemals hat ein Unrecht Rache verdient, das jemand auf Befehl ausführte. Niemand verurteilt mit Recht einen Gehorsamen. Ein von bäuerischer Redeweise zugefügtes Unrecht hat sich derjenige selbst zuzuschreiben, der einen Unkundigen herausfordert. Es ist Hochmut, Höherstehenden nicht zu gehorchen, <aber es ist $>$ größerer

$388(13,5)$ ista sunt digna memoria, quotiens inter novos concordiae nexus $u d o, u t$ ita dixerim, animorum libro caespitibus validis fetura nobilis iuncta maritatur. illae mentes promittunt poma concordiae, quae quid in cultura sudoris sit opus agnoscunt. gaudeo tamen, quod iam indissolubili societate moribus iungimur et ab ostio affectionis per examinis lancem caritatis incrementa pensamus. $-\mathrm{Zu}$ caespes $=$ frutex siehe VogEL $(1885,371)$.

$389(95,1)$ novo me genio infucata pectoris vestri ornavit diligentia. eliciti utor stili testimonio, qui doctis supra inscitiam garrulitate displiceo. - Zur Formulierung cf. $(65,1)$ eliciti utor stili genio, unten 320 ; siehe auch 155,2 unten 315. 
$<$ Hochmut $>$, wenn man auf das herabblickt, von dem man weiß, dass es von einem Gehorchenden stammt. Man könnte eine Bestätigung dafür, dass ein Wunsch unbillig ist, darin sehen, wenn einer nicht schätzt, was er fordert. Wer darauf verzichtet, einen Gehorchenden zu kritisieren, handelt in Übereinstimmung mit seiner Urteilskraft <sc. die ihn den Gehorsam verlangen ließ>. Eine übel beharrliche Strenge ist es, bei einem Gehorchenden die Qualität zu betrachten. Derjenige hat seinen Anstand nicht aus dem sicheren Hafen gebracht, der es einem Befehl verdankt, dass er spricht“ (\$1f.). ${ }^{390}$ Ausnahmsweise markiert Ennodius den Übergang von der Praefatio zum konkreten Hauptteil mit einer Konjunktion (siehe dazu unten 259); er fasst die Reihe der Gemeinplätze zusammen und bezieht sie auf seine Situation: "Daher wird in meinem Fall das, was an Redekunst gering erscheint, durch den Gehorsam empfohlen. Ihr mögt sehen, wie das ist, was aufgrund Eures Befehls dargeboten wird. Ich meine, dass Ihr verdient habt zu erhalten, was Ihr wünschtet - ohne Nachteil für mich und meinen Ruf $\left(\$_{3}\right) .{ }^{391}$ Ennodius betont also, dass er dem Adressaten zwar den Wunsch nach einem Brief erfüllen wollte, aber ohne nachteilige Folgen für sich selbst und seinen Ruf. Diese Rücksicht auf sein >Image< erklärt sich im Folgenden, wenn Ennodius ausführt, warum das Schreiben eines Briefes für ihn ungute Folgen haben könnte. Denn es folgen nun in Form einer Praeteritio ( $\$ 3$ taceo; $\$ 4$ excusationem [...] non praetendam; taceo) die Gründe dafür, dass er eigentlich nicht schreiben darf bzw. keine weltliche gelehrte Korrespondenz aufnehmen kann: Er hat letztlich, anders als man beim Lesen der Allgemeinplätze denken muss, keine Sorgen um den Ruf seiner eloquentia, sondern um seinen Ruf als Diakon: »Dabei verschweige ich, was an erster Stelle zu sagen gewesen wäre: dass die kirchliche Demut all dem abgeschworen hat, was hätte gefallen können, dass derjenige, der das Gebet liebt, nicht nach Redeprunk ${ }^{392}$ gestrebt hat, dass ich in Anbetracht meiner Vorsätze auch jenes fliehe, was zum Ruhm führt, <dass ich> wie einem Laster all dem ausweiche, was mich emporheben könnte, für eine Schuld halte, was erheben oder erhöhen kann,

$390(95,1 \mathrm{f}$.$) coactus sermo pretium, quod non habet ex eloquentia, ab inpacta necessitate sub-$ ripuit. nunquam fuit digna ultione contumelia, quam iussus exhibuit; nemo oboedientem iuste condemnat. sibi debet inlatas iniurias de eloquio rusticante, qui provocat imperitum. (\$2) supercilium est celsioribus non parere; maius, si quae noveris descendisse ab obsequente despicias. inprobi desiderii putetur adsertio non amare quod exigis. adstipulatur iudicio suo, qui censuram de obtemperante suspendit. male pertinax districtio est, quae meritum in parente considerat. pudorem ab statione non expulit, qui quod loquitur debet imperio.

$391(95,3)$ itaque in nobis quod sordet eloquentia commendatur obsequiis. vos videritis, quale sit quod iussistis offerri. ego vos sine frontis meae dispendio meruisse aestimo, quod desiderastis accipere. - VoGELs Erklärung (Index, 384) »sine insolentia" für sine frontis meae dispendio $\left(\$_{3}\right)$ ist m.E. nicht treffend.

392 Mit diesen beiden Bedeutungen von oratio spielt Ennodius häufiger, siehe auch: $(452,26)$ si pomposa oratione non valui, oratione vos memor professionis adiuvi; ähnlich $(21,4) \mathrm{cum}$ diu sit quod oratorium schema affectus a me orationis absciderit. 
und dass ich mich um verdientes berechtigtes Lob bringe, wenn ich Beifall anstrebe $<$ d.h. von ihm wird zwar lobenswertes Verhalten erwartet, er darf aber nicht auf Lob aus sein $>$. Ich bringe nicht die mit dem Pinsel der Wahrheit gefärbte Entschuldigung vor, ${ }^{393}$ wenn ich wiederhole, dass ich das, was immer die Bemühung um die freien Studien mir geschenkt hatte, längst aufgegeben habe, und dass im Bett des einst reichlichen Stromes kaum ein Tropfen einer vertrockneten Rede fließt. Ich verschweige (weil meine Zunge, die die Praxis beweglich gemacht hatte, eine andere Praxis abgestumpft hat), dass Schweigen an die Stelle von Beredsamkeit getreten ist, dass von uns Niedrigkeit statt Erhabenheit geliebt wird" $\left(\$_{3} \mathrm{f}.\right) .{ }^{394}$

Dann verweist er nochmals auf die anfangs vorgebrachte Entschuldigung: "Ich komme darauf zurück, dass ich nicht scheu im Verborgenen bleiben und die Schwäche meiner Begabung mit dem Mantel der Schweigsamkeit bedecken durfte. Das, was ich vorgetragen habe, rechne ich als vollständige Verteidigung « $\left(\$_{5}\right){ }^{395}$ Anstelle der in der Praeteritio vorgebrachten (tatsächlichen) Gründe sollen also die eingangs angeführten zur Rechtfertigung dienen. Nach der Lektüre des ganzen Briefes bekommt so die anfängliche Entschuldigung für die (angeblich mangelhafte) Qualität des Briefes, die in einer Reihe von Allgemeinplätzen über obsequium und imperium formuliert wird, eine andere Dimension. Ennodius muss sich letztlich nicht für seine unzureichenden Fähigkeiten entschuldigen, sondern dafür, dass er als Kleriker überhaupt noch schreibt - er rechtfertigt sich damit, dass er ja dazu aufgefordert wurde. ${ }^{396}$

393 Der als Variante zu dem zweifachen taceo verwendete Ausdruck excusationem veritatis coloratam peniculo non praetendam erklärt sich so: An anderen Stellen ist der Pinsel der der Lüge, des Truges: $(21,5)$ ficta $[\ldots]$ et peniculo decorata mendacii; (Dictio 363,2) peniculo fucata mendacii [...] elocutio; (49,2 Libellus pro synodo) loquellam, quae peniculo artis est colorata; $(49,60)$ fallaciae peniculo depicta verba. Im Brief an Mascator bringt Ennodius in einer Praeteritio die tatsächlichen Gründe vor und verwendet als witzige Einleitung für diese Praeteritio, dass er die Entschuldigung, die mit dem "Pinsel der Wahrheit gefärbt « ist, nicht vorbringen wolle.

394 (95,3f.) taceo inter ista, quae principe fuerant loco narranda, ecclesiasticam humilitatem quod placere poterat abiurasse, orationum pompam qui orationem diligit non secutum, propositi consideratione et illud me fugere quod ducit ad gloriam, quasi vitium declinare quicquid attollit, culpam putare quod erigit aut sublimat, perdere iustae laudationis meritum favoris affectu. (\$4) excusationem veritatis coloratam peniculo non praetendam, dum replico, quod illud, quicquid studiorum dederat cura liberalium, iam reliqui, quod alveo quondam copiosi fluminis vix arentis gutta fundatur eloquii. taceo, quod linguam, quam usus mobilem fecerat, alter usus hebetavit: esse pro facundia silentium, abiectionem a nobis diligi pro coturno.

$395(95,5)$ ad illud redeo, quia mihi non licuit intra verecundum penetrale delitiscere nec debilitatem ingenii tegere taciturnitatis indumento: hoc ad defensionem integram quod praetuli conputabo.

$396(95,1)$ eliciti [...] stili; coactus sermo; inpacta necessitate; iussus; oboedientem; $(\$ 2)$ parere; imperio; obsequiis. 
Wenn er als Kleriker schreibt, darf er nicht für literarische Qualitäten gelobt werden; darum malt er aus, wie unfähig er sei und dass der Brief nur aufgrund seines Gehorsams - und auch das obsequium gehört zum Amt des Diakons - gefallen könne, lies: dürfe. - Abschließend entschuldigt er die Länge des Briefes mit seiner Freundschaft $\mathrm{zu}$ Mascator ( $\$ 5$ amore provocatus epistulares terminos inconsiderata loquacitate transcendi) und bittet ihn, durch seine Reaktion zu zeigen, was er von diesem Brief halte, indem er entweder schweige oder häufig schreibe ( $\$_{5}$ aut taciturnitate aut scriptione multiplici).

\section{Florianus $(20 ; 21)$}

Florianus (zu seiner Person unten 188) erhält zwei Briefe (20;21), in denen Ennodius (zunächst ohne Erfolg) deutlich macht, dass er mit ihm keinen Briefwechsel führen möchte. Aus dem zweiten Brief geht hervor, dass Florianus auf den ersten nicht so reagiert hat, wie Ennodius es erwartet hatte. Mit dem ersten Brief wollte Ennodius Florianus von weiterer Korrespondenz abhalten; doch dieser hat nochmals geschrieben, woraufhin Ennodius mit einer ausführlicheren Weigerung antwortet. Er begründet die Ablehnung mit seinen Grundsätzen silentium und humilitas, die ihm verbieten, in einen brieflichen Wettstreit (certamina; scribendi contentiones) einzutreten. ${ }^{397}$

Zunächst zu dem zweiten Brief, da dieser Hinweise zum besseren Verständnis des ersten enthält. Der Brief beginnt mit einem - angesichts von Ennodius' unendlichen Bitten um Briefe und seinen Klagen über Schreibfaulheit gegenüber anderen Adressaten - unerwarteten Satz, dass nämlich Florianus nach dem ersten Brief von Ennodius nicht nochmals hätte schreiben sollen: »Bruder, Du hättest für die Freundschaft zu mir das aufbringen können, was bei wahrer Freigebigkeit zum Vorteil des Gebenden auch dem richtigen Benehmen genützt hätte, ich meine natürlich: da Du schon einen Brief bekommen hattest, der meine Einstellung deutlich machte, mit dem Schreiben aufzuhören $[\ldots] \ll(21,1) .{ }^{398}$ Ennodius bezieht sich auf seinen vorangehenden Brief mit seiner Weigerung, eine Korrespondenz aufzunehmen; Florianus habe seine Worte nicht ernst genommen und mit einem umso längeren Brief

397 Anders verstanden von KeNNELl $(2000,63): »[\ldots]$ one thanking him for a letter rich in Roman endowment, the other extolling his command of the Latin language [...].» - Gionnni referiert als Inhalt der beiden Briefe, es gehe um Stil und Sprache, vgl. (2001, 168) zu (20): "Dans une première lettre très courte, Ennode se borne à le féliciter pour sa belle slettre riche du génie romain où brille la beauté du style latin«; mais, dans la seconde, le ton est tout différent: Ennode critique violemment Florianus qui, n'ayant pas apprécié ses conseils, lui aurait sèchement répondu en qualifiant sa rhétorique de pur sartifice de langagec. Brief 21 nennt Gionnnı (ibid. 170) als Beispiel für Briefe, die Probleme der Rhetorik, in diesem speziellen Fall Stilkritik, behandeln.

$398(21,1)$ Illud fraternitas tua amori meo potuisset inpendere, quod vera liberalitate cum tribuentis conpendio proficeret et pudori, in ea scilicet parte, ut cum indices studii mei litteras iam teneres, ab scriptionis te cura suspenderes. $[\ldots]$ 
geantwortet: "[...] Denn nachdem ich geantwortet hatte, dass ich das Schweigen liebe, habe ich - so als hätte ich zustimmend geantwortet - längere Seiten erhalten und nach meiner Absage die lange zufällig versteckte Fruchtbarkeit Deiner Rede hervorgelockt « $(21,2) .{ }^{399}$ Ennodius habe Schweigen angekündigt, doch Florianus habe nicht entsprechend reagiert: $»$ Was würdest Du tun, wenn ich einen Wettstreit angesagt hätte, wenn ich den Eifer Deiner Studien mit irgendeinem bissigen Angriff unvorsichtig berührte, wenn ich mich nicht selbst gut einschätzen könnte und deshalb nicht sicher im Verborgenen bliebe? Ich denke, gegen mich wäre die Tiefe des Ciceronischen Meeres, die Eigentümlichkeit des Sallust, die Eleganz des Maro aufgeboten worden, und ich hätte nirgends Rückhalt gefunden, da es mir nicht einmal genützt hat, mich einem Schreibwettkampf zu entziehen, nicht einmal, indem ich trotz ausdrücklicher Aufforderung geschwiegen habe $\ll(21,2) .{ }^{400}$ Der erste Brief des Florianus wird hier als eine Herausforderung bezeichnet (cf. lacessitus), die Ennodius aber nicht annehmen wollte; der wichtigste Grund für seine Weigerung ist: die Angst vor Lob (siehe oben 176): "Selbst wenn mich das Bewusstsein meines Könnens und meine Redekraft ermutigten, würde ich außer allen anderen Risiken beim Schreiben das Lob fürchten, das $I h r<$ hingegen $>$ mit viel Mühe erstrebt « $\left(\$_{3}\right) .{ }^{401}$ Florianus habe geschrieben, dass Ennodius seine rhetorischen Fähigkeiten schlau einsetze (worauf sich dies bezieht, ist an dem vorausgehenden Brief zu zeigen), doch das könne - lies: dürfe - gar nicht sein: »Hinzu kommt, dass Du gesagt hast, ich verfügte über rhetorische Wendigkeit, wo es doch aber lange her ist, dass die Neigung zum Gebet mich von den Redefiguren entfernt hat und ich mich nicht mehr mit schmückenden Worten beschäftigen kann, da mich der Ruf meines Amtes laut zu Klagen und Gebeten ruft « (\$4). ${ }^{402}$ Florianus solle also seine Briefe zurückhalten, da sie keinen guten Rat enthielten; er solle auf keinen Fall wieder schreiben, sei es, dass er seine Bemerkungen über Ennodius' Redekunst ehrlich gemeint habe, sei es, dass er nur geheuchelt habe: »Unterlasse also Deine erweichenden und schlecht ratenden Briefe. Wenn Du Dir das Geschriebene nur ausgedacht und mit dem Pinsel der Lüge geschmückt hast, ändere Deine Vorsätze wenigstens jetzt, wo Du siehst, dass herausgekommen ist, mit welcher Absicht

$399(21,2)[\ldots]$ nam postquam me silentium amare rescripseram, quasi pro allegationis responso prolixiores paginas inpetravi et diu forte repositum post negationem meam eloquii uber elicui.

$400(21,2 \mathrm{f}$.) quid faceres, si certamina promisissem, si studiorum tuorum fervorem quocumque dente incautus adtingerem nec mei idoneus aestimator penetralia tuta servarem? $\left(\$_{3}\right)$ adhibita credo adversus me fuisset Tulliani profunditas gurgitis, Crispi proprietas, Maronis elegantia, nec in ulla invenissem parte subsidium, cui nec illud profuit, quod scribendi contentiones, nec cum reticerem lacessitus, effugi.

$401(21,3)$ me etsi peritiae conscientia et dicendi vigor adtolleret, post diversa scribentum discrimina laudem, quam multo sudore vos petitis, formidarem.

$402(21,4)$ huc adcedit, quod rhetoricam in me dixisti esse versutiam, cum diu sit quod oratorium schema affectus a me orationis absciderit et nequeam occupari verborum floribus, quem ad gemitus et preces evocat clamor officii. 
Du es gemacht hast <sc. Ennodius von seinen guten Vorsätzen abzubringen>. Wenn es wahr ist und von der Waage des Urteils herrührt, schließ es tief im Verborgenen Deines Herzens ein und erweise der Freundschaft Deine Verehrung, indem Du Deinen Freund nicht antastest. Bewahre mir gegenüber ein unwandelbares Herz und schmeichle anderen mit Deinen Briefen « $(\$ 5) .{ }^{403}$ Wenn Florianus schon seine bisher genannten Weigerungsgründe nicht anerkenne, solle er doch jedenfalls Rücksicht nehmen auf Ennodius' Beschäftigungen: "So also habe ich das Maß eines Briefes überschritten, wo ich auf einen langen Brief antworten will; doch eine Schuld, die für ihre Fehler ein Beispiel hat, muss man nicht mit besonderer Strafe ahnden. Mein Herr, ich grüße schuldigst und bitte Dich, wenn Du Dich mit Wendigkeit hineindenkst in meine Wünsche, die ich hinsichtlich der Liebe zum Schweigen gefasst habe, wenigstens meine Beschäftigungen als Hinderungsgrund anzuerkennen « $(\$ 6) .404$

Aus diesem zweiten Brief an Florianus lässt sich erschließen, in welcher Situation Ennodius den vorangehenden (20) geschrieben hat: Florianus hat einen rersten Brief (siehe unten 303) geschrieben, um Ennodius zu einem anspruchsvollen Briefwechsel aufzufordern. Ennodius lehnt dies in seiner Antwort ab (20), aber Florianus schreibt trotzdem noch einmal, wobei er von der rhetorica versutia des Ennodius spricht; er hat also offenbar die Weigerung nicht ernstgenommen. Wie hat also Ennodius seine erste Weigerung formuliert? Nach einer Praefatio (siehe unten 187) beginnt der konkrete Teil des Briefs, wobei Ennodius zunächst seine Aufrichtigkeit betont: »Ich würde die Wahrheitsliebe für meine Vorsätze (propositum) aufbringen, wenn ich sie nicht meiner Herkunft schuldete« $(\$ 1) .{ }^{405}$ Dann geht er explizit auf den Brief des Florianus ein: "Ich habe Deinen Brief erhalten, der reich ist an römischer Gabe und der den lateinischen Stil gleich im glänzenden Anfang zeigt; darauf zu antworten zwang mich die Freundschaft - gegen die ablehnende Haltung meiner Unfähigkeit -, obwohl in mir seit langem das, was das Schweigen verspricht, die Lust am Schreiben verdrängt hat und die Stille als Ruhm rechnet“ $(\$ 2) .{ }^{406}$ Ennodius antwortet also auf-

$403(21,5)$ delenifica ergo et malesuada conpesce conloquia. si ficta sunt quae scribis et peniculo decorata mendacii, muta propositum vel posteaquam vides mentem innotuisse qua feceris; si vera sunt et a iudicii lance descendunt, profundo ea pectoris include secreto, ut reverentiam diligentiae, dum amico res integras servas, exhibeas. mihi inmutabile cor custodiens alios demulce conloquiis.

$404(21,6)$ ecce epistulae modum, dum productae paginae cupio respondere, transcendi. sed non est culpa speciali plectenda supplicio, quae in erratis habet auctorem. domine mi, salutationem debendam restituens precor, ut si desideriis meis, quae de amore taciturnitatis concepi, pernix te scrutator interseris, saltim occupationibus, quibus inpedimur, ignoscas.

$405(20,1)$ ego veri diligentiam proposito inpenderem, si sanguini non deberem.

$406(20,2)$ suscepi epistulam tuam Romana dote locupletem et stilum Latiarem in ipsa principiorum luce monstrantem, cui me respondere obponente manus inscitia coegit affectio, cum diu esset quod antiquaverat apud me scribendi studium spes tacendi et in locum gloriae silentium conputabat. 
grund der Freundschaft (coegit affectio), obwohl er eigentlich dem Schreiben das für ihn ruhmvollere silentium vorzieht, d.h. obwohl er als Diakon seine literarische Tätigkeit einschränken muss. Doch außer der knapp genannten Freundschaft gibt es noch einen weiteren Grund dafür, dass er antwortet; er wolle Florianus zeigen, dass er diesen durchschaut habe: "Doch wenn ich nicht geantwortet hätte, wüsstest $\mathrm{Du}$ nicht, dass Du ertappt wurdest, wie Du mit kunstvoller Beredsamkeit und der Maske der Romulus-Schläue mit weniger kunstfertigen Talenten Dein Spiel triebst. Eine Klinge, die der Rost in Besitz genommen hat, schneidet nicht so gut wie eine polierte, und Erstarrung kann nicht den gleichen Kampf aufnehmen wie Geübtheit« $(\$ 2) .{ }^{407}$ Ennodius wirft Florianus also vor, dass er in seinem sprachlich ausgefeilten Brief mit Ennodius, dessen sprachliche Fertigkeiten verkümmert seien, sein Spiel treibe.

Auf Florianus' Verhalten in seinem ersten Brief könnte sich daher die Praefatio der Antwort beziehen, in der er nämlich zunächst vom Verhältnis zwischen humilitas und adrogantia (zu große Demut beweise letztlich Hochmut), dann von rhetorischen 'Topoir spricht: "Es ist das Gleiche, die Grenze des Hochmuts nicht zu kennen und die $<$ Grenze $>$ der Demut zu überschreiten. Man zeigt Hochmut, wenn man über das rechte Maß hinaus demütig ist. Es ist üblich, neue Schmeicheleien für Staunende zu erfinden, und es ist hoher Stil, seine Angst beim Reden vorzutäuschen und eine Bewertung zu fürchten, wenn man sich des Lobes sicher ist « $(20,1) .{ }^{408}$ Hierauf folgt der konkrete Teil des Briefs, der mit betontem ego beginnt; Ennodius selbst wolle sich nicht verstellen (simulare), er sei aufrichtig. Er setzt sich von dem Verhalten, wie er es in der Praefatio beschreibt, $a b ;{ }^{409}$ er will also nicht Demut heucheln, er will nicht Angst vor dem Urteil des kundigen Lesers vorgeben, er will keine Schmeicheleien ausdenken (gegen diese >Topoi ‘ wendet er sich auch an anderen Stellen). ${ }^{410}$ Wenn En-

$407(20,2)$ sed nisi respondissem, nescires te esse deprehensum, quod minus fabricatis ingeniis artifici facundia et fuco Romuleae calliditatis inluseris. non aequa ad secandum virtus est politae lamminae et eius, quam rubigo possederit, nec parem conflictum usus potest et torpor adsumere.

$408(20,1)$ Idem est terminum in adrogantia non tenere quod in humilitate transcendere. supercilii affectus est iusto amplius esse subiectum; familiare est graviter hiantibus novas invenire blanditias, et grandis coturnus, in eloquentia simulare formidinem vel examen metuere de laude securum.

409 Dass es sich um einen Gegensatz handelt, muss vom Leser aus dem Sinn erschlossen werden; Ennodius deutet dies nur durch den betonten Einsatz mit ego an. Dazu, dass die gedankliche Verbindung zwischen Praefatio und Hauptteil vom Leser zumeist selbst erkannt werden muss, siehe unten 259.

$410(20,1)$ simulare formidinem vel examen metuere de laude securum. Dieses Motiv kommt häufiger vor: $(4,2)$ timere te scriptionem quasi fronte tener insinuas $[\ldots],[\ldots]$ peregrinam mentita formidinem; der junge Johannes wird aber nicht dafür getadelt, sondern Ennodius betont, dass dieser es nicht nötig habe. - Der junge Avienus wird für diese Haltung gelobt (23,1 amplector amabilem allegationem formidinis). Siehe auch unten 227. - In einem anderen Brief bezeichnet Ennodius es als Übel der Zeit (15,2 vitia temporis), unend- 
nodius später hervorhebt, Florianus' Brief zeige artifex facundia und fucus Romuleae calliditatis, so dürfte er damit genau das in der Praefatio beschriebene Verhalten meinen; denn an etlichen Stellen spricht er von Verstellung und Heuchelei u.a. mit den Worten fucus, fallere, simulare (siehe unten 226f.). In der Praefatio deutet Ennodius also nicht nur an, wie er selbst sich nicht verhält, sondern auch, wie Florianus sich in seinem Brief verhalten hat.

Ennodius beruft sich auf seine Wahrheitsliebe und verstößt gegen sein Prinzip des silentium, um Florianus seines Versuchs, als Gebildeter mit einem (angeblich) Unwissenden zu spielen, zu überführen; auch hierin wird seine rhetorica versutia offenbar, denn indem er die rhetorischen Mittel aufdeckt, zeigt er ja, dass er sie kennt, also gerade nicht, wie er behauptet, von einem Gebildeten übervorteilt wird.

Dann beendet Ennodius den Brief: »Mit einem kurzen Brief zufrieden wende ich mich nun zum geschuldeten Gruß, indem ich mit Freundschaft aufwiege, was ich durch Sprache nicht kann, und indem ich Freundschaft biete statt Redeprunk und -figuren. Soviel ich meiner Arbeit <an Zeit> entwenden konnte, habe ich schnell geschrieben. Gott möge geben, dass Du, wenn Du eine Antwort wünschst, das Herz des von Sorgen Geschlagenen davon frei vorfindest « $\left(\$_{3}\right) .{ }^{411}$

Florianus hat sich durch diesen ersten Brief nicht beeindrucken und von seinem Wunsch nach einem Briefwechsel abbringen lassen: Immerhin konnte er Ennodius mit Recht seinerseits entgegenhalten, dass er Unfähigkeit nur vortäusche. Florianus hat offenbar diesen Brief nicht ernstgenommen, sondern als rhetorica versutia verstanden - ein Beispiel sowohl dafür, dass auch schon ein Zeitgenosse Ennodius nicht richtig verstanden hat, als auch für Ennodius' Wunsch, dass die Adressaten seine Worte ernstnehmen sollen. - Immerhin antwortet Ennodius überhaupt (obwohl er den ersten Brief mit "Schweigen " gleichsetzt, cf. 21,3 nec cum reticerem lacessitus, effugi); er hätte ja auch, zumindest statt des zweiten Briefs, tatsächlich schweigen können. Offenbar liegt ihm sehr daran, dass Florianus seine Gründe kennt.

Von dem Adressaten wissen wir nichts Sicheres; das Thema und der Ton der Briefe weisen darauf hin, dass zwischen beiden kein allzu großer Unterschied an Rang und Alter besteht, denn Florianus möchte mit Ennodius seine brieflichen Kräfte messen. Ob man ihn mit jenem Abt Florianus identifizieren kann (so bei KeNNELL 2000, 63; Gioanni 2004, 532), der in einem Brief (abgedruckt bei Vogel, Praef. LIX) von Ennodius als seinem Taufpaten spricht und dem Arator seine Acta Apostolorum widmet, erscheint daher nicht gesichert. Auf jeden Fall geht es aber zu weit, die bei-

liche Lobreden zu schreiben und zu schmeicheln; er selbst wolle nicht kunstvoll mit dem Adressaten spielen (15,3 pictis verborum inludens artificiis), siehe dazu oben 119.

$411(20,3)$ nunc epistulae brevitate contentus ad salutationis debita me converto, quod eloquio non potui, gratia pensaturus, reddendo amicitiam pro schemate et pompa sermonum. ecce quantum occupationi subducere potui, celer scripsi. dabit deus, ut si responsa desideras, vacuum curis pulsati pectus invenias. 
den Briefe an Florianus als Beispiel dafür anzuführen, dass die Gattung >Brief`von Christen als Instrument bei der Unterweisung in christlicher Moral verwendet wurde. ${ }^{412}$

Darauf, dass Florianus Kleriker ist, könnten zwei Wörter in den Briefen hinweisen: Im ersten Brief betont Ennodius, dass er ihn ertappt habe ( $\$ 2$ deprehensum), d.h. Florianus hätte so nicht schreiben dürfen. Im zweiten Brief spricht Ennodius von seiner eigenen culpa und bezeichnet es als errata $(\$ 6)$, dass er einen langen Brief geschrieben habe, wobei er auf die gleiche culpa des Florianus hinweist. Warum sollte es für Florianus eine culpa sein, lange Briefe zu schreiben, wenn er nicht in vergleichbarer Situation wäre wie Ennodius? Diese beiden Wörter könnten also darauf hinweisen, warum Ennodius dem Florianus eigentlich Vorwürfe macht - die hinter den Vorwürfen der Schmeichelei und der übertriebenen Demut versteckt sind -, nämlich dass er ihn trotz beider Stellung in der Kirche zu einem literarischen Wettstreit einladen will.

\section{Pomerius (39)}

Julianus Pomerius kam gegen Ende des 5.Jh. aus Mauretanien nach Südgallien und ließ sich dort zum Priester weihen (cf. Gennad. vir. ill. 99: Pomerius, natione Maurus, in Gallia presbyter ordinatus [...]). Nach Auskunft der Vita des Caesarius von Arles, eines der einflussreichsten Bischöfe des spätantiken Gallien, wurde Pomerius zum Lehrer des jungen Caesarius ausersehen, der sich aber nach einem Traum dieser weltlichen Ausbildung verweigerte (cf. contempsit haec protinus); $;^{413}$ (zu Ennodius' Brief an Caesarius siehe unten 352). ${ }^{414}$ Von Pomerius' Schriften ist nur das im Mittelalter viel gelesene Werk De vita contemplativa erhalten, Gennadius (vir. ill. 99) berichtet von weiteren Werken.

Der an Pomerius gerichtete Brief (39) gehört zu den wenigen Briefen, die aufgrund der Person des Adressaten außerhalb der speziellen Ennodius-Forschung etwas Beachtung gefunden haben, wobei allerdings Missverständnisse aufgetreten sind.

412 So Gionnn $(2004,532)$ : »l'abbé Florianus, qui reçut deux lettres d'Ennode d'édification morale lorsqu'il était encore jeune, considère Ennode comme son père spirituel«; letzteres bezieht sich wohl darauf, dass der Abt Florianus im besagten Brief schreibt (\$4), Ennodius sei sein Taufpate, pater ex lavacro.

413 Vita Caesarii $\$ 9$ (ed. MorIN 1942, p. 299f.): Erat autem ipsis personis familiarissimus quidam Pomerius nomine, scientia rhetor, Afer genere, quem ibi singularem et clarum grammaticae artis doctrina reddebat. Concipiunt igitur animo generosae personae, quatinus tanta dei gratia sanctus Caesarius refertus, tantaque memoria dono Christi videretur esse fulcitus, ut saecularis scientiae disciplinis monasterialis in eo simplicitas poliretur. Sed eruditionis humanae figmenta non recepit, quem instruendum per se sibi divina gratia praeparavit. [...]. Igitur contempsit haec protinus, sciens quia non deesset illis perfectae loqutionis ornatus, quibus spiritalis eminet intellectus.

$414 \mathrm{Zu}$ Pomerius und zu Caesarius von Arles siehe besonders KLINGSHIRN 1994. 
Z.B. schreibt Klingshirn (1994, 73), dass Pomerius in Arles geblieben sei trotz der Bemühungen sowohl von Ennodius als auch von Ruricius von Limoges, ihn in ihre jeweilige Stadt zu ziehen. ${ }^{45}$ Wenn man allerdings den einen Brief des Ruricius an Pomerius ansieht, so scheint es sich bei den Worten des Ruricius um den Wunsch zu handeln, dass Pomerius ihn besuchen solle, so wie er selbst bereits Pomerius besucht hat; von einer erhofften Umsiedlung des Pomerius ist nicht die Rede (Ruric. 2,10). ${ }^{416}$ In einem zweiten Brief des Ruricius an Pomerius scheint sich der Wunsch des Ruricius, mit Pomerius in einer Stadt vereint zu sein, eher auf das Jenseits zu beziehen ( $\mathrm{Ru}-$ ric. 1,17) ${ }^{417}$ Bei Ennodius hingegen hält sich der Wunsch, Pomerius zu treffen, sehr in Grenzen, wie gleich zu zeigen ist.

Ennodius beginnt den Brief (nur) auf den ersten Blick sehr freundlich, letztlich aber beschwert er sich darüber, dass Pomerius den Stil seiner Briefe, die an andere gerichtet waren, kritisiert habe; er klagt nicht deshalb, weil Pomerius die Briefe nicht hätte lesen sollen - denn das Weitergeben von Briefen war durchaus üblich -, sondern deshalb, weil er den Stil kritisiert hat. Er zeigt dem Bewohner Galliens die Grenzen von dessen Ruhm auf und betont, dass sich Männer der Kirche mit der christlichen Lehre beschäftigen sollen und nicht mit rhetorischen Spielereien, was nicht nur Ennodius' eigene Situation, sondern auch die des Adressaten betrifft.

Obwohl die ersten beiden Worte "Quousque tantum « wegen der Anspielung an Cic. Cat. 1,1 einen heftigen Vorwurf erwarten lassen, klingt der Beginn insgesamt beim ersten Lesen recht freundlich. Allerdings wird der den Brief eröffnende Ausruf: »Wie lange noch wird der Abwesenheit so viel erlaubt sein? « $\left(\$_{1}\right)^{418}$ im weiteren Verlauf des Briefes eine andere Bedeutung bekommen, sobald Ennodius sich über eine ihm hinterbrachte Bemerkung des Pomerius beklagt $(\$ 3)$; doch zunächst wird

415 KLINGSHIRN $(1994,73)$ »He then took up residence in Arles, where he remained despite efforts by Ruricius of Limoges and Ennodius to bring him to their towns."

416 (Ruric. 2,10,2): nam ex quo a vestra unanimitate discessi, divisum esse me sentio partemque meam vobiscum residisse cognosco: "Denn seitdem ich von Euch, mein Lieber, weggegangen bin, habe ich das Gefühl, dass ich geteilt bin und dass ein Teil von mir bei Euch geblieben ist." $\left(\$_{4}\right)[\ldots]$ omni precum ambitione deposco [...] ad desiderantem fratrem ... quantocius venire: "Ich bitte Euch mit aller Kraft [... so schnell wie möglich ... zu dem sehnsüchtigen Bruder zu kommen«. etc.

417 (Ruric. 1,17,5) orate dominum, cui omnia possibilia confitemur, ut etsi per diversum iter, ad unam nos tamen urbem faciat convenire, in quam nos misericordia potest inferre, vos merita. "Betet zum Herrn, dem alles möglich ist, dass er uns, wenn auch auf verschiedenen Wegen, so doch in eine Stadt zusammenkommen lässt, in die mich seine Barmherzigkeit und Euch Eure Verdienste bringen können.«

418 (39,1) Quousque tantum licebit absentiae? quousque fama nobilis epistularibus destituta conmerciis veterescet? nolo evadere opinionem temerarii, dummodo ad notitiam possim pervenire perfecti. volo esse paginarum praevius destinator, ut Galliarum bona ad Italiam migrent sine ullo formae suae translata dispendio. an forsitan putabas te in quocumque loci delitiscere, quem scientiae lux longe positorum monstrabat aspectui? 
der Ausruf so weitergeführt, dass die Abwesenheit durch Briefe ausgeglichen werden sollte: "Wie lange noch soll Dein edler Ruhm verblassen, da er nicht vom Briefverkehr unterstützt wird? « Hat Ennodius damit schon angedeutet, dass Pomerius' Ruhm von der Korrespondenz mit Ennodius durchaus profitieren könnte, so wird er im folgenden deutlicher, wenn er die Gründe für sein Schreiben darlegt: "Ich will die Einschätzung, unbedacht zu sein <sc. weil ich es wage, Dir als erster zu schreiben>, nicht vermeiden, wenn ich nur den Kontakt mit einem Vollkommenen aufnehmen kann. Ich will als erster einen Brief senden, damit < danach auch $>$ die Vorzüge Galliens <sc. die Redekunst des Adressaten> nach Italien wandern ${ }^{419}$ und <sc. als Brief> in ihrer vollendeten Gestalt überbracht werden. "Ennodius sendet also diesen Brief, um Kontakt mit Pomerius aufzunehmen; ${ }^{420}$ daraufhin sollen dann die bona Galliae nach Italien kommen, womit Briefe von Pomerius gemeint sein müssen. Diese bona sollen ohne Einschränkung überbracht werden; im folgenden wird deutlich, dass sich Ennodius auf einen mündlichen Bericht über Pomerius stützt, den er als unzulänglich bezeichnet ( $\$ 2$ relatio ... pauper; relatoris ... exilitas); er möchte daher Briefe von ihm erhalten, um seine Fähigkeiten sine ullo formae suae translata dispendio, "in ihrer vollen Schönheit ", selbst zu betrachten, anstatt auf einen ungenügenden Bericht angewiesen zu sein. Ennodius hebt zunächst hervor, dass er trotz der Entfernung von Pomerius erfahren hat: »Oder dachtest Du vielleicht, irgendwo verborgen sein zu können, <sc. Du,> den das Licht des Wissens dem Anblick der weit Entfernten zeigt? «. Anschließend betont er aber, dass Pomerius auf die Korrespondenz mit Italien angewiesen sei, da er nur durch diese dafür sorgen könne, dass er ohne Einschränkung wahrgenommen werde; Grund dafür ist die weite Entfernung, auf die Ennodius auch im Weiteren hinweist ( $\$ 3$ seiunctissimus). Dass der Ruhm des Pomerius sich nicht völlig von selbst verbreitet - d.h. auf jeden Fall eines Korrespondenten in Italien bedarf - macht Ennodius weiter dadurch deutlich, dass er sich mit seiner Beschreibung der literarischen Kenntnisse und Fähigkeiten des Pomerius auf den nach seiner Einschätzung unvollkommenen Bericht des Boten Felix (der Name fällt in \$3) beruft: »Und wenn mich nicht im Lob auf Dich die Erzählung einschränkt, die zwar von einem stammt, der Dich kennt, die jedoch wegen der Unerfahrenheit dürftig ist, und <wenn nicht > die Dürftigkeit des Berichtenden die umfangreichen Lobreden Deiner Verdienste schmälert:“ Er beginnt sein Lob mit der großen Belesenheit

419 Wenn Klingshirn in diesem Brief eine Einladung des Pomerius gesehen hat, so ist das wohl auf eine Überinterpretation dieser Anfangspassage, besonders der Wörter absentiae und migrent, zurückzuführen. Denn insgesamt ist der Brief überhaupt nicht freundlich, sondern Ennodius reagiert recht gereizt auf eine ihm übermittelte kritische Äußerung des Pomerius.

420 Er beklagt sich also nicht über ein langes Schweigen des Pomerius, vgl. Kennell (2000, 63): "reproaches Pomerius for a lengthy epistolary absence» 
des Pomerius: „Du hältst als eine Klammer beider Bibliotheken die größten Teile der von beiden Seiten kommenden Vollkommenheit zusammen $[\ldots]$ « $(\$ 2) .^{421}$

Doch Ennodius bricht das Lob bald darauf ab, um zu seinem eigentlichen Anliegen zu kommen, zu einer Antwort auf etwas, das Pomerius in belehrender Weise über ihn gesagt hat, wie der Bote berichtet habe: »Ich komme zu dem, worin Du mich aus der weiten Ferne unterwiesen hast. Soweit der verehrungswürdige Felix, der Bote dieser Zeilen, berichtete, suchtest $\mathrm{Du}$, Zögling der Rhône, in meinen ohne Sorgfalt geschriebenen Briefen römisches Ebenmaß und eine Ader lateinischen Wassers. Ein wohl sorgfältiger und gründlicher Forscher hat gefunden, was die Feile glätten könnte, während er die ungefeilten Wörter durchging « $(\$ 3) .{ }^{422}$ Pomerius hat also offenbar, wie es durchaus üblich war, Briefe von Ennodius an andere Adressaten zu lesen bekommen; er hat sie kritisch auf ihre literarische Qualität hin betrachtet und war nicht zufrieden. Wenn Ennodius Pomerius im Zusammenhang mit römischem Stil (Romanam; Latiaris) als alumnus der Rhône bezeichnet, dürfte er ironisch darauf anspielen, dass Pomerius in Gallien war bzw. aus Afrika nach Gallien gekommen war (etwas weiter unten spricht er es deutlich aus: $\$ 4$ extraneos). An diesem Punkt bekommt der erste Satz des Briefes seinen vollen Sinn: "Wie lange noch wird Abwesenden so viel erlaubt sein? “ ( $\$ 1$ quousque tantum licebit absentiae?), d.h. ,Wie lange noch wird ein alumnus der Rhône über einen Brief von mir herziehen dürfen?`, nachdem bei der ersten Lektüre des Anfangs zunächst der Eindruck entstehen musste, Ennodius sei um den Ruhm des Adressaten besorgt und Ennodius' größter Wunsch sei ein Brief von diesem. Ennodius gelingt es also, sowohl ehrlich als auch geschickt vorzugehen, um den Adressaten langsam in die Falle zu locken: Er beginnt direkt mit dem Vorwurf ( quousque«), den er später im Brief ausführt, der aber zunächst verborgen bleibt, da der Gedanke anders weitergeführt wird; so kann der Adressat weder beim ersten Lesen der Anfangsworte ahnen, worauf es letztlich hinausläuft, noch dem Verfasser Heuchelei vorwerfen.

Ennodius fährt fort, dass Pomerius seinen Brief offenbar eben in der Absicht gelesen habe, um ihn kritisieren zu können; doch auch Homer (!) sei nicht vor Angriffen von Kritikern sicher gewesen, wie Ennodius mit einem Zitat aus (dem nicht genannten) Claudian deutlich macht: "Weiß man nicht, dass die Absicht, mit der jemand etwas gelesen hat, seine Meinung über das Gelesene bestimmt? Zumal ge-

$421(39,2)$ et nisi me in laudibus tuis domestica quidem relatio, sed per inperitiam sui pauper angustet et amplissima meritorum tuorum praeconia relatoris artet exilitas: utriusque bybliothecae fibula, perfectionis ex gemino latere venientis partes maximas momordisti [...].

$422(39,3)$ ad illud venio, in quo me seiunctissimus instruxisti. quantum habuit praesentium portitoris sancti Felicis adsertio, in epistulis meis sine cura dictatis Romanam aequalitatem et Latiaris undae venam alumnus Rhodani perquirebas. sollicitus credo scrutator et diligens quid lima poliret invenit, dum per infabricata verba discurreret. 
schrieben ist: ,Den Vater der Dichter selbst, den Herrn des Helikon Homer, trafen strenge Geschosse des Urteils seines Kritikers` $\left(\$_{4}\right) .{ }^{423}$

Es folgt ein nicht ganz sicher überlieferter und schwer verständlicher Satz, der wohl einen Hieb gegen den aus Afrika nach Arles gekommenen Pomerius zu enthalten scheint: "Also: Auch wenn die Latinitas die Einheimischen und die auf den Übungsplätzen ihrer Studien Bewanderten unterstützt, ist es sonderbar zu sagen, dass sie Fremden Waffen gibt [codd. amat, conieci armat] « $(39,4) \cdot{ }^{424}$ Vielleicht spielt Ennodius hier auf Äußerungen des Pomerius selbst an. In seinem erhaltenen Werk De vita activa et contemplativa, das wohl gegen Ende des 5.Jh. entstanden ist, so dass Ennodius es gekannt haben könnte, äußert sich Pomerius über die Bedeutung der Latinitas für den Prediger: Tam simplex et apertus, etiamsi minus Latinus, disciplinatus tamen et gravis sermo debet esse pontificis, ut ab intelligentia sui nullos, quamvis imperitos, excludat (Buch 1,23, PL 59, 439 A). Wenn Ennodius diese oder ähnliche Äußerungen des Pomerius kannte, könnte er hier meinen, dass die Latinitas offenbar doch von großem Nutzen ist - da sie Pomerius sogar zu Angriffen befähige.

Weiter legt Ennodius dar, dass er aufgrund seines Amtes (professio) keinen literarischen Wettstreit aufnehmen könne: »Ich darf den Prunk meiner Beredsamkeit nicht erproben, und ich maße mir nicht an, zu messen, wer über welche Kräfte verfügt, da es reicht, dass mein Amt sich um die einfache <sc. die christliche> Lehre bemüht. Doch wenn mich damals, als ich mich über die mir noch neuen freien Studien freute, jemand mit solcher Bissigkeit angerührt hätte, hätte ich etwas verfasst, das entweder zur Entschuldigung geeignet gewesen wäre oder dessen man sich als Erwiderung nicht hätte schämen müssen « $\left(\$_{5}\right) .{ }^{425}$ Doch Ennodius unternimmt mit diesem Brief genau das, was er nicht zu tun vorgibt: Er bringt sowohl eine Entschuldigung vor (dass sein Amt ihm das von Pomerius Geforderte verbiete), und er antwortet auch mit einem unsanften Gegenhieb: Pomerius sei in Gallien und damit weit ab vom Geschehen, und ohne Korrespondenz mit Ennodius vergehe sein Ruhm; dass Pomerius, ein alumnus der Rhône, in Briefen des Ennodius nach dem römischen und lateinischen Stil suche, wird ironisiert.

Ennodius schließt: "Nun leb wohl, mein Herr, und zeige Dich mir gegenüber lieber als Unterstützer der kirchlichen Lehre: Schreib oder lass ausrichten, wer die Eltern des Melchisedek waren, eine Erklärung der Bundeslade, das Geheimnis der

$423(39,4)$ nescimus quia quid qua [cf. den Apparat bei VoGEL] mente homo legerit, hac profert deliberatione sententiam? maxime cum scriptum sit: ipse parens vatum, princeps Heliconis, Homerus / iudicis excepit tela severa notae [Claud. carm. min. 23,13f.].

$424(39,4)$ ergo etsi indigenas et inter studiorum suorum palestra versatos fulcit latinitas, mirum dictu, quod armat [codd. amat] extraneos.

425 (39,4f.) periclum facere de eloquentiae pompa non debeo nec praesumo qualiter quis valeat experiri, cum professionem meam simplici sufficiat studere doctrinae. (\$5) si me tamen quondam studiorum liberalium adhuc novitate gaudentem aliquis tali dente tetigisset, parassem vel quod ad excusationem esset idoneum vel quod non puderet obiectum. 
Beschneidung und was die prophetischen Geheimnisse bedeuten. Die Phrasen der Weltlichen sollen verworfen werden, denn sie sind auf vergängliche Überredungskünste ausgerichtet, ähnlich wie das Gewebe der Penelope « $(39,6) .426$

Maganis Deutung (1886, Bd. 1, 262-264), Ennodius' Korrespondent Pomerius habe ihn mit Anregungen und Briefen über Themen der religiösen Bildung unterstützt, ${ }^{427}$ beruht darauf, dass er den Kontext nicht genügend beachtet: Wenn Ennodius Pomerius dazu auffordert, ihm solche theologischen Fragen zu beantworten, statt den Stil seiner Briefe zu kritisieren, ist dies in erster Linie eine Aufforderung, Letzteres gefälligst zu unterlassen. Wenn man die Fragen zur Bibel betrachtet, so sind sie wohl nicht leicht mit wenigen Worten zu beantworten. ${ }^{428}$

Wenn man Pomerius' Werk De vita activa et contemplativa einbezieht, drängt sich die Hypothese auf, dass Ennodius sich nicht nur über die Kritik des Pomerius geärgert hat, sondern dass er ihm weitere Vorwürfe macht. Pomerius selbst wendet sich darin gegen weltlichen Redeprunk, z.B.: »Daher lässt sich erkennen, dass ein Lehrer der Kirche nicht mit ausgefeilter Sprache prunken und prahlen darf, damit es nicht so aussieht, als wolle er nicht die Kirche Gottes erbauen, sondern vielmehr zeigen, wie gebildet er ist « (Pomer. 1,23) ${ }^{429}$ Auffällig sind im Vergleich immerhin die Worte, mit denen sich Pomerius im abschließenden Kapitel für seinen Stil entschuldigt (Pomer. 3,34,2): quia quod ab homine doctore studendo non didici, id exhibere loquendo non potui ("da ich das, was ich nicht von einem Lehrer durch Studieren gelernt habe, durch meine Worte auch nicht bieten konnte «) und Ennodius' Worte über Pomerius $(39,2)$ : [...] dotibus sine humano adiutorio supernis instructum. recte enim hoc aestimatur venire de superis, quod inter homines nullo constat exemplo ("[...] dass Du durch himmlische Gaben ohne menschliche Unterstützung ausgebildet bist. Denn zurecht glaubt man, dass das von den Himmlischen kommt, wofür es unter den Menschen kein Beispiel gibt«). Außerdem hat Pomerius einen (nicht erhaltenen) Traktat De contemptu mundi ac rerum transiturarum ad principium verfasst; darauf könnte der Schluss des Briefes anspielen (ista quae sunt saecularium schemata respuantur [...] ). Es könnte also durchaus sein, dass Ennodius Pomerius hier unterschwel-

$426(39,6)$ nunc vale, mi domine, et circa me ecclesiasticae magis disciplinae exerce fautorem. scribe vel manda, Melchisedech parentes quos habuerit, explanationem arcae, circumcisionis secretum et quae profeticis mysteriis includuntur. ista quae sunt saecularium schemata respuantur, caducis intenta persuasionibus, telae similia Penelopeae.

427 Ebenso KenNell $(2000,63)$ : Ennodius asks for advice on himself and his writing."

428 Anders Kennell $(2000,64)$ : »a list of Old Testament trivia questions. « - Zur Frage nach den »Eltern des Melchisedek « cf. Hbr 7,1 ff.: Hic enim Melchisedech rex Salem [...]/ deinde autem et rex Salem quod est rex pacis / sine patre / sine matre / sine genealogia [...].

429 Siehe z.B. (Pomer. 1,23, PL 59, 438 D) Unde datur intelligi quod non se debeat Ecclesiae doctor de accurati sermonis ostentatione iactare, ne videatur Ecclesiam Dei non velle aedificare, sed magis se quantae sit eruditionis ostendere eqs. (1,24, PL 59, 439 B) Denique alia est ratio declamatorum et alia debet esse doctorum eqs. 
lig vorwirft, dass er, wie seine Kritik an Ennodius' Stil zeigt, literarischen Fragen noch solche Bedeutung beimisst und so selbst nicht befolgt, was er in seinem Werk vertritt. ${ }^{430}$ Immerhin endet Pomerius' Werk mit vergleichbaren Gedanken wie Ennodius' Brief: Quapropter ea mihi visa est compositio satis ornata, quae conceptiones animi cum necessaria quadam perspicuitate proferret, non quae illecebris aurium deserviret. Ea est enim, nisi fallor, iudicata Latinitas, quae breviter et aperte, observata duntaxat usitatorum verborum proprietate, res intelligendas enuntiat, non quae vernantis eloquii venustate atque amoenitate luxuriat; et prudentibus viris non placent phalerata, sed fortia, quando non res pro verbis, sed pro rebus enuntiandis verba sunt instituta (Buch 3,34,2, PL 59, 519f. A).

\section{Hormisda (317)}

Auch gegenüber dem römischen Diakon (und nachmaligen Papst) Hormisda macht Ennodius deutlich, dass er auf seine Art schreiben möchte und nicht in der von Hormisda begonnenen Form eines certamen (vgl. \$2 vocet in medium; concertatio). Wie in den Briefen an Florianus verweist er auf seine Vorsätze, gegen die zu verstoßen ihn der listige Adressat nicht überreden könne. Immerhin bleibt Ennodius Hormisda gegenüber freundlich, und er möchte die Korrespondenz mit ihm auch nicht insgesamt beenden (es sind insgesamt 7 Briefe an ihn überliefert, 3 vor und 3 nach diesem Brief). - Die Praefatio (vgl. allgemein dazu unten 258) führt in allgemeinen Formulierungen den Gedanken aus, dass Ungebildete nur kurze Briefe schreiben dürften (vgl. damit die Gedanken in der praefatio an Mascator, oben 181); Ennodius verweist so auf seine angebliche Unfähigkeit als den Grund für die Kürze seines Briefes: "Für Ungebildete gäbe es keine Entschuldigung mehr, wenn sie viel sagten: nur die Kürze kann Ungebildete empfehlen. Eine lange Rede eines Ungebildeten übersteigt jedes Vergehen. Wenn man von einem Ungebildeten ein langes Schreiben erzwingt, hat sich der, der dies gefordert hat, seinen Ärger selbst zuzuschreiben. Will etwa irgendjemand, dass Abstoßendes weit ausholt und dass das, was mit keiner Würze gewürzt ist, keine engen Grenzen hat?« $\left(\$_{1}\right) .{ }^{431}$ Ennodius betont, dass Hormisda es mit seinem kunstvollen Brief zwar geschafft habe, ihm eine Antwort zu entlocken, dass er aber dennoch nicht seine eigenen Vorsätze vergesse: »Bruder, Du hast diesen Brief mit römischer und allzu kunstvoller Feinheit gefordert: doch mich schützt vor den <sc. rhetorisch> Kunstvollen meine Schlichtheit, die nicht mit Blendwerk gefärbt ist. Denn wie sehr Du mich auch mit der verlockenden Rede Deines Briefes gelockt hast,

430 Weiter könnte Ennodius mit den Worten circa me ecclesiasticae magis disciplinae exerce fautorem (\$6) darauf anspielen, dass Pomerius sich sowohl als ecclesiasticae disciplinae fautor, als auch als Lehrer - z.B. des Caesarius - betätigt.

$431(317,1)$ nullus remaneret imperitis locus veniae, si plura loquerentur: sola brevitas commendat indoctos. supra errorem est prolixa narratio rusticantis. quando ab ignaro extortum fuerit quod diu legatur, sibi rancorem suum debet exactor. quisquamne hominum in longum vult fastidienda procedere et nullo sapore condita breves terminos non habere? 
so hast Du mich doch nicht dazu gebracht, mich zu vergessen. Ich weiß meinen Brief kurz zu fassen, dessen Wert ich als sein Verfasser kenne. Wisse also, dass ich mir treu bleibe, obwohl mich jemand herausfordert, der sowohl fein gebildet als auch Kleriker ist. Doch was ziehe ich den Brief in die Länge, dessen Kürze ich oben versprach? « $(\$ 1 f.) .{ }^{432}$ Weiter unten wird dargestellt, dass sich Ennodius häufig explizit auf seine eigene simplicitas bezieht und betont, dass er das Verhalten eines fabricatus bzw. urbanus ablehnt; als feines, surbanes Verhalten bezeichnet er Verstellung, als simplicitas hingegen Aufrichtigkeit (siehe unten $226 \mathrm{ff}$.). Hier bezeichnet Ennodius Hormisda als et urbanus et clericus (\$2), und er stellt klar, dass er selbst nur als clericus gelten möchte.

In einem knappen Satz kommentiert Ennodius die (nun wohl enttäuschten) Erwartungen des Hormisda, die sich in dessen Brief gezeigt haben: "So sieht mein Wettstreit mit einem Freund aus, so der Genuss eines Briefes von mir.« Der Brief endet mit einem Hinweis darauf, welche Funktion die Korrespondenz haben soll: "Mein Herr, ich grüße herzlich und bitte Euch, mir durch Christi Erbarmen häufig in wunschgemäßen Briefen Euer Wohlergehen zu melden, indem Ihr Euch nach meinem erkundigt « $(\$ 2 f.) .{ }^{433}$

Hormisda trifft also eigentlich der gleiche Vorwurf wie Pomerius und Florianus, dass sie nämlich trotz ihrer geistlichen Ämter weltliche certamina in der Korrespondenz aufnehmen wollen. Dass sich Ennodius gegenüber Hormisda mit Vorwürfen anders als gegenüber Florianus und Pomerius sehr zurückhält, dürfte daran liegen, dass er mit Hormisda, der zum Zeitpunkt des Briefes Diakon in Rom ist, häufiger dienstlich zu tun hat und um gute Beziehungen bemüht ist.

Fazit

In den vorgestellten recusationes spricht Ennodius davon, dass er sich in seiner Korrespondenz - jedenfalls mit diesen Adressaten - bewusst Beschränkungen auferlegt. Anders als der Bischof Sidonius Apollinaris verabschiedet er sich also nicht nur (halbwegs) von der Dichtung, sondern er betrachtet auch bestimmte Aspekte der weltlichen Korrespondenz unter Gebildeten als unpassend; in dieser Hinsicht ist er

432 (317,1f.) Romana hoc, frater, et nimium artifici subtilitate flagitasti: sed nos contra fabricatos munit simplicitas nullis colorata praestigiis. (\$2) etenim quamvis me delenifica epistolae tuae oratione produxeris, mei immemorem non fecisti. scio artare paginam, cuius pretium promulgator intellego. noveris me tamen meis partibus non deesse, quamvis vocet in medium et urbanus et clericus. sed quid produco paginam, cuius superius angustiam pollicebar?

433 (317,2f.) haec mihi cum amante concertatio, talis fructus est litterarum. $(\$ 3)$ domine mi, salutem uberrimam dicens precor, ut Christi nostri tribuente misericordia crebro salutem vestram votivis mihi, dum meam quaeritis, nuntietis affatibus. 
strenger, obwohl er nicht Bischof, sondern erst Diakon ist (und das Bischofsamt anstrebt). U.a. aus dem Grund, dass er kein Lob anstreben darf und sich offenbar seines möglichen Erfolges recht sicher ist, vermeidet er Wettkämpfe der literarischen Fähigkeiten. Das heißt allerdings nicht, dass er in den recusationes seinen Scharfsinn und z.B. seine Fähigkeit, einen Gedankengang anders enden zu lassen als der Beginn erwarten lässt, unterdrücken würde; im Gegenteil - ganz in der Tradition der recusatio war ihm offenbar daran gelegen, dass seine Adressaten sein literarisches und rhetorisches Potenzial erkannten. Deutlich wird außerdem, dass Ennodius' Äußerungen immer auf den aktuellen Adressaten bezogen sind (siehe auch oben 83): Gegenüber weltlichen Adressaten drückt er sein Bedauern über seine Ablehnung aus, doch gegenüber Geistlichen macht er deutlich, dass auch sie ihn gar nicht zu solchem Briefwechsel einladen dürften.

\section{c. Eine Nebenrolle: Der freundliche Diakon}

An den Briefen des Ennodius wird sehr deutlich, dass Briefe sich nicht als $>$ Spiegel der Seeler verwenden lassen, um von ihnen auf den Charakter des Verfassers zu schließen (siehe oben 154f.), da er, was der Forschung bisher entgangen ist, in verschiedenen Briefen in geradezu gegenteiligen Rollen und Sprechhaltungen auftritt: Nur selten gibt er sich in seinen Briefen als ein freundlich-frommer Mann der Kirche. Seine Hauptrolle ist die eines unzufriedenen, nörgelnden amicus, und nur sehr selten ist er ein freudiger Freund und/oder Verwandter. Zunächst sind einige Briefe vorzustellen, die am ehesten der allgemeinen Erwartung an Briefe von einem Diakon entsprechen dürften, die allerdings unter den Briefen des Ennodius Ausnahmewert haben. Diese Briefe, in denen Ennodius sich als freundlich-gütiger Mann der Kirche gibt und über im weitesten Sinne christliche, jedenfalls nicht-weltliche, Themen spricht, sind eine wichtige Folie für die spätere Betrachtung der vielen Briefe, in denen er als unzufriedener amicus (und/oder Verwandter) seinen Korrespondenten Vorwürfe macht.

So freundlich und demütig wie in den folgenden vier Beispielen $(302 ; 394 ; 441$; 449) schreibt Ennodius nicht oft, wobei zudem auffällt, dass er sich so fast nur gegenüber Frauen gibt; wenn er gegenüber männlichen Geistlichen einen demütigen Ton anschlägt, behält er diesen nur selten den ganzen Brief hindurch bei (siehe unten 295). Allerdings gibt er sich auch nicht gegenüber allen Frauen gleich, denn an Speciosa schreibt er in einer Mischung aus Trotz, Ergebenheit und Koketterie (siehe unten 273, 318), an seine Schwester Euprepia schreibt er überwiegend sehr streng und vorwurfsvoll (siehe unten 300), und die Vorwürfe an Camella (431), die gegen die Abmachung ihren Sohn der Kirche weihen ließ, bevor sie ihn zu Ennodius zur Ausbildung schickte, waren bereits zu sehen (siehe oben 85 ). Dennoch fallen etliche Briefe an Frauen innerhalb der ganzen Sammlung dadurch auf, dass Ennodius sehr freundlich schreibt, sich demütig zurücknimmt und lobende Worte für die Adressatinnen 
findet. Regelmäßig steht zumindest am Ende eine Bitte um Gottes Hilfe, häufig verwendet er aber im ganzen Brief reichlich christliches Vokabular. Der Mann der Kirche (z.B. 449,1 religiosi homo propositi; 441,2 religionem profitenti) spricht in diesen Briefen über Themen wie den Witwenstand der Adressatin (449), er findet viele lobende Worte über die Lebensweise der Adressatin (319), von der ihr im Kloster lebender Sohn noch lernen könne, er erwähnt die eines frommen Mannes würdige Kopfbedeckung, die er von der Adressatin geschenkt bekommen hat (441), oder er bittet um unterstützende Gebete bzw. lobt die Kraft der Gebete seiner Adressatinnen (302; 394; 439). In anderen ebenfalls freundlich, aber ohne speziell christliche Gedanken formulierten Briefen spricht er über die Bande der Verwandtschaft (285) oder über die Freude über einen erhaltenen Brief (177; 305, dazu unten 299).

Im Brief an Domnina (302; sie erhält nur diesen Brief; auf eine verwandtschaftliche Beziehung weist Ennodius nicht hin) nimmt die Bitte um unterstützende Gebete recht großen Raum ein. Ennodius antwortet offenbar nicht auf einen Brief von ihr (cf. \$1 elegi [...] subsidium, ut [...] litteras destinarem; prospera vestra $[\ldots]$ vix datur agnosci). Er klagt über seine Bedrängnisse ( $\$ 1$ curae; molestiae; angustiae) und seine kranke Seele ( $\$ 2$ aeger animus); die Adressatin solle ihm mit ihren Gebeten beistehen. Worin seine Probleme konkret bestehen, sagt er nicht, sondern er nennt die Entfernung von Domnina als das schlimmste: "In Betrübnis und Sorgen, die mich aufgrund der Last meiner Sünden bedrücken, wähle ich einen einzigartigen Trost: Euch, meiner Herrin, einen Brief zu senden, damit mir durch Eure Gebete alles gut gelingen möge und ich nach Auflösung der beengenden Wolken zur ungetrübten Freude gelangen möge. Denn der erste Grund meines Kummers, aus dem mein ganzes Unglück entsteht, ist, dass ich über Euer Wohlbefinden kaum informiert bin, da Ihr weit entfernt lebt« (\$1). ${ }^{434}$ Domnina solle also für ihn beten: "Steht also mir Demütigem mit Euren Gebeten bei, dass meiner kranken Seele durch die Unterstützung der Heiligen Gottes geholfen wird. Meine Herrin, ich grüße untertänigst und bitte und flehe Euch an - bei Gott, den Ihr verehrt, - dass Ihr mich mit beständigen Bitten und Tränen, durch die das Himmelreich Gewalt erleidet <cf. Mt 11,12>, dem Herrn empfehlen mögt; denn das halte ich für eine besondere Gabe und ziehe sie allen Gütern vor « (\$2)..$^{435}$ - Es ist zu vermuten, dass der Briefbote Domnina über Ennodius’

434 (302,1) Inter curas et molestias, quibus pro peccatorum fasce subicior, elegi singulare subsidium, ut ad vos domnas meas litteras destinarem, quarum precibus omnia mihi secunda contingerent et ad serena laetitiae depositis angustiarum nubibus reformarer. prima enim maeroris causa est, quod prospera vestra, dum in longinquo degitis, vix datur agnosci, ex qua nascitur circa personam meam omnis adversitas.

$435(302,2)$ adeste ergo supplici precibus vestris, ut per sanctorum dei suffragia aegro animo medella tribuatur. domina mi, servitium salutationis inpendens deprecor et per deum vos, quem colitis, optestor, ut continuis me postulationibus et lacrimis, quibus regnum caeleste vim patitur, domino commendetis, quia hoc munus speciale conputo et omnibus commodis antepono. 
konkrete Sorgen unterrichtet hat und ihr auch ausgerichtet hat, was sie zur Abhilfe unternehmen solle. Dass sein Kummer in erster Linie von seiner Unkenntnis über das Wohlergehen der Adressatin hervorgerufen werde, ist ein wiederkehrendes Motiv, das dazu dient, die Verbundenheit zur Adressatin auszudrücken (vgl. unten 243).

Stefania, die Schwester von Ennodius' wichtigstem Korrespondenten Faustus, erhält drei Briefe $(394 ; 439 ; 442)$. Im ersten schreibt Ennodius davon, dass er eine schwere Krankheit überstanden habe (zu der Krankheit siehe oben 17), was er den erfolgreichen Gebeten der Stefania zuschreibt (um ihre Gebete bittet Ennodius auch in seinem zweiten Brief an sie, 439, in dem er sich bei ihr dafür bedankt, dass ihr Neffe Avienus ihm brieflich Grüße von ihr überbracht habe). So wie sie es offenbar aus einer Ahnung heraus schon getan habe, solle sie weiterhin für ihn beten. "Ich glaube, dass Ihr mir in den Gefahren, auch ohne davon zu wissen, zu Hilfe gekommen seid. Oder warum sollte ich glauben, dass diejenigen etwas nicht wissen, denen Gott es gibt, alles zu erahnen? Denn seit ich aus Rom zurück bin, sind an mir göttliche Wunder wiederholt worden, und es ist durch neue Beispiele wiedererstanden, was durch die lange Zeit fast vergessen wurde. Wieder wurde ein Lazarus aus dem Grab zurückgerufen, der allerdings nicht zu vergleichen ist mit jenem, der es verdiente, Freund des Erlösers zu heißen; doch in der Verschiedenheit der Geschehnisse zeigt sich die Gestalt eines einzigen Wunders" $\left(\$_{1}\right) .{ }^{436}$ Seine erste Tat nach der Genesung sei es, ihr zu schreiben: "Durch vielfache Krankheiten in die Nähe des Grabes geführt, doch durch die himmlische Stimme zurückgerufen, wende ich mich zuerst diesem Dienst zu, der Euch gilt, weil ich glaube, dass es Gott gefällt, wenn mit der Sprache, die er selbst gegeben hat, an erster Stelle seinen Verehrern ein Dienst erwiesen wird « $(\$ 2) .{ }^{437}$ Sie solle also weiterhin für ihn beten: »Ich grüße also ehrerbietig und bitte Euch, wie ich <schon einmal> gebeten habe, intensiv für mich zu beten, damit die göttliche Milde um Euretwillen bewahren möge, was sie gegeben hat, und <ich bitte Euch,> mich häufig mit frommem Schreiben von Briefen aufzumuntern “ $(\$ 2) .{ }^{438}$ Für die erhofften Briefe hat er noch eine besondere Bitte: "Ich bitte Dich bei der Seele des Herrn Asterius <sc. ihres verstorbenen Mannes> und bei Deinem Bekenntnis, niemand anders für Dich schrei-

$436(394,1)$ credo vos et ignorantes meis periculis subvenisse. aut quare confidam nescire quicquam quos per deum contingit universa praenoscere? postquam enim ab urbe redii, reparata sunt in me divina mysteria et, quod senuerat temporibus, novellis resurrexit exemplis. iterum vocatus est Lazarus de sepulchro, non quidem illius par merito qui amici redemptoris nomen emeruit; sed in diversitate actuum unius convenit forma mysterii.

437 (394,2) deductus per aegritudines multiplices ad sepulchra, sed caelesti voce revocatus, ad haec primum quae vobis solvuntur officia me converti, credens placere deo, si cultoribus eius per linguam, quam ipse reddidit, principe loco exhibeantur obsequia.

$438(394,2)$ ergo reverentia salutationis inpensa deprecor, ut pro me, sicut poposci, orare adtentius procuretis, ut per meritum vestrum divina clementia dignetur confirmare quod tribuit, et frequenter me pia litterarum vestrarum promulgatione sublevetis. 
ben zu lassen. So möge ihm <sc. dem Bekenntnis (?)> der von Dir gewünschte Glanz bis zur Zeit des Endes erhalten bleiben « $\left(\$_{3}\right){ }^{439}$ Interessant ist, dass er Stefania auch in seinem dritten Brief an sie nochmals dazu auffordert, doch bitte ihre Briefe selbst zu schreiben. Dort wird sie gebeten, »niemals Euren frommen Briefen rohe advokatenmäßige Schreiben beizumischen " (442,3 ut numquam scholasticorum indociles conpositiones sanctis dictationibus misceatis). ${ }^{440}$ Auch an Barbara (in der "Paraenesis" wird sie als gutes Beispiel genannt, vgl. oben 115) richtet er eine solche Bitte: [...] doch lasst nicht jemand anders diktieren, was Ihr mir schreibt « (393,4 sed nec alterum dictare patiamini quae ad me scribetis). Offenbar haben Barbara und Stefania sich zuweilen helfen lassen, um in der Korrespondenz unter Gebildeten keine Schwächen zu zeigen. Ennodius hält jedoch den eigenen Stil dieser Frauen für angemessener.

Bei seiner Verwandten Apodemia (441, sie erhält nur diesen Brief) bedankt sich Ennodius für eine Kopfbedeckung, die sie ihm gesandt hat, wobei er betont, dass er des Geschenks nicht würdig sei. Zunächst führt er den allgemeinen Gedanken aus, dass das Band der Verwandtschaft über weite Entfernungen hinweg bestehe (dieser Gedanke findet sich in weiteren Briefen an Frauen, siehe unten 217): „Die alte Auffassung verdient festen Glauben, dass verwandtschaftliche Nähe durch räumliche Entfernung nicht beeinträchtigt wird. Die Rechte der Familie bleiben fest in ihren Angeln, und die Seelen derer, die entfernt voneinander wohnen, sind nicht getrennt. Die himmlische Kraft fließt dorthin, wohin immer sie durch Blutsverwandtschaft geleitet wird. Und jener himmlische Teil <sc. des Menschen> wird nicht in den engen Grenzen eines einzigen Landes festgehalten " $(\$ 1){ }^{441}$ Dann erläutert er, wie er den konkreten Beweis für diese Auffassung gefunden habe: "So hast Du, meine Herrin, den weit weg wohnenden Ennodius aufgesucht, und dem, dessen Anblick Du vermisst, ein edles Geschenk gemacht " ( $\$ 2) .{ }^{442}$ Er betont, dass das Geschenk einem frommen Mann gebühre, er dessen aber noch nicht würdig sei: "Ich habe eine Kopfbedeckung erhalten, wie sie eine überaus fromme Frau einem Mann der Kirche schicken sollte. Bete darum, dass Eure Gaben, wenn sie mich auch als jemanden vorgefunden haben, der der Kleidung Demütiger nicht würdig ist, mich dennoch durch ihre edle Wohl-

$439(394,3)$ rogo, ut nullum alium dictare facias, per domni Asteri animam et professionem tuam: sic ei nitor quem optas usque ad consummationis tempus adsistat.

440 SUNDWALL $(1919,67)$ vermutet offenbar in scholasticorum $[\ldots]$ conpositiones einen Bezug auf die »Paraenesis«, was aber eindeutig ein Missverständnis ist.

$441(441,1)$ Non clauda fides est opinionis antiquae, quae perhibet quod propinquitas generis non defrudetur longinquitate regionis. manent familiarum suis iura cardinibus, nec quae sunt divisa habitaculis, dissociantur animabus. percurrit aetherius vigor, ubicumque carnis cognatione producitur, et illa caelestis portio unius patriae non continetur angustiis.

442 (441,2) sic tu, domna mea, longe a corpore degentem Ennodium perquisisti, efferendo desideratis nobile munus aspectibus. 
tat ihrer würdig machen mögen « $(\$ 2) .{ }^{443}$ Apodemia solle häufig schreiben und die übrigen Kleidungsstücke möglichst bald schicken: "Meine Herrin, ich grüße herzlich und bitte, dass Ihr mich mit Euren verehrungswürdigen Briefen oft aufmuntern möget. Den Mantel und die Umhänge - in welcher Farbe Ihr wollt, rot oder gelb -, schickt mir schnell « $(\$ 3) .444$ - Ob Apodemia ihm in ihrem Brief weitere Gaben versprochen hat oder ob Ennodius auf diese sehr direkte Weise weitere Wünsche äußert, lässt sich nicht entscheiden.

Sehr fromm und sanft schreibt Ennodius an seine Verwandte Agnella (449, cf. \$3 parente; sie erhält nur diesen Brief), nachdem er davon gehört hat, dass sie als Witwe leben und nicht wieder heiraten wolle. Ennodius verehrt (cf. \$1 veneretur) und lobt sie ( $\$ 2$ bene fecisti; $\$ 3$ praedico; extollo) für diesen Entschluss: Da in Teil I (oben 118 ff.) zu sehen war, dass Ennodius mit Lob insgesamt sehr sparsam umgeht, fällt dieses Lob umso mehr auf (vgl. auch das ausführliche Lob für Archotamia in 319, unten 270). Er schreibt: "Es ist mir eine Freude, Eurer Hoheit einen Brief zu schreiben, da diese Ehre Eurer Herkunft und Eurem Herzen weniger geschenkt als vielmehr <sc. als Euch zustehend $>$ wiedergegeben wird. Es ist richtig, dass ein Mann mit geistlichem Amt eine fromme Witwe und dass ein Adliger eine Adlige verehrt. Ich danke meinem Gott, dass die gute Kunde Eures Rufes bis zu uns gedrungen ist. Möge derjenige <sc. Gott> bis zum Lebensende Erträge gewähren, der die gute Wurzel in dieser weltlichen Lebensweise gepflanzt hat. Du hast gut daran getan, verehrte Agnella, die Annehmlichkeiten dieser Welt zu verschmähen und bei Deinem Streben nach Erhabenerem auch diejenigen <Annehmlichkeiten> nicht zu haben, die von erlaubtem Trost kommen könnten <d.h. nach dem Tod des Mannes wieder zu heiraten >. Du hast es verstanden, nicht nur Vergebung, sondern die Krone zu erstreben. Die Leidenden mögen sich über Medizin freuen <sc. die Agnella hingegen nicht benötigt>: Es fehlt wenig, dass derjenige der Vollkommenheit ganz nahe ist, dem gewährt ist, sich von den Verlockungen glücklich zu trennen. Meine Verehrte, ich erweise Dir also mit herzlichen Grüßen die Ehre und bitte Dich, nicht aufzuhören, für mich, Deinen Freund und Verwandten, an

$443(441,2)$ accepi cucullam qualem debuit dirigere religionem profitenti sanctissima. ora ut dignum me humilium indumentis etsi non invenerunt dona vestra, tamen meriti sui nobilitate perficiant. - Dafür, mit ora den neuen Satz beginnen zu lassen (mit Hartel gegen Vogel, der mit sanctissima den Satz beginnt), spricht außer der Tatsache, dass so debuit ein sinnvolles Subjekt hat, auch, dass Ennodius sonst nie Sätze mit einem Vokativ im Superlativ beginnt, cf. z.B. $(17,1)$ Ego te, inlustrissime hominum $[.] ;.(27,5)$ Non aliter me, vir amplissime $[\ldots] ;(34,1)$ Diu, frater carissime $[\ldots] ; 49,7,69,5,138,2,150,2,151,3,176,3$, $221,4,221,6,222,6,222,9,223,5,314,1$. Überhaupt erscheint als Vokativ weniger häufig der bloße Superlativ ohne Attribut, z.B. (174,4) Iungo et ego, amplissimi, [...] (175,4) Vale, dulcissime, $[\ldots] .(239,3)(334,2)$.

$444(441,3)$ domina mi, salutem largissimam dicens rogo, ut crebro me venerandis relevetis alloquiis. laenam et racanas cuius vos volueritis coloris, rubei aut fusci, mihi sub celeritate dirigite. 
den Schwellen der Apostel zu beten, dass mir zuteil wird, <auch selber> einzuhalten, was ich lobe, und selbst nicht missachte, was ich an anderen lobe « (449). ${ }^{445}$ - Hier spricht Ennodius als Mann der Kirche; er lobt Agnellas Entschluss, nicht wieder zu heiraten, und bittet sie, für ihn zu beten. Dies hält ihn allerdings nicht davon ab, auch auf seinen Adel und den der Adressatin hinzuweisen $(\$ 1)$.

Auf diese Briefe ${ }^{446}$ wird bei der folgenden Untersuchung der Briefe, die Ennodius in der Rolle des nörgelnden, unzufriedenen, vorwurfsvollen Freundes schreibt, häufig zum Vergleich zu verweisen sein. Wenn diese sfreundlichen Briefe an Frauen beim ersten Lesen wenig interessant, ja vielleicht geradezu langweilig erscheinen, so wird sich dieser Eindruck durch die Erkenntnis ändern, dass Ennodius seine verschiedenen Rollen offenbar ganz bewusst und gezielt einnimmt und dass er sich auch inhaltlich gegenüber diesen Frauen anders äußert als gegenüber männlichen Adressaten. $\mathrm{Zu}$ bedenken ist auch, dass die Rolle des freundlich-gütigen Diakons, die in den Briefen nur eine Nebenrolle ist, im rwirklichen Leben seine Hauptrolle gewesen sein dürfte, die ihm den Aufstieg zum Bischof ermöglichte.

d. Die Hauptrolle: Der unzufriedene, fordernde Freund (und Verwandte)

d. 1 >Korrespondenz und Freundschaft

Die `brieftypischen Themen ` Korrespondenz $\triangleleft$ und >Freundschaft spielen in den Briefen des Ennodius eine unübersehbar wichtige Rolle; nur selten und mehr im Vorübergehen betont Ennodius dabei, dass es sich um Freundschaft speziell unter Christen handelt ${ }^{447}$ (wie es ganz besonders Paulinus von Nola thematisiert). Ennodius schreibt häufig in Form von allgemeinen Betrachtungen bzw. Sentenzen (zu

$445(449,1)$ Gratum mihi est ad magnitudinem vestram litterarum munera promulgare, quia et generi et conscientiae vestrae non tam exhibetur honor iste quam redditur. iustum est ut religiosi homo propositi sanctam viduam et nobilem veneretur ingenuus. ago deo meo gratias, quia bonus opinionis vestrae ad nos odor emanavit. (\$2) ille usque ad consummationem vitae fructus tribuat, qui bonam radicem in hac saeculi conversatione plantavit. bene fecisti, domna Agnella, mundi istius blandimenta respuere, et dum celsiora sequeris, etiam quae potuerunt venire a legitimis remediis non habere: scisti non solum veniam quaerere sed coronam. gaudeant de medicina languentes: prope est ut proximus sit integritati cui conceditur, ut feliciter dediscat inlecebras. $(\$ 3)$ ergo, domina mi, salutationis gratiam honorificentiamque persolvens rogo, ut pro me amico et parente tuo apostolorum liminibus non desinas subplicare, ut merear servare quod praedico et quod in aliis extollo ipse non neglegam.

$446 \mathrm{Zu}$ weiteren auffällig freundlichen Briefen siehe in anderen Zusammenhängen: 305 an Firmina, unten 299; 319 an Archotamia, unten 270.

447 Ausnahmen siehe: 13,3f., siehe oben 180 ; 309,1 unten 228; 312,1 unten 230; 249,1 unten 272. 
deren Form und Funktion siehe unten 252) über Freundschaft und über die Bedeutung des Briefwechsels für die Freundschaft, z.B.: " die Unterhaltung per Brief dient der Freundschaft" (63,1); "ohne irgendeinen Trost müsste man die Abwesenheit von Freunden ertragen, wenn nicht heilende Briefe zu Hilfe kämen, die die hungernden Seelen der Sehnsüchtigen mit der Speise des Gesprächs nähren können « $(419,1) .448$

Ennodius spricht explizit von einem Unterschied zwischen Briefen an gute Freunde und enge Verwandte einerseits und "gewöhnlichen" Briefen (die er z.B. sollemnia conloquia nennt) an andere Adressaten andererseits, in denen sich keine oder jedenfalls keine echte Freundschaft zeigt. Dass er selbst von Freunden und Verwandten etwas Anderes als "gewöhnliche« Briefe erwartet, sagt er in einem Brief an seine Schwester Euprepia: "Obwohl ich von Dir, meine Liebe, nur einen ganz gewöhnlichen Brief bekommen habe, der weder unserer Liebe noch unserer Verwandtschaft angemessen war, verlangt doch die Sache, dass ich mit einem Brief antworte - in ähnlichem Stil ohne Liebe [...] « $(109,1){ }^{449}$ Gegenüber seinem jungen Korrespondenten Avienus spricht er im Allgemeinen davon, dass die meisten Briefe ganz gewöhnlich seien und nur einige von ihnen Freundschaft zeigten: "Wenn auch die Eigenschaften von Briefen vom Talent abhängig sind und oft nichts Besonderes darstellen und <nur> manchmal Anzeichen der Freundschaft bezeugen [...] « (113,1).450 Bei Senarius (zu ihm unten 290) beschwert er sich, dass dieser nicht einmal "gewöhnliche Briefe« schreibe, d.h. solche, die zwar keine echte Freundschaft zeigen, aber immerhin Freundschaft heucheln: »Ich hätte nicht gedacht, dass Deine Hoheit so lange Zeit so wenig an mich denken würde, dass Du nicht einmal gewöhnliche Briefe schreibst, und dass <auch> unter denen, die die Fesseln des (Freundschafts-) Vertrags binden, solche Briefe, die mit gespielter Miene Liebe nur vortäuschen, verweigert werden " $(116,2) .{ }^{451}$ - "Gewöhnlich" sind für Ennodius also solche Briefe, die entweder gar keine Freundschaft zeigen oder diese nur vorgeben. Echte Freundschaft in Briefen hält er offenbar für etwas Besonderes; dass er selbst zu unüblichen und ganz anderen Mitteln als etwa Symmachus greift, um seine eigene Freundschaft zu ‘beweisen', ist im Folgenden zu zeigen.

$448(63,1)$ ministra affectionis est epistularis confabulatio; $(419,1)$ insolabiliter amantum ferretur absentia, nisi opem darent remedia litterarum, quae ieiunas desiderantum animas pascunt esca conloquii.

449 (109,1) Quamvis caritatis vestrae paginam sollemnibus tantum accepissem muniis obsecutam nec affectui nec necessitudini congruentem, res tamen postulavit me vicariis per stili similitudinem peregrinante diligentia respondere conloquiis [...].

$450(113,1)$ Quamvis epistularum qualitas pro ingeniis conponatur et saepe sollemnitati militet, nonnumquam affectionis testetur indicia [...].

$451(116,2)$ non credidi tanto tempore amplitudinem tuam mei inmemorem sic futuram, ut etiam sollemnibus conloquiis abstineres, ut illa, quae solent affectionem imaginata fronte simulare, negarentur inter personas catenis foederis obligatas. 
Die Bedeutung des Themas 'Freundschaft‘ für die Briefe des Ennodius ist in der Forschung mehrfach hervorgehoben worden, sei es aus sozialhistorischer Perspektive, dass nämlich Ennodius mit seinen Briefen die Aufgabe, die Freundschaft zu pflegen, aus gesellschaftlichen Gründen erfülle (NÄF 1995, 197), sei es mit dem biographischen Blick auf die Persönlichkeit, dass Freundschaft eines der Prinzipien sei, nach denen Ennodius seine schriftlichen Werke und sein Leben ausrichte (KENNELL 2000, 20). LÉGLISE bezeichnet in der Einleitung zur Übersetzung eines Teils der Briefe diese geradezu als "un charmant traité de Amicitia, dicté par le besoin d'aimer et de se savoir aimé« $(1906,5)$.

Allerdings ist noch nicht untersucht worden, auf welche Weise Ennodius seine Gedanken über die Freundschaft vorbringt, und daher ist auch bisher nicht aufgefallen, dass die entsprechenden Passagen ganz besondere Züge aufweisen und sich nicht pauschal einer schon immer und allgemein verbreiteten Freundschafts- und Brieflehre zuweisen lassen. Bisher wurde nicht bemerkt, dass Ennodius auf ganz eigene Weise mit den sbriefspezifischen Themen anderen Verfassern zu beobachtenden Konventionen verstößt. Zwar lassen sich die Briefe durchaus als "traité de Amicitia «ezeichnen, kaum aber als »charmant traité«. Im Gegenteil: Ennodius trägt seine Vorstellungen und Wünsche häufig sehr direkt, fordernd und wenig konziliant vor; er zögert nicht, auch Klagen und Tadel deutlich zu formulieren.

Als erste Annäherung an die Briefe soll betrachtet werden, wie Ennodius sich an der Schnittstelle zwischen den Themen `Freundschaft ‘ und `Korrespondenz $<$ verhält, d.h. dort, wo er sich über den Zusammenhang zwischen beidem äußert: über die Bedeutung von Korrespondenz für die Freundschaft. In Passagen, wo er sich über das Ausbleiben von Briefen beklagt bzw. um Briefe bittet, wird, besonders im Vergleich mit entsprechenden Äußerungen von Symmachus und auch Hieronymus, deutlich, von welchem Verhalten Ennodius sich distanziert und welches er selbst favorisiert bzw. von seinen Adressaten fordert.

\section{d.1.1 Funktionen und Inhalte von Briefen}

Für die Betrachtung sowohl der ganzen Sammlung als auch einzelner Briefe sind nicht nur die grundsätzliche Haltung des Verfassers und der von ihm angeschlagene Ton wichtig, sondern auch seine zu den sbrieftypischen Themen ' gehörenden $\ddot{A} u-$ Berungen darüber, welche Bedeutung Briefe für ihn haben und welche Funktionen sie übernehmen sollen. Sowohl in der modernen Theorie als auch von einigen antiken Epistolographen wird als Grund der sErfindung c von Briefen die Nachrichtenfunktion genannt. Doch nicht nur an den Briefen selbst, sondern auch an den expliziten Äußerungen der Epistolographen ist zu beobachten, dass sie sich durch etwaige 'Grundaufgaben von Briefen` in ihrer persönlichen Gestaltung und Verwendung von Briefen keineswegs eingeengt fühlen. Wie insgesamt bei der Untersuchung von ‘Topoir (siehe Thraede 1970, 30) fällt auf, dass die Epistolographen über die reigent- 
licher Funktion von Briefen meistens gerade dann reflektieren, wenn sie mit dieser Probleme haben, d.h. wenn sie im Begriff sind, einem Brief eine andere Funktion zu geben. Inwieweit die Aussagen der Epistolographen über ihre Briefe tatsächlich zutreffen, ist ein anderes umfangreiches Thema, das in diesem Rahmen nur am Fall des Ennodius behandelt werden kann. Hier soll zunächst exemplarisch dargestellt werden, was einige Epistolographen explizit über die Funktion von Briefen schreiben, um dann im Vergleich Ennodius' Äußerungen zu betrachten. Dabei soll nicht gesagt sein, dass Ennodius die vergleichbaren Passagen bei Cicero etc. gekannt haben muss, sondern diese dienen als analoge Fälle aus einer langen Tradition, mit der Ennodius durch viele ältere und zeitgenössische Briefe vertraut war. Hier zeigt sich, wie flexibel die 'Topoi` sind, d.h. dass der >Topos` nur den Ausgangspunkt darstellt, der dann neu gestaltet und im Extremfall zum Gegenteil verkehrt wird.

Der 'Nachrichtenaustausch ‘ spielt in den überlieferten Briefsammlungen sowohl inhaltlich als auch hinsichtlich der brieftheoretischen Reflexionen eine immer geringere Rolle. Schon Cicero, ${ }^{452}$ der zwar den Austausch von Nachrichten das "Eigentliche « nennt und als den Grund ansieht, warum Briefe überhaupt erfunden wurden, ${ }^{453}$ kennt (und nutzt intensiv) etliche andere Funktionen von Briefen. Zuweilen erwähnt er den Mangel an Nachrichten und begründet damit, dass er einfach etwas plaudere (iocari); ebenso fordert er einige seiner Adressaten zum Schreiben auf, auch wenn es nichts zu schreiben gebe. Besonders die Briefe an und von Atticus haben noch eine weitere Funktion: Sie ersetzen als sermo absentium das hoch geschätzte persönliche Gespräch (tecum loqui) mit all seinen Möglichkeiten zu Aussprache, Problemlösung, Scherz oder Ablenkung und Trost.

Plinius äußert sich kaum explizit zur Funktion von Briefen. Allerdings weist er an zwei Stellen darauf hin, dass es ihm an abwechslungsreichem und bedeutendem Stoff mangele und dass Briefe über die res publica nach dem Muster Ciceros kaum mehr möglich seien: "[...] Dies habe ich erstens geschrieben, um etwas Neues zu schreiben, zweitens, um auch einmal über den Staat zu sprechen; denn je seltener wir eine Gelegenheit $\mathrm{zu}$ diesem Thema haben als die Alten, umso weniger dürfen wir sie übergehen. Und, beim Herkules, wie lange noch diese Floskeln: ,Wie geht es Dir? Geht es Dir auch gut? Auch unsere Briefe sollen etwas enthalten, das nicht ge-

452 Ausführlich zu Ciceros Äußerungen über Briefe: Thraede 1970, 27-47, Cugusi 1983, bes. $76,105-115$.

453 (Cic. Q. fr. 1,1,37) quod est epistulae proprium, ut is ad quem scribitur de iis rebus quas ignorat certior fiat [...]. (Cic. fam. 2,4,1) epistularum genera multa esse non ignoras, sed unum illud certissimum, cuius causa inventa res ipsa est, ut certiores faceremus absentis, si quid esset, quod eos scire aut nostra aut ipsorum interesset. $[\ldots]$ reliqua sunt epistularum genera duo, quae me magno opere delectant, unum familiare et iocosum, alterum severum et grave. 
wöhnlich und unbedeutend und auf die privaten Dinge beschränkt ist " (Plin. $3,20,10 f.) .{ }^{454}$ "Denn wir sind nicht in der gleichen Situation wie M. Tullius, auf dessen Beispiel Du mich verweist; denn ihm stand <sc. für seine Briefe> ein reichhaltiges Talent und eine seinem Talent entsprechende Vielfalt und Bedeutung der Dinge reichlich zur Verfügung [...] «(Plin. 9,2,2).455 - Die Klage über mangelnden Stoff und über die ständige bloße Grüßerei wird sich bei Symmachus wiederfinden.

Hieronymus spricht zwar von der Nachrichtenfunktion, bezieht sie aber ausdrücklich auf den privaten Bereich. Allerdings erwähnt er diese Funktion in dem Moment, als er einen Brief gerade mit anderen Inhalten füllen möchte und darauf hinweist, dass in Briefen zuweilen auch theologische Fragen behandelt werden können (wozu er seine Briefe ja auch in großem Ausmaß nutzt): "Aufgabe von Briefen ist es, etwas über die Angelegenheiten zu Hause oder über das tägliche Leben zu schreiben..., indem man sich gegenseitig mitteilt, was man möchte oder was geschehen ist, wobei eine solche gesellige Unterhaltung zuweilen auch mit dem Salz der Lehre gewürzt werden kann « (Hier. 29,1). ${ }^{456}$ Als er einmal darüber schimpft, dass einer seiner Briefe unerlaubt weitergegeben worden sei, zählt er auf, zu wie vielen Zwecken er seine Briefe nutze: »Ich möchte in meinen Briefen irgendwelchen Unfug schreiben, die Schrift auslegen, Angreifer zurückschlagen, mein Mütchen kühlen, mich in Allgemeinplätzen üben« (Hier. 57,4). ${ }^{457}$ Häufiger spricht Hieronymus davon, dass Briefe helfen, die Trennung zu überwinden, indem sie den "Anschein persönlicher Anwesenheit « erschaffen: »[...] wenn wir uns durch den Austausch von Briefen einen Anschein von Anwesenheit vortäuschen « (Hier. 3,1). ${ }^{458}$ Allerdings ist der Brief nicht immer ein Abbild seines Verfassers für den Empfänger, sondern beim Schreiben sieht

454 (Plin. 3,20,10-12) Haec tibi scripsi, primum ut aliquid novi scriberem, deinde ut non numquam de re publica loquerer, cuius materiae nobis quanto rarior quam veteribus occasio, tanto minus omittenda est. (\$11) et hercule quousque illa vulgaria »quid agis? ecquid commode vales? « habeant nostrae quoque litterae aliquid non humile nec sordidum nec privatis rebus inclusum. eqs.

455 (Plin. 9,2,2) [...] neque enim eadem nostra condicio quae $M$. Tulli, ad cuius exemplum nos vocas; illi enim et copiosissimum ingenium et par ingenio qua varietas rerum qua magnitudo largissime suppetebat.

456 (Hier. epist. 29,1,1) Epistolare officium est de re familiari aut de cotidiana conversatione aliquid scribere..., dum mutuo, quid aut velint aut gestum sit, nuntiant, licet interdum confabulationis tale convivium doctrinae quoque sale condiatur.

457 (Hier. 57,4,1) volo in chartulis meis quaslibet ineptias scribere, commentari de scripturis, remordere laedentes, digerere stomachum, in locis me exercere communibus [...].

458 (Hier. 3,1,1) si vicissitudine litterarum imaginem nobis praesentiae mentiremur. Siehe auch: (Hier. 4,4,1) Ut absentiam corporum spiritus confabulatione solemur; (Hier. 5,1,1) [...] pro me tibi litteras repraesento. etsi corpore absens, amore et spiritu venio inpendio exposcens, ne nascentes amicitias, quae Christi glutino cohaeserunt, aut temporis aut locorum magnitudo divellat $[. .$.$] ; (Hier. 8,1,1) praesens inter absentes; (Hier. 76,1) absentiam corporum$ vince sermone; (Hier. 104,6,3). 
man den Adressaten vor sich (den Gedanken nimmt Ennodius auf, siehe oben 154 und unten 292), so wie Cicero beim Schreiben an Atticus das Gefühl hat, sich mit diesem zu unterhalten: "jetzt unterhalte ich mich mit Eurem Brief, ihn umarme ich, er redet mit mir...; und während ich diesen schreibe, sehe ich Euch “ (Hier. 7,2,1); "bei schwierigen Fragen schreibe ich verschiedene Ansichten, so dass ich eher mit Dir persönlich zu sprechen als Dir zu schreiben scheine« (Hier. 72,5).459

Ambrosius nennt den Austausch von Nachrichten überhaupt nicht als Funktion von Briefen. Briefe seien erfunden worden, damit man sich mit Abwesenden unterhalten könne, sie dienten der Freundschaft und optimalerweise zur Auslegung der $\mathrm{Hl}$. Schrift: »[...] dass wir briefliches Geplauder und das Gespräch zwischen Abwesenden zur Auslegung der himmlischen Aussprüche verwenden « (Ambr. 1,1,1), "Es gibt keinen Zweifel, dass Briefe deshalb erfunden wurden, damit wir uns mit Abwesenden unterhalten können. Doch es ist umso schöner als Tat und als gutes Beispiel, wenn es zwischen dem Vater und den Söhnen viele angenehme Gespräche gibt, so dass unter den körperlich Getrennten ein gewisser Anschein von Anwesenheit entsteht. Denn durch den Austausch von Briefen wächst die Liebe, so wie sie durch Deine Briefe an mich und meine an Dich wächst $[\ldots]$ « (Ambr. 7,48,1). Ambrosius betont den Nutzen für die Freundschaft, um dann hervorzuheben, dass der briefliche Austausch über Fragen der Hl. Schrift zu einer wirklichen Verschmelzung der Seelen führe und ein erfülltes Gespräch darstelle (7,37,4 ff.). ${ }^{460}$

Symmachus erwähnt wie Cicero die Nachrichtenfunktion als das 'Eigentlicher, sieht aber auch, dass seine Briefe dieser Definition nicht (immer) entsprechen; dies veranlasst ihn zur an Plinius erinnernden Klage (siehe oben 205) und zur Suche nach Auswegen. Er beklagt zuweilen das Fehlen von mitteilungswürdigen Stoffen bzw. meint, diese seien eigentlich nötig: »Fast hätte ich nur ganz kurz mit Dir gesprochen, da es nichts Erwähnenswertes gibt und es die Mühe nicht lohnt, Worten zu frönen,

459 (Hier. 7,2,1) nunc cum vestris litteris fabulor, illas amplexor, illae mecum loquuntur $[\ldots]$ et cum has scriberem, vos videbam; (Hier. 72,5) in rebus obscuris diversas ponimus opiniones, ut non tam scribere quam loqui tibi coram videamur.

460 (Ambr. 1,1,1) [...] ut epistulares fabulas et sermonem absentium ad interpraetationem conferamus oraculi caelestis. (Ambr. 7,48,1) Epistularum genus propterea repertum, ut quidam nobis cum absentibus sermo sit, in dubium non venit. Sed fit hoc usu exemploque pulchrius, si inter parentem ac filios crebra et iucunda alloquia caedantur, ut vere inter disiunctos corpore quaedam imago referatur praesentiae; his enim adolescit officiis amor, sicut tuis ad me aut meis ad te augetur litteris [...]. (Ambr. 7,37,4) [...] epistulis, quarum eiusmodi usus est, ut disiuncti locorum intervallis affectu adhaereamus, in quibus inter absentes imago refulget praesentiae et collocutio scripta separatos copulat, in quibus etiam cum amico miscemus animum et mentem ei nostram infundimus. (\$5) Iam si, ut hortaris, aliquid et de veteribus scriptis redoleat in epistulis, non solum animi conglutinari videntur per verae doctrinae profectum, sed etiam plenioris colloquii species et forma exprimi, ut inter quaerendi et respondendi mutuas vices assumpta concertatio in unum conducere et coram videatur amicos locare, qui tali se lacessunt et complectuntur munere [...]. 
wenn es an Stoff fehlt« (Sy. 1,15,1); „Denn wie lange werden wir Worte des Grüßens und Zurückgrüßens plappern?« (Sy. 2,35,2). ${ }^{461}$ Doch an anderer Stelle wendet Symmachus die Tatsache, dass er nichts mehr zu schreiben habe und daher nur kurz einen Gruß schreiben könne, positiv; zwar gebe es nichts mehr zu berichten, doch er wolle wenigstens seine Freundschaft zum Ausdruck bringen: »Einerseits vermindern kurze Briefe Dir, der Du mit öffentlichen Aufgaben betraut bist, den Überdruss beim Lesen, andererseits ist, da ich so oft geschrieben habe, alles, was zu schreiben war, aufgebraucht. [...] Denn die Freundschaft zu bekunden ist eine Sache, mit der Beredsamkeit zu prahlen, eine andere. Und so war es mir wichtiger, meine Verbundenheit zu zeigen, als zu reden« (Sy. 1,56). ${ }^{462}$ Ein Grund dafür, dass der Brief nur einen Gruß enthält, kann auch sein, dass der Bote die Nachrichtenfunktion übernimmt, z.B.: "Nicht dass ich es ablehne zu schreiben, aber ich wollte es lieber meinem lieben Sibidius überlassen, persönlich in Ruhe zu berichten. Daher hat dieses Blatt nur die Aufgabe, zu grüßen, das in seiner Kürze einerseits Euch genügend Ehre erweist, andererseits ihm nichts von seinem Bericht wegnimmt « (Sy. 6,50). ${ }^{463}$ Symmachus betont, er freue sich über einen Brief vom Adressaten, auch wenn er keine Neuigkeiten enthalte: „Wenn es aber nichts zu schreiben gibt, reicht es mir, wenn ich mich über Dein Wohlergehen freuen kann" $\left(\right.$ Sy. 1,91) ${ }^{464}$ Ebenso schreibt er selbst: "Meine Pflicht ist zu vermelden, dass es mir gut geht, mein Wunsch ist zu erfahren, dass es Dir gut geht [...]« (Sy. 7,92). ${ }^{465} »$ Es gibt keinen Stoff, um mein Schreiben zu verlängern. Du weißt von meiner Untätigkeit, von der ausführlich mit Dir zu reden uns beiden Verdruss bereiten würde: viele Worte passen besser zu wichtigen Aufgaben [...]; Möge also, um die Freundschaft zu pflegen, einmal ausreichen: Wenn es Dir gut geht, freue ich mich. Ich hoffe, dass ein solcher Austausch von Grüßen, wie Du sie als zu kurz beklagen wirst, unter uns während meiner Abwesenheit lange bestehen wird « $\left(\right.$ Sy. 4,28,3). ${ }^{466}$

461 (Sy. 1,15,1) Paene evenerat, ut tecum succincta brevitate loqueremur, quoniam deerant digna memoratu et in defectu rerum nihil operae est indulgere verbis; (Sy. 2,35,2) quousque enim dandae ac reddendae salutationis verba blaterabimus?

462 (Sy. 1,56) Et tibi publicis negotiis occupato breves litterae demunt fastidium lectionis, et mei officii adsiduitas, quidquid scribendum videbatur, exhausit. [...] alia est enim protestatio amoris, alia linguae ostentatio. atque ideo mihi antiquior fuit obsequendi opera quam loquendi.

463 (Sy. 6,50) Scribere non recuso, sed malui domno filio meo Sibidio narranda coram per otium reservare. sola igitur salutatione fungetur haec pagina, cuius brevitas et vestro honori satisfaciet nec illi referenda decerpet. vale. - Siehe auch: (Sy. 6,13).

464 (Sy. 1,91) quod si scribenda defuerint, mihi satis erit, ut tibi gratuler sospitatis.

465 (Sy. 7,92) officii mei est nuntiare, quod valeam, voti, ut te salvere cognoscam.

466 (Sy. 4,28,3 f.) nihil argumenti suppetit ad propaganda, quae scribimus. nosti otium meum, de quo apud te largiter loqui utriusque fastidium est; magis negotiis plura verba conveniunt [...]; (\$4) sufficiat aliquando celebrandae amicitiae: si vales, bene est. opto has ipsas, quas tu breves quereris, salutationum vices, dum absumus, inter nos longum manere. 
In zwei Briefen, einem Empfehlungsbrief und einem Bittbrief, nennt Symmachus die Freundschaft bzw. den Wunsch, den Adressaten zu grüßen, als ersten, und den tatsächlichen Anlass als zweiten Grund für sein Schreiben (zu dieser überraschenden Gewichtung der expliziten Gründe unten 357): "Mein erster Grund zu schreiben ist der Grundsatz, unsere Freundschaft mit Briefen zu pflegen; den zweiten Grund lieferte die Freundlichkeit, nämlich meinem Bekannten, dem ausgezeichneten Thalassus, Deine Freundschaft zu vermitteln« $($ Sy. 7,84). Ähnlich in einer Bitte: »Mein erster Grund zu schreiben ist, Dir die Ehre des Grußes zu erweisen, der zweite, mich mit einer gerechtfertigten Bitte an Dich und Deine erprobte Redlichkeit zu wenden " (Sy. 9,140). ${ }^{467}$ - Es ist also insgesamt zu beobachten, dass Symmachus zwar in Ausnahmefällen darauf hinweist, dass er lieber inhaltsreichere und gewichtigere Briefe schreiben würde, dass er aber an vielen Stellen auch die Bedeutung des bloßen Austauschs von Grüßen hervorhebt.

Ennodius wählt aus dieser Auswahl an `Topoi`, die die Tradition seit Cicero zu bieten hatte, sehr gezielt aus. Er spricht überhaupt nicht von der bei Cicero, Plinius, Hieronymus und Symmachus erwähnten sNachrichtenfunktion`von Briefen (auch wenn er zuweilen Nachrichten mitteilt, siehe unten 210), und entsprechend klagt er auch nicht über einen Mangel an Mitteilungswürdigem. Er vertritt die Ansicht, dass Briefe überhaupt nur deshalb erfunden wurden, um Freundschaften über Entfernungen hinweg zu erhalten, d.h. durch einen Gruß zu zeigen, dass man den Freund nicht vergessen habe: "Oder haben Briefe einen anderen Zweck, als mit dem Schlüssel der Rede aufzuzeigen, was man im Inneren verbirgt <sc. die Freundschaft >? « $(251,2)$; "ich entbiete meine Grüße, derentwegen man Briefe schickt « $(22,1)$. Briefe wurden erfunden, um Freunde über die Trennung hinwegzutrösten: »[...] denn als Trostmittel, wenn man jemanden vermisst, hat die Voraussicht der Alten die Briefe erfunden « $(448,1) \cdot .^{468}$

Den Hinweis auf die ,Alten formuliert Ennodius mehrfach; ausführlich müsste er etwa lauten: >Unsere Freundschaft kann keinen Schaden nehmen, da ja die Vorfahren so weise waren, den Brief zu erfinden, mit dessen Hilfe wir unsere Freundschaft pflegen können`; Ennodius verkürzt dies: »denn die Voraussicht der Alten wollte, dass dank dieser Gaben <sc. der Briefe> die Abwesenheit keine Macht haben sollte" $(173,1)$; »der Trost durch Briefe, durch den nach dem Willen der Alten die Abwesen-

467 (Sy. 7,84) Primam mihi scribendi causam religio fecit, ut amicitia nostra litteris excolatur; secundam suggessit humanitas, ut viro optimo Thalasso familiari meo tua concilietur adfectio. (Sy. 9,140) Prima mihi scribendi causa est, ut tibi honorificentiam salutationis exhibeam, secunda, ut probatam mihi modestiam tuam iusta petitione conveniam.

$468(251,2)$ an ad aliud adtributae sunt paginae, nisi ut secreta pectorum oris clave manifestent? $(22,1)$ reddo salutationis obsequia, propter quae promulgantur epistulae. $(448,1)[\ldots]$ quia in remedio desiderii senior providentia munus litterarum comparavit. 
heit keine Macht hat" $(357,1) .{ }^{469}$ Dies erklärt sich mit dem Blick auf zwei von Symmachus formulierte Gedanken und auf den von Ennodius besonders in den Praefationes der Briefe nachgeahmten Kanzleistil (dazu ausführlich unten 256): Bei Symmachus findet sich zum einen der allgemeine Gedanke über die Erfindung von Briefen: „Dafür hat entweder die Natur oder der Fleiß mit Kunstfertigkeit die Briefe erfunden, dass Freundschaft niemals stumm sein muss, und dass, wenn wir einmal getrennt sind, die Zeichen der Wörter den Dienst der Zunge übernehmen können" (Sy. 3,17,2). ${ }^{470}$ Zum anderen verweist Symmachus auf das "Gesetz «, dass diejenigen, die verreist seien, die Korrespondenz eröffnen müssten: "Der alte Brauch hat folgende Regel im Schreiben eingeführt, dass diejenigen, die abgereist sind, mit dem Schreiben von Briefen beginnen " (Sy. 6,60). ${ }^{471}$ Diese Formulierung des für die Korrespondenz geltenden "Gesetzes" weist ebenso wie die Formulierungen bei Ennodius auf wirkliche Gesetzestexte: Herrscher weisen in den Proömien ihrer Verlautbarungen häufig auf die vetustas, antiquitas, consuetudo etc. hin, d.h. auf das Vorbild der Vorfahren, auf die Tradition, die es zu wahren gelte (FrIDH 1956, 36f.; HonIG 1960 18; 131f.), siehe z.B. in Cassiodors Variae: "mit Bedacht hat die vorausschauende alte Zeit entschieden [...] " (Cassiod. 4,35,1 consulto provida decrevit antiquitas) ${ }^{472}$ Solche Ausdrücke werden für Gedanken der Brieftopik und die 'Spielregeln ‘bzw. leges der Korrespondenz übernommen. Das Motiv aus der Sprache der Erlasse und Gesetze, das Symmachus zur Formulierung einer festen Regel unter Korrespondenten einsetzt (Sy. 6,60 prisca observantia [...] fecit), verwendet Ennodius zur Formulierung der grundsätzlichen Bedeutung von Briefen. - In einigen Fällen bezeichnet Ennodius die Möglichkeit, Briefe auszutauschen, auch als Geschenk des Himmels (siehe z.B. in 427 , siehe unten 293 , in 151 , u. 370 ).

Da Ennodius die Pflege der Freundschaft als Hauptzweck von Briefen sieht, äuBert er sich zuweilen dazu, wenn der konkrete Zweck ein anderer ist, d.h. wenn es sich um paginae negotiosae handelt: Einen Brief, in dem er mitteilt, dass er vermutlich einen entlaufenen Sklaven des Faustus gefunden habe, beginnt er: "Ich danke Gott, der entsprechend meinen Wünschen, niemals vom Schreiben abzulassen, dafür sorgt, dass über konkrete Angelegenheiten zu schreiben ist. Denn was die Kraft der

$469(173,1)[\ldots]$ per haec enim munia voluit senior providentia absentiae nil licere; $(357,1)$ solacium litterarum, per quod vetustas voluit absentiae nil licere; siehe auch: $(149,1)$ iure veterum sapientia epistolis usa $[\ldots] ;(291,1)$ haec in usu vocavit antiquitas $[\ldots] ;(151,1)[\ldots]$ veteris aevi providentia [...]. Sehr verkürzt und daher nicht leicht zu verstehen: $(396,1)$.

470 (Sy. 3,17,2) ideo litteras adfabra rerum vel natura vel industria peperit, ut numquam muta esset adfectio, et si quando absumus, linguae ut operam fungerentur signa verborum.

471 (Sy. 6,60) Prisca observantia hunc scribendi ordinem fecit, ut domo profecti officium litterarii muneris auspicentur. Siehe auch unten Anm. 492.

472 Siehe auch z.B.: (Cassiod. var. 2,4,1) delectamur vetustatis invento; (var. 6,5,3) sit imitator prudentissimus antiquorum; (var. 8,13,5) priscorum $[. .$.$] constituta; ($ var. $9,18,1)$ provide decrevit antiquitas. 
Liebe fordert, kann auch dem Nutzen dienen. Deshalb, mein Herr, gebe ich Bescheid über meine Gesundheit und [...] « (89). ${ }^{473}$ An Avitus, der wohl sonst keine Korrespondenz mit Ennodius unterhält, sich aber wegen der Bischofswahl in Aquileia mehrfach an ihn wendet (siehe unten 270): "Während ihr mir wegen einer konkreten Angelegenheit schreibt, erweist Ihr der Freundschaft einen Dienst « $(178,1) .{ }^{474}$ In anderen Fällen wertet Ennodius es sogar als Verstoß gegen die eigentliche Aufgabe von Briefen, wenn eine dringende Angelegenheit behandelt werden muss; einen Bittbrief für einen Dritten beginnt er: „Wenn meine Tage wunschgemäß verliefen, würde ich nicht für Briefe mit einem konkreten Anliegen mehr Mühe aufwenden als für solche, die meine Verbundenheit zeigen, und ich würde nicht aus einer Freundschaftsgabe einen Dienst für andere machen <sc. für denjenigen, für den er sich mit diesem Brief einsetzt $>$. Doch gezwungenermaßen ersetzt ein Schreiben in dringender Angelegenheit einen Freundschaftsbrief « $(161,1)$; »Briefe, die die Freundschaft sich als Trost erfunden hat, dürften sich nicht mit Geschäftlichem befassen $[\ldots]$ « $(283,1){ }^{475}$

Die einzigen $>$ Nachrichten $<$, die ausgetauscht werden, betreffen die Gesundheit: "Ich komme zu dem Punkt, weswegen man Briefe schickt: Ich kann berichten, dass ich körperlich gesund bin [...] « $(296,2$; allerdings ist der Zweck dieses Briefes wohl die Empfehlung des Überbringers, der eingangs als zuverlässig gelobt wird); "durch die Nachricht, dass es mir gut geht, kann ich Eure Sorge erleichtern, und - weshalb es überhaupt Briefwechsel gibt - ich frage nach Eurem guten Befinden « (397); »[...] weshalb man Briefe schickt: ich kann berichten, dass ich gesund bin und frage nach dem Zustand Eures Wohlergehens [...] « (319,8; allerdings hier als Abschluss eines längeren Briefs, siehe unten 270). ${ }^{476}$

Im Brief malt sich der Verfasser ein Bild vom Adressaten und unterhält sich mit ihm, siehe oben 154 zum >Brief als Spiegel.

\section{Fazit}

Ennodius äußert sich zur Funktion von Briefen also anders als die übrigen Epistolographen, die alle Briefen mehrere verschiedene Funktionen zuweisen. Nicht am

473 (89) Deo gratias, qui iuxta desideria mea, ne aliquando ab scriptione temperem, negotiosa facit esse conloquia. potest enim et utilitati prodesse quod exigit vis amoris. proinde, domine, indicia meae valitudinis faciens [...].

$474(178,1)[\ldots]$ dum enim negotiosas paginas destinatis, ministerium praebetis affectui.

$475(161,1)$ Si mihi ex sententia dies fluerent, non negotiosis operam paginis potius quam obsequentibus exhiberem nec munus caritatis ad officia peregrina transducerem. sed coactus rem diligentiae necessariis commutavi. $(283,1)$ Non deberent esse negotiosa conloquia, quae pro remedio sibi amor invenit eqs.

$476(296,2)$ ad illud revertor, propter quod epistolae destinantur: valere me corpore nuntio [...]; (397) sollicitudinem vestram nuntio prosperitatis meae relevo et, propter quod concessum est epistolare commercium, vestram requiro $[\ldots] ;(319,8)[\ldots]$ propter quod mittuntur epistolae, corpore me valere significans prosperitatis vestrae statum requiro [...]. 
wenigsten unterscheidet er sich von Symmachus: Während dieser zuweilen über den Austausch bloßer Grüße klagt, sich bemüht, bloße Grüße irgendwie zu rechtfertigen, und das Motiv ,Freundschaft als Anlass, zu schreiben ‘ nur zuweilen verwendet, zeigt sich Ennodius davon überzeugt, dass Briefe überhaupt zu dem Zweck erfunden wurden, um die Freundschaft zu pflegen, indem man Grüße und Fragen, wie es dem anderen gehe, austauscht.

Zu diesen Äußerungen des Ennodius über die Funktion von Briefen passt, dass tatsächlich, wie bereits angedeutet wurde, ein Großteil seiner Briefe beziehungsorientiert ist (Gruppe 4, siehe oben 149; siehe zu diesen Briefen unten Kap. II 3.b). Weiter unten wird darzustellen sein, dass Ennodius die These, dass Briefe nur der Pflege der Freundschaft $\mathrm{zu}$ dienen hätten, so konsequent vertritt, dass er auch andere Arten von Briefen, Empfehlungsbriefe (Gruppe 3) und Gratulationsschreiben (Gruppe 2), so gestaltet, als dienten sie in erster Linie dazu, die Freundschaft zu pflegen (Kap. II 3.c bzw. d).

\section{d. 1.2 Grundsätze des Verhaltens im Vergleich mit Symmachus}

Obwohl Ennodius' Briefe den gleichen Anlässen dienen wie die des Symmachus, präsentiert er sich ganz anders als dieser: Als ein Charakteristikum der Briefe des Symmachus wird mit Recht die Höflichkeit angesehen, z.B.: "<sc. die Briefe> strömen über von Höflichkeit " (PETER 1901, 140), "careful observance of etiquette and its polite attentions" (MATthews 1974, 91), "Zelebrieren von Höflichkeit « (FuHRMANN, ${ }^{2} 1995,266$ ). Doch im Gegensatz zu Symmachus, der immer freundlich bleibt und zudem viele Briefe mit einer gefälligen Pointe beendet, gibt sich Ennodius durchaus nicht immer freundlich, sondern häufig vorwurfsvoll und unzufrieden. Anders als bei Symmachus liegen die Pointen bei Ennodius oft nicht beim ersten Lesen offen, sie stecken etwas verborgen im Aufbau der Argumentation, im Spiel mit der Erwartung des Lesers. Schmunzeln kann der Adressat - auf einer anderen Ebene - häufig darüber, dass Ennodius wieder einmal einen Anlass gefunden hat, Unzufriedenheit zur Schau zu stellen.

Es zeigt sich, dass man die Briefe des Symmachus, die Ennodius zweifellos kennt, nicht ohne Weiteres als sein Vorbild bezeichnen kann, ${ }^{477}$ sondern dass man das Verhältnis zwischen beiden differenzierter charakterisieren muss: Die brieftypischen Gedanken und Motive bei Ennodius bilden zum Teil einen absoluten Gegensatz zu denen des Symmachus, zum Teil aber nimmt Ennodius dessen Gedanken auf, um sie strenger und geradezu radikal umzusetzen. Dies soll nun gezeigt werden anhand der Schlüsselbegriffe indulgentia, urbanitas, querellae, inportunitas, sinceritas, simplicitas

477 Siehe z.B. Funrmann $\left({ }^{2} 1995,268 f\right.$.): "Seine Briefe $[\ldots]$ bekunden allenthalben, dass sie in der Nachfolge des Symmachus stehen; " "<es> wuchern die stereotyp wiederkehrenden Motive, die dem Kenner der Symmachus-Briefe nur allzu vertraut sind.« 
und der Untersuchung, welche Bedeutung für die Freundschaft Symmachus und Ennodius Briefen zuschreiben.

\section{indulgentia / urbanitas - querellae / inportunitas}

Eines der Prinzipien, auf denen das Verhalten des Symmachus in seinen Briefen beruht, ist die 'Nachsicht ( (siehe oben 156) gegenüber dem Verhalten seiner Adressaten, d.h., da ein Großteil seiner Briefe der `Beziehungspflege dient, überwiegend gegenüber deren Verstößen gegen die `Spielregeln` der Korrespondenz. Die »erlesene Höflichkeit« des Symmachus (von AlBRECHT II, 1146) reicht so weit, dass die nachsichtige Haltung auch dann überwiegt, wenn er einmal Anlass für einen Tadel sieht, z.B. wenn der Adressat schweigt: "[...] l'obiurgatio légitime d'un ami privé d'une lettre demeure toujours indulgente" (BRUGgISSER 1987, 137). Von seiner Nachsicht spricht Symmachus häufig auch selbst; Klagen bringt er nur in Ausnahmefällen vor. Ennodius' Stärke ist die Nachsicht hingegen überhaupt nicht; er hat keine Scheu, seine Briefe mit Klagen (querellae) über das Verhalten seiner Korrespondenten zu füllen, überwiegend über deren Verhalten in der Korrespondenz (d.h. in der Regel über ihren fehlenden Eifer), selten einmal aber auch über Fragen ihrer Lebensweise (siehe unten 274 zu Asturius). Wie Symmachus stützt sich Ennodius als Epistolograph auf das Prinzip der Freundschaft, aber Ennodius leitet daraus eine gegensätzliche Haltung ab: Aufgrund seiner Freundschaft werden Klagen über das Verhalten der Korrespondenten nicht unterdrückt, sondern vielmehr gerade vorgebracht. Diese im Folgenden zu entwickelnden Ergebnisse widersprechen Stefanie Kennells Annahme, dass Ennodius sich grundsätzlich freundlich verhalten wolle, und ihrer Feststellung, dass ihm dies auch in den allermeisten Fällen gelinge (»his unfailing courtesy», 2000, 42); ${ }^{478}$ sie beobachtet allerdings im Laufe ihrer Monographie auch einige Ausnahmen von dieser Regel, ${ }^{479}$ ohne daraus Schlüsse zu ziehen.

478 KenNell $(2000,185)$ : "When they obtruded, temporal exigencies were not to be taken as opportunities for incivilities, though Ennodius occasionally fell short of his own ideal, as we saw in the literary-critical exchange with Beatus. The letters in which he tried to obtain repayment of a loan made to Pope Symmachus are models of tactful forbearance; when his friend Maximus marries, polite behavior is the subject of his letter to Arator. Through reassurance instead of stinging rebuke, by nurturing emotional proximity through little kindnesses, with admissions of weakness that entail pleas for prayer and mutual aid - this is how Ennodius discharges the obligations of friendship [...]. «

479 KenNell (2000): »singular sharpness « (36, zum Beginn von 412), "accuses« (37, zu 455), "unusually prickly in tone" ( $71, \mathrm{zu} 317)$, "uncharacteristically disagreeable mood " (126, $\mathrm{zu} 362$ ), "appreciably more brusque" (134, $\mathrm{zu} 109$ ), "in pugnacious tones" (145, $\mathrm{zu} 454)$. "Notwithstanding his resolve to keep his discourse as euphoniously civilized as possible, Ennodius left us four letters that unambiguously request repayment of certain monies $[\ldots] \ll(40)$. 
Symmachus thematisiert seine Haltung in einem Brief (Sy. 3,18), in dem er sich zunächst über die Schreibfaulheit des Adressaten beschwert (siehe unten 222), bis hin zu der Feststellung: "Denn wenn Du die Korrespondenz häufig vernachlässigst, liegt es daran, dass Du sehr beschäftigt bist, wenn aber immer, dann daran, dass Du mich vergessen hast “ $(\$ 1) .{ }^{480}$ Dann aber ändert sich der Ton, und Symmachus erläutert seine Grundsätze (religio), nämlich Geduld (patientia) und Gelassenheit (aequus animus): "Glaubst $\mathrm{Du}$, ich zürne? Wenn das geschehen könnte, würde ich schweigen. Spielst Du also mit meiner Geduld? Doch Du solltest einsehen, dass mein Gleichmut mit einem höheren Preis belohnt werden müsste. Es ist besonders unwürdig, wenn jemand verletzt wird, dessen Grundsätze es nicht zulassen, sich verletzen zu lassen « $(\$ 2) .{ }^{481}$ An anderer Stelle begründet er seine Nachsicht mit den Worten: »[...] da ich ja meinen Freunden gegenüber wohlwollend gestimmt bin [... « $(4,55$ ut sum placido in meos animo, siehe dazu unten 332). Symmachus bestätigt seine Selbstcharakterisierung als quem religio non permittit offendi mit seiner Reaktion auf unerfreuliches Verhalten seiner Briefpartner immer wieder. Er findet immer eine gedankliche Wendung und oft eine Pointe, um aus dem tadelnswerten Verhalten des Adressaten das Beste zu machen. Ennodius hingegen nutzt jede Gelegenheit, sich verletzt zu zeigen; er ließe sich in Anlehnung an die Formulierung des Symmachus bezeichnen als jemand, >quem religio amicitiae poscit offendi`, oder, wie er selbst sagt: ad querellam descendi caritatis imperio $(426,2)$.

Dieser grundlegende Unterschied zwischen Symmachus und Ennodius zeigt sich z.B. an der jeweiligen Gestaltung des ১brieftypischen Themas $\triangleleft$, welche Bedeutung für die Freundschaft sie der Korrespondenz zumessen.

\section{'Briefe und Freundschaft ' bei Symmachus}

Symmachus beweist seine Gelassenheit besonders dadurch, dass er sich der Beständigkeit seiner Freunde auch dann sicher zeigt, wenn Briefe von diesen ausbleiben; er sieht darin in aller Regel ausdrücklich keinen Anlass, sich um den Zustand der Freundschaft wirklich zu sorgen und zu klagen, z.B.: "Da ich mir Deiner Treue sicher bin, habe ich auch dann keinen Zweifel, wenn die Freundschaft stumm ist « $($ Sy. 8,35); "denn die Einschätzung einer guten und erprobten Freundschaft ist unumstößlich, auch wenn Briefe ausbleiben" (Sy. 1,95,1); "Um mir einer Freundschaft sicher zu sein, reicht es mir, dass ich glaube, dass meine Freundschaft erwidert wird « (Sy. 3,2); "Die Bewahrung der Freundschaft [...] muss man mehr an der Treue der Seele als an prunkenden Worten messen « $\left(\right.$ Sy. 8,12) ${ }^{482}$ Denn Symmachus weiß auch, dass man Briefen

480 (Sy. 3,18,1) nam officia si plerumque deseras, occupatio est, si semper, oblivio.

481 (Sy. 3,18,2) irasci me putas? hoc si fieri posset, tacerem. inludis ergo patientiae meae? atqui intellegas, aequum animum maiore pretio munerandum. indignius laeditur, quem religio non permittit offendi.

482 (Sy. 8,35) certus fidei tuae etiam de tacito amore non dubito; (Sy. 1,95.1) nam bonae et exploratae amicitiae, vel si cesset officium, satis tutae aestimationes sunt; (Sy. 3,2) satis est 
nicht immer trauen kann: »In dargebotenen Worten verbirgt sich oft Verstellung « (Sy. 8,11); "Was bittest Du um Briefe, denen man oft nicht glauben kann?« (Sy. 4,21,4). ${ }^{483}$ - Nur ausnahmsweise findet sich bei Symmachus innerhalb einer Aufforderung zu künftiger regelmäßiger Korrespondenz der Gedanke, dass Freundschaft nicht ohne Briefe auskommen könne: »denn schweigende Eintracht unterscheidet sich nicht von Abneigung « (Sy. 3,17,2). ${ }^{484}$ - Symmachus erwartet auch, dass seine Korrespondenten sich seiner Freundschaft sicher sind, wenn er selbst einmal keine Gelegenheit zum Schreiben hat, z.B.: "das Vertrauen auf unsere Freundschaft soll also nicht von unseren Briefen abhängen “ (Sy. 4,28,2); "Oder glaubst Du etwa, dass die Erinnerung an die Freundschaft durch Schweigen entgleiten kann? Hüte Dich, so etwas von Seelen zu denken, deren Entscheidungen unumstößlich sind « (Sy. 4,33). ${ }^{485}$ - Symmachus erwähnt zwar häufig, dass Briefe vom Adressaten ausbleiben, doch er zeigt Verständnis, da er die Gründe kenne und respektiere, nämlich die zeitraubenden Ämter, z.B.: "Dein derzeitiges Schweigen schreibe ich Deinen schwierigen öffentlichen Aufgaben zu « (Sy. 3,2); "Denn ich weiß, dass Korrespondenz meistens nicht durch Missachtung der Freundschaft, sondern durch die alles überlagernden Aufgaben verzögert wird « $\left(\right.$ Sy. 7,117). ${ }^{486}$ Auch er selbst bittet vorsorglich einen Adressaten, derartige Gründe zu bedenken, falls er einmal länger nicht von sich hören lasse: "[...] mit der Bitte [...], den Grund für mein Schweigen nicht in meiner Absicht oder Trägheit, sondern in meinen Beschäftigungen zu suchen " (Sy. 7,119) ${ }^{487}$ - Symmachus gelingt es nicht, einem schweigenden Adressaten gegenüber auch selbst zu schweigen: "Wie ich sehe, vernachlässigst Du Deine Korrespondenz mit mir ohne Risiko; denn Du weißt, dass Dir diese Schuld ohne Vergeltung ausgehen wird. Wie oft habe ich Dir mit gleichem Schweigen gedroht, wenn Du nicht schreiben würdest? Doch die Freundschaft ist stärker als ich, und ich freue mich über diese meine Lüge. Daran kannst Du sehen, wie beständig meine Freundschaft zu Dir ist, da ich Dir so unbeständig böse bin « $\left(\right.$ Sy. 3,26). ${ }^{488} \mathrm{Da}$ er selbst so nachgiebig ist, reagiert er mit Unverständnis, wenn je-

mihi ad amicitiae fiduciam, quod me credo redamari; $($ Sy. 8,12$)$ religio $[. .$.$] magis fide animi$ metienda est quam ostentatione verborum.

483 (Sy. 8,11) in verborum officiis latet plerumque simulatio; (Sy. 4,21,4) quid [...] scripta postulas, quibus saepe male creditur? Siehe auch unten $304 \mathrm{zu}$ (Sy. 4,42,2) amor fictus.

484 (Sy. 3,17,2) quippe tacita concordia instar odiorum est.

485 (Sy. 4,28,2) ergo amicitiae nostrae fiducia non ex litteris pendeat; (Sy. 4,33,1) an interlabi amicitiae memoriam per silentium putas? cave talia de animis opinari, quorum aeterna iudicia sunt.

486 (Sy. 3,2) hoc silentium tuum difficultatibus publicae occupationis adscribo; $($ Sy. 7,117$)$ scio enim plerumque non amicitiae neglegentia sed obstrepentibus curis officia retardari. Siehe auch z.B. Sy. 1,26; 2,32 .

487 (Sy. 7,119$)[\ldots]$ petens, ut [...] causam silentii non voluntati aut desidiae meae sed occupationibus adplicetis.

488 (Sy. 3,26) Securus, ut video, scribendi ad me vices neglegis; scis enim tibi istiusmodi culpam sine talione cessuram. quotiens tibi minatus sum par silentium, si a litteris temperasses? 
mand sich anders verhält und ihm vorwirft, nicht geschrieben zu haben: „Es ist richtig, dass Du oft um Briefe von mir bittest, doch es ist nicht richtig, dass Du aufgrund meines Schweigens etwas Schlimmes vermutest. Du hast gemeint, ich hätte Dich vergessen, weil ich bis heute geschwiegen habe. Ist die Treue meiner Seele so wankend oder hast Du so wenig Qualitäten aufzuweisen, dass es für eine solche Meinung über mich Raum geben konnte? Daher hat unsere Freundschaft durch Deinen Verdacht mehr Unrecht erlitten als durch mein Schweigen. Denn es ist weniger schlimm, notgedrungen die Korrespondenz zu vernachlässigen, als freiwillig vorschnell zu urteilen « (Sy. 3,4,1); ${ }^{489}$ er erkJärt dann, was ihn vom Schreiben abgehalten hat, und schließt damit, dass er lieber eine Entschuldigung schreiben als seinen Kummer zeigen möchte ( $\$ 2 u t[\ldots]$ excusationem meam potius indicasse videar quam dolorem).

Symmachus fordert nicht ausdrücklich Antworten von seinen Adressaten, sondern er betont mittels einer >Praeteritio ‘ sein Vertrauen darauf, dass er sowieso eine Antwort erhalten werde, z.B.: "Ihr werdet dies aufgrund Eurer außerordentlichen Gewissenhaftigkeit von selbst tun, und daher ist es nicht nötig, für Briefe, die von selbst geschrieben werden, anstachelnde Aufforderungen auszusprechen “ (Sy. 2,26); "Ich darf eine Antwort nicht fordern [...], da ich denke, dass ein Mann, der den Freundschaftsbund äußerst treu bewahrt, sie mir auch ohne Aufforderung zukommen lassen muss « (Sy. 2,68). ${ }^{490}$ Eine weitere Methode der indirekten Aufforderung besteht darin, die Hoffnung auszudrücken, dass der Korrespondent seinem guten Beispiel folgen werde, z.B.: "damit Du dies als Einladung und Anregung nimmst, die Korrespondenz fortzusetzen « (Sy. 3,40); »um Dich durch das Beispiel meines Briefes zu ähnlichem Eifer anzuregen $\ll\left(\right.$ Sy. 4,25). ${ }^{491}$

Doch auch Symmachus, der üblicherweise unerschütterliche Gelassenheit demonstriert, zeigt sich in seltenen Fällen leicht ungeduldig, so dass auch er einmal gegen die Etikette verstößt, was er selbst anmerkt. Üblicherweise muss derjenige, der abgereist ist, als erster schreiben: "nach der Sitte [...], die unter Freunden Gesetz

vincor tamen adfectione et delector tali mendacio meo. ex quo intellegere potes, quam constanter te diligam, qui tam inconstanter irascor.

489 (Sy. 3,4,1) Decet, ut litteras meas frequenter efflagites, nec tamen convenit, ut de silentio grave quidpiam suspiceris. oblitum me tui, quod in hanc diem silueram, censuisti. an ita vel mei animi fides clauda est vel tui meriti angusta momenta sunt, ut huic de me opinioni locus esse debuerit? quare amicitia communis plus accepit iniuriae ex tua suspicione quam ex silentio meo. minus est enim necessitate officium deserere quam voluntate praepropera iudicare. $[\ldots]$

490 (Sy. 2,26,2) hoc pro insigni religione sponte facietis, atque ideo non est necesse voluntariis officiis aculeos exhortationis adhibere; (Sy. 2,68) vicissitudinem [...] efflagitare non debeo, quam mihi arbitror a viro amicitiae servantissimo etiam sine admonitione referendam. Siehe auch z.B. Sy. 2,$88 ; 2,89 ; 5,3 ; 7,98$.

491 (Sy. 3,40) [...] ut hoc invitamento ad perseverantiam litterarii muneris provoceris; $($ Sy. 4,25$)$ [...] ut te exemplo officii ad curam similem provocarem. 
ist, dass diejenigen, die in der Fremde sind, eher Briefe schreiben als erhalten " (Sy. 5,30). ${ }^{492}$ Dennoch schreibt Symmachus zuerst an einen verreisten Adressaten, denn: "wahre Freundschaft ist bei jeder Verzögerung ungeduldig, und sei sie noch so begründet und berechtigt « (Sy. 5,30); "Freundschaft, die keinen Aufschub aushalten kann « (Sy. 3,3). ${ }^{493}$ Allerdings erklären sich diese Verstöße gegen die Spielregeln tatsächlich damit, dass Symmachus sowohl in 3,3 als auch in 5,30 ein dringendes Anliegen hat, nämlich beide Male eine Empfehlung (vgl. unten 358); die Verstöße haben also einen Grund, der allerdings nicht in der von Symmachus explizit benannten Freundschaft besteht. In einem anderen Brief weist seine Ungeduld in der Verbindung mit querellae auf die Haltung des Ennodius voraus: "Dein Schweigen kann ich nur sehr schwer ertragen - eine gewohnte Klage unter Freunden [...].« Allerdings sind hier die ungeduldigen Erwartungen gerade schon befriedigt worden, denn Symmachus fährt fort, dass der Adressat mit dessen letztem Brief seine Sehnsucht gestillt habe (Sy. 1,82). ${ }^{494}$ Hier wie auch an anderen vergleichbaren Stellen äußert Symmachus seine Klagen erst, als der Grund dazu bereits vergangen ist (siehe unten 222).

\section{,Briefe und Freundschaft ‘ bei Ennodius}

Ennodius misst der Korrespondenz eine andere Bedeutung für die Freundschaft bei als Symmachus: Er sagt nur ausnahmsweise einmal (siehe unten $229 \mathrm{zu} 312$ an Helpidius), dass Freundschaft auch ohne Korrespondenz bestehen könne. Ansonsten lässt er nicht für Freundschaft, sondern nur für Verwandtschaft geiten, dass diese auch durch weite Entfernungen nicht beeinträchtigt werden könne, und auch dies sagt er nur in wenigen bestimmten Fällen, nämlich gegenüber weiblichen Adressaten, an die jeweils nur ein Brief überliefert ist und zu denen der Kontakt wohl nicht besonders eng war. Diese Ausnahmen $(177,285,291)$, in denen er zu Adressatinnen über die Kraft der Verwandtschaft spricht, sollen zuerst betrachtet werden; auch bei diesen wird sich zeigen, dass er die Topoi je nach Situation variiert.

Wenn er diesen Frauen gegenüber betont, dass Verwandtschaft auch durch räumliche Trennung nicht leiden könne, ohne dass er dabei irgendwie auf die Bedeutung von Korrespondenz hinweist, macht er deutlich, dass er keine regelmäßige Korrespondenz mit ihnen anstrebt. In einigen Fällen $(177,285,441)$ reagiert er auf Briefe von Frauen, die ihm als erste geschrieben haben: Einmal bedankt er sich für einen Brief von Helisea, die ihm endlich einmal geschrieben hat (allerdings aus einem sehr konkreten Grund, um nämlich für eine Bischofswahl Ennodius' Unterstützung ihres

492 (Sy. 5,30) more [...], qui solet amicis esse pro lege, ut peregre locati tribuant prius scripta quam sumant; siehe auch z.B. (Sy. 4,23,1) [...] hunc enim morem quaedam institutio vetusta constituit, ut [...]; Sy. 3,3,1.

493 (Sy. 5,30) est vera adfectio omnis inpatiens etiam iustae ac legitimae tarditatis; (Sy. 3,3,1) adfectus moris inpatiens.

$494($ Sy. 1,82) Sum quidem silentii tui vehementer inpatiens, quod genus querellae amantibus familiare est, sed proximis litteris tibi desiderium meum expletum esse confiteor [...]. 
Wunschkandidaten zu sichern, siehe unten 271). Dass Helisea ihm mit ihrem Brief einen lange gehegten Wunsch endlich erfüllt habe, zeige: "[...] Verwandtschaftliche Nähe lebt überall auf der Erde. Die Trennung der Körper kann die Kette des Blutes nicht zerreißen. Die Liebe erleidet keinen Schaden durch die räumliche Entfernung, da diejenigen, die entfernt voneinander leben, an Stelle der Anwesenheit die Zuneigung haben. Ich danke dem allmächtigen Gott, dass er Euch die Liebe nicht vergessen ließ und dass er Euch bei dieser frommen Gelegenheit an Eure Herkunft denken ließ [...] « $(177,1$ f. $) .{ }^{495}$ - Dieser Gedanke wird auch im bereits besprochenen Brief an Apodemia ausgeführt (441, siehe oben 200), ebenso im Brief an Domnica (285), die wohl ihrem Schwiegersohn auf eine Reise nach Ligurien Grüße oder einen Begleitbrief an Ennodius mitgegeben hat (vgl. \$2): "Verwandtschaft ist überall auf der Welt lebendig, und es lassen sich diejenigen, die durch das Band der Verwandtschaft verbunden sind, nicht durch räumliche Entfernung trennen. Glaubt mir, heilige Liebe vergeht nicht, und die Natur lässt sich durch räumliche Trennung keinen Schaden zufügen « $(285,1) .{ }^{496}$ Mit diesen drei Briefen an Frauen, in denen Ennodius die Macht der verwandtschaftlichen Bande beteuert, reagiert er auf Briefe von ihnen; mit seinen Bestätigungen, wie groß die Macht von Verwandtschaft sei, entlastet er sich selbst, da er zuvor nicht geschrieben hat und wohl auch nicht beabsichtigt, in der Folge häufig zu schreiben.

In einem anderen Fall, wo er selbst zuerst an Archotamia schreibt (291), um den Briefboten zu empfehlen, stellt er die Sache etwas anders dar: "Obwohl das Recht der Zuneigung, das vom Recht der Verwandtschaft gefestigt wird, durch weite Entfernung nicht vergeht und die Kette der Herkunft, die die Seelen verbindet, durch räumliche Trennung nicht zerteilt werden kann, ist es dennoch Nahrung für die Liebe, denjenigen, den man mag, entweder zu sehen oder ihn anzusprechen. Wenn die Zungen nichts verrieten, bliebe unbekannt, was in den Seelen verborgen ist. Dieses $<$ sc. das Briefeschreiben $>$ hat die alte Zeit ins Leben gerufen, damit das, was in den Herzen verborgen ist, nicht verborgen bleibt. - Wenn ich auch Gallien, das mich Euretwegen ganz für sich beansprucht, nicht mit Augen sehen kann, so verlässt es doch meine Zuneigung nicht« $(291,1) .{ }^{497}$ Hier nimmt Ennodius selbst die Korrespondenz

495 (177,1f.) [...] vivit in quacumque terrarum parte proximitas; sequestratione corporum sanguinis catena non rumpitur; per discreta regionum caritas damna non sentit, quando inter eos qui habitatione separantur praesentiae vice tenetur affectio. $(\$ 2)$ deo omnipotenti gratias refero, quia vos memores fecit esse pietatis et prosapiae sub religiosa occasione reminisci.

$496(285,1)[\ldots]$ in quacumque terrarum parte vivit adfinitas, nec separantur regionibus parentellae catena sociati. credite mihi, dilectio sancta non deperit nec ullum patitur per divisiones itinerum natura dispendium.

497 (291,1) Quamvis ius affectionis consanguinitatis lege constrictum regionum prolixitate non pereat nec catena generis, quae animas nectit, terrarum separatione dividatur, attamen pabulum caritatis est aut videre aut officio sermonis appellare quem diligas. nescirentur secre- 
auf und begründet zunächst, warum trotz des ohnehin sicher bestehenden Bandes der Verwandtschaft ein Brief nötig sein kann. Dass er die Bedeutung von Briefen hier anders beurteilt als in den Briefen an Apodemia, Helisea und Domnica, erklärt sich damit, dass er in einer anderen Situation schreibt, nämlich die Korrespondenz mit Archotamia selbst eröffnet, um ihr jemanden zu empfehlen. Das Phänomen, dass er hier einen Empfehlungsbrief so einleitet, als schriebe er nur um des Schreibens und um der Verbundenheit willen, wird bei der Behandlung der Empfehlungsschreiben häufiger zu beobachten sein.

Außer diesen Briefen an Frauen, in denen Ennodius die Macht der Verwandtschaft betont, macht er fast immer unmissverständlich deutlich, dass für ihn aus dem foedus der Freundschaft (die häufig mit Verwandtschaft zusammengeht) die Verpflichtung zur Korrespondenz hervorgeht, denn das Schreiben zeige die Freundschaft, z.B.: "denn durch das Zeugnis der Zungen wird eröffnet, was in den Seelen verborgen ist « $\left(152,1\right.$; weitere Beispiele oben 202) ${ }^{498}$ Explizit gilt für Ennodius auch der bei Symmachus nur ausnahmsweise (3,17, siehe oben 215$)$ zu lesende Umkehrschluss, dass, wer nicht schreibe, die Schwäche oder gar das Fehlen der Freundschaft zeige, z.B.: "Durch den Verzicht auf das Schreiben wird die Kraft der Freundschaft unterbrochen « $(16,1)$; "Es sieht aus wie Abneigung, wenn man nicht mit Worten darlegt und bezeugt, dass man liebt “ $(30,1)$; "Die Freundschaft der Herzen bliebe unbekannt, wenn nicht die Sprache sie deutlich zeigen würde" $(149,1) .{ }^{499}$ Typisch ist etwa folgender Brief an Agnellus (zur Person siehe unten 337), in dem Ennodius deutlich macht, dass Schweigsamkeit auf das Fehlen von Freundschaft schließen lasse (316): "Es bereitet mir Unbehagen, dass Euer Überfluss mir von den Gaben seiner Rede nichts zuteilt und den Reichtum seiner Redekunst so sehr hütet, dass diesen zu teilen für Frevel gehalten wird. Zwar ist Geiz in jeder Hinsicht schändlich: doch er ist noch schändlicher, wenn man Worte verweigert. Es kommt <zwar> sogar oft vor, dass die, die häufig schreiben, wenig Freundschaft empfinden; doch es kommt niemals vor, dass einer etwas Freundschaft bewahrt, der in dauerndem Schweigen verharrt. Schmeicheleien in Briefen können zu falschen Schlüssen verleiten; <doch > man kann sich sicher sein, dass man von einem, der schweigt, nicht geliebt wird [...]« $(\$ 1) .{ }^{500}$

ta mentium nisi proditione linguarum. haec in usu vocavit antiquitas, ut illa, quae pectoribus clausa sunt, non laterent. - (\$2) ego Gallias, quae totum me propter vos sibi vindicant, si oculis non inspicio, affectione non desero.

$498(152,1)$ linguae enim indicio animorum secreta panduntur.

$499(16,1)[\ldots]$ per paginarum abstinentiam intercipitur vis amoris; $(30,1)$ odiorum simulacrum est non aperire quod diligas contestatione sermonis; $(149,1)$ nesciretur amor pectorum, nisi illum sermo proditor indicaret.

$500(316,1)$ Male est animo meo, quod de facundiae suae dotibus mihi abundantia vestra nil tribuit et ita eloquentiae opibus incubat, ut partem ex eis facere sacrilegium computetur. turpis est equidem universarum rerum avaritia: contigit tamen, si verba deneges, plus pudenda. saepe etiam evenit, ut frequenter scribentes minus diligant; numquam tamen accessit, ut 
Entsprechend erkennt Ennodius anderweitige Beschäftigung ausdrücklich nicht als Entschuldigungsgrund für Schweigen an - allerdings bringt er seine eigene occupatio gegenüber Florianus als den Grund für sein Schweigen an, den dieser auf jeden Fall respektieren müsse (siehe oben 186,188 ). Wenn er vermutet, dass ein Korrespondent diese Entschuldigung vorbringen werde, weist er darauf hin, dass dieser auch früher sehr beschäftigt gewesen sei und trotzdem geschrieben habe, z.B.: »Doch vielleicht möchtet Ihr, Erhabener, andeuten, dass Ihr nicht zum Schreiben kommt, weil Ihr mehr und mehr zu tun habt und dadurch davon abgehalten werdet. $<$ Doch $>$ ich werde antworten, dass Ihr lange in der gleichen erhabenen Situation wart und $<$ dennoch> Briefe sandtet « $(29,2) .^{501}$ - Auch in einem Brief an Senarius (171; zu ihm unten 290), dessen Zweck die am Ende vorgebrachte Empfehlung ist, wird die Inanspruchnahme durch Tätigkeiten bei Hofe als mögliche Entschuldigung für Schweigen ausdrücklich abgewiesen: »[...] Doch ich glaube, Du stellst meinen Klagen Eure spezielle Stellung, die sich für Entschuldigungen eignet, entgegen: Dass man nicht mit Recht von Beschäftigten die Gaben der Müßigen fordern könne und dass man, wenn man am Hofe in Diensten stehe, zu so etwas kaum kommen könne. Ich habe solches zwar oft gehört, aber offengestanden nicht akzeptiert; denn oft können Wünsche erschwerende Umstände überwinden, und dauernd weicht <sogar> die Furcht vor der Liebe. Schuldig ist der Wille, der mit einer kunstvollen Entschuldigung verteidigt werden muss « $(171,3) .{ }^{502} \mathrm{Vgl}$. auch die witzige Wendung in 122 (unten 368 ).

Ennodius fühlt sich missachtet, wenn ein Freund nicht schreibt, z.B.: "Schweigsamkeit zeigt nichts als Geringschätzung, sooft sie nicht unvermeidlich ist « $(17,2)$; "[...] die Geringschätzung mir gegenüber, die durch das Ausbleiben der ehrenvollen Briefe deutlich wurde [...] « $(35,1)$; »denn wir glaubten, dass sie <sc. Adressatin, von der hier in der dritten Person gesprochen wird > lebendig begraben sei, weil sie uns nicht beachtete « $(52,2)$; "Doch es ist so, dass Deine Hoheit in Verachtung meiner Person mit Schweigen statt mit Schreiben antwortet « $(304,1)$; » mit bisher ungekanntem Hochmut verachtest Du mich; [...] Du missachtest Deine alten Freunde« $(468,2) .{ }^{503}$

aliquid caritati reservet qui in perpetua taciturnitate perdurat. potest nasci de epistolaribus blandimentis ambiguitas: certa fides est ab eo, qui servat silentium, non amari.

$501(29,2)$ per occupationum forsitan amplitudo vestra praepedientium incrementa significet ad haec vos officia non venire. replicabo, quia idem status fuit culminis vestri dudum paginas destinantis. (Ebenso in 255,2).

502 (171,3) sed, credo, querellis meis illud ordinis vestri aptum excusationibus genus opponas: non recte $a b$ occupatis otiosorum munia postulari, vix ad haec officia posse descendere obsequiis principalibus adhaerentes. audivi quidem saepe talia, sed confiteor non recepi, quia frequenter necessitates desideria transcendunt et sine intermissione timor cedit affectui. voluntas in culpa est, quae concinnata excusatione defenditur.

$503(17,2)$ nihil praeter contemptum monstrat, quotiens taciturnitas non habet necessitatem (cf. 40,1 [...] maxime cum sit dicendi, ut Tullius refert, nisi cum necessaria nimis inepta condicio, und Cic. de orat. 1,112 nam quid est ineptius quam de dicendo dicere, cum ipsum dicere 
Auch das bei Symmachus zu beobachtende Vorgehen (siehe oben 216), in einer ,Praeteritio a ausdrücklich auf eine Aufforderung zu verzichten und sie damit indirekt umso deutlicher zu formulieren, nutzt Ennodius nicht. Er formuliert seine Hoffnung auf eine Antwort direkt, z.B.: »ein gesandter Brief verspricht eine Antwort " $(32,1)$; "Zwar habe ich zuerst auf einen Brief von Euch gewartet, doch ich wollte mich nicht, indem ich lange schweige, selbst um eine Antwort bringen « $(38,2) .{ }^{504}$ Ennodius bittet und fordert ohne Umschweife, z.B.: "beehre Deinen Freund mit häufigen Briefen « $(4,7)$; »ich bitte, dass Ihr [...] mir schnell zu Hilfe eilt mit der Wohltat eines Briefes, der mir Fröhlichkeit bringt « $(28,2)$; "Schick mir einen Brief zur Erinnerung an die versprochene Treue « $(30,2)$; "muntert Euren Freund durch Schreiben auf « $(61,3) .505$ Dass aber Ennodius' Briefpartner die von Symmachus praktizierte sindirekter Methode der Bitte um Briefe kennen und erwarten und sich daher über die Direktheit des Ennodius wundern, geht aus einer Antwort an Avienus hervor (111, siehe unten 288).

Ungeduld, wie sie Symmachus nur selten einmal aufkommen lässt, ist für Ennodius selbstverständlich, und er erwähnt seine offenkundige und die Mehrzahl der Briefe bestimmende inpatientia nur selten explizit. Wenn Ennodius schreibt, ohne an der Reihe zu sein, d.h. ohne zuvor einen Brief bzw. eine Antwort erhalten zu haben, spricht er nicht von seiner (in-) patientia, sondern er hebt das Problem auf eine 'moralische، Ebene, indem er durch das vorschnelle Schreiben seinen pudor (im Sinne: ,Anstand ‘, , richtiges Verhalten`) bedroht sieht: "Wenn du fragst, warum ich nach Eurem strafenden Schweigen meinen Anstand aufgebe statt zu schweigen, und wenn - bei falscher Deutung - Freundschaft Schamlosigkeit genannt wird und wenn du sagst, dass meine Geschwätzigkeit bei ausbleibendem Erfolg hätte gezähmt werden müssen [...] « $(17,1)$; »Die Sehnsucht nach einem Brief von Euch lässt mich mein gutes Benehmen aufgeben $[\ldots]$ « $(32,1) .{ }^{506}$

numquam sit non ineptum, nisi cum est necessarium?). - (35,1) contemptus circa me, qui per abstinentiam venerandi sermonis innotuit $[. ..] ;(52,2)[\ldots]$ quam credebamus per contemptum nostri viventem busta conplesse; $(304,1)$ sed magnitudinem tuam in contemptu mei contigit silentium pro scriptione redhibere $[\ldots] ;(468,2)$ ignorato hactenus tumore me despicis; $[\ldots]$ amicos veteres $[\ldots]$ contemnis.

$504(32,1)$ tabella promittit promulgata responsum (ähnlich 73$) ;(38,2)$ expectans quidem a vobis praevium munus in litteris, sed non volui mihi ipse, dum diu taceo, negare responsum $[\ldots]$.

$505(4,7)$ amantem tui frequentibus cole muniis litterarum (ebenso 23,6; ähnlich 40,6 u.ö.); $(28,2)$ precor, ut $[\ldots]$ sedulo mihi hilaritatem deferentium litterarum beneficio succurratis; $(30,2)$ ad memoriam promissae fidei scripta transmitte; $(61,3)$ amantem vestri stili usu relevate (häufig ähnlich).

$506(17,1)$ Si quaeras, cur silentio vestro multata non reticet prodiga frons pudoris, et male interpretando inpudentia vocetur affectio, si garrulitatem meam fructu dicas cessante debuisse conpesci $[\ldots] ;(32,1)$ Desiderio paginarum vestrarum facta est mihi prodiga frons pudoris $[\ldots]$. 


\section{Ärger verschweigen - beneficium querellarum}

Ein wichtiger Zug der indulgentia des Symmachus ist, dass er, wenn er sich über einen Adressaten ärgert, dies verschweigt bzw. dass er überhaupt schweigt, wenn er sich ärgert (vgl. die bereits oben 214 herangezogene Stelle: irasci me putas? hoc si fieri posset, tacerem, Sy. 3,18), da es der Konvention widersprach, Ärger oder Gekränktheit zu zeigen. Auch Ennodius kennt diese Konvention: »[...] vielleicht würde stumme Verstellung meinen Kummer über Eure Enthaltsamheit im Schreiben besser ausdrücken " (455,1; siehe dazu unten 335). ${ }^{507}$ Üblicherweise spricht Symmachus von seinem eventuellen dolor über das Ausbleiben von Briefen erst dann, wenn dieser dank einem erhaltenen Brief schon wieder vergangen ist: "Sobald ich Deinen Brief erhalten hatte, erfüllte Freude meine Seele, und die Klage verschwand « (Sy. 1,91); »Ich ärgerte mich über Dein Schweigen...; die Freude <sc. über den erhaltenen Brief> war stärker als die Kränkung, und es ist dahin gekommen, dass ich dem danke, den ich freundlich tadeln wollte $\left(\right.$ Sy. 3,81); ${ }^{508}$ (siehe auch oben 217 zu Sy. 1,82, unten $250 \mathrm{zu}$ Sy. 4,65, unten 237 zu Sy. 6,69).

Nur ausnahmsweise verstößt Symmachus einmal gegen die in epist. 3,18 erwähnte Konvention, bei Ärger zu schweigen, als er gegenüber Ausonius seinen Ärger offen ausspricht (Sy. 1,34; vgl. auch unten 331 zu Sy. 1,16,2, ebenfalls an Ausonius). Dieser Symmachus-Brief ist in verschiedener Hinsicht für die Betrachtung der Briefe des Ennodius wichtig, da Ennodius die Gedanken teils aufnimmt, teils sich davon absetzt. Symmachus betont, dass er aus Freundschaft immer wieder schreibe, wobei seine Klage über Ausonius' Schreibfaulheit für seine Verhältnisse ungewohnt heftig ausfällt: "Ich widme mich einer mühevollen Aufgabe, wenn ich fortfahre, Dich Schweigsamen so oft anzusprechen. Wenn ich jedoch nicht fortfahre, Dich anzutreiben und Dir irgendetwas Schriftliches abzuringen, wächst das Vergessen. [...] Daher klage ich über Dein Schweigen. Denn die enge Freundschaft bewirkt, dass man zum Klagen neigt. Die Seele eines Freundes ist weich und zeigt jedes schmerzliche Gefühl deutlich: Wenn man sie nachlässig behandelt, welkt sie schnell wie eine Rose; wenn man sie hart anfasst, verfärbt sie sich wie Lilien. Ich erinnere mich, gelesen zu haben, dass die pietas oft schon durch einen Blick verletzt werde. Wie hätte jener so strenge Richter über das beständige Schweigen und die Nachlässigkeit im Schreiben geurteilt? Du wirst bei Dir selbst gründlicher darüber nachdenken, ich aber hatte Bedenken, meinen Kummer zu verbergen. [...]« (Sy. 1,34)..$^{509}$ Dies ist, wie gesagt, ein für Symma-

$507(455,1)[\ldots]$ forte melius maerorem de abstinentia sermonis vestri loqueretur muta dissimulatio.

508 (Sy. 1,91) simul atque accepi litteras tuas, animum subiit laetitia, querella deseruit; (Sy. $3,81,1)$ Suscensebam silentio tuo [...]; vicit offensionem voluptas, et in eam condicionem res rediit, ut ei agam gratias, quem pie obiurgare meditabar.

509 (Sy. 1,34,1f.) Plenum laboris negotium gero, qui conpellare totiens tacitum persevero. contra nisi instigare pergo atque exculpere a te aliquid litterarum, gliscet oblivio. [...] propterea silentium tuum conqueror. (\$2) facit enim tenerior adfectio, ut sit querella proclivior. mollis 
chus äußerst untypischer Brief, und es ist wohl kein Zufall, dass er offenbar an einer späteren Stelle diesen Brief am liebsten dem Vergessen übergeben möchte; er führt die gezeigte Reizbarkeit auf die Stärke seiner Freundschaft zurück: »Denk bitte nicht mehr daran, dass ich Dir einmal gezürnt habe. Freundschaft nährt das Selbstvertrauen. Was ist so frei wie die Freundschaft? Schwache Treue zeigen diejenigen, die immer schmeicheln " (Sy. 1,37,2). An einer weiteren Stelle äußert er sich ähnlich: "Denn niemand pflegt eine Freundschaft leidenschaftlicher als der, der sich über die Nachlässigkeit <sc. des Freundes> ärgert « (Sy. 4,21,2).${ }^{510}$ Noch heftiger formuliert Hieronymus diesen Gedanken: „Gekränkte Freundschaft muss zornig werden; da Du meine Bitten ignoriert hast, hörst Du vielleicht auf meine Vorwürfe (Hier. 14,2). ${ }^{511}$

Zwar weiß auch Ennodius von der Möglichkeit der »stummen Verstellung “ (455,1 muta dissimulatio, siehe unten 335), doch er scheint sich den Satz des häufiger gereizten Hieronymus oder einen vergleichbaren des Symmachus wie: facit enim tenerior adfectio, ut sit querella proclivior (Sy. 1,34), der bei diesem in einem nur ausnahmsweise unnachsichtigen Brief steht, zu einem seiner Prinzipien gemacht zu haben, um seine Klagen nie zurückhalten zu müssen. Zuweilen spricht Ennodius auch aus, warum er so gereizt ist, z.B. gegenüber seiner Schwester Euprepia (52): Nach langen Vorwürfen, weil sie erst nach sehr langer Zeit wieder geschrieben habe, äußert er die Sorge, wie sie wohl darauf reagieren werde: »doch diese Vorwürfe sind <nur dann> bitter, wenn man sie für sich sieht - wenn man allerdings nach dem Grund dafür sucht, sind sie mit allem süßen Honig gezuckert. Wer das Schweigen eines Verwandten offen anklagt, der ärgert sich über die Nachlässigkeit in der Liebe« $(\$ 5) .{ }^{512}$

est animus diligentis et ad omnem sensum doloris argutus. si neglegentius tractes, cito marcet ut rosa; si durius teras, livet ut lilia. legisse me memini, "vultu saepe laedi pietatem "<cf. Cic. S. Rosc. 37>. quid ille tam serius arbiter super continuo silentio ac dissimulato scribendi munere censuisset? tecum haec pensius aestimabis, sed mihi religio fuit tegere, quae dolebant. [...]

510 (Sy. 1,37,2) nolo memineris, quod animo tuo aliquando suscensui. amor fiduciam nutrit. quid tam liberum quam amicitia? [...] quassa fide sunt, qui iugiter blandiuntur; $($ Sy. 4,21,2) nam nemo flagrantius amicitiam colit, quam qui irascitur neglegentiae.

511 (Hier. 14,2,1) debet amor laesus irasci; qui rogantem contempseras, forsitan audies obiurgantem. - Cf. dazu auch Plinius, der nur ein einziges Mal eine solche Klage äußert: (Plin. 2,2,1) Irascor, nec liquet mihi, an debeam, sed irascor. scis, quam sit amor iniquus interdum,

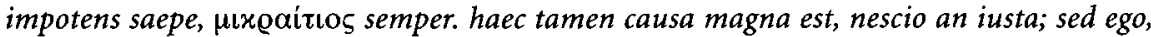
tamquam non minus iusta quam magna sit, graviter irascor, quod a te tam diu litterae nullae [...]. Einmal ist Plinius selbst vorgeworfen worden, dass er nicht geschrieben habe, und er ist froh über den - jedenfalls seiner Meinung nach - unberechtigten Vorwurf: (Plin. 6,12,5) Proinde etiam atque etiam rogo, ut mihi semper eadem simplicitate, quotiens cessare videbor (videbor dico, numquam enim cessabo), convicium facias, quod et ego intellegam a summo amore proficisci et tu non meruisse me gaudeas.

$512(52,5)$ sed exprobratio ista, si per se respiciatur, aspera est, si origo eius inquiratur, omni dulcedinis melle condita. graviter fert circa caritatem neglegentiam, qui parentis silentium liber accusat. 
Auch im Brief an Probinus betont er den Zusammenhang zwischen Freundschaft und Klagen: »Durch die Macht der Freundschaft habe ich mich zu Klagen hinreiBen lassen « (426,2 ad querellam descendi caritatis imperio, zu diesem Empfehlungsschreiben siehe unten 367). Gegenüber Johannes betont er, dass es besser sei, seinen Ärger auszusprechen als ihn zu verschweigen (siehe unten 251). In Briefen an andere Adressaten setzt er die Kenntnis des Zusammenhangs zwischen Freundschaft und Klagen offenbar voraus, denn er beklagt sich häufig, ohne diese entschuldigende Begründung anzubringen.

Ennodius betrachtet querellae als ein erfolgversprechendes und brauchbares Mittel, um seine Adressaten zum Schreiben zu bringen; der erste der überlieferten Briefe an Faustus (6), mit dem er auf einen lange erwarteten Brief von diesem antwortet, beginnt: "Der Prozess meiner Sehnsucht ist dank meiner Klagen abgeschlossen. Schamlosigkeit hat erreicht, was feines Benehmen nicht erreichen konnte " $(\$ 1$ acta est causa desiderii mei beneficio querellarum; meruit inpudentia quod negabat urbanitas). Innerhalb dieses Briefes apostrophiert Ennodius seine Klagen, mit denen er Faustus zum Schreiben bewegt habe: »Ich schulde euch Freundschaft, meine Klagen; ich werde euch sehr lieben, da ihr meinen Wünschen zum Erfolg verhelft. Mag auch euer Ursprung von begründetem Schmerz herrühren, ich werde, nachdem ihr dies geleistet habt, häufig auch ohne vorausgehende Kränkung mit euch beginnen « $(\$ 3) .{ }^{513}$ Diese Androhung, von nun an auch unbegründet Klagen vorzubringen, macht Ennodius in vielen Fällen und gegenüber vielen Adressaten wahr.

\section{inpudentia - inportunitas}

In dem eben zitierten ersten Satz an Faustus fallen zwei weitere wichtige Begriffe: inpudentia, mit der Ennodius sein Ziel erreicht habe, und urbanitas, mit der ihm dies zuvor nicht gelungen sei. Von seiner inpudentia oder inportunitas ("Dreistigkeit«, »Frechheit«) spricht Ennodius häufig; im Verlauf des ersten Briefs an Faustus erläutert er den eingangs verwendeten Begriff inpudentia: "Mit einer solchen Tat bin ich den Worten der Evangelien gefolgt und war erfolgreich aufgrund der Wahrheit der Lehre, die lehrt und zeigt, dass Gott für den Anklopfenden oft aufsteht und ihm < die Erfüllung seiner Wünsche> gewährt, wenn auch nicht wegen seiner Verdienste, so doch wegen seiner Dreistigkeit. [...] Durch häufige Bitten habe ich das Gewünschte erlangt. Der Stetigkeit der Bitten wurde gewährt, was ihrer Prüfung verweigert wurde $<$ d.h. die Bitten wurden erfüllt, weil sie häufig vorgebracht wurden, nicht, weil sie als berechtigt beurteilt wurden>« $(\$ 2) .{ }^{514}$ Ennodius bezieht sich damit auf das im Lukas-

$513(6,3)$ debeo vobis amicitiam, querimoniae meae, quas, dum votis effectum tribuitis, plus amabo. fuerit licet origo vestra a iusto dolore veniens, frequenter a vobis, postquam praestitistis, etiam inlaesus incipiam.

$514(6,2)$ evangelicis tali facto obsecutus oraculis fructum de praecepti sum veritate sortitus, cuius declarat instructio, quod pulsanti saepe surgat et tribuat deus, si non propter meritum, 
Evangelium (Lk 11,5-8) im Zusammenhang mit der Frage des richtigen Betens überlieferte Gleichnis über den Freund, der mitten in der Nacht anklopft und um Brot für einen unerwartet eingetroffenen Freund bittet: et si non dabit illi surgens eo quod amicus eius sit / propter inprobitatem tamen eius surget et dabit illi [...]. (Die Parallelisierung einer Handlung Gottes mit der eines Menschen ist in spätantiken Texten nichts Ungewöhnliches; so bezieht z.B. Paulinus von Nola die Worte des Psalmisten (iuxta LXX 118,103): quam dulcia faucibus meis eloquia tua super mel ori meo auf einen Brief von Sulpicius Severus.)

Mit einer Anspielung auf die Stelle bei Lukas endet z.B. auch der vorwurfsvolle Brief an Olybrius und Eugenes (32): "Lebt also wohl, meine Herren, und kehrt zum einträchtigen Briefwechsel mit mir zurück, damit Ihr nicht gegen die Ermahnungen des Evangeliums handelt, wenn Ihr auch der Frechheit verweigert, was die Freundschaft vielleicht mit Recht erbeten hätte $(\$ 2) .{ }^{515}$ - An anderen Stellen spricht Ennodius ohne den Hinweis auf die zugrundeliegende Bibelstelle nur davon, dass er dank seiner inportunitas erhalten möchte, was ihm der amor des Adressaten sonst nicht gewähre: »Ich bitte, dass nun immerhin meine Dreistigkeit die Schuld der Freundschaft einfordern kann « $(304,2){ }^{516}$ (Siehe auch: 17,6 an Avienus; 29,2).

Ohne Bezugnahme auf die Stelle bei Lukas sprechen auch Hieronymus und Sidonius Apollinaris von inpudentia in der Korrespondenz: "Endlich [...] habe ich einen Brief erhalten [...], und ich schäme mich nicht meiner Dreistigkeit, dass ich Euch häufig Briefe aufgedrängt habe, obwohl ihr schwiegt « (Hier. 126,1). ${ }^{517}$ Sidonius Apollinaris äußert seine Sorge, es könne ihm als Geschwätzigkeit und unfeines Verhalten ausgelegt werden, dass er dem Adressaten zuerst schreibe, um mit ihm in Kontakt zu kommen: »Entschuldige also bitte, dass ich zuerst schreibe; denn ebenso wie es Trägheit gewesen wäre, nicht zu schreiben, fürchte ich, dass das Schreiben Geschwätzigkeit sein könnte. Doch mein Schreiben wird den Makel der Geschwätzigkeit verlieren, wenn Du durch einen Antwortbrief dieses Schreiben von Unverschämtheit freisprichst« (Sidon. 3,11,2). ${ }^{518}$ - Während also andere Epistolographen nur aus-

vel propter inportunitatem. [...] frequenti oratione optata promerui, concessum est precum adsiduitati quod negabatur examini.

$515(32,2)$ valete ergo, mi domini, et ad scriptionis mecum remeate concordiam, ne contra evangelii faciatis monita, si et inportunitati denegetis quod iuste forsitan inpetrasset affectio. Siehe auch: $(295,1)$ [...] ut quod amor non exigit, iuxta evangelicam lectionem mereatur inportunitas, siehe dazu unten 264.

$516(304,2)$ quaeso, ut debitum gratiae vel nunc exigat inportunitas.

517 (Hier. 126,1) tandem [...] litteras [...] accepi et non paenitet inpudentiae, qua tacentibus vobis epistulas meas frequenter ingessi.

518 (Sidon. 3,11,2) igitur dona venia litteras primas, quas ut necdum mittere desidia fuerat, ita vereor ne sit misisse garrulitas. carebit sane nostrum naevo loquacitatis officium, si exemplo recursantis alloquii impudentiam paginae praesentis absolveris. 
nahmsweise mit inpudentia handeln bzw. diese vermeiden wollen, macht Ennodius sie explizit zu einem der Charakteristika seiner Briefe.

\section{urbanitas - sinceritas}

Auch an anderen Stellen distanziert sich Ennodius ausdrücklich vom Gegenteil der häufig erfolgreichen inpudentia oder inportunitas, von der urbanitas ("feines Benehmen "), die gegenüber Faustus versagt habe (siehe oben 224). Ennodius' Verwendung der Wörter urbanus und urbanitas ist ungewöhnlich, ${ }^{519}$ denn es ist für ihn das "feine Benehmen « in malam partem, d.h. das nicht natürliche, nicht aufrichtige Benehmen, im Gegensatz zu simplicitas (»Einfachheit, Schlichtheit«) und sinceritas (»Aufrichtigkeit «): »unter Freunden lehnen wir urbanitas ab wie Gift « $(172,3$ urbanitatem inter caros ut venena respuimus). urbanitas zeigt sich für Ennodius an der Fähigkeit zur Verstellung (dissimulatio, fucatio), siehe z.B.: »Du weißt, dass meine Seele keine Maskierung kennt und sich das unter Freunden verachtenswerte sfeine Benehmen « nicht zu eigen machen kann « $(268,4)$; "urbanitas brauchen diejenigen, die täuschen wollen “ $(363,2) .{ }^{520}$ Verstellung und Täuschung wäre es etwa, seinen Ärger zu verschweigen bzw. zu überspielen - also eine der Konventionen, an die Symmachus sich hält (siehe oben 222). Täuschung hält Ennodius für eine Methode der 'Welt ‘: "Die Welt mag ihre eigene Schlauheit haben und - wofür sie zu verdammen ist - schlaues Täuschen urbanitas nennen « (312,2; zum ganzen Brief unten 229); ${ }^{521}$ Ennodius betont, dass ein solches Verhalten für ihn nicht in Frage komme.

Symmachus bezeichnet es als elegans commentum $(6,69$, siehe unten 238$)$, als sich ein Korrespondent für längeres Schweigen entschuldigt, weil er traurige Nachrichten verheimlichen wollte, bis sich die Lage gebessert hatte. Er verwendet das Wort urbanitas gar nicht, und urbanus nur im konkreten Sinne von "mit der Stadt (Rom) verbunden, in der Stadt, städtisch«, z.B. negotia urbana, urbanae laetitiae, curae urbanae, quies urbana (cf. die Konkordanz von V. Lomanto, Hildesheim 1983).

Sidonius Apollinaris erwähnt einmal in lobender Weise die urbanitas eines Adressaten: Er bedankt sich für einen Brief, der sich durch dreifachen Glanz auszeichne; die erste Qualität sei caritas, die zweite verecundia, "aufgrund derer Du Dir, indem Du zu Unrecht nervös bist, zu Recht Lob erwirbst « (zu Ennodius’ Haltung zu diesem

519 Zum gewohnten Gebrauch von urbanus im meist übertragenen Sinne von festivus, lepidus (cf. OLD: "elegant and sophisticated, polished, smart", "polished or elegant in style", »elegantly amusing, witty, smart«) siehe: E. S. RAmAGE, Urbanitas. Ancient Sophistication and Refinement, Oklahoma 1973. R. VAlenti, Per un'analisi semantica di urbanitas in Cicerone, BStudLat 6, 1976, 54-61. A. BARBieri, Praeco-poeta, sal e urbanitas, RCCM 29, 1987, 111-150.

$520(268,4)$ animus meus quia fuci sit nescius cognovisti nec detestabilem inter amantes urbanitatem possit adsumere; $(363,2)$ fallentes decet urbanitas etc.

$521(312,2)$ habeat suas mundus astutias et urbanitatem fallendi prudentiam damnandus appellet. 
Topos , formidinem simulare (vgl. oben 187), die dritte urbanitas, "die sich daran zeigt, dass $\mathrm{Du}$ in feinster Weise behauptet hast, unbeholfen zu sein, wo Du doch aus der Quelle der römischen Beredsamkeit getrunken hast $[\ldots]$ « $(4,17,1) .{ }^{522}$ Dieses hier auf urbanitas zurückgeführte Verhalten, seine Fähigkeiten herunterzuspielen, »die geistreiche Gewandtheit, welche hier die eigene Bescheidenheit herausstreicht und die eigene Leistung verachtet, obwohl sie es eigentlich verdienen würde, anerkannt zu werden « (NäF 1995, 143 z. St.), also der >Bescheidenheits-` oder ,Unfähigkeitstopos`, gilt als ein wichtiges Merkmal des spätantiken gallischen »esprit précieuX « (LOYEN 1943, 99). Wenn also z.B. Ruricius von Limoges mehrfach von seiner angeblichen sprachlichen ineptia (z.B. 1,12,3; 1,4,2; 1,9,1) bzw. rusticitas (z.B. 1,3,2; 1,4,2) spricht, beweist er damit - paradoxerweise - seine urbanitas, die ihn sein Licht so unter den Scheffel stellen lässt. urbanitas und rusticitas meinen also nicht Gegensätze auf gleicher Ebene, sondern: Es gilt als urbanum, von der eigenen rusticitas zu sprechen; urbanitas ist die Haltung, die zur Verwendung bestimmter Topoi führt, wohingegen die (angebliche) rusticitas das sprachlich-stilistische Unvermögen meint. ${ }^{523}$ (Ennodius' Bemerkungen über seine eigenen sprachlichen Fähigkeiten sind weiter unten zu betrachten, siehe 231.)

Wenn Ennodius diese urbanitas (»feine Verstellung «) häufig explizit ablehnt, hingegen sinceritas ("Aufrichtigkeit«) und simplicitas (»Einfachheit, Schlichtheit«) fordert, so ist wichtig zu beachten, dass er auch simplicitas auf die Haltung des Verfassers, die bestimmte Inhalte bedingt, bezieht und keineswegs auf das Niveau von Sprache und Stil. Mit sinceritas wie mit simplicitas meint er keineswegs das Gleiche wie rusticitas, sondern das Gegenteil der urbanitas, nämlich seinfaches, nicht-künstliches, unverstelltes Verhalten', siehe z.B. $(455,4)$ : [...] Italica simplicitate, unde tristitiam habuerim, sine dissimulatione manifesto (siehe zu dem Brief unten 337) - und diese sinceritas / simplicitas kann durchaus in kunstvoller Sprache präsentiert werden. Dies ist in der Forschung bisher nicht erkannt worden, so dass man annahm, Ennodius fordere von seinen Korrespondenten Einfachheit im Stil (was rusticitas wäre), vgl. z.B.: "Il y avait quelque paradoxe, en effet, à célébrer la simplicité de l'expression dans une langue aussi recherchée“ (Groanni 2001, 168).

Ennodius legt seine Einstellung in einem Brief an Agnellus (309; zur Person siehe unten 337) dar, der abgereist ist, ohne sich zu verabschieden; er sagt einleitend ausdrücklich, dass er die "feine" Verstellung (dissimulatio urbana) ablehne, ihr die Schlichtheit (simplicitas) vorziehe und daher lieber seinen Kummer deutlich ausspreche: "Briefe dienen sonst der Freundschaft, doch nun drängt der Kummer dazu, um sich kundzutun, und er bringt die Diener der Freude dazu, das Unrecht auszu-

522 (Sidon. 4,17,1) [...] cuius instinctu dum inmerito trepidas, merito praedicaris; tertia urbanitas, qua te ineptire facetissime allegas et Quirinalis impletus fonte facundiae [...].

523 Rusticitas in diesem Sinne auch bei Ennodius, z.B. in einem Brief an Avienus' Bruder Messala, siehe unten 286. 
sprechen und offenbar zu machen; er hat die innersten Gedanken weder mit Schweigen bedeckt noch mit irgendeiner Schmeichelei überspielt, so als gefiele ihnen die Maske der feinen Verstellung. Ich kenne zwar das Gekünstelte, doch ich hüte mich davor; mir gefällt die Schlichtheit und ich treffe meine Freunde mit ungetrübt heiterer Haltung der Seele $(\$ 1) .{ }^{524}$ Dann folgen die Vorwürfe: "Wo in aller Welt war die vor Gott als Zeugen versprochene Freundschaft, dass Ihr mich bei Eurer Abreise wie einen Unbekannten ohne Gruß verlassen habt und ich zurückblieb ohne eine Möglichkeit, das Nötige zu sagen? [...] « $(\$ 1) .{ }^{525}$ Im letzten Satz verweist Ennodius darauf, dass seine - wohl ungewöhnliche - Direktheit für Agnellus ein besonderer Grund zur Wahrung der Freundschaft sein sollte: "Leb nun wohl, mein Herr, und lasst meine Seele, die aufgrund meiner Integrität, meiner Herkunft und meiner Vorsätze nicht wankt, mehr an Eurer Freundschaft teilhaben, da sie Euch aufrichtig offenliegt« $(\$ 3) .{ }^{526}$

Diese Ablehnung von urbanitas zeigt Ennodius durchweg: So erhält der Diakon (und nachmalige Papst) Hormisda, den Ennodius vielleicht in Rom kennengelernt hat, eine Aufforderung zum Schreiben (172), in der die urbanitas, in diesem Fall das Vortäuschen von Freundschaft aufgrund der Zeitumstände, thematisiert wird. Ennodius beklagt sich zunächst, dass Hormisda, obwohl er nun aus dienstlichen Gründen in seiner Nähe sei, weniger schreibe als vorher (von dieser vorangehenden Korrespondenz gibt es allerdings keine Spur; dies ist der erste der überlieferten Briefe an Hormisda): "Seit Eure meinen Wünschen entsprechende <dienstliche> Verpflichtung dank der räumlichen Nähe die Erfüllung meiner Wünsche zu versprechen begann, habt Ihr Euch mit dem Geist weiter entfernt, und obwohl Ihr Ligurien fast mit den Händen berühren könnt, habt Ihr Eure Zunge der Untätigkeit überlassen. Die Abwesenheit hatte weniger Macht, als weite räumliche Entfernungen Eure Heiligkeit festhielten. Das <briefliche> Gespräch konnte den fehlenden Anblick aufwiegen, und es wurden Briefe gewährt, wie sie als Unterstützung für die Freundschaft vorgesehen sind, wodurch der Freundschaft zwischen voneinander entfernt Lebenden nichts abging “ (\$1f.). ${ }^{527}$ Als möglicher Grund für dieses Schweigen des Hormis-

$524(309,1)$ Semper famulantes diligentiae paginas nunc in proditione sui dolor exegit et gaudiorum ministras in vocem reserandae traxit iniuriae, nec contenta fuco dissimulationis urbanae secreta pectoris aut taciturnitate vestivit aut in partem aliam transtulit blandimento. novi quidem fabricata, sed fugio et simplicitate contentus cum amantibus serena animi fronte congredior.

$525(309,1)$ ubi gentium fuit sub obtestatione dei inter nos promissa devinctio, ut proficiscentes insalutatum me velut incognitum linqueretis nec potestatem remanens sortirer necessaria suggerendi?

$526(309,3)$ nunc vale, mi domine, et animum meum, quem in statione consistere suadet innocentia origo propositum, ad potiorem gratiae partem, quia vobis sinceritate patuit, invitate.

527 (172,1f.) Postquam votiva mihi necessitas vestra benificio proximitatis desiderii spondere coepit effectum, animo ad longiora transistis et, cum Liguriam pene manu contingitis, lin- 
da wird erwogen, dass dieser nur dann Briefe schreibe, wenn mit einiger Mühe weite Entfernungen zu überbrücken seien: "Doch ich glaube, Ihr zieht es vor, Freunden lieber Aufwändigeres <d.h. Briefe über weite Entfernungen > zu schenken, und Ihr haltet es nicht für eine Wohltat, wenn ich mich in solch enger Nachbarschaft über Briefe freuen kann « $(\$ 2) .{ }^{528}$ Aber Ennodius deutet die Situation anders, er habe Angst, dass das früher gezeigte freundliche Verhalten des Hormisda nur den Umständen $<$ d.h. der Situation des Schismas?>, nicht wirklicher Freundschaft zuzuschreiben sei: »Doch ich muss, wenn sich Deine Einschätzung gewandelt hat, über meinen Fall seufzen <und befürchten>, dass nicht etwa Deine Seligkeit das, was sie mir schmeichelnderweise erwiesen hat, nun einem <strengen> Urteil unterzogen hat und das Gewesene den Zeitumständen zuschreibt und nicht der Freundschaft « $\left(\$_{3}\right) .^{529}$ Gegen ein solches Verhalten wehrt sich Ennodius, denn solche Verstellung - Freundlichkeit nicht aus Freundschaft, sondern weil es die Situation erfordert - passe nicht zu ihrer beider propositum: "Fern sei von unseren Vorsätzen eine verstellte Miene bei Freundschaften: Uns hat nicht in früheren Studien eine Feile zu solcher Kunst gefeilt, wir können zur Verbindung ungeschminkte Eintracht mitbringen. >Feines Benehmen unter Freunden hassen wir wie Gift. Mein Herr, nimm also meinen Gruß an und ahme lieber Deinen Freund darin nach, dass Du häufige Briefe für die Pflege der Freundschaft aufwendest und mir meinen Wunsch erfüllst und mir aus dem innersten Herzen unverfälschte Worte schenkst. Leb wohl « $(\$ 3 f.) .{ }^{530}$

Gegen urbanitas wendet Ennodius sich auch in dem ersten überlieferten Brief an den Diakon Helpidius (312; eine Reihe von Details zu diesem Diakon und Arzt in PLRE II, p.537: "Helpidius 6«). Dieser Brief fällt außerdem zum einen dadurch auf, dass Ennodius betont von Freundschaft unter Christen spricht (vgl. oben 202) und dafür, anstatt wie sonst Synonyme zu häufen, dreimal caritas verwendet. Zum anderen betont Ennodius in der Praefatio die Macht der Freundschaft, ohne dabei auf die Erfordernis von Briefen hinzuweisen (vgl. seine zuversichtlichen Worte über die

guam feriis deputastis. minus licuit absentiae, dum sanctitatem vestram prolixa viarum intervalla tenuerunt. $\left(\$_{2}\right)$ pensabat confabulatio dispendia visionis et in remediis provisa diligentiae litterarum commercia praestabantur, per quae officia inter habitatione discretos nihil peribat affectui.

$528(172,2)$ sed credo eligitis amicis difficiliora tribuere non putantes beneficium, si pascar in tanta vicinitate conloquiis.

$529(172,3)$ at ego casum meum versa aestimatione suspiro, ne beatitudo tua retulerit ad iudicium quod exhibuit blandimentis, dum quod praecessit adscribit tempori non amori.

$530(172,3 \mathrm{f}$.) facessat a nostro in amicitiis frons picta proposito, nos ad hanc fabricam nulla praecedentium studiorum lima conposuit, nudam scimus ad coniunctionem adferre concordiam. urbanitatem inter caros ut venena respuimus. (\$4) ergo, mi domine, salutationem accipiens amantem tui in hac potius parte sectare, ut et culturam fidei per frequentiam sermonis inpendas et ex secreto pectoris infucata expectanti verba concedas. vale. 
Macht der Verwandtschaft gegenüber weiblichen Adressaten, oben 217); vielleicht hat er ein Anliegen, denn er erinnert ausdrücklich daran, dass Helpidius ihn »angenommen « habe ( $\$ 2$ fove ... quem suscepisti). Die beiden haben schon zuvor in irgendeiner Form Kontakt gehabt, denn Ennodius hofft, dass Helpidius das Freundschaftsversprechen ernst gemeint und sich nicht verstellt habe: »Vollkommene Freundschaft kann durch körperliche Abwesenheit keinen Schaden erleiden, und eine ungetrübt heitere Verbindung von Seelen kann durch räumliche Trennung nicht beeinträchtigt werden. Die Seelen derer, die durch den verbindenden Christus zur Freundschaft zusammenkommen, können nicht durch dazwischen liegende Länder getrennt werden. In dieser Hoffnung oder vielmehr mit dieser Gewissheit hinsichtlich Eures Herzens spreche ich meinen Freund voller Vertrauen an, als hielte ich ihn in meinen Armen. Unterstütze den, verehrter Helpidius, den Du dank Gottes Hilfe <sc. als Deinen Schutzbefohlenen> aufgenommen hast. Die Welt mag ihre eigene Schlauheit haben und - wofür sie zu verdammen ist - schlaues Täuschen 'Feinheit‘, urbanitas, nennen. $<$ Doch $>$ mische Du der Freundlichkeit, an der ich Gefallen gefunden habe, nichts bei außer dem, was uns schrittweise zum Gut der vollkommenen Freundschaft führen kann.« (312). ${ }^{531}$

(Zu Ennodius' Ablehnung von urbanitas siehe auch z.B. zu 113 an Avienus unten 289, zu 178 an Avitus unten 271.)

So explizit wie Ennodius Verstellung ablehnt, fordert er an anderen Stellen Aufrichtigkeit: In einem Brief an Olybrius (13, dazu oben 180) weist er darauf hin, dass die Mutter Kirche sie beide mit der Milch des Glaubens nähre, damit sie Wahres sprächen ( $\$ 3$ ut vera loquamur). Er weiß, dass häufig geheuchelt wird: »Andere bezeugen mit den Lippen eine Freundschaft, die ihr Geist nicht kennt [... « (114,1). ${ }^{532}$ Doch Ennodius ist keineswegs konsequent: In einem Brief an Passivus (114) beruft er sich zwar auf seine sinceritas, lässt sie aber deutlich vermissen (siehe unten 327 ).

531 (312,1) Perfecta caritas corporalis absentiae damna non patitur nec animorum serena coniunctio itinerum sequestratione multatur. quorum animae Christo in caritatem sociante conveniunt, nulla possunt separari interiectione terrarum. hac ego spe vel securitate de conscientia vestra securus amantem mei adloquor tamquam in amplexibus constitutum. (\$2) fove, domne Helpidi, quem deo medio suscepisti. habeat suas mundus astutias et urbanitatem fallendi prudentiam damnandus appellet: $t u$ illi dulcedini quam probavi nihil admisceas, nisi quod gradibus ad perfectae caritatis nos bona perducat.

$532(114,1)$ alii affectum, quem mente nesciunt, ore testantur $[\ldots] ;(116,2)$ affectionem $[\ldots]$ simulare; (siehe auch zu 316, oben 219). 


\section{modestia - fiducia sui}

Man kann Ennodius keineswegs pauschal eine "perversa modestia“ oder "affectata modestia " zuschreiben, wie das häufig getan wird, ${ }^{533}$ sondern es ist festzustellen, dass sich ebenso Beispiele für explizites Selbstbewusstsein finden wie auch für mehr oder weniger ausführliche Hinweise auf seine sprachliche Unfähigkeit oder niedere Stellung.

In etlichen Passagen zeigt Ennodius unmissverständlich ein starkes Selbstbewusstsein. Es wurde bereits erwähnt, dass er häufig tadelt und selten lobt (siehe oben 119, 124; siehe auch unten 266, 268) und dass er im ersten überlieferten Werk nicht etwa die Sorge äußert, dass seine Rede nicht gut genug sein könnte, sondern die, dass man ihn für ruhmsüchtig halten werde (siehe oben 66); (siehe auch z.B. oben $65 \mathrm{zu}$ 210).

Ein Brief an den jungen Avienus endet: »Leb also wohl, mein Herr; nimm meine kleine Gabe an und miss sie nicht nach ihrer eigenen Nichtigkeit, sondern nach dem Wert des Absenders" (108,2; zum ganzen Brief unten 288). - Selbstsicher ist auch die Reaktion auf ein Lob von Papst Symmachus: Mit der Feststellung, dass es einen guten Feldherrn ausmache, seine erprobten Soldaten zu loben, um sie zu weiteren Taten zu ermutigen (117,1 die ganze Praefatio unten 253), reagiert Ennodius offenbar auf ein Lob, das er selbst von Symmachus erhalten hat; er erwidert nicht etwa: IIch habe so viel Lob doch gar nicht verdient, meine Leistung war nicht so bedeutend.. Mehrfach formuliert Ennodius Mahnungen gegenüber Persönlichkeiten, die Karriere gemacht haben, besonders die Ermahnung, im Zuge von Erfolgen und gelingender Karriere nicht hochmütig zu werden und die alten Freunde zu vergessen, wenn er z.B. in der Grußformel die Hoffnung ausdrückt, dass der Adressat in seiner Machtposition sich nicht den Hochmut der Mächtigen aneignen, sondern dass er seine Stellung durch Demut noch erhöhen werde ( 78 , siehe unten 290 ); ebenso z.B. in einem Glückwunschbrief an Iulianus (125, siehe unten 341) und in einer Aufforderung zum Schreiben an den Diakon Helpidius (445,1).

Sein Selbstbewusstsein und seine Reizbarkeit zeigt Ennodius im zweiten Teil seines Briefs an den Rechtsanwalt Honoratus ${ }^{534}$ (64; er erhält nur diesen Brief), der Ennodius unterstellt hat, sich für ihn nicht mit aller Kraft einzusetzen. Der Brief beginnt freundlich und mit einer gewissen Demut (cf. \$1 sic mereor); Ennodius rechnet die Tatsache, dass Honoratus nun zwar in der Nähe, aber krank sei, zu dem Phänomen, dass sich für ihn, Ennodius, immer Erfreuliches mit Unerfreulichem mische (zu diesem 'Selbstbezug siehe 235): "Ihr habt neulich geschrieben, dass Ihr Euch in meiner Nähe aufhaltet, wobei Ihr zur Verringerung meiner Freude <sc. die Nachricht

533 Siehe etwa Vogel 1885, Praef. III, XXV; Brunn 1911, 24-27 Caput II: De affectata modestia, qua in epistulis Symmachus Sidonius Ruricius Ennodius utuntur.

534 Cf. $\$ 3$ iura; scholasticus (= advocatus, causidicus, iuris consultus, cf. M. KASER, Das römische Zivilprozeßrecht, 2. Aufl. neu bearb. v. K. HACKL, München 1996, 563). 
über> Euren beeinträchtigten Gesundheitszustand hinzufügtet. Ich kann es nicht abstreiten, ich habe es so verdient, dass sich für mich immer Bitteres mit dem SüBen verbindet. Bis jetzt wart Ihr mit der Sorge um Ravenna beschäftigt, und die Widrigkeiten ließen Euch nicht los; weil Ihr Euch <nun> davon entspannen konntet, ist Eure körperliche Substanz geschwächt, damit es Euch nicht vergönnt wäre, das Gewünschte vollends zu erlangen. (\$2) Wie hart ist das menschliche Los, das, sooft es einem ein kleines Häppchen des Gewünschten gegeben hat, bald und noch an der Schwelle das Gewährte verändert « $(\$ 1) .{ }^{535}$ Nachdem Ennodius so seine Verbundenheit mit Honoratus betont hat, wird deutlich, dass es außer der Krankheit noch etwas Bitteres gibt, das sich mit der Freude über die Nähe des Honoratus mischt: Honoratus hat Ennodius gebeten, in einer Streitsache (causa) für ihn einzutreten, und dabei offenbar angedeutet, dass er annehmen werde, Ennodius habe ihm nicht helfen wollen, wenn er sage, er habe nicht helfen können: "Mich hat also die schikanöse Bemerkung erschreckt, die Du Deinem Brief vorsorglich mit rednerischem und sehr kunstfertigem Weitblick beigegeben hast, nämlich dass Du glauben würdest, dass ich den Dir nützenden Auftrag nicht ausführen wolle, falls ich mitteilen würde, dass ich es nicht konnte $(\$ 2) .{ }^{536}$ Über diesen rhetorischen Kunstgriff, der ihn zum vollen Einsatz seiner Kräfte zwingen soll, gibt sich Ennodius empört: »Oh, geheimnisvolles kunstvolles Talent, das mehr für seinen Nutzen sorgt als der Freundschaft vertraut. Gott ist Zeuge, dass ich Dir nicht verweigern werde, was ich vermag“ $(\$ 2 f.) .^{537}$ Honoratus solle lieber zusehen, dass er Ennodius' Einsatz nicht durch solche Briefe störe: »Bitte Du Gott, nicht zuzulassen, dass mein Handeln behindert wird durch Deine unglückseligen, unheilvollen Briefe, wie Du sie liebst. Denn es gibt nichts, was ich bei dem Auftrag als Hindernis mehr fürchte als die Tatsache zu wissen, dass ein Anwalt nichts zu bekommen verdient. Richte Du Dein Talent lieber auf das schmutzige Recht, durch das die unsaubere Zunge, was immer sie fordert, bald zu bekommen verdient oder, wenn sie es nicht verdient, bald an sich reißt« $\left(\$_{3}\right) .{ }^{538}$ Der Brief en-

$535(64,1 \mathrm{f}$.$) In vicinitate vos degere moderna scriptione signastis, iungentes ad dispendia gaudio-$ rum statum vestrae valitudinis inminutum. non nego, sic mereor, ut semper mihi cum dulcibus amara socientur. hactenus vos Ravennatibus occupatos excubiis adversa tenuerunt, unde quia laxari contigit, corporalis in vobis est labefactata substantia, ne in totum liceret optata promereri. (\$2) quam dura est humanarum rerum condicio, quae quotiens desideriis aliquo sapore responderit, mox et in foribus concessa permutat.

$536(64,2)$ expavi tamen calumniam, quam oratoria et nimis daedala provisione litteris indidisti, ut iniuncta pro utilitate tua nolle me credas, si efficere non potuisse signavero.

537 (64,2f.) o artificis ingenii secretum, quod plus commoditati prospicit quam de amore confidat! $\left(\$_{3}\right)$ deus testis est me tibi non negaturum esse quod valeo.

$538(64,3)$ tu deum roga, ut actionem meam infelicium quas diligis litterarum non patiatur calamitatibus inpediri. nihil est enim, quod magis pro obice metuam actionis inpositae quam illud, quod novi accipere scholasticum nil mereri. confer magis ingenium tuum ad squalentia iura, per quae quidquid scabrida poposcit lingua mox meruit aut, si non meruit, mox avulsit. - Unerklärlich ist mir GiOANNis Bemerkung zu nihil est quod magis [...] nil mere- 
det mit einer selbstbewussten Bemerkung, die zeigt, dass Ennodius sich die zu seinem propositum gehörige humilitas, die er oft thematisiert, offensichtlich noch nicht durchweg zu eigen gemacht hat.: »Mein Herr, ich grüße herzlich und hoffe, dass Du meine Mühen mit reichlichen Gebeten unterstützt, weil ich, obwohl ich nicht die Verdienste eines Gebildeten oder Gelehrten habe, in Streitsachen oft das Schicksal eines Vollkommenen ertrage $<$ d.h. den Sieg davontrage $>\ll(\$ 4){ }^{539}$

Doch an etlichen anderen Stellen gibt sich Ennodius bescheiden, indem er behauptet, seine sprachlichen Fähigkeiten seien unzureichend. Wie schon erwähnt wurde, gehört es zu den Normen, die die Korrespondenz des Symmachus bestimmen, die eigenen Fähigkeiten herabzuspielen und gleichzeitig die des Adressaten hochzuloben (BRUGgisser 1993, 20: "la bienséance«). Es ergibt sich das Paradox der "humilté savante« (BRUGGISSER, 55-59), dass man seine Beredsamkeit zeigt, indem man seine Fähigkeiten herabspielt, um die modestia zu betonen. Wenn Ennodius seine eigene Unfähigkeit beteuert, entspricht er also sowohl dieser `weltlichen〈 Konvention also auch seinem >frommen Vorsatz der humilitas. Wenn man nun aber diese Passagen betrachtet, so zeigt sich, dass Ennodius seine `Unfähigkeitsbeteuerungen` ganz gezielt und keineswegs beliebig oder etwa nur wegen der Konventionen einsetzt, z.B.:

Von seinem angeblichen Unvermögen spricht er mehrfach in den Recusationes (besonders in 20 an Florianus, siehe oben 187; 95 an Mascator, oben 184; 317 an Hormisda, oben 195), d.h. in Situationen, wo er tatsächlich eine bestimmte Art von Briefwechsel nicht aufnehmen will. Besonders ausführliche Beteuerungen seiner Unfähigkeit finden sich in dem Brief an Passivus, mit dem er keinen Kontakt zu wünschen scheint (114, siehe unten 326). - Eine andere Funktion haben die Beteuerungen im ersten Brief an Firminus (12), die in diesem Fall dazu dienen, die Kraft der Freundschaft zu bezeugen, die ihn trotz der Unfähigkeit schreiben lasse (siehe unten 247). Im zweiten Brief an Firminus (40) gehen die Beteuerungen in den leisen, aber hörbaren Vorwurf über, dass dieser nicht geschrieben habe; Ennodius stellt sein Unvermögen heraus, um dann aber deutlich zu betonen, dass Firminus ihm antworten müsste. - Wenn Ennodius an den jungen Iohannes schreibt, er habe sich in dessen Lobreden nicht wiedererkennen können (4, siehe oben 121), so ist dies die Einleitung zu einer strengen Ermahnung.

Besondere Fälle liegen vor, wenn eine ausführliche Beteuerung in einer Pointe endet (118, siehe unten 306) oder wenn sie sozusagen stellvertretend dafür steht, dass Ennodius einen Auftrag (noch) nicht erledigt hat (176, siehe unten 328).

ri: "Car ce qu'il redoute le plus, c'est de srecevoir des lettres qui n'offrent rien de littéraire`.« (2001, 167; ähnlich 2004, 521).

$539(64,3)$ domine, salutationis gratiam solvens spero, ut effusis laborem meum precibus iuves, quia, cum non habeam docti aut eruditi meritum, saepe in causis sustineo fata perfecti. 
Ennodius befolgt also keineswegs blind die Forderung nach modestia: teils widerspricht er ihr völlig, teils erfüllt er sie, wenn er so bestimmte Ziele erreichen kann.

\section{Freud und Leid}

Ennodius betont immer wieder die Funktion von Briefen, Zeichen der Freundschaft zu sein, und ein Großteil seiner Briefe dient ja auch tatsächlich der Kontaktpflege (siehe unten Kap. II 3b). Was schreibt man nun in solchen Briefen, die keine dienstlichen Anlässe haben, die nicht dem Austausch von Nachrichten dienen (weil vielleicht der Bote mündlich eine Nachricht überbringt), die auch keine ,Kabinettstücke` im Sinne des Plinius und Sidonius Apollinaris sein sollen, die aber über die stereotype Formulierung >Wie geht es Dir? Mir geht es gut. Viele Grüße [...]< hinausgehen, sie zumindest anspruchsvoll variieren sollen? Zum Vergleich bieten sich auch hier besonders die Symmachus-Briefe an, die ja ebenfalls überwiegend der Kontaktpflege dienen (worüber sich Symmachus in seltenen Fällen beklagt, siehe oben 207). In solchen Briefen werden überwiegend ,brieftypische Themen`variiert, besonders werden Informationen und Fragen über das Wohlergehen ausgetauscht, und auch hierbei hält sich Symmachus an bestimmte Spielregeln. Eine von Symmachus beachtete und auch explizit benannte Konvention besteht darin, in Briefen nur von Erfreulichem zu berichten, von Unerfreulichem wie z.B. Krankheit hingegen erst dann, wenn es schon wieder vorüber ist (wie man ja auch Ärger über den Adressaten erst dann ausspricht, wenn er vergangen ist, siehe oben 222). Briefe sollen Freude bereiten (cf. officii voluptas, Sy. 1,5,2).

Die Korrespondenten möchten wissen, ob es dem anderen gutgeht, z.B.: $»[\ldots]$ denn ich weiß, dass Du alles Erfreuliche über uns erfahren möchtest; auch ich bin ebenso besorgt, über Dein Wohlergehen und Deine Taten Erfreuliches und Wünschenswertes zu hören [...] « (Sy. 3,8); ${ }^{540}$ ebenso bei Ennodius, z.B.: "Ich bitte Gott, dass er von Euch das vermelden lässt, was mich zu hören freut « $(269,2)$; " [...] ich bitte, dass ein Brief mir Euer Wohlergehen melden möge « $(426,3){ }^{541}$ Vom Erfolg der Freunde hört man gern, und Symmachus rechnet deren Erfolg auch zum eigenen hinzu: "Deine Erfolge rechne ich zu meinem Vermögen “ (Sy. 1,37,2); "Dass Dein Vermögen wunderbar angewachsen ist, rechne ich als meinen Vorteil; denn meine Haltung ist es nicht, zu denken, dass das Wohlergehen meiner Freunde mit meinem eigenen Befinden nichts zu tun hat [...]. Man hat mehr Freude, wenn man sich auch

540 (Sy. 3,8$)[\ldots]$ scio enim te prospera quaeque de nobis velle cognoscere. mihi quoque par cura est de salute atque actibus tuis laeta et optata noscendi [...]; siehe auch z.B. (Sy. 2,69) peto, ut me prosperorum tuorum indicio munereris; (Sy. 5,58) [...] ut auctus laetitia salutis meae parem voluptatem mihi de prosperis tuis referas.

$541(269,2)$ deum quaeso, ut illud a vobis indicari faciat quod me delectet agnoscere; $(426,3)[\ldots]$ rogo, ut prosperitatem vestram epistolaris cura manifestet. 
am Erfolg der anderen nährt « (Sy. 3,24,1) ${ }^{542}$ Erfreuliches muss geteilt werden, daher schreibt Symmachus: "<dies> wirst Du gern hören; denn Du teilst ja immer gern die Freuden Deiner Freunde « (Sy. 7,63); "Ich freue mich über die Stellung meines Bruders als Vicarius, als wäre mir selbst diese ruhmreiche Ehre zuteil geworden « (Sy. $3,19) .{ }^{543}$

Diesen Gedanken des 'Selbstbezugs` verwendet auch Ennodius; das Glückwunschschreiben (9, dazu ausführlich unten 347) an Faustus anlässlich des Konsulats von dessen Sohn Avienus beginnt damit, dass Ennodius die Auswirkungen des Konsulats auf sich selbst - nicht etwa auf den Konsul Avienus oder dessen Vater Faustus (cos. i.J. 490) - benennt: Er, Ennodius, sei durch Gottes Geschenk erhöht worden, so dass er nun einen Konsular, nämlich Faustus, fast von gleich zu gleich ansprechen könne; ${ }^{544}$ Grund dafür ist, dass Ennodius mit Avienus über dessen Mutter verwandt ist. Ennodius freut sich über das Konsulat des Avienus nicht zuletzt - besser gesagt, zu allererst - aus dem Grund, dass so seiner eigenen Familie wieder Glanz verliehen werde ( $\$ 1$ familiae nostrae; $\$ 2$ nostrae nobilitatis insignia; dignitatum nostrarum; $\$ 6$ generi [...] nostro). Solch extremer 'Selbstbezug', d.h. das Motiv, den Erfolg des anderen mit den eigenen Verdiensten und der eigenen Situation in sehr enge Beziehung zu setzen und das vom anderen Erreichte sogar mehr in Bezug auf sich selbst als auf diesen zu sehen, findet sich häufiger (siehe z.B. in 64, oben 231; in 125, u. 341 ; in 173, u. 308; in 242, u. 344 und 346). Dazu, dass auch erlittenes Leid sich auf den Korrespondenten auswirke, siehe unten 243.

Dem Wunsch, miteinander alles Freudige zu teilen, entspricht umgekehrt die von Symmachus erwähnte und ausdrücklich gebilligte Konvention, dass man von Gefahren erst schreiben solle, wenn sie vergangen seien. ${ }^{545}$ Auch bei Cicero findet sich eine Stelle, an der er solche Rücksichtnahme billigt: De Attica pergratum mihi fecisti quod curasti, ante scirem recte esse quam non belle fuisse (Cic. Att. 14,16,4). BRUGGisser (1993, 22-24) fasst dies unter das Prinzip der >Zurückhaltung` (»retenue«)

$542($ Sy. 1,37,2) [...] processus tuos in meo aere duco; (Sy. 3,24,1) Quod fortunae tuae pollucibiliter floruerunt, meum duco conpendium, quando ita animatus sum, ut amicorum prospera meis commoditatibus externa non arbitrer. [...] latius gaudet, qui et alterius bonis pascitur; siehe auch: Sy. 3,43,1; 8,29 (diese Haltung beim Adressaten).

543 (Sy. 7,63) (...) libenter audies; nam soles amicorum prospera voluptate partiri; (Sy. 3,19) germani mei vicaria potestate gaudeo, tamquam mihi decus honoris accesserit.

$544(9,1)[\ldots]$ beneficiorum eius [sc. dei] [...] sublimis iam consularem virum quasi aequalis adgredior.

545 Abgesehen davon spricht auch Symmachus zuweilen von Problemen: (2,6,2; über Nahrungsmittelknappheit in Rom) litteras sperate meliores, si fortuna urbis nostrae secundis amara mutaverit; $(2,7,3)$ plura tecum loqui quam necesse est, de adversis communibus non libet; $(6,22,4)$ si in manus meas venerint monumenta gestorum, legendo noscetis, quae verborum meorum verecundia noluit explicare. 
und das $>$ Bestreben, seine Freunde nicht mit seinem Kummer zu behelligen`, siehe z.B.: "Bisher konnte ich nicht schreiben, da eine beklagenswerte Krankheit im Wege stand, über die wir lieber nicht schreiben [...] « (Sy. 2,49); ${ }^{546}$ »lange war die Gesundheit mit mir uneins. Du hast Dich nun ein wenig erschrocken, ich weiß. Aber lass die Sorge: ich bin schon wieder gesund « (Sy. 3,47).${ }^{547}$ Die Krankheit muss nicht dazu führen, dass man nicht schreibt, wohl aber dazu, dass man sie verheimlicht: »[...] ich kann Dir nun mitteilen, dass ich meine Gesundheit wiederhabe, nachdem ich es vermieden habe, Dich über meine vergangene Sorge zu informieren; doch ich weiß, dass ich nicht einmal zu der Zeit, wo mich die Krankheit vom Schreiben abzuhalten versuchte, diese Pflicht vernachlässigt habe $[\ldots]$ « (Sy. 1,85). ${ }^{548}$ Von gegenwärtigen Bedrohungen wird ungern gesprochen, und als Symmachus dies einmal nicht vermeiden kann, kommentiert er: "[...] doch nichts mehr darüber < sc. über die problematische Situation der Landgüter>, damit mein Gruß nicht zur Klage wird und so die Freude am Brief vermindert « (Sy, 1,5,2); "Dieser unglückselige Bericht bedrückt mich, und daher werde ich mich bei dieser Darstellung kurz fassen " (Sy. 6,40); "Es gibt schon etwas zu schreiben, doch ich schrecke davor zurück, von etwas zu sprechen, dessen Erwähnung quält « (Sy. 6,65). ${ }^{549}$ Doch nicht immer lassen sich Krankheiten verheimlichen, da z.B. der Überbringer des Briefs manches erzählen wird: » [...] Es wäre besser, von den körperlichen Beschwerden meines Sohnes zu schweigen, um Eure Sorgen nicht zu vermehren; und sicher wird mein Bruder Comazon, der aus Sehnsucht nach Euch Rom verlassen hat, ganz ausführlich darlegen, was ich verschweige $($ Sy. 6,41 $) .{ }^{550}$ Manchmal ist auch zu befürchten, dass Gerüchte das verbreiten, was man lieber verheimlicht hätte: »Ich kann mich nicht entscheiden, wie ich am besten antworten soll. Denn schon lange belastet mich die Maßlosigkeit der Gerüchte, so dass ich meine besten Freunde darüber weder mit Lügen täuschen noch mit der Wahrheit beunruhigen sollte« (Sy. 2,37). ${ }^{551}$ Außer der häufiger zu lesenden Begründung, dass man dem

546 (Sy. 2,49) Scribere hucusque non libuit obstrepentibus inbecillitatum querellis, quas indicare vitamus $[\ldots]$. Siehe auch (Sy. 4,54,1).

547 (Sy. 3,47) diu a me bona valetudo dissensit. inhorruisti paululum, scio. pone sollicitudinem! iam valemus.

548 (Sy. 1,85) [...] nunc te societate meae commoditatis inpertio, quem praeteritae sollicitudinis participem habere vitavi; etsi scio, ne illo quidem tempore, quo officium meum morbus inhibebat, ab huiusmodi munere temperatum.

549 (Sy. 1,5,2) [...] verum haec missa facio, ne salutatio in querellam versa minuat officii voluptatem; $($ Sy. $6,40,1)$ offendit me infausta narratio, atque ideo in hac expositione servabo brevitatem. (Sy. 6,65) scribenda non desunt, sed horret animus loqui dura memoratu.

550 (Sy. 6,41) [...] cuius corporales querellas praestat silere, ne sanctitatis vestrae sollicitudo geminetur; et certe frater meus Comazon desiderio vestro urbe digressus cumulatius, quae tacemus, expediet.

551 (Sy. 2,37) Nequeo definire, quae potissimum mihi rescribendi forma conveniat. ea quippe iamdiu intemperantia vexor rumorum, ut de his neque decipere falsis neque sollicitare veris amantissimos mei debeam. $[\ldots]$ 
Adressaten die Sorge ersparen wollte, findet sich auch folgende, die der eigentliche Grund sein dürfte, dass nämlich der Verfasser einfach aufgrund seiner schwierigen Lage nicht schreibt: »denn im Unglück schenkt man der Pflege der Korrespondenz mit seinen Bekannten keine Beachtung " $\left(\right.$ Sy. 8,73). ${ }^{552}$

Doch zuweilen klingt durch, dass diese Konvention, den Freund von Sorgen zu verschonen, auch Nachteile hat. Zwar billigt Symmachus das entsprechende Verhalten seines Adressaten: »[...] Daher muss ich, der ich mir wegen Deines Schweigens Sorgen machte, zugeben, dass ich es gutheiße, dass Du die schlechte Nachricht bis zum Zeitpunkt der Freude über Deine Genesung aufgeschoben hast, damit ich nicht eher in Sorge über das Dir zugestoßene Unglück geriete, als ich über das vergangene beruhigt würde« (Sy. 3,86,1). ${ }^{553}$ Der Fortgang des Briefes zeigt jedoch, dass dieses vorläufige Verschweigen von Unerfreulichem auch Nachteile hat, da man sich nie sicher sein kann, ob gerade etwas verschwiegen wird: „Da sich nun die Gesundheit wieder mit Dir versöhnt hat, schenke bitte unserer Freundschaft besonders reichliche Briefe; sonst werde ich beim Ausbleiben von Briefen fürchten, dass wieder etwas Ähnliches geschehen ist " (Sy. 3,86,1). Auch in einem anderen Brief, der insgesamt ein gutes Beispiel für seine Nachsicht ist, zeigt Symmachus die negativen Konsequenzen dieser Konvention auf: "Ihr wolltet Euer Schweigen mit einer feinen Ausflucht rechtfertigen: Ihr bezogt Euch auf den Grundsatz der Zurückhaltung bei traurigen Nachrichten, bis Erfreuliches einträte, damit das, was die Unterbrechung der Korrespondenz zuvor verborgen hatte, durch erfreulichere Nachrichten ans Licht käme. Doch zum einen wussten wir durch Boten sehr wohl davon, und zum anderen erschien uns dies $<$ sc. der Brief mit der freudigen Nachricht > recht spät. Denn der Verdacht, der durch das Ausbleiben eines Briefes aufkam, vergrößerte die Zügellosigkeit der Gerüchte. Und dennoch können wir nicht zürnen, nachdem die Freude über den erhaltenen Brief die Erinnerung an den vergangenen Kummer ausgelöscht hat. Denk also daran, das Briefeschreiben zu den allerwichtigsten Dingen zu zählen, damit nicht die Erinnerung an diesen Fall uns wieder einmal in große Angst bringt, weil wir denken, dass uns in der Hoffnung auf Besserung etwas Widriges verschwiegen wird " (Sy. 6,69)..${ }^{554}$ Die vorgebrachte Entschuldigung, man habe traurige Nachrichten erst

552 (Sy. 8,73) [...] familiarium quippe usus officiorum inter adversa neglegitur.

553 (Sy. 3,86,1) itaque ego ille de silentio sollicitus probare me fateor, quod asperae nuntium rei usque ad sanitatis tuae gaudia distulisti, ne de te ante caperem exorti incommodi sollicitudinem quam securitatem remoti. nunc quia tecum valetudo in gratiam rediit, indulgentioribus paginis amicitiam munerare; alioquin cessantibus epistulis simile aliquid rursus timebo.

554 (Sy. 6,69) Eleganti commento silentium vestrum purgare voluistis: allegata est enim cautela tristium nuntiorum, quamdiu secunda succederent, ut ea, quae intermissio scriptionis ante celaverat, laetioribus indiciis proderentur. sed nobis et illa per nuntios incognita non fuerunt, et haec sera admodum visa sunt, augebat enim rumorum licentiam suspicio cessantis officii. et tamen suscensere non possumus, postquam gratia praesentium litterarum memo- 
dann vermelden wollen, wenn sich die Lage gebessert habe, bezeichnet Symmachus hier als elegans commentum; er selbst verhält sich ähnlich wie der Adressat, indem er seinen Kummer über dessen Schweigen erst erwähnt, als er vergangen ist (praeteriti doloris). - Symmachus selbst sorgt vor gegen die Gefahr, dass Gerüchte Schlimmeres verbreiten, als wirklich der Fall ist, indem er kurz von seiner Krankheit schreibt und für die Zeit nach seiner Genesung einen freudigen Brief verspricht: »Mich quälen Nierenschmerzen. Doch damit Euch nicht schlimmere Gerüchte zu Ohren kommen, schreibe ich Euch kurz von meinem momentanen Gesundheitszustand. Wenn es mir wieder besser geht, werde ich Euch treu meiner Gewohnheit einen fröhlicheren Brief schreiben« $\left(\right.$ Sy. 6,73). ${ }^{.55}$

Symmachus billigt also diese Konvention der 'Verschonung bis zum Verzug der Gefahr explizit und entspricht ihr auch selbst, wenn er auch zuweilen auf deren negative Folgen hinweist und selbst versucht, solche zu vermeiden. Ennodius hingegen zeigt- zumindest gegenüber engeren Korrespondenten wie Faustus und auch Avienus - häufig keine Hemmungen, von eigener Krankheit zu berichten, und er bittet diese ebenfalls, ihn nicht nur über Erfreuliches, sondern auch über Unerfreuliches zu informieren.

Ennodius möchte nicht, dass die ihm verbundenen Korrespondenten sich an diese Konvention der ,Verschonung, halten: In seinem ersten überlieferten Brief an Faustus (6), in dem er von seinen querellae und seiner inpudentia / inportunitas schreibt, die ihm im Gegensatz zur urbanitas zum Erfolg, d.h. zu einem Brief von Faustus, verholfen hätten (siehe oben 224), beschwert er sich sehr deutlich darüber, dass Faustus ihm seinen Kummer vorenthalten habe. "Ich freue mich über die besänftigenden Worte in dem Brief und danke herzlich, dass Ihr lange nicht wolltet, dass ich von dem Traurigen erfuhr. Ihr habt dies vielleicht in fürsorglicher Absicht getan, doch ich schreibe es meinen Sünden zu, dass ich, während Ihr keinen Brief sandtet, von großen Ängsten bewegt wurde. Mir allein gerät Fürsorge zum Gegenteil, da ich immer das, was in Betrübnis verschwiegen wird, für sehr schlimm halte; denn ich glaube, dass über mäßige Leiden häufig Worte gewechselt werden, während die Nähe des Grabes Schweigen befiehlt, das bald <sc. durch Jammern $>$ gestört werden wird. [...] Ich hätte mir also gewünscht, dass Ihr in Eurer Freundlichkeit meiner Wenigkeit gegenüber eine solche Einstellung gehabt hättet, mit dem, den ihr bei Euren Freuden häufig zum Gefährten genommen habt, auch Euer Unglück zu teilen. Oder glaubt Ihr, dass ich es als Empfang einer Wohltat ansehen werde, wenn ich von den

riam praeteriti doloris exemit. modo memento curam stili inter praecipua et prima sortiri, ne huius exempli recordatio maiores denuo nobis adferat metus, dum credimus sub expectatione meliorum rursus aliqua adversa reticeri. vale.

555 (Sy. 6,73) Rienum dolore discrucior. sed ne maior ad aures vestras fama perveniat, praesentem statum valetudinis meae breviter indicavi. cum laeta successerint, morem meum secutus dabo ad vos paginam laetiorem. vale. Siehe auch (Sy. 6,16). 
Unruhen Eures Herzens so wie ein Unzuverlässiger ausgeschlossen werde? « $(\$ 3-5) .{ }^{556}$ Ennodius ist betont unzufrieden, dass Faustus nur von der allgemeinen betrüblichen Lage ( $\$_{7}$ generaliter deflenda $[. .$.$] incommoda) geschrieben habe, aber nicht so, dass$ Ennodius die Lage nun wirklich beurteilen könne. Wenn Faustus ihn wirklich für fidelis halte - denn so bezeichne er ihn (cf. \$7; \$9) - solle er nicht nur seine Freuden, sondern auch seinen Kummer mit ihm teilen und ihn nicht davon ausschließen ( tamquam male fidelis excludar \$5).

Faustus muss außerdem an einem anderen Brief (25) erkennen, dass Ennodius auch die Nachricht von vergangenem Unglück sehr trifft. Er hat die Nachricht von der Genesung der Söhne des Faustus erhalten, bevor er überhaupt von deren Krankheit wusste $(\$ 1)$. Doch das hindert ihn nicht, bei aller Dankbarkeit über den glücklichen Verlauf (cf. \$1) häufig an die Gefahren zu denken $(\$ 3)$ : »Ich sage ehrlich und verhülle die Stimme, die ich meinen Vorsätzen schulde, nicht mit einer Lügenwolke, dass meine Worte sich mit Schluchzen vermischen und ich beim ununterbrochenen Dank mit tränenreichen Augen oft auf das zurückblicke, dem ich entkam. Wo in aller Welt waren wir? Aus welchem Verderben hat uns die himmlische Milde dem menschlichen Dasein wiedergegeben?« $\left(\$_{3}\right){ }^{557}$ Dieser Brief enthält viel pathetische Klage, obwohl Ennodius doch bei diesem Anlass auch einen ganz freudevollen Brief hätte schreiben können. Er führt auf diese Weise eindringlich und ausführlich vor, dass die 'Konvention des Verschonens` zumindest in seinem Fall nicht den erwünschten Effekt hat. - Auch in einem Brief an Faustus' Sohn Avienus spricht Ennodius zwar nicht explizit von dieser `Konvention`, führt aber vor, dass er auch bei der Mitteilung, dass eine Krankheit bereits vergangen ist, leidet: »Die Nachricht von Eurer Krankheit hat meine $<$ Krankheit $>$ verschlimmert. Denn so geht es gewöhnlich und fast von Natur her einem Besorgten, dass er kaum glauben kann, dass vorübergegangen ist, was er

556 (6,3-5) delenificam allegationem amplexus epistularis alloquii ago atque habeo gratias, quod me diu tristium noluistis esse participem. fecistis hoc forsitan voto et studio consulentis, sed adscribo peccatis meis, quod maioribus, dum temperatis alloquio, sum iactatus angoribus. mihi uni in adversum provisa contingunt, dum graviora semper in maerore aestimo quae tacentur, quia credo quod de mediocribus saepe communicentur verba languoribus, cum proximitas funeris imperet silentia cito rumpenda [cf. Lucan. 2,21-23 sic funere primo / attonitae tacuere domus, cum corpora nondum / conclamata iacent]. [...] (\$5) voluissem tamen talem circa parvitatem meam dignatio vestra tenuisset affectum, ut quem comitem saepe gaudiis adhibuistis, cum eo elegissetis etiam adversa partiri. an putatis tale beneficium in acceptum me esse relaturum, si ab aestibus pectoris vestri tamquam male fidelis excludar?

$557(25,3)$ dico integre et vocem quam proposito debeo nulla mendacii nube concludo, confundi verba singultibus et sub solida gratulatione uberioribus in fletum oculis saepe me respicere quod evasi. ubinam gentium fuimus? de qua nos ad humanam conversationem ruina clementia superna restituit? 
fürchtet, und dass er über das, was unser Erlöser in seiner himmlischen Güte bereits vorübergehen ließ, seufzt, als stünde es vor Augen « $(420,1) .{ }^{558}$

Bei Avienus beklagt sich Ennodius auch darüber (323), dass er nicht über die Krankheit von dessen Mutter informiert worden sei, wohl aber Gerüchte darüber gehört habe. Hier verwendet Ennodius das Motiv des extremen >Selbstbezugs` (siehe oben 235), indem er sowohl ihre Krankheit mit seinen eigenen Sünden als auch ihre erhoffte Genesung mit eigener Besserung in Verbindung bringt. "Wenn Ihr Euch noch etwas um meine Wenigkeit sorgtet, würde Euer Schweigen nicht so eine lange Zeit anhalten, besonders da durch verschiedene Gerüchte die Krankheit meiner Herrin und Eurer Mutter mich in der Ferne ohne Abhilfe bedrückt. Denn ich weiß, dass die fromme Frau nur durch die eine Last bedrückt wird, dass sie einem Unwürdigen $<$ sc. Ennodius > ihre maßlose Güte erweist. Doch was soll ich viele Worte schreiben, die mit den Fesseln der Traurigkeit gebunden sind? Wenn die himmlische Güte ihr ihre Gesundheit zurückgegeben hat, schreibt es mir schnell. Denn ich rechne damit, dass mir in dem Moment Wohlbefinden zuteil wird, wenn ich von ihrem < Wohlbefinden $>$ erfahre. Ihr habt den Grund meines Kummers erfahren, gebt Ihr gleich nach Gott mir <Grund zur $>$ Erleichterung $[\ldots] \ll .(\$ 1 f)$.

In einem weiteren Brief an Faustus (19) führt Ennodius vor, wie hart es für ihn selbst ist, von - immerhin auch nicht gegenwärtigen, sondern vergangenen - Gefahren zu berichten. Er schreibe dies nur, weil er immer die Wahrheit schreiben müsse: Hier muss er Faustus von der Krankheit seines Bischofs und den damit verbundenen Sorgen und Ängsten berichten. Er betont, er würde lieber nicht davon sprechen, damit die überwundene Traurigkeit nicht wieder aufkomme ( $\$ 1$ ne [...] habeam tristitiae meae redivivum in narratione principium).$^{560}$ Einerseits entspricht dies Aeneas' einleitenden Worten seiner Erzählung vor Dido (Aen. 2,3 infandum, regina, iubes renovare dolorem), andererseits widerspricht es der gegenteiligen Haltung, wie sie Aeneas nach dem Seesturm zeigt: forsan et haec olim meminisse iuvabit (Aen. 1,203), vgl. auch: habet enim praeteriti doloris secura recordatio delectationem (Cic. fam. 5,12,4). "Denn

558 (420,1) Aegritudinis vestrae indicium in mea contigit incrementum. nam talis semper est usus et pene natura solliciti, ut vix credat transisse quod metuit et, quae fecit redemptor noster caelesti benignitate praeterita, quasi sint in oculis locata, suspiret.

559 (323,1f.) Si vobis de parvitate mea fuisset ulla curatio, tanti temporis silentium non maneret, maxime cum inaequalitas domnae meae matris vestrae per varios rumores sine remedio adfligat absentem. scio enim hoc solo sanctam feminam fasce praegravari, quia inmodicam pietatem exhibet non merenti. sed quid produco verba catenis obligata tristitiae? si bonam valitudinem eius caelestis favor refudit, properato litteris nuntiate. (\$2) expecto enim ut tunc mecum prospera concilientur, quando cum illa esse conperero. didicistis causam maeroris, indifferenter post deum date remedii. [...].

560 Siehe auch $(36,2)$ : vereor dicere quod remansit, ne loquendo cogar denuo sustinere transacta. 
wer nicht davor zurückscheut, von vergangenen Sorgen zu berichten, der ist beinahe selbst schuld an seinen Sorgen. Wer möchte wohl seine zu Ende gebrachten Ängste durch den Zwang einer unpassenden Rede erneuern? « $(19,1) .{ }^{561}$ Mit dieser Aussage und der rhetorischen Frage stellt Ennodius den Nutzen der Konvention, dass man von Sorgen und Unglück erst dann berichtet, wenn sie überstanden sind, in Frage. In diesem Brief beteuert er, nur aufgrund seiner Treue (fides) gegenüber dem Adressaten, seiner Vorsätze (propositum) und seiner Aufrichtigkeit (sinceritas) könne er über das Vergangene schreiben $(\$ 2)$. Der veritas dürfe nichts verloren gehen $(\$ 2$ dummodo veritati nil pereat), falsitas könne aus keinem Grund hingenommen werden. Er berichtet dann von der Krankheit des Bischofs, die ihn, Ennodius, außerordentlich betroffen habe $\left(\$_{3}\right.$ me $[. .$.$] specialis maeror adflixit), da er ihm viel verdanke$ ( $\$ 3$ eius debeo plus amori). Doch sobald der Bischof genesen und er, Ennodius, wieder zu sich gekommen sei ( $\$ 4$ mens mea ad stationem rediit), habe er wieder an das ihm Aufgetragene gedacht $<$ d.h. an Faustus zu schreiben $>$. Er habe also Sklaven mit diesem Brief auf den Weg geschickt, um sich nach dem Wohlergehen des Faustus und seiner Familie zu erkundigen - und sei nun wiederum in Sorge, wie die Antwort ausfalle ( $\$ 4$ inter spem et metum dubia aestimatione distringor; sollicitum). So viele Sorgen wie er habe niemand sonst. Dann beginnt unvermittelt ein anderes Thema: Er komme wieder zum Klagen zurück (vgl. die querellae in 6,1; dazu oben 224): Faustus hätte Ennodius sofort schreiben müssen (\$5 paginas vestras [...] me [...] subsequi debuisse; paginas ist Subjekt im AcI), um ihn über seine Abreise zu informieren. Doch Faustus könne diese culpa durch häufiges Schreiben wettmachen.

Ennodius schreibt nicht selten von eigener akuter Krankheit; da er aber auch von der Konvention in Briefen weiß, dass man nicht von gegenwärtigem Unglück schreiben soll, begründet er sein ungewöhnliches Verhalten damit, dass er sich von den Gebeten des Adressaten Hilfe verspreche: "Ich schreibe nicht deshalb, um Euch mit der bitteren Nachricht von meiner Krankheit zu belasten, sondern um Euch und Eure Sorge darum zu bitten, eifrig < für mich> zu beten “ $(269,1)$; "Ich würde meine Sorgen verschweigen, wenn ich nicht wüsste, dass Eure Fürsorge mir helfen kann. Denn solange Ihr nicht wisst, welche diversen unangenehmen Krankheiten mich quälen, befällt mich aufgrund meiner Sünden häufig das Fieber, und die Kräfte, die wiederhergestellt schienen, brechen. Gewährt mir also die gewohnte Hilfe und setzt Euren heiligen Lebenswandel zu dem Nutzen ein, dass Ihr durch Gebete an unseren Gott das erreicht, was die Medizin der Menschen nicht vermag « (391). ${ }^{562}$ - An anderer Stelle

561 (19,1) paene enim sibi debet angustias suas, qui earum relegere transacta non refugit. quis ad calcem perductas anxietates suas reparet intempestivi necessitate sermonis?

$562(269,1)$ Non scripsi, ut amaro incommoditatis meae indicio vos gravarem, sed ut sollicitudinem vestram, quatenus insistat orationibus, convenirem. (391) Tacerem molestias meas, nisi intellexissem, quod sollicitudo vestra me sublevat. nam dum agnoscitis, quam variis morborum fatigor incommodis, pro peccatis meis febribus frequenter addicor et vires, quae 
spricht er konkret von Problemen mit den Augen, wobei hier offenbar eine tatsächliche körperliche Krankheit die Metapher liefert für den Kummer über die Trennung vom Freund: »Die Arbeit, die mir auferlegt wurde, bevor ich meine Gesundheit ganz wiedererlangt hatte, haben meine Augen ungut aufgenommen. Alles Licht ist mit Euch von mir gegangen « $(269,1) .{ }^{563}$ - Hochpathetisch schreibt er an eine Adressatin, dass er ihr trotz seiner Krankheit einen Brief sende: "Obwohl ich immer noch in höchster Gefahr schwebe und Wohltaten meines Gottes wegen der Last meiner Sünden nicht eintreten, weil ich es verdiene, lange gequält zu werden, hat meine < von Euch $>$ abhängige Seele dennoch nicht vergessen, was sie der Ehrfurcht und dem Dienst Euch gegenüber schuldet. Fast wird sie <sc. die Seele $>$ schon zum Gericht $<$ sc. Gottes > gerufen, und doch beachtet sie noch die, die sie verehrte. Wie wahr ist jenes Wort, dass eine heilige Freundschaft nicht einmal mit dem Tod vergeht! Meine Herrin, ich grüße also pflichtschuldigst und bitte, dass Ihr, da Ihr nun wisst, wie es um mich steht, entsprechend dem Glanz Eurer Herkunft und dem Strahlen Eures Lebenswandels - in beidem übertrefft Ihr alle - meinen Herrn, den Apostel, und seine Brüder anfleht, dass die Macht Gottes sich durch sie erweichen lässt und die Wohltaten ihrer Milde, die gewöhnlich nicht langsam ist, nicht zurückhält" $(404,1) .{ }^{564}$

Anders als Symmachus, der seine Korrespondenten möglichst nicht beunruhigen möchte, hält Ennodius sich also zuweilen überhaupt nicht zurück. Doch auch er schreibt häufiger davon, dass das Schlimmste vorüber sei (siehe z.B. 383,2, 393, 394, 401-403, 407), z.B. in einem Brief (382) an Avienus, der einen Brief von diesem erwirken soll: »Ich glaube, es ist eine Sache der Gerechtigkeit, das, was ich von Euch erwarte, als erster zu tun. Denn es gehört sich, wenn man Gutes erwartet, mit seinem eigenen Beispiel dazu aufzufordern. Wer ein Beispiel für eine Handlung bietet, besiegt mit Sporen die Langsamkeit. Damit also erbiete ich meinen pflichtgemäßen Gruß und melde, dass ich nach einer Krankheit, die ich wegen meiner Sünden erlitten habe, wieder gesund bin; ich frage nach dem Zustand Eures Wohlergehens und hoffe, dass

videbantur restitutae, franguntur. ergo vos remedia consueta praestate et usum illum sanctae conversationis inpendite, ut quidquid medicina mortalium non valet, fusis ad deum nostrum precibus inpetretis.

$563(269,1)$ male oculos meos ante receptae valitudinis substantiam inpositus labor accepit. omne a me vobiscum lumen abscessit.

564 (404,1) Quamvis adhuc inter extrema sim positus et pro peccatorum meorum mole domni mei beneficia, dum mereor in longum conteri, non sequantur, reverentiae tamen vestrae et obsequiis quod debet pendens anima non omisit. paene iam vocatur ad iudicium et adhuc suspicit in hac luce quos coluit. quam vera est illa sententia, quod sanctus affectus nec morte pereat! (\$2) ergo, domina mea, servitiis vos debitae salutationis prosequens rogo, ut agnitis quae circa me geruntur, pro illo quo omnibus eminetis et sanguinis nitore et conversationis radiis, domno meo apostolo et ceteris eius fratribus subplicetis, ut per eos exorata dei potentia clementiae suae, quae tarda esse non solet, beneficia non refrenet. 
Du Dich bei der Lösung dieser Sache sehr anstrengst « (382). ${ }^{565}$ Ob Ennodius mit haec res tatsächlich eine durch den Boten mündlich übermittelte Angelegenheit meint, ist fraglich; es ist gut möglich, dass er damit seine in dem Brief vorgebrachte Bitte um einen Brief meint, ebenso wie er im vorigen Brief an Avienus seine Aufforderung zum Schreiben als suggestio bezeichnet (376,2, der Brief oben 105).

Ein weiterer Grund zur Klage außer Krankheit ist in etlichen Briefen die Trennung von Faustus. In einem Brief, mit dem er Faustus nach einer persönlichen Begegnung ${ }^{566}$ über seine glückliche Rückkehr informieren möchte (siehe am Ende: reditus mei facere indicia), führt er anhand von Paradoxa aus, dass es ihm nun noch schlechter gehe als zuvor: Nach der Begegnung sei das Schreiben nur ein minderwertiger Ersatz $(\$ 1)$, und es wäre besser gewesen, wenn die Trennung, an die er sich schon gewöhnt habe, nie unterbrochen worden wäre: "Hartes wird durch die Gewohnheit gebrochen. Die Gewohnheit nimmt viel von der Schwere einer Last. Zu Ersehntem, das nicht andauern wird, führt ein trauriges Los. Leichter ist das Schicksal dessen, der ununterbrochen von Sorgen erfasst ist. Ich bin durch meine Sündenlast umso unglücklicher, weil ich den Geschmack guter Dinge gekostet habe« $(286,1) .{ }^{567}$ Dann bricht er ab: "Doch davon ein anderes Mal« (sed hinc alias), d.h. über das erlebte Schöne schreibt er nicht! - (Siehe auch den ähnlichen Brief 307 , ebenfalls nach einer Begegnung mit Faustus.)

Ennodius hebt zwar zuweilen den guten Einfluss fremden Erfolgs auf sich selbst hervor (siehe oben 235), aber er dreht den Gedanken auch um, dass nämlich sein eigener Kummer sich auf das Glück des Adressaten auswirken müsse (siehe auch oben 240). Er schreibt an Faustus (246) über seinen Kummer wegen ihrer Trennung nach einer Zeit der Nähe, als Faustus in Ravenna war. Für Faustus hat sich im Zusammenhang mit dem Wechsel nach Rom ein (nicht näher bezeichneter, aber wahrscheinlich mit

565 (382) Credo ad iustitiam pertinere, ut quod a vobis expecto primus exhibeam. decet enim, ut qui bona opera praestulatur invitet exemplo. expugnat calcaribus tarditatem qui formam ministrat officii. his ergo salutationis munus inpertiens sanum me esse post inaequalitatem, quam pro peccatis sum passus, enuntio et statum vestrae prosperitatis inquiro, sperans ut in huius rei solutione multus incumbas.

$566(286,1)$ Postquam desideriis meis videndi vos facultas elapsa est, iterum ad litteras mens revertit: "Nachdem meiner Sehnsucht die Gelegenheit, Euch zu sehen, <wieder> entschwunden ist, wendet sich meine Seele wieder zum Brief. "Falsch aufgefasst von SundWALL $(1919,46)$, dass Ennodius seine Enttäuschung darüber ausdrücke, dass ihm die Gelegenheit eines Treffens nicht gewährt worden sei. Dass Ennodius Faustus tatsächlich getroffen hat, ergibt sich aus dem Folgenden.

$567(286,1)$ quae dura sunt continuatione franguntur: multum de gravitate oneris usus incidit. flebilis condicio ad optata, quae non sunt mansura, perducit. levior sors est curis iugibus occupati. hoc sum infelicior peccatorum fasce, quod de bonarum rerum sapore gustavi. 
einem Amt verbundener) Wunsch erfüllt ( $\$ 3$ sibi $[\ldots]$ cupita contigisse), doch der Brief beginnt mit Sentenzen darüber, wie unvorhersehbar Unglück sei: »Kaum je rechnet man, wenn man sich in einer glücklichen Lage befindet, mit einem Unglück. Denn wie vor einem unheilvollen Vorzeichen schreckt man davor zurück, mit vorgreifenden Gedanken etwas von der unfreundlichen Zukunft zu sehen. Sicher schaudert sogar das Erkennen der Übel davor, dass sie < die Übel> sich zur Unzeit in unangenehmer Weise dazumischen " $(\$ 1) .{ }^{568}$ Diese allgemeinen Bemerkungen beziehen sich auf den konkreten Fall des Ennodius, der die Nähe zu Faustus in Ravenna genossen hatte, nun aber unter der Trennung leidet: "Ich glaubte nicht, dass - das jetzt ungeliebte - Ravenna irgendwie entfernt war, als es an meinen Schätzen reich war; nicht lockte mich Dürstenden so sehr eine Quelle, mich Schwitzenden ein Lufthauch zu sich wie jenes, nicht mich Erschöpften die Ruhe. Doch ich glaube, jetzt ist sogar Rom aufgrund meiner Sündenlast noch weiter in die Ferne gerückt. Wo sind die häufigen Briefe, die ich für selten hielt? Wo ist der häufige Anblick <sc. per Brief $>$ ? Wo die vielen Tröstungen für die Freundschaft? Ich muss wirklich über mich selbst sagen: Ich verachte das Leben, das < doch> nicht einmal die hassen, die in Not sind " $(\$ 2) .{ }^{569}$ Wenn Faustus einwende, dass doch aber seine, Faustusı, Wünsche erfüllt seien, so antwortet Ennodius darauf, dass das Glück des Faustus nicht vollkommen sein könne, da er, Ennodius, leide: "Eure Hoheit mag einwenden, dass dank der himmlischen Vorsehung ihre Wünsche erfüllt wurden. <Doch:> Das Glück ist nicht vollkommen, wenn einer, der zu Euch gehört, vom Unglück der harten Trennung betroffen ist. Glaubt mir: Was ich beklage, ist nicht fingiert, und um die Tragödie meines Herzens darzustellen, reicht weder das Verfassen eines Briefes noch die Beschränktheit meiner Sprache « $(\$ 2 f.) .{ }^{570}$ Um die Härte der Lage zu betonen, wird Christus um Hilfe angerufen, und abschließend wird Faustus um Briefe gebeten: "Christus, Richter aller Dinge, komm meiner Not zu Hilfe, damit nicht meine menschliche Schwachheit, die der Last des unermesslichen Kummers nicht gewachsen ist, niedergedrückt wird und unterliegt. Mein Herr, ich erweise gehorsam meinen Gruß und bitte, dass per

$568(246,1)$ Vix est ut intentus rebus felicibus adversa praenoscat. velut sinistrum enim omen repudiat, si quid de austeritate futurorum intellectu praecedente respexerit. certe ne et alieno tempore amare se misceant, ipsa molestiarum horret agnitio.

569 (246,1f.) nullo credebam intervallo nunc inamabilem Ravennam, dum erat thesauris meis plena, distare; non me sic sitientem fons, aestuantem aura ut illa ad se, non lassum requies, invitabat. (\$2) at nunc ipsa Roma, puto, ad longiora pro peccatorum meorum fasce translata est. ubi est illa quae rara putabatur frequentia litterarum? ubi crebra visio? ubi tot solacia diligentiae? vere pro meis partibus loquor: detestor vitam, quae nec in aerumna constitutis est odio.

$570(246,2 \mathrm{f}$.) adleget forsitan culmen vestrum, sibi pro superna dispensatione cupita contigisse. non est plena felicitas, quando vestrorum aliquis miseriis durae sequestrationis adfligitur. $(\$ 3)$ ideo credite [cf. den Apparat bei VoGEL], non sunt fucata quae defleo, nec ad explicandam cordis tragoediam aut epistularis concinnatio sufficit aut sermonis angustia. 
Brief die Sorge um mich anhält, damit wenigstens durch dieses Mittel mein in Unruhen befindlicher Geist aufatmen kann “ $(\$ 3) .{ }^{571}$ Wenn tatsächlich Faustus zuvor unter unerfreulichen Umständen das Amt des Quaestors verlassen hatte (siehe unten 347), er nun rehabilitiert ist und ein neues Amt angetreten hat (was zu dem Ortswechsel geführt hat), ist besonders der Anfang des Briefs, aber auch der Brief insgesamt sehr ungewöhnlich - der klagende Ton hätte zu einem Brief nach der Entlassung gepasst.

\section{Zur Symmachus-Rezeption bei Ennodius}

Es war bereits zu erkennen, dass Ennodius keineswegs versucht, ein zweiter Symmachus zu sein, sondern dass er sich in vieler Hinsicht deutlich von ihm absetzt. Nun sind einige der Passagen zu betrachten, in denen Ennodius direkt auf Stellen in den Symmachus-Briefen rekurriert und die daher in der Forschung als Belege für die Vorbildfunktion des Symmachus angeführt werden: In einem Brief (48) verweist er auf Symmachus als quaedam eloquentiae persona sublimis, um eine von dessen Aussagen zu kommentieren, in zwei anderen Briefen $(55 ; 141)$ >verarbeitet $<$ er offenbar Symmachus-Briefe. Auch hier wird deutlich, dass Ennodius sich mit Symmachus auseinandersetzt, um sich in Charakter und Stil von ihm abzusetzen, nicht um ihm nachzufolgen.

Die Stelle, die in der Forschung als der wichtigste Beleg für die Vorbildfunktion des Symmachus gilt, ist bisher ohne ihren Kontext zitiert und nicht genauer angesehen worden. Schaut man genauer hin, zeigt sich, dass Ennodius auch hier nicht einem Vorbild nacheifert, sondern sich von einem Vorgänger distanziert. Ennodius widerspricht hier dem von Symmachus formulierten Prinzip der dissimulatio artis, d.h. dass Briefe an Bekannte den Eindruck einer gewissen Nachlässigkeit bei der sprachlichen Gestaltung erwecken sollen, der jedoch künstlich hergestellt wird (artifex incuria).

Ennodius beginnt diesen Brief ( 48, zu dem Brief auch oben 102) an Olybrius (zur Person siehe oben 178) mit den Worten: „Eine Kapazität der Redekunst hat gesagt, in Briefen gelte Nachlässigkeit als Gesetz, und eine künstliche Nachlässigkeit verschaffe ihnen den wahren Glanz « $(48,1$ Ut tradit quaedam eloquentiae persona sublimis, lex est in epistulis neglegentia et auctorem genii artifex se praebet incuria). Er spielt damit auf eine Stelle bei Symmachus an, wo dieser den Briefstil seines Sohnes kritisiert: »Ein vielfältiges Talent muss in Briefen an Bekannte eine gewisse Nachlässigkeit nachahmen, in offiziellen <sc. Briefen> jedoch die Waffen der Redekunst schwingen " (Sy. 7,9 ingeniorum varietas in familiaribus scriptis neglegentiam quandam debet imi-

$571(246,3)$ Christe rerum arbiter, propriae succurre necessitati, ne humana fragilitas ad inmensi fascem doloris non sufficiens pressa subcumbat. domine mi, salutationis servitia dependens rogo, ut paginalis circa me cura servetur, ut vel hoc remedio inter aestus mens constituta respiret. 
tari, in forensibus vero quatere arma facundiae). ${ }^{572}$ Zunächst fällt auf, dass Ennodius sich nur auf die erste Hälfte dieser Aussage bezieht und dabei unterschlägt, dass Symmachus neglegentia nur in Briefen an Bekannte fordert, keineswegs grundsätzlich; Ennodius spricht allgemeiner: lex est in epistulis. Dass Ennodius sich hier auch insgesamt nicht auf Symmachus bezieht, um ihm zuzustimmen, sondern um ihm zu widersprechen, zeigt erst der weitere Verlauf des Briefes.

Nach dem zitierten ersten Satz beschreibt Ennodius, was die artifex incuria bedeutet: Um zu fragen, wie es dem anderen geht, braucht man keine ausgefeilte Sprache, keine kunstvollen Formulierungen; solchen Briefen soll man nicht ansehen, dass das Verfassen Mühe gemacht hat: "In einem solchen Schreiben entzieht man das der Anerkennung, was der Schweiß, Zeuge der Qualen, erdacht hat. Wer die eigene Gesundheit vermeldet und nach der des anderen fragt, braucht keine Worte, die in Handwerksöfen gebrannt sind. Es ist besser, wenn sich hierbei unsere Reden mit schmucklosem Antlitz begegnen; der einfache Schmuck des Briefes verzichtet auf Juwelen. Indem der Briefwechsel künstlichen Schmuck vermeidet, erhält er welchen “ $(48,1) .{ }^{573}$ Es geht also um die Formulierungen, um verba, elocutio, decor, und im Folgenden spricht Ennodius dann konkret über den Stil des Adressaten: dives et elucubrata narratio $(\$ 2)$. Wenn Ennodius hier von simplex conloquii cultus und pura elocutionum frons spricht, meint er den sprachlichen Aufwand, nicht die Haltung und das Verhalten des Verfassers, simplicitas bzw. fucus, die ihn sonst beschäftigen (siehe oben 226).

Dann geht Ennodius dazu über, den Stil des Olybrius zu beschreiben, was er allerdings mit sed als einen Gegensatz anschließt: "Doch die reiche und ausgefeilte Redeweise Eurer Hoheit lässt sich nicht in ärmliche Grenzen schließen, noch lässt sie den Schatz der Rede durch irgendwelche Begrenzungen einengen. Wie große Ströme missachtet sie die Zügel der Ufer $[\ldots] \lll(\$ 2) .{ }^{574}$ Olybrius entspricht der Forderung des Symmachus, in (Privat)Briefen die Sprachgewalt einzuschränken bzw. sie nur verborgen einzusetzen, offenbar nicht. Er wird aber deshalb nicht getadelt, sondern gelobt ( $\$ 3$ f., siehe oben 102), und Ennodius stellt heraus, dass er Olybrius immer be-

572 An dieser wichtigen Stelle geht es Symmachus eindeutig um zwei verschiedene Briefstile (in familiaribus scriptis - in forensibus vero), nicht aber um den Gegensatz von Brief und Rede, wie es allerdings CALLU 1995 übersetzt (in forensibus: "alors qu'il agitera les armes de l'éloquence devant les tribunaux «, siehe auch die betreffende Anmerkung). Doch forensis ist hier eindeutig als Gegensatz zu domesticus gebraucht.

$573(48,1)$ in quo opere illud subducitur gratiae, quod cruciatuum testis sudor invenerit. caminis excocta fabrilibus verba non flagitat salutis suae nuntius et quaesitor alienae. melius si in his commerciis pura elocutionum fronte congredimur; diademata simplex conloquii cultus abiurat: epistularis communio si quando affectatum decorem fugit, obtinuit.

$574(48,2)$ sed magnitudinis vestrae dives et elucubrata narratio mendicis limitibus nescit includi nec oris thesaurum quibuscumque artare confiniis: magnorum more fluminum riparum frena contemnit. 
wundert habe, z.B.: "Dieser Zunge, dieser Macht, schulde ich, ich muss es gestehen, einzigartige Verehrung [...] « $(\$ 5) .{ }^{575}$ - Ennodius widerspricht also Symmachus an dieser Stelle, indem er sich, wie auch sonst, gegen Verstellung ausspricht, in diesem Falle gegen die artifex incuria, gegen die Bemühung, mit den Mitteln der Kunst den Eindruck von Nachlässigkeit zu erwecken, also gegen die dissimulatio artis. Während im Brief des Symmachus artifex positiv besetzt ist im Sinne von »kunstvoll", verwendet Ennodius es im negativen Sinne von »künstlich «, »mit Verstellung«. Die den Brief eröffnenden praecepta für den Briefstil sollte man also nicht als Ennodius' eigene betrachten (so jedoch zuletzt GIOANNI 2001, 167; 2004, 523), da er sich im Weiteren davon distanziert.

Dass Ennodius die Forderung des Symmachus, den Eindruck von neglegentia zu erwecken, offenbar nicht unterstützt, zeigt sich deutlich auch an anderer Stelle, wo er betont, wie wichtig Mühe und Ausgefeiltheit seien: In (12,1) beschreibt Ennodius zunächst, welche Art von Briefen Gefallen finden könnte: »Willkommen sind Briefe, die von einem gebildeten Verfasser konzipiert sind, solche, in denen der Glanz einer bis auf die letzte Kleinigkeit ausgefeilten Sprache hervorleuchtet, wo eine reiche Sprache von den Zügeln des Könnens geleitet wird. Wenn ein unermüdlich Suchender eine reiche Sprach-Ader ans Licht gebracht hat, dann gehen daraus Briefe hervor, die den Wünschen des Empfängers entsprechen« $(12,1) .{ }^{576}$ Andere Briefe hingegen würden keinen Gefallen finden: "Doch wo schäbige Sprache die Begrenztheit einer armen Begabung erkennen lässt und dadurch, dass sie ihre Gedanken nicht richtig anordnet, in die eifrige Rede Dunkel bringt und durch die Unklarheit der nebelhaften Erzählung gerade mit der Erläuterung eine gewisse Dunkelheit erzeugt - wer, der sich auf dem Gipfel der Redekunst befindet, dürfte nicht die Zuneigung einer solchen Person verschmähen?« $(12,2) .{ }^{577}$ Im Folgenden wird deutlich, dass Ennodius den ersten Teil der allgemeinen Vorrede konkret auf den sprachmächtigen Adressaten, den zweiten hingegen auf sich selbst und seine vorgebliche Unfähigkeit bezieht; ${ }^{578}$ er vermutet da-

$575(48,5)$ huic ego linguae, his opibus reverentiam, fateor, $[\ldots]$, debeo singularem.

$576(12,1)$ Iucunda sunt commercia litterarum docto auctore concepta: illa in quibus ad unguem politi sermonis splendor effulgorat, ubi oratio dives frenis peritiae continetur. quando abundantem loquellae venam laboriosus in lucem scrutator adduxerit, tunc procedunt officia suscipientis desideriis paritura.

$577(12,2)$ at ubi scaber sermo angustiam pauperis signat ingenii nec conceptum suum in ordinem digerendo noctem studio elocutionis interserit et nebulosae narrationis ambiguo quandam generat de ipsa explanatione caecitatem: quis non personae talis in eloquentiae arce constitutus spernat affectum?

578 Anders Kennell $(2000,62)$ : »An early letter addressed to Firminus exemplifies Ennodius' delight at keeping in touch with individuals of taste and ability. [...] he intimates how much more entertaining it is to write to people whose linguistic accomplishments are comparable to his own and with whom he can trade self-deprecating Ciceronian quips about rhetorical technique." 
her, dass sich der Adressat über seinen Brief nicht freuen werde, und er entschuldigt sein Schreiben damit, dass sein amor ihn dazu gedrängt habe.

Zum Abschluss dieses Kapitels über die wenig konziliante Haltung des Ennodius und als Beispiel, wie er Formulierungen aus Symmachus-Briefen aufnimmt, seien zwei Briefe $(55 ; 141)$ an einen Johannes vorgeführt; Ennodius verweist in 141,3 auf ihre enge Verwandtschaft; nicht zu entscheiden ist wohl, ob es sich bei diesem Johannes um den gleichnamigen Schwiegersohn des Olybrius handelt (siehe oben 121). In diesen Briefen greift er offenbar direkt auf Formulierungen aus Symmachus-Briefen zurück, was bisher nur zum Teil bemerkt wurde (nur die Anspielungen in 141 sind in Vogels Ausgabe und bei Dubois 1903, S.81, vermerkt).

Im ersten Brief schreibt Ennodius von seinem Ärger darüber, dass in seinem Beisein anderen ein Brief von Johannes übergeben wurde, ihm selbst aber nicht: (Die Parallelen zu Symmachus sind kursiv markiert.) "Ich habe berechtigte Gründe, Euch, mein Lieber, mit meinem beißenden - wenn auch rostbefleckten - Griffel anzugreifen, von denen Du Dich nicht reinwaschen kannst, obwohl Du reichhaltige Gaben der Natur hast und reich bist an geistigen Fähigkeiten " $(55,1) .{ }^{579} \mathrm{Vgl}$. die Briefeingänge bei Symmachus: "Ich habe berechtigte Gründe, mich bei Dir zu beschweren, da $[\ldots]$ « (Sy. 3,17,1 $)^{580}$ und: »Du hast zwar reichhaltige Gaben der Natur und geistige Fähigkeiten, aber auch für Dich ist es schwierig, Dich von der Schuld des andauernden Schweigens reinzuwaschen " (Sy. 3,18,1) ${ }^{581}$ Symmachus sieht Gründe dafür, »sich zu beschweren « (expostulandi), Ennodius gibt sich kämpferischer: er habe Gründe, "mit meinem beißenden Griffel anzugreifen " (stili mei morsu ... incessam). Symmachus bezeichnet die Entschuldigung des Adressaten als schwierig (purgare difficile est), Ennodius hingegen als unmöglich (purgare non possis). Ennodius fährt dann fort, den Grund seines Ärgers zu beschreiben: „Hätte ich je glauben können, dass jemand anders schneller die Nachricht von Eurer Rückkehr erhält <sc. als ich $>$ ? Hätte ich glauben können, dass die Sorge um mich aufgrund von irgendwelchen Beschäftigungen jenes den Freunden geweihte Herz verlassen kann? Doch sieh: Vor meinen Augen erhalten andere einen Brief und meine angenehme Erwartung <sc. jetzt auch einen Brief zu erhalten> wird mit aller Verachtung meiner Einfalt enttäuscht « ( $\$ 1$ f. $){ }^{582}$ Symmachus nennt im ersten Brief nur kurz den Grund seiner Klage, beschließt aber so-

$579(55,1)$ probabiles causas habeo, quibus unianimitatem vestram stili mei morsu quamvis rubigine sordentis incessam, quas, cum sis abundans naturae bonis et ingenii facultatibus locuples, purgare non possis.

580 (Sy. 3,17,1) Habeo expostulandi tecum probabiles causas, quandoquidem pontificio litterati honoris auctus nullum mihi indicium communis gaudii praestitisti.

581 (Sy. 3,18,1) Abundas quidem naturae bonis et ingenii facultatibus, sed continui silentii culpam tibi quoque purgare difficile est.

582 (55,1f.) ego umquam credidi ad alium reditus vestri citius indicia posse perferri? ego curam mei inter quasvis occupationes illud amicis censui consecratum pectus excedere? $(\$ 2)$ ecce ante 
fort, den Brief nicht mit Klagen zu füllen: "[...] mich zu beschweren, da Du in das ehrwürdige Amt des Sekretärs erhoben wurdest und mir gegenüber keine Andeutung über diesen Anlass zu allgemeiner Freude gemacht hast. Doch ich will diesen ersten Brief $<$ d.h. den ersten an Dich in Deinem Amt $>$ nicht in bitterem Tadel tränken, damit die bittere Rede nicht Deine Seele bedrückt. Daher lasse ich ab von den Klagen und gestehe Dir Verzeihung zu unter der Bedingung, dass Du künftig der Pflege der Freundschaft das nötige Gewicht gibst [...] « (Sy. 3,17,1f.); ${ }^{583}$ er fährt fort mit Aufforderungen zum Briefwechsel (u.a. mit der für ihn ungewöhnlich scharfen Formulierung tacita concordia instar odiorum est, vgl. oben 215) und mit Bemerkungen zum Sinn von Briefen im Allgemeinen. Symmachus schreibt mehr darüber, dass er nicht klagen wolle, sondern Verzeihung gewähre, als dass er sich über den Grund seiner Klage äußert. Im Vergleich mit Symmachus' kurzer expliziter Klage überrascht Ennodius mit der Bezeichnung seiner als rhetorische Fragen gestalteten Klagen als stricta narratio: "Ich will den Brief nicht mit weiteren bitteren Tadeln anfüllen. Für Trauriges reicht ein knapper Bericht « $(\$ 2) .{ }^{584}$ Ennodius verweist dann darauf, dass seine eigene Freundschaft unverändert sei und dass der Adressat sich an seine Versprechen erinnern solle: "Meine Seele ist immer noch in dem Zustand, in dem sie Deine Hoheit bei der Abreise ermahnte: Es ist an Euch - wenn Ihr die Übel der Gegenwart verachtet <sc. z.B. die Übel, Versprechen nicht zu halten und Freundschaften zu vergessen>,- die versprochene Eintracht zu bewahren $\ll(\$ 2) .{ }^{585}$ Doch Ennodius beendet den Brief nicht, ohne nochmals auf seinen Kummer hinzuweisen, den es durch einen Brief zu beenden gelte: "Leb wohl, mein Herr, und erfreue Deinen Freund mit einem Brief, um durch Schreiben den Kummer zu vertreiben, der, wie Du siehst, Deinen Freund durch Deinen Verzicht auf das Schreiben befallen hat “ $\left(\$_{3}\right){ }^{586}$ Symmachus endet ähnlich: "Ich hoffe, dass ich demnächst Stoff für eine Antwort bekomme durch die Freude über einen Brief von Dir, nicht durch den Kummer über Deinen Hochmut <sc. der sich daran zeigt, dass Du nicht schreibst>« $(\text { Sy. } 3,17,2)^{587}$.

oculos meos redduntur aliis paginae et amica expectatio sub omni credulitatis meae despectione frustratur.

583 (Sy. 3,17,1) [...] quandoquidem pontificio litterati honoris auctus nullum mihi indicium communis gaudii praestitisti. sed nolo primas litteras meas felle obiurgationis imbuere, ne animum tuum contrahant amara sermonum. quare decedo querimoniis et tecum hanc veniam sic paciscor, ut in reliquum pensi habeas amicitiae diligentiam. $[\ldots]$

$584(55,2)$ nolo litteras maiori obiurgationis felle conplere; sufficit tristibus stricta narratio.

$585(55,2)$ in eo adhuc animus meus, quo magnitudinem tuam discedentem monuit, persistit statu: vestrum est, si temporum mala contemnitis, promissam servare concordiam.

$586(55,3)$ salve, mi domine, et amantem tui releva communione sermonis, ut scribendo deleas dolorem, quem vides amico per scriptionis abstinentiam contigisse.

587 (Sy. 3,17,2) opto deinceps materiam mihi ad respondendum dari gratia muneris tui non dolore fastidii. 
Auch im nächsten Brief an denselben Johannes (141), in dem auf den vorangegangenen Brief (55) angespielt wird, greift Ennodius eindeutig auf Briefe des Symmachus zurück; es ist daher anzunehmen, dass auch Johannes die Symmachus-Briefe gut kannte, da es wenig Sinn macht, in Briefen auf einen Text anzuspielen, den der Adressat nicht kennt. Offenbar hat Johannes auf den Vorwurf der Schreibfaulheit in (55) seinerseits mit einem solchen geantwortet. Zunächst der Brief des Symmachus (Sy. 4,65), dessen erstem Teil die Eingangspassage des Briefes an Johannes offensichtlich folgt; Symmachus weist hier, wie häufig (siehe oben 222), gerade in dem Moment auf seinen Kummer hin, als dieser vergangen ist: "Schon lange war ich mir beim Warten auf einen Brief von Dir nicht sicher, was dieses so lange Säumen zu bedeuten hätte; doch seit Du mir die erwünschte Gabe hast zukommen lassen, hat sich die Sorge in Freude gewandelt. Und tatsächlich ist es ja von Natur her so, dass die Klage darüber, dass man auf einen Brief lange gewartet hat, vergeht, wenn wir das Erwünschte erhalten. $<$ Bis zu dieser Stelle greift Ennodius den Brief des Symmachus auf.> Ich freue mich also außerordentlich, dass mir das Pfand des Freundschaftsbundes erneuert worden ist. [...] " $\left(\right.$ Sy. 4,65).$^{588}$ Ennodius beginnt: "Von Natur her ist es so, dass Sorge sich in Freude wandelt und aus Klagen Lobreden werden, wenn Wünsche erfüllt werden. Ich war mir nicht sicher, was dieses so lange Säumen Deiner Hoheit $z u$ bedeuten hätte. Aber da ich das Gewünschte erhalten durfte [...]. « Bis hierher ist deutlich der Brief des Symmachus verwendet. Auch weiterhin ist der Ton recht freundlich und erinnert an die nachgiebige Art des Symmachus, wenn Ennodius sich selbst als gutes Beispiel herausstellt: "Aber da ich das Gewünschte erhalten durfte, suche ich selbst für Dich nach einer ehrenhaften Art der Entschuldigung < sc. für das vorangegangene lange Schweigen $>$. Sieh, was die ungetrübte Heiterkeit der Freundschaft bewirken kann: So als ob für mich alles wunschgemäß gelaufen wäre, verzeihe ich, durch eine einfache Gabe besänftigt, Deine Fehler. Du weißt nun, wo Du ein Beispiel treuer Freundschaft finden und woher Du ein Beispiel an Beständigkeit in der Freundschaft nehmen kannst. Wenn Du meinem Beispiel folgst, entfernen Dich Fehler nicht mehr von der Freundschaft, und eine gute Tat Deines Freundes hat die Schuld ausgelöscht" (\$1f.). ${ }^{599}$ Hat sich Ennodius bis hierhin an den freundlichen

588 (Sy. 4,65) Iamdudum in expectatione eram litterarum tuarum incertus animi, quid sibi vellet tam longa cessatio, sed ubi compotem desiderati me muneris reddidisti, cura vertit in gaudium. et revera ita natura partum est, ut expetiti diu officii querella decedat, si potiamur optato. ergo magno inpensu gratulor, integratum mihi esse pignus religionis. $[\ldots]$

$589(141,1)$ natura partum est, ut cura migret in gaudium et mutetur querella praeconiis, quotiens cupita tribuuntur. incertus animi fui, quid sibi vellet sublimitatis tuae tam longa cessatio; sed cum potiri datur optato, ipse pro partibus tuis honestum excusationis genus inquiro. vide quid faciant serena diligentiae: quasi totum mihi ex sententia fluxerit, ita simplici munere placatus errata concessi. (\$2) habes unde pii amoris formam possis adsumere et circa amicitiam constantiae exempla mutuari. me si sequeris, nec plura te a coniunctione peccata retrahunt et unum benefactum sodalis tui culpas absolvit. 
Ton des Symmachus gehalten und direkt auf einen seiner Briefe angespielt, so schlägt der Ton nun um, und es wird deutlich, dass er auf einen Vorwurf des Johannes antwortet. Er weist diesen Vorwurf zurück bzw. gibt ihn mit aller Wucht zurück, indem er abermals erwähnt, dass Johannes anderen geschrieben habe, ihm selbst aber nicht (vgl. oben zu Brief 55): „Bruder, mir wirfst $D u$ Schweigen, mir Vergessen vor? Wo war diese Einstellung, als weder meine gesandten Briefe eine Antwort bekamen noch Du darin vorangingst, <sc. in eigenen Briefen> eifriges Schreiben zu verlangen? Wo war sie, als Du Schweigen wahrtest - allerdings nicht gegenüber allen in Ligurien? Während Du zur Verstärkung ${ }^{590}$ meines Kummers vielen schriebst, die Dir fernstehen, hast Du mir gegenüber das Schweigen fortgesetzt und jenen gegen <d.h. wohl: ohne> ihre Wünsche einen Brief gewährt." Johannes habe denen geschrieben, die ihm sowohl fernstünden als auch ungebildet seien, so dass sie seine Briefe nicht würdigen könnten: "Es ist nämlich bei den Menschen so, dass es gleiche Interessen immer bei enger Verwandtschaft gibt. An diese Regel dachtest Du nicht und wolltest eine Korrespondenz mit irgendwelcher Unkenntnis <? sc. mit Adressaten, die Ennodius für ungeeignet hält> anknüpfen, in der Annahme, dass unerreichbar Entferntes in Zuneigung zusammenkommen könne. Was hat Deine gewinnende Rede, die in ausgefeilter Sprache verfasst war, bewirkt, indem sie - unter Zurücksetzung des Freundes - solche anredete, die von den Schönen Künsten nichts wissen? Doch davon ein anderes Mal « (\$2f.). ${ }^{591}$ Dann bricht er die Vorwürfe ab und legt noch dar, dass er sie vorgebracht habe, weil Verschweigen sie nicht beseitigen könne; hier wendet er sich also explizit gegen die Konvention der muta dissimulatio (siehe oben 222): "Ich will die vielen Vergehen nicht wieder durchgehen, weil ich durch eine kurze Buße besänftigt bin. Denn ich hätte mir die Worte darüber gespart, wenn ich nicht glaubte, dass Ihr wisst, dass von Kränkungen das bleibt, was man verdeckt, und das entfernt wird, was man ausspricht. Mein Herr, ich bitte Dich, von nun an nicht, so als würdest Du Besserung ablehnen, nach Dingen zu trachten, von denen Du weißt, dass sie schlecht sind. Sondern sende mir oft süße Briefe, auf dass dem Redebegabten die Gabe <sc. der Rede> wachse, indem er die Eide der Freundschaft wahrt « $(\$ 4) .{ }^{592}$ - Auf diesen

590 Cf. den Index bei Vogel $(1885,411)$ s.v. solacium.

$591(141,2 \mathrm{f}$.) me silentii, frater, me oblivionis incessis? ubi erat iste animus, quando nec promulgata conloquia meruere responsum nec ad stili imperandam sollicitudinem praevius existebas? ubi fuit in abstinentia tabellarum non circa omnes in Liguria custodita? (\$3) multis a desiderio tuo peregrinantibus in solacio doloris mei paginas exhibendo et mihi taciturnitatem continuasti et illis praebuisti contra vota conloquium; quia est ista humanarum rerum ratio, ut pro magna cognatione par studium semper existat. cuius ordinis immemor voluisti sociare quaedam imperita cum litteris, putans coire posse in affectum toto calle distantia. quid promovit suada oratio tua elucubratis concinnata sermonibus, quando bonarum artium nescios appellabat amante posthabito? sed hinc alias.

$592(141,4)$ nolo excessuum multitudinem relegere, qui brevi satisfactione delenitus sum. nam parcitate in eloquendis illis usus fueram, nisi nosse vos crederem, de offensis illud remanere 
Brief von Johannes bezieht er sich auch im darauf folgenden Brief an Constantius, bei dem er sich dafür bedankt, dass er Johannes zum Schreiben gebracht habe (142; Briefe an Constantius und Johannes nebeneinander auch 54-57).

Schon diese beiden Briefe an Johannes zeigen, dass Ennodius sich von Symmachus unterscheidet und dass seine Selbstcharakterisierung mit den Begriffen inportunitas und inpudentia durchaus treffend ist. Dass er am Ende mit wenigen Worten dann doch noch einlenkt, indem er auf die bestehende Freundschaft verweist, zeigt, dass die inportunitas eine Pose ist und dass daran nicht zuletzt die Idee und die Abweichung von der Norm, der Verstoß gegen die Spielregeln gewürdigt werden will (zuweilen jedoch wird der strenge vorwurfsvolle Ton auch bis zuletzt durchgehalten, siehe z.B. zu 455 unten 336). Die Haltung des inportunus und Verstöße gegen die Spielregeln werden im Folgenden häufig zu beobachten sein, besonders in Kapitel II 3 bei der Präsentation ganzer Briefe.

Nachdem bereits deutlich geworden ist, dass Ennodius den Themen 'Freundschaft ' und 'Korrespondenz' große Bedeutung zumisst, ist nun eine besondere Methode zu betrachten, mit der er diese Bedeutung häufig formal unterstreicht: Sehr auffällig ist sowohl der Beginn von Briefen mit Prooemien, in denen er allgemeine Gedanken zu >Freundschaft‘, ,Korrespondenz ‘ oder (viel seltener) zu anderen Themen äußert, als auch die Clusterbildung von Sentenzen.

\section{d.1.3 Die 'Topoi-Cluster}

Gedanken zu den Themen >Freundschaft ‘ und >Korrespondenz finden sich häufig am Anfang von Briefen, überwiegend in Form von (Reihen von) Sentenzen bzw. Variationen ein- und derselben Sentenz; auf die häufigen "Ketten von Sentenzen " bei Ennodius macht Fuhrmann aufmerksam (1995, 270). Z.B.: "Durch Schreiben wird die Freundschaft ernährt oder erhalten. Die briefliche Unterhaltung dient der Freundschaft. Stumme Freundschaft bietet das Bild eines Abweisenden. Freundschaft, die nicht in Worte hervorbricht, vermindert ihren Glanz. Das Geheimnis des Her-

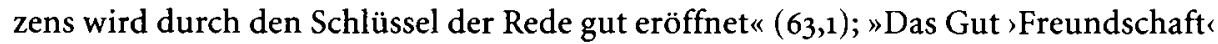
zeigt sich durch häufiges Schreiben. Denn durch die Aussage der Zunge werden die Geheimnisse der Seelen offengelegt. Wer Muße gegen Freundschaft eintauscht, wendet Mühe für dauernde Gespräche auf. Durch diese Handlungen wird die schweigsame Freundschaft bekannt « $(152,1) ;{ }^{593}$ Auch zu anderen Themen äußert Ennodius

quod tegitur, et quod in vocem erumpit amoveri. domine mi, precor, ut posthac ad ea quae male habere didicisti non tamquam emendationis contemptor adspires: sed crebro mihi dulces paginas dirige, ut crescat dos facundo, dum servat sacramenta concordiae.

$593(63,1)$ aut alitur aut sustentatur scriptione diligentia. ministra affectionis est epistularis confabulatio. muta caritas simulacrum praesentat ingrati. depretiat genium suum quae in vocem non prorumpit amicitia. bene secretum pectoris reseratur clave sermonis. $(152,1)$ exercetur bonum diligentiae scriptione multiplici. linguae enim indicio animorum secreta 
sich in dieser Weise, z.B. dazu, dass Lob zu weiteren Taten anstachelt: »Es zeichnet einen guten Feldherrn aus, die Qualitäten eines Soldaten, die sich im Kampf gezeigt haben, zu bestärken, damit die Tapferkeit durch Lob genährt und dazu gebracht wird, in einem zweiten Kampf die Liebe zum Sonnenlicht zu vergessen. Wessen Kraft würde durch das Lob des Anführers nicht vergrößert? Welchen Kämpfen würden sich auch weniger starke Glieder eines jungen Soldaten verweigern, wenn er am Zeugnis des Anführers sieht, dass seine Taten nicht vergeblich waren? Dass das Vergessen gute Taten nicht zerstört, ist der einzige Weg, den Kampfeseifer wachsen zu lassen « $(117,1)$. Ein weiteres Thema, das in Sentenzen ausgeführt wird, ist, dass gute Nachrichten schnell verbreitet werden: "Üblicherweise verbreitet erfreuliche geschmückte Rede gute Nachrichten, indem das, was Redegewandten an Gutem widerfahren ist, mit der wahren Sprache der Freude durch die Völker läuft. Es ist leichter, mit der Zunge ein für den Scheiterhaufen angefachtes Feuer zu ersticken, als zu schweigen, wenn Wünsche sich erfüllt haben. Es ist ein Gesetz der Menschlichkeit und ein Befehl der Natur, dass die Freude der Seele durch das Schreiben entströmt. Denn Erfreuliches verbreitet sich, auch wenn es in Kammern eingeschlossen wird « $(322,1) .{ }^{594}$

Vorreden dieser Art leiten etwa ein Viertel der Briefe ein. Sie beginnen ganz unpersönlich, ohne Personalpronomina, ohne Anrede, nur mit allgemeinen Aussagen, und es dauert eine Weile, bis das "Ich" des Briefs sich meldet und das "Du " angesprochen wird. Charakteristisch sind die unverbundene Parataxe (siehe dazu ausführlich unten 259) und die Verwendung von Prädikativsätzen mit est, von numquam, nemo, semper, vix est ut etc., z.B.: $(38,1)$ Numquam inter amantes silentio bene multatur offensa. gravius inventorem percutit vindictae novitas quam errantem. nefas est pro emendatione culparum culpas adhiberi, dum studio curationis qui medetur aegrescit. volui $[\ldots]$ : »Es ist niemals gut, einen Freund, über den man sich geärgert hat, mit Schweigen zu bestrafen; die Rache trifft ihren Urheber, der nicht daran gewöhnt ist, stärker als den, der den Fehler begangen hat; es ist nicht richtig, sich falsch zu verhalten, um falsches Verhalten zu korrigieren, da in der Absicht zu heilen der, der heilt,

panduntur. adsiduis curam inpendit adloquiis, qui otium amore commutat. haec sunt officia, per quae tacitus innotescit affectus. Weitere Beispiele: 22,1. 30,1. 84,1. 173,1. 259,1. $291,1$. 299,1.312,1. 358,1.383,1. 419,1.

$594(117,1)$ Boni imperatoris est probatam in acie militis animare virtutem, ut fortitudo laudis pabulis invitata in secundis congressibus dediscat lucis affectum. cuius robur ducis praeconio non nutritur? quibus se denegent etiam minus valida tironis membra conflictibus, quando rectoris testimonio videt sibi non perire quod gesserit? sola via est, qua ad proeliandum crescat intentio, quotiens bene gesta non delet oblivio. - $(322,1)$ Solet prosperorum indicia dispergere sermonis iucunda festivitas, dum quicquid boni facundis adcesserit, germana gaudiorum per populos voce discurrit. facilius est ignem in pyras animatum lingua conprimere, quam silentium inter optata servare. humanitatis lex est et naturae imperium, hilaritatem mentis opibus scriptionis effluere; emanant enim vel si artentur secunda conclavibus. 
selbst krank wird. - Ich wollte... «; oder $(20,1)$ Idem est terminum in adrogantia non tenere quod in humilitate transcendere. supercilii affectus est iusto amplius esse subiectum; familiare est graviter hiantibus novas invenire blanditias, et grandis coturnus, in eloquentia simulare formidinem vel examen metuere de laude securum. ego [...]: „Es ist das gleiche, zu anmaßend zu sein wie zu demütig. Es ist eine hochmütige Haltung, unterwürfiger zu sein, als angemessen ist. Es ist weit verbreitet, für heftig Staunende neue Schmeicheleien zu erfinden, und es ist erhabener Stil, in der Redekunst Scheu vorzutäuschen bzw. die Prüfung zu fürchten, wenn man sich des Lobes sicher ist. - Ich [...]«.

Ennodius selbst weist zuweilen ausdrücklich darauf hin, dass er Briefe mit Vorreden einleitet; dabei verwendet er die Begriffe praefatio $(66,2.268,3.358,1)$, praefata concinnatio $(84,3.91,1)$, praefata generalitas $(60,1)$; praeloqui $(293,1)$ o.ä. So sagt er nach solchen Sentenzenketten z.B.: "Ich will also den Grund für diese Vorrede nennen, damit ich nicht $[\ldots]$ meinen erstrebten Nutzen durch die Länge der Rede aufzuschieben scheine« $(66,2)$; »Die vorangestellten Ausführungen betreffen Dich, liebe Schwester « $(84,3)$; »Damit habe ich also vorweg gesagt, welcher Grund mich vom Schreiben abhielt $[\ldots] \lll(293,1) .{ }^{595}$

\section{Prooemien in Briefen}

In Briefen der spätantiken Epistolographen sind Prooemien mit Betrachtungen zu den verschiedensten Themen oder mit Sprichwörtern keine Seltenheit. Z.B. schreibt Hieronymus eine allgemeine Einleitung über die Kürze des Lebens und leitet dann zum eigentlichen Thema über: $»$ Du wirst sagen, wozu dieser weithergeholte Anfang [...]; natürlich um Dich in Deinem Alter zu loben « (Hier. 20,2,1); ${ }^{596}$ " Du treibst einen Laufenden an`, sagt derjenige, der gebeten wird, etwas zu tun, was er sowieso tun wollte, auch ohne Aufforderung. Du fragst vielleicht, mit welcher Absicht ich dies vorausschicke. Der Briefbote bittet eindringlich [...] « (Sidon. 4,7,1). ${ }^{597}$ Dass solche Vorworte üblich sind, zeigt Augustin, wenn er ausdrücklich darauf hinweist, dass er keines schreibt: »Ich verzichte auf eine Vorrede und beginne schnell mit dem, was

$595(66,2)$ causam ergo praefationis insinuo, ne [...] utilitatem meam differre videar prolixitate sermonum; $(84,3)$ germanitatem tuam respicit praefata concinnatio; $(293,1)$ ecce praelocutus, quae me causa ab his muniis suspenderet [...].

596 (Hier. 10,2,1) Quorsum, ais, ista tam alto repetita principio et ita procul coepta [...]? videlicet ut senectutem tuam $[\ldots]$ praedicem. Siehe auch z.B. (Hier. 13,1) [...] cur, ais, tale principium?; (Hier. $16,1,1)[\ldots]$ quorsum ista tam longo repetita prooemio? videlicet, ut [...]. (Hier. $52,4,1)[\ldots]$ quorsum haec tam longo repetita principio? ne [...]. Siehe auch: (Hier. 58,4,1).

597 (Sidon. 4,7,1) Solet dicere »currentem mones" qui rogatur, ut faciat quod facturus fuerat etiam non rogatus. percontere forsitan, quo spectet ista praemitti. baiulus apicum sedulo precatur [...]. Siehe auch: (Sidon. 4,14,1) [...] »quo respicit«, ait, "ista praefari?«; (Sidon. $4,21,1)[\ldots]$ nos, unde haec ipsa praemisimus, persequamur. (Sidon. $3,8,1)[\ldots] " q u o r s u m$ istaec? « inquis. 
Du schon so lange von mir hören willst [...] « (Aug. 7,1), ähnlich Nebridius an Augustin: "Da ich schnell zum Thema kommen möchte, mag ich keine Vorrede, keinen Einstieg « (Aug. 8,1)..$^{598}$

Besonders häufig verfasst Symmachus Prooemien, und zwar mit Sprichwörtern bzw. Sentenzen, z.B.: "Nicht umsonst heißt es, dass die Seelen der Menschen bei strahlendem Himmel leuchten und sich verdunkeln, wenn sich eine Wolke bildet. Meine Seele hat dieses bestätigt. Denn [...] « (Sy. 1,37,1); "Es ist ein alter Spruch, dass 'die Ehre die Künste nährt «. Dies bestätigt auch die Erfahrung zu unserer Zeit. Denn [...] « (Sy. 1,43). ${ }^{599}$ Symmachus lässt etliche Briefe in ähnlicher Weise beginnen, und er benennt dieses Vorgehen auch genauso wie Ennodius (und ebenso wie Ennodius verwendet er diese Art Einleitung viel häufiger, ohne sie explizit zu benennen), z.B.: "Es liegt in der Natur der Dinge, dass diejenigen, die stottern, besonders viel reden; denn aus Scham über diese Schwäche streben sie nach Masse. Dieses Beispiel zielt auf mich [...] « (Sy. 1,76); "Sich um die Bitten der Freunde zu kümmern, ist eine Aufgabe mit gutem Gewinn [...]; worauf diese Vorrede zielt, will ich kurz erklären [...] « (Sy. $1,77) ;{ }^{600} "[. .$.$] die vorangestellten allgemeinen Betrachtungen betreffen meinen Sohn "$ (Sy. 2,91,1). Symmachus liefert auch eine allgemeine Begründung für die Verwendung solcher Einleitungen (mit dem paradoxen Ergebnis, dass im vorliegenden Fall keine Einleitung nötig sei): „Eine Vorrede ist nötig, wenn man um etwas Schwieriges bittet; bei mühelosen und leichten Dingen muss man keine Umschweife machen « $\left(\right.$ Sy. 6,3). ${ }^{601}$

\section{Sentenzen in Briefen}

Die Sentenzen, die sich einzeln bei Symmachus und gereiht bei Ennodius finden, könnten zunächst daran erinnern, dass Cicero besonders in die Briefe an Atticus, aber auch in die übrigen, viel Proverbielles einfließen lässt, dass andere Epistolographen ihm darin folgen und dass auch die Brieftheorie Sprichwörter neben griechischen Wörtern und Dichterzitaten als Teil des Schmucks empfiehlt: et proverbio

598 (Aug. 7,1,1) Prooemio supersidam et cito incipiam, quod me iam iamque vis dicere [...]; (Aug. 8,1) Festinanti mihi ad rem pervenire nullum prooemium, nullum placet exordium.

599 (Sy. 1,37,1) Non frustra praedicant mentes hominum nitere liquido die, coacta nube flavescere. meus animus fidem fecit exemplo. nam [...]. (Sy. 1,43) Vetus sententia est artes honore nutriri. eam nostrae aetatis confirmavit usus. nemo enim [...].

$600($ Sy. 1,76$)$ natura rerum est, ut qui balbutiunt, plus loquantur; adfectant enim copiam pudore defectus. hoc exemplum me expetit $[\ldots]$; (Sy. 1,77) Amicorum orata curare bonae frugis officium est $[\ldots]$ quorsum spectet hoc anteloquium breviter explicabo $[\ldots] ;($ Sy. 2,91,1) $[\ldots]$ ad filium meum [...] pertinet praefata generalitas; siehe auch z.B. 3,41 praeloquor; 7,62 praefata sententia; 9,40 proloquor.

601 (Sy. 6,3) Praefato opus est, si ardua postulentur; pronis ac facilibus admoveri ambitum non oportet. 
uti non ignoto percommodum est, et versiculo aut parte versus (Iul. Vict., p.106, 15f.). ${ }^{602}$ Doch Cicero, Plinius und Fronto verwenden zwar Sprichwörter, aber nicht Sentenzen der Art, wie sie bei Ennodius zu lesen sind, schon gar nicht als Briefeingang; CuGUSI $(1989,389)$ verweist hinsichtlich von Prooemien auf einen einzigen Brief von Fronto. ${ }^{603}$ Die Idee für Sentenzenketten zum Thema Freundschaft könnte Ennodius bei Hieronymus gefunden haben, allerdings am Ende eines Briefs: »Freundschaft kann man nicht kaufen; Freundschaft ist nicht für Geld zu haben; eine Freundschaft, die enden kann, war niemals eine wirkliche Freundschaft « (Hier. 3,6) ${ }^{604}$ Insgesamt aber erklärt sich die massive Präsenz der Sentenzen bei Ennodius, besonders innerhalb der Praefationes, durch einen vergleichenden Blick auf die Variae von Ennodius' etwas jüngerem Zeitgenossen Cassiodor: Dieses Element der Briefe entstammt ursprünglich wohl nicht der epistolographischen Tradition, sondern entspricht dem sog. >Kanzleistik, d.h. dem Stil von Kaiserurkunden, -edikten und -gesetzen. ${ }^{605}$ LUISELLI $(1982,72 \mathrm{f}$.) hat (mehr im Vorübergehen und recht summarisch in einer Fußnote) darauf aufmerksam gemacht, dass Ennodius' Briefe nach dem Kompositionsschema spätantiker Dokumente und vieler Briefe der Variae gestaltet seien und dass er seinen Briefen so einen gewissen offiziellen Charakter verleihe. Dieser wichtigen Beobachtung, die in der Forschung bisher unbeachtet geblieben ist, soll hier genauer nachgegangen werden.

\section{Der Kanzleistil}

Die Gestalt und die Geschichte solcher Praefationes sind untersucht worden im Zusammenhang mit Cassiodors Variae (siehe einleitend dazu oben 165). Die Variae, die Cassiodor teils im eigenen Namen als Praefectus praetorio, aber überwiegend als Sekretär Theoderichs und anderer Herrscher in deren Namen verfasste, sind inhaltlich und stilistisch den Kanzleischreiben zuzuordnen. Der Aufbau der Schreiben folgt einem festen Schema: Vorwort (exordium), Bekanntmachung (notificatio / provulgatio), Darstellung der Umstände, die zu dem Schreiben geführt haben (narratio), Verfügung / Besiegelung des juristischen Aktes (dispositio), Abschluss / Bekräftigung (sanctio / corroboratio). Es gab demnach schon in der Spätantike ein festes Briefformular, das der mittelalterlichen Praxis der Kanzleischreiben entspricht bzw. diesem zugrundeliegt (siehe PFerschy 1986, aufbauend auf FrIDH 1956, gf.).

602 Siehe dazu: Отто 189o, XXXV; Отто gibt auch Beispiele für Proverbielles in anderen Briefsammlungen, bei Plinius, Fronto etc. - Siehe auch Cugusi (1983, 96-98). - Viel Sprichwörtliches findet sich bei Sidonius Apollinaris (siehe AMHERDT 2001, 46).

603 Fronto (ad am. 1,1,2) Quorsum hoc tam ex alto prohoemium? [...] (van den Hout, 2.Aufl. 1988, p.170).

604 (Hier. 3,6 ) caritas non potest conparari; dilectio pretium non habet; amicitia quae desinere potest, vera numquam fuit.

605 Siehe einführend dazu B. SowINSKI, »Kanzleistil«, HWRh, Bd. 4 (1998), 882-887. 
Die Entwicklung der Praefationes lässt sich anhand von senatus consulta, Kaiserbriefen, Edikten und Reskripten beobachten (FRIDH 1956, 40-45). Es lässt sich zeigen, dass zu den in den Codex Theodosianus und in den Codex Iustinianus aufgenommenen Gesetzen ursprünglich auch solche allgemeinen Praefationes gehört hatten, die aber bei der Erstellung der Codices als überflüssig betrachtet und weggelassen wurden, ${ }^{606}$ da die Redaktoren offenbar der Auffassung waren, dass die Praefatio nicht eigentlich wichtig sei (ibid. 20-22; 44). ${ }^{607}$

Die Praefatio ist der Ort für eine Bekräftigung der guten Absichten und der Prinzipien des Verfassers, für eine philosophische Betrachtung, ein allgemein akzeptiertes ethisches Axiom (FridH 1956, 12). Häufige Themen der Praefationes in den Variae sind daher: Bekräftigung der Pflichten des Herrschers, seine Sorge um seine Untertanen, sein Einsatz für Recht und Gesetz, sein Eifer, treue Dienste zu belohnen etc. (ibid. 31f.), z.B.: "Wir lieben es, unsere Wohltaten zu vermehren, und niemals bereitet erwiesene Freigebigkeit Verdruss [...] «(var. 2,2,1); »Unsere Menschlichkeit kann sich Bitten beugen, und sie kann wegen der Liebe zur Milde die Grenzen der Gerechtigkeit unbeachtet lassen « (var. 2,9,1); »Die königliche Milde hat den Vorsatz, ungerechtfertigtem Hass den Boden zu entziehen und den Hochmut der bewaffneten Macht durch die Achtung vor den Befehlen zu zügeln « (var. 3,27,1); »Es ist ein königlicher Vorsatz, denen, die von einem verderblichen Schicksal bedrückt werden, mit tröstender Milde zu Hilfe zu kommen und die harten Fälle des Unrechts gegen ein besseres Schicksal zu tauschen « (var. $4,41,1){ }^{608}$

Solche Vorworte sind nicht ornamental, sondern sie haben die Funktion, in allgemeiner Weise die verkündete Entscheidung zu rechtfertigen (FrIDH 1956, 39). Erklären lässt sich das moralische Vorwort zu Gesetzen damit, dass durch den vorangestellten allgemeinen Moralkodex Einverständnis zwischen den Gesetzgebern und denen, die das Gesetz befolgen sollen, erzielt und so der Abstand zwischen Herrscher und Beherrschtem überdeckt werden soll..$^{609}$

606 Cod. Iust. de novo 2 (528): resecatis [... praefationibus; siehe auch De Iust. I (529). In wenigen Fällen hat man nur den allgemeinen Teil stehenlassen (FRIDH 1956, 49).

607 Zur Entwicklung siehe auch R. M. HoNIG, Humanitas und Rhetorik in spätrömischen Kaisergesetzen, Göttingen 1960. - G. Rins, Prolog und Epilog in Gesetzen des Altertums, München 1983. - Zum Weiterleben der Praefatio in der mittelalterlichen Arenga siehe P. КосH, "Arenga«, HWRh Bd. 1 (1992), 877-889.

608 (Cassiod. var. 2,2,1) Amamus beneficia nostra geminare nec semel praestat largitas collata fastidium $[. .$.$] ; (var. 2,9,1) Inclinari precibus nostra novit humanitas nec pro affectu pietatis$ fines potest iustitiae custodire; (var. 3,27,1) Propositum est pietatis regiae locum iniustis odiis amputare et potestatis armatae supercilium cohibere reverentia iussionum; (var. 4,41,1) Propositum regale est pressis labe fortunae pietatis remedio subvenire et acerbos casus iniuriae meliore sorte mutare.

609 Siehe z.B. Benner 1975; sie zeigt die frühen Anfänge auf: Platon (Gesetz als Erziehung, Motivation zur Befolgung des Gesetzes); Cicero (Cic. leg. 2,14 persuadere aliquid, non omnia vi ac minis cogere). - $\mathrm{Zu}$ den Themen der Vorworte siehe: H. FichtenaU, Arenga, 


\section{Die Funktion der Praefatio bei Ennodius}

Ennodius entwirft in den Praefationes (und zuweilen auch an anderen Stellen in den Briefen) einen Kanon von Idealbildern der Freundschaft, der Korrespondenz und verschiedener anderer Verhaltensweisen, so wie die Herrscher in ihren Verlautbarungen die Idealbilder ihres Handelns. Während von der Sache her die Praefationes bei Ennodius, die den briefspezifischen Themen >Freundschaft $`$ und )(Aspekte der) Korrespondenz، gewidmet sind, keine Entsprechung bei Cassiodor haben, formuliert Ennodius zuweilen auch Maximen, Erfahrungen und Gedanken über Verhaltensweisen, wie sie mutatis mutandis auch in den Variae stehen oder stehen könnten, z.B.: "Die himmlische Vorsehung verweigert frommen Wünschen niemals die Erfüllung; denn was wir fromm wünschen, gibt sie mit schnellem Eifer « $(303,1)$; »Von Natur her wird aus Sorge Freude und wandelt sich Klage zu Lob, wenn Wünsche erfüllt werden « (141). ${ }^{610}$ Wie gleich zu zeigen ist, folgen auch bei Ennodius, ebenso wie in den Verlautbarungen der Herrscher, auf die allgemeine Betrachtung häufig ein Vorwurf und eine Aufforderung.

Ennodius lässt so nicht nur in die (wenigen) Briefe zu konkreten dienstlichen Angelegenheiten, sondern vor allem in solche Briefe, die nur der Kontaktpflege dienen, in großem Maße ein Element des offiziellen Stils einfließen; dass Ennodius in der Tat direkt an den Kanzleistil anschließt, zeigen weitere Details, die er aus dem betreffenden Vokabular entlehnt (vgl. z.B. oben 210). Indem er solche am Kanzleistil orientierten Praefationes formuliert, erhalten diese Briefanfänge einen offiziellen Ton (cf. Luiselli 1982, 72). Ennodius spricht über Freundschaft und Korrespondenz so, wie Cassiodor den Herrscher in Kanzleibriefen, offiziellen Dokumenten, Edikten, Reskripten, Ernennungen, Empfehlungen und der diplomatischen Korrespondenz mit anderen Herrschern sprechen lässt. So erscheint der Verfasser in einer gewissen Erhabenheit, und die Themen der Korrespondenz wie >Freundschaft ‘ und `Frequenz der Korrespondenz« werden formal auf eine offizielle Ebene gehoben. FuHrmanN bezeichnet die Verwendung der Sentenzen bei Ennodius als »besonders geeignet, dem Brief den Charakter des Einmaligen zu nehmen, ihn zu entindividualisieren “ ( ${ }^{2} 1995$, 270). Doch zum einen folgt auf die allgemeinen Sentenzen in jedem Brief der konkrete Fall (der in Bezug auf die Sentenz als gewöhnlich oder als Ausnahme dargestellt wird), zum anderen ist nicht bekannt, ob auch andere Briefschreiber ihre Privatbriefe nach dem offiziellen Schema geschrieben haben oder ob dies gerade ein in-

MIOG Erg.-Bd. 18, 1957.- H. Hunger, Prooimion. Elemente der byzantinischen Kaiseridee in den Arengen der Urkunden, Wiener Byzantinistische Studien 1, Wien 1964, 211 f.: "Propaganda im Prooimion«. - P. Classen, Kaiserreskript und Königsurkunde. Diplomatische Studien zum Problem der Kontinuität zwischen Altertum und Mittelalter, Thessaloniki 1977.

$610(303,1)$ Caelestis dispensatio religiosis desideriis numquam negat effectum; nam quod pie cupimus, maturo praestat studio; (141,1) Natura partum est, ut cura migret in gaudium et mutetur querella praeconiis, quotiens cupita tribuuntur; siehe auch z.B. $(117,1)$ oben 253 . 
dividueller Zug des Ennodius ist. Vielleicht wäre es daher besser zu sagen, dass das konkrete Thema bzw. das konkrete Verhalten des Adressaten entindividualisiert wird, indem es in Bezug zur Verallgemeinerung der Praefatio gesetzt wird.

Mit den in der Praefatio vorgebrachten allgemeinen Gedanken begründet Ennodius entweder sein eigenes Verhalten, z.B. warum er selbst schreibt, oder warum er vom Adressaten ein bestimmtes Verhalten erwartet bzw. dessen bisheriges Verhalten missbilligt. Bevor dies an einigen Beispielen gezeigt werden kann, muss zunächst auf eine formale Besonderheit hingewiesen werden, durch die er das Verständnis der Praefatio bzw. des Zusammenhangs zwischen Praefatio und Hauptteil erschwert.

\section{Verwendung von Konnektoren}

Der Zusammenhang zwischen Praefatio und Hauptteil in den Variae Cassiodors und insgesamt in den vom besagten Formular bestimmten Kanzleischreiben ist gründlich untersucht worden: Fast ausnahmslos wird die Praefatio sprachlich deutlich abgesetzt, indem der Übergang zum nächsten Abschnitt durch zumeist konklusive Partikeln (z.B. itaque, igitur, quapropter) markiert wird (FrIDH 1956, 15). ${ }^{611}$ PFERschy (1986, 73f.) weist darauf hin, dass Cassiodors Variae mit der ausnehmenden Häufigkeit der Konjunktionen ein charakteristisches Element der spätantiken Latinität aufweisen; die Konjunktionen wende er systematisch an, um die Gliederung der Briefe zu verdeutlichen, so dass die logische Entwicklung der einzelnen Formularteile klar zum Ausdruck kommt.

Bei Symmachus ist fast immer ein solcher Konnektor zwischen allgemeiner Praefatio und Hauptteil vorhanden, z.B.: "Nicht an der Seltenheit von Briefen darf man die Treue und den Eifer von Freunden messen; denn meistens fehlt denen, die gerne schreiben möchten, die Gelegenheit, und doch vergeht die Erinnerung an die Freundschaft nicht durch zeitweises Schweigen. - Deshalb [...] « (Sy. 5,89); "Freundschaft lässt sich an den Seelen, nicht an den Jahren messen. - Deshalb [...] « (Sy. 6,17); "Man muss ausführlicher schreiben, wenn man Unbekannte empfiehlt. - Iustinus aber $[\ldots] \ll\left(\right.$ Sy. 6,27). ${ }^{612}$

Ennodius hingegen verzichtet zumeist darauf, den Übergang von der Praefatio zum Hauptteil zu markieren und das gedankliche Verhältnis zwischen den Teilen durch Konnektoren zu verdeutlichen, ${ }^{613}$ wodurch das Verständnis der Briefe nicht

611 Siehe auch: SKahiLl 1934, 188f.. - ClasSEN 1977, 77. -VIDÉN 1984.

612 (Sy. 5,89) Non ex officii raritate amicorum religio et cura pendenda est. plerumque enim scribendi cupidis defit occasio, nec tamen amicitiae memoria temporali silentio consenescit. itaque $[\ldots]$; $($ Sy. 6,17) Amicitia animis non annis aestimatur; rudis igitur [...]; (Sy. 6,27) Uberius scribendum est, si commendentur incogniti; Iustini autem [...]; siehe auch z.B. Sy. 2,$10 ; 2,29 ; 5,75 ; 6,22 ; 6,44 ; 7,87 ; 7,88 ; 7,102$.

613 LUiselli $(1982,72 f$ ), der darauf aufmerksam macht, dass Ennodius diesem offiziellen Kompositionsschema folgt, hat diese Besonderheit übersehen und gerade solche Beispie- 
eben erleichtert wird. Wenn die Gedanken asyndetisch aneinander gereiht werden, muss man sehr aufmerksam lesen, um überhaupt zu bemerken, dass der Hauptteil beginnt; erkennbar ist dies bei Ennodius häufig nur an der Verwendung eines Personalpronomens oder einer diesbezüglich deutlichen Verbform, z.B. Numquam inter amantes silentio bene multatur offensa. gravius inventorem percutit vindictae novitas quam errantem. nefas est pro emendatione culparum culpas adhiberi, dum studio curationis qui medetur aegrescit. - volui taciturnitatem [...] imitari $(38,1$, Übersetzung oben 253); Aut alitur aut sustentatur scriptione diligentia. ministra affectionis est epistularis confabulatio. muta caritas simulacrum praesentat ingrati. depretiat genium suum quae in vocem non prorumpit amicitia. bene secretum pectoris reseratur clave sermonis. - dignatione vestra... (63,1, Übersetzung oben 252). Zur Erleichterung der Lektüre füge ich bei den Zitaten in dieser Arbeit immer einen Gedankenstrich ein, um die Schnittstelle zwischen den beiden Teilen zu markieren. (Weitere Beispiele unten 260-262, 308.)

Wenn Ennodius auf den Konnektor verzichtet, ist es dem Leser überlassen, zunächst zu bemerken, dass die Praefatio abgeschlossen ist und der Hauptteil beginnt, und dann das gedankliche Verhältnis zwischen beiden Teilen zu erkennen. Der Leser wird also nicht geführt, sondern ist gezwungen, den Aufbau selbst zu durchschauen und den Gedankengang sehr genau nachzuvollziehen. Für den zeitgenössischen Leser wird das gedankliche Verhältnis vielleicht ebenfalls oft nicht beim ersten linearen Lesedurchgang deutlich gewesen sein, auch wenn dieser, anders als der moderne suneingeweihte Leser, den Kanzleistil mit den dazugehörigen Praefationes und Sentenzen im Prinzip kannte. Ennodius erhöht so einerseits die Schwierigkeit, andererseits aber auch den Reiz für den Adressaten. An einigen Beispielen soll nun gezeigt werden, wie Praefatio und Hauptteil bei Ennodius inhaltlich zusammenhängen können.

\section{Begründung des eigenen Verhaltens}

Ziel eines Briefes (38) an Laconius (PLRE II, 653) ist es, ihm seine Schreibfaulheit vorzuwerfen; er, Ennodius, habe sich selbst mit Schweigen rächen wollen, habe aber nun doch mit diesem Brief die Schreibfaulheit des Adressaten durch die eigene Redseligkeit aufgewogen. Die Praefatio (numquam [...] aegrescit, zitiert oben 253) formuliert allgemein, dass derjenige, der sich für die Schreibfaulheit eines anderen durch eigenes Schweigen rächt, sich selbst am meisten schade. Nach der Praefatio fährt Ennodius fort (ohne den Hauptteil durch einen Konnektor mit der Praefatio zu verbinden): "Ich wollte das Stillschweigen, das Ihr, weil Ihr nicht an mich denkt, mir gegenüber bis jetzt an den Tag gelegt habt, nachahmen, doch als ein sanftmütiger Mensch

le angeführt, in denen Ennodius Konnektoren verwendet. - Ausnahmen (mit Konnektor) z.B. in 95 (itaque), oben 182; in 30 (ista ...) unten 263; in 305 (sic ...), unten 299; in 419,1 . 
konnte ich die Geringschätzung, zu der starke Seelen fähig sind, nicht nachahmen “ $(38,1) \cdot{ }^{614}$ In der Praefatio hat Ennodius also eine allgemeine Begründung für sein eigenes Verhalten vorangestellt. Er fährt fort, er habe eigentlich zuerst einen Brief von seinem Adressaten erwartet, doch nun erhoffe er sich zumindest eine Antwort; auch wer nicht von sich aus schreibe, sei doch immerhin verpflichtet, auf einen erhaltenen Brief zu antworten (siehe oben 155 zu den sSpielregeln`): "Zwar habe ich zuerst auf einen Brief von Euch gewartet, doch ich wollte mich nicht, indem ich lange schweige, selbst um eine Antwort bringen; denn ich denke, dass ich eine beispielhafte Anregung zum Reden nur durch Reden geben kann $[\ldots] \ll(\$ 2) .{ }^{615}$ Die Praefatio erklärt, warum er schreibt - damit tadelt er zugleich indirekt den Adressaten.

In der Praefatio zu einem Empfehlungsschreiben (425) begründet Ennodius, warum er dieses verfasst: Der junge Ambrosius habe zwar keine Empfehlung nötig, aber es wäre unklug, wenn Ennodius sich die Gelegenheit entgehen ließe, dessen Vater Faustinus einen Gefallen zu tun, wenn dieser so sehr darum bitte. Er beginnt mit allgemeinen Gedanken: "Wie wenn man die Sonne mit Fackeln unterstützen und das Meer mit einem kleinen Tropfen bereichern wollte, so treibt man überflüssigen Aufwand, wenn man etwas empfiehlt, das von sich aus gefällt. Doch es wäre dumm, sich eine Gelegenheit zu einem Gefallen entgehen zu lassen, wenn ein Starker um Unterstützung bittet. Ein Reicher ist unermesslich reich, wenn er das für Hilfe hält, was ein Armer gibt. Ein Geschenk wird königlich, wenn ihm der Empfänger außergewöhnlichen Wert zumisst “ $(\$ 1){ }^{616}$ Dann folgt (unverbunden) der konkrete Anlass: "Der Herr Faustinus ist über das Vorankommen seines Sohnes besorgter, als es die väterliche Sorge fordert, und dachte, dass unser Ambrosius bei Euch mit diesem Geleitbrief bewaffnet sein müsste [...].«

Wie in diesen beiden Beispielen nutzt Ennodius die Praefatio häufig zur Begründung dafür, warum er den vorliegenden Brief schreibe (siehe noch z.B. unten 311).

$614(38,1)$ volui taciturnitatem quam circa me hactenus mei inmemores servastis imitari, sed homo lenis animorum fortium non potui aequare contemptum.

$615(38,2)[\ldots]$ expectans quidem a vobis praevium munus in litteris, sed non volui mihi ipse, dum diu taceo, negare responsum, aestimans, quod loquendi formam dare nisi loquendo non possem.

$616(425,1)$ Quasi solem facibus adiuvet et mare exiguo umore locupletet, ita superfluis laborat inpendiis qui per se placitura commendat. sed stultum est perire occasionem beneficii, quando auxilium fortis inplorat. opum largus supra copias ditatus est, si credit subsidium quod pauper obtulerit. regale munus fit, cui insigne pretium praestat accipiens. - domnus Faustinus de prolis suae profectu supra quam poscit paterna cura sollicitus, Ambrosium nostrum hac apud vos credidit prosecutione communiri [...]. 


\section{Erwartungen an den Adressaten}

In der Praefatio zu einem Empfehlungsbrief (416) an Papst Symmachus für den jungen Beatus, der zur Fortsetzung seiner Studien nach Rom geht, formuliert Ennodius seine Zuversicht, dass seine Empfehlung Erfolg haben werde: "Nicht ohne Erfolg bittet man, wenn man dem Vater aller <sc. dem Papst $>$ Fremde empfiehlt. Adligen schuldet man <nur > eine allgemeine Empfehlung, besonders bei denen, die < auch> ungebeten Gefallen tun. - Den jungen erhabenen Beatus [...] « $(\$ 1) .{ }^{617}$ - Der Gedanke, dass der Herrscher die Schwachen schützen muss, findet sich in Praefationes des Herrschers in den Variae häufig, z.B.: "Die Fürsorge des Herrschers muss das Erschöpfte aufrichten, damit die Milde der Befehle die Härte der Zufälle mildert. Denn die Widrigkeit wird nicht gespürt, wenn gewährtes Wohlergehen zeigt, dass aufgerichtet wurde, was durch das Unglück niedergedrückt war « (Cassiod. var. 4,19,1). ${ }^{618}$ Cassiodor lässt hier und in unzähligen anderen Fällen den Herrscher über sich selbst und seine Pflicht sprechen - bei Ennodius betreffen ähnliche Aussagen den Adressaten, für den daraus eine Pflicht erwächst; diese Formulierungen könnte man unter die Kategorie sverpflichtendes Lob rassen. ${ }^{619}$ Ennodius formuliert so weniger eine Bitte, für deren Erfüllung er sich bedanken müsste, als vielmehr ein 'Gesetz‘, das nicht $\mathrm{zu}$ befolgen nach seinen Worten undenkbar und ausgeschlossen ist. Das gewünschte beneficium wird zur vorgeschriebenen, eigentlich unausweichlichen Handlung (ob es dann tatsächlich so war, ist - wie bei allen Gesetzestexten - eine andere Frage). Bei Symmachus findet sich eine ähnliche Formulierung, allerdings in dem umgekehrten Fall, als er selbst eine Bitte erfüllt: »denn unter Freunden muss es bei Bitten so sein, dass dem Gewährenden leicht erscheint, was für den Bittenden viel ist « (Sy. 7,26); ${ }^{620} \mathrm{vgl}$. auch bei Plinius in der Antwort auf eine Bitte: [...] rogari non debeo, ut faciam, quod mihi non facere turpissimum est (Plin. 4,17,1). - Weitere Beispiele dafür, dass in der Praefatio in allgemeiner Weise das vom Adressaten erwartete Verhalten formuliert wird, sind besonders in den Empfehlungsschreiben zu finden (siehe z.B. unten 357).

$617(416,1)$ Non inefficaciter poscit, qui parenti omnium peregrinos insinuat. nobilibus generalis debetur adsertio, maxime apud eos qui beneficia tribuunt non rogati. - Beatum sublimem adulescentem [...].

618 (Cassiod. var. 4,19,1) Decet principalem providentiam fessa refovere, ut asperitatem casuum mitiget lenitas iussionum. non enim sentitur incommodum, si, quod per adversitatem constat oppressum, concessa prosperitas ostenderit sublevatum.

619 Der Begriff z.B. bei: I. Oppermann, Zur Funktion historischer Beispiele in Ciceros Briefen, Leipzig 2000, 294.

620 (Sy. 7,26) ea quippe inter amicos petitionum debet esse condicio, ut praestantibus prona videantur, quae sunt magna poscentibus. 


\section{Kritik am Adressaten und Aufforderung zur Besserung}

Ein Brief an Senarius (30; zur Person unten 290) beginnt mit einer Reihe allgemeiner Aussagen über den Nutzen von Korrespondenz für die Freundschaft bzw. über den entsprechenden Schaden, der durch Schreibfaulheit entsteht: "Freundschaft verliert ihre Kraft, wenn sie durch die Starre des Schweigens geschwächt wird, und die Freundschaft kann nicht im Überfluss strömen, wenn sie des gemeinsamen Gesprächs entblößt wird. Stumme Freundschaft stellt fast die Gestalt eines Nicht-Liebenden dar, und ein Abbild von Abneigung ist es, nicht durch die Bestätigung der Rede zu eröffnen, was man liebt « $(30,1) .{ }^{621}$ Diese Sätze implizieren bereits die Vorwürfe gegenüber dem Adressaten, denn dieser hat sich nicht wie erforderlich verhalten: "Diese Dinge habe ich Dir, Erhabener, im persönlichen Gespräch dargelegt, als Du zum Trost für meine Abwesenheit Briefe versprachst. (\$2) Doch was für ein Vergessen meiner Person hat nun Eure Seele befallen, dass ich über so einen langen Zeitraum keinen Brief erhalten habe, der Eure gute Gesundheit anzeigte? Dass ich nur nicht die Briefe - Aushängeschilder der Seelen - als Zeugen der Liebe vorlade! Wende also Dein dem Freund gegenüber gewissenloses Verhalten zum Besseren und übersende Schriftliches zur Erinnerung an die versprochene Treue« (\$1f.). ${ }^{622} \mathrm{Am}$ Ende wird der Ton allerdings versöhnlicher mit der Versicherung, Ennodius nehme an, dass die Bande zwischen ihnen unauflösbar seien: "Mein Herr, ich begleiche die Schulden des Grußes und bitte, dass mein gesandter Brief, wenn er Euch im Zustand der früheren Freundlichkeit mir gegenüber antrifft, eine Antwort verdient; denn ich glaube, dass die doppelten Bande von Freundschaft und Verwandtschaft zwischen uns nicht zerreißen können " $(\$ 3) .{ }^{623}$ (Zu einem weiteren Brief an Senarius, 78 , siehe unten 290.)

In dem (einzigen) Brief an den Bischof (von Ravenna?) Senator (66) erinnert Ennodius diesen an eine Abmachung; Senator habe Ennodius persönlich versprochen, dass ihm ein Sklave zurückgegeben werde $(\$ 2)$, doch seitdem Ennodius Ravenna verlassen habe, sei dies nicht geschehen $\left(\$_{3}\right)$; diesen Brief sende er mit einem Boten, der diese Sache nochmals bei Senator betreiben solle $\left(\$_{4}\right)$; ansonsten droht Ennodi-

$621(30,1)$ Perdit affectio valitudinem silentii debilitata torpore nec ad usum suum diligentiae cursus exuberat, si nudetur communione conloquii. muta caritas pene repraesentat speciem non amantis, et odiorum simulacrum est non aperire quod diligas contestatione sermonis.

$622(30,1 \mathrm{f}$.) ista sublimitati tuae coram positus intimavi, cum ad solacium absentiae meae litteras promittebas. (\$2) at nunc quae animum vestrum mei invasit oblivio, ut nullas per tanta temporum spatia, quae bonam valitudinem vestram significarent, litteras suscepissem? ne de amoris credo testimonio animorum indices epistulas convenirem. inreligiosum ergo circa amantem tui in meliorem partem verte propositum et ad memoriam promissae fidei scripta transmitte.

$623(30,3)$ domine mi, salutationis debita solvens precor, ut si vos in antiquae circa me dignationis statu pagina directa reppererit, responsa mereatur, quia puto inter nos gemina vincula disrumpi non posse caritatis et sanguinis. 
us damit, rechtliche Schritte einzuleiten ( $\$ 4$ a.E.). Der Brief beginnt mit einer allgemeinen Betrachtung: »Zweifellos ist das erste, was den heiligen Vorsätzen entspricht: von selbst für die Gerechtigkeit zu tun, was andere gewöhnlich <erst> nach Ermahnungen tun; doch der Ehrenhaftigkeit äußerst oder doch sehr nahe kommt es, auf richtige Vorschläge nicht verstimmt zu reagieren. Wenn dabei auch derjenige, der ermahnt wird, nicht den ersten Platz einnimmt, gehört ihm doch die Freude Gottes darüber, dass er sich den Empfehlungen der Wahrheit nicht widersetzt « $(\$ 1){ }^{624} \mathrm{Da}$ mit ist angedeutet, was im Folgenden konkretisiert wird: dass der Adressat sein Versprechen einhalten und nicht gekränkt reagieren solle, weil der Diakon Ennodius den Bischof zum richtigen Verhalten auffordere.

Um einen Adressaten, der bisher nicht geschrieben hat, wenigstens zu einer Antwort zu bewegen, formuliert Ennodius in der Praefatio einen Grundsatz für diejenigen, die vom Glück begünstigt sind: »Üblicherweise trösten diejenigen, die durch Gottes Weisung Glück und Macht haben, Niedrige mit Briefen und teilen ihr Wohlergehen, indem sie Briefe schreiben.« Dann folgt der konkrete Fall, dass nämlich der Adressat sich nicht nach der eingangs formulierten Regel verhalten habe: "Ich habe lange darauf gewartet, dass ich auf diese Weise aufgemuntert würde, aber da Ihr zögert, halte ich es für nötig, nicht zu schweigen, damit gemäß dem Evangelium die Dreistigkeit verdient, was die Liebe nicht erlangen kann « $(295,1) .{ }^{625}$ (Zum Bezug auf das Evangelium siehe oben 224.)

\section{Fazit}

Die Untersuchung der Praefationes hat gezeigt, dass Ennodius den traditionellen 'gattungsimmanenten $>$ Themen, die die Korrespondenz an sich und die Freundschaft zwischen den Korrespondenten betreffen, nicht nur rein quantitativ, sondern besonders auch qualitativ durch die Art der Präsentation viel Gewicht beimisst: Nach dem Vorbild offizieller Verlautbarungen von Herrschern spricht er in deren Tonfall über die `Gesetze`von Freundschaft und Korrespondenz, und ähnlich wie diese begründet er sein eigenes Verhalten, führt aus, was er vom Adressaten erwartet, oder rügt dessen Verhalten. Anders als in den offiziellen Texten fehlen in den Briefen des Ennodius jedoch zumeist die Konjunktionen und Partikeln, die dem Leser die Gedan-

$624(66,1)$ Prima res est sancto conveniens sine dubitatione proposito, sponte pro iustitia facere quidquid alii solent monitis exhibere, sed honestati proxima vel secunda, rectis suggestionibus non gravari. in qua parte etsi principem locum non possidet qui monetur, habet tamen dei gratiam, quod veritatis insinuationibus non repugnat. - $(\$ 2)$ causam ergo praefationis insinuo [...].

$625(295,1)$ Solent quibus felicitas et potentia deo ordinante conceditur humiles consolari officio litterarum et prospera sua paginarum promulgatione partiri. - ego multo tempore ut his sublevarer muniis expectavi, sed cessantibus vobis necessarium credidi non tacere, ut quod amor non exigit, iuxta evangelicam lectionem mereatur inportunitas. 
kenführung verdeutlichen können; die Adressaten werden so zum Mitdenken geradezu gezwungen.

Zum Themenkomplex amicitia ist nun noch zu betrachten, wie sich Ennodius über seine Korrespondenten bzw. amici äußert. Auch dabei zeigt sich, dass er sich deutlich von Symmachus absetzt, wobei er einzelne bei diesem zu findende Gedanken und Motive gezielt auswählt, manche gar nicht verwendet, manche in stark abgewandelter Form übernimmt und manches Neue aufweist.

\section{d. 1.4 laudes amicitiae et amici}

,Freundschaft، ist in spätantiken Briefen häufig in der Weise Thema, dass sie oder der konkret angesprochene Freund beschrieben bzw. gelobt wird. Beispiele ausführlicher Beschreibungen der zwischen den Korrespondenten bestehenden Freundschaft finden sich besonders bei Paulinus von Nola, wobei der Akzent speziell auf der Freundschaft zwischen Christen liegt: der gemeinsame Glaube wirkt in der Weise verbindend, dass Freundschaft zwischen Korrespondenten bestehen kann, die sich nie gesehen haben (siehe Trout 1999, bes. 198-218; Conybeare 200o, bes. 60-90; White 1992). Ausführungen über die traditionelle >weltliche` Freundschaft finden sich bei Sidonius Apollinaris (zu seiner "Welt der Freundschaft" siehe NäF 1995, 142-144; LOYEN 1943, bes. 95-100). Er stellt in einigen Briefen dar, worauf seine Freundschaft zum Adressaten beruhe, wodurch sie entstanden und gewachsen sei, z.B.: "Durch viele Bande der Zuneigung hatte sich von Kindheit an bis heute, wo wir erwachsen sind, unsere Freundschaft zueinander gefestigt, zum einen wegen der engen Blutsverwandtschaft unserer Mütter, zum anderen, weil wir zur selben Zeit geboren sind, dieselben Lehrer hatten, in denselben Künsten ausgebildet wurden, uns bei denselben Spielen erholt haben, unter denselben Herrschern Karriere gemacht und dieselben Ämter ausgeübt haben « [...] (Sidon. 3,1,1). ${ }^{626}$

Symmachus bricht häufig begonnene Ausführungen über die Freundschaft und den Freund nach wenigen Sätzen oder sogar nur Worten explizit ab oder bringt sie nur in Form einer Praeteritio vor (oft verbunden mit der Figur der Correctio): Er beginnt über seine Freundschaft zu Ausonius zu schreiben, hält aber ein, weil er nicht sagen müsse, was Ausonius lieber fühlen solle (Sy. 1,42,1); er verweist darauf, dass die Freundschaft die Worte übertreffe (Sy. 6,48); er lehnt es ab, sich für die täglich wachsende Freundschaft des Adressaten mit aufwändigen Worten zu bedanken, da er wisse, dass dessen Verhalten nicht auf Lob abziele, sondern aufrichtig sei (Sy. 7,32);

626 (Sidon. 3,1,1) Multis quidem vinculis caritatis ab ineunte pueritia quicquid venimus in iuventutem gratiae sese mutuae cura nexuerat, primum quia matribus nostris summa sanguinis iuncti necessitudo; dein quod ipsi isdem temporibus nati magistris usi, artibus instituti lusibus otiati, principibus evecti stipendiis perfuncti sumus eqs. Siehe auch z.B. Sidon. 4,$1 ; 5,9 ; 5,11$. 
eine solche Freundschaft dulde es nicht, durch Lob genährt zu werden $\left(\right.$ Sy. 8,58). ${ }^{627}$ Der Gedanke, dass Freundschaft sich nicht an prunkenden Worten messen lasse: religio [...] magis fide animi metienda est quam ostentatione verborum $($ Sy. 8,12$)$, muss dabei nicht immer auf das Verhalten des Adressaten zielen: Symmachus entschuldigt sich damit auch im Voraus für eine eventuelle zukünftige Säumnis seinerseits.

Symmachus zeigt also bei aller Häufigkeit des Themas eine gewisse Distanz gegenüber einem Übermaß an Worten über die Freundschaft; er spricht das Thema kurz an und verstärkt es durch Figuren wie Praeteritio oder Aposiopese, und er gibt Hinweise darauf, dass zuweilen Misstrauen und Zweifel an der Aufrichtigkeit solcher Worte angebracht sind.

Bei Ennodius finden sich zwar viele Bemerkungen zur Freundschaft im Allgemeinen, besonders in den Praefationes (siehe oben 202), aber nur selten lobende Worte auf seine konkrete Freundschaft zum Adressaten. Eines der wenigen Beispiele ist z.B. ein Brief (389) an Florus, der gebeten wird, gegenüber Faustus Ennodius' Wunsch nach einem Haus zu unterstützen; er beginnt: "Wie eng ich Dir verbunden bin, mit welcher Freundschaft ich Dich umarme, kannst Du aus dem Zustand Deiner eigenen Seele schließen. Denn selten wird einer geliebt, der nicht selbst aufrichtig liebt. Die himmlische Kraft der Seelen kommt zusammen und offenbart ihre Zuneigung in lautlosen Gesprächen. Wenn Du deshalb vorhast, mir Gleiches mit Gleichem zu vergelten, dränge den Herrn <sc. Faustus>, zu befehlen, dass jenes Suburbanum, das ich bezahle, wenn er es zulässt, erworben wird. Das möchte ich, solange ich in Ligurien sein werde, glücklich besitzen, und nach meinem Tod sollen er und die Seinen es besitzen $[\ldots] \ll(\$ 1) .{ }^{628}$

Doch zumeist formuliert Ennodius anstelle von direkten Worten über die konkrete Freundschaft die schon oben untersuchten allgemeinen Maximen zum Thema ,Freundschaft‘, darunter auch die folgende, mit der sich erklären lässt, warum er die traditionellen laudes amicitiae noch konsequenter verweigert als Symmachus: Er vertritt die Ansicht, dass jede Redekunst vor der Beschreibung wahrer Freundschaft kapitulieren muss: $(75,2)$ pauper est caritas, in cuius narratione sermo non deficit, "armselig ist eine Freundschaft, bei deren Beschreibung die Sprache nicht versagt «, und:

627 (Sy. 1,42,1) neque enim me oportet haec dicere, quae te malo sentire; (Sy. 6,48) copiosior tamen in sensibus manet gratia quam sermone profertur; (Sy. 7,32) curam in me diligentiae tuae usu probatam crescere in dies gaudeo; cui inpense verbis gratias agerem, si id laudis potius adfectatione quam sincera pietate faceres; (Sy. 8,58) vestrae in nos diligentiae grates referrem, si se amor speratus et ex mutuo debitus lactari laude pateretur.

$628(389,1)$ Qua te devinctione teneam, qua diligentia conplectar, ex animi tui potes qualitate colligere. vix enim amari contigit, nisi quos sinceriter amare constiterit. congreditur inter se caelestis vigor animarum et studia sua mutis sibi pandit affatibus. et ideo si vicissitudinem mihi reddere disponis, insiste domno, ut suburbanum illud, dato si dignatur a me pretio, comparari iubeat: quod dum in Liguria fuero, feliciter habeam et post obitum meum ipse suique possideant. [...] 
$(313,3)$ parvus amor est, qui oris testimonio sufficienter aperitur. confessio est tepidae caritatis, quotiens in ea non cedit eloquium, "gering ist eine Freundschaft, die durch das Zeugnis der Sprache hinreichend beschrieben werden kann; man gesteht eine laue Freundschaft ein, wenn vor ihr die Sprache nicht kapituliert«. Dass diese allgemeinen Aussagen für ihn selbst gelten sollen, gibt er dadurch zu verstehen, dass er keine Lobreden auf seine Freundschaft zu den Adressaten schreibt und dass seine Redekunst sich an die Größe seiner Freundschaft nicht heranwagt. An zwei weiteren Stellen betont Ennodius, dass Redekunst zwar alles erhöhen könne (vgl. Kap. I 4c), seine Worte aber dennoch nicht ausreichten, um seine Freundschaft zum Adressaten auszudrücken: "Es gibt nichts, was nicht durch prunkende Rede größer werden könnte $(110,1)$; »es gibt nichts [...], was nicht durch prunkende Rede über die Wahrheit hinaus emporgehoben werden könnte « $(116,1) .{ }^{629}$ Ennodius fährt beide Male fort, dass er dennoch seine Freundschaft zum Adressaten nicht ausdrücken könne: »ich bezeuge meine dürre Sprachlosigkeit bei der Darstellung meiner Freundschaft zu Euch « (110.1), »doch ich muss hinsichtlich meiner Freundschaft zu Euch die Sprachlosigkeit meiner Rede hinnehmen « $(116,1) .{ }^{630}$ Ennodius will also mit dem >Unsagbarkeitstopos die Stärke seiner Freundschaft aufzeigen, cf. bei Symmachus: »obwohl Worte einfacher sind als Taten, kann ich der Größe Deines Gefallens mit Worten nicht gleichkommen « (Sy. 4,4,1). ${ }^{631}$

Ausführungen über die Freundschaft verbanden sich in der Regel mit lobenden Worten über den Adressaten; besonders in `ersten Briefen` zur Kontaktaufnahme wurde üblicherweise Lob vorausgeschickt, siehe unten 304. - Sidonius Apollinaris spart weder in den carmina noch in den epistulae mit Lob (siehe NÄF 1995, 155-159). Er steht auch damit in der Tradition des Plinius, der seine Adressaten bzw. Dritte, die Thema von Briefen sind, besonders positiv darstellt. KRASSER ${ }^{632}$ nennt die Haltung des Plinius »engagierte Bewunderung «: indem er bewundere, lasse er seine eigenen Wertvorstellungen deutlich werden (S. 62f.); durch die Art der Darstellung komme der Leser letztlich dazu, Plinius für seine positive Haltung und für seine hohen Ansprüche, die sich an den von ihm bewunderten Objekten zeigten, zu bewundern. In diesem Zusammenhang ist bemerkenswert, dass Ennodius selbst sich nicht nur einmal über den Nutzen von Lob für den Lobenden äußert: Bewunderung wirke auf den Bewunderer zurück, da man nämlich annehme, jemand könne auch selbst erreichen, was

$629(110,1)[\ldots]$ nec existat quod crescere nequeat ambitione dicendi; $(116,1)$ nihil est $[\ldots]$ quod non a veritate in altum ambitioso tollatur eloquio.

$630(110,2)[\ldots]$ ego in explicanda circa vos diligentia arentem testor infantiam; $(116,1)[\ldots]$ sed ego ad diligentiam circa vos meam patior sermonis infantiam.

$631($ Sy. $4,4,1)[\ldots]$ cum sint verba rebus faciliora, beneficii tui magnitudinem dictis aequare non possum. Cf. auch Sy. 6,48, siehe Anm. 627.

$632 \mathrm{H}$. Krasser, Claros colere viros oder über engagierte Bewunderung. Zum Selbstverständnis des jüngeren Plinius, Philologus 137, 1993, 62-71. 
er an anderen schätze: dum creditur quicumque sectari posse quod diligit $(360,2$, siehe unten 312; cf. auch in 249,2, unten 272).

Auch Symmachus sieht seine Adressaten durchweg in günstigem Licht (cf. die `Normen` seiner Korrespondenz, oben 156). Doch ebensowenig wie über die Freundschaft an sich schreibt er über die konkreten Freunde bzw. Adressaten lange Lobreden. Er bricht ein begonnenes Lob ab mit Rücksicht auf die Bescheidenheit des Adressaten: "[...] Ich würde gern mehr sagen, aber man darf Dich in Deiner Bescheidenheit nicht mit zu ausschweifendem Lob belasten " (Sy. 4,26); "[...] Daher bewahre ich den erwiesenen Gefallen in meinem Gedächtnis und bezeuge ihn mit Worten. Doch Deine Bescheidenheit lässt mich nur kurz darüber sprechen; denn Du wünschst Dir Freundschaft, nicht Worte « $\left(\right.$ Sy. 7,97).$^{633}$

In einem Brief an einen Johannes ${ }^{634}$ (15) antwortet Ennodius auf ein Lob: "Ich würde mit Gleichem antworten, wenn eine erwiderte Lobrede nicht die Freundschaft des befreundeten Herzens belastete « $(15,1),{ }^{635}$ denn leicht komme der Verdacht der Schmeichelei auf $(15,1$ ne dum in praeconiis mutuum videmur scabere, adulationis suspicione polluatur adfectio). Auch Hieronymus vermeidet es mit diesem Argument, den Adressaten zu loben: "Ich scheue mich, Dich vor Deinen Augen zu loben, um nicht in den Verdacht der Schmeichelei zu geraten “ (Hier. 99,2,2). ${ }^{636}$ Dieser Gedanke findet sich auch bei Symmachus, ausgedrückt mit derselben Redewendung wie bei Ennodius "mutuum $[. .$.$] scabere :^{637}$ Symmachus bedankt sich hier $(1,31,1)$ bei Ausonius für einen Brief und lobt dessen facundia; doch er bricht das Lob ab mit den Worten: si plura de te praedicem, videbor mutuum scabere; die folgenden Sätze führen das Lob allerdings dennoch in anderer Weise fort. - Ennodius macht in dem Brief an Johannes (15) ernst mit der Verweigerung gegenseitigen Lobes unter Freunden: Er formuliert eine strenge Mahnung und fordert den jungen Adressaten zu eifrigem Studium auf, denn er sei noch nicht am Ziel seiner Bemühungen ( $\$ 4$ nisi de messe non gratulor), und er sagt, was ihm nicht gefällt: $(\$ 5)$ pulchra sunt quae scribis, sed ego amo plus fortia. ${ }^{638}$

Ennodius findet nur selten lobende Worte, wie schon in Teil I im Zusammenhang mit seinen Briefen an jüngere Adressaten zu beobachten war. Dort zeigte sich, dass Ennodius vorzugsweise indirekt, d.h. gegenüber Dritten lobt oder in Momenten, wo man

633 (Sy. 4,26) plura vellem, sed verecundiam tuam nimio laudis excursu non oportet onerari; $($ Sy. 7,97$)[\ldots]$ quare acceptam gratiam et mente contineo et ore contestor. facit autem verecundia tua, ut de hoc parcius loquar; adfectum enim non verba desideras.

634 Siehe oben Anm. 276.

635 (15,1) Vicem redderem, nisi oneraret diligentiam amici pectoris restituta laudatio [...].

636 (Hier. 99,2,2) in os laudare te vereor, ne assentandi crimen incurram.

$637 \mathrm{Zu}$ »mutuum muli scabunt« siehe OтTо (189o, 232f.). - Ein weiteres Mal bei Symmachus (epist. 10,1,3).

638 Cf.: (Hor. ars 99) non satis est pulchra esse poemata; dulcia sunto. 
es nicht erwartet. Gegenüber den anderen Adressaten verfährt er ähnlich: So werden Olybrius und Faustus besonders in Briefen an ihren Schwiegersohn bzw. Sohn gelobt (siehe oben 121f.) oder aber in Verbindung mit Tadel (siehe oben 179, 192, unten 283). Direktes Lob findet sich auffälligerweise in Momenten, wo Anderes zu erwarten wäre, etwa eine Entschuldigung (siehe oben 168, unten 318). Auch der Dank für erhaltene Briefe enthält bei Ennodius selten lobende Worte (siehe unten 294); einmal preist er die Qualitäten eines Briefes, als der Adressat eigentlich einen Glückwunsch erwartet, stattdessen im Weiteren aber streng ermahnt wird (125,2, siehe unten 341). - Zunächst sollen zwei Ausnahmen, Briefe mit direktem Lob für den Adressaten bzw. die Adressatin vorgestellt werden:

Ein auffälliges Beispiel für direktes Lob in unerwarteter Form ist ein Brief an Liberius (zur Person siehe oben 103), der in dem Moment ausführlich für seine Leistungen als Praefectus Praetorio in Italien gelobt wird, als Ennodius sich eigentlich für ein persönliches beneficium bedankt, wobei es wohl um den endlich erfüllten Wunsch nach einem Haus geht (cf. auch 457 an Liberius). In diesem Brief (447) rechtfertigt Ennodius sich explizit dafür, dass er etwas Anderes schreibt als vom Adressaten in der Situation erwartet wird. Er betont, trotz des großen beneficium objektiv über Liberius urteilen zu können und trotz der persönlich genossenen Gunst nichts schreiben zu wollen, was über die Erfahrungen der Allgemeinheit hinausgehe: "[...] Es kommt von Gott, wenn jemand, der Dir viel verdankt, unbestochen von Dir spricht, und wenn er nichts zu Schweres auf die Waage der Wahrheit legt, weil er von der Macht Deiner Geschenke unterjocht ist. (\$2) Denn warum sollte, wo man über die Höchsten spricht und etwas gestaltet, das zu den Ohren der Welt kommen soll, ein privater Dank das öffentliche Zeugnis verdecken? Zwar verdanke ich Eurer Hoheit mehr als die Allgemeinheit, doch ich will nichts Größeres vorbringen, als es der Mund der Allgemeinheit kann, und mit dem Gesetz der brieflichen Kürze zufrieden berühre ich nur eine Kleinigkeit von jener Ernte an Wohltaten [...] « (447). ${ }^{639}$ Es folgen regelrecht panegyrische Ausführungen über Liberius (die aus historischer Sicht nicht unwichtig sind, siehe O'DonNel 1981, 37; 39; 45). Ennodius nutzt also hier die Gelegenheit, dass er einen Dankbrief für ein persönliches beneficium zu schreiben hätte, dazu, den Adressaten umfänglicher zu loben und so seine Fähigkeiten in der Panegyrik zu beweisen. Einem solchen Brief über Liberius' Leistungen für Italien rechnet Ennodius wohl auch mehr Chancen ein, vielen vorgelesen zu werden (cf. \$2 in aures mundi itura), als einem Dank für einen persönlichen Gefallen. Hier erhält der Adressat einmal einen deutlichen Hinweis, dass er den Brief auch anderen vor-

$639(447,1)[\ldots]$ divinum est, quando sine corruptione de te loquitur cui multa contuleris, nec iniquum ponit aliquid in lance veritatis donorum tuorum opibus subiugatus. $(\$ 2)$ nam ubi de potissimis sermo est et in aures mundi itura formantur, publicum testimonium privata actio cur obumbret? debeo equidem celsitudini vestrae plus quam universitas, sed nolo maius aliquid quam universitatis possunt ora depromere, et epistularis angustiae lege contentus satis modicum de illa meritorum messe praelibo. 
lesen solle; Ennodius scheint also nicht mit Kritik daran zu rechnen, dass er sich auf panegyrische Wege begeben hat.

Am meisten lobt Ennodius einige weibliche Adressaten (siehe oben $201 \mathrm{zu} 449$ an Agnella), z.B.: Archotamia, an die er außerdem ein Empfehlungsschreiben richtet (siehe unten $365 \mathrm{zu} \mathrm{291}$ ), wird in einem längeren Brief (319) für ihren vorbildlichen Lebenswandel gelobt, von dem Ennodius gerüchtweise und besonders von seiner Schwester Euprepia gehört hat $\left(\$_{3}\right)$; Archotamias Sohn, der in Lérins im Kloster lebt, könne von ihr lernen (\$5). Der Brief beginnt: „Durch das Licht Eures Charakters habt Ihr den Glanz Eurer Familie noch übertroffen und es so weit gebracht, dass Eure guten Taten Euch sogar diejenigen unterwerfen, die mit Euch nicht verwandtschaftlich verbunden sind. Denn wer wäre nicht bereit, einer Seele von erhabener Frömmigkeit vollkommene Ehrfurcht entgegenzubringen? « Diese Bewunderung ist nicht ganz uneigennützig, da sie auf den Bewundernden zurückwirkt (vgl. die »engagierte Bewunderung « bei Plinius, oben 267): "Denn wer zu den Dienern Gottes nicht aufschaut, der entfernt sich von der Gnade des Erlösers. Es ist nämlich ein Anzeichen eines vorzüglichen Lebenswandels, wenn man die Verehrer unseres Christus liebt. Wer diejenigen liebt, die schon anerkannt sind, ist den Vollkommenen nahe. Man gibt zweifellos ein Zeugnis ab für <eigene> gute Taten, wenn man sich bemüht, Vollkommene wie geschuldet ununterbrochen zu loben. Den Heiligen kommt nahe, wer ohne Verstellung ihre Heiligkeit rühmt. « $(\$ 1) .{ }^{640}$ Hier spricht Ennodius nicht als amicus, der der Konvention entsprechend einen Freund lobt, sondern als Diakon (der mit der Adressatin nicht verwandt zu sein scheint, cf. \$1), der sich zum vorbildlichen frommen Lebenswandel der Adressatin äußert (vgl. oben $197 \mathrm{zu}$ den freundlichen >demütig-frommen Briefen an Frauen).

Abgesehen von solchen Ausnahmen folgt Ennodius seinem Prinzip, Freunde nicht direkt, wohl aber vor anderen zu loben. Recht ausführlich spricht er in einem Brief (249) an seinen Verwandten Avitus (»a high ranking person«, wie den Briefen von Ennodius zu entnehmen ist, siehe PLRE II, 195) darüber, wie sehr er nach Kräften, ja geradezu wie Fama selbst, lobende Worte über diesen verbreite. Zuvor hatte sich das Verhältnis zwischen beiden anlässlich der Wahl des Bischofs von Aquileia getrübt, wie sich an mehreren Briefen beobachten lässt: Da der vorige Bischof von Aquileia im Schisma auf der Seite des Laurentius gestanden hatte, sahen die Anhänger von Papst Symmachus nun eine Gelegenheit, einen ihm gewogenen Kandidaten zum Bischof

$640(319,1)$ Ita supra claritatem generis morum luce profecistis, ut quos etiam vobis non nectit propinquitas, actuum vestrorum bona subiciant. quis enim non perfectam reverentiam sit paratus inpendere animae in dei cultura sublimi? quia peregrinum se facit a redemptoris gratia qui deo non suspicit obsequentes. indicium enim est conversationis praecipuae Christi nostri amare cultores. proximus est emendatissimis, qui diligit iam probatos. (\$2) testimonium das bonorum sine dubitatione meritorum, si studeas laudibus prosequi sub debita continuatione perfectos. fit sanctis proximus, qui in illis sine fuco praedicat sanctitatem. 
zu machen (und gaben sich auch keine Mühe, sich über den Tod des Bischofs betrübt zu zeigen, cf. 168,1) ${ }^{641}$ Vor der Wahl wenden sich aus Aquileia Avitus und auch seine Mutter Helisea (cf. 178,2), die mit Ennodius verwandt sind (cf. 177,1, siehe oben 218), an Ennodius, um um Unterstützung für ihren Wunschkandidaten zu werben (cf. 168 und 178 an Avitus, 177 an Helisea). Ennodius macht in seinen Antworten deutlich, dass er nur unter ganz bestimmten Bedingungen, nämlich dass der Kandidat auf Seiten des Symmachus sei, zustimmen könne; Avitus dürfe nicht denken, dass Ennodius sich aus bloßer Freundschaft auf die falsche Seite ziehen lasse $(168,2)$. Im Brief an Helisea geht es um die gemeinsame Abneigung gegen einen bestimmten Kandidaten; Ennodius bekräftigt, dass er jenen ablehne und dass er gefürchtet habe, Helisea könne ihn unterstützen (177). Im nächsten Brief an Avitus hebt Ennodius hervor, dass er nicht mit großen Versprechungen aufwarten könne; Avitus solle sich bemühen, den ungewollten Kandidaten von seiner Bewerbung abzubringen: "Ich kann keine >feinen Versprechungen machen und mit maskiertem Antlitz denen schmeicheln, denen ich meine Seele schulde. Bleibt Ihr nur bei dem, was Ihr begonnen habt: Leistet den himmlischen Aufträgen Folge und bringt den, wie Ihr sagt, schlechten Mann von seinen Absichten $\mathrm{ab}$ « (178) ${ }^{642}$ - Ein Brief an Liberius zeigt, dass dieser Ennodius dazu gebracht hat, den Kandidaten Marcellinus zu unterstützen (cf. 174, dazu oben 103); Ennodius macht deutlich, dass dies nur der Überzeugungskraft des Liberius zu verdanken ist und dass er von den Qualitäten des Marcellinus letztlich nicht überzeugt ist. VoGEL (1885, Praef. XV) nimmt an, dies sei eben der homo malus, den Helisea verhindern wolle.

Doch die Korrespondenz mit Avitus reißt danach nicht ab; wahrscheinlich bringt gerade diese Vorgeschichte Ennodius dazu, den nächsten Kontakt zu Avitus mit lobenden Worten einzuleiten; Ennodius richtet ein Bittschreiben (248) an ihn für jemanden, dessen Bruder in der Nähe von Aquileia in Gefangenschaft geraten ist. In der Praefatio betont er, dass er dem Hilfesuchenden dankbar sei, da er nun eine Gelegenheit zum Schreiben habe; er hebt lobend hervor, dass Avitus prädestiniert sei, hier zu helfen: »Die Gewohnheiten Eures frommen Hauses sind weithin bekannt. Euer Leben hat bisher Eure Bereitschaft zu guten Taten so unter Beweis gestellt, dass diejenigen, die von Unheil bedrückt werden, um Hilfe bitten wie um etwas, das ihnen

641 Auch ein Brief an Papst Symmachus bezieht sich auf dieses Ereignis: $(166,1)[\ldots]$ agnoverunt adversarii sedis vestrae quo propugnante vincantur: quod proxime de Aquileiensi redemptor noster persona reseravit: "[...] Die Gegner Eures Sitzes haben erkannt, von welchem Vorkämpfer sie besiegt werden: das hat kürzlich unser Heiland hinsichtlich des Aquileiers offenkundig gemacht.« - Auch im darauf folgenden Brief an den Vir illustris Eugenes (167) ist von Freude und vergangenem Kummer die Rede; Ennodius könnte auch hier auf die Situation in Aquileia anspielen.

$642(178,1)$ urbanus in promissionibus esse non sapio nec eis, quibus animam debeo, fucata fronte blandiri. (\$2) vos tantum coeptis insistite et mandatis caelestibus obsequentes malum hominem, quem dicitis, a desideriis deducatis. [...] 
zusteht « $(248,2) .{ }^{643}$ Offenbar hat Avitus diesen Anlass genutzt, seinerseits an Ennodius zu schreiben, worauf dieser mit (249) antwortet. Aus diesem Brief geht hervor, dass Avitus im Begriff ist, nach Ligurien zu gehen (cf. $\$ 2$ ante adventum culminis tui ... in Liguria ... innotuit); wahrscheinlich hängt dieser Ortswechsel mit einem Amt zusammen ("he possibly held judicial office at Milan in 507-508«, PLRE II, 195), aufgrund dessen Ennodius wohl auch die übrigen Briefe an Avitus richtet, bei denen es sich um Bitten und Empfehlungen handelt (253, 28of.).

Avitus hat sich an Ennodius gewandt, bevor er Aquileia in Richtung Ligurien verließ; wie der Antwort zu entnehmen ist, hat Avitus Ennodius darum gebeten, viel und gut von ihm zu sprechen; er hat wohl auch gebeten, die vorige Meinungsverschiedenheit bei der Bischofswahl in Aquileia zu vergessen (cf. \$3) bzw. nicht deswegen die Freundschaft zu beenden; Ennodius antwortet, dass es dieser Bitte nicht bedurft hätte, da es sein Prinzip sei, Freunden immer treu zu bleiben; dies ist einer der wenigen Fälle, wo er von Freundschaft im Zusammenhang mit mores Christiani spricht: »Eurem guten Ruf dienlich zu sein, bittet mich Eure Hoheit so eindringlich, als sei ich erst neulich auf dem Amboss für die Freundschaft geschmiedet worden oder als würde nicht derjenige seinen eigenen Glanz vermindern, der den Vorsatz der Freundschaft bei irgendeiner Gelegenheit ändert. Fern sei von christlichem Verhalten eine schwankende Meinung über einen Freund! Wer die Handlungen seines Mundes der Lobrede gewidmet hat, dem steht es nicht frei, das Begonnene aufzugeben, um nicht die Süße des vorangegangenen Lobes durch die Nichtigkeit des Folgenden zu verderben. $(\$ 2)$ Vielleicht hält irgendjemand es für edel, Neues anzustreben: <doch> ich wähle Freunde ebenso langsam aus, wie ich an ihnen unveränderlich festhalte.« Wieder wird der Nutzen von Lob für den Lobenden selbst betont (siehe oben 267): "Ich denke an mich, sooft ich Euren Ruhm zu den Sternen emporhebe; denn von denjenigen, die unsere Eigenschaften nicht kennen, werden wir anhand unserer Bekannten eingeschätzt. Tatsächlich: Wie Fama habe ich den Glanz Eures Herzens reichlich verbreitet. <Schon > Vor der Ankunft Deiner Hoheit wurde in Ligurien durch den Einsatz meiner Rede Euer Wert bekannt. Dank sei Gott, der die Allgemeinheit mit meiner Meinung übereinstimmen ließ $[\ldots] \ll(249,2) .{ }^{644}$ Nach Bemerkungen über die Un-

$643(248,2)$ sanctae domus vestrae consuetudo vulgata est. talem vitam bonorum actuum obsidem iam dedistis, a qua velut debitum poscat qui calamitate deprimitur.

$644(249,1)$ Adstipulatorem me opinionis suae fieri magnitudo vestra ita supplicatione postulat, quasi ad amicitias recenti adhuc sim incude formatus aut non genio suo defrudet, qui propositum diligentiae sub quacumque occasione commutat. facessat a Christianis moribus varia de amante sententia! qui officium oris sui dedicaverit laudibus, liberum non habet inchoata deserere, ne devenustet praefati mella praeconii vilitate sequentium. (\$2) videro qui ingenuum credat esse sectari novitatem: ego ut tarde amicos eligo, ita in his indemutabiliter persevero. mihi adsum, quotiens opinionem vestram astris aequavero, quia apud quos ignoti sumus moribus nostris, de sodalibus aestimamur. vere fateor splendorem conscientiae vestrae famae vice copiosius effudi. ante adventum culminis tui obsequio sermonis mei in $\mathrm{Li}$ - 
zulänglichkeit seiner Lobreden $\left(\$_{3}\right)$ kommt Ennodius andeutungsweise auf frühere Meinungsverschiedenheiten zu sprechen: „Es gibt bei Euch keine Schuld an einem Irrtum, wie ihr sie ausführlich beschrieben habt, an die ich mich erinnern könnte. Und wenn sie durch meine Handlungen entstanden wäre, würde sie in Erinnerung an vergangenes Gutes begraben $«\left(\$_{4}\right) .645$

\section{Contestatio diligentiae}

Was Ennodius, der lange Beschreibungen seiner konkreten Freundschaft zu Adressaten vermeidet, unter einer amoris contestatio $(4,7)$ versteht, zeigt er in einem Brief an Speciosa, ${ }^{646}$ den er abschließend zusammenfasst: $(36,4)$ ecce contestationem diligentiae meae [...] adserui, "Da habe ich nun also einen Nachweis meiner Freundschaft erbracht! « Hier beschreibt er aber nicht die Freundschaft zur Adressatin an sich, sondern deren Folgen für ihn. In dem Brief geht es um eine nicht stattgefundene Begegnung mit Speciosa; offenbar hatte ihn sein Bischof mit einem Auftrag nach Pavia zu Speciosa geschickt. - Zunächst beklagt er, dass Sündern zwar das, was sie wünschen, nahe sei, sie es aber nicht erreichen könnten. $\mathrm{Zu}$ diesem Allgemeinplatz folgt dann das konkrete eigene Beispiel: Er hatte sich dienstlich auf den beschwerlichen Weg nach Pavia begeben, wobei ihm aber eigentlich weniger daran lag, seinen Auftrag zu erfüllen (das sollte nur der Auftraggeber, der Bischof, denken, cf. $\$ 1$ ), sondern daran, Speciosa zu treffen und sich mit ihr zu unterhalten. Doch dazu kam es nicht: »Oh Kummer, der du mich vom Ton des Briefes zu dem der Tragödie bringst! ( pro dolor, qui me de epistolari alloquio ad tragoediam vocas! \$2). Denn Speciosa hat jemanden gebeten, ihm entgegenzugehen, so dass er sich den weiteren Weg dorthin sparen konnte, was bedeutete, dass er Speciosa nicht sehen konnte. Diese unerwartete Wendung brachte ihn völlig aus der Fassung: "Da sahen meine Begleiter, was mein eigentliches Ziel war [...]; aufgrund der Qualen der Zuneigung konnte ich weder meine Absicht verbergen noch mein Gewissen mit irgendeiner Maske verde-

guria quanti essetis innotuit. deo gratias, qui cum sententia mea generalitatem fecit habere concordiam.

$645(249,4)$ nulla est quam opime texuistis in vobis erroris causa, quam recolam; et si pro meis meritis extitisset, bonorum veterum recordatione sopiretur.

646 Die Vermutung, es handle sich bei Speciosa um Ennodius' ehemalige Verlobte (so VogeL 1885, praef. VI) bzw. Ehefrau (KenNell 2000, 7; 147-149), ist reine Spekulation (skeptisch äußert sich auch Sundwall, 12). Kennell (147) bezeichnet Speciosa als Nonne, wohl wegen der Anreden als lux ecclesiae (35,2) und ecclesiae decus $(36,2)$; doch aus diesen Anreden lässt sich nicht darauf schließen, dass Speciosa eine Nonne war, vgl. die Anrede für die Witwe Stefania: $(452,25)$ Stefania, splendidissimum catholicae lumen ecclesiae, und $(442,2)[\ldots]$ vos supra claritatem seniorum sanctae viduitatis in vobis fulgor inradiat. - Wenn Speciosa zum Zeitpunkt von (35) und (36) Nonne gewesen wäre, könnte sie erst recht nicht die Verlobte sein, da über deren Entschluss zu einem religiösen Leben dort im Zusammenhang mit Ennodius' Genesung von der Krankheit, d.h. im Jahr 511, berichtet wird $(438,27)$. 
cken « $(36,3) .{ }^{647}$ Dieser Vorfall zeigt deutlich, was Ennodius an vielen anderen Stellen betont (siehe oben 226), dass er nicht in der Lage sei, sich zu verstellen. Es folgt ein weiterer Beweis seiner Aufrichtigkeit und Offenheit, indem er ausdrücklich sagt, ihm habe nicht gefallen, dass ihm Mühe erspart geblieben sei ( $\$ 3$ fatigationis meae, fateor, conpendia non amavi) - obwohl doch Speciosa dafür verantwortlich war ( $\$ 2$ quem me tu [...] desiderare feceras).$^{648}$ Ennodius' contestatio diligentiae besteht also zum einen in seiner Reaktion auf Speciosas Handlung, als nämlich alle das eigentlich Ziel seiner Reise erkennen, und zum anderen darin, dass er die gutgemeinte Handlung der Speciosa offen kritisiert. (Speciosa erhält einen weiteren Brief, siehe unten 318).

Als eine contestatio diligentiae bezeichnet Ennodius auch einen Brief völlig anderer Art an Asturius; innerhalb seines zweiten Briefs an diesen nennt er den vorangegangenen Brief so: $(47,2)$ ad contestationem diligentiae prioribus litteris exhibui $[\ldots]$ responsum, »um meine Freundschaft zu beweisen, habe ich auf Deinen ersten Brief $[\ldots]$ geantwortet«. Die zwei Briefe an Asturius $(31 ; 47)$ fallen innerhalb der ganzen Sammlung dadurch stark auf, dass Ennodius dem Adressaten Vorwürfe nicht nur wegen seines Verhaltens in der Korrespondenz, sondern letztlich wegen seiner Lebensweise macht ${ }^{649}$ Allerdings wird dies - jedenfalls für heutige Leser - beim ersten Lesen nicht sofort deutlich; nur wenn man weiß, wie der erste Brief endet, lässt sich der Gedankengang nachvollziehen: Am Ende spricht Ennodius deutlich von der verwerflichen Lebensweise des Adressaten: "was ich sonst [...] jemandem schreiben könnte, der in solcher Unreinheit des Fleisches lebt, wie sie Dir gefällt, weiß ich nicht « $(31,3) .{ }^{650} \mathrm{Um}$ zu verstehen, warum Ennodius einen Brief, der so endet, als contestatio diligentiae bezeichnet, muss dieser schwierige Brief ausführlicher dargestellt werden.

Der Brief beginnt mit dem Vorwurf, dass der Adressat darüber klage, nur wenige Briefe zu erhalten, obwohl dieser doch selbst wenig schreibe; Asturius sehe zwar die Fehler anderer, gehe aber nicht gegen seine eigenen Vergehen vor ( $\$ 1$ tuas culpas nulla falce resecando); die gewählte Formulierung culpas falce resecare wirkt recht hart, solange es um den Vorwurf der Schreibfaulheit zu gehen scheint; doch Ennodius meint

$647(36,3)$ ibi comites mei videre quid peterem [...]; nescivi occultare per caritatis tormenta quod volui nec fucis aliquibus colorare conscientiam.

648 Ich fasse quem als Objekt zu feceras auf und me als Objekt zu desiderare: "den Du veranlasst hattest, mich zu suchen."

649 Nicht erkannt von Gionnni (2001, 170), der Brief 31 als Beispiel für Briefe nennt, die Probleme der Rhetorik, in diesem Fall Stilkritik, behandeln. Ebenfalls übersehen von KENNELL: "[...] Ennodius candidly shows his allegiance to urban manners, asserting that his adressee's lengthy residence in the vicinity of the Alps reflects and influences his literary behavior. [...] Men are supposed to cool down in their old age, not become hotter and more choleric $[\ldots]$ « $(2000,86 \mathrm{f}$.).

$650(31,3)$ praeter ista $[\ldots]$ quae scribere possim in illa carnis quam tu diligis illuvie viventibus non inveni. 
am Ende weniger die Schreibfaulheit des Adressaten als dessen Lebensweise. Asturius, ein gebildeter Mann und Senator, lebe nun seit vielen Jahren in der Nähe der Alpen; während er die schneebedeckten Gipfel betrachte, sei sein Haar grau geworden, und er ernähre sich dort von Eicheln, wie sein Brief gezeigt habe. Dann wird fürs erste klar, worauf die im vorangehenden Satz unvermittelt erscheinende Benennung des Wohnortes hinausläuft: auf eine Invektive gegen Sprache und Stil des Adressaten, auf den der Wohnort Einfluss genommen habe: "Der Schmuck Deines Briefes macht dies <sc. dass Du dort wohnst> glaubhaft, da sich das Merkmal dieser Nahrung <sc. aus Eicheln> am Rülpsen der geschwollenen Brust und der alpinen Sprache zeigte« $(31,1) .{ }^{651}$

Bis hierher ([...] adparuit) hat Ennodius zwei Aspekte genannt, hinsichtlich derer der Ort Einfluss auf den Adressaten genommen habe: auf die Haarfarbe und auf die Sprache; bis jetzt entsteht der Eindruck, Ennodius wehre sich gegen den Vorwurf der Schreibfaulheit mit einer Invektive gegen den Stil des Adressaten. Im folgenden ( $a b \$ 2$ miror) drückt er seine Verwunderung darüber aus, dass ein anderer, und zwar wünschenswerter Einfluss ausgeblieben sei. Zugrunde liegt folgender Gedankengang: >Der Wohnort hat in zwei Punkten seinen Einfluss deutlich gezeigt; es ist also verwunderlich, dass er in anderer Hinsicht keine Wirkung gezeigt hat, nämlich im Hinblick auf die Lebensweise.

Er sei verwundert, dass in der Eiseskälte, die den Adressaten umgebe, seine innere Flamme stärker brenne und sein Herz sich nicht durch den Einfluss des Ortes mäßige $(31,2) .{ }^{652}$ Was mit iecoris flamma und pectus konkret gemeint ist, sagt er hier noch nicht - es lässt sich zunächst unschwer auf die eingangs erwähnten Vorwürfe gegen Ennodius beziehen, d.h. auf Asturius' Hang, sich über das Verhalten anderer zu beschweren ( $\$ 1$ prodigus in querella).

Der Adressat werde alt, und er lebe in einer Umgebung, die sogar Wasser gegen seine Natur hart werden lasse: "Doch von Dir hört man, dass Du dort so lebst, als ob Dein Feuer durch den Frost noch genährt und verstärkt würde« $(31,2) .{ }^{653}$ Das ist das erste klare Wort, dass sich die Vorwürfe letztlich gegen den Lebensstil richten: sic vivere diceris. Die hinführenden Bemerkungen, dass die Umgebung auf Haarfarbe und Sprache Einfluss genommen habe, dienten nur dazu, den Kontrast zu schaffen und den Ausgangspunkt für die Verwunderung (miror tamen).

Im folgenden bleibt Ennodius deutlich: Er ermahne ihn mit der Stimme eines Verwandten; dem Adressaten und seinen eigenen Vorsätzen schulde er eine tadelnde Stimme. ${ }^{654}$ Wenn Asturius also künftig Briefe erhalten wolle, solle er für diese Ermah-

$651(31,1)$ cuius rei fidem litterarum tuarum decora fecerunt, cum cibi huius significantia in ructu turgidi pectoris et Alpini sermonis adparuit.

$652(31,2)$ quod $[. .$.$] iecoris tui flamma plus aestuat nec aliquam sortitur pectus de mansione$ temperiem.

$653(31,2)$ tu tamen inter ista sic vivere diceris, quasi ignis tuus algoris pabulis inritetur.

$654(31,3)$ ego te ore parentis stimulo, quia tibi et proposito meo vocem debeo castigantis. 
nung dankbar sein ( $\$ 3$ de admonitione gratulari). Der Brief endet mit dem schon zitierten Satz: Er wisse nicht, was er sonst noch Menschen schreiben solle, die in solcher fleischlichen Unreinheit lebten, wie es Asturius gefalle. Auch im zweiten Brief $(47)^{655}$ wird auf den Lebenswandel des Adressaten hingewiesen ( $\$ 3$ maculata conversatio; crimina): "Es ist die Folterstrafe für einen befleckten Lebenswandel, zu glauben, keine Gleichgesinnten zu haben. Dies schreibe ich in dem Sinne, dass ich Vergehen meinen Vorsätzen entsprechend hassen muss« $(47,3){ }^{656}$

Am Ende des ersten Briefs rechtfertigt sich Ennodius also nochmals gegen den Vorwurf, dass er nicht schreibe, nachdem er eingangs schon darauf verwiesen hat, dass der Adressat ja auch nicht schreibe ( $\$ 1$ ut $[\ldots]$ exigas frequentiam litterarum quam ipse non tribuis). Letztlich sagt er mit diesem ersten Brief: ,Du beschwerst Dich, dass ich Dir nicht schreibe. Aber ich weiß nicht, was ich Leuten schreiben soll, die so leben wie Du. Ändere Deine Lebensweise, und wir können miteinander korrespondieren.4

Wenn Ennodius im zweiten Brief an Asturius (47) den dargestellten ersten Brief als diligentiae contestatio bezeichnet, macht er deutlich, was er unter diligentia verstehen möchte: Keine Heuchelei, sondern deutliche Worte, um den Adressaten zur Besserung zu bewegen.

\section{Fazit zu d.1 (amicitia)}

Für Ennodius spielt das Thema amicitia eine wichtige Rolle. Er zeigt dies z.B. dadurch, dass er häufig Maximen über Freundschaft in offizieller Manier formuliert. Doch er folgt nicht dem in anderen Briefsammlungen zu beobachtenden Verhaltenskodex, sondern er wendet sich gegen mehrere verbreitete Verhaltensweisen: Er lehnt unverbindliche lobende Worte über den Adressaten und über die Freundschaft mit

655 Gioanni (2004, 531) vermutet, die Strenge des Ennodius richte sich dagegen, dass Asturius heidnische Praktiken ausübe; er missversteht den Anfangssatz (47,1 Profeticis oraculis sublimitas tua praestat obsequium) in dem Sinne, als glaube Asturius an heidnische Orakel; gemeint sind aber "christliche prophetische Sprüche«, wie völlig eindeutig aus dem Folgenden hervorgeht: [...] scriptum enim est per dei cultores, quorum aures prudentum debeat doctrina transire, quos salsi sermonis sapore pertrahere, allegans perire monita, quae in alia constitutis deliberatione praestantur ("Deine Hoheit entspricht den prophetischen Weissagungen [...]; denn es ist von den Verehrern Gottes geschrieben, an wessen Ohren die Lehre der Vernünftigen vorbeigehen und wen sie mit dem Geschmack würziger Rede anlocken soll, d.h., dass Ermahnungen vergebens sind, die man denen erteilt, die an anderem Rat festhalten «). Als möglichen Bezug vgl. (Prv 23,9): in auribus insipientium ne loquaris quia despicient doctrinam eloquii tui.

$656(47,3)$ tormenta sunt maculatae conversationis non sibi credere esse participes. haec illa mente descripsi, qua memor propositi odium conpellor debere criminibus. 
ihm ab, außerdem wendet er sich explizit gegen eine oberflächliche amicitia, lehnt Verstellung ab und fordert sinceritas. Anders als Symmachus betont Ennodius immer wieder, dass Freundschaft unter entfernt Wohnenden nicht ohne Briefwechsel auskommen könne, und er äußert die Überzeugung, dass Briefe überhaupt erfunden wurden, um Freunde über die Trennung hinwegzutrösten. Den Adressaten wird Säumen beim Schreiben daher heftig vorgeworfen, nicht selten in Kombination mit einer offiziell klingenden allgemeinen Praefatio über die Funktionen von Korrespondenz und/oder ideale bzw. zu missbilligende Verhaltensweisen von Briefpartnern. Außerdem resultiert für Ennodius aus der Freundschaft, dass man nicht nur Erfreuliches mitteilen, sondern dass man einander auch über Unglück informieren muss. Verstellung wie z.B. das Verschweigen von Ärger (hauptsächlich über das unbefriedigende Schreibverhalten des Adressaten) oder Krankheit lehnt er ausdrücklich ab. Ennodius selbst spricht häufig von seiner inportunitas. "Die Unverfrorenheit dieser höflichen Impertinenz ${ }^{657}$ ist ein wesentliches Charakteristikum der Briefe. All dies führt Ennodius ebenso ausdrücklich auf die Freundschaft zurück, wie Symmachus seine demonstrative Freundlichkeit und unermüdliche Nachsicht auf die amicitia gründet.

Die betrachteten Aussagen zur amicitia mit den Folgerungen, die sich für Ennodius daraus ergeben, und seine Verwendung von Brieftopoi zeigen, dass er Vorgängern, zumal seinem vermeintlichen Vorbild Symmachus, nicht blind folgt, sondern eine eigenständige Position einnimmt. Besonders fällt auf, dass Ennodius seine Erwartungen sehr direkt formuliert, seinen eigenen Standpunkt selbstbewusst darlegt, seine Adressaten gern tadelt und durchaus eine eigene Vorstellung von Freundschaft hat, aus er bestimmte Forderungen ableitet.

\section{d. 2 Propositum}

Bisher wurde dargestellt, wie sehr das Konzept der amicitia die Briefe bestimmt, wobei darauf hingewiesen wurde, dass bei den vielen Ausführungen zur Freundschaft nur wenige Male ausdrücklich von einer spezifisch christlichen Freundschaft gesprochen wird (siehe oben 202). Dies bedeutet jedoch keineswegs, dass die Briefe durchweg einen ausschließlich ,weltlichen ‘ Eindruck vermitteln. Es finden sich immer wieder kurze Passagen mit christlichem Vokabular, recht häufig sind z.B. Bitten um unterstützende Gebete (siehe z.B. oben 198f., 202, 233). Im Folgenden soll dargestellt werden, inwieweit Ennodius auch außerhalb der bereits interpretierten Recusationes (siehe oben $177 \mathrm{ff}$.) auf sein Amt hinweist. Entgegen der communis opinio spielt er

657 Diese Formulierung ist einem Artikel („Möpse für Millionen“) der Süddeutschen Zeitung vom 15./16. November 2003, S.18, von Jan Weiler über eine Fernsehsendung zum 80. Geburtstag von Vicco von Bülow entnommen. 
nämlich in den Briefen häufig darauf an, wenn auch überwiegend anders, als man es vielleicht erwarten würde.

Es war bereits an den Recusationes an Pomerius, Florianus, Hormisda, Olybrius und Mascator zu sehen, dass Ennodius u.a. mit den Begriffen professio und propositum auf sein Amt, seinen Stand und die damit verbundenen Vorsätze / Gelübde hinweist. Wenn er in den Recusationes darüber schreibt, dass er eine bestimmte Art von Briefen nicht schreiben wolle, oder wenn er in den 'freundlichen Briefen an weibliche Adressaten von seinem Stand spricht, fallen verschiedene Begriffe: officium (21,4 an Florianus), professio (39,5 an Pomerius), ecclesiastica humilitas, propositum (95,3 an Mascator), religiosi homo propositi (449,1 an Agnella), religionem profitenti (441,2 an Apodemia).

Auch in verschiedenen anderen Situationen verweist er mit unterschiedlichen Begriffen auf seinen Stand, z.B. in einem Bittbrief: »Der Mann des Hofes <sc. der Adressat $>$ möge < den Hilfesuchenden $>$ ihren adligen Rang wiedergeben; denn der Kirche muss es genügen, zu bitten « $(444,1) .{ }^{658}$ Auch längeres Schweigen lässt sich mit dem geistlichen Stand entschuldigen: Er habe lange nicht schreiben können, weil er keinen Boten gehabt habe; es denke keiner von den Mächtigen <sc. die ja mehr Möglichkeiten zum Transport von Briefen hatten $>$ daran, einem Kleriker anzubieten, für ihn Briefe zu transportieren bzw. transportieren zu lassen: "Demütige Kleriker werden von den Mächtigen der Welt wie etwas Fremdes übergangen « $(440,1) .{ }^{659}$ - Auf sein Amt als Diakon beruft er sich, um Maximus, von dessen Hochzeitsplänen er bisher nur von anderer Seite gehört hat, stichelnd zur \Beichte〈 aufzufordern: »Es gibt etwas, das Du, Frömmster, mir als Diakon mit dem bekannten Reichtum Deiner Rede über Deinen Lebenswandel mitteilen könntest $[\ldots]$ « $(334,2) .{ }^{660}-$ Er fordert Avienus nicht nur auf zu schreiben, sondern er erwartet, dass dieser dabei die literarische Qualität seines Vaters erreicht, "damit ich erkenne, was ich als sein Diener von Gott erbitten kann « (17,5); der Brief des Avienus soll also zeigen, dass die Gebete des Diakons für ihn bzw. seine sprachlichen Fortschritte erfolgreich sind. ${ }^{661}$

Doch am häufigsten verweist Ennodius mit dem bloßen Begriff propositum auf seinen Stand und sein Amt, was bisher nicht erkannt wurde. ${ }^{662} \mathrm{Im}$ folgenden ist eine

$658(444,1)$ reddat ingenuitatem homo palatii, quia ecclesiae nihil amplius sufficit quam precari.

$659(440,1)$ ecclesiastica humilitas a mundi potentibus quasi res peregrina transitur.

$660(334,2)$ habes quae cum diacono, sanctissime, de institutis morum nota dicendi ubertate communices.

$661(17,5)[\ldots]$ ut quid ministerium meum a deo valeat inpetrare cognoscam.

662 Der Bezug auf das konkrete Amt wurde bisher nicht gesehen, vgl. z.B. zu $(69,13)$ si pietas amica proposito, nostri fiunt fili, qui parentum suorum praesidio denudantur die Übersetzung von KenNelL $(2000,138)$ : if devotion is gracious by intention, they who are deprived of the bulwark of their parents become our sons. «Es dürfte aber gemeint sein: »Wenn Liebe mit unseren Vorsätzen <sc. für das Amt des Diakons> verbunden ist, wer- 
Reihe der Stellen zu betrachten, an denen Ennodius sein propositum in unterschiedlichen Zusammenhängen erwähnt. Dabei zeigt sich, dass er den Begriff propositum häufig wie ein gängiges Element der Brieftopik verwendet, um Effekte zu erzielen und/oder unerwartete Wahrheiten auszusprechen. Seine nicht immer seriöse Verwendung von propositum macht deutlich (wie auch manche 'Scheinlösung im Umgang mit silentium und humilitas, siehe oben 68), dass die Wandlung zum Diakon noch keine vollständige ist.

propositum (allgemein: "Vorsatz«, "Vorhaben«, "Plan«) kann in spezifisch christlichem Sinne »(religiöses) Vorhaben« bedeuten oder auch die gewählte »Lebensform«, "Lebensweise «, der eine religiöse Verpflichtung entspringt. ${ }^{663}$ Wenn Augustin sich mit den Forderungen seines propositum auseinandersetzt, geht es für ihn insbesondere um die Verpflichtung zu continentia und paupertas, also um christliche Grundtugenden, die nichts mit dem literarischen Schaffen zu tun haben.

Wo Ennodius das Wort verwendet, ist zumeist gemeint: "Vorsätze, die im Zusammenhang mit dem Diakonat gefasst wurden «, »Prinzipien/Grundsätze, die beim Antritt des Diakonats aufgestellt wurden « ${ }^{664}$ Diese Grundsätze enthalten für Ennodius außer silentium und humilitas auch die Verpflichtung zu sinceritas und veritas. Ennodius verbindet mit dem Begriff propositum häufig dessen direkte Wirkung auf seine Briefe - sei es, dass sie überhaupt, sei es, dass sie in einer bestimmten Art geschrieben werden. Er stellt nicht heraus, wie das propositum auf sein Leben im Allgemeinen Einfluss nimmt, etwa durch die Forderung, auf weltliche Vergnügungen und Genüsse zu verzichten. - Auch Sidonius Apollinaris gibt in seinen Briefen nicht nur etliche Hinweise auf seinen Stand als Bischof (nostra professio; ordo), sondern besonders darauf, dass es sich dabei für ihn um etwas Neues handelt (nova professio); allerdings spricht er davon im Zusammenhang mit anderen Themen als Ennodius: Sidonius erwähnt seine Stellung, seine Kirche und Gemeinde überwiegend im Zusammenhang mit Themen, die das kirchliche und religiöse Leben betreffen. ${ }^{665}$ Nur in wenigen Pas-

den die unsere Söhne, die des Schutzes ihrer Eltern beraubt sind «; der Diakon war für die Unterstützung der Witwen und Waisen zuständig.

$663 \mathrm{Zu}$ propositum in spezifisch christlicher und theologischer Verwendung bei Augustin siehe besonders ZUMKELLER 1987 und auch LAWLESS 1987, 294 ("rule of life«, "standard of conduct«). Cf. den Abschnitt "propositum« (von C. WICK) im Artikel »proponere«, ThlL vol. X,2, fasc. XIII, Sp. $2070 \mathrm{ff}$.

664 Er verwendet propositum auch in herkömmlicher profaner Bedeutung, z.B.: $(13,2)$ res $[\ldots]$ amicitiarum indigna proposito $(30,2)$ inreligiosum $[. .$.$] circa amantem tui [\ldots]$ verte propositum; $(108,1)$ patior aliis aliud esse propositum; $(249,1)$ propositum diligentiae; $(385,1 \mathrm{f}$.) Si iam te favor divinus a proposito neglegentiae ad votiva ducit studia $[\ldots] ;(454,2)$ quale vultis circa me exhibete propositum; $(468,1)$ rigidioris propositi [...] supercilia.

665 Z.B. (Sidon. $4,6,1)$ novae professionis communione; $(4,9,5)$ nostrae professionis homines; $(4,14,3)$ humilitas nostrae professionis; $(6,7,2)$ clericalis tirocinii in nobis reptantia rudimenta. 
sagen äußert er sich zum Einfluss seines neuen Standes auf seine literarische Tätigkeit (siehe oben 172).

Von einem propositum, das seine Korrespondenz bzw. den Umgang mit seinen Freunden beeinflusst, spricht Symmachus, z.B.: "Obwohl ich Dir schon vor langer Zeit schrieb, habe ich von Dir keine Antwort erhalten, und doch bleibe ich meinen Grundsätzen (propositum) treu und erneuere die Ehre des Grußes [...]« (Sy. 8,50); »[...] denn Du bist gegen Deine Gewohnheit wortkarg. Doch ich bleibe bei meiner Beständigkeit in der Freundschaft und lasse mich von meinen Grundsätzen (propositum) durch keine Argumente abbringen « (Sy. 8,51); [ [...] denn vieles behinderte und zügelte plötzlich meinen Eifer zu schreiben; doch da ich nun eine passende Gelegenheit gefunden habe, sende ich in diesem Brief ein Zeichen meiner Grundsätze (propositum) und meiner Freundschaft zu Dir [...] « (Sy. 5,89). Ebenso nimmt Symmachus an, dass seine Adressaten bestimmte Grundsätze für ihre Korrespondenz haben: "Bleib also bei Deinem Grundsatz (propositum), beständig zu schreiben [...] « (Sy. 3,12,1). ${ }^{666}$ Bei Symmachus gehört das propositum also zur Topik des Freundschaftsbriefs.

Zuweilen spricht auch Ennodius von einem solchen propositum amicitiae, ${ }^{667}$ doch überwiegend hat das propositum, dessen Einfluss auf seine Korrespondenz er häufig erwähnt, eine andere Bedeutung: Er meint damit sein christliches propositum, d.h. seine mit dem Diakonat tatsächlich verbundenen Grund- und Vorsätze wie silentium und humilitas und die damit verbundenen Einschränkungen. Er orientiert sich bei seinem Gebrauch von propositum offenbar sowohl an Vorbildern mit "christlichem propositum " wie z.B. Augustin, als auch an Symmachus, der ein propositum für Korrespondenz und Freundschaft hat. ${ }^{668}$ Oben (siehe 176) wurde schon dargestellt, dass das propositum es Ennodius verbietet, für Briefe gelobt zu werden bzw. gelobt werden zu wollen; hier sind nun einige Beispiele für weitere Auswirkungen des propositum auf die Korrespondenz zu zeigen:

Einige Bittbriefe werden aufgrund des propositum geschrieben; das Amt ist hier die (wohl auch tatsächliche) Begründung dafür, dass Ennodius jemanden unterstützt (andere Begründungen unten in Kap. II 3.d bei der Untersuchung der Empfehlungsschreiben): "Ein Brief, mit dem man Bedrängte empfiehlt, entspricht meinen Vorsät-

666 (Sy. 8,50) Iamdudum datis ad te litteris mutua scripta non merui, et tamen propositum meum servans honorificentiam scriptionis instauro $[\ldots] ;($ Sy. 8,51$)[\ldots]$ es enim praeter solitum parcus eloquii. sed tueor constantiam diligentiae nec a proposito argumentatione deducor; $($ Sy. 5,89) [...] multa enim studium nostrum fortuita impedimenta frenarunt. sed ubi tempestivam conperi facultatem, contuli in has litteras mei circa te propositi atque amoris indicium [...]; (Sy. 3,12,1) mane ergo in proposito adsiduae scriptionis [...].

667 Siehe oben Anm. 664.

668 Vgl. auch bei Cassiodor, z.B.: (var. 3,27,1) Propositum est pietatis regiae [...]; (var. 4,41,1) Propositum regale est $[\ldots]$. 
zen « $(115,1) ; »[$... ] dem die Vorsätze befehlen, Bedrängte anzuhören « $(145,1) ; »$ Das Gesetz meiner Vorsätze lehnt Geiz im Leisten von Fürbitte ab « $(280,1){ }^{669}$

Ennodius wirft einem Adressaten dessen Schweigen vor, sagt aber, dass es zu seinem propositum nicht passe, seinerseits durch Schweigen Rache zu üben: "Fern sei es von meinen Vorsätzen, die Handlung nachzuahmen, die mich betrübt, und durch Stille an Eurer Schweigsamkeit Rache zu nehmen « $(77,2) .{ }^{670}$ Allerdings muss man sagen, dass er hier auch selbst gar nicht schweigen könnte, denn er hat ein wichtiges Anliegen (er mahnt die Rückzahlung von Auslagen an, die der Bischof in Ravenna für den Papst getätigt und für die Ennodius gebürgt hat), und die Ausführungen über die Freundschaft und die mangelnde Korrespondenz dienen lediglich als Einleitung.

Das propositum verbietet dem Verfasser egoistische bzw. für den Adressaten ungünstige Wünsche, die daher nur vorgebracht bzw. vorgetäuscht werden, um sofort mit dem Hinweis auf das propositum verworfen zu werden; ${ }^{671}$ dabei tut Ennodius so, als wären diese Wünsche ohne das propositum problemlos. Er kann auf diese Weise extreme Gedanken formulieren, wie sie sich sonst verbieten; überwiegend drückt er so aus, wie wichtig ihm die Korrespondenz ist: Das Schreiben eines Bittbriefes für Dritte ist eine gute Gelegenheit (da die Bittenden als Briefboten fungieren), um an Faustus zu schreiben; daher drängt sich der Wunsch danach auf, dass viele Menschen Bittbriefe brauchen: „Wie wünschte ich mir - wenn es das propositum nicht verbieten würde -, dass oft die ruhige Lage von vielen ins Wanken gerät « $(33,1) .{ }^{672}$ - Avienus hat sich offenbar beklagt, dass Ennodius nicht geschrieben hat, sondern nur mündlich etwas ausrichten ließ; so kommt der Wunsch auf, dass sich der Adressat häufig ärgern möge, da er Ennodius immerhin geschrieben hat, um seinem Ärger Ausdruck zu verleihen: "Wenn es nicht meinem propositum widerspräche, würde ich Dir Gründe zum Ärgern bieten « (75,1; der ganze Brief an Avienus unten 321). ${ }^{673}$ Siehe auch den Beginn des Briefes an Deuterius (24, oben 167).

669 (115,1) Proposito obsecuntur paginae, quibus commendatio praestatur afflictis; $(145,1)[\ldots]$ cui inperat propositum adflictos audire; $(280,1)$ lex propositi intercessionis refutat avaritiam.

$670(77,2)$ facessat a proposito meo imitari quod factum doleo et per silentium sumere de vestra taciturnitate vindictam.

671 Cf.: Ein Konflikt zwischen propositum und caritas entsteht für Hieronymus einmal, als ein Brief von seinem Korrespondenten, d.h. die Liebe zu diesem, ihn fast dazu bringt, etwas zu tun, was seinem propositum widerspricht: [...] quibus lectis ita reaccensus est animus Hierosolymam proficiscendi, ut paene nocuerit proposito, quod profueri caritati (Hier. $5,1)$.

$672(33,1)$ quam vellem, si propositum non vetaret, multorum saepe quieta titubare; ähnlich $(71,1)$ confiteor, nisi repugnaret proposito, inimica paene ad turbandam aliquorum securitatem vota conciperem: »Ich muss gestehen, wenn nicht das propositum dagegenstünde, käme bei mir fast der böse Wunsch auf, die ruhige Lage mancher zu stören."

$673(75,1)$ nisi adversaretur proposito, causas indignationis ingererem. 
Seiner Schwester Euprepia gegenüber gibt Ennodius das propositum als Grund dafür an, harte Vorwürfe machen zu dürfen; er beruft sich hier auf die Freiheit, die ihm sein propositum gewähre. Da sie ihrem in der Obhut des Ennodius lebenden Sohn nicht schreibt, macht er ihr Vorwürfe: »Ich sage mit der Freiheit meiner Vorsätze die Wahrheit, besonders da Du ihm auch <sc. briefliche> Gespräche verweigerst, wo doch zwischen den Herren unserer Länder dank Gottes Geneigtheit der Frieden mit allen Wurzeln gefestigt ist: Du übertriffst in deiner Rohheit einen Tiger “ $(84,3) . .^{674}$

Zuweilen wird ausdrücklich gegen die Forderungen des propositum verstoßen. An einer Stelle bittet Ennodius sich aus, ohne Rücksicht auf sein propositum sprechen zu dürfen. Hier schreibt er einen ironischen Brief an Faustus, eine paradoxe Vituperatio auf den Comersee, auf den Faustus ein Enkomium geschrieben hatte: ${ }^{675} »[\ldots]$ wenn es dem frommen propositum erlaubt ist, ohne Gefahr einer drohenden Beichte zu sprechen « $(10,1){ }^{676}$ Rücksicht auf das propositum würde eine solche ironische, paradoxe Sprechhaltung wohl eigentlich verbieten. - Im Glückwunschschreiben an Faustus anlässlich des Konsulats von desssen Sohn Avienus (siehe dazu ausführlich unten 347) bricht er das Lob auf die rhetorischen Fähigkeiten des Avienus mit dem Hinweis darauf $a b$, dass dies seinem propositum widerspreche: »Aber ich vergesse mein propositum und nenne den Konsul gebildet, wo doch meine Begabung nicht an ihn heranreicht $\ll(9,11){ }^{677}$

Ennodius verweist also in seinen Briefen häufig auf sein propositum, das ihm bestimmte Dinge zu schreiben verbiete oder erlaube; allerdings verwendet er den Begriff nicht, um auf Auswirkungen seines Diakonats auf sein reales Leben hinzuweisen, sondern er erscheint häufig gleichsam als Element seiner Brieftopik.

Fazit: Bedeutung von Briefen:

non tam delicias verba $[\ldots]$ pariunt quam salutem $(6,7)$

Das Diakonat bzw. die im Zusammenhang damit gefassten Vorsätze spielen in den Briefen entgegen der communis opinio eine große Rolle, wenn auch überwiegend in ungewöhnlicher Weise: quasi als Element der Brieftopik. Indem Ennodius nicht von den Auswirkungen seines propositum allgemein auf seine Lebensweise, sondern von dessen Auswirkungen auf seine Briefe spricht, gibt er zu erkennen, in wie enger

$674(84,3)$ vere fateor sub libertate propositi, modo maxime quando ei a te et conloquia denegantur pace deo propitio inter regionum nostrarum dominos omni radice solidata, tigridem te inmanitate superasse.

675 Siehe dazu ausführlich: SCHRÖDER 2003 a.

$676(10,1)[\ldots]$ si religioso liceat sine discrimine confessionis enarrare proposito.

$677(9,11)$ divisus proposito consulem eruditum ingenio inpar appello. 
Verbindung er Leben und Schreiben sieht. Dass für ihn ’Korrespondenz und 'Lebensweise، eng verflochten sind, zeigt sich auch besonders in einem Brief (108), mit dem er Avienus zum Schreiben auffordern möchte; jeder habe seine eigenen Vorsätze, und er habe seinen mos vivendi: »[...] Ich muss es ertragen, dass jeder seine eigenen Vorsätze hat: Ich selbst muss auf meine Art leben, und das heißt, dass die Fülle der Freundschaft durch den Schlüssel der Rede eröffnet wird. Ich kann es nicht ertragen, dass die Gewohnheit <sc. zu schreiben> schwindet und sich in der Freundschaft widerwärtiges Schweigen einstellt« (108,1; zu dem ganzen Brief unten 287). ${ }^{678}$ Dies geht weit über andere Stellen hinaus, wo er darstellt, dass sein propositum auf seine Briefe Einfluss nehme - denn dort ist das propositum ja immer durch die Grundsätze des Amtes definiert, selbst wenn Ennodius nicht im vollem Ernst darüber spricht. Hier charakterisiert er gar seinen mos vivendi über Freundschaft und Korrespondenz. Dies verweist wieder einmal darauf, dass die , Verwandlung zum Diakon noch nicht vollständig vollzogen ist, sondern dass Ennodius weiterhin an der literarischen Tätigkeit hängt und besonders zum Briefeschreiben, wenn auch eingeschränkt, seine Zuflucht nimmt.

Auf diesen hohen Wert des (Brief-)Schreibens verweist Ennodius an vielen Stellen: Im ersten überlieferten Brief an Faustus (6), mit dem er endlich auf einen lange ersehnten Brief von diesem antworten kann und in dem er sich darüber beklagt, dass Faustus ihn nicht über alles informiere (siehe oben 238), legt er in vielen Bildern dar, wie wichtig für ihn die Briefe des Faustus seien: »[...] da ich Worte von Euch heftig wünsche; da ich, wenn mir die gewünschte Anrede verweigert wird, erschlaffe wie Erde, der vom Himmel nichts herabfließt, um ihre Adern mit dem Saft feuchten Nasses zu füllen, womit sie den auf ihr wachsenden Halmen Nahrung bieten und die Ähren gefüllt zur Sichel bringen könnte. Wie ein Fisch ohne Wasser, seiner lebenspendenden Umhüllung beraubt, vergeht, so gehe ich zugrunde, wenn mir die Fluten Eures Gesprächs entzogen werden. Andere mögen Luxus wünschen: Ich <aber> bitte um das, was die Seele betrifft. Mir bereiten Eure Worte nicht so sehr Genuss als vielmehr Wohlergehen. Ich gestehe, ohne es zu maskieren und zu verfälschen, ohne es mit nebelhaften Erfindungen auszumalen, da ich kein Künstler bin in der Verstellung: Ich glaubte, dass meinem Leben etwas fehlte, während Ihr schwiegt " $(6,6) .{ }^{679}$ Die dramatischer Aussage: mihi non tam delicias verba vestra pariunt quam

$678(108,1)[\ldots]$ patior aliis aliud esse propositum: mihi meo vivendum est more, ut amoris plenitudo reseretur clave sermonis; ego in affectione cariosam subripere taciturnitatem usu fugiente non perfero.

$679(6,6 \mathrm{f}).[\ldots]$ mihi $[. .$.$] vestra inpendio verba cupienti; cui si votivi negentur affatus, fatiscam,$ ut terra cui caelo nihil liquitur nec venas suas suco bibuli umoris infundit, unde innatis alimenta culmis exhibeat et ad falcem gravidas aristas adducat. ut piscis aqua abstractus vitalibus indumentis privatus extinguitur, sic ego subductis alloquii vestri fluentis interimor. quaerant alii quod delectet: ego res ad animam pertinentes expostulo. $\left(\wp_{7}\right)$ mihi non tam delicias verba vestra pariunt quam salutem. rem fateor nullis coloratam fucis, nullis nebu- 
salutem (\$7) erinnert auffällig an Ciceros Worte gegenüber Varro (i.J. 46 v. Chr.): [...] in studiis nostris, a quibus antea delectationem modo petebamus, nunc vero etiam salutem (Cic. fam. 9,2,5), auch wenn sowohl die Situationen als auch die Art der studia grundverschieden sind. Dennoch könnte es Ennodius weniger um 'topische lobende Worte für Faustus als vielmehr tatsächlich um die Beschreibung seiner eigenen Situation gehen: Angesichts der Ergebnisse von Teil I, dass Ennodius sich als Diakon nicht mehr so ausgiebig und intensiv und vor allem nicht ohne Weiteres offentlich mit der ihm am Herzen liegenden Sprachkunst beschäftigen kann, verwundern Bitten um Briefe wie z.B. auch die folgende nicht: "[...] und ich bitte Euch zu glauben, dass ich mit häufigen $<$ brieflichen $>$ Anreden aufgemuntert werden muss, ich, für den es unter den Lasten des Kummers keinen Beistand geben kann außer dem Trost Eurer Rede« $(53,4){ }^{680}$

In Teil I ist deutlich geworden, dass Ennodius das Überleben der Bildung insgesamt besorgt im Blick hat, wenn er junge Adlige zu eifrigen Studien ermahnt. Hier zeigt sich nun die Bedeutung von Briefen für Ennodius selbst. Es ist sicher richtig, dass Ennodius die Bedeutung von Korrespondenz sowohl für den Zusammenhalt der Aristokratie, für Aufbau und Erhalt des Netzes der Verbindungen, als auch als Mittel zur Bewahrung und zum Vorzeigen der Kultur erkennt, wie GIOANni betont (2001, $172,175)$. Doch nicht zu unterschätzen ist auch die ganz persönliche Bedeutung des Briefeschreibens für ihn als eine seiner wenigen Möglichkeiten der literarischen Betätigung. Wenn Sidonius Apollinaris den Grund dafür, dass er mit seinem Sohn Terenz gelesen hat, in seiner natura sieht (naturae meminens et professionis oblitus, Sidon. 4,12,1), so kann man wohl Ennodius eine ähnliche natura zuschreiben, die ihn die literarische Tätigkeit nicht aufgeben lässt.

\section{Gestaltung bestimmter Briefe: ,Kontaktpflege`, Glückwünsche, Empfehlungen}

\section{a. Einleitung}

Nachdem bisher einzelne Motive und Verhaltensweisen überwiegend an isolierten Passagen vorgestellt wurden, soll in diesem Kapitel eine Reihe von vollständigen Briefen analysiert werden. Zu betrachten sind (b) Briefe, deren Inhalt der Kontakt-

larum depictam mendaciis, quia non sum simulandi artifex: decerptum aliquid vitae meae censui, dum tacetis.

$680(53,4)[\ldots]$ supplico, ut crebris me relevandum ducatis adfatibus, cui inter maeroris sarcinas nullum praeter oris vestri solacia potest esse subsidium. 
aufnahme und -pflege dient (Gruppe 4, siehe oben 149), also solche, in denen Ennodius zum Schreiben auffordert, sich für erhaltene Briefe bedankt, erstmals Kontakt aufnimmt oder seinerseits auf Aufforderungen zu schreiben antwortet; (c) Glückwunschbriefe (als Beispiel für Briefe der Gruppe 2), (d) Empfehlungsschreiben (Gruppe 3).

Es war bereits mehrfach festzustellen, dass Ennodius keineswegs Symmachus nachahmt, sondern dass er sowohl insgesamt in der häufig eingenommenen Haltung der inportunitas ein Gegenbild zum nachsichtigen Symmachus darstellt als auch in etlichen Details eigene Wege geht. Auch die nun folgende Analyse bestimmter Typen von Briefen wird Eigentümliches aufdecken und deutlich machen, dass Ennodius sich nicht ohne Weiteres als Nachahmer eines anderen Epistolographen beschreiben lässt. Die communis opinio hingegen sieht Ennodius völlig im Einklang sowohl mit der Brieftheorie als auch mit den anderen Epistolographen, siehe z.B.: »Diese Dank-, Empfehlungs- und Glückwunschbriefe [...] spiegeln zumeist die schwulstige und umständliche Höflichkeit des spätrömischen Adels wieder« (FonTAINE 1962, 400); »Tous ces efforts de théorisation font de la Correspondance d'Ennode une sorte de guide pratique du genre épistolaire en société« (GIOAnni 2001, 173); »His <sc. Iulius Victor's $>$ precepts and Ennodius' practice as an epistolographer thus coincide rather well“ (KenNell 2003, 126); KenNell führt eine Reihe von Briefen vor, um zu zeigen, dass Ennodius die Vorschriften des Iulius Victor erfülle. Im Gegensatz dazu wird im Folgenden ersichtlich, dass Ennodius sich bei der Gestaltung von Briefen zur Kontaktpflege, von Glückwunsch- und Empfehlungsschreiben ausgesprochen häufig sowohl über die bereits (oben 156) genannten Konventionen der Korrespondenz, wie sie sich an den Briefen des Symmachus ablesen lassen, als auch über die Vorschriften der Brieftheorie, wie sie bei Iulius Victor zu greifen sind, hinwegsetzt.

Hier zeigt sich die bereits beobachtete große Bedeutung der amicitia noch auf einer anderen Ebene, da Ennodius auch Glückwunsch- und Empfehlungsschreiben, ja sogar Briefe, die konkrete dienstliche Anlässe haben, häufig so aussehen lässt, als dienten sie in erster Linie oder gar ausschließlich der Beziehungspflege. Worte über die Freundschaft findet er fast bei jedem Anlass, allerdings ist er, wie schon zu beobachten war, kein fröhlich-gelassener Freund, sondern er sucht Möglichkeiten, um zu klagen, zu kritisieren, zu ermahnen. Wenn er in solchen strengen Briefen zuweilen am Ende doch noch mit wenigen freundlicheren Worten einlenkt (siehe z.B. in 13 oben 181 , in 24 o. 169 , in 30 o. 263 , in 141 o. 252 , in 224 unten 334 , in 251 u. 323 , in 322 u. 339, in Glückwunschschreiben unten 332), zeigt er, dass seine Strenge - wie sie in Briefen eigentlich unüblich ist - eine Pose ist, die in ihrer Besonderheit gewürdigt werden will; außerdem >beweist ` die Strenge anschaulich, wie stark seine Freundschaft ist, dass er sich zu Klagen hinreißen lässt; allerdings schwächt er seine Strenge nicht gegenüber allen Adressaten schließlich durch Einlenken doch noch ab (siehe z.B. in 455 unten 336 ). 
Wie es schon im letzten Kapitel zu beobachten war, zeigt sich auch im Folgenden an der Gestaltung bestimmter Arten von Briefen, dass Ennodius keineswegs Höflichkeit zum durchgehenden Charakteristikum seiner Briefe gemacht hat und er sich auch häufig nicht an die von anderen befolgte Etikette hält. Zwar ist eine Reihe von Empfehlungsschreiben freundlich gehalten (vermutlich an Adressaten, die Ennodius nicht so gut kennt), viele jedoch beginnen mit Vorwürfen. Auch in Glückwunschschreiben ist er selten durchweg freundlich, manche sind vorwurfsvoll und/ oder mahnend, manche halten die Schwebe zwischen Lob und Anspielungen auf weniger Erfreuliches. Die verschiedenen $>$ Rollen` des Ennodius und der Einfluss des jeweiligen Adressaten und des Verhältnisses zwischen beiden treten deutlich hervor: Für Briefe an Äbte und Bischöfe schöpft er häufig, allerdings keineswegs immer, aus einem anderen Wortschatz und Gedankenarsenal als für Briefe an weltliche Adressaten, an Frauen schreibt er häufig, aber nicht immer, anders als an Männer. In jeder speziellen Art von Briefen zeigt sich die ganze Bandbreite vom demütigen und/oder freundlichen Diakon bis zum vorwurfsvollen und/oder strengen amicus.

\section{b. >Kontaktpflege`}

\section{b. 1 Aufforderung zum Schreiben}

Es war bereits an etlichen Ausschnitten aus Briefen zu sehen, dass Ennodius häufig um Briefe bittet und dass er dabei sehr zu direkten Forderungen, Tadel und Vorwürfen neigt. Es sollen nun noch einige vollständige Briefe dargestellt werden, mit denen Ennodius um Briefe bittet; damit die ganze Bandbreite deutlich wird, ist in diesem Abschnitt sowohl auf Beispiele für auffällige inportunitas als auch auf einige der >freundlicheren Ausnahmen` hinzuweisen.

Zuweilen versucht Ennodius mit Beleidigungen, dem Adressaten einen Brief zu entlocken (z.B. 385,2 ecce vel iniuriis provocatus scribe): Gegenüber Faustus' Sohn und Avienus' Bruder Messala (385) äußert er seine Befürchtung, dass diesem, wenn er denn endlich schreiben wolle, der Himmel zuvor noch Redekunst schenken müsse: »Wenn Dich die Gunst Gottes nun endlich vom Vorsatz der Nachlässigkeit zum gewünschten Eifer führt, wenn Du beachtest, wohin Dich Deine Herkunft und der verehrte Faustus rufen, kannst Du nicht schweigen, wenn ein Brief gewünscht wird. Doch ich fürchte, dass ich, während ich Deinen Eifer wünsche, Deine Ungeschliffenheit ertragen muss und dass das, was ich wünschte, anfängt, meinen Wünschen zu widersprechen. Möge der himmlische Reichtum diese Trägheit mit dem Stachel der Liebe aufwecken und die Bettelarmut Deiner Rede mit himmlischen Mitteln bereichern. So schreib also wenigstens jetzt, wo Du durch eine Beleidigung provoziert wurdest! 
Ich grüße also und bitte Dich, mich durch einen Brief erfahren zu lassen, wie es Dir ergeht « ( $\$ 1 f.){ }^{681}$ (Vgl. auch Brief 5 an Florus.)

Besonders harte Worte gebraucht Ennodius in einer kleinen Sequenz von inhaltlich zusammenhängenden Briefen $(108,111,113)$ an Faustus' Sohn Avienus, in denen neben den allgegenwärtigen Themen 'Freundschaft und Korrespondenz` und 'Macht der Freundschaft، auch urbanitas ausführlich thematisiert wird. Doch direkt zuvor (107) bedankt sich Ennodius bei Avienus einmal ungewohnt freundlich für einen Brief: »Deine Hoheit tut ihre Pflicht und zeigt den Glanz der Abstammung durch das Zeugnis der Lauterkeit. Liebende Herzen können Freundschaft nicht aufgeben, ein edler Sinn bewahrt die treue Freundschaft. « Der Grund für diese Worte ist ein Brief von Avienus, in dem sich lobenswerter Inhalt und Stil verbanden: »Ich habe also einen Brief erhalten, der in doppeltem Licht glänzt, indem die ungetrübt heitere Rechte schrieb, was das verehrungswürdige Herz dachte. Ich bitte Gott, wenn er Rom liebt, die Veranlagung zur Liebe in Euch ewig zu bewahren und diese Aufmerksamkeit mir gegenüber mit dem von Euch versprochenen Eifer zu vermehren * (107) ${ }^{682}$ Doch im direkt folgenden Brief (108) stimmt Ennodius einen fordernden und selbstbewussten Ton an, den Avienus nicht unkommentiert lassen wird (siehe unten zu 111). Ennodius nimmt offenbar die gute Gelegenheit, dass er nach dem letzten Brief (107) schon wieder eine Möglichkeit zum Schreiben hat, zum Anlass, auch von Avienus so häufige Briefe zu fordern. Dass Avienus vielleicht in der Zwischenzeit noch gar nicht wieder antworten konnte, ist wohl ein Grund mehr, diese gute Gelegenheit so unerbittlich sauszunutzen r. - Zunächst betont Ennodius, dass er Schweigen in der Freundschaft nicht ertragen könne, wobei er es als seinen mos vivendi bezeichnet, dass Freundschaft sich in Korrespondenz zeigen müsse (cf. oben 283): "Ich weiß nicht, ob Eure Hoheit gern viele Briefe bekommt, doch ich werde das, was ich von meinen Freunden erwarte, selbst immer tun. Ich muss es ertragen, dass jeder seine eigenen Vorsätze hat: Ich selbst muss auf meine eigene Art leben, und das heißt, dass die Fülle der Freundschaft durch den Schlüssel der Rede eröffnet wird. Ich kann

681 (385,1f.) Si iam te favor divinus a proposito neglegentiae ad votiva ducit studia, si quo te vena, quo domnus Faustus vocat adtendis, optata scriptione non taceas. sed timeo, ne dum officiosum desidero, sustineam rusticantem et incipiat hoc desideriis meis resistere quod cupivi. caelestes divitiae illam inertiam stimulo pietatis exsuscitent et mendicitatem oris tui superna ope locupletent. (\$2) ecce vel iniuriis provocatus scribe! salutem ergo dicens rogo, ut quid circa te agitur tabellarum promulgatione cognoscam.

682 (107,1f.) Adest magnitudo tua partibus suis et adserit splendorem sanguinis testimonio puritatis. caritatem nesciunt pia corda deserere, religiosam diligentiam mens generosa custodit. gemina ergo luce fulgentia scripta suscepi, dum quod pectus sanctum repperit, dextera serena signavit. $(\$ 2)$ deum precor, ut piam in vobis indolem, si Romam diligit, sub perennitate conservet et huiusmodi circa me studia sub ea qua promisistis cura multiplicet. - SUNDWALI $(1919,24)$ hat gemina luce ... fulgentia scripta nicht richtig aufgefasst und angenommen, Avienus habe Ennodius "zwei Schreiben« zukommen lassen. 
es nicht ertragen, dass die Gewohnheit <sc. zu schreiben> schwindet und sich in der Freundschaft widerwärtiges Schweigen einstellt" $(\$ 1) .{ }^{683}$ Avienus solle schreiben: "Wenn es also Deiner Hoheit auch so geht, möge dies durch häufige Briefe deutlich werden, möge es sich durch häufigen Briefwechsel zeigen. Wenn Du aber bis jetzt mit anderen Dingen beschäftigt warst, stimm jetzt auf Befehl der Freundschaft meiner Meinung zu. So viel Du von Deinem Recht aufgibst, so viel wirst Du von meinem Gehorsam besitzen. «Auch der abschließende Satz zeugt von Selbstbewusstsein und mangelnder Bescheidenheit, wenn Ennodius auf das gesandte Geschenk (das auch mit dem Brief identisch sein könnte) hinweist: "Leb also wohl, mein Herr; nimm die kleine Gabe an und miss sie nicht nach ihrer eigenen Nichtigkeit, sondern nach dem Wert des Absenders" (\$2). . $^{684}$

Avienus' Reaktion hierauf lässt sich aus dem nächsten Brief an ihn (111) erahnen: Offenbar hat er seine Verwunderung über den befehlenden Ton zum Ausdruck gebracht. Ennodius antwortet nun seinerseits mit Erstaunen über den Ton des Avienus und wiederholt und begründet seinen Gedanken aus dem vorigen Brief; wie schon in früheren Briefen an Avienus $(17 ; 23)$ reagiert Ennodius auf Verwunderung von seiten des Adressaten damit, dass er seinen Standpunkt nochmals, und zwar strenger darlegt. Ennodius spricht wieder in der Rolle des Mahners, diesmal allerdings ausnahmsweise nicht hinsichtlich der sprachlichen Fähigkeiten, sondern hinsichtlich von Freundschaft und Demut: Das Verhältnis zwischen den Adressaten, von denen einer in weltlichen Ehren steht, der andere durch sein kirchliches Amt zur humilitas verpflichtet ist, das in Briefen an Avienus bisher zweimal kurz mit verschiedenen Worten angeklungen ist $(65,4 ; 108,2)$, wird nun deutlich zum Thema. - Die ersten Worte könnte auch Avienus nach einem Vergleich der letzten beiden Briefe (107/108) von Ennodius so geschrieben haben: "Ich muss mich darüber wundern, dass sich mit der Honigsüße Deiner Hoheit Unerfreuliches verbindet und dass strenge Worte Dein heiteres Herz befleckt haben [...].« Avienus hat sich offenbar über den Ton des letzten Briefes von Ennodius geäußert: "[...], wenn Du schreibst, dass ich Briefe mehr befehle als sie aufgrund der Forderungen der Freundschaft zu verdienen.« Avienus ist wohl der Ansicht, wie sie auch Symmachus vertritt, dass man Briefe nicht ausdrücklich fordern dürfe, vgl. bei Symmachus: »eine Antwort von Dir erwarte ich, doch ich fordere sie nicht. Denn es ist nicht richtig, heftig zu fordern, was man wünscht, da-

$683(108,1)$ Nescio utrum magnitudini vestrae grata sint crebra conloquia, ego tamen semper quod expecto ab amantibus exhibebo. patior aliis aliud esse propositum: mihi meo vivendum est more, ut amoris plenitudo reseretur clave sermonis; ego in affectione cariosam subripere taciturnitatem usu fugiente non perfero.

$684(108,2)$ nunc si culmini tuo par cura est, monstretur assiduitate conloquii, patescat frequentia litterarum; sin aliis hactenus praeoccupatus studiis, in meam modo concesseris diligentia imperante sententiam. quantum de tuo iure submiseris, tantum de meis obsequiis possidebis. ergo vale, domine, et munusculum suscipe non vilitate sui sed taxatum pretio destinantis. vale. 
mit es nicht so aussieht, als würde das, was freiwillig ist, jemandem abgerungen « (Sy. 1,36). ${ }^{685}$ - Avienus muss sich nun über die Macht der Freundschaft belehren lassen: „Glaubst Du, irgendeine Art der Herrschaft sei erhabener als die, die uns mit Liebe unterwirft? Verehrter Avienus, es gibt keine Gipfelpositionen, die vom Joch der Liebe befreit sind. Keine Freiheit der Welt kann sich diesem Sklavendienst entziehen " (\$1). ${ }^{686}$ Und als Reaktion auf die Verwunderung des Avienus wiederholt Ennodius das, worüber dieser sich gewundert hatte, in verschärfter Form: „So sieh: Ich, in niedriger Position und ohne Ehrenstellung, werde auf diese Weise Euch in Eurer Machtfülle Befehle erteilen, bereit, meinerseits Gleichem unterworfen zu sein. Leb nun wohl, und erweise mir - wie jemand, der Anvertrautes zuverlässig zurückgibt - so viel Freundschaft, wie Du merkst, dass Dir erwiesen wird “ $(\$ 2){ }^{687}-$ Damit ist das Thema allerdings noch nicht abgeschlossen.

Den nächsten Brief (113) erhält Avienus wohl, ohne inzwischen geantwortet zu haben; Ennodius fordert ihn wieder (wie in 108,2) dazu auf, seiner Meinung zuzustimmen und häufig zu schreiben. In diesem Brief geht es um Aufrichtigkeit und Verstellung (zu urbanitas siehe oben 226) in Korrespondenz und Freundschaft. Ennodius betont, dass ihm deutliche Aufrichtigkeit am liebsten sei, was wohl nochmals seinen strengen Ton der vorigen Briefe rechtfertigen soll. - Voran geht eine syntaktisch komplizierte Betrachtung über Aufrichtigkeit bzw. Verstellung in Briefen überhaupt; im ersten Teil der langen Periode gibt Ennodius eine Einschätzung von Briefen im allgemeinen; es gebe verschiedene Arten von Briefen, gewöhnliche und solche, die die Freundschaft bekunden, aufrichtige und unaufrichtige (in denen mit urbanitas Freundschaft nur geheuchelt werde): »Wenn auch die Eigenschaften von Briefen vom Talent abhängig sind, oft nichts Besonderes darstellen und $<$ nur $>$ manchmal Anzeichen der Freundschaft bezeugen, <sc. von Briefen, > die manchmal die Aufrichtigkeit, meistens aber ein mit Schminke vergleichbares Komponieren diktiert, das den Glanz der Freundschaft nachahmt und sich durch eben die verhüllende ,Feinheit`zeigt, wenn sie < die Komposition> von den gekünstelten Hüllen entblößt wird

$685($ Sy. 1,36) tuas $[\ldots]$ vicissim litteras expecto non exigo. iniurium quippe est magnopere flagitare, quod speres, ne quod est voluntarium, videatur extortum.

686 (111,1) Miror favis magnitudinis tuae iniucunda copulari et serenitatem conscientiae verborum austeritate maculatam, dum scribis imperare me potius paginas quam diligentia exactrice promereri. putas ullum genus dominandi esse sublimius quam illud quod amore nos subicit? nulla sunt, domne Aviene, culmina a iugo caritatis inmunia; quidquid in orbe libertatis est, tali non subtrahitur servituti.

$687(111,2)$ ecce ego loco humilis, ignotus honoribus vestris fascibus sic iubebo, parili contentus ordine subiacere. nunc vale, et quantum tribui tibi senseris, tantum mihi sicut fidelis restitutor affectionis inpende. 
und der Blick unter die Bedeckung offen ist $[\ldots] \ll(\$ 1) .{ }^{688}$ Trotzdem könne er die wahre Einstellung der Adressaten unterscheiden und Freundschaft erkennen: »[...] dennoch glaube ich, dass Briefe Spiegel des Herzens sind und dass man aus der Entfernung sehr wohl Freundschaft erkennen kann. Dennoch ist klar, was eine einfache $<$ sc. aufrichtige>, was eine künstliche <sc. verstellte> Rede übermittelt « $(\$ 2){ }^{689} \mathrm{Un}$ ter "künstliche Rede" (sermo artifex) versteht Ennodius dasselbe wie fuci similis concinnatio oder fabricata tegmina: verstellte, unaufrichtige Rede; er spricht hier nicht über das Niveau von Sprache und Stil, sondern über die Haltung des Verfassers. Diese lasse sich eben, wenn man kundig sei, erkennen: "Ein Verstand, der das Gesagte deutet, zerreißt die Wolken, die das Gesagte umhüllen, und gelangt schnell zum Verständnis, indem er den Weg der Worte mit seinen Sicheln eröffnet « $(\$ 2) .{ }^{690} \mathrm{Ihm}$ selbst seien aufrichtige Briefe - sc. wie seine beiden vorigen - am liebsten. Und sofort schließt er wieder eine solche Bemerkung über Avienus' Pflicht zu antworten an, über die sich dieser erneut wundern oder ärgern kann: "Ich also habe viel Freude an solchen Briefen, in denen sich Aufrichtigkeit offenbart und in die sich keine Gelegenheit zur Täuschung einschiebt. Ich freue mich also über Gründe zu schreiben und über sich anbietende Boten, so dass ich durch häufiges Schreiben meinen Wünschen entsprechen und Euer Gewissen belasten kann, wenn Ihr das Erhaltene nicht erwidert. Leb wohl, mein Herr, gehorche dem Befehl der Freundschaft und stimme meiner Meinung zu. Leb wohl« $(\$ 3) .691$

Nicht nur mit jüngeren Adressaten wie Avienus spricht Ennodius in solch strengem Ton, auch Briefe an wichtige Amtsträger füllt er häufig mit Klagen und tadelnden Betrachtungen. Senarius (zu ihm siehe PLRE II, 988f.; SCHÄFER 1991, 103f.; aus seinem Epitaph geht hervor, dass er schließlich den Rang eines Patricius erreichte; siehe auch unten 345) wird mehrfach um Briefe gebeten bzw. getadelt, weil er nicht schreibe. Der vorwurfsvolle Ton, der schon den ersten Brief bestimmt hat (30, siehe oben 263), überwiegt auch im zweiten (78): Ennodius beginnt mit einer Art Selbstanklage, dass er nämlich der Freundschaft des Senarius niemals würdig gewesen sei und er

$688(113,1)$ Quamvis epistularum qualitas pro ingeniis conponatur et saepe sollemnitati militet, nonnumquam affectionis testetur indicia, quas aliquando dictat sinceritas, plerumque fuci similis concinnatio, quae candorem imaginata diligentiae urbanitate qua tegitur innotescit, dum fabricatis nudata tegminibus intra velamen aperitur [...].

$689(113,2)$ ego tamen in paginis speculum puto esse conscientiae, per quas amicitiam discernere absentia vix praesumit; clarum est tamen, quid in illis simplex, quid artifex sermo deferat.

$690(113,2)$ scindit nubes eloquii mens dictationis interpres, cito ad intellectum pervenit falcibus suis verborum calle reserato.

691 (113,2f.) ergo his valde delector officiis, quibus panditur sinceritas nec occasio se interserit secura fallendi. (\$3) gaudeo tamen mihi vel causas scribendi vel perlatores accidere, ut sub hac frequentia meo voto satisfaciam et pudorem vestrum onerem, nisi a vobis suscepta redduntur. salve, mi domine, et in sententiam meam affectu imperante concede. vale. 
sich dieser nur so lange habe erfreuen können, wie Senarius nicht sein endgültiges Urteil über Ennodius gefällt habe: »Wenn Eure Seele die Erinnerung an die Freundschaft zu mir nicht getilgt hätte und wenn Du, Hoheit, sie < die Seele > nicht zwingen würdest, nach der < gezeigten $>$ Sympathie < nun > zu einem <bedachten $>$ Urteil zu kommen, würdest Du häufig schreiben. Aber was soll ich tun, da unverdiente Liebe sich nicht auf starke Wurzeln stützen kann und bald alles einer prüfenden Betrachtung unterzogen wird, was sich aufgrund von Sympathie eingeschlichen hat $<$ ? $>$ ? Ich weiß, dass ich der einzige bin, der eher geliebt als begutachtet werden musste. Ich habe lediglich die Frucht der Freundschaft genossen, die ich mir im Voraus nehmen konnte, ohne wirklich bekannt zu sein « $\left(\$ 1\right.$ If.). ${ }^{692}$ Doch nach diesen Betrachtungen über die eigene Unwürdigkeit folgt ein Einwand (sed), dass Senarius den einmal »Freund « genannten nicht so schnell wieder hätte aufgeben dürfen: "Doch es hätte sich für Euch gehört, Euch nicht gleich wieder von dem zurückzuziehen, den ihr Freund nanntet - damit nicht der Fall eingetreten wäre <sc. was jetzt geschehen ist $>$, dass es nicht immer meine Schuld ist, wenn mir versprochene Zuneigung nicht bewahrt wird <sc. jetzt liegt die Schuld bei Senarius>. Denn das Herz eines eng Verbundenen kennt gewöhnlich keine Strenge, und ein treues Herz muss beständig festhalten, was es einmal aufgenommen hat $(\$ 2) .{ }^{693}$ In Verbindung mit der Grußformel bringt Ennodius einen möglichen Grund für die Schreibfaulheit des Senarius vor, nämlich den Hochmut der Mächtigen: »Ich grüße Euch also, wie ich es schuldig bin, und hoffe, dass ihr den widerwärtigen Hochmut der Mächtigen verachtet und so Eure Ehrenstellung und die von Gott gewährten Möglichkeiten durch die Macht der Demut erweitert. Dass dies so ist, möge die Zunge, die unsere Gedanken zum Ausdruck bringt, bestätigen, und die in einem Brief gezeigte Freundschaft möge ein wahrheitsgemäßes Zeugnis unseres Denkens sein « $(\$ 3){ }^{694}$

Auch in einer späteren Aufforderung an Senarius (116) klagt Ennodius darüber, vergessen zu sein (dieser Brief zeigt einige Parallelen zu Brief 110 an Eugenes, siehe unten). Der Brief beginnt mit dem allgemeinen Gedanken, dass durch die Rede alles

692 (78,1f.) Si diligentiae memoria circa personam meam animus vester non exueretur, si reverti eum ad iudicium sublimitas tua non cogeret post favorem, frequentia scripta prorogares. sed quid faciam, quia non validis radicibus nititur amor indebitus et cito ad examen reducitur, quidquid gratiae aura subripuit? (\$2) me novi solum prius debuisse diligi quam probari. hunc tantum fructum de caritate possedi, quem incognitus provisione subtraxi.

$693(78,2)$ sed vos convenerat non cito ab eo, cui amici nomen inposuistis, abscedere, ne non semper ad meam culpam redeat, quod promissa mihi non tenetur affectio. solet enim esse ignara districtionis devincti conscientia, et opus est ut perpetuo teneat quidquid semel fidum pectus acceperit.

$694(78,3)$ salutem ergo debitam dicens spero ut despicientes rancida potentum fastidia honorem vestrum et quam deus tribuit possibilitatem humilitatis fascibus sublimetis. cuius rei fidem interpres animorum lingua confirmet et testimonium fidele mentibus deferat caritas monstrata per litteras. 
gesteigert werden könne: "Es gibt zwar nichts, das nicht durch ehrgeizige Rede über die Wahrheit hinaus in die Höhe gehoben werden kann. " Doch sofort hält Ennodius dagegen, dass dies für ihn nicht gelte, da er seine Freundschaft zu Senarius nicht angemessen ausdrücken könne: »Doch ich muss hinsichtlich meiner Freundschaft zu Euch die Sprachlosigkeit meiner Rede ertragen. Niemals ist die Sprache der Freundschaft ebenbürtig, immer ist die Leistung des Wortes dem Gut des Herzens unterlegen « $(\$ 1) .{ }^{695}$ Daraus ergibt sich (ob hoc) für Ennodius, dass er als Mahner auftreten könne, d.h. von der Stärke seiner Freundschaft schließt er auf sein Recht, deutliche Worte gebrauchen zu dürfen: "Deswegen bin ich in der sicheren Position des Mahners: Ich hätte nicht gedacht, dass Deine Hoheit so lange Zeit so wenig an mich denken würde, dass Du nicht einmal gewöhnliche Briefe schreibst, und dass unter denen, die die Fesseln des (Freundschafts-) Vertrags binden, <auch > solche Briefe, die mit gespielter Miene Freundschaft nur vortäuschen, verweigert werden. Wenn ich in der Lage wäre, dies hinreichend zu beschreiben, hieße das, dass ich es ertragen könnte ${ }^{696}$ « (\$1f.). ${ }^{697}$ Ennodius hebt hervor, dass er selbst ausführe, was er von anderen erwarte (vgl. 110,2); er weist abschließend auf seinen Kummer hin, aber auch - man höre und staune - auf seine erprobte Geduld: "So: ich schreibe wieder und bekunde durch Beispiele, was ich mit Worten als erstrebenswert bezeichne. Entscheidet Ihr, was es bedeutet, fortan ehrenwerte Wünsche zu missachten: Ich trage, durch die Erfahrung geübt, den Schmerz mit Geduld « $(\$ 2) .{ }^{698}$ - Mit diesem unerwarteten Hinweis auf seine Geduld dürfte die ganze Bandbreite des von Ennodius angeschlagenen Tones deutlich geworden sein.

Ähnlich in Aufbau und Gedanken wie dieser Brief an Senarius, aber recht mild im Ton, ist die ebenfalls erneute Aufforderung an Eugenes (110; zu ihm siehe unten 346). Der Brief beginnt so, dass man zunächst nicht ahnt, dass ein Vorwurf folgen wird, nämlich mit einer Ausführung des Motivs >Brief als Spiegel ‘; allerdings spiegelt hier nicht der Brief des Schreibers diesen für den Adressaten (siehe oben 206), sondern beim Schreiben spiegelt sich der Adressat für den Verfasser; das `Gespräch ‘ührt nicht der Leser des Briefs, sondern der Verfasser: "Sooft Worte als Unterpfänder des

$695(116,1)$ nihil est equidem quod non a veritate in altum ambitioso tollatur eloquio. sed ego ad diligentiam circa vos meam patior sermonis infantiam. numquam par fuit lingua caritati, semper subiacuit oris officium bono conscientiae.

696 D.h. ebensowenig wie seine starke Freundschaft lässt sich sein Kummer in Worte fassen.

697 (116,1f.) ob hoc utor securitate monitoris: (\$2) non credidi tanto tempore amplitudinem tuam mei inmemorem sic futuram, ut etiam sollemnibus conloquiis abstineres, ut illa, quae solent affectionem imaginata fronte simulare, negarentur inter personas catenis foederis obligatas. haec si sufficienter valerem narrare, poteram sustinere.

$698(116,2)$ ecce iterum scribo et, quae verbis adsero sequenda, testor exemplis. vos videritis quale sit posthac desideria honesta neglegere, ego dolori patientiam usu institutus adhibeo. vale. 
Sinnes dienen, malt die Sprache im Brief so wie in einer Art Spiegel ein ihr angenehmes Bild, mit dem sie wie lebendig spricht; und sie freut sich darüber, wie das süße Bild den Wünschen entspricht « $(\$ 1) .{ }^{699}$ Es folgen Gedanken über die ,Unbeschreiblichkeit ‘ der Freundschaft: »Zwar kann keine Redefülle die Gedanken eines befreundeten Herzens aussprechen, und obwohl Worte leichter sind als Wohltaten und es nichts gibt, das man nicht durch ehrgeiziges Reden steigern könnte, bezeuge ich meine dürre Sprachlosigkeit bei der Darstellung meiner Freundschaft zu Euch « $(\$ 1) .^{700}$ Dies ist ein für Ennodius erstaunlicher Beginn, wenn man daraufhin den Vorwurf liest, dass Eugenes auf bereits zwei Briefe nicht geantwortet habe: »Ich werfe also Euch, lieber Gleichgesinnter, Schweigen vor, weil Du zwei Briefe bekommen und nicht an eine Antwort gedacht hast «. Ennodius weist darauf hin, dass er selbst seinen Prinzipien entspreche: "So: Ich schreibe wieder, denn ich weiß zu geben, was ich selbst erwarte" $(\$ 2) .^{701}$ Nach diesen kurzen Verweisen enthält der letzte Satz schon wieder lobende Worte: "Leb wohl, mein Herr, und schreib Deinem Freund mit dem Glanz, für den Du berühmt bist, und unterstütze ihn mit der Anständigkeit, die Dich so auszeichnet« $(\$ 2) .^{702}$

Vergleichsweise mild ist der Ton auch in einem Brief an den Diakon Hormisda (427; zu ihm siehe PCBE 2,1, p.1015f.), in dem Ennodius nur schreibt, dass er sich über dessen Schweigen wundere ( $\$ 1$ admiror), und dann seine Zuversicht äußert, dass dieser immerhin antworten werde. - Eine kurze Praefatio spricht über die Fähigkeit von Briefen, Getrennte zu verbinden, wobei Ennodius dies hier als eine göttliche Wohltat bezeichnet (und nicht wie sonst als Erfindung der Vorfahren, vgl. oben 209): "Die himmlische Vorsehung verbindet die in Freundschaft Verbundenen durch die Wohltaten der Briefe, indem die Freundschaft diejenigen, die eine weite Entfernung voneinander trennt, als Trost für diesen Kummer verbindet, wenn das <briefliche $>\mathrm{Ge}$ spräch gepflegt wird « $(\$ 1) \cdot{ }^{703}$ Aus diesem Grund müsse sich Ennodius über das da-

$699(110,1)$ Quotiens sensuum pignoribus verba famulantur, quasi in quodam speculo ita in paginis sermo sibi amicam pingit effigiem, cum qua viva vice conloquitur, et dulci simulacro desideriis obsequente gratulatur.

$700(110,1)$ nulla quidem conceptum foederati pectoris eloquitur oris affluentia, et cum sint faciliora verba beneficiis nec existat quod crescere nequeat ambitione dicendi, ego in explicanda circa vos diligentia arentem testor infantiam. [Nach dicendi besser Komma wie bei HARTEL statt des Punktes bei VoGEL.]

$701(110,2)$ unianimitatem tamen vestram taciturnitatis incesso, quod gemina scriptione donatus nihil de vicaria relatione cogitasti. ecce iterum paginas mitto sciens tribuere quod expecto.

$702(110,2)$ vale, mi domine, et amantem tui adloquere nitore quo clarus es, fove integritate qua praevales.

$703(427,1)$ Caelestis dispensatio epistolaribus beneficiis iunctos caritate consociat, dum quos discernit itinerum prolixitas, in remedio sollicitudinis iungit affectio, si sit cura sermonis. 
von abweichende Verhalten des Hormisda wundern: "Ich wundere mich also sehr über Euer Schweigen, dass Ihr mich, seitdem ich die Last der Krankheit abgelegt habe, durch keinen Brief aufgemuntert habt«. Doch auf diesen Brief von Ennodius werde Hormisda antworten müssen: »Aber weil wir Dich durch Sprechen gut zum Sprechen bringen können, antworte wenigstens, indem Du mich Redseligen nachahmst. Denn man kann das, was man wünscht, gut durch Beispiele erbitten und erlangen. Ich erweise Dir also grüßend die Ehre und melde, dass es mir dank Gottes Gnade schon besser geht, und ich bitte, dass Du mich in einem Antwortbrief segnen mögest « (\$1f.). ${ }^{704}$ Diese Zurückhaltung gegenüber Hormisda lässt sich vielleicht damit erklären, dass dieser schon zum Nachfolger von Papst Symmachus ausersehen ist (siehe auch unten 366).

\section{b. 2 Dank für erhaltene Briefe}

Dass Ennodius sich für erhaltene Briefe nicht in dem Maße überschwänglich bedankt, wie er über deren Ausbleiben vorwurfsvoll klagt, sondern auch hier seinem Prinzip folgt, nach Möglichkeit niemanden ins Angesicht zu loben - zumindest nicht dann, wenn es zu erwarten wäre -, war im Laufe der Untersuchung schon an manchen Passagen zu sehen: So wird z.B. Avienus für einen Brief zunächst gelobt, dann aber umso deutlicher ermahnt (23, dazu oben 122); auch Avienus' Bruder Messala wird sehr gelobt, muss sich aber dennoch auch Ermahnungen anhören (434, oben 120). ${ }^{705}$ Dass Ennodius nicht nur mit jüngeren Korrespondenten, für die die Korrespondenz sozusagen zur >Ausbildung gehört, so umgeht, zeigt der erste überlieferte Brief an Faustus, in dem er sich zwar für den endlich erhaltenen Brief bedankt, aber sowohl diesen Dank ironisch gestaltet (mit dem Dank an seine eigenen Klagen, die ihm geholfen hätten) als auch zeigt, dass er mit dem Inhalt des Briefs nicht zufrieden war (6, oben 224). Für einen Brief von Olybrius bedankt er sich, indem er zunächst dessen sprachliche Qualitäten beschreibt, wie er es nur selten tut, sich dann aber auf ein Detail in dessen Brief bezieht, das ihm gar nicht gefallen habe (13, oben 180). Dass Ennodius sich über Briefe gefreut hat, sagt er besonders deutlich in dem Moment, wenn weitere ausbleiben ( einen Brief stellvertretend für die Freude darüber, dass der Adressat ein Amt erlangt hat (in 125, unten 341).

$704(427,1 \mathrm{f}$.) silentium tamen vestrum nimis admiror, quod post depositae sarcinas aegritudinis nulla me adlocutione sublevastis. sed quia loquendo oportune cogimus, ut loquaris, vel garruli imitatione responde. bene enim res desiderii et poscitur et inpetratur exemplis. (\$2) ergo honorem salutationis inpendens indico me deo propitio iam valere, subplicans, ut vicaria mihi stili promulgatione benedicas.

705 Siehe auch zu 4 oben 121, zu 15 o. 119, zu 125 u. 341; zu 141 o. 250; zu 314 o. 123. 
Auch Dankbriefe sind also nicht immer ungetrübt von Tadel, Vorwürfen, Ironie oder offenherzigen Bekundungen von Egoismus. Im Folgenden sind nun noch weitere Auffälligkeiten an Ennodius' >Dank für Briefe‘ aufzuzeigen: Mehrmals sieht er sich in der paradoxen Situation, dass er trotz eines erhaltenen Briefs nicht zufrieden ist (siehe unten zu 313 an Euprepia und zu 42 an Olybrius). Hingegen fällt auf, dass er sich zuweilen besonders ausführlich für solche Briefe bedankt, mit denen er um einen Gefallen gebeten wurde, und zwar in der Weise, als gehe es in der Korrespondenz nur um die Kontaktpflege. Wenn man Briefe an geistliche und solche an weltliche Adressaten vergleicht, so fällt auf, dass sich im Wortschatz und im Motivarsenal zwar deutliche Unterschiede zeigen, es jedoch in beiden Gruppen Briefe gibt, in denen die Worte des Dankes durch andere kritische und/oder ironische Äußerungen überlagert werden.

\section{Dank für Briefe von Geistlichen}

Für Briefe von kirchlichen Amtsträgern bedankt sich Ennodius mit demütig-frommen Worten, wobei aber auch hier kritische Untertöne (etwa dass der Adressat nur schreibe, wenn Ennodius helfen solle) oder freimütige Äußerungen, worin er seinen eigenen Nutzen sehe (etwa dass er, weil er helfen solle, nun endlich von gleich zu gleich angeredet werde), nicht ausbleiben. Ennodius bedankt sich für die erhaltenen Briefe, die z.T. offenbar Bitten an ihn enthielten, besonders aus dem Grund, dass sich durch die Ansprache der Geistlichen bzw. durch ihr Denken an ihn seine Sündenlast verringert habe. In den Briefen an die Äbte Stefanus $(71 ; 79)$ und Porcianus $(411)$ ist das Thema samicitia ganz ausgeblendet (er verwendet ausschließlich das Wort gratia), und die Sprache ist insgesamt demütig-fromm, was allerdings nicht bedeutet, dass Ennodius' Haltung gegenüber den Adressaten dies ebenfalls immer ist. Gegenüber Porcianus bleibt der demütige Ton durchweg erhalten und wird nur durch eine kurze offene Äußerung gestört, gegenüber Stefanus hingegen zeigt Ennodius sich recht selbstbewusst.

Einen ssanften $`$ Dankbrief (411) erhält Abt Porcianus (dies ist der einzige Brief an ihn), mit dem Ennodius schon bekannt war (cf. \$1 eliminetur oblivio); dieser hatte sich offenbar mit einer Bitte an Ennodius gewandt, die er zu erfüllen verspricht (cf. \$2 suscipio [...] oboedientiam; inperantem). Ennodius antwortet sehr ergeben und voller Demut und mit - für seine Verhältnisse - langen Komplimenten für das gottgefällige Leben des Adressaten. Den demütigen Ton durchbricht er hier nur ganz kurz mit dem Hinweis auf seinen eigenen Vorteil, nämlich dass er sich aufgrund dieser Zuwendung des Porcianus der Gnade Gottes schon nahe fühle und dass auch derjenige, der gehorcht bzw. eine Bitte erfüllt, etwas Ehre erlange. - Zunächst führt Ennodius es auf die Gnade Gottes zurück, dass er von Porcianus einen Brief erhalten habe: "Himmlische Beispiele zeigen, dass Besuch <sc. per Brief, cf. oben 168> von himmlischen Männern nur durch die Gnade Gottes kommt. Denn welche Erinnerung an Sünder könnte es geben, wenn nicht die himmlische Gunst auf verborgenen 
Wegen wirkte und auf eine der Seele eingehauchte Weise das Vergessen, das sich aufgrund der Sünden einschleichen konnte, beseitigt würde? « Da der gottgefällige Porcianus ihn nicht vergessen habe, sei auch er, Ennodius, dem Erbarmen Gottes schon nahe <sc. weil Porcianus an ihn denke und für ihn bete>: "Man ist voller Zuversicht, das göttliche Erbarmen schon erbeten zu haben, wenn man den Seelen der Verehrer Gottes nicht fern ist. ${ }^{706}$ Ich danke also unserem dreieinigen Gott, der Euer Ehren dazu brachte, mich per Brief zu besuchen “ $(\$ 1) .{ }^{707}$ Dann verspricht er, Porcianus' Bitte zu erfüllen, wobei er seinen eigenen Vorteil nicht verschweigt: "Ich will auch tun, was Ihr befehlt. Denn keine geringe Wertschätzung wird den Gehorsamen geschuldet, während der Ruhm Christi den Befehlenden erwartet« (\$2). Es folgen lobende Ausführungen über das gottgefällige Leben des Porcianus und die Bitte um weitere Briefe: »Betet für mich, die Ihr die menschliche Schwachheit schon im Leben abgelegt habt, die Ihr es geschafft habt, noch vor der Trennung vom Körper von den Lasten des Fleisches erlöst zu werden; empfangt meine dienstbaren Grüße und lasst mich dadurch in den Genuss Eurer Gunst kommen, dass die Pflege der Korrespondenz wächst « $(\$ 2){ }^{708}$ Dass Ennodius hier ungewöhnlich sanft ist und dass die lobenden Worte (qui humanitatis inbecilla - absolvi) für seine Verhältnisse recht lang sind, wird im Vergleich mit dem Brief an einen anderen Abt deutlich:

Der Brief an Abt Stefanus (71; er erhält noch einen weiteren ähnlichen Brief, 79; außer diesen beiden Briefen ist nichts bekannt, cf. PCBE 2.2, p. 2114: "Stefanus 12«), der sich mit einer Bitte erstmals in einem Brief an Ennodius gewandt hat, besteht aus einer Mischung aus Demut, Unterwürfigkeit, Ironie, Selbstbewusstsein und unverhohlenem Triumph. Ennodius gibt zwar ausführlich seiner Freude Ausdruck, endlich einmal einen Brief von dem gottgefälligen Stefanus, den er schon immer verehrt habe, erhalten zu haben, doch ist kaum zu überhören, wie er sich darüber mokiert, dass ihm nur geschrieben werde, wenn er helfen solle. ${ }^{709}$ Befriedigt betont er, dass Stefanus, der bisher geschwiegen habe, nun von gleich zu gleich mit ihm spreche. -

706 Cf. z.B. 71,2 unten 297. - Der gleiche Gedanke im Zusammenhang mit räumlicher Nähe bei Ruricius: non ex toto malum est qui bonis iungitur (Ruric. 1,12,2).

707 (411,1) Divinis declaratur exemplis, nisi per dei gratiam visitationem hominum caelestium non venire. quae enim recordatio potest esse peccantium, nisi occultis itineribus favor caelestis operetur et per viam mentibus inspiratam quae propter peccata subripere poterat eliminetur oblivio? inpetratae iam divinae misericordiae fiducia est cultorum dei animis non deesse. ergo gratias refero trinitati deo nostro, qui ut me reverentia vestra alloquiis visitaret exegit.

$708(411,2)$ suscipio et oboedientiam vestram: nec enim exiguus cultus debetur obsequentibus, cum Christi gloria maneat inperantem. orate pro me, qui humanitatis inbecilla, dum adhuc estis homines, evitastis, quos contigit necdum corpore sequestrato ponderibus carnis absol$v i$, et servitiis salutationis adceptis frugem circa me gratiae, dum sermonis adulescit cultura, concedite.

709 Dies ist Sundwall entgangen $(1919,19)$ : "Diesen Landsmann hält Ennodius hoch in Ehren und freut sich, von ihm endlich einmal einen Brief zu bekommen.« 
Zunächst geht es um die Freude über den Brief, die paradoxerweise einer Notlage Dritter zu verdanken ist (zu diesem in Empfehlungsschreiben gängigen Motiv siehe unten 360): »Wie angenehm ist der in Eurem Brief mitgeteilte Auftrag, der mir ein geistliches Geschenk gemacht hat. Wie sehr entspricht die Notlage der Boten meinen Wünschen, da sie in der Absicht, Abhilfe zu suchen, fremde $<=$ meine $>$ Sehnsüchte $<$ sc. nach einem Brief> stillt. Ich muss gestehen: Wenn es nicht meinen Vorsätzen widerspräche, würde ich mir boshafterweise fast wünschen, dass die Sicherheit anderer gestört wird. « Der Ausdruck der Freude über den Brief geht über in den Gedanken, dass Ennodius ohne diese Notlage nie einen Brief von Stefanus erhalten hätte: »So sieh: Eine widrige Situation schenkt das, was eine günstige nicht verschafft. Aus welchen Gründen könnte ich Sünder in einer ruhigen Situation von Heiligen einen Brief erhalten, den der Glanz meiner Verdienste niemals erlangen konnte? « (\$1). ${ }^{710}$ Durch die briefliche Ansprache des Stefanus, die den Unterstützung Suchenden und Gott zu verdanken sei, habe sich auch die Situation des Ennodius verbessert: »Siehe: So eine große Unterstützung haben mir nun diejenigen erwiesen, die sagen, sie von Euch erhalten zu haben <sc. indem sie von Stefanus den Empfehlungsbrief an Ennodius erhielten $>$. Ich denke, dass das ein Geschenk der göttlichen Vorsehung ist. Ich glaube, ich habe schon viel von der < Sünden-> Last meines schlechten Lebenswandels abgelegt. Äußerst nah ist man selbst der Unschuld, wenn man es verdient, von Heiligen angesprochen zu werden. ${ }^{711}$ Weshalb habe ich, solange mich die unreine, ausschweifende Welt festhielt, niemals Briefe von einem so hohen Mann verdient, auch hinterher lange Zeit niemals solches Gut erhalten <sc. so dass die eigene Sündenlast schon eher durch die Zuwendung des Stefanus verringert worden wäre >? GroBer Gott, welche Würde lässt Du Deinen Dienern zukommen, dass Du die, die Du zu beachten beginnst $<$ sc. Ennodius $>$, auch Deinen Freunden $<$ sc. Stefanus $>$ angenehm sein lässt “ $\left(\$ 2 f\right.$.). ${ }^{712}$ Auch das Verhältnis zwischen Stefanus und Ennodius habe sich nun verändert, wobei Ennodius auffälligerweise von seiner Unterwürfigkeit als

$710(71,1)$ Litterarum vestrarum quam dulce negotium est, quod mihi spiritale munus exhibuit! quam votiva perlatorum necessitas, quae remedii sui studio desideriis medetur alienis! confiteor, nisi repugnaret proposito, inimica paene ad turbandam aliquorum securitatem vota conciperem. ecce praestant adversa, quod secunda non tribuunt. sanctorum litteras tranquillis rebus unde peccator acciperem, quas numquam meritorum meorum nitor exegit?

711 Die bloße Nähe oder Aufmerksamkeit der Heiligen bessert den Sünder, cf. z.B. 411, 1 oben 296.

712 ( $71,2 \mathrm{f}$.$) ecce quantum mihi contulerunt suffragium qui a vobis obtinuisse se confitentur.$ divinam aestimo providentiam ista tribuere. multum iam credo quod de malae conversationis fasce deposui. proximus est innocentiae, qui sanctorum meretur alloquia. quare dum me saecularis licentia inmunda possedit, numquam tanti viri apices merui, post etiam per longa intervalla numquam huiusmodi bona suscepi? [Fragezeichen statt Punkt bei Vogel] (\$3) deus magne, quam dignitatem servientibus tibi tribuis, ut quos respicere coeperis, etiam amicis tuis reddas acceptos! 
ebenso vergangen spricht wie zuvor von seiner Sündenlast: "In der Tat habe ich immer mit besonderer Verehrung zu Euch aufgesehen, immer meinen von Sünden gebeugten Nacken vor Euren verehrungswürdigen Eigenschaften gebeugt. Siehe: Nun werde ich fast von gleich zu gleich angesprochen. Die lange gezeigte Unterwerfung hat mich <am Ende> erhöht « $\left(\$_{3}\right) .{ }^{713}$ Solch eine unverhohlene Äußerung, wie sich durch Stefanus' Bitte Ennodius' eigene Situation verändert habe, gehörte vermutlich üblicherweise nur in die eigenen stillen Gedanken, aber nicht zu dem, was man offen aussprach; Ennodius geht hier sehr weit mit seiner Ungeschminktheit und sinceritas. Dass er einen Grund hat, so selbstbewusst aufzutreten, zeigt sich im folgenden, wenn er allmählich zu der konkreten Angelegenheit kommt, deretwegen Stefanus geschrieben hatte; der Verlauf war zwar nicht plangemäß, zeugt aber dennoch bzw. umso mehr von Ennodius' Autorität: „Unterstütze mich also mit Deinen Gebeten. Denn Du zeigst in Deinem Brief, dass von Euch kein schwacher Schutz geboten wird. Denn Ihr habt auch diejenigen als Eure Schützlinge aufgenommen, die mir das Gute zufügten, über das ich mich freue <gemeint ist der Brief von Stefanus>. Doch zur Sache: Jener verruchte Kleriker hatte Angst, seine Sache vor dem Bischof zu vertreten $^{714}$, als er sah, dass ich diejenigen verteidigen würde, für die Ihr meinen Einsatz bestimmt habt. Ich schlage vor, dass, wenn Ihr es wünscht, einer von ihnen mit einem Empfehlungsbrief von Euch nach Ravenna zu Eurem Sohn Faustus geht, damit nicht zu ihrem Nachteil ein gekauftes Urteil der Richter, die in Mailand im Überfluss vorhanden sind, herauskommt $"\left(\$ 3\right.$ f..${ }^{715}$ Mit dieser Nachricht zeigt Ennodius vollends seine Stärke: Wenn er in einem Streitfall auftritt, weiß die Gegenseite, dass sie keine Chance hat (und begibt sich nun lieber in die Hände der weltlichen Justiz). Dass damit die Sache der Hilfesuchenden wieder offen ist, hat der Adressat beim Lesen des Anfangs mit Formulierungen wie dulce negotium, votiva necessitas wohl kaum geahnt. Dem paradoxen Ausgang, dass Ennodius von einem Beweis seiner Macht berichten kann, Stefanus damit aber in keiner Weise geholfen ist, entspricht der Wechsel im Ton zwischen Demut und Triumph.

$713(71,3)$ vere semper vos singulari cultura suspexi, semper venerandis moribus gravata peccatis colla summisi. ecce iam quasi aequalis appellor. erexit me diu custodita subiectio.

714 Allgemein zur bischöflichen Gerichtsbarkeit in Zivilsachen (audientia episcopalis) siehe z.B. E. DassmanN, Kirchengeschichte II/1, Stuttgart u.a. 1996, 47 f.

715 ( $71,3 \mathrm{f}$.) fove ergo me orationibus tuis; ostendis enim paginis, fragile a vobis non exhiberi patrocinium. nam et isti suscepti sunt, qui mihi bona, de quibus gestio, contulerunt. (\$4) ad rem redeo. perditus ille clericus expavit causam dicere apud episcopum, postquam defendi a me vidit eos, quibus meum deputastis obsequium. suggero, si iubetis, ut unus de ipsis Ravennam ambulet cum vestris ad filium vestrum domnum Faustum commendaticiis, ne in praeiudicio ipsorum venalis iudicum, qui Mediolani exuberant, sententia depromatur. 


\section{Dank an weltliche Adressaten}

Auch die Dankbriefe an weltliche Adressaten sind untereinander recht verschieden. Manche sind freundlich gehalten, in anderen befindet sich Ennodius in der paradoxen Situation, trotz des erhaltenen Briefs nicht zufrieden zu sein. In einer ganzen Reihe von Briefen mischt sich der Dank bzw. das Lob für den Brief mit Tadel und/ oder Ermahnungen.

Freundliche Dankbriefe erhalten die weiblichen Adressaten Firmina und (ausnahmsweise einmal auch) seine Schwester Euprepia, wobei Ennodius allerdings in diesem Brief die paradoxe Situation aufzeigt, dass er trotz des Briefs nicht zufrieden sei.

Durchweg freundlich und sharmlos` ist der Brief an Firmina (305), ${ }^{716}$ der einen Hinweis auf die zumindest zeitweise vielen Dienstreisen des Ennodius gibt. - Zunächst äußert Ennodius ausführlich seine Freude darüber, dass er im rechten Moment einen Brief von ihr erhalten habe und ihr mit demselben Boten auch selbst einen senden könne. Seine Freude betrifft sowohl die Tatsache, dass er einen Brief bekommen hat, als auch den Inhalt, dass Firmina gesund ist und dass sie ihn aufgefordert hat, die gratia zu wahren. Ennodius beginnt mit einer Praefatio (wobei auffälligerweise die Sätze durch enim verbunden sind und der Hauptteil mit sic beginnt, vgl. oben 259): "Sooft man eine erwünschte Sache schnell erlangt, erhält sie ihren Wert durch eben die Kürze der Zeit. ${ }^{717}$ Denn damit der Glanz der himmlischen Wohltat anwächst, gibt der Spender seine Gabe sofort, damit nicht das lange Warten der Hoffenden sein Almosen verunstaltet. Denn wer wird nicht, wenn er schnell den Erfolg seines Wunsches sieht, das Erlangte noch mehr schätzen? - In dieser Weise habe ich, der ich danach dürstete, kurz vor meiner Abreise einen Brief von Eurer Hoheit erhalten. Ich muss sagen, ich war betrübt und sehr bekümmert, solange ich weder einen Überbringer für einen Brief von mir finden noch vor meiner Abreise über Eure gute Gesundheit informiert werden konnte. Siehe: Eine gute Fügung hat beides gewährt: Ich habe gleichzeitig die erwünschten Nachrichten erhalten - die ich erwidern kann -, und kann berichten, dass ich aus den Cottischen Alpen <=Teil der Westalpen> zurückgekehrt bin und von Ravenna aufbrechen werde. Betet dafür, dass das Geschenk des himmlischen Segens dem in vielen Mühen Umhergetriebenen Geduld einflößen möge«. Offenbar ist Ennodius zur Zeit viel unterwegs. Es folgt eine Beteuerung seiner Verbundenheit (gratia) zu Firmina und die abschließende Bitte um unterstützende Gebete: »Dass aber der Glanz Eurer Hoheit mich auffordert, die Gunst

716 Firmina erhält nur diesen Brief; außerdem beschreibt ein sechszeiliges Epigramm (229) einen Ring, der Firmina gehörte, und vier Epigramme (165-165c) widmen sich variierend einer besonders feinen Kette der Firmina. Sie erhält außerdem (um 492/496) einen Brief von Papst Gelasius (685 Jaffé), der sie bittet, bestimmte Güter wieder instandzusetzen, um Kriegsflüchtlingen zu helfen; weiter ist über sie nichts bekannt (cf. PLRE II, 470).

717 Dieser Gedanke auch in $(93,1)$, siehe unten 357 ; der gegenteilige Gedanke in $(321,1)$, siehe dazu unten 337 , und in $(177,1)$. 
zu bewahren, so glaube ich, dass eher der Lauf der Flüsse die Richtung ändern und Fische das nährende Wasser verlassen und zum Himmel streben, als dass ich mich so vergehen könnte, solche Dinge <sc. die Gunstbezeugungen der Firmina> zu vergessen. Es bleibt, Lebwohl zu sagen, meine Herrin; bittet unseren Erlöser unaufhörlich für Euren Schutzbefohlenen « (305)..$^{718}$ - In diesem Brief zeigt sich Ennodius von seiner freundlichen Seite, besonders die Beteuerung seiner gratia durch die Adynata ist ungewöhnlich ausführlich und freundlich.

Ungewöhnlich freundlich ist auch ein Brief (313) an seine Schwester Euprepia, der er zuvor häufig in harten Worten vorgeworfen hat, dass sie nicht schreibe und ihn selbst und ihren Sohn Lupicinus, der in seiner Obhut ist, vernachlässige (siehe 52; 84; 109; 268; 293; 219 hat ein anderes Thema, dort sendet er ihr ein Grabgedicht für eine Bekannte). Doch um die Stärke seiner Zuneigung auszudrücken, hebt er hervor, dass er auch angesichts des erhaltenen Briefs nicht zufrieden sei, da dadurch seine Sehnsucht mehr verstärkt als beruhigt sei. - Ennodius beginnt mit dem Gedanken, dass er sich bereits gut an die Trennung gewöhnt hatte, als er den Brief erhielt (dieser Gedanke findet sich auch in einem Brief an Faustus, siehe oben 243): "Wie gut hatte die Gewöhnung an Eure Abwesenheit meine Seele befähigt, die Trennung zu ertragen, indem langes Schweigen aufgrund der Zwänge der Umstände <d.h. der Unmöglichkeit, Briefe auszutauschen $>$ eine Gleichgültigkeit gegenüber dem Süßen erzeugt hatte. Die Narbe, die sich zur Heilung der lieben Zuneigung gebildet hatte, ist wieder aufgebrochen. Verehrte Schwester, ich muss gestehen, dass Dein Brief, der mit dem mir sehr bekannten feinen Geschmack gewürzt ist, mich wieder zur alten Sehnsucht gebracht hat. So sieh nun, mit welcher Kunst Du mit mir kämpfst: Du lässt mir weder durch Deine Anwesenheit Zufriedenheit noch durch Schweigen Vergessen zuteil werden." Dann beschreibt er, wie durch ihren Brief seine Seele zu ihr geflogen sei; dieses Bild der dank des Briefes fliegenden Seele findet sich bei Ennodius nur hier: "Der höchste Prüfer der Seelen weiß, dass meine Seele beim Lesen Deines Briefs nicht

$718(305,1)$ Quotiens votiva res repente contigerit, pretium de ipsa temporis brevitate sortitur. caelestis enim ut crescat benificii genius, subitum facit esse quod tribuit, ne devenustet sperantum prolixitas misericordiam largitoris. quis enim effectum desiderii repente suscipiens non avidius impetrata veneretur? sic litteras magnitudinis vestrae sitiens tempore profectionis accepi. (\$2) dolebam fateor et vehementer angebar, dum nec obsequiorum meorum perlator existeret nec sospitatis vestrae digressurus bona cognoscerem. ecce utrumque fors [vel sors coni. VOGEL, frons mss.] bona concessit: accepi pariter indicia optata quae refero, et uno eodemque tempore regressum me de Alpibus Cottiis et Ravennate significo iter adrepturum. orate ut variis laborum iactato incommodis patientiam supernae benedictionis munus infundat. $\left(\$_{3}\right)$ me autem quod ad custodiam gratiae culminis vestri splendor hortatur, facilius credo cursus fluminum in diversa revocari et relictis fluentorum alimoniis aether vacuum pisces expetere, quam tantorum me inmemorem delicta restituant. quod superest, valete, mi domina, et redemptori nostro pro persona suscepti $[\mathrm{zu}$ susceptus = cliens siehe den Index bei VoGeL s.v.] incessabiliter supplicate. 
in ihrem eigenen Inneren bleiben konnte und, durch die honigsüße Liebe gezwungen, dorthin weggeflogen ist, wo Du Dich aufhältst. Obwohl mich die Mailänder Mauern umschlossen, war ich in Arles, und während der Geist frei zum süßen Ort hinlief, hielt mich das Gefängnis des Körpers in Italien fest. « Es folgt eine der Stellen, an denen Ennodius von der Unterlegenheit seiner Redekunst gegenüber der Zuneigung spricht (siehe oben 266); besonders auffällig ist hier jedoch, dass es nicht nur der mangelnden Redekunst zugeschrieben wird, dass die Liebe nicht beschrieben werden kann, sondern auch dem pudor, der ihn nicht alles sagen lässt, was er sagen könnte (dieser Gedanke nur hier): "O wenn doch die Sprache reich genug wäre, das auszudrücken, was die Seele will, bzw. wenn doch das, wofür die Zunge ausreicht, nicht die Scheu zurückhielte. Gering ist eine Liebe, die sich durch das Zeugnis der Sprache hinreichend darstellen lässt. Es ist ein Eingeständnis für eine nur laue Liebe, wenn hinter ihr die Sprache nicht zurücksteht. « Den Abschluss bildet diesmal nicht die Bitte um ein Gebet, sondern die Versicherung, dass er selbst für sie bete: »Es bleibt zu sagen, dass ich Gott bitte, dass es Dir gutgeht und dass Du, um meinen Kummer, den Du durch Dein allzu kunstvolles Schreiben verdoppelt hast, zu stillen, bewahrt wirst zum Nutzen von unser beider Wohlergehen« (313).$^{719}$ - Obwohl Ennodius in einer Reihe von Briefen über ihr Schweigen geklagt hat, klagt er nun also wiederum, weil sie ihr Schweigen gebrochen hat. Auf diese Weise betont er, wie sehr er seine Schwester vermisst: Dies ist ein gutes Beispiel dafür, wie ihn seine Liebe und Freundschaft häufig zu Klagen veranlasst (cf. 426,2 ad querellam descendi caritatis imperio). Außerdem zeichnet sich dieser Brief dadurch aus, dass Ennodius die Wirkung des erhaltenen Briefes ausmalt wie sonst an keiner anderen Stelle.

Die gleiche Methode, durch die Unzufriedenheit mit dem erhaltenen Brief die Stärke der Sehnsucht auszudrücken, findet sich in einem Brief an Olybrius (42; zur Person oben 178). Ennodius spricht zunächst von seiner Freude über den Brief, wobei er allerdings andeutet, dass er lange darauf warten musste: »Endlich ist einmal das,

719 (313,1) Quam bene animum meum ad patientiam sequestrationis absentiae vestrae usus aptaverat, dum prolixa silentia contemptum dulcedinis rerum suarum necessitate pariebant! rescissa est cicatrix, quae ad medicinam pii amoris accesserat. confiteor, soror venerabilis, ad antiquum me desiderium litterae tuae nimis noto conditae sapore revocarunt. ecce vide qua mecum arte contendis, cui nec satietatem de praesentia tua nec oblivionem de silentio pateris subvenire. $\left(\$_{2}\right)$ scit mentium discussor altissimus, lectione apicum tuorum animam meam inter penetralia sua non potuisse consistere et ad praesentiam tuam diligentiae evolasse melle conpulsam. habuit Arelatensis habitatio, cum Mediolanensibus muris includerer, et dum ad dulcem sedem libertas mentis excurreret, intra Italiam me corporis captivitas includebat. (\$3) o si suppeteret sermonis abundantia ad ea quae cupit animus exponenda aut illa, ad quae lingua sufficit, non pudor eriperet! parvus amor est, qui oris testimonio sufficienter aperitur. confessio est tepidae caritatis, quotiens in ea non cedit eloquium. quod restat, deum precor, ut valeas et ad sublevandum maerorem meum, quem scriptione tua nimis daedala arte geminasti, bono prosperitatis mutuae reserveris. 
was ich lange ersehnt habe, wunschgemäß eingetreten, nämlich dass eine Welle reicher Redekunst meinen Durst stillte, den ich durch die Glut Eurer $<$ früheren $>$ Briefe bekommen hatte, und dass Fluten, die die Lippen erfreuen, die Hitze löschten, die das lange Warten verdoppelt hatte. « Doch er wendet sofort ein, dass er nicht wirklich zufrieden sei: "Aber warum soll ich betonen, zur Erfüllung meiner Wünsche gelangt zu sein, wo mir doch aus der Erfüllung ein größeres Verlangen erwächst, da mein Herz aufgrund Eures Redeflusses in Flammen gerät? « $(\$ 1) .{ }^{720}$ Doch das sei nicht ungewöhnlich: "Es ist offenkundig, wie töricht die menschliche Seele ist, die, während sie den Wert des von ihr Erstrebten erkennt, sich daran gewöhnt, mehr zu lieben, was sie spät bekommt; und während gegenwärtig im Überfluss vorhanden ist, worüber sie sich freuen kann, gibt es mehr, was ihr fehlt « $(\$ 2) .{ }^{721}$ Im zweiten Teil dieses Briefs geht Ennodius ähnlich vor wie schon in einem früheren Brief an Olybrius: Er greift ein Detail aus dessen Brief heraus, um es zu kritisieren (vgl. in 13 die Erwähnung des Kampfes von Herkules gegen Antaeus, oben 180). Hier bedeutet die Kritik aber gleichzeitig ein Lob: Ennodius bezieht sich darauf, dass Olybrius behauptet habe, seinen Worten fehle der rechte Antrieb, und er weist ihn darauf hin, dass er solche Zweifel an seinen eigenen Fähigkeiten ihm gegenüber nicht vorzubringen brauche bzw. dürfe. Da einerseits er sich selbst bzw. seine Fähigkeiten gut einschätzen könne, andererseits der Brief Olybrius' Redekunst bewiesen habe, seien solche Bedenken nicht gestattet, da sie nicht der Wahrheit entsprächen (zur formido simulata siehe oben 187 mit Anm. 410): "Nun muss ich sagen, dass ich, der ich mich <sc. selbst gut> einschätzen kann, mich in Eurem Brief über die überflüssige schützende Bemerkung erschreckt habe, wo Ihr - während die Segel Eurer Rede von günstigem Wehen auf das hohe Meer getragen werden und gehorsam alles Wehende dient - sagt, dass Eurer Rede das Ruder fehle. Nicht zulässig ist eine von der Wahrheitsliebe getrennte Furcht, die Worte ausmalen. "In einer Reihe von Sentenzen begründet er, warum Olybrius keine Furcht vorgeben dürfe: "Ruder braucht man immer dann, wenn Schiffe nicht vom Anstoß der Winde unterstützt werden; nicht braucht sie derjenige, dem die ergebene Einigkeit der Winde eine günstige Fahrt bereitet. Die Sonne lässt sich von Fackeln nicht unterstützen, und die versammelten kleineren Sterne erhellen nie die Helligkeit des

720 (42,1) Vix aliquando mihi ea quae diu cupita sunt ex sententia successerunt, ut sitim, quam ex litterarum vestrarum ardore conceperam, eloquentiae divitis unda satiaret et aestus, quos expectatio longa geminaverat, adridentia labiis fluenta restinguerent. sed cur me ad votorum adseram summam fuisse perductum, cui maius nascitur de inpetratione desiderium, dum de sermonum vestrorum flumine pectus ardescit?

$721(42,2)$ ostenditur mihi liquido quam sit rerum nescia mens humana, quae dum pretium propriae ambitionis intellegit, adsuescit plus amare ad quod tarde pervenit, et dum abundat in praesentia quod laetetur, magis superest quod requirat. - Vgl. (Verg. Aen. 10,501f.): nescia mens hominum fati sortisque futurae / et servare modum rebus sublata secundis. 
Mondkreises« $(42,3) .^{722}$ Diese Sentenzen implizieren ein Lob für den erhaltenen Brief: Olybrius kann sich auf seine Fähigkeiten völlig sicher verlassen, daher muss bzw. darf er keine Zweifel an seinen Fähigkeiten vorbringen. Eine Bitte um weitere Briefe schließt den Brief ab $\left(\$_{4}\right)$. - In diesem Brief geht Ennodius ebenso vor wie im zuvor besprochenen an Euprepia: Zum einen betont die hier zweifache Unzufriedenheit (der Brief hat die Sehnsucht nicht stillen können; Olybrius hat unberechtigterweise Furcht vor Ennodius' Urteil vorgetäuscht) sowohl die Freude über den Brief als auch das Lob für dessen Gestaltung. Zum anderen ist es wohl kein Zufall, dass Ennodius für seinen Brief ausgerechnet diese geradezu >methodische`Unzufriedenheit wählt, um nicht vollends zu loben und zu schmeicheln.

\section{b. 3 Kontaktaufnahme: praevius sermo}

Besonderen Charakter und Inhalt weisen serste Briefe $`$ an Personen auf, die man nur vom Hörensagen kennt, denen man erst einmal begegnet ist oder denen man sehr lange nicht mehr geschrieben hat. Wegen der mageren Informationslage lässt sich bei den Briefen des Ennodius nicht immer entscheiden, ob er mit den Adressaten zuvor schon einmal Kontakt hatte, sei es persönlich oder brieflich. Zumeist bleibt außerdem unklar, welcher konkrete Anlass (sei es eine Nachricht oder Bitte, sei es der Wunsch, sich mit einem neuen Amtsträger bekannt zu machen) zu der ersten oder erneuten Kontaktaufnahme geführt hat, da die konkreten Informationen den mündlichen Ausführungen des Boten überlassen werden konnten; manchmal immerhin geht der konkrete Anlass aus dem Brief hervor (z.B. in 71, siehe oben 296; eine Empfehlung in 118; siehe auch unten $360 \mathrm{zu}$ Empfehlungsschreiben als Möglichkeit zur Kontaktpflege).

In solchen Briefen, die der Kontaktaufnahme dienten, waren traditionell besondere Höflichkeit und lobende Worte gefordert, um hervorzuheben, aus welcher Motivation heraus man den Kontakt suche. Ennodius zeigt in der Tat in einigen dieser Briefe eine bei ihm sonst nicht oft zu beobachtende Freundlichkeit in Verbindung mit lobenden Worten, in seltenen Fällen sogar geradezu Ergebenheit. Doch nicht zu allen Adressaten, denen er einen sersten Brief، schreibt, ist er besonders höflich; in einigen dieser Briefe gibt er sich gegen die Konvention überaus selbstbewusst und überlegen. Auch bei der Behandlung der Empfehlungsschreiben wird zu beobachten

$722(42,2)$ nunc, confiteor, in litteris vestris superforaneam cautionem mei aestimator expavi, ubi dum secundis in altum loquellae vestrae portarentur vela proventibus et in obsequio militaret quidquid spirat, remigium vestris dicitis deesse conloquiis. $\left(\$_{3}\right)$ non est licita veri diligentia sequestrata quam depingunt verba formido. remis opus est, quotiens nullo flaminum puppes iuvantur inpulsu: his non eget cui secundam navigationem fecit conspiratio devota ventorum. sol facibus non iuvatur nec lunaris globi claritudinem minorum siderum aliquando inlustravere collegia. 
sein, dass er nicht alle Schreiben an Adressaten, zu denen er lange keinen Kontakt mehr hatte, freundlich beginnt, sondern dass er häufig zunächst dem Adressaten Vorwürfe macht, dass dieser nicht schreibe (siehe dazu unten 365 ).

Symmachus spricht explizit von der Konvention, in einem die Korrespondenz eröffnenden Brief ausführlich die Qualitäten des Adressaten und die darauf beruhende eigene Motivation, mit ihm Freundschaft zu knüpfen, zu beschreiben. Er erwähnt dies in einem Brief an jemanden, den er schon länger kennt, und er setzt sich von dieser Sitte ab: "[...] mehr Gewicht hat verborgene Verehrung. Wir wollen den Austausch von schmeichelnden Worten neuen Freunden überlassen; sie mögen Lobreden austauschen, bis die Treue des Bundes gewiss ist [...]. Derartigen Worten wird unechte Liebe beigegeben " (Sy. 4,42,1) ${ }^{723}$ Derartige Lobesreden, wie sie bei der Kontaktaufnahme gebräuchlich seien, halte er in Anbetracht seiner schon bestehenden Freundschaft zum Adressaten für unnötig.

Häufig folgt Symmachus dieser Konvention, bei der Kontaktaufnahme den Adressaten zu loben, wenn dies bei ihm auch (wie ja insgesamt viele seiner Briefe) recht knapp ausfällt, z.B.: »Die häufige Beteuerung der Gutgesinnten über Deinen ehrwürdigen Charakter hat in mir den Wunsch hervorgerufen, ungeduldig die Freundschaft mit Dir zu wünschen « (Sy. 5,4); „ [...] ermuntert vom einstimmigen Ruhm und von der Zuverlässigkeit der besten Zeugen reiche ich also der Freundschaft mit Dir meine Hand [...] « (Sy. 9,2). ${ }^{724}$ Ähnlich beginnt auch Hieronymus einmal: »Wie sehr Gespräche über Dich, Gesegneter, die vielfältigen Münder der Menschen füllen, kann Du daraus ersehen, dass ich Dich eher zu lieben als zu kennen beginne [...]« (Hier. $4,1,1) .{ }^{725}$

Ziemlich ausführliche lobende Worte bei der Kontaktaufnahme findet hingegen Sidonius Apollinaris, z.B.: "Seliger Bischof, ich freue mich, dass durch die himmlische Gnade viele gute Eigenschaften in Dir vereint sind. Denn man erzählt, dass Du edel bist ohne Hochmut, mächtig ohne Neid zu erregen, fromm ohne Aberglaube, gebildet ohne Prahlerei, seriös ohne Getue, witzig ohne Gezwungenheit, beständig ohne Starrheit, zugänglich ohne Anbiederung. [...] Aufgrund dieser Berichte <sc. von Deinen Taten> beeile ich mich, die Initiative zu ergreifen und - wie es sich für jemanden gehört, der weit unter Dir steht - als erster zu schreiben; und ich habe keine Angst, dass mir meine Redseligkeit vorgeworfen wird, da mir auch mein bishe-

$723($ Sy. 4,42,1) [...] plus habet ponderis tecta veneratio. relinquamus verborum blanditias novis inter se amicis; illos iuvent alterna praeconia usque ad fidem foederis [...]. (\$2) amor fictus in illa verba summittitur.

724 (Sy. 5,4) Bonorum frequens adstipulatio de sanctis moribus tuis in hoc me desiderium provocavit, ut amicitias tuas inpatienter exoptem eqs.; (Sy. 9,2) [...] invitatus igitur consensu famae et optimorum testium fide amicitiae tuae dexteram porrigo [...].

725 (Hier. 4,1,1) Quantus beatitudinis tuae rumor diversa populorum ora conpleverit, hinc poteris aestimare, quod ego te ante incipio amare quam nosse [...]. 
riges Schweigen hätte vorgeworfen werden können« $(8,13,1 f.) \cdot{ }^{726}$ Der Anlass für diese Kontaktaufnahme wird später im Brief deutlich, denn Sidonius schließt eine Empfehlung an.

Ennodius erwähnt, dass viele in einem ersten Brief, der der Kontaktaufnahme dient, mit schönen Worten ihre Freundschaft zum Adressaten beschreiben - und es dann dabei bewenden lassen. Er sagt dies deutlich zu Johannes, um diesen zu einem besseren Verhalten zu bewegen, d.h. dazu, nach einem ersten Lob auch weiterhin zu schreiben. Hier antwortet Ennodius auf einen Brief des Johannes, in dem dieser Ennodius gelobt und seine Freundschaft bekundet hat (cf. 4,3 amici [...] praeconiis; $\$ 7$ amoris contestatio). Ennodius macht einerseits deutlich, dass er sich darüber gefreut habe (4,3 ago atque habeo gratias; amplector; laudo; $\$ 4$ gaudia), betont aber andererseits auch, dass das von Johannes gezeichnete Bild von ihm, Ennodius, nicht der Wahrheit entspreche $(4,3$ licet non agnoscam mea esse quae loqueris). Dies ist allerdings einer der wenigen Briefe, in denen ein Adressat bzw. dessen Begabung gelobt werden - indirekt lobt Ennodius hier allerdings Olybrius, den Schwiegervater des Johannes (siehe oben 121). Am Ende fordert er Johannes dazu auf, häufig zu schreiben, damit es nicht - so wie bei vielen anderen - nur bei der einmaligen Beteuerung der Freundschaft in dem sersten Brief bleibe $(4,7$ ne amoris contestatio sola, sicut in quibusdam esse solet, praevii in te putetur extitisse sermonis).

Dass Ennodius Lobeshymnen unter Freunden nicht schätzt, war schon mehrfach zu sehen (siehe z.B. oben 268), und dies lässt sich auch an vielen seiner versten Briefer bestätigen. Er verwahrt sich ausdrücklich dagegen, den Adressaten bei der ersten Kontaktaufnahme ausführlich zu loben. Häufig schreibt er in einer Mischung aus Freundlichkeit und Selbstbewusstsein (siehe zu 118; 173). Der einzige Brief (443), in dem sich Ennodius sehr unsicher gibt, scheint ironisch zu sein.

\section{„Erster Brief، ohne vorherige Bekanntschaft}

Aus den Briefen an Alico (118) und an Apronianus (173) geht hervor, dass Ennodius die Adressaten nie zuvor getroffen hat. Er verzichtet in diesen Fällen nicht auf lobende Worte, ebensowenig aber auch auf sein ausgeprägtes Selbstbewusstsein. Der Brief an Alico endet mit einer witzigen Wendung, der an Apronianus hingegen mit Worten, die auf Ennodius' konkrete Erwartungen an eine gewisse Zusammenarbeit mit dem Adressaten anspielen.

726 (Sidon. epist. 8,13,1) Multa in te genera virtutum, papa beatissime, munere superno congesta gaudemus. siquidem agere narraris sine superbia nobilem sine invidia potentem, sine superstitione religiosum sine iactantia litteratum, sine ineptia gravem sine studio facetum, sine asperitate constantem sine popularitate communem. (\$2) [...] quarum <sc. actionum tuarum> relatione succensus ultro primus, ut longe inferiorem decet, ad solvenda officia procurro nec vereor garrulitatis aliquando argui, qui potui taciturnitatis hucusque culpari. - Weitere Beispiele für Briefe, die der Kontaktaufnahme dienen: Sidon. 3,11; 8,14. 
Den (einzigen) Brief an Alico (118; über ihn ist außer diesem Brief nichts bekannt, cf. PLRE II, 60) schreibt Ennodius in der gleichen ungewöhnlichen Situation wie Sidonius den eben erwähnten Brief $(8,13)$, doch er gestaltet ihn völlig anders. Ennodius schreibt auf Wunsch des Unterstützung suchenden Presbyters Amantius, obwohl er selbst Alico noch nicht kennt; dies ist ungewöhnlich, da sich üblicherweise Bitt- und Empfehlungsbriefe an Bekannte richten. Während sonst der Empfohlene ein neuer >Freund ‘ des Adressaten werden soll, bringt in diesem Fall Ennodius auch seinen eigenen Wunsch nach der Freundschaft zum Adressaten vor. - Er beginnt mit Variationen zu dem in Empfehlungs- und Bittbriefen verbreiteten Gedanken, dass er es nun dem Wunsch des Amantius verdanke, dass er sich selbst einen Wunsch erfüllen und der Freundschaft dienen könne ( $\$ 1 ;$ zu dem Motiv unten 360). Wenn Ennodius schreibt, dass der Brief dazu diene, weinen Neuen zum Recht der Freundschaft hinzuzuziehen und sich das Herz eines alten Freundes zu verpflichten $"(\$ 1),{ }^{727}$ dann ist ausnahmsweise der Neue nicht der Empfohlene. Ennodius betont, dass ihn Amantius durch seine lobenden Worte über Alico dazu gebracht habe, diesen als Freund zu wählen, ohne ihn zu kennen: »er brachte mich durch seine Beteuerungen dazu, Euch eher auszuwählen als zu kennen « $(\$ 1) .{ }^{728}$ Dieses 'prius eligi quam cognosci ist ein wandelbarer Topos bei der Kontaktaufnahme, cf. bei Hieronymus: meum [...] amicum ante quam notum (Hier. 58,11,1; ähnlich Hier. 4,1,1, siehe oben 304). Auf das gegenteilige Verhalten beruft sich Sidonius: »es ist nämlich meine Gewohnheit, erst zu wählen, dann zu lieben « (Sidon. 5,11$),{ }^{729}$ wozu auch Seneca rät: post amicitiam credendum est, ante amicitiam iudicandum (Sen. epist. 3,2). ${ }^{730}$

Ennodius hebt den Einfluss des Amantius auf sich hervor: "Selten geht der Bekanntschaft die Freundschaft voraus. Wem ist es je gelungen, vor der Betrachtung zu gefallen? Seht, welches Gewicht der Überbringer < des Briefes> bei mir hat, auf dessen Wink hin mein Urteil sich beugt « (\$1f.). ${ }^{731}$ Es fällt auf, dass Ennodius mehrfach betont, wie sehr der Empfohlene den Adressaten lobe ( $\$ 1$ praeco; per adstipulationem suam; \$2 quem laudat; extollit), dass er aber - anders als etwa Sidonius im zuvor betrachteten Brief - mit keinem Wort konkrete lobenswerte Aspekte benennt (vgl. Sidon. 8,13,1 sine superbia nobilem etc.). Nachdem er diese ungewöhnliche Situation einer Freundschaft zu einem Unbekannten und den Einfluss des Amantius auf sich

$727(118,1)[\ldots]$ dum et novum in ius diligentiae adtrahit et amici senioris pectus obligat.

$728(118,1)[\ldots]$ prius vos per adstipulationem suam fecit eligi quam cognosci.

729 (Sidon. 5,11,1) est enim consuetudinis meae, ut eligam ante, post diligam.

730 Ennodius stellt in anderen Briefen diesen Gedanken in Bezug auf sich selbst häufiger auf den Kopf, wenn er über die Schreibfaulheit des Adressaten klagt: Er befürchtet, dass die Freundschaft zu ihm aufgegeben werde, sobald man ihn kenne, z.B. in $(78,1)$, siehe oben 290; cf. auch $(63,2)$, unten 313 .

$731(118,1 \mathrm{f}$.$) raro notitiam praecessit affectio. cui contigit ante placere quam inspici? (\$2) quan-$ tum apud me pondus est perlatoris advertite, ad cuius nutum iudicia nostra flectuntur $[\ldots]$. 
selbst beschrieben hat $(\$ 2)$, leitet er eine längere Periode mit einer Propositio ein, in der er seine sprachlichen Fähigkeiten in Frage stellt: »Wenn nun meine dürftige Begabung die Fülle meiner Freundschaft ausdrücken könnte, wenn das Gestammel meiner dürren Rede an der Quelle des Freundschaftsbundes nicht zu schwach wäre, wenn die Vorschriften für den Briefstil, die auch denen, die wortreich reden können, Zügel anlegen, mich weiter ausholen ließen, würde ich darlegen, [...].« Als Fortführung dürfte der Adressat wohl Worte erwarten wie z.B.: >dann würde ich ausdrücken, wie sehr ich diesen Freundschaftsbund mit Dir wünsche, wie sehr ich Dich schätze. Doch Ennodius entspricht dieser Erwartung nicht: Denn er würde über sein eigenes Verdienst, als erster geschrieben zu haben, und die erforderliche Dankbarkeit des Adressaten sprechen: "[...] dann würde ich darlegen, wieviel Du, Edler, mir verdankst, dass ich als erster den Briefwechsel begonnen und die Tür der Freundschaft mit dem Schlüssel der Rede geöffnet habe« $\left(\$_{3}\right) .{ }^{732}$ Diese unerwartete Wendung des Satzes zeigt ebenso Witz wie Selbstbewusstsein.

Auch im Brief an den Vir illustris Apronianus (173; er erhält nur diesen Brief) gibt sich Ennodius sowohl freundlich als auch sehr selbstbewusst, wobei hier am Ende Worte stehen, die verdeckt Ennodius' Ansprüche an Apronianus formulieren. Der konkrete Anlass des Schreibens wird zwar nicht genannt, doch sowohl der letzte Satz als auch der in der Überschrift explizit erwähnte Titel eines Vir illustris könnten darauf hinweisen, dass Apronianus gerade ein Amt erlangt hat; wahrscheinlich war er Comes rerum privatarum (der Verwalter des kaiserlichen Krongutes), siehe SснӓFER (1991, 23). Wie im Brief an Alico lobt Ennodius auch hier nur allgemein, ohne konkrete Qualitäten des Adressaten zu erwähnen. Außerdem beruft er sich hier ausdrücklich auf sein Prinzip, Lob lieber gegenüber Dritten als direkt ins Angesicht des Gelobten auszusprechen. - Den Brief eröffnet eine Praefatio mit ১brieftypischen Themen, in der er begründet, warum er diesen Brief schreibt: "Männer, die durch ihre strahlenden Eigenschaften glänzen, haben die Gewohnheit, ihre treue Freundschaft durch die Pflege des Briefwechsels zu nähren, damit die vereinbarte Verbindung Früchte trägt, indem die Knospen der Freundschaft durch das pflegende Gespräch belebt werden. Denn die Fürsorge der Alten wollte, dass dank dieser Gaben die Abwesenheit keine Macht haben sollte <cf. oben 209> « $(\$ 1) .{ }^{733} \mathrm{Da}$ Ennodius mit diesen vorangestellten Gedanken konkret den Briefwechsel zwischen dem Adressaten

$732(118,3)$ nunc si ubertatem gratiae ingenii macies explicaret, si ad fontem foederis aridi sermonis non lassaretur infantia, si epistularis qualitas, quae etiam copiosis eloquentia frenos inponit, progredi me ad longiora permitteret, adsererem quantum nobilitas tua mihi debeat, quod ad epistulare commercium primus adcessi, quod ianuam diligentiae reseravi clave sermonis.

$733(173,1)$ In usu est viris morum claritate fulgentibus religionem amicitiae per culturam nutrire conloquii, ut dum gratiae germina fotu confabulationis animantur, ad messem coniunctio foederata perveniat. per haec enim munia voluit senior providentia absentiae nil licere. 
und sich selbst meint, zeugt der Beginn mit viris morum claritate fulgentibus nicht nur von seiner Wertschätzung des Adressaten, sondern ebenso von seinem eigenen Selbstbewusstsein (cf. eine ähnliche Formulierung in 258,2, unten 311). Dass diese Vorrede begründen soll, warum Ennodius die Korrespondenz aufnimmt, muss der Leser selbst erschließen; denn der Hauptteil beginnt abrupt mit der Erwähnung des Faustus, der sehr lobend über den Adressaten spreche: "Zu Recht stellt Euch Faustus, der beste der Menschen, ein einzigartiges Zeugnis aus. Einen, den ein Geschätzter lobt, kann man ohne Verhüllung erkennen, über ihn kann man nicht im Zweifel sein" $(\$ 1){ }^{734}$ Das Lob des Faustus bleibt sehr abstrakt (praedicat singulare testimonium), und mehr über Apronianus zu sagen, verbiete sich aus guten Gründen: "Doch nun halte ich mich an die engen Grenzen des Briefs und verschließe das geschuldete Lob tief im Innersten, damit nicht das, was man gegenüber Außenstehenden tun muss <sc. Apronianus loben>, bei Euch wegen meiner Dreistigkeit Abscheu erregt" $(\$ 2) .{ }^{735}$ Während Symmachus sagt, dass lobende Worte nur ganz am Anfang nötig seien, und Sidonius solche ausführlich vorbringt, hält Ennodius diese auch im rersten Brief، für überflüssig, vielmehr für unpassend. Im abschließenden Gruß geht Ennodius davon aus, dass Apronianus nunmehr sein Freund sei, indem er einen Bezug zwischen dem Erfolg seiner Freunde und seinem eigenen herstellt (siehe oben 235): "Leb wohl, mein Herr, und nimm meinen pflichtgetreuesten Gruß an. Ich bitte Gott, dass er Euer Wohlergehen lange anhalten lassen und auch mir aufgrund der guten Erfolge meiner Freunde weiteres Gedeihen versprechen möge " $(\$ 2) .{ }^{736}$ Dieser Abschluss hängt wahrscheinlich eng mit Ennodius' Amt zusammen; da er als Diakon u.a. für die Finanzen der Gemeinde zuständig war, war ein gutes Verhältnis zum Comes rerum privatarum wichtig.

Der Brief an Agnellus (443) fällt dadurch auf, dass Ennodius sich sehr unsicher gibt, sogar direkt von seiner mangelnden fiducia (\$2) spricht und recht viel lobt. Der Brief ist nicht leicht zu analysieren, da keine Einigkeit darüber herrscht, ob dieser Agnellus mit dem gleichnamigen Adressaten anderer Briefe identisch ist (er erhält zuvor 7 Briefe; zur Person siehe unten 337). Vogel verzeichnet im Index zwei Agnelli, für den PLRE-Artikel (II, 35f.) hingegen, für SCHÄFER (1991, 13-15) und auch schon für Sundwall $(1919,67)$ handelt es sich um eine Person; Sundwall bemerkt dazu, dass Ennodius an den Briefwechsel nach längerer Pause »ziemlich kühl« wieder anknüpfe. Je nachdem, ob es sich hier um einen zweiten Adressaten des Namens handelt oder

$734(173,1)$ merito de vobis emendatissimus hominum domnus Faustus praedicat singulare testimonium. sine nube datur agnosci, nihil de eo dubitandum quem probatus attollit.

735 (173,2) sed nunc ad epistulae angustias me reducens secretis debitam laudem claudo penetralibus, ne quod apud externos faciendum est, apud vos inportunitate ranciscat.

$736(173,2)$ vale, mi domine, salutationem obsequentissimam accipiens; deum precor, ut prospera vestra in longum producens mihi quoque secundis amicorum successibus spondeat auctionem. vale. 
nicht, ist der Brief unterschiedlich zu interpretieren: Wenn es sich um einen anderen Agnellus handeln sollte, wäre dies der einzige Fall einer durchweg vorsichtigen, schüchternen Kontaktaufnahme bei Ennodius. Wenn es sich hingegen um den aus anderen Briefen bekannten Agnellus handelt, ist Ennodius hier tief ironisch; denn dann tut Ennodius so, als ob er mit Agnellus noch nicht bekannt sei, und verfasst einen zwar konventionellen, aber für seine Verhältnisse auffällig schüchternen Brief, um ihn vielleicht durch diese Pointe zum Schreiben $z u$ bringen. Dafür, dass es sich um ein und denselben Adressaten handelt, spricht, dass sowohl in anderen Briefen an Agnellus das Thema ,Geben ‘ bzw. ,Geld c eine Rolle spielt (176,5, siehe unten 328; 316,1, siehe oben 219), dieser Ennodius ein Pferd schenken wollte, woran er aber mehrfach erinnert werden muss (cf. 257; 359,1; 397,1), als auch hier auf dessen Möglichkeiten zum Geben ( $\$ 2$ largiri; dare) angespielt wird; außerdem hebt Ennodius hervor, wie schwierig es sei, einen Brief von Agnellus zu bekommen. Daher neige ich dazu, hierin einen ironischen Brief an einen alten Bekannten zu sehen, der sich nicht meldet.

Er spricht zunächst von seinem Schwanken, ob er den Brief schreiben oder lediglich über Dritte Grüße überbringen lassen sollte: ${ }^{737}$ "Lange war ich unsicher und schwankte, ob ich aus dem Wunsch nach der Bekanntschaft mit Euch heraus mit liebenswerter Anmaßung an die Tür des Schreibens klopfen und das Herz eines hervorragenden Menschen auf diesem Weg betreten sollte, oder ob ich damit zufrieden sein sollte, durch Eure Leute einen flüchtigen Gruß zu übermitteln und so aus der Verborgenheit, die mich umgab, auszubrechen <?> [...].« Nach diesen Ausdrücken der Unsicherheit folgt der Grund, warum Ennodius mit dem Adressaten bekannt sein möchte: "[...] denn mir schien, dass einer <sc. Ennodius>, den der höchste Mensch $<$ sc. Agnellus > nicht kennt, nicht zu den Menschen zu zählen sei. Und überhaupt geben weder die Sitten noch der Charakter demjenigen Selbstvertrauen, der vor denen, die an der Spitze stehen, verborgen ist - besonders vor Euch, den beide Teile der Welt bei aller Verschiedenheit gemeinsam freundschaftlich für sich in Anspruch nehmen, den die Gottesfurcht durch die Gunst ihrer Gnade stärkte und schon dazu brachte, höchste Ehren zu vergeben und, wozu kaum die Besten veranlasst werden können, zur Steigerung seines guten Rufes den Geringen etwas zu schenken [...].« Doch die größte Gabe wäre ein Brief von Agnellus: »Briefe sind lobenswert, doch man kommt kaum mit größter Mühe dazu <sc. einen zu erhalten>- was jedoch nicht als schlechtes Zeichen gesagt sein soll -, und sie sind die Spitzen unter Euren Gaben.« Obwohl Ennodius hier nun mehr lobende Worte gefunden hat als für seine meisten Adressaten, endet er: "Ich grüße also achtungsvoll und schließe den Brief in dieser Kürze, damit vor Eurer Freundlichkeit <d.h. bevor Ihr freundlicherweise antwortet $>$ mein Lob nicht dreist erscheint. Nach einem Antwortbrief werdet Ihr ausführlicher

737 Anders verstanden von Sundwall $(1919,67)$, nämlich dass Agnellus nur Grüße gesandt habe. Doch da im Folgenden gesagt wird, dass Agnellus Ennodius nicht kenne ( $\$ 1$ ignoraret), wird er auch keine Grüße ausgerichtet haben. 
lesen, was Eurem Charakter und Eurer Macht zusteht, was die Welt mit mir zusammen bezeugen wird « $(433,3){ }^{738}$ Wenn es sich hier tatsächlich um denselben Agnellus handelt, der von Ennodius bereits einige Briefe bekommen hat, dann ist die vorsichtige Annäherung ironisch und der ganze Brief ein witziger Versuch, endlich einen Brief von ihm zu erhalten.

\section{'Erster Brief` nach vorangehendem Kontakt}

Bei manchen Briefen lässt sich erschließen, dass es sich dabei um den jeweils ersten nach einem persönlichen Treffen handelt, wenn Ennodius nämlich einerseits von schon bestehender Freundschaft, andererseits von seinem sersten Briefı spricht. In den Briefen an Symmachus (358) und an Probus (360) gibt sich Ennodius recht vorsichtig und freundlich und lässt nur jeweils einmal kurz seine Offenheit durchscheinen; in beiden Briefen werden die Adressaten zwar mit knappen Worten, aber dennoch eindeutig gelobt. Ein anderer Ton bestimmt einen Brief an Liberius, in dem Ennodius sich fordernd auf die ja schon beim persönlichen Treffen geschlossene Freundschaft beruft und selbstbewusst darauf hinweist, dass er jedenfalls sich an den Freundschaftsbund halte und schreibe.

An Symmachus (den Schwiegervater des Boethius) (358) und an Probus (360) schreibt Ennodius offenbar nach einem Aufenthalt in Rom (der sich aus 361,2 erschlieBen lässt), um die neuen Kontakte brieflich fortzuführen. An diese beiden Adressaten ist jeweils nur der eine Brief überliefert, aber sie erscheinen noch an anderen Stellen im Werk des Ennodius: Symmachus, den Ennodius in diesem Brief als Romanae gentis nobilitas (\$2) anredet und den er in einem späteren Brief an den jungen Beatus und in der "Paraenesis" mit dem Titel patricius nennt $(405,2 ; 452,19)$, wird in der "Paraenesis" den jungen Adressaten als leuchtendes Beispiel vor Augen gestellt. Der gebildete Senator Symmachus gehört einer älteren Generation an, Symmachus hat zwischen 476 und 485 das Amt des Praefectus Urbi übernommen, Ennodius ist 473/4 geboren (Details zu seinen Ämtern und Tätigkeiten bei SCH ÄFER 1991, 108-110). Auch der Vir illustris $(452,21)$ Probus, den Ennodius in einem Brief an Beatus als hochge-

738 (443,1) Longo animus meus pependit incerto, utrum pro diligentia notitiae vestrae ianuam scriptionis amabili praesumptione pulsarem et excellentissimi hominis per hunc callem pectus ingrederer an per homines vestros vaga salutatione contentus secreta quibus obsidebar inrumperem, quia visum mihi est non esse in hominum numero conputandus quem hominum potissimus ignoraret. (\$2) et plene illi nec mores suggerunt fiduciam nec natura, qui in arce locatis absconditur, vobis praecipue, quos uterque orbis amica et socia diversitate conplectitur, quos dei timor gratiae suae comitate firmatos fecit iam honorum summa largiri et, ad quod vix praecipui perducuntur, ad opinionis gloriam dare subiectis. laudandi sunt apices, sed ad eos sudore maximo vix venitur - quod tamen feliciter dictum sit - et inter munera vestra sunt culmina. (\$3) ergo salutans reverenter epistolam brevitate concludo, ne ante dignationem vestram videatur inportuna laudatio. latius post responsum paginale, quod moribus, quod potentiae vestrae convenit, eritis mundo mecum adtestante lecturi. 
bildet (398,1 arcem tenenti inter doctos) bezeichnet, zählt zu den in der "Paraenesis « genannten Vorbildern (cf. Sch ÄFER, 99). ${ }^{739}$ An den beiden Briefen im Zusammenhang mit den weiteren Erwähnungen der Adressaten wird deutlich, dass man nicht vorschnell annehmen sollte, die überlieferten Briefe dokumentierten vollständig jeden je stattgehabten Kontakt zwischen den Korrespondenten. - In den beiden Briefen an Symmachus und an Probus ist Ennodius recht vorsichtig: Er nutzt jeweils die Praefatio dazu, sich dafür zu rechtfertigen, dass er die Korrespondenz aufnimmt, wobei er von seiner Freundschaft und fides spricht (sie müssen also schon vorher Kontakt gehabt haben). Er macht beiden Komplimente, Symmachus nur kurz, Probus hingegen für seine Verhältnisse recht deutlich. Doch auch in diesen Briefen deutet er gegenüber Symmachus in einer doppeldeutigen Formulierung sein Selbstbewusstsein an und zeigt gegenüber Probus seine Offenheit, indem er von seinem Eigennutz spricht.

In der Praefatio im Brief an Symmachus (358) legt er die Gründe dar, die ihn zum Schreiben gebracht haben, worauf er hier einmal ausdrücklich verweist ( $\$ 1$ hac praefatione me tueor, quia ad epistolas primus adspiro); er entschuldigt sein Schreiben mit der Macht der Freundschaft, weist aber gleichzeitig darauf hin, dass es sich hierbei um ein angenehmes Vergehen handle: »Ein Gesetz, das Sehnsüchten auferlegt ist, wird nicht anerkannt. Freundschaft erträgt keine harten Vorschriften, und weil sie frei ist, hat sie nicht andauernd Tadel verdient <sc. dafür, dass man schreibt $>$. Aufgrund des Vorwurfs wird sie häufig liebenswerter, weil sie durch die Zügellosigkeit den Glanz großen Gefallens bekommt. Denn sie empfiehlt ihren Fehler irgendwie mit der Süße eben der Anmaßung. - Mit dieser Vorrede verteidige ich mich selbst, dass ich als erster einen Brief schreibe « (\$1) ${ }^{740}$ In die Bitte um Antwort flicht er ein kurzes Lob auf die Redekunst des Adressaten ein: "Es steht in der Macht Eurer Hoheit, - wenn Ihr Euch entscheidet, mich Redseligen zu ertragen, - nicht zu schweigen und mich mit der echten Milch von der Symmachus-Quelle zu nähren. Leb wohl in Christus, Adel des römischen Volkes, und halte mich nun gemäß dem Glanz der Sitten und des Charakters für würdig, Dein Schutzbefohlener und Diener zu sein « $(\$ 2) .{ }^{741}$ Nur in wenigen Fällen äußert Ennodius so deutlich den Wunsch, cliens und famulus sein zu dürfen (er bezeichnet sich als susceptus in 305,3, siehe oben 300); doch dadurch, dass er nicht sagt, wessen lux morum et naturae er meint - den Glanz des Symmachus oder seinen

739 Wenn Kennell (2000, 126 und 2003, 122) angibt, Probus sei der Vater des Beatus, so scheint dies auf einer Fehlinterpretation von 398,2 zu beruhen.

$740(358,1)$ Lex desideriis scripta vix creditur; inpatiens rigidioris praecepti diligentia non iugiter dignum facit reprehensione quod libera est. redditur saepe amabilior de reatu, cum per effrenationem sortitur genium plus placendi: nam delictum suum quodam ipsius praesumptionis melle commendat. ego hac praefatione me tueor, quia ad epistolas primus adspiro.

$741(358,2)$ restat in potestate celsitudinis vestrae, si sustinere eligitis garrulum, non tacere et de originario Symmachiani fontis lacte me pascere. vale in Christo nostro, Romanae gentis nobilitas, et me iam ut clientem et famulum pro morum et naturae luce dignare. 
eigenen? - wird der Eindruck der Unterwürfigkeit zumindest gemildert (vgl. den ähnlichen Fall in 173,1, oben 308). Dass Ennodius mit dieser vorsichtigen Annäherung Erfolg hatte, ergibt sich aus einem Brief an den jungen Beatus, in dem er erwähnt, dass er die "Paraenesis« an Symmachus geschickt habe, damit dieser den Text korrigiere $(405,2$ quam <sc. epistolam admonitionis> ad domnum patricium Symmachum idcirco dirigere procuravi, ut quod in ea emendatione dignum est corrigatur). Es scheint schwer vorstellbar, dass Ennodius den Text mit der Bitte um Korrektur an Symmachus geschickt hätte, wenn sie nicht inzwischen weiterhin in Kontakt gestanden hätten; dass kein weiterer Brief überliefert ist, heißt nicht automatisch, dass es keinen brieflichen oder persönlichen Kontakt gegeben hat. ${ }^{742}$

Im Brief an Probus (360), den er vermutlich während desselben Aufenthalts in Rom kennengelernt hat, ist er freigebiger mit Lob, zeigt aber auch seine sinceritas, indem er andeutet, dass er Probus nicht zuletzt aus Eigennutz verehre. In der Vorrede stellt er zwei Arten von >Fehlverhalten` einander gegenüber, zwischen denen er zu wählen habe: entweder unaufgefordert zu schreiben oder seine Freundschaft nicht zu zeigen: "Ich entscheide mich dafür, meinem guten Benehmen Abbruch zu tun, um nicht die Schande auf mich zu laden, kein Freund zu sein; denn ich weiß, dass man ein Defizit an gutem Benehmen leichter beheben kann als eines an Treue. Nicht gebildet zu sein, ist ein Unglück, < doch> die Leistungen Eurer Familie zu missachten, ist ein Vergehen. Es kann sein, dass man ohne eigenes Verschulden nicht an der höheren Bildung teilhat: <aber> niemand verfügt über ein Argument, mit dem er seine Gesinnung entschuldigen könnte $(\$ 1){ }^{73}$ Das in der Vorrede schon angeklungene Lob auf Probus und seine Familie (virtutes familiae vestrae) wird im Folgenden deutlicher, wobei Ennodius allerdings offen darauf hinweist, dass vom Objekt der Verehrung viel Glanz auf den Verehrenden falle (siehe oben 267): »Ich sollte die vielen in Eurer Hoheit vereinigten Verdienste nicht in einem Brief würdigen? Ich sollte dieses durch Bildung und Redlichkeit verstärkte Licht der Familie nicht verehren? Wer Tadellose verehrt, scheint mir nicht weit von der Ehrbarkeit entfernt zu sein: Denn man denkt, dass jeder das, was er schätzt, auch selbst befolgen kann. Lebe also mit Gottes Gunst wohl; billige meinen Eifer und bereichere Deinen Freund mit Briefen « $\left(360,1 \mathrm{f}\right.$.). ${ }^{744}$

742 Anders BArtlett $(2003,62)$ zu dem Brief an Symmachus: »[...] there is no evidence that he was successful; « er verweist auf die Erwähnung des Symmachus in der "Paraenesis« als lediglich "another appeal for Symmachus' patronage. « Vgl. auch im Folgenden zum Brief an Probus.

$743(360,1)$ Eligo iacturam pudoris, ne subeam dedecus non amantis, sciens facilius sarciri posse frontis damna quam fidei. indoctum esse infelicitatis est, virtutes familiae vestrae odisse res criminis. potuimus disciplinis liberalibus defuisse non delinquentes: nulli sufficit, unde mores excuset.

$744(360,1 \mathrm{f}$.$) ego in amplitudine vestra tot coacervata epistolari sermone bona non venerer? ego$ non illud generis lumen amplificatum studiis et probitate suspiciam? (\$2) videtur mihi non 
- Kennell (2003, 122f. $)^{74}$ nimmt an, dass Ennodius auf diesen Brief keine Antwort erhalten habe (da kein weiterer Brief an Probus überliefert ist); doch da wir später davon hören, dass der junge Beatus Probus ein Gedicht des Ennodius vorgelesen und dieser Kritik daran geübt hat (cf. 398) und Probus auch in der "Paraenesis« lobend erwähnt wird (während andere übergangen werden, cf. 452,22), kann man nur daraus, dass dies der einzige erhaltene Brief an Probus ist, nicht schließen, dass es keinen weiteren Kontakt gegeben hätte.

Während sich Ennodius in diesen Briefen an Symmachus und Probus auffällig zurücknimmt, schreibt er andere erste Briefer voller Selbstvertrauen und ohne lobende Worte für den Adressaten; vielmehr gibt er Ratschläge für deren Verhalten.

Sehr selbstbewusst wendet er sich an Liberius (63; zur Person siehe oben 103), dem er, nachdem sie Freundschaft geschlossen haben, nun einen ersten Brief schreibt; es sind fünf weitere Briefe an ihn erhalten. - Ennodius beginnt mit einer Praefatio mit allgemeinen Bemerkungen zum Thema >Freundschaft und Korrespondenz` (zitiert oben 252), um dann zu betonen, dass er als erster schreibe und welche Konsequenzen das habe: "Ich übertreffe Eure Freundlichkeit schon und bringe Euch der Kraft meines Talents entsprechend diesen ersten Brief dar, durch den ich den Anspruch erhebe, mir das Verdienst zuzuschreiben, der bessere Freund zu sein. Denn keiner, der den geschlossenen Bund nicht vergisst und den die Rede, die den Sinn bekanntmacht, nicht verlässt, reicht den Mund den Riegeln der Verschwiegenheit hin. Ich habe also den ersten Platz in unserem Briefwechsel und bin größerer Verehrung würdig, da ich als erster durch das Zeugnis der Sprache offenbart habe, was ich wünsche.« Dass dies deutliche Worte waren, sagt Ennodius selbst: »Siehe: Ich habe meine Grundsätze beim Briefeschreiben unverhüllt dargelegt.» Weiter wird Liberius darauf aufmerksam gemacht, dass er sich über den Brief freuen müsse, da er Ennodius ja schon vorher als der Bekanntschaft wert ausgewählt habe: "Es ist an Euch, das Erhaltene um meinetwillen gut zu finden, damit nicht ich darniederliege und sich die Urteilskraft Eurer Hoheit einer Prüfung unterziehen <lassen> muss. Denn wer nicht beschützt, was er erwählt hat, setzt seine Meinung harter Kritik aus « (63). ${ }^{746} \mathrm{Ab}$ -

longe ab honestate desciscere, qui colit emendatos, dum creditur quicumque sectari posse quod diligit. proinde vale per gratiam dei et studium meum adprobans amantem tui amplifica muniis litterarum.

745 Nachdem sie den Inhalt zusammengefasst hat, schließt sie: "Despite these spirited plays on largeness of several sorts, this appeal fell on deaf ears; perhaps $[\ldots]$ Probus found them a little too jocular for his taste, or perceived the light of discourse somewhat overwhelmed by the sanxious toilı of verbal construction. " Leider begründet sie nicht, was an dem Brief "jocular « ist oder warum gerade dieser Brief »anxious toil of verbal construction « aufweise.

$746(63,1)[\ldots]$ dignatione vestra iam potior haec pro ingenii viribus paginalis conmercii libamenta dedicavi, per quae usurpo vindicare mihi meritum plus amantis. nemo enim ta- 
schließend folgen der Gruß und die Bitte um Gottes weiteren Beistand für Liberius. Angesichts der hohen Position des Liberius und auch im Vergleich mit den Briefen an Symmachus und Probus fällt an diesem Brief der trotzig-selbstbewusst-witzige Ton auf: Ennodius habe hiermit den Briefwechsel eröffnet und sei daher maiori cultura dignus. Die Briefe an Symmachus und Probus zeigen, dass dies nicht der einzige ihm mögliche Ton bei einer brieflichen Kontaktaufnahme war. Da die weiteren erhaltenen Briefe und nicht zuletzt die Tatsache, dass Liberius Ennodius dabei behilflich war, ein Haus zu bekommen (siehe oben 26), eindeutig vom weiteren Kontakt zeugen, scheint Liberius an diesem Ton Gefallen gefunden zu haben.

\section{Erster Brief، auf Anforderung}

An Dominator (155) und an Stephanus (357) schreibt Ennodius, weil er von ihrem Wunsch nach einem Brief von ihm bzw. Kontakt zu ihm erfahren hat; ob er die Adressaten schon einmal getroffen hat, bleibt unklar. In diesen Briefen spielt er seine bessere `Startposition` in der Korrespondenz, auf die er auch im eben vorgeführten Brief an Liberius verweist, vollends aus.

An den uns sonst unbekannten Dominator schreibt Ennodius (155), da Agnellus ihn über dessen Wunsch nach einem Brief informiert hat. Ennodius schreibt in einer Mischung aus Triumph und Bescheidenheit und gibt dem Adressaten Ratschläge, wie er auf diesen Brief reagieren solle. Zunächst hält er Dominator in tadelndem bis triumphierendem Ton vor, dass er, Ennodius, sich nun eindeutig in der besseren Situation befinde, da Dominator auf jeden Fall antworten müsse; Dominator hätte die Chance ergreifen und zuerst schreiben sollen, um Ennodius zu einer Antwort zu zwingen: »Es hätte sich zwar gehört, dass mir ein Brief < von Euch> Eure Wünsche, wie sie mir die Ausführungen von Bruder Agnellus offenbart haben, offengelegt hätte, und dass ein vorangehender Brief < von Euch> ein Beispiel geboten hätte, um einen Brief < von mir > hervorzulocken. Denn dann hätte Dir <von mir > wiedergegeben werden können, was Du mir nun schulden wirst <sc. die Antwort>; auch könnte ich mich auf keine Weise verteidigen, wenn ich mich des Schreibens enthielte, während Du sprächest. Es lag in Deiner Hand, die Untätigkeit meiner Zunge gegen Aktivität einzutauschen und den Rost meiner ungeschliffenen Sprache mit handwerklichem Eifer zu entfernen. ${ }^{747}$ Denn ebenso wie es der Freundschaft schadet, einem, der es

citurnitatis repagulo ora porrigit, quem decisi foederis memorem proditor mentis loquella non deserit. (\$2) principem ergo locum in litteraria communione possideo et maiori cultura dignus sum, qui prior quid gestirem patefeci linguae testimonio. - ecce religionem dirigendae paginae sine nube disserui. vestrum est in me fovere quod recepistis, ne iudicia culminis vestri me iacente patiantur examen. exponit enim censurae sententiam suam quisquis quod elegit non tuetur. [...]

747 Anders verstanden von KeNNELl $(2003,118) »$ He freely admits that he has no excuse for not writing and that it is indeed just for his correspondent to make him cut his break short to scrape the rust from his linguistic tools $[\ldots]$.. 
wünscht, nicht zuerst einen Brief zu schreiben, so rät weder der Gedanke an die Freundschaft noch der an den Anstand dazu, auf einen gesandten Brief mit Schweigen zu reagieren $\ll(\$ 1) .{ }^{78}$ Dominator hat also seine gute Ausgangsposition nicht genutzt, und Ennodius kann sich rühmen, zum Schreiben aufgefordert worden zu sein (cf. 95,1 eliciti utor stili testimonio, oben 181); allerdings schade diesem Ruhm wiederum die Qualität seines Briefs: „Doch nun ist mein Glanz dadurch gewachsen, dass Du Dir einen Brief gewünscht hast, wenn auch dieses Zeugnis < dafür, dass sich jemand einen Brief von Ennodius ausdrücklich gewünscht hat $>$ dadurch geschmälert wird, dass ich in der Freundschaft niemals meine Kräfte frage <sc. und aus Freundschaft meine Kraft im Schreiben überschätze $>^{749}$. $<$ Doch $>$ fern sei es einem Gebildeten, eine Last für untragbar zu halten, die ein Freund <sc. z.B. Dominator> auferlegt " $(\$ 2){ }^{750}$ Ennodius habe mit dem Schreiben zwar eine zu große Last auf sich genommen, ${ }^{751}$ doch Dominator solle nicht streng über seinen Brief urteilen, da er ja darum gebeten habe (diese Argumentation auch gegenüber Liberius in 63,2, siehe oben 313, und Mascator, o. 181): "Freue Dich nur über das Erbetene, unterdrücke Deine Kritik und lege den Abscheu erregenden Hochmut der Urteilenden ab. Fern sei Dir, denjenigen nicht zu mögen, der Dir gehorchte <sc. indem er diesen Brief schrieb>. $\mathrm{Zu}$ der Hoffnung auf eine beträchtliche Anerkennung wird derjenige verleitet, der, auch wenn er von der gewöhnlichen Prägestätte kommt, Dir den auferlegten Dienst eines Briefs erwiesen hat $"(\$ 2) .{ }^{752}$ Abschließend betont Ennodius, dass Dominator die Verantwortung dafür trage, ob die Korrespondenz weitergeführt werde: „Leb also wohl, mein Herr - denn ich will nicht, dass der Brief, der nicht nach dem Lot gebaut ist, zu lang wird. Erneuere Du meiner Zuversicht entsprechend die Ernte der Freund-

$748(155,1)$ Oportuerat quidem desideria vestra, quae fratris Agnelli patefecit allegatio, ut tabella reseraret et ad elicienda conloquia formam sermo praevius exhiberet, quia potuit tibi restitui quod debebis, nec ullo me colore defenderem te loquente a paginis abstinendo. in tuo iure fuit linguae nostrae ferias exercitio commutare et rubiginem rusticantis eloquii fabrilibus studiis amovere, quia sicut damnum caritatis est primum cupienti non dedicare sermonem, ita promulgatae scriptioni silentium reddere nec amicitiae suadet memoria nec pudoris.

749 Cf. $(87,1)$ numquam se metitur quem stimulat caritatis imperium, unten 366.

$750(155,2)$ nunc tamen adcessit ad genium meum, quod paginas inperasti, etsi subtrahitur testimonio, quod numquam in amore vires interrogo. facessat ab ingeniis liberalibus, ut credas fascem esse intolerabilem, quem amicus inponit. - tamen korrespondiert mit quidem ganz am Anfang.

751 Anders verstanden von KeNNELL (2003, 118f.): "[...] he remains unconvinced that Dominator has scommanded pages (from him in a spririt of true friendship and admonishes him never to regard a friend's request as an intolerable burden."

$752(155,2)$ tu tantum exacta conplectere et censuram castigans rancida iudicantum depone fastidia. absit a te eum non fovere qui paruit. in spem altioris meriti trahitur, etiamsi veniat a moneta triviali [cf. Iuv. 7,55; cf. auch Sy. 3,11,2, 1,3,2], qui tibi inpositum oris mancipavit obsequium. 
schaft wie ein fruchtbarer Boden; denn von nun an hängt es von Deiner Entscheidung ab, wenn Du oft von mir Briefe bekommen möchtest, mich mit entsprechenden Gaben dazu aufzufordern $4(\$ 3) .{ }^{753}$ - In diesem Brief spielt Ennodius zwar einerseits seine Fähigkeiten herunter (rusticantis eloquii; a moneta triviali; non ad perpendiculum fabricata conloquia), spart aber andererseits nicht mit triumphierenden Bemerkungen darüber, dass Dominator seine Chance nicht genutzt habe: Ennodius sei in der besseren Position, weil er zuerst geschrieben habe; Dominator dürfe über den Brief nicht hart urteilen, da er ja darum gebeten habe; Ennodius' Glanz sei vermehrt worden, da er um einen Brief gebeten worden sei. Die trotzig-selbstbewusste Aussage: 'meine sprachlichen Fähigkeiten sind zwar ungenügend, aber Du hast Deine Chance verpasst,${ }^{754}$ erinnert im Ton insgesamt an den Brief an Liberius (63, siehe oben 313).

Stephanus erhält einen sersten Brief` (357), weil sein Sohn Marcellus, ein Junge, um dessen Ausbildung sich Ennodius in irgendeiner Weise kümmerte, darum gebeten hat. Auch hier sagt Ennodius wenig bescheiden, dass ihm selbst großer Dank gebühre, weil er zuerst schreibe. - Zunächst hebt er hervor, dass er auf eine Aufforderung hin schreibe: »Die Bitte unseres gemeinsamen Sohnes Marcellus, den Euch die Natur und mir die Zuneigung gab, bringt mich dazu, Euch zuerst zu schreiben und, von der Liebe <sc. wohl eher zu Marcellus als zu seinem Vater Stephanus> überwältigt, das Trostmittel eines Briefs zu verwenden, durch das nach dem Willen der Alten die Abwesenheit keine Macht hat." Dann benennt Ennodius die Konsequenzen daraus, dass er zuerst schreibt: "Damit schuldest Du mir doppelten Dank, auch wenn Du mir antwortest; denn ich habe den Anfang gemacht. Wer beim Schreiben ein Beispiel setzt, öffnet die Tür zur Freundschaft. Wer antwortet, folgt $<$ lediglich $>$ dem gegebenen Beispiel « $(357,1) .{ }^{755}$ Es folgt das, was sich Stephanus wohl eigentlich gewünscht hatte, nämlich Nachrichten über seinen Sohn; Ennodius, der gegenüber seinen jungen Adressaten zumeist Strenge zeigt, ist hier gegenüber dem Vater eines Schützlings milder und lobt dessen Fortschritte: »Ich schicke also auf Gottes Veranlassung diesen Brief als Boten unseres Wohlergehens. Damit sich Eure Vaterseele noch mehr freut, können wir zu Eurer Freude hinzufügen, dass Euer Sohn in den Freien Künsten schon das Zeugnis

753 (155,3) ergo vale, mi domine, quia nolo fieri prolixa quae non sunt ad perpendiculum fabricata conloquia. tu messem gratiae iuxta fiduciam meam tamquam uber solum restitue, quia in tuo posthac erit arbitrio, si crebro epistolas meas accipere volueris, his me muniis invitare.

754 Anders Kennell $(2003,119) »[\ldots]$ Ennodius did his best to strike the right note by following <Iulius> Victor's advice to avoid brusqueness when writing to someone less familiar.\&

755 (357,1) Exigit a me filii communis Marcelli adhortatio, quem natura vobis, mihi dedit affectus, ut ad scriptionis munia praevius adspirarem et solacium litterarum, per quod vetustas voluit absentiae nil licere, amore victus inpenderem. iam debes mihi duplicem gratiam, etsi responsa restitueris, ob hoc quod primus incepi. ille dilectionis ianuam pandit, qui in conloquiis praestat exemplum: propositam custodiunt formulam qui scripta restituunt. 
seines Adels besitzt und sich darin als so gut erweist, dass er die maßlosen Wünsche der Seinen übertrifft. Ein ehrenvoller Beginn bei einem jungen Mann bedeutet Hoffnung auf Vollkommenheit, und von einem Gebildeten unterscheidet sich nicht, wer am Anfang den Ruf guter Bildung hat. Ich grüße also mit der geschuldeten Freundschaft und hoffe, dass Du mich bei nächster Gelegenheit mit der guten Nachricht Eures Wohlergehens erfreust « $(\$ 2 \mathrm{f}) .{ }^{756}$ - Auch in diesem Brief wechselt der Ton: Ennodius lobt zwar den Sohn, aber erst, nachdem er im ersten Teil den Vater unbescheiden darauf hingewiesen hat, dass er ihm doppelten Dank für diesen Brief schulde.

\section{b. 4 Reaktion auf Aufforderungen zu schreiben}

Trotz all seiner Klagen über die Schreibfaulheit seiner Korrespondenten ist auch Ennodius selbst nicht immer ein zuverlässiger Korrespondent, und so bekommt auch er selbst entsprechende Vorwürfe zu lesen. Seine Reaktionen auf derartige Vorhaltungen zeigen eine große Bandbreite im Ton und in der Taktik: Nur selten reagiert er 'harmlos` und führt die Gründe für sein Schweigen an; echte Worte der Entschuldigung wie z.B. bei Symmachus $(1,35)$ silentio superiori venia iusta praestetur fallen nie. Ennodius entwickelt verschiedene Strategien, um sich nicht entschuldigen zu müssen, z.B. Entrüstung angesichts des Vorwurfs oder Gegenangriff. Er stellt die Situation so dar, dass er sich völlig richtig verhalten habe bzw. dass sein Verhalten nicht wirklich einen Tadel verdiene, und in manchen Fällen gibt er sich selbstbewusst und rechthaberisch. Auffällig ist, dass er - quasi anstelle einer Entschuldigung - gerade in einige dieser Briefe Komplimente für die Adressaten einflicht: Deuterius und Boethius werden bei der Gelegenheit für ihre sprachlichen Fähigkeiten gelobt, Adeodatus für die Macht seiner Gebete, und Speciosa wird als Ennodius' Vorbild in jeder Hinsicht bezeichnet.

Symmachus antwortet auf entsprechende Aufforderungen zu schreiben häufig entweder mit der Angabe der Gründe für sein Schweigen oder mit dem Hinweis, dass beide Seiten länger nicht geschrieben hätten. In einem Brief an Ausonius z.B. nennt Symmachus seinen Aufenthaltsort als Entschuldigung für sein Schweigen (wobei allerdings nicht deutlich wird, ob Ausonius ihm überhaupt schon Vorhaltungen gemacht hat): »Lange war ich zur Erholung im abgelegenen Campanien und hatte keine Gelegenheit zu schreiben <d.h. keinen Boten>. Deshalb ist eine Zeitlang mein

$756(357,2 f$.) ergo auctore deo nuntiam prosperitatis nostrae epistolam destinamus. illud ad gaudium vestrum, quo uberius paterna mens exultet, adiungimus, flium vestrum in studiis liberalibus ingenuitatis testimonium iam tenere et talem se in hac cura praestare, ut avara suorum vota transcendat. spes perfectionis est honesta in adulescente incoatio, nec ab erudito distat qui inter exordia boni gloriam occupat instituti. $\left(\$_{3}\right)$ salutans ergo adfectione qua debeo spero, ut reparata oportunitate de bono me faciatis [Coni. HARTEL, faciat trad.] vestrae prosperitatis adtolli. 
Eifer im Schreiben an Dich erschlafft. Doch seit ich meinen Fuß wieder in die Heimat gesetzt habe, bin ich wieder so eifrig wie früher, Dir zu schreiben. Daher grüBe ich Dich mit aller geschuldeten Ehre und bitte zum einen, dass meinem bisherigen Schweigen gebührende Verzeihung gewährt wird, und zum anderen, dass dieser Brief eine Antwort erhalten wird « (Sy. 1,35). ${ }^{757}$ - In einem anderen Fall entschuldigt Symmachus sein Schweigen mit dem Tod seines Bruders: „Es ist ein Zeichen Deiner Treue, dass Du mir mein Schweigen vorwirfst. Doch glaube bitte, dass es am Unglück lag und nicht an meinem Willen, dass ich so lange nicht geschrieben habe. Und ich glaube, dass Du auch weißt, wie sehr das Schicksal gegen uns gewütet hat [...] (Sy. $1,83) \cdot{ }^{758}$

Ennodius hingegen entschuldigt sich nicht, sondern bemüht sich zu zeigen, dass er sich mit seinem Schweigen völlig richtig verhalten habe. Diese Taktik, die bereits im Brief an den Lehrer Deuterius zu beobachten war (24, siehe oben 167), verfolgt er häufiger $(35 ; 65 ; 75)$ :

In einem Brief an Speciosa (35; zu ihr und einem weiteren Brief an sie oben 273) betont Ennodius, dass sein Schweigen das richtige Verhalten gewesen sei. Er hält ihr seinerseits ihr langes Schweigen vor und verbindet diesen Gegenvorwurf mit Komplimenten für ihre Lebensweise. Auffällig ist, dass er wie im Brief an Deuterius (siehe oben 167) auch Speciosa gegenüber, die er als lux ecclesiae anredet, in nicht völlig ernsthafter Weise von seinem propositum spricht, mit dem er sein Verhalten eindeutig in Einklang sehe. - Sein Schweigen sei nur die Antwort auf das Schweigen der Speciosa gewesen; wie sonst hätte er sich rächen sollen?»Mein Schweigen wurde von meinem Kummer verursacht, der, während er über eine mögliche Vergeltung nachdachte, zuließ, dass die Zuneigung immer mehr Schaden nahm. Denn was konnte ich tun, außer mich durch Schweigen an derjenigen, die Briefe verweigerte, zu rächen, außer die Geringschätzung mir gegenüber, die durch das Ausbleiben der ehrenvollen Briefe deutlich wurde, mit gleicher Waffe zu schlagen, indem ich Briefe vorenthielt?" $(\$ 1){ }^{759}$ Wie im Brief an Deuterius entgegnet er nun ihrem möglichen Vorwurf, dass er gegen sein propositum verstoße, wobei er in diesem Brief betont, dass nichts seinem

757 (Sy. 1,35) Diu in Campaniae secessibus otiatus occasione carui scriptionum. ideo paulisper sermonis mei circa te munus intepuit. sed ubi in patriam pedem retuli, antiqua mihi fuit instaurandi officii diligentia. ergo debito te honore salutationis inpertio utrumque deposcens, ut et silentio superiori venia iusta praestetur et praesenti obsequio vicissitudo respondeat. vale.

758 (Sy. 1,83) Religionis indicium est, quod me taciturnitatis incessis. sed velim credas, infortunii fuisse non voluntatis, quod diu officio scriptionis abstinui. nec puto ignorare te, quatenus in nos fortuna saevierit [...]. - Cf. auch z.B. Sy. 3,5. 4,28. 4,30. 4,54. 4,57. 7,16. 7,77. 8,11 .

759 (35,1) Silentium meum dolor exegit, qui passus est crescere, dum de vindicta cogitat, dispendia caritatis. quid enim fieri potuit, nisi ut tacendo vicem restituerem litteras deneganti, 
propositum widersprechen könne, worin er sie nachahme: "Du magst vielleicht sagen, dass der Gedanke an Vergeltung mit meinen Vorsätzen unvereinbar sei. Aber ich betrachte alle meine Fehler, deren Urheber Ihr seid, gleichsam als Ausführung eines Gesetzes. (\$2) <Denn:> Könnte irgendjemand für ein Vergehen halten, etwas zu tun, was Du getan hast, und glauben, dass vom göttlichen Gericht bestraft werden muss, was erkennbar von Dir ausgegangen ist? “ (\$1f.) ${ }^{760}$ Sie könne ihm also keine Vorwürfe machen, da er nur ihr Verhalten nachgeahmt habe: „Ertrage also gleichmütig mein Vergehen: da Du, Licht der Kirche, in dieser Sache vorangehst, hast Du es selbst so gewollt. Ich bewahre die Haltung, die ich versprach, nämlich: wenn ich würdig bin, Dir in allem nachzueifern. Den Beweis dafür habe ich erbracht, indem ich schweige, wenn Ihr schweigt, und spreche, wenn Ihr sprecht. Also habe ich, nachdem es mir befohlen wurde, zu schreiben begonnen, der ich bis jetzt die unerwünschten Worte scheu im Verborgenen zurückgehalten habe, und ich werde mit gleichem Gehorsam in Briefen gehorchen “ $(\$ 2) .{ }^{761}$ Der Brief endet mit einer der bei Ennodius selten zu findenden Entschuldigungen für die Kürze: "Leb wohl, meine Herrin, wolkenloser Glanz eines guten Herzens, und lebe lange als Beispiel für eine fromme Lebensführung; sei so freundlich, wenn ich es verdiene, an mich zu denken, und verzeih den kurzen Brief, den die Eile des Boten so einengte $\ll\left(\$_{3}\right) .^{762}-$ Auch von Speciosa erwartet Ennodius offensichtlich Verständnis dafür, dass er sein propositum so eng mit seinem Schreibverhalten verbindet (siehe oben $277 \mathrm{ff}$.); die lux ecclesiae Speciosa war offenbar so weltoffen, dass Ennodius keine konventionelle Entschuldigung, sondern eine freche Mischung ${ }^{763}$ aus Trotz und Schmeichelei für angemessen hielt.

ut contemptus circa me, qui per abstinentiam venerandi sermonis innotuit, dum subduco conloquia, pari mucrone feriretur?

760 (35,1f.) dicas forsitan, vindictam inimicam esse proposito. sed omnia errata ita conputo quasi legis obsequium, in quibus vos esse contingit auctores. (\$2) quisquamne culpam putet fa cere quod fecisti, et plectendum iudicio divino censeat, quod a te processisse cognoscat?

761 (35,2f.) aequo ergo animo sustine quod deliqui: dum in ea re praecedis, lux ecclesiae, ipsa voluisti. ego servo animum, quem promisi, ut in universis, si mereor, aemulator existam; cuius rei fidem, dum tacentibus vobis taceo et quod loquentibus loquor, ostendi. (\$3) ad scriptionis ergo officium, postquam iussus sum, me reduxi, qui hactenus intra verecundum penetrale quae non amabantur verba continui, simili in paginis pariturus obsequio.

$762(35,3)$ salve, mi domina, bonae splendor sine nube conscientiae, et ad exemplum sanctae conversationis in longum producere et mei, si mereor, meminisse dignare, epistulari dans veniam brevitati, quam in angustum artavit festinatio portitoris.

763 Anders charakterisiert von KenNell $(2000,147)$ : »Ennodius expresses his profound respect, praising her as a shining adornment of the Church $[\ldots] .[\ldots]$ he apologizes for failing to write, then calls her slight of the Church<, giving her the credit for leading the way in religious devotion as he recalls his promise to emulate her in all things, conforming his silences and speech to hers [...]. «Diese Zusammenfassung ließe auf eine konventionelle Entschuldigung schließen. 
Auch Avienus, den Ennodius häufig zum Schreiben auffordert, hat seinerseits um einen Brief gebeten (65). Ennodius bringt nun nicht etwa die wirklichen Gründe dafür vor, die ihn bisher vom Schreiben abgehalten haben, sondern er beruft sich auf seinen pudor und seine verecundia; auch der Dank für den erhaltenen Brief richtet sich weniger an Avienus als vielmehr an Gott, der diesen zum Schreiben gebracht habe. Ironisch führt Ennodius seine Freude darüber aus, dass er nun endlich einmal selbst um einen Brief gebeten werde und sich nicht wie sonst aufdrängen müsse. Auch eine stichelnde erzieherische Bemerkung darüber, dass Avienus, "unser Konsul«, sich gebessert habe, fehlt nicht. Ennodius spricht in diesem Brief weniger mit Avienus (der nur am Anfang und am Ende angesprochen wird), als über ihn: „Dank sei Gott - was zuerst gesagt werden muss -, dass er Deine Hoheit das fordern ließ, was ich geben sollte. Du hast meiner Redseligkeit, die ich bis jetzt mühsam scheu im Verborgenen zurückhielt, Wert verliehen. Mir bringt es Glanz, dass mein Griffel, den ich nur mit Mühe vom aufdringlichen Schreiben zurückhalten konnte, angefordert wurde. Ich habe das Verdienst, dass meine Stimme aufgefordert wurde. Denn indem Du mir aufgetragen hast, einen Brief zu schreiben, hast Du meiner Seele als gut empfohlen, dass ich geschwiegen hatte" $(\$ 1) .{ }^{764}$ Dann spricht Ennodius mit sich selbst, das heißt er wendet sich an sein eigenes gutes Benehmen, das in diesem Fall gesiegt habe; denn er könne nun einen Brief schreiben, ohne gegen das gute Benehmen zu verstoBen, d.h. ohne unaufgefordert zu schreiben (cf. in 360,1 oben 312): "Bravo, mein gutes Benehmen, das Du Dich oft selbst aufgeben musstest. Endlich einmal gelange ich, ohne Dir Schaden zuzufügen, zur Fülle der Freundschaft. Wir wollen lernen, nicht zu hassen, was hilft <sc. das Schweigen>. Die Gunst der Stille hat bewirkt, dass ich nun offen sprechen kann, ohne dass Du Dich einschränken musst. Man erwartet von mir einen Brief, was oft verschmäht wurde. Ich will nicht weiter gehen. Wie ich sehe, wird der Dienst der Sprache durch die Seltenheit der Gespräche empfohlen. In dieser Hinsicht wankt meine Freude nicht im Glauben. Meine Meinung stützt sich auf die Zustimmung der Wahrheit« $(\$ 2){ }^{765}$ Dann verlagert sich der Schwerpunkt vom eigenen Schweigen auf das Verhalten des Avienus: „Siehe: Jener, der die Briefe von Gebildeten, die mit der Ernte eines reichtragenden Gesprächs bereichert sind, kaum mit

764 (65,1) Deo gratias, quod principe loco ponendum est, qui magnitudinem tuam, quae a me erant offerenda, fecit exigere. dedisti pretium garrulitati, quam vix hactenus intra verecundum penetrale continui. eliciti utor stili genio, quem duriter ab inportuna scriptione revocavi. meritum coactae vocis inusitata loquacitate possideo. nam postquam me iussisti paginas destinare, animo meo, quod tacueram, commendasti.

$765(65,2)$ euge, frons diu prodiga, aliquando mihi contigit ad affectionis copiam sine tui dispendio pervenire. discamus non odisse quod adiuvat. silentii gratia fecit, ut te libera iam loquamur. expectantur a nobis saepe fastidita conloquia. non ibo longius. adseritur, ut video, linguae officium raritate sermonum. in qua parte non clauda laetitiae meae fides est <cf.: (Sil. 13,33) laetus opum, sed clauda fides, bei Silius in anderem Sinne: "Loyalität $«\rangle$, sententia nostra veri adstipulatione fulcitur. 
der Zungenspitze probierte, hat nichts dagegen, die Ähren unseres Briefleins anzunehmen.« Immer noch redet er Avienus nicht direkt an, vielmehr wird nun der eigene pudor angesprochen wie oben die frons: "Gutes Benehmen, du hast mir zu doppelter Freude verholfen, da <zum einen $>$ du sicher vor Anker liegst und <zum anderen $>$ meine häufig verschmähte Anrede gewünscht wird. Der Wille meines Freundes ist also besser geworden. Also habe ich mit gutem Benehmen für mich und mit Verbesserung für unseren Konsul ${ }^{766}$ gesorgt « $\left(\$_{3}\right) .{ }^{767}$ Ennodius lässt den Brief nicht ohne neue Ermahnungen enden; Avienus, der schon Konsul war und Aussichten auf weitere weltliche Ämter hat, solle ihm schreiben und so seine humilitas und communio beweisen, d.h. er soll nicht arrogant werden und seine alten Freunde vergessen: »Aber damit der Brief nicht zu lang wird und die festgesetzten Grenzen überschreitet und wir durch viel Reden zeigen, dass unser Schweigen nicht auf Überlegung beruhte: Leb wohl, mein Herr, und würdige Deine Freunde mit dieser Gemeinschaft <sc. des Schreibens $>$, weil die erhabenen Spitzen Deiner Ehren nur die Erweiterung erfahren, die aus der Demut entsteht “ $(\$ 4) .{ }^{768}$ - Solche Hinweise, dass die Korrespondenz mit ihm eine Möglichkeit für Inhaber hoher Ämter sei, ihre Demut zu zeigen, gibt Ennodius häufig ( siehe z.B. in 125, unten 342), besonders führt er dieses Thema in späteren Briefen an Avienus aus (siehe oben 288).

Auch den nächsten Brief an Avienus (75) schreibt Ennodius als Antwort auf eine Klage von diesem, dass nämlich Ennodius einen Diener nur mit einer mündlichen Botschaft, aber ohne Brief zu ihm geschickt habe. ${ }^{769}$ Ennodius begründet sein Verhalten, wobei er gleichzeitig zeigen möchte, dass der Vorwurf unberechtigt war. Hauptmotiv dieses Briefes ist das Paradox, mit dessen Hilfe Ennodius ironische Bemerkungen macht zum Fortgang der Korrespondenz bzw. zu Avienus' mangelndem Eifer darin. - Zunächst äußert Ennodius seine Freude über die paradoxe Situation, dass er dem Ärger des Avienus einen Brief von diesem zu verdanken habe (cf. 24,1 oben 167): „Wenn eine Kränkung dazu führt, dass die Zahl der Briefe Deiner Hoheit größer wird, wie oft wollte ich jene Ruhe Deines heiteren Herzens gestört wissen! Und wenn

766 Diese Anrede bedeutet nicht, dass Avienus zur Zeit dieses Briefes Konsul ist, siehe SunDWALL 1919, 19; VOGEL 1898, 66.

$767(65,3)$ ecce ille, qui doctorum epistulas gravidi dotatas messe conloquii summis labiis vix libabat, tabellae nostrae culmos non dedignatur accipere. gemina, pudor, mihi hilaritate profuisti, cum tu in statione certus es et cum frequenter contempti desiderantur affatus. facta est ecce melior eius sententia, quem amamus. nobis ergo verecundia, consuli nostro emendatione prospeximus.

$768(65,4)$ sed ne in longum procedat pagina transcendens terminos praefinitos et loquendo multa quod tacuimus demonstremus non fuisse consilii, vale, mi domine, et amantes tui hac communione dignare, quia praecelsi honorum tuorum apices haec sola recipiunt augmenta, quae de humilitate nascuntur.

769 Anders Sundwall $(1919,21)$, Avienus habe gekränkt auf den ironischen Brief 65 geantwortet. 
es nicht gegen meine Vorsätze wäre, böte ich Dir viele Anlässe, Dich zu ärgern, da ich durch schuldhaftes Verhalten bekommen habe, was Liebe nicht verdienen kann" $(\$ 1) . .^{770}$ Doch sofort führt Ennodius aus, dass er von Avienus unschuldig angeklagt worden sei; in der Aufregung (cf. \$1 turbatus; mens confusa) habe er nur die Nachricht übermitteln lassen können, einen Brief aber könne man nur in Muße schreiben: "Doch ich kann vermelden, dass ich in der Sache, in der Ihr mir, indem Ihr meine Nachlässigkeit tadelt, eine Belohnung <sc. den Brief> zukommen ließt, ohne Schuld bin. In der Aufregung schickte ich einen Diener, durch den ich nur das Allernötigste melden ließ. Wenn das Herz unbeschwert ist, hat die Zunge Zeit für ihre brieflichen Pflichten, ein verstörter Geist kennt die Annehmlichkeit eines Grußes nicht « $(\$ 1){ }^{771}$ Es folgt ein weiterer Dank für die paradoxe Situation und nochmals der Vorwurf, dass Avienus aus bloßer Freundschaft nicht geschrieben habe: "Dank sei also Gott für beides, dass nämlich ich nicht schuldig bin und dass Ihr mich für schuldig hieltet. Eure Verärgerung hat mir eine Wohltat zukommen lassen, die Eure Zuneigung kaum gewährt hätte" $(\$ 2) .{ }^{772}$ Der Brief endet mit einem Hinweis auf die Freundschaft zu Avienus, der allerdings lediglich in einer Praeteritio vorgebracht wird, und mit der Bitte, immer alles zu schreiben: "Ich kann nicht ausdrücken, was ich Dir schulde. Armselig ist eine Liebe, bei deren Beschreibung die Sprache nicht versagt. Mein Herr, ich sage den geziemenden Gruß und bitte Gott, dass Du immer alles schreiben mögest, was Du in der Seele trägst« $(\$ 2) .{ }^{773}$

Eine andere Taktik, auf Aufforderungen zum Schreiben zu reagieren, sind Gegenvorwürfe (413; 251), wie sie auch schon im Brief an Speciosa zu sehen waren: So bestimmen in Verbindung mit Komplimenten verschiedene Vorhaltungen auch die Antwort (413) auf Boethius' Aufforderung zu schreiben; dieser hat offenbar Zweifel an Ennodius' Freundschaft vorgebracht. Während Ennodius am Schweigen zwischen sich und Speciosa bedauert, dass dieses der Freundschaft geschadet habe, beklagt er hier, dass Boethius sich durch sein Schweigen die Möglichkeit entgehen ließ, seine Bildung zu zeigen. - Der Brief beginnt, als habe Ennodius keinen Brief vom Adressaten erhalten, denn er spricht zunächst über dessen langes Schweigen: "Deine Zun-

$770(75,1)$ Si offensa praestat, ut magnitudinis tuae scripta geminentur, quam vellem saepe illa sereni pectoris tui tranquilla turbari! et nisi adversaretur proposito, causas indignationis ingererem, quando quod amor non meretur per culpas obtinui.

$771(75,1)$ ego tamen errore vacare me nuntio in ea causa, in qua dum accusatis neglegentiam, praemium contulistis. puerum turbatus direxi, per quem nihil aliud quam quod opus esset ostendi. libero pectore lingua vacat officiis, mens confusa gratiam salutationis abiurat.

$772(75,2)$ ecce deo in utroque gratias, quia nec ego reus sum et vos me reum esse credidistis. beneficium mihi commotio vestra contulit, quod vix dedisset affectio.

$773(75,2)$ ego quid tibi debeam explicare non possum. pauper est caritas, in cuius narratione sermo non deficit. domine mi, salutem debitam dicens deum rogo, ut quodlibet animo gesseris semper scribas. 
ge hatte ihren Wert, den die Bildung bedeutet, verloren, während Du schwiegst; denn während Dein Schweigen die Eleganz der Rede verbarg, glaubte man, dass nicht existierte, was neulich aufleuchtete. «Dann erst wird erwähnt, dass inzwischen ein Brief eingetroffen ist, in dem allerdings Ennodius zum Schreiben aufgefordert wurde: »Du hast einen neuen Lichtschein der Sprache ans Licht gebracht, und während Du es im Brief hell werden lässt, glaubt man, dass die Brillanz, die $\mathrm{Du}<$ erst> kürzlich erlangt hast, eine schon reife $<$ Brillanz $>$ ist. Ich danke Dir, dass Du mich mit Deinem ausgeschmückten Brief zur Bewahrung der Freundschaft bringst « $(\$ 1) .{ }^{774}$ Hat Ennodius schon im ersten Satz angedeutet, dass seiner Meinung nach Boethius zu lange geschwiegen habe, so führt er den Vorwurf jetzt weiter aus mit Worten, die an ein Prinzip des Symmachus erinnern: "Doch wenn Du Dir meiner Treue bewusst wärest, hättest Du keine Zweifel an Beständigem «, cf. z.B. (Sy. 8,35), oben 214. Aber anders als Symmachus gibt er den Vorwurf zurück: »Ich fürchte, dass die Unzuverlässigkeit, die Du bei mir vermutest, bei Dir selbst zu finden ist und dass Du, während Du die Lauheit Deines Freundes befürchtest, <selbst> in der Freundschaft abkühlst « $(\$ 2) .{ }^{775}$ In der abschließenden Bitte um Briefe weist Ennodius nochmals darauf hin, dass Boethius aufgrund seiner Fähigkeiten schreiben müsse: "Mein Herr, ich entbiete freundliche Grüße und hoffe, dass Du häufig Briefe an mich richten mögest, weil Dich sowohl die Freundschaft als auch Deine Meisterschaft ermahnen, Dich beim Schreiben sehr anzustrengen “ $(\$ 2) .{ }^{776}$ In diesem Brief gibt sich Ennodius nicht witzig oder trotzig o.ä., sondern er weist Boethius zurecht und gibt ihm Ratschläge. Vergleichbare Ermahnungen, sich anzustrengen und in Briefen die Bildung zu zeigen (vgl. auch in 318,4 an Boethius), finden sich auch sonst in Briefen an jüngere Adressaten (siehe oben I 4.d; siehe auch z.B. 16,3; 175,4).

Heftigere Gegenvorwürfe ohne 'milderndes` Lob richtet Ennodius (251) an Constantius, der zu dieser Zeit wahrscheinlich Praefectus urbis Romae war (cf. SCH ̈̈FER 1991, 53f.); nur am Ende lenkt Ennodius etwas ein. Er wirft Constantius vor, einen sTrick، angewandt $z u$ haben, wozu allerdings zu sagen ist, dass es sich hierbei um eine Variante eines seiner eigenen ,Lieblingstricks (handelt, wie besonders an einigen seiner Glückwunschschreiben zu beobachten ist (siehe unten 332). Eigentlich verdiene Con-

$774(413,1)$ Perdiderat eruditionis pretium lingua, dum retices, quia dum venustatem eloquentiae taciturnitas includebat, credebatur non esse quod nuper efferbuit. produxisti in lucem novum iubar eloquii et, dum diem in epistula facis, splendorem recens adeptus crederis iam maturum. gratias ago, quod me ad amicitiae custodiam paginae tuae flore conpellis.

$775(413,2)$ sed si fidei meae esses conscius, dubitationem de rebus constantibus non haberes. timeo, ne ambiguitatem quam credis exhibeas et, dum amantis teporem metuis, in adfectione frigescas.

$776(413,2)$ domine, ut supra, salutationis gratiam persolvens spero, ut crebro ad me epistolarum commercia dirigas, quia in his muniis et diligentia te admonet et perfectio ut multus incumbas. 
stantius, der nach Rom gegangen sei und nicht geschrieben habe, Vorwürfe; doch dieser habe schlauerweise selbst einen tadelnden Brief geschrieben, um einem Tadel von Ennodius zuvorzukommen: "Wenn es mir freistände, mit Eurer Hoheit von gleich zu gleich zu streiten, wenn Ehren, Alter und Verdienste, die Euch eine Fackel vorantragen, mich nicht in den Schatten drängten, würde eher ich zu Recht Eure Hoheit wegen der Schreibfaulheit tadeln; denn seit Ihr nach Rom gegangen seid, hat sie $<$ die Hoheit> mich mit keiner Frucht der Erinnerung ermuntert " $(\$ 1) .{ }^{777}$ Doch Constantius habe den von früheren Briefschreibern erfundenen Kunstgriff angewandt, Ennodius anzuklagen, bevor dieser selbst seinen Kummer vorbringen konnte: "Doch sieh, wie sehr die Maßnahmen der Alten in ihrer Voraussicht auf der Hut sind und wie reich an kunstvollen Reden: Durch Klagen kommt man der Unschuld zuvor, und damit sie nicht ihren Kummer ans Licht bringen kann, wird sie angeklagt; sie wird zur Angeklagten, um nicht anklagen zu können « $(\$ 2) .{ }^{778}$ Dennoch bringt Ennodius noch seinerseits Vorwürfe vor: "Also das hast Du mir beim Abschied versprochen? Du hast mich geküsst und mit der Aussicht darauf getröstet, zu glauben, dass Ihr mich vergessen würdet? Oder sind Briefe für etwas anderes da, als die verborgenen Gedanken des Herzens mit dem Schlüssel des Mundes zu eröffnen?" (\$2). ${ }^{779}$ Der Brief endet einigermaßen versöhnlich mit der Bitte, dass Constantius in Rom bei den Aposteln für Ennodius beten solle; die explizite Erwähnung, dass die mortalis angustiae obscenitas überwunden werden müsse, könnte darauf hindeuten, dass sich Constantius mit einem konkreten Anliegen an Ennodius gewandt und deshalb endlich geschrieben hat: "Doch ich sehe von einem langen Brief ab, damit nicht ein ausgedehntes Gespräch noch mehr Abscheu erregt. Ich komme zum pflichtgemäßen Gruß und bitte Dich, für mich vor den Aposteln Gottes Deine Gebete auszubreiten, dass durch ihre Wohltaten die Hässlichkeit der sterblichen Beschränktheit überwunden wird und sich eine ungetrübt heitere Seele über den reinen Weg der himmlischen Gebote freuen kann « $(\$ 3){ }^{780}$ - Hier haben wir einen Beweis dafür, dass nicht nur En-

777 (251,1) Si liceret cum magnitudine vestra aequa sorte contendi, si honores aetas meritum quod vobis facem praetulit, nos non in umbram cogeret, ego potius culmen vestrum de tabellarum abstinentia iure culparem, qui<a coni. VoGEL $>$ postquam ad urbem Romam profecti estis, nulla me recordationis fruge sublevavit.

$778(251,2)$ sed vide per rerum providentiam quam cauta est seniorum dispensatio et fabricatis plena sermonibus: praevenitur querelis innocentia et, ne dolorem suum in lucem producat, arguitur; fit rea, ne faciat.

779 (251,2) ergo haec mihi digrediens promissa contuleras? hac deosculatum fiducia sublevasti, ut crederem mei inmemores vos futuros? an ad aliud adtributae sunt paginae, nisi ut secreta pectorum oris clave manifestent?

$780(251,3)$ sed abstineo prolixitate paginali, ne grandiorem generet confabulatio producta rancorem. ad salutationis obsequia me reduco rogans, ut pro me apud apostolos dei preces effundas, ut eorum beneficiis mortalis angustiae superetur obscenitas et de puro mandatorum caelestium tramite mens serena gratuletur. 
nodius bemüht war, seinen Korrespondenten Vorwürfe zu machen: Constantius war in Rom und hätte als erster schreiben sollen; bevor Ennodius ihm vorwerfen konnte, nicht geschrieben zu haben, hat Constantius seinerseits Ennodius getadelt.

Erst im Vergleich zu diesen unterschiedlichen Strategien, die darauf abzielen, Entschuldigungen zu verdecken bzw. zu vermeiden, sieht man, wie konventionell andere Briefe in der gleichen Situation sind. Bei den folgenden sunauffälligen ' Reaktionen hat Ennodius es also offenbar für unnötig gehalten oder aber nicht gewagt, vor den Adressaten seine rhetorica versutia spielen zu lassen. Dafür kann es verschiedene Gründe gegeben haben: Ennodius kann sich auf das Niveau des Adressaten eingestellt haben, der ein Spiel mit den Konventionen vielleicht nicht verstanden hätte; er kann sich nach der Erwartung des Adressaten gerichtet haben, der Ennodius nur als Diakon kannte und nichts von dessen ,rhetorischer Vergangenheit ‘ wusste; und auch wenn der Adressat davon Kenntnis hatte, kann Ennodius absichtlich so geschrieben haben, um seine Vergangenheit als Redner und Dichter zu verleugnen bzw. vergessen zu lassen.

Nur in einem Brief (82) an Apollinaris (außer den 3 Briefen von Ennodius ist nichts über ihn bekannt, cf. PLRE II,115: »Apollinaris 4«; zu Brief 41 siehe unten 361 , zu 151 u. 369) erläutert Ennodius ausführlich die Gründe für sein Schweigen. Zwar verlange seine Liebe zu Apollinaris häufiges Schreiben, doch er habe gewartet, bis sich ein zuverlässiger Bote angeboten habe, da man vielen anderen keine Briefe anvertrauen könne: »[...] Doch was soll ich tun, wenn ein solches Durcheinander von Leuten kommt, dass man nicht weiß, wen man am besten auswählen könnte, um ihm einen Brief an Euch, frommes Herz, zu übergeben? Denn Nichtsnutze wollen das, was wir für die Freundschaft tun, zu ihrem Vorteil ausnutzen. Und es ist unerträglich, wenn das, was die Kraft der Freundschaft veranlasst, der Gier dient. Daher habe ich bis zur Gelegenheit eines vertrauten Boten vom Schreiben Abstand genommen, damit nicht der Freundschaftsdienst durch unwürdige Boten verdorben und durch die Dreistigkeit Fremder widerwärtig wird und mich so eine Schuld trifft, die nicht von mir ausging. So also habe ich kurz dargelegt, wodurch es zwangsläufig zu meinem Schweigen gekommen ist, und kann wieder zum gewohnten Schreiben kommen, $[\ldots] \lll(\$ 1 f.){ }^{781}$ Abschließend bittet er um viele Briefe.

$781(82,1)[\ldots]$ sed quid faciam, quando tanta est venientum confusio, ut nescias qui potissimum deligendus sit, cui reddenda sanctae conscientiae vestrae possint scripta committi? (\$2) trahunt enim in occasionem conpendii sui viliores, quicquid nos praestamus affectui; et grave est ut serviat cupiditati, quod exigit vis amoris. idcirco animum usque ad domestici perlatoris oportunitatem ab scriptione suspendi, ne diligentiae ratio sparsa per inmeritos perlatores aliena inportunitate ranciscat et ad me culpa redeat, quae a me non sumpsit exordium. (\$3) necessitatem ergo procurati silentii breviter explicans ad usum me paginalem converto $[. .$.$] .$ 
Der römische Presbyter Adeodatus (74; siehe auch oben 124; zu ihm cf. PCBE 2.1, p. 19f.: "Adeodatus 8 «) hat Ennodius offenbar vorgeworfen, dass er ihn vergessen habe. ${ }^{782}$ Ennodius antwortet mit einer Mischung aus Entrüstung über diesen Gedanken und Komplimenten für den frommen Lebenswandel des Adeodatus. Er beginnt mit rhetorischen Fragen und der Beteuerung, dass gerade er der Freundschaft und Unterstützung des Adeodatus dringend bedürfe: "Wer außer einem Unmenschen könnte die Freundschaft mit Euch vergessen? Wer wollte auf die Unterstützung eines vollendet Gläubigen vor Gott verzichten? Zumal ich, der ich von schweren Sündenlasten erdrückt werde und Eure Gunst erlangt habe, was mich vollständige Absolution <sc. vor Gott> erhoffen lässt « $(74) .{ }^{783}$ Abschließend bittet Ennodius ihn um unterstützende Gebete: "Ich grüße also ehrfurchtsvoll und schuldigst und hoffe, dass Du an allen heiligen Orten für mich Gelübde tust. Diese werde ich sofort erfüllen, wenn ich die Wohltaten Gottes empfangen habe; denn ich weiß, dass Du es verdienst, erhört zu werden « (74). ${ }^{784}$ Die letzten Worte kann man als Anspielung darauf verstehen, dass dem Adressaten gerade mit diesem Brief von Ennodius ein Wunsch erfüllt wird, nämlich der nach einem Brief von Ennodius. Er endet also mit dem Trugschluss, dass durch seine eigene Antwort seine Hoffnung darauf wachsen könne, dass auch andere Wünsche des Adeodatus - und zwar Wünsche für Ennodius - erfüllt werden.

Bei Passivus (114; der Adressat ist sonst nicht bekannt) bringt Ennodius seine angeblich mangelnden Fähigkeiten als Grund für sein Schweigen vor. Er folgt hier ausgiebig der Konvention, seine Fähigkeiten herabzuspielen; der Gedanke, dass seine Sprache nicht ausreiche, um die Freundschaft zum Adressaten zu beschreiben, findet sich bei ihm zwar noch häufiger (siehe oben 233), nirgends aber so ausführlich: "Wenn meine Sprache ausreichte, um die Freundschaft auszudrücken, wenn meine Sprachlosigkeit die Freundschaft ganz beschreiben könnte: Wem würde ich lieber viele Briefe schreiben als Euch? Und meine Sprache würde niemandem würdiger dienen, wenn dadurch nicht das Verdienst des Herzens geschmälert würde <sc. wenn das Gesagte nicht hinter der Freundschaft zurückbliebe>." Manche, so Ennodius, empfinden keine Freundschaft, schreiben aber schmeichelnde Briefe: »Andere bezeugen mit dem Mund eine Liebe, die sie in der Seele nicht kennen, und malen in schmeichelndem Briefwechsel nur für den Augenblick, wobei das Innere Pause macht und die ganze Liebe nur auf der Zunge ist und nichts Anderes ins Innere ge-

782 Sundwalls Angabe "<Ennodius $>$ sendet $[\ldots]$ nur einen kurzen Gruß« $(1919,20)$ trifft m.E. nicht den Kern. Die rhetorischen Fragen erklären sich am besten, wenn Vorwürfe von Adeodatus oder Fragen, ob Ennodius ihn vergessen habe, vorausgegangen sind.

783 (74) Quis vestrae affectionis inmemor, nisi qui est inhumanus, existat? quis totius religionis personae apud deum nolit habere suffragium? ego maxime, qui et gravibus peccatorum sarcinis premor et vestram gratiam optinui, quae res mihi absolutionem integram pollicetur.

784 (74) salutans ergo veneranter et debite spero, ut pro me per omnia sanctorum loca vota facias. quae consecutus dei beneficia sine mora dissolvam, quia conpertum mihi est, quod mereris audiri. 
bracht wird als das, was im Brief mitgeteilt wird « $(\$ 1) \cdot{ }^{785}$ Ennodius ergeht es anders, seine Freundschaft sei so groß, dass seine Sprache nicht an sie heranreichen könne: "Doch mein Empfinden für Euch wird von der Magerkeit der Sprache und der Fülle der Freundschaft erdrückt und ist verstummt. Denn ich fürchte, dass ein ärmlicher Brief der Gunst ein Ende setzt, dass Du glaubst, Rede und Freundschaftsbund hätten das gleiche Maß. Es ist besser, durch Schweigen meinen Ruf etwas zu mindern als durch Briefe Einbuße an Liebe zu zeigen.« Ennodius zählt also Passivus zu denjenigen Briefschreibern, die eine niveauvolle Korrespondenz unterhalten, und er möchte ausdrücklich lieber schweigen als ihm nicht angemessen schreiben. Er verweist auf seine sinceritas, mit der er seine Gründe dargelegt habe: "So also habe ich begründet, warum ich selten schreibe, in der Meinung, dass Ihr die geschuldete Aufrichtigkeit der Beredsamkeit vorzieht. « Der Brief endet mit Bemerkungen, die sicher einen konkreten Bezug hatten, der für uns aber unkenntlich ist: "Abschließend: Lebt wohl, mein Herr; erfüllt im Besitz göttlicher Wohltaten in einem langen Leben die himmlischen Aufträge. Denn bei Euch findet die Güte, nachdem sie auf dem Gipfel begonnen hat, eine Steigerung “ $(\$ 2 f.){ }^{786}$ - Dieser Brief klingt konventionell, aber dennoch bzw. gerade deswegen ist daran einiges für Ennodius auffällig: Dass er lieber schweigen als in Briefen sein Unvermögen bloßlegen möchte, widerspricht seiner sonst vertretenen Meinung, dass stumme Freundschaft keine sei (siehe oben 219) und dass man in Briefen an Freunde auf die sprachlichen Kräfte keine Rücksicht nehmen solle (siehe z.B. 155,2 oben 315; siehe auch 12,3). Ausgerechnet in diesem Brief beruft er sich auf seine sinceritas, wo doch die mangelnden Fähigkeiten ganz sicher nicht der wahre Grund seines Schweigens sind; von seinen wahren Gründen, wie er sie in den $R e$ cusationes nennt, schweigt er hier. Selten spricht er so direkt von der ubertas seiner Freundschaft. Aus diesem konventionellen Inhalt ist daher wohl zu schließen, dass Passivus und Ennodius sich nicht gut kannten und dass Ennodius auf den Kontakt auch keinen großen Wert legte.

785 (114,1) Si ad eloquendam sufficeret sermo caritatem, si totum infantia explanaret affectum, cui magis quam vobis paginarum frequentiam praestaremus? et nisi artaret meritum pectoris, nulli dignius sermonis militaret officium. alii affectum, quem mente nesciunt, ore testantur et pingunt inlecebrosis epistularum momenta<nea coni. Verf. $>$ commerciis [commenta coni. HARTEL; commercia commentis coni. VoGEL], quando feriatis penetralibus amor totus in lingua est nec aliud ad interiora perducitur, nisi quantum in scriptione confertur.

$786(114,2 \mathrm{f}$.) at meus erga vos animus eloquii pressus macie et amicitiae ubertate conticuit. metuo enim, ne gratiae terminum ponat mendica confabulatio, ne idem modus putetur esse sermonis et foederis. melius est plus aestimationi per silentium dimittere quam monstrare diligentiae damna per litteras. ecce rarioris conloquii causas adserui, credens apud vos a sinceritate debita facundiam posthaberi. $\left(\$_{3}\right)$ quod superest, salvete, mi domini, et divinis usi beneficiis procedente vita in longum caelestia mandata conplete. invenit enim apud vos, cum a cumulo coeperit benignitas, incrementum. vale. 
Mit seinem Unvermögen rechtfertigt sich Ennodius auch in einem Brief (176) an den Vir illustris Opilio (siehe SCH ÄFER 1991, 9of,; er erhält einen weiteren Brief) dafür, dass er nun erst auf den zweiten Brief von diesem antworte. ${ }^{787}$ Es sei nicht gut, wenn auch die humiles wie Ennodius diesem Übel (illud mali genus) verfielen, nicht zu antworten (\$1). Opilio könne also zufrieden sein, dass Ennodius wisse, "was für einen Fehler ich durch das Schweigen begangen habe.« Doch er habe sich nicht getraut zu schreiben: "Aber ich muss sagen, dass ich fürchtete, mich würde die Flucht vor dem Fehler <sc. zu schweigen> zum Laster <sc. schlecht zu schreiben> führen, und das Schreiben, das doch Gunst erzeugen soll, könnte Anstoß erregen, weil es nicht mit der Feile des Könnens geglättet war. Ich schreckte vor dem Entsetzen zurück, das bei Unkundigen bei der Gelegenheit zu gehorchen aufkommt. « $(\$ 2) .{ }^{788} \mathrm{Er}$ betont dann, dass er sich also richtig verhalten habe. Doch in diesem Brief scheinen die Entschuldigungen für das Schweigen zunächst sozusagen stellvertretend dafür vorgebracht zu werden, dass Ennodius am Ende darauf zu sprechen kommen muss, dass er einen Auftrag des Opilio bisher nicht erfüllen konnte; wie meistens bleibt es bei (für uns) dunklen Andeutungen: »[...] Agnellus täuscht mich in Bezug auf die Häuser mit verschiedenen falschen Versprechungen, weil er will, dass von Euch ein Gesamtpreis benannt wird. Aber Ihr wisst ja bereits, dass die Gier dieses schlechten Menschen unersättlich ist und nur durch Verachtung des Geldes geheilt werden kann« $(\$ 5) .789$

Fazit zu b. (>Kontaktpflege $)$

In einem Brief an den jungen Avienus bezeichnet Ennodius es als seinen mos vivendi, »dass die Fülle der Freundschaft durch den Schlüssel der Rede eröffnet wird « (108,1 mihi meo vivendum est more, ut amoris plenitudo reseretur clave sermonis). Dieser Definition des mos vivendi mit den Kriterien >Freundschaftı und 'Schreiben ‘ entspricht die Tatsache, dass viele Briefe des Ennodius der Kontaktpflege mit seinen Adressaten dienen. Diese vielen Briefe zeigen trotz der wiederkehrenden Topoi eine große Bandbreite in Ton und Argumentation, so dass Charakterisierungen wie z.B. "schwulstige und umständliche Höflichkeit« (Fontaine 1962, 400) zu kurz greifen. Um seine Adressaten zum Schreiben zu bringen, versucht er es z.B. mit Provokation,

787 (176,1) Debeo equidem prioribus responsa conloquiis [...].

788 (176,2) ergo sufficiat magnitudini vestrae, quod post duplicem scriptionem sentio quid per silentium erroris incurrerim. sed timui confiteor, ne ad vitium me duceret fuga culparum et sermo deputatus ad gratiam, dum nulla peritiae lima comeretur, inveniret offensam. refugi horrorem, qui ignaris de parendi occasione generatur.

$789(176,5)$ Agnellus de casis per varias promissionum mihi inludit effigies, volens a vobis summam pretii designari. sed mali hominis ardorem insatiabilem esse didicistis, qui nisi contemptu pecuniae non sanetur. 
dass der Adressat gar nicht angemessen schreiben könne oder dass er mächtig und hochmütig geworden sei, er versucht es mit der Forderung, dass die Macht des Adressaten sich der Macht der Liebe unterwerfen müsse, mit Selbstvorwürfen, dass er die Freundschaft des Adressaten gar nicht verdient habe, mit bloßer Verwunderung, dass der Adressat nicht schreibe, oder gar mit Hinweisen auf seine patientia, die ihn weiter hoffen lasse. Wenn er sich für erhaltene Briefe bedanken kann, reagiert er z.B. mit dem paradoxen Gedanken, dass der Brief die Erinnerung an die Trennung wieder verstärkt habe, mit einem freundlichen Dank oder auch mit Ironie und einer Mischung von Demut und Triumph, wenn er ausführt, dass er nur deshalb endlich einen Brief erhalten habe, weil er um einen Gefallen gebeten werde. Wenn er einen Kontakt erstmals oder neu aufnehmen möchte, versucht er es entweder vorsichtig und freundlich oder voller Selbstvertrauen mit dem Hinweis, dass er mit diesem ersten Brief die bessere \Startposition \ habe, oder mit einer witzigen unerwarteten Wendung. Muss Ennodius seinerseits auf Vorwürfe antworten, nicht geschrieben zu haben, antwortet er entweder mit Entrüstung und Gegenangriff, mit Ironie oder auch mit Hinweisen auf fehlende Boten oder seine angeblich mangelnden Fähigkeiten. - Die Bedeutung von `Freundschaft « und `Schreiben` für den mos vivendi zeigt sich auch daran, dass Ennodius, wie im Folgenden zu zeigen ist, auch Briefe zu anderen Anlässen so gestaltet, als dienten sie in erster Linie der Freundschaft.

\section{c. Glückwunschschreiben}

Für das Verfassen von Glückwünschen findet sich in dem Abschnitt De epistolis bei Iulius Victor die Anweisung, man solle zu erfreulichen Ereignissen ausführlich gratulieren: rem secundam prolixius gratulare, ut illius gaudium extollas (p. 106,1f. Giomini/Celentano). Beispiele dafür liefert Sidonius Apollinaris, z.B. mit Brief 1,4: Er schreibt zunächst, auf wie redliche Weise der Adressat das Amt erlangt habe und wie glücklich er sich schätzen könne: „Herzlichen Glückwunsch, edler Herr, zu dem Amt, das Du dank Deiner Verdienste erlangt hast. Um den Ehrentitel und die Spitzenstellung zu erlangen, hast Du nicht die Einkünfte Deiner Mutter, nicht die Geschenke Deines Großvaters, nicht den Schmuck Deiner Frau, nicht das Geld Deines Vaters ausgegeben; denn Du hast im Gegenteil durch Deine erprobte Aufrichtigkeit, Deinen gezeigten Eifer und durch Deine erlebte Umgänglichkeit im Haus des Herrschers Lob erlangt [...]. O, drei- und vierfach Glücklicher: Durch Deine Erhöhung erhalten Deine Freunde Freude, Deine Neider eine Strafe, Deine Nachkommen Ruhm [...]« $(1,4,1) .{ }^{790}$

790 (Sidon. 1,4,1) Macte esto, vir amplissime, fascibus partis dote meritorum; quorum ut titulis apicibusque potiare, non maternos reditus, non avitas largitiones, non uxorias gemmas, non paternas pecunias numeravisti, quia tibi e contrario apud principis domum inspecta 
Weniger ausführlich formuliert Symmachus seine Glückwünsche; mit knappen Worten lobt er den Adressaten, spricht über die Mitfreude der Standesgenossen und äußert gute Wünsche für das Amt, z.B.: »Zwar hast Du ehrenvolle Ämter immer durch den Glanz Deiner Lebensführung und Deiner Bildung übertroffen, doch nun können sich alle Ehrenhaften darüber freuen, dass Dir auch eine öffentliche Auszeichnung zuteil geworden ist. Ich hoffe also, dass Du nach Wunsch die erlangte Ehre genießen und, zum Gipfel des Ruhms gelangt, dieser hohen Einschätzung des Kaisers $<$ sc. der Dich des Amtes für würdig befunden hat> entsprechen mögest« $($ Sy. 7,91$) .{ }^{791}$

Ennodius folgt der Vorschrift des Iulius Victor oder den Beispielen anderer Epistolographen nur selten; etliche Briefe an Adressaten, die gerade ein höheres Amt erlangt haben oder sich in anderen erfreulichen Situationen befinden, schreibt er gerade nicht in lobenden und freudigen Tönen, sondern voller Klagen, Vorwürfe und/oder Ermahnungen. Zunächst sollen solche Glückwunschschreiben betrachtet werden, die am meisten der Konvention widersprechen, also keine längeren freudigen oder lobenden Passagen enthalten.

\section{c. 1 Vorwurfsvolle Glückwunschschreiben}

In den sunkonventionellen Schreiben, mit denen Ennodius auf Erfolge seiner Korrespondenten reagiert, finden sich kaum panegyrische Elemente (höchstens in einer Praeteritio); er sucht nach Möglichkeiten, gerade keine Briefe voller Lob und Freude zu schreiben, sondern im Gegenteil Vorwürfe, Klagen und Mahnungen zu formulieren. Einen dieser Briefe (125) schreibt er, nachdem er vom Adressaten über dessen Erfolg informiert worden ist, andere (18; 224; 321f.; 455) schreibt er in der Situation, dass er vom Erfolg des Adressaten schon weiß, bevor er von diesem selbst davon in Kenntnis gesetzt wurde. Den Brief an Avienus zur Hochzeit (459) beginnt Ennodius mit ausführlichen Klagen, weil er nicht in seiner Nähe ist.

Die Konvention verlangt, dass, wer ein Amt erlangt hat, dies seinen Freunden schnell brieflich mitteilt, bevor sie davon gerüchteweise hören. Wenn Korrespondenten des Symmachus dieser Konvention nicht entsprechen, formuliert er so-

sinceritas, spectata sedulitas, admissa sodalitas laudi fuere. o terque quaterque beatum te, de cuius culmine datur amicis laetitia, lividis poena, posteris gloria [...]. Siehe auch: (Sidon. 2,3,1) Gaudeo te, domine maior, amplissimae dignitatis infulas consecutum [...]; (Sidon. $3,6,1$ ) [...] ita namque fascibus vestris gratamur omnes [...]; (Sidon. 5,18,1) Haeduae civitati te praesidere coepisse libens atque cum gaudio accepi $[\ldots]$.

791 (Sy. 7,91) Honores quidem semper vitae ac litterarum splendore praecessisti, sed bonorum nunc omnium gratulatio est, etiam publicum tibi decus esse delatum. opto igitur ex sententia partis fruaris insignibus et provectus in cumulum gloriae magnitudinem iudicii imperialis aequiperes. 
wohl einen gemäßigten Tadel als auch seinen Willen, nicht zu sehr zu klagen. So schreibt er tadelnd an Ausonius, dessen Sohn Hesperius ein Amt erlangt hat: "Er hätte mit einem Brief den Gerüchten zuvorkommen sollen, die lange unsicher und nicht vertrauenswürdig genug waren, um Freude hervorzurufen « $\left(\right.$ Sy. 1,16,2) ${ }^{792}$ Dass Hesperius zu schüchtern gewesen sei und Prahlerei habe vermeiden wollen, will Symmachus bei ihrer engen Verbundenheit nicht anerkennen $(\$ 2)$. Dennoch gibt er nach: "Doch ebenso, wie ich dies zu Recht beklage, höre ich gern damit auf, da es weder zu meiner Liebe zu Euch passt, meinen Kummer zu verschweigen, noch zur Freundschaft, das Maß des zugefügten Kummers zu überschreiten« $(\$ 2) .{ }^{793}$

Ein anderes Mal erhält Ausonius selbst von Symmachus ein Gratulationsschreiben, obwohl er Symmachus noch nicht informiert hat. Symmachus beginnt mit einer Reflexion über die Fortuna, die im Fall des Ausonius begründet gehandelt habe: "Zu Unrecht denkt man, Fortuna könne keine begründeten Urteile fällen; denn sie hat - im Gedenken an die Vergangenheit, in Fürsorge für die Gegenwart, in Voraussicht für die Zukunft - Dir <sc. als Dir zustehend> wiedererstattet, was sie anderen $<$ sc. lediglich> geschenkt hat. Sie ist also nicht plan- und ziellos, da wir wissen, dass andere von ihr ein Geschenk bekommen haben, Du aber eine Belohnung. " Dann wird deutlich, dass Symmachus auf eine Erfolgsmeldung reagiert, die er nicht von Ausonius selbst bekommen hat: "Wer, so wirst Du fragen, hat Dir von meiner Ehrung berichtet? Das Gerücht in aller Munde, dem man sofort glaubt, wenn es Berechtigtes erzählt. "Symmachus schreibt es der verecundia des Ausonius zu, dass er nicht geschrieben habe: ${ }^{794}$ "Oder hätte ich auf Deinen Brief darüber warten sollen, den Du aus Zurückhaltung aufschobst? Keineswegs; denn es ist schwierig, in der Freude geduldig zu sein. "Und er schließt humorig: "Ich übernehme also, wie Du siehst, Deinen Part, und ich wollte das, was ich hätte erfahren sollen, lieber auf irgendeine Weise mitteilen. Aber ich möchte nicht, dass diese Eile meines Briefs Deinen Brief aufhält. Tu so, als ob ich nicht wüsste, was ich hier schreibe, und teile es mir wie eine neue Nachricht mit, zu der ich bei der Wiederholung gratulieren werde« $($ Sy. 1,38$) .{ }^{795}$

792 (Sy. 1,16,2) scriptis debuit famam praevenire, quae diu incerta fluxam fidem gaudiis exhibebat.

793 (Sy. 1,16,2) verum ego, ut religiose ista conqueror, ita libenter omitto, quia nec amori in vos meo convenit silere, quod doleam, nec amicitiae incussi doloris transire mensuram.

794 Auch in anderen Fällen bedenkt Symmachus die verecundia des Adressaten: (Sy. 9,91) »Ich durfte nicht Deinen Brief abwarten, mit dem Du mir Deine Ehrung mitteilen würdest. Daher komme ich Deiner Zurückhaltung mit meiner Gratulation voraus«, Expectare non debui litteras tuas, quibus indicium mihi faceres honoris accepti. itaque verecundiam tuam gratulatione praevenio [...] «. Siehe auch Sy. 7,110.

795 (Sy. 1,38,1) Falso creditur nesciam iudicii esse fortunam; illa vero et praeteritorum memor et praesentium diligens et prudens futuri tibi rependit, quidquid ceteris praestitit. non ergo vaga neque erratica est, a qua scimus alios donum cepisse, te praemium. quis tibi honoris, inquies, nostri fecit indicium? celebritas famae, cui iusta narranti statim creditur. an op- 
Auch in anderen vergleichbaren Fällen findet Symmachus mit einem Lächeln eine versöhnliche Wendung: Einen Brief, in dem er sich darüber beklagt, nicht durch einen Brief vom Adressaten über die Hochzeit von dessen Sohn informiert worden zu sein, beginnt er damit, dass es verständliche Gründe dafür gebe, dass sie so selten Briefe austauschten. Dann kommt er auf die Hochzeit zu sprechen: »Doch Du wirst Dich nicht ebenso leicht $<$ sc. wie für die Seltenheit von Briefen $>$ dafür entschuldigen können, dass ich von der Hochzeit unseres lieben Minervius durch den Bericht anderer statt durch einen Brief von Dir erfahren habe. Oder hast Du befürchtet, dass ich von Dir eine geprägte Goldmünze <sc. als Geschenk> erwarten würde? Meine Zurückhaltung hätte beim Ausbleiben eines Geschenks schweigen können, aber meine Freundschaft kann die Verweigerung einer Freude nicht verzeihen.« Doch Symmachus nennt sofort selbst eine Möglichkeit, wie der Adressat dies wieder gutmachen könne: »Und dennoch - wohlwollend wie ich meinen Freunden gegenüber bin - verspreche ich Dir, dieses Vergehen nachzusehen, wenn Du nach der Geburt eines Enkels mit einem Brief die Gerüchte an Geschwindigkeit übertriffst« (Sy. 4,55) ${ }^{796}$

Auch Ennodius schreibt in solchen Situationen, wenn er vom Erfolg des Adressaten nicht durch eine Mitteilung von diesem selbst, sondern nur gerüchteweise erfahren hat $(18 ; 224 ; 455 ; 321 f$.$) . Er scheint es geradezu darauf anzulegen, der Mitteilung des$ Adressaten zuvorzukommen, um die Situation ausnutzen und diesen tadeln zu können; in einer anderen Situation wirft er es einmal seinerseits dem Adressaten vor, diese Strategie zu verfolgen: praevenitur querelis innocentia (251,2, siehe oben 324). Während Symmachus zwar tadelnd auf die vom Adressaten nicht eingehaltene Konvention verweist, aber entweder eine witzige Wendung oder eine ehrenvolle Entschuldigung findet, zeigt sich Ennodius kaum zur Nachsicht bereit. Wenn er dennoch einmal einige lobende Worte findet, bricht er sie schnell wieder ab, und meistens zeigt erst eine versöhnlichere abschließende Grußformel, dass es doch nicht ganz so böse gemeint war, sondern es letztlich darum ging, die aktuelle Situation rhetorisch auszunutzen, d.h. etwas Unerwartetes und der Konvention Widersprechendes zu schreiben, die rhetorica versutia zu zeigen.

perirer super hoc tuas litteras, quas verecundia differebat? minime; siquidem difficilis est patientia gaudiorum. fungor igitur, ut vides, partibus tuis, et quae debui cognoscere, malui quodammodo nuntiare. sed nolo ista properatio litterarum mearum tuum munus inpediat. scire me, quod nunc scribo, dissimula, et tribue quasi novum nuntium, quem ego gratulabor iteratum.

796 (Sy. 4,55) [...] non eadem tamen facilitate purgabis, quod filii nostri Minervii nuptias aliorum potius relatu quam litteris tuis conperi. an veritus es, ne a te nomisma auro cusum desiderarem? potuit iacturam sportulae tacere verecundia mea, negationem gaudii amor nescit ignoscere. et tamen, ut sum placido in meos animo, spondeo remissionem tibi huius offensionis, cum de nepote suscepto anteveneris scripto nuntiorum celeritatem. 
So schreibt Ennodius z.B. an Agapitus (18; er erhält fünf weitere Briefe), der ein (nicht bezeichnetes) hohes Amt in Ravenna erlangt (cf. ScHÄFER 1991, 10-13; PLRE II, 30-32: "Agapitus 3") und ihn nicht davon unterrichtet hat. Ganz anders als Symmachus, der in einer vergleichbaren Situation mit dem Glückwunsch beginnt und seine Erwartungshaltung am Ende witzig wendet, beginnt Ennodius den Brief mit vorwurfsvollen Worten: »Mir ist nicht wohl zumute, seit Deine Hoheit, die < doch sonst> genau weiß, was sich gehört, und an Freundschaften festhält, sich dahin verändert hat, nachlässig zu sein und nicht mehr an mich zu denken, so dass sie die Freundschaft vergaß und das Gute einer besseren Zeit, das durch den Fortschritt Deiner Ehren eingetreten ist, lieber durch das Hörensagen als durch einen glücklichen Brief melden ließ « $(18,1),{ }^{797}$ Nach weiteren Klagen und der Vermutung, dass jemand einen Keil zwischen die beiden getrieben haben müsse ( $\$ 2$ mit Zitaten aus Verg. ecl. 2,58, georg. 4,10), und der Feststellung, dass Agapitus diese Unterlassung mit Worten nicht wieder werde gutmachen können $\left(\$_{2} f_{\text {. }}\right)$, ruft sich Ennodius sein propositum vor Augen $\left(\$_{3}\right)$. Doch anders als man vielleicht erwarten könnte, bringt der Gedanke an das propositum ihn nicht dazu, seine harten Worte zurückzunehmen oder eine Entschuldigung für das Verhalten des Adressaten zu finden: Er führt vielmehr zu der Einsicht, wem es zu verdanken sei, dass er von Agapitus' Erfolg erfahren habe: "Doch ich besinne mich auf meine Vorsätze, von denen man, wenn sich die Gottheit erbarmt, niemals abweichen darf: Ich verdanke es Gott, dass ich von Deinem Glück trotz Deines Schweigens als erster in Ligurien erfahren habe. Du bist um den Ertrag Deines eifrigen Schweigens gekommen $\left(\$_{3} f\right) .{ }^{798}$ Es folgen Sentenzen zu dem Thema, dass Erfolg nicht geheim bleiben kann: »Das Glück der Guten wird von der Zunge der Welt gepriesen; was den Höchsten geschieht, kann nicht unbekannt bleiben « $(18,4) .{ }^{799}$ Unvermerkt geht Ennodius in lobende Worte über: "...] diese altehrwürdige Ehre kommt spät, aber verdient. Gerufen wurde sie <sc. die Ehre > von Eurer Redekunst, der sie <sc. die Ehre> folgt; gefordert wurde sie <sc. die Ehre> von Eurer Integrität, mit der sie einst in der goldenen Zeit verbunden war “ $(18,4) .{ }^{800}$ Schnell bricht Ennodius das begonnene Lob ab: "Doch ich bin schon wieder beim freundlichen und vertrauten Ton, auch nach der Kränkung. Leb wohl, mein Herr, und mach durch

$797(18,1)$ Male est animo, postquam magnitudo tua aequi observantissima et amicitiarum tenax in hanc meae oblivionis se vertit incuriam, ut diligentiae inmemor bona melioris saeculi, quae adcesserunt de profectu honorum tuorum, fama potius quam felici epistula nuntiasset.

798 (18,3f.) sed revertor ad propositum, a quo numquam est, si miseretur divinitas, discedendum: deo debeo, quod prospera tua te silentium procurante in Liguria primus agnovi. perdidisti fructum studiosae taciturnitatis. [Nach discedendum besser ein Doppelpunkt statt des Punktes bei Vogel.]

$799(18,4)$ bonorum felicitas mundi lingua celebratur; ignorari non potest quod summis accesserit. $[\ldots]$

$800(18,4)[\ldots]$ venit ad vos cana dignitas sera, sed debita. vocavit eam lingua, quam sequitur; exegit innocentia, quam habuit aurea quondam aetate coniunctam. 
reichhaltige Briefe wieder gut, was Du zum Schaden des versprochenen Bundes vernachlässigt hast« $(18,5){ }^{801}$ - Agapitus in seiner Situation dürfte wohl kaum einen so vorwurfsvollen Brief erwartet haben, zumal er ja offenbar noch niemandem in Ligurien von seinem Erfolg berichtet hatte: Ennodius bezieht sich auf Gerüchte, durch die er ausdrücklich als erster in Ligurien davon erfahren habe. Dies ist nicht das einzige Schreiben an Agapitus, das durch Inhalt und Gedankengang verblüfft (siehe zu 122 unten 368).

Einen indignierten Brief (224) statt eines Glückwunsches zum erlangten Amt bekommt auch Petrus (cf. PLRE, s.v. »Petrus 28«, p.871; SCHÄFER 1991, 96f.; dies ist der einzige Brief an ihn). Ennodius beginnt mit Vorwürfen: »Seit Dir nach einer Prüfung des Charakters Deiner Hoheit die Beurteilung des ehrwürdigen Princeps für Deine reichen und reifen Qualitäten einen Spross der Ehren geschenkt hat, hast Du durch Ferien vom Reden ungebührliches Schweigen gepflegt und so sowohl gegen Deine Beredsamkeit als auch gegen meine Freundschaft gesündigt, denn Beredsamkeit, die < bereits> durch ihre natürlichen Gipfel stark ist, wächst <noch>, sooft sie der Anzeige von Erfolg dient « $(224,1){ }^{802}$ Petrus habe sich eine Gelegenheit entgehen lassen, seine Beredsamkeit zu zeigen: "Siehe: Dein unerfreuliches Schweigen hat Euch um den Glanz der Rede gebracht und mir die Freude als Ergebnis <der Rede> vorenthalten “ $(\$ 2) .{ }^{803}$ Dem möglichen Einwand des Petrus, dass Ennodius sich nicht beklagen könne, über ihn nicht informiert zu sein, da doch Fama alles berichte $(\$ 2)$, begegnet Ennodius: »Doch ich kann es nicht ertragen, vom Aufstieg meiner Freunde nur gerüchteweise zu hören und mir aus unsicheren Meinungen sichere Freude erschließen zu müssen « $(224,2) .{ }^{804}$ Nach weiteren Klagen und Vorwürfen folgen etwas versöhnlichere Worte: »[...] nachdem Du die Ursachen für meinen Kummer erfahren hast, wirst Du mir schnelle Abhilfe nicht verweigern, da Euch, wie ich vermute, weder die Treue in der Freundschaft fehlt noch die bis aufs letzte ausgefeilte Sprache im Gespräch « $(224,4){ }^{805}$ - Es folgt noch ein zweiter Teil des Briefs mit einem Gedicht auf die heißen Quellen des Flusses Aponus. Aus der Vorrede zu dem Gedicht geht her-

$801(18,5)$ sed iam redeo ad gratiam familiaris alloquii etiam post offensam. salve, mi domine, et quod in damno promissi foederis neglexisti, restitue ubertate sermonis.

$802(224,1)$ Postquam venerabilis iudicium principis periclitatis moribus magnitudinis tuae donavit te honorum germine pro messe virtutum, per linguae ferias fovens inreligiosa silentia et in eloquentia tua et in meo amore peccasti, quia naturalibus adolescit elocutio munita superciliis, quotiens prosperorum famulatur indicio. [...]

$803(224,2)$ ecce inamabilis taciturnitas et vobis dicendi abstulit genium et mihi laetitiae invidit effectum. [...]

$804(224,2)[\ldots]$ sed ego agnoscere carorum culmina rumore non patior et manifesta gaudii colligere de opinionis inconstantia.

$805(224,4)[\ldots]$ agnitis dolorum causis remedia properata non deneges, quia, quantum praesumo, nec fides in diligentia nec ad unguem ductus sermo vos deserit in loquella. 
vor, dass sich Petrus am Aponus befindet, wo er sowohl das Essen als auch die Bäder genießt. Ennodius fordert den Adressaten auf, dieses Gedicht nur selbst zu lesen und nicht zu verbreiten: "Hier ist also ein Gedicht, das Dich zum Lachen bringen wird; gib Dich damit zufrieden, dass nur Du Deinen schlechten Dichter erkennst und setze mich nicht der allgemeinen Strenge aus; denn wenn etwas an dem Gedicht vielleicht gefällt, dann reicht mir Eure Meinung; wenn etwas Kritik verdient hat, dann glaube ich, dass sicher verborgen bleibt, was Du von den Sünden Deines Freundes weißt « $(224,5) \cdot{ }^{806}$ Dies sollte man angesichts von Ennodius' Situation wohl durchaus ernst nehmen und nicht als >Bescheidenheitstopos ‘ bzw. als Aufforderung zum Gegenteil verstehen. Ennodius wird nicht jemandem ein Gedicht gesandt haben, den er nicht gut kannte, sondern nur jemandem, von dem er wusste, dass dieser nicht sorglos damit umgehen würde. Von Petrus erfahren wir zwar nur in diesem einen Brief, doch wenn jemand nur wenige Briefe erhält, kann das bedeuten, dass Adressat und Verfasser überwiegend am gleichen Ort sind.

Aurelianus, ein in Gallien lebender (cf. 412,3) Verwandter des Ennodius (cf. 455,2 propinquitatis privilegia), dürfte ebenfalls Glückwünsche erwarten, denn er ist zum Bischof gewählt worden ( $\$ 2$ postquam pater esse meruisti; $\$ 3$ evectionem meriti vestri; $\$ 4$ apicem ecclesiastici honoris ascendit); um welchen Bischofssitz es sich handelt, ist unbekannt, doch es wird vermutet, dass er in der von den Ostgoten beherrschten Provence lag (cf. PLRE II, p. 200: »Aurelianus 8«). Der Brief (455) beginnt allerdings in einem Ton, den Aurelianus in dieser Situation wohl nicht erwartet hätte, mit Klagen über dessen Schreibfaulheit: »Ich schulde zwar meinem Kummer eine Stimme, doch Euch, Verehrter, Schweigen. Und vielleicht würde stumme Verstellung meinen Kummer über Eure Enthaltsamheit im Schreiben besser ausdrücken. Denn es wäre feiner und hoher Stil, wenn die Vergehen Höherer mit den gleichen Mitteln bestraft würden, mit denen mir Unrecht getan wird, so dass die Schuld die Rache in sich trüge" $(\$ 1){ }^{807}$ Dass es neben Schweigen oder Klagen durchaus noch eine dritte Alternative gäbe, wie sie bei Symmachus zu lesen ist, nämlich: Nachsicht zu zeigen und freudig zu gratulieren, blendet Ennodius völlig aus. In den folgenden Sätzen verweist er auf die Problematik seiner Situation und auf seine Furcht zu missfallen, wobei er noch weitere Vorwürfe formuliert, die mit der Schreibfaulheit eng verbunden sind bzw.

806 (224,5) accipe ergo risum motura poemata et Glovidenum tuum te solum agnovisse contentus a publico rigore me subtrahe, quia, si est quod forte placeat, sententia mihi vestra sufficit, si quod morsu dignum sit, secretum puto quod de amici culpis agnoveris. - Der schlechte Dichter, der bei Juvenal 1,80 Cluvienus heißt, erscheint bei Ennodius noch in $(26,3)$, cf. den Kommentar von VANDONE.

807 (455,1) Debeo equidem dolori meo vocem, sed reverentiae vestrae taciturnitatem. et forte melius maerorem de abstinentia sermonis vestri loqueretur muta dissimulatio. urbanum enim et subtile erat, ut isdem lineis, quibus in me delinquitur, potiorum delicta ferirentur, ut secum haberet culpa vindictam. 
aus denen diese resultiert: "Doch was soll ich tun, der ich nicht aufhören kann, einen, der nicht an mich denkt und der die Bekanntschaft mit Niedrigeren ablehnt, mit hartnäckiger Zuneigung zu verfolgen? Ist die Dreistigkeit eines Verschmähten etwa nicht ein Ursprung der Ablehnung, wenn der Wunsch zu gefallen durch die Beharrlichkeit Gründe des Missfallens hervorbringt? Denn das, wovor die Seele flieht, sieht man nicht, wenn es sich vor die Augen drängt “ $(455,1) .{ }^{808}$ Nun erst kommt ein Hinweis, dass Ennodius von Aurelianus' Wahl zum Bischof weiß: »O wenn ich mich doch mit Dir, Seliger, noch von gleich zu gleich auseinandersetzen könnte! Doch bei Dir, Höchster, ruhen die unter Verwandten bestehenden Vorrechte, seit Du Bischof geworden bist « $(\$ 2) .{ }^{809}$ Es sei - behauptet Ennodius - noch nie vorgekommen, dass jemand aufgrund von Erfolg seine Verwandten vergessen habe: „Erinnert sich irgendjemand daran, dass durch Erfolge die Rechte der Verwandtschaft vergehen und dass durch den Antritt eines frommen Amtes die Bande von Verwandtschaft und Freundschaft gelöst werden? « $\left(\$_{3}\right) .{ }^{810}$ Ennodius klagt, dass er von der Wahl nur gerüchteweise gehört habe: »War es also richtig, dass ich von Deiner Erhebung, Verdienstvoller, durch unsichere Gerüchte erfahren habe und dass ich mich bis jetzt damit zufrieden geben muss, hinsichtlich der allgemeinen Freude vom Hörensagen abhängig zu sein? Ich wurde ausgewählt, vom allgemeinen Glück nichts zu erfahren, so dass ich von einem Ereignis eines goldenen Zeitalters aufgrund des Dunkels meines Herzens als einziger nichts weiß. Ein Mann von edler Lebensweise und Herkunft besteigt den Gipfel der kirchlichen Ehre, und er würdigt mich nicht eines Briefs « $(\$ 3 f.) .^{811}$ Der Brief endet in diesem vorwurfsvollen Ton, ohne jegliche versöhnliche Note: »So etwas - egal, ob es aus Absicht oder durch Unachtsamkeit geschehen ist, - kann man nicht billigen. Doch ich schicke gehorsamste Grüße und mache mit italischer Einfachheit ohne Verstellung deutlich, warum ich bekümmert bin« $(455,4) .{ }^{812}-$ Es fällt auf, dass Ennodius in diesem Brief nicht am Ende noch einlenkt, um zu zeigen, dass der

808 (455,1f.) sed quo me vertam, qui inmemorem mei et humilium notitiam respuentem pertinacia amoris insequi non desisto? $(\$ 2)$ numquid non repudiati inportunitas mater horroris est, cum placendi per adsiduitatem desiderium materiam exigat displicendi? nam quicquid mente fugimus, ingestum oculis vix videmus.

809 (455,2) o si mihi liceret adhuc aequali cum beatitudine tua sorte contendere! sed dormiunt apud coronam tuam propinquitatis privilegia, postquam pater esse meruisti.

$810(455,3)$ retinet quisquam hominum perire suis iura necessitudinis incrementis et adcessione piae dignitatis et generis et diligentiae vincla dissolvi?

811 (455,3f.) ergo decuit evectionem meriti vestri instabili mihi esse rumore conpertam et de communibus gaudiis adhuc pendere opinione contentum? electus sum, cui bonum generale taceretur, ut rem aurei saeculi solus pro conscientiae meae obscuritate nescirem. (\$4) nobilis vita vel genere apicem ecclesiastici honoris ascendit, et me dedignatur adloquio.

$812(455,4)$ vere tale factum, aut studio aut neglegentia evenerit, non probatur. ego tamen servitia salutationis inpendo et Italica simplicitate, unde tristitiam habuerim, sine dissimulatione manifesto. 
vorwurfsvolle Ton nur eine Pose ist (siehe oben 252, 285). Ungewöhnlich ist auch, dass er seine Ablehnung der dissimulatio $(\$ 1 ; \$ 4)$ bzw. seine Forderung nach simplicitas hier nicht auf sein propositum zurückführt (siehe oben 226f.), sondern die unterschiedlichen Haltungen mit dem jeweiligen Wohnort begründet: Er beruft sich gegenüber dem gallischen Bischof auf seine Italica simplicitas und betont so wie auch im Brief an Pomerius (siehe oben 191f.) die Unterschiede zwischen Italien und Gallien. Wenn er hier den vorwurfsvollen Ton bis zum Ende durchhält, ist dies ein Hinweis auf sein gespanntes Verhältnis sowohl zu manchen Galliern als auch zu einigen seiner (teils mit diesen identischen) Verwandten.

Agnellus erhält anlässlich der Berufung in ein Amt gleich zwei Briefe (321f.; siehe auch zu 309 oben 227, zu 316 o. 219, zu 443 o. 308). Es handelte sich entweder um das Amt des Magister officiorum oder das des Comes sacrarum largitionum (cf. PLRE II,35; SCHÄFER 1991, 14). Eine Formulierung im zweiten Brief könnte angesichts von Ennodius' grundsätzlicher Sorgfalt bei der Wortwahl auf das letztere anspielen: Er schreibt über die Redekunst des Agnellus, dass er "die Prägestätte der lateinischen Redekunst" innehabe (322,2 monetam Latiaris eloquentiae teneas), und dem Comes sacrarum largitionum, dem Finanzminister, unterstanden u.a. die Leiter der Münzstätten. Ennodius gebraucht moneta insgesamt nur noch einmal, ebenfalls metaphorisch, im Brief an Dominator, dem er ausdrücklich auf Bitten des Agnellus schreibt (155, siehe oben 314 ).

Im ersten Brief, an dessen Ende der Überbringer empfohlen wird, deutet Ennodius nur an, dass er etwas wisse, was Agnellus noch für sich behalte; er macht ihm aber keine Vorwürfe, sondern schreibt sehr freundlich, dass Agnellus die Ehren verdient habe und er sich darüber freue. Im zweiten Brief wirft Ennodius ihm dann direkt vor, ihm nicht davon geschrieben zu haben. Der erste, sehr freundliche Brief (321) beginnt mit einer Einleitung darüber, dass Agnellus' Wünsche zwar spät, aber verdient erfüllt würden: »Dank sei Gott, der hinsichtlich Eurer Hoheit die Erfüllung der Wünsche zwar aufgeschoben, aber nicht abgeschlagen hat. Denn damit das Vertrauen des Bittenden nicht wankt, wird die Erfüllung von Wünschen aufgeschoben, da eine schnelle Erfüllung den wahren Glanz der folgenden Freude entstellt. ${ }^{813}$ Und es ist deutlich, dass Ihr Ehren zwar verdient, aber nicht ersehnt habt « $(\$ 1) .{ }^{814}$ Doch dann betont Ennodius, dass es sich hierbei vorerst noch um Wunschdenken handle bzw. dass er vorgegriffen habe auf etwas, das Agnellus selbst noch nicht öffentlich mache: "Doch diese vorangehende Einleitung drückt die Wünsche der Freunde aus. Der Allmächtige weiß: Mich hat der strahlende Ruhm Eurer Familie

813 Der gegenteilige Gedanke in $(305,1)$, siehe oben 299.

814 (321,1) Deo gratias, qui circa magnitudinem vestram licet protulerit cupita, non reppulit. etenim ne fides claudicet supplicantis, desideria differuntur, quia devenustat secuturae hilaritatis genium velox impetratio. et vos quidem honores meruisse, non optasse manifestum est. 
veranlasst und das Vertrauen auf die Gunst, die Ihr versprochen habt, ermuntert, bei Eurem Glück vorwegzunehmen, was immer Ihr aus Selbstbeherrschung oder Überlegung zurückhaltet « $(\$ 1) .{ }^{815}$ Abschließend empfiehlt Ennodius den Überbringer des Briefs: "Möge an der Schwelle <zum Amt> ein kurzer Brief reichen. Antwortet dem, der über Euer Wohlergehen besorgt, doch über die Freundschaft nicht im Zweifel ist. Mein Herr, ich erweise Euch meine herzlichsten Grüße und empfehle den Überbringer des Briefs, weil mir seine Zuverlässigkeit und Ehrenhaftigkeit bekannt sind, in dem Wunsch, dass der Allgemeinheit nicht verschwiegen wird, wie groß Eure Gunst mir gegenüber ist, so dass die, die darauf hoffen, von der Ernte der gemeinsamen Freundschaft ernährt werden « $(\$ 2){ }^{816}$ Dieser Wunsch dürfte bedeuten, dass es sich herumsprechen wird, wenn diese Empfehlung des Ennodius bei Agnellus erfolgreich ist, und dass er mit vielen weiteren Bitt- und Empfehlungsbriefen an diesen in dem neuen Amt Erfolg haben möchte. Dies ist einer der seltenen Fälle, wo Ennodius andeutet, dass es sein eigenes Prestige steigert, wenn er an bestimmte Adressaten Empfehlungen richten kann (siehe unten 358); allerdings verbindet er dies unmittelbar damit, dass viele davon profitieren werden.

Dass Agnellus nicht geantwortet hat, geht aus dem nächsten Brief an ihn hervor (322). Die Praefatio (zitiert oben 253) legt dar, dass üblicherweise von erfreulichen Ereignissen immer sofort berichtet werde. Doch Agnellus halte die frohe Kunde zurück und schade damit der Freundschaft: »Doch Eure Hoheit beschränkt die Freude mit den Zügeln der Mäßigung in dem Maße, wie Euer Alter durch die altehrwürdigen Gaben des Anstandsgefühls und der Bildung reift. Doch muss etwa die Selbstbeherrschung zum Schaden der Freundschaft ausgehen und das der Freundschaft abgezogen werden, was zum Schmuck des Charakters hinzukommt? « (\$2). ${ }^{817}$ Mit all seiner Redekunst werde Agnellus sich nicht für sein Verhalten entschuldigen können: „Obwohl Du die Prägestätte der lateinischen Redekunst besitzt, kannst Du doch nichts ausdenken, wie Du behaupten könntest, dass mit Recht geschehen sei, dass Du mir Wartendem nicht schreibst. Ist es also richtig, dass die himmlischen Wohltaten Freunden nur durch Gerüchte gemeldet werden und dass der, der sich schon freut,

$815(321,1)$ sed praecedens concinnatio eloquitur vota diligentum. novit omnipotens, et generis vestri luce permotus et gratiae quam polliciti estis invitatus fiducia praecessi in prosperis vestris, quicquid vos disciplina aut ratione cohibetis.

$816(321,2)$ sufficiant in foribus stricta conloquia. respondete de prosperitate vestra sollicito, quamvis de amore non dubio. domine mi, salutationis plenissimae obsequia dependens litterarum portitorem commendo, quia mihi fide et honestate conpertus est, volens universis quid dignationis vestrae habeam non taceri, ut sperantes de communis gratiae messe pascantur.

$817(322,2)$ sed in magnitudine vestra sicut aetas cana est pudoris et scientiae dote maturescens, ita laetitiam frenis moderationis adstringitis. sed numquid in damnum gratiae disciplina debet excurrere et hoc minui amicorum diligentiae, quod ad morum ornamenta sociatur? 
nicht richtig zu gratulieren wagt?« $(\$ 2 f.) .{ }^{818}$ Nach diesen Vorhaltungen lenkt Ennodius ein mit dem Hinweis auf seine Zuversicht, doch noch einen Brief zu erhalten: "In dieser Notlage habe ich einen Diener geschickt, der einen Brief nicht fordern, sondern erlangen soll. Du kennst die Zuversicht einfacher Freunde, besonders derer, deren Hoffnung Ihr, wie Ihr Euch erinnert, durch das Versprechen Eurer Gunst gestärkt habt. Mein Herr, ich grüße herzlich und bitte, dass Ihr viele und nicht kurze Briefe schreibt. Seht die Zuversicht meiner Seele: Ich erbitte lange Briefe, der ich bis jetzt gar keinen bekommen habe $\ll\left(\$_{3} f.\right){ }^{819}$ - Diese beiden Briefe an Agnellus sind unter denen, die in vergleichbarer Situation geschrieben wurden, diejenigen mit den wenigsten Vorwürfen. Ennodius zeigt im ersten Brief mit sehr freundlichen Worten, dass er schon Bescheid weiß; im zweiten macht er deutlich, dass er sich schlecht behandelt fühlt, doch am Ende schreibt er von der ihm versprochenen gratia und von seiner Zuversicht.

Es lässt sich also beobachten, dass Ennodius unterschiedliche Strategien verfolgt, wenn er einem Adressaten vorwerfen möchte, dass dieser ihn nicht über Erfolge informiert habe: vorwurfsvoller Ton bis zuletzt (an Aurelianus), zunächst ein sehr freundlicher Brief (an Agnellus), Einlenken am Ende nach Vorwürfen (an Agapitus, Petrus, Agnellus). So ergeben sich Anhaltspunkte für sein Verhältnis zu den Adressaten: Gegenüber Aurelianus scheinen die Vorwürfe ernst gemeint zu sein, was ein weiteres Indiz für Ennodius' gespanntes Verhältnis zu Gallien und zumindest zu Teilen seiner Verwandtschaft sein dürfte. Von Agapitus und Petrus erwartet er, dass sie seine rhetorica versutia verstehen (und schätzen) und ihm die Vorwürfe nicht übelnehmen; sie scheinen sich also recht gut zu kennen. Die Beziehung zu Agnellus scheint weniger eng zu sein, denn ihm gegenüber ist er vorsichtiger; dieser hat ein hohes Amt erlangt, und Ennodius möchte seine Beziehung zu ihm nutzen.

In diesen Briefen an Agapitus und Petrus etc. kann Ennodius sich mehr oder weniger vorwurfsvoll geben, weil er der entsprechenden Information vom Adressaten zuvorkommt. Doch auch wenn er vom Korrespondenten selbst informiert wurde, ist der Ton seines Glückwunschschreibens nicht unbedingt freudig und lobend. Er nutzt vielmehr die Gelegenheit, den Adressaten davor zu warnen, durch den Erfolg arro-

818 (322,2f.) quamvis monetam Latiaris eloquentiae teneas, non potes tamen invenite quemadmodum iure factum adseras, quod expectanti mihi verba non tribuis. (\$3) decet ergo beneficia superna sola amantibus opinione nuntiari et de solida gratulatione trepidare gaudiis iam potitum?

819 (322,3f.) hac ego necessitate puerum direxi, qui non reposcat scripta, sed exigat. nostis quae sit fiducia simpliciter amantum, eorum praecipue, quorum spem retinetis gratiae promissione firmatam. (\$4) domine mi, salutationem plenissimam dicens quaeso, ut et frequentes et non in artum coactas epistolas destinetis. videte animi mei securitatem: prolixas posco paginas, qui adhuc nullas accepi. 
gant zu werden und die alten Freunde wie ihn selbst zu vergessen. Auch hier zeigt sich wieder, dass Ennodius Elemente, die sich bei Symmachus vereinzelt oder knapp angedeutet finden, in ihrer Bedeutung verstärkt, breiter ausführt oder gar zum Prinzip macht: Symmachus schreibt nur indirekt, dass die Karriere einen schlechten Einfluss auf das (Schreib-)Verhalten des Adressaten haben könnte - bei Ennodius wird daraus eine strenge Ermahnung, die in der Situation, dass ein Glückwunsch erwartet wird, besonders auffällt.

Bei Symmachus findet sich der Gedanke, dass eine erfolgreiche Karriere negativen Einfluss auf die Haltung des Adressaten haben könnte, einmal in einem Brief, der aber wohl nicht zu Beginn der Amtszeit des Adressaten verfasst wurde: »Ich weiß sicher, dass Du Dich durch eine Spitzenstellung nicht zu verändern pflegst [...].« Deshalb sei er verwundert: "und daher muss ich gestehen, dass ich mich überaus wundere, dass $\mathrm{Du}$ - bei solchen Qualitäten und solcher Freundlichkeit - Dich schon so lange im Schreiben an mich zurückhältst.« Symmachus kennt zwar die Gründe, bittet aber dennoch um Briefe: »Wenn ich auch denke, dass dies eher wegen der vielen Beschäftigungen als absichtlich geschehen ist, höre ich dennoch nicht auf zu bitten $[\ldots]$ « (Sy. 8,1). ${ }^{820}$ - Doch auch in einem Glückwunschschreiben deutet Symmachus an, dass die Karriere negativen Einfluss haben kann, allerdings hier nicht mit Bezug auf das Verhalten in der Korrespondenz. In diesem kurzen Brief betont Symmachus zunächst, dass sich die Allgemeinheit freuen könne, dass der Adressat das Amt erhalten habe; doch er wolle seine Freude nicht ausführlich beschreiben, um nicht in den Verdacht der Schmeichelei zu geraten (ne adulationis suspicio devenustet iudicii veritatem); er hoffe also, dass der Adressat an dem Amt Gefallen finde, "wobei ich nicht daran zweifeln kann, dass Anständigkeit unveränderlich ist [...] « (Sy. 8,30) ${ }^{821}$ - Ein weiteres Glückwunschschreiben nutzt Symmachus zu einer Ermahnung anderer Art. Nachdem er seiner Freude Ausdruck verliehen hat, spornt er den Adressaten an, sich diesem Erfolg entsprechend anzustrengen: Da sich dies also nach dem Wunsch aller ergeben hat, gib Dir Mühe entsprechend der Einschätzung des Herrschers <sc. der Dich des Amtes für würdig befunden hat $>$. Dich drängt die Erwartung, die immer auf Guten lastet [...]. Du lebst in einer Zeit, die guten Eigenschaften freund ist, in der es die Schuld des Einzelnen ist und nicht die der Umstände, wenn sich nicht jeder wirklich Gute Ruhm erwirbt [...] « (Sy. 3,43,1f.). ${ }^{822}$

820 (Sy. 8,1) Conpertum habeo, quolibet honorum culmine animum tuum non solere mutari [...], et ideo mirari me ac stupere confiteor, cur tanta virtute atque humanitate praeditus iampridem circa me munere litterarum abstineas. quod ego etsi occupatione magis quam voluntate arbitrer accidisse, tamen orare non desino [...].

821 (Sy. 8,30) [...] dubitare non possim, neque mutari posse probitatem et bonas artes stimulo praemiorum felicius incitari.

822 (Sy. 3,43,1f.) [...] ergo quia res sese ex voto omnium dedit, perage operam iudicio tanti principis congruentem. urguet te expectatio bonis semper onerosa $[\ldots] .(\$ 2)$ habes saeculum virtuti amicum, quo nisi optimus quisque gloriam parat, hominis est culpa non temporis [...]. 
Ennodius verbindet in einem Brief (125) den Gedanken, dass Erfolg schlechten Einfluss haben könne, mit einer ausführlichen Ermahnung; allerdings ermahnt er nicht wie Symmachus dazu, das Amt erfolgreich auszuführen und Ruhm zu erwerben, sondern ausschließlich dazu, nicht arrogant zu werden und die alten Freunde zu vergessen. Aus einem Brief an Iulianus (cf. PLRE II, 640f.: »Iulianus 24 «; SCH ÄFER 1991, 77f.; er erhält zwei weitere Briefe), der als Comes patrimonii tituliert ist (Verwalter des Privatbesitzes), geht hervor, dass er erst kürzlich in dieses Amt aufgestiegen ist. Ennodius reagiert in diesem Brief offenbar erstmals auf diese neue Situation. Es ist daher anzunehmen, dass Iulianus in dem Brief, auf den Ennodius hier antwortet $(\$ 1$ suscepi litteras), von seiner erfolgreichen Karriere berichtet hat, so dass er wohl ein Glückwunschschreiben erwarten dürfte. - Ennodius beginnt den Brief in lobenden Tönen mit seiner Freude über den erhaltenen Brief und über die Wohltaten Gottes; wieder verwendet er das Motiv des 'Selbstbezugs` (siehe oben 235), indem er auf die Diskrepanz zwischen seinen eigenen geringen Verdiensten und den reichen Gaben Gottes für den Adressaten hinweist: »Ich habe Euren in zweifachem Glanz erstrahlenden Brief erhalten, dessen Wert die hohe Stellung des Schreibenden in Verbindung mit Eurer Freundlichkeit vermehrte, und ich danke Gott dem Allmächtigen, der meine mageren Wünsche mit reichlicher Wohltat übertrifft, dass er, wenn wir - im Bewusstsein unserer Unzulänglichkeit - nur begrenzte Wünsche haben, die Fülle seiner reichen Güte nicht zügelt “ $(\$ 1) .{ }^{823}$ Dann allerdings wird deutlich, dass sich Ennodius' Wünsche und sein Dank an Gott gar nicht auf das neue Amt des Iulianus beziehen, sondern auf die Tatsache, dass dieser einen langen und beeindruckenden Brief geschrieben hat; um nicht explizit seine Freude über das Amt auszudrücken, formuliert Ennodius sozusagen sstellvertretend` dafür seine Freude über den Brief: »Ich dachte, es sei genug, wenn Ihr mich mit einem großartigen Brief auszeichnet. Doch Ihr, nicht zufrieden damit, nur das zu geben, was eine ärmliche Bitte enthält, sandtet einen Eurer Redegabe würdigen und lobenswerten Brief, nach der Art eines großen Flusses, der, sooft er zu einem seitlichen Abstecher vom Flussbett aufgefordert wird, um benachbarter Trockenheit abzuhelfen, dort wo ein zarter Bach gewünscht wird, ganz hineinströmt und den ausgetrockneten und welken Boden mit einer Fülle von heilbringendem Wasser bewässert « $(\$ 2) .{ }^{824}$ Doch dann wendet sich Ennodius dem Amt zu, und zwar mit ausführlichen Ermahnungen, dass nämlich Iulianus auch weiterhin

$823(125,1)$ Suscepi litteras gemino splendore radiantes, quibus purpura dictatoris vestrae iuncta dignationi crevit in pretium, gratias omnipotenti deo restituens, qui votorum maciem beneficii ubertate transgreditur, ut quando in desideriis meritorum conscii sectamur angustiam, divitis indulgentiae copias non refrenat.

$824(125,2)$ credidi satis esse, si me feceritis amplissima scriptione sublimem; sed vos non hoc tantum contenti praestare, quod habet mendica postulatio, linguae idoneas et laude locupletes paginas destinastis magni more fluminis, qui quotiens ab alveis, ut ariditatem finitimam temperet, ad obliqua invitatur, optanti tenuem rivulum totus inlabitur et marcida profundo squalore terga per ebrietatem undae salutaris infundit. 
an die vor der Erlangung des Amtes versprochene Freundschaft denken solle: »Möge also Deine Hoheit der Gewohnheit starker Menschen treu sein und nicht aufgeben, was sie meiner Wenigkeit gegenüber so gut begonnen hat, so dass zum Zeugnis der Freundschaft der Briefwechsel gepflegt wird und süße Briefe eine Bestätigung der aufrichtigen Freundschaft bringen. Die Freundschaft, die Ihr vor dem Erreichen des Gipfels verspracht, möge keinen Untergang kennen!“ (\$3). ${ }^{825}$ Durch die Wahrung der Freundschaft zu Ennodius könne Iulianus zeigen, dass er nicht hochmütig geworden sei: "Möge Eure Freundschaft zu mir in dem Maße wachsen, wie Euch hohe Würden verliehen worden sind, damit man nicht glauben muss, dass die Macht die Freundschaft, die die mittlere Stellung gepflegt hat, nicht mehr kennt. Denn wer in einer hohen Stellung den Hochmut bezwingt, zeigt, dass er verdient hat, was er erlangt hat. Zeigt durch Euer redliches Herz, dass Erfolg sich der Herrschaft der Freundschaft unterwerfen kann. Unterwerft jene freien Nacken der Vornehmen der Freundschaft, indem ihr ein Beispiel dafür setzt. Möge von Euch die Gewohnheit ausgehen, dass der Höchste im Staat an demjenigen festhält, den er in niedriger Stellung kennengelernt hat « ( $\left.\S_{3} \mathrm{f}.\right){ }^{826}$ Iulianus' Freundschaft zu Ennodius wird so gewissermaßen zum Testfall für Iulianus' Charakter, ihre Beziehung wird zum nachahmungswürdigen Muster für andere in vergleichbarer Position. Dies sei durchaus zum Nutzen der Mächtigen, denn wer im Glück seine Freunde vergesse, könne sich auch selbst auf nichts verlassen: "Der Zufall spielt mit denen, die er ihre Bekannten vergessen lässt, weil er sie aufsteigen lässt <? $>(\$ 5){ }^{827}$ Dann folgt abrupt die Versicherung, dass der Adressat zum richtigen Verhalten prädestiniert sei (vgl. oben bei Sy. 3,43,3): "Bei einem Kundigen zwingen Ausführungen über gute Verhaltensweisen nicht zur Ermahnung, sondern sind eine Gelegenheit zu loben. Ich weiß, dass Eure Veranlagung unerschütterlich auf das Streben nach Gutem eingestellt ist, und ich erwähne sie deshalb extra, um zu zeigen, dass Ehren kein Recht haben, wo feste Freundschaft besteht " (\$5). ${ }^{828}$ Abschließend bezeichnet Ennodius seine Worte als "Empfehlung"

825 (125,3) fortium tamen servans consuetudinem personarum magnitudo tua circa exiguitatem meam bene coepta non deserat, $u$ t in testimonio diligentiae cura paginalis habeatur et puri amoris adstipulationem deferant blandimenta conloquii. occasum nesciat caritas, quam ante culmina promisistis.

826 (125,3f.) tantum circa me crescat gratia, quantum vobis iuncta sunt fastigia dignitatum, ne amicitiam, quam fovit mediocritas, credatur abiurasse potentia. (\$4) nam qui fastum in sublimitate castigat, docet se meruisse quod adeptus est. resignate per probitatem conscientiae, felicitatem submitti posse amoris inperiis. illa libera procerum colla, dum formam tribuitis, subiugate diligentiae. fas sit de vobis adsuesci, ut amplissimus in societate retineat quem minor adquirit.

$827(125,5)$ ludit de illis casus, quibus oblivionem suorum indicet quod ad celsa perducit.

$828(125,5)$ apud scientem rerum relegere bona non est admonitionis necessitas, sed laudis occasio. novi fabricatam ad bona studia ingenii vestri tranquillitatem, quam ideo speciatim conmemoro, ut ostendam, ubi affectio solida est, honoribus nil licere. 
seiner Person: »Doch ich habe den Umfang von Briefen überschritten, während ich mich lange mit meiner Empfehlung aufhalte. Ich komme zum Zweck des Briefs und melde, dass es mir gutgeht, und wünsche sofort Günstiges über Euer Wohlergehen zu erfahren “ $(\$ 6){ }^{829}$ - So erhält Iulianus anstelle eines zu erwartenden Glückwunsches eine deutliche Ermahnung; Ennodius formuliert seine Freude über Iulianus' Aufstieg nur indirekt mit der >stellvertretenden` Freude über den betreffenden Brief. Anders als Symmachus in einem vergleichbaren Brief $(3,43$, siehe oben 340$)$ ermahnt Ennodius mit keinem Wort dazu, das Amt erfolgreich und ruhmvoll auszuführen; er fordert Iulianus ausschließlich dazu auf, nicht hochmütig zu werden, sondern als Amtsinhaber Demut zu zeigen - und zwar indem er die Freundschaft zu Ennodius wahrt und die Korrespondenz mit ihm pflegt; Ennodius sempfiehlt s sich selbst dem Adressaten damit, dass er diesem die Möglichkeit biete, seine Demut zu beweisen. Dieser Brief ist ein klarer Ausdruck seines Verständnisses von amicitia. Er lässt diesen Brief Ausdruck der in ihm formulierten Überzeugung sein, dass Ehrenstellungen über feste Freundschaft keine Macht haben ( $\$ 5$ ubi affectio solida est, honoribus nil licere; $\mathrm{cf}$. besonders 111 an Avienus, oben 289).

In dem Schreiben (459) an Avienus zu seiner Hochzeit ist weder der Anlass von Anfang an erkennbar (erst $\$ 4$ ipse ergo coniunctionis tuae copulam respiciat: ipse unum faciat ex duobus [...]; $\$ 5$ hymeneis tuis interesse non potui), noch herrscht ein freudiger Ton vor. Denn zunächst führt Ennodius aus, warum er sich, als sich ihm die Möglichkeit zu schreiben bot, gar nicht darüber freuen konnte: Die Tatsache, dass die persönliche Begegnung mit Avienus noch nicht lange zurückgelegen und er seine Stimme noch im Ohr gehabt habe, sei ein gutes Mittel gewesen, den Trennungsschmerz zu lindern. Er habe gezögert, ein anderes Mittel, nämlich einen Brief zu schreiben, anzuwenden, denn er habe die Illusion nicht zerstören wollen (\$1f.). Doch er habe keine Wahl gehabt: "Da also das, was ich erwähnt habe, nicht weiter bestehen konnte, muss ich nun tun, was mir noch übrig bleibt. Gibt es wohl noch einen Menschen, der aufgrund seiner Sündenlast so zu leiden hat? Ich wäre unglücklich, Euch nicht zu sehen; ans Ziel meiner Wünsche <sc. eine Gelegenheit zu schreiben> gelangt gräme ich mich, weil das, was ich erbat, von Gott gegeben und gewährt wurde. Hat jemals jemand bei einem freudigen Anlass etwas bekommen, das ihn quält, oder ist aus der Ernte der Freuden eine Pflanze der Traurigkeit hervorgekommen?« (\$2f.) ${ }^{830}$ Diese

$829(125,6)$ sed epistolarem transcendi terminum, dum commendationi meae multus inhaereo. redeo ad officia paginalis alloquii et valere me nuntians prosperitatis vestrae actutum secunda disquiro.

$830(459,2$ f.) ergo nunc mihi, quia illud quod praefatus sum stare non licuit, exequendum est quod remansit. $(\$ 3)$ aliquis hominum pro peccati sui onere sic laborat? adfligerer nisi vos viderem: ad cupita perductus maceror, quia quae poscebamus deo tribuente concessa sunt. numquid alicui adcessit de laetitiae occasione quod torqueat, aut de messe gaudiorum egressa est planta tristitiae? 
Paradoxa werden mit einem Hinweis auf Gott und einem weiteren Paradox beendet: "Dank sei der unteilbaren Dreifaltigkeit, dem wahren Gott, der zuweilen Wünsche nicht beachtet, um sie zu erfüllen « $(\$ 3) .{ }^{831}$ Erst diese Erwähnung Gottes führt weiter zum eigentlichen Thema und damit zu den guten Wünschen zu Avienus' Hochzeit: »Er selbst also möge sich um Deine eheliche Verbindung kümmern: Er selbst möge aus zweien Eines machen, der mit dem Körper des ersten Menschen, als sich dieser noch über die ursprüngliche und unversehrte Unsterblichkeit freute, beide gestaltete. Möge Dir eine Gattin verbunden werden, wie Sarah dem Abraham, wie Rebecca dem Isaak, wie Rachel dem Jakob unter dem himmlischen Segen verbunden wurde. [...] « $(\$ 4){ }^{832}$ (In einem späteren Brief, 463, drückt Ennodius seine Freude darüber aus, dass, wie er höre, die Frau des Avienus alle Wünsche übertreffe).

\section{c. 2 Freundliche Glückwünsche}

In einigen Glückwünschen (159 und 242 zu einem neuen Amt, 9 und 370 zum Konsulat, 461 an Caesarius von Arles zum glücklichen Verlauf der Begegnung mit Theoderich) zeigt sich Ennodius auf den ersten Blick bzw. zumindest stellenweise recht freundlich - wenn auch das Lob auf den zweiten Blick nicht immer uneigennützig ist oder z.T. durch andere Eindrücke überlagert wird. Am freudigsten und freundlichsten ist bei näherem Hinsehen Brief 242 an Pamfronius, wogegen sich in den anderen Briefen Lob und Freude mit Egoismus, Bitten oder Ironie und/oder recht hohem Selbstbewusstsein mischen.

Pamfronius erhält ein Glückwunschschreiben (242), da er ein Amt in Ravenna erlangt hat, das den Anfang seiner Karriere bedeutet (cf. PLRE II, 825; SCH ̈̈ FER 1991, 93f.). Dieser Brief fällt durch den durchweg freundlichen Ton auf, wobei nur am Ende angedeutet wird, wodurch die Freude eingeschränkt werden könnte. - Der Brief beginnt mit zwei kurzen Sentenzen, die Ennodius' Veranlassung zum Schreiben benennen, dass nämlich Freude zur Sprache dränge: „Freude hat große Macht. Freude kennt keine Zurückhaltung und will in Worte ausbrechen « $(\$ 1) .{ }^{833}$ Er habe diesen Tag immer ersehnt, wenn er ihn auch aufgrund seiner - eigenen - Verdienste nicht erhoffen konnte (zu diesem extremen >Selbstbezug siehe oben 235): "Gekommen ist der von meinen Wünschen ersehnte Tag, und Deine Hoheit hat jenen Glanz erhalten,

$831(459,3)$ gratias inseparabili trinitati deo vero, qui ut vota inpleat, aliquotiens vota contemnit.

$832(459,4)$ ipse ergo coniunctionis tuae copulam respiciat: ipse unum faciat ex duobus, qui in primi hominis corpore, dum adhuc nativa et intemerata inmortalitate gauderet, utrosque formavit. iungatur tibi uxor, ut Abrahae Sarra, ut Isaac Rebecca, ut Iacob Rachel caelesti benedictione sociata est. [...]

833 (242,1) Magna sunt imperia gaudiorum. expers est continentiae hilaritas et in vocem gestit erumpere. 
den ich nie aufgrund meiner Verdienste, sondern immer von der himmlischen Liebe erbeten habe. Deiner Familie und Deiner Lebensweise ist eine hohe Würde gegeben, durch die die Integrität Deines zuverlässigen Herzens ohne Zaudern ans Licht treten kann <d.h. er hat in dem Amt die Gelegenheit, seine integritas zu beweisen>" $(\$ 1){ }^{834}$ Ennodius bittet Gott sehr zuversichtlich um weitere Unterstützung des Pamfronius: "Guter Gott, bewahre das Gewährte, vermehre das Gegebene durch Erfolg, lass für Deinen Diener diesen höchsten Schritt den ersten <sc. von vielen (weiteren) noch höheren> sein. In der Erwartung nehme ich das Künftige vorweg, um das ich bitte. Was vom Himmel gewährt wird, kann nicht am Anfang stehenbleiben. Immer geht man steigend bis zum Gipfel hinauf, wenn die himmlische Gunst den Anfang schenkt“ $(\$ 2) .{ }^{835}$ Wie Ennodius schon eingangs eine Verbindung zwischen seinen eigenen Verdiensten und dem Erfolg des Pamfronius hergestellt hat, so bezieht er auch weiterhin dieses und ein weiteres erfreuliches Ereignis, die Rückkehr des Senarius, ${ }^{836}$ auf sich selbst: „Wer - und sei es ein Mensch, der seinen Lebenswandel von jeglicher Verdüsterung reinhält - darf sich darüber freuen, dass ihm an einem einzigen Tag solches zuteil wurde, dass Du den Anfang der Ehren betreten hast und dass mein lieber Senarius von den äußersten Enden der Welt zurückgekehrt ist? Nur wenige Stunden lagen dazwischen, dass Du dem Hof geboren und er ihm zurückgegeben wurde. Wirklich, ich sage, und im Vertrauen auf die Barmherzigkeit Gottes verspreche ich mir zuversichtlich, dass meiner Schwachheit vom willfährigen Himmel Schutz gewährt wird. In dem, was Euch gewährt wurde, liegt ein Versprechen für mich “ $(\$ 3) .{ }^{837}$ In den Gruß eingeflochten wird die Bitte, dass Pamfronius Senarius dazu bewegen solle, bei Ennodius zu wohnen (auch in dem vorangehenden Brief an Senarius hat

$834(242,1)$ venit optatus desideriis dies et ille, quem numquam de meritis meis sed semper de superna pietate postulavi, magnitudini tuae splendor adcessit. redditus est generi et moribus tuis apex, per quem conscientiae fidelis in lucem prodire non formidet integritas.

$835(242,2)$ deus bone, indulta custodi, auge successibus quod dedisti, fac circa servum tuum primum esse gradum qui summus est. praecipio spe futura quae deprecor. nesciunt in foribus haerere, quae caelo auctore tribuuntur. semper incrementis ad culmen ascenditur, ubi supernus favor praestat exordium.

836 Pamfronius steht offenbar in enger Verbindung zu Senarius, einem Adressaten, der etliche Briefe von Ennodius erhält und den Ennodius in diesem Brief an Pamfronius als dulce meum $(242,3)$ und domnus animae meae $(242,4)$ bezeichnet. Vor dem Brief an Pamfronius steht ein kurzer Brief an Senarius (241), in dem Ennodius seine Freude über dessen Rückkehr äußert. Sowohl in Cassiod. var. 4,3 als auch in Senarius' Epitaph ist von seinen vielen Gesandtschaftsreisen die Rede, cf. PLRE II, 988f.; SCHÄFER 1991, 103f.

$837(242,3)$ quis hoc in vita hominum vel eorum, qui conversationem suam nulla custodiunt nube sordentem, adcessisse sibi die una gratuletur, te honorum auspicia ingressum et dulce meum Senarium ab ultimis terrarum partibus restitutum? brevis horarum cursus interfuit, ut et tu palatio natus et ille sit redditus. in veritate dico et de dei misericordia mihi securus spondeo, fragilitati meae praesidia caelo obsequente concedi. spondetur mihi, quod vobis est praestitum. 
Ennodius sein hospitium erwähnt, cf. 241,2): "Mein Herr, ich grüße ergebenst und bitte Dich, wenn Du meine Freundschaft nur irgendwie schätzt, nicht damit aufzuhören, Senarius, den Herrn meiner Seele, inständig zu bitten, bei mir zu wohnen. Wenn Du das nicht erreichst, wirst Du die Fülle meiner Freude erheblich verringern" $(\$ 4){ }^{838}$ - In diesem Schreiben hebt Ennodius auffällig häufig hervor, dass dieses Amt erst der Anfang sei: primum gradum, in foribus, exordium (\$2), honorum auspicia ingressum $\left(\$_{3}\right)$, palatio natus $\left(\$_{3}\right)$. So zeigt er einerseits, wie zuversichtlich er auf Weiteres hofft, deutet aber umgekehrt auch an, dass Pamfronius dabei nicht stehenbleiben dürfe (vgl. oben 119). - Dieser Brief ist außerdem ein Beispiel dafür, wie enge Bezüge Ennodius zwischen sich und seinen Korrespondenten bzw. amici herstellt und wie sehr er auf sich bezieht, was diese erleben. Er verwendet nicht nur das Motiv, dass ihr Erfolg auch für ihn selbst erfreulich ist (oben 235), sondern er stellt einen Kausalbezug her zwischen seinen Verdiensten und ihrem Ergehen: Pamfronius hat eine Ehre erlangt, wie sie Ennodius nie aufgrund seiner eigenen Taten erwarten konnte; Senarius ist zurück und Pamfronius wird geehrt - so viel Glück wie Ennodius wurde noch niemandem zuteil. Der Hinweis auf seine eigenen merita, aufgrund derer er nicht auf einen solchen Erfolg des Pamfronius habe hoffen mögen, könnte sich konkret darauf beziehen, dass Ennodius zuvor für ihn Empfehlungsschreiben an Faustus (53; 144; außerdem später ein weiteres, 307) und an Agapitus (146) verfasst hat.

Ein weiteres freundliches Glückwunschschreiben (159), das allerdings auch eine ausgesprochene Bitte für ihn selbst und eine angedeutete Bitte für den Amtsvorgänger des Adressaten enthält, bekommt Eugenes (cf. PLRE II, 414-416; SCHÄFER 1991, 60f.). Dieser wurde in das Amt des Quaestor palatii (Justizminister, der die kaiserlichen Erlasse formulierte) berufen, und Ennodius bittet ihn, die bestehende Freundschaft zu wahren und sich ihm gegenüber so zu verhalten wie sein Amtsvorgänger (zu diesem gleich unten). Ennodius beginnt mit guten Wünschen für das Amt: "Ein gnädiges vom Himmel kommendes Zeichen möge Euren Amtsantritt stärken, und Euren Dienstbeginn in dem altehrwürdigen Amt möge die Gottheit mit ihrem Rat stärken. Möge durch Euch die himmlische Gunst den Herrn der Freiheit <sc. Theoderich> lenken, so dass aus der Quelle Eures Herzens zu den Ohren des Herrschers fließt, was der Himmel von oben herab in Euch hineingegossen hat « $(\$ 1) .{ }^{839}$ Es folgt ein etwas trotzig wirkender Hinweis, damit getan zu haben, was nötig war: "So: Ich habe, wie ich musste, die Wünsche für den Anfang vorgebracht, wenn auch in kurzgefassten Worten. "Es folgen Bitten an Eugenes: „Erinnert Euch bitte an die verspro-

$838(242,4)$ domine mi, salutationis obsequia suscipiens rogo, ut si quid amori meo tribuis, domnum animae meae Senarium, ut apud me maneat, exorare pleniter non omittas. quod nisi obtinueris, multum mihi de hilaritatis cumulo decerpsisti.

$839(159,1)$ Faustum caelo omen adveniens auspicia vestra conroboret et tirocinia canae dignitatis suis muniant divina consiliis. per vos supernus favor regat dominum libertatis, ut ex pectoris vestri fonte ad aures principis defluat, quod in vobis aetherius imber infuderit. 
chene Freundschaft und das Bündnis, so dass mir die Quaestur ohne Nachteile durch den Wechsel <sc. des Amtsinhabers> ihrer Schuldigkeit nachkommt. Bewahrt mir gegenüber die Einstellung Eures Vorgängers; möge das Versprechen, das Euer würdiges Amt gemacht hat, nicht gebrochen werden, nachdem die Personen gewechselt haben. Mein Herr, lebt entsprechend den Wünschen des Bittenden wohl, und nehmt bei der großen Verkündung von Wohltaten <sc. in Ausübung des Amtes> diesen kurzen Brief an. Es ist nämlich bei den Erfolgreichen und von Natur her Besseren so, dass sie an Taten und Gaben das übertreffen, was mit Worten gesagt werden kann « $(\$ 2) .^{840}$ - Es ist wohl kein Zufall, dass der Brief mit einer Anspielung auf den Amtsvorgänger Faustus beginnt (faustum [...] omen). Wenn Faustus das Amt wirklich unter unerfreulichen Umständen verlassen musste, ${ }^{841}$ dann kann man aus diesem Brief an den Nachfolger die Bitte um Unterstützung des Faustus herauslesen; so würde sich sowohl der Wunsch nach einem faustum omen, das vom Himmel kommen solle, erklären, als auch die Bezeichnung des Verfassers als supplex $(\$ 3)$ und der Wunsch am Ende nach Taten des Adressaten.

In zwei Briefen gratuliert Ennodius zur Erlangung der Konsulwürde; der eine Brief (9) richtet sich an Faustus anlässlich des Konsulats seines Sohnes Avienus, der andere an Boethius (370); beide Briefe sind relativ lang (9: zwei Seiten bei Vogel; 370: eine ganze Seite). In diesen werden die Konsuln ausführlich gelobt, so dass man - zumindest abschnittsweise - von Panegyrik im weiteren Sinne sprechen kann. Den Briefcharakter wahrt Ennodius durch die Abschlüsse der Briefe, indem er sich wieder direkt an den Adressaten Faustus wendet und über die Macht Gottes und die Macht von Gebeten spricht bzw. indem er Boethius eine sehr konkrete Bitte vorträgt.

Als Avienus, mit dem Ennodius über dessen Mutter verwandt ist, die Konsulwürde erhält, sendet Ennodius ein Glückwunschschreiben (9) an dessen Vater Faustus. Avienus selbst erhält wenig später einen Brief (17), in dem er recht streng zum Schreiben aufgefordert wird, ${ }^{842}$ sein Konsulat aber mit keiner Silbe erwähnt ist; auf das

$840(159,2)$ ecce quae debui vota rudimentis licet coactis in artum sermonibus enarravi. vos mementote promissi amoris et foederis, ut sine mutationis dispendio debitum mihi quaestura dissolvat. tenete circa me animum decessoris; dignitatis vestrae pollicitatio non frangatur variata personis. domini mei, salvete pro desiderio supplicis et in magna beneficiorum promulgatione suscipite parca conloquia. talis enim est usus felicium et natura meliorum, ut linguae copias rebus et praestitis antecellant.

$841 \mathrm{Vgl}$. (157,2) inimicorum valitudine et rumorum procellis, siehe Sundwall (1919, 30), RoH R (1995, 22f.); allerdings keine Erwähnung dieser Vorfälle im Artikel zu Faustus in PLRE II.

842 In diesem Brief (17) findet sich eine ganze Reihe von charakteristischen Elementen: Ennodius spricht von Freundschaft, von Bildung und von der Bedeutung von Briefen, von seinem kirchlichen Amt, von seinem Kummer, dass Avienus nicht schreibe und ihn vernachlässige, wobei er sich auf die sinceritas beruft; er malt aus, wie schön es wäre, einen Brief von Avienus zu erhalten, wobei das Lob von der fordernden Erwartung, Avie- 
Konsulat spielt Ennodius lediglich einmal in einem späteren Brief an, und zwar in ironischem Zusammenhang (65,3, siehe oben 320). Dass dem Vater des Konsuls gratuliert wird, erklärt sich damit, dass die Auszeichnung des Sohnes mit dem Konsulat eine Ehre für den Vater bzw. die Familie war. Das Konsulat galt als höchste erreichbare Ehre, wobei allerdings die Funktion des Amtes inzwischen fast ausschließlich eben darin bestand, eine Ehrenbezeugung zu sein: Die »vornehmste Aufgabe <des Konsuls $>$ war die feierliche Eröffnung des Jahres, dem er den Namen gab, und in dieser Verewigung des Namens erblickte man die eigentliche Ehre" (DemandT 1989, 282f.); davon spricht auch Ennodius in diesem Brief: qui anno nomen inposuit (\$1). Um Konsul zu werden, war kein Mindestalter gefordert, und es musste zuvor auch kein cursus honorum durchlaufen werden (vgl. Boethius, für den wahrscheinlich das Konsulat das erste Amt war). Dem entspricht, dass Avienus noch jung ist, auch wenn in Lobschriften wie dieser mit der Topik des 'puer senex ‘ gern übertrieben wird ( $\$ 6$ Avieni $[. .$.$] adhuc teneri; \$ 7$ limen felicis infantiae consul meus cum honore senis ingressus est), und dass Ennodius betont, dass man sich diese Würde früher in langen Jahren hart habe erarbeiten müssen, sie jedoch für Avienus das erste Amt darstelle (\$7f.).

Gleich im ersten Satz und noch mehrmals verwendet Ennodius auch in diesem Glückwunschschreiben das Motiv des ,Selbstbezugs` (vgl. oben 235) und stellt die Konsequenzen von Avienus' Konsulat für sich selbst heraus: Er hebt ausführlich hervor, dass die Konsulwürde des Avienus für ihn selbst, Ennodius, ein Anwachsen des Prestiges bedeute, was im Weiteren damit erklärt wird, dass er nun endlich mit einem Konsul blutsverwandt sei, wohingegen er früher nur mit einem Konsul, gemeint sein dürfte der Adressat Faustus (Konsul i.J. 490), verschwägert war: »Ich bete um die überreiche Barmherzigkeit Gottes und empfehle ihm den Beginn eines glücklichen Jahres an; durch seine wohltätigen Gaben ausgezeichnet, kann ich mich nun einem Konsular fast von gleich zu gleich nähern. Bisher verliehen fremde Auszeichnungen meiner Familie die Pracht der purpurverzierten Erhabenheit, und wir konnten uns darüber freuen, durch Verschwägerung mit dem verbunden zu sein, der dem Jahr seinen Namen gab, nicht aber durch direkte Verwandtschaft. Ein Geschenk war es, aber nichts, das uns zustand, dass man von uns freundlicherweise sprach als zu denen gehörend, die die Amtssessel innehaben [...] « (\$1f.). ${ }^{843}$

Nachdem Ennodius ausgemalt hat, wie Scharen von Nachkommen Avienus auf diesem wieder eröffneten Weg folgen werden (\$2f.), macht er deutlich, worin er die

nus solle die Fähigkeiten seines Vaters nachahmen, übertönt wird; am Ende bezeichnet Ennodius selbst sein Verhalten als inportunitas.

$843(9,1)$ Abundantem dei misericordiam precatus commendo ipsi anni felicis auspicia et beneficiorum eius muneribus sublimis iam consularem virum quasi aequalis adgredior. hactenus trabealis coturni pompam familiae nostrae peregrina ornamenta tribuebant et pertinere nos ad eum magis adfinitate quam genere gaudebamus, qui anno nomen inposuit. munus erat, non debitum, quod inter curulium possessores diligentum fabulis addebamur. 
Bedeutung des Konsulats sieht, nämlich in der Tatsache, dass der Name des Konsuls die Zeiten überdauert $(\$ 3 f$.). Er betont dann nochmals die Bedeutung, die das Konsulat des Avienus für die mütterliche Seite seiner Verwandtschaft hat, zu der ja auch er selbst gehört ( $\$ 4$; auch $\$ 6$ ). Es folgt die bereits (oben 10o) untersuchte Passage über die Möglichkeiten des Redners, ein wenig ergiebiges Thema bedeutender zu machen. Avienus übertreffe nicht nur die Alten, sondern auch seinen Vater Faustus ( $\$ 5 f$.). Ein besonderes Geschenk des Himmels sei es, dass Avienus diese Ehre in so jungem Alter zuteil geworden sei; man könne also viel von ihm erwarten, wenn er später erst seine vollen Kräfte aufbieten werde $(\$ 7 f$.). Doch die Ehre sei nicht nur ein Geschenk, man könne sie nicht nur der felicitas zuschreiben, sondern er habe sie auch verdient durch seine Bildung (\$9-11). Die Gedanken über die Bildung werden dann aber abgebrochen mit den Worten: "Aber ich erkenne, wohin mich die Flut meiner Zuneigung reißt, die keine Grenze kennt. Ich vergesse meine Vorsätze und erkläre, obwohl ich an Begabung unterlegen bin, den Konsul für gebildet « $(\$ 11) .{ }^{844}$ Hier wird der Adressatenbezug überdeutlich: Während Ennodius in seinen Briefen an Avienus diesen immer wieder aus der Warte des Mahnenden und Erziehenden dazu auffordert, in seinen Bemühungen nicht nachzulassen, schmeichelt er hier dem stolzen Vater.

Im letzten Abschnitt ( $\$ 11 \mathrm{ff}$.) wendet sich Ennodius an Faustus, wobei der Ton des Lobredners nun in den des Klerikers übergeht: Mit ihm zusammen wolle er Gott um die Bewahrung der gewährten Gaben bitten $(\$ 11)$; er halte die Konsulwürde des Avienus für eine Belohnung der elterlichen Gebete $(\$ 12)$. Gebete solcher Personen hätten Erfolg, denn: »Wenn zwei oder drei unter Euch eins sind, dann werdet ihr erlangen, was ihr erbittet « (cf. Mt 18,19f.).

Dieser Brief bietet eine eigentümliche Mischung: Freude über das Konsulat des Avienus, nicht zuletzt allerdings aufgrund der Auswirkungen auf Ennodius; Lob, das jedoch offensichtlich stark übertrieben ist; Lob mit gleichzeitigen Hinweisen auf die Macht der Rhetorik, bei Bedarf alles zu vergrößern. Auch in diesem Brief (vgl. den Brief an Pamfronius, oben 346) hebt Ennodius hervor, dass er zuversichtlich weitere Erfolge erwarte: "Denn es ist nicht das eine, sondern das erste Konsulat meines Avienus" $(9,3)$; "Ich ahne bereits, was durch Anstrengung erreicht werden wird, wenn Derartiges schon am Anfang gezeigt wird. Durch nie gesehene Erfolge wird dem ein Zuwachs an Gedeihen zukommen, den wir mit Konsulehren beginnen sehen " $(9,7 \mathrm{f}.){ }^{845}$ Diese Zuversicht verweist darauf, dass Avienus nicht aufhören darf, sich zu bemühen.

$844(9,11)$ sed quo me rapiat processus affectionis terminum refutantis, agnosco: divisus proposito consulem eruditum ingenio inpar appello.

$845(9,3)$ nam Avieni mei non unus, sed primus est consulatus [...]; (9,7f.) spe praecipio quid paretur laboribus, cum talia primordiis exhibentur. $(\$ 8)$ inauspicatis successibus illi profectuum incrementa ventura sunt, quem coepisse videmus a fascibus. 
Das Gratulationsschreiben (370) für Boethius, den Konsul des Jahres 510, mit dem Ennodius verwandt war (z.B. \$5 propinquus, \$7 parentes), enthält sowohl im weiteren Sinne panegyrische Elemente (Ennodius verwendet sogar die Begriffe laudator $\$ 2$, laudare $\$_{5}$ ) als auch eine große Bitte. ${ }^{846}$ Auf eine Vorrede (dazu gleich unten) folgen viele lobende Worte für Boethius und seine Familie: "Dem allmächtigen Gott sei also Dank, der, während er das alte Gut Eurer Familie bewahrt, Euch vielfältiges neues Gut zukommen lässt und - was den Gipfel der Ehrenstellung übertrifft - Euch der Spitzenstellung würdig sein lässt. Diesen Ruhm <sc. das Konsulat> erlangt Ihr zwar, weil er Eurer Herkunft zusteht, aber <auch deshalb> - was besser ist - weil es die Qualitäten Eurer Person erfordern [...] « $(\$ 2 f.) .{ }^{847}$ Diesen Aspekt, dass er die Fähigkeiten des Boethius für wertvoller halte als die edle Abstammung, wobei Boethius über beides verfüge, greift er später nochmals auf $\left(\$_{5} f_{\text {. }}\right)$. Ennodius betont, dass Ehrenstellungen früher durch Erfolge im Krieg erworben werden mussten, nun aber ein anderes genus virtutis gefordert sei: »Es mag bei den Alten üblich gewesen sein, das hohe Konsulat mit den Mühen des Schlachtfelds zu erwerben und aufgrund der Verachtung des Sonnenlichts in der Sonne der Ehren zu erstrahlen; doch seit Rom eine Beute von Siegern geworden ist <? d.h. seit unser campi sudor nicht mehr gebraucht wird, weil andere um uns bzw. um Rom kämpfen $>$, ist eine andere Tugend erforderlich “ $(\$ 3){ }^{848}$ "Unser Konsul erlangt nach einem deutlichen Entscheidungskampf den verdienten Triumph, ohne jemals den Krieg gesehen zu haben. Durch seinen Verstand erlangte er den Lorbeer, und er hielt es nicht für nötig, Bewaffneten entgegenzutreten " $(370,3) .^{849}$ Mit dieser Stelle ist ein Spottepigramm (339) des Ennodius in Verbindung gebracht worden, in dem die fehlende militärische Begabung des Boethius angegriffen wird (cf. z.B. 339,3 emollit gladios inbellis dextra Boeti) ${ }^{850}$ Auch wenn Ennodius im Glückwunschschreiben auf denselben Aspekt bzw. dieselbe Situation anspielen sollte, findet sich hier kein Spott darüber; ohne Kenntnis des Epigramms würde man diese Variante von Ciceros cedant arma togae, concedat laurea laudi wohl nicht verdächtigen. Ennodius zeigt hier also, dass er einen Sachverhalt je nach Gattung unterschiedlich deuten und darstellen kann; ein vergleichbarer Beweis

846 PIETRI urteilt darüber folgendermaßen $(1981,440)$ : "Ennode $[\ldots]$ compose un éloge, flagorneur et inintelligent, pour le philosophe."

$847(370,2)$ deo ergo omnipotenti gratias, qui in vobis, dum vetera familiae vestrae bona custodit, nova multiplicat et, quod plus est apice dignitatis, dignos facit esse culminibus. redditur quidem vestrae gloria ista origini, sed, quod est clarius, merito inpetrante personae. [...]

$848(370,3)$ fuerit in more veteribus curulium celsitudinem campi sudore mercari et contemptu lucis honorum sole fulgere: sed aliud genus virtutis quaeritur, postquam praemium facta est Roma victorum.

$849(370,3)$ noster candidatus post manifestam decertationem debitum triumphum, dum numquam viderit bella, sortitur. iudicio exegit laureas et congredi non necessarium duxit armatis.

850 Sundwall $(1919,55)$ vermutet einen Zusammenhang mit Zirkusspielen. Siehe dazu bes. ShANZer 1983, NäF 1990, 107 und den Kommentar von Di Rienzo 2005. 
seiner ,Flexibilität findet sich im Brief an Caesarius von Arles, siehe unten 352. Anstatt eine Anspielung auf einen heiklen Punkt ganz zu unterdrücken, zeigt er, dass der geübte Panegyriker einen achtbaren Ausweg findet.

Danach werden besonders Boethius' Beherrschung des Griechischen und seine Redekunst hervorgehoben $\left(\$_{4}\right)$, z.B.: »er erstrahlte zwischen den Schwertern von Cicero und Demosthenes, und er eignete sich den Scharfsinn beider ,Schulen، an, als wenn er mitten im Frieden der Künste geboren wäre. Niemand sollte befürchten, dass die griechische und die lateinische Vollkommenheit sich nicht vertragen, oder bezweifeln, dass die besonderen Vorzüge dieser Völker zusammenpassen $[\ldots]$ « $(\$ 4){ }^{851}$ Die Hinweise auf mögliche Dissonanzen zwischen Latein und Griechisch könnten sich auf die Spannungen zwischen West und Ost aufgrund des Acacianischen Schismas beziehen; so bringt er Boethius' singuläre Kenntnisse in einen weiteren (kirchen-) politischen Zusammenhang.

Die lobenden Worte werden gerahmt von einer Vorrede (\$1f.) und einem Abschluss ( $\$ 7$ f. redeo ad tabellarum fidem etc.); zunächst zum Ende des Briefs: An die Frage nach der Gesundheit des Boethius und die Bitte um Briefe schließt Ennodius wie nebenbei eine große Bitte an (... hoc quoque deprecans [...]): Er möchte ein Haus übernehmen, das Boethius gehört, das dieser aber nicht pflegen und erhalten lässt: "[...] und ich bitte, dass Ihr mir das Haus in Mailand, das Euer Überfluss und Eure Achtlosigkeit schon fast verlassen haben, überlasst, unter welchen Bedingungen Ihr wollt $[\ldots] \lll(\$ 7) .852$

Sobald man weiß, dass der Brief auf diese Bitte hinausläuft, bekommt die Vorrede einen zweiten Sinn. Solange man das Ende nicht kennt, muss man am Beginn die Worte wie spes, beneficia, desideria, vota als Wünsche für die Amtszeit und weitere Zukunft des Boethius verstehen (vergleichbar mit dem Beginn des Briefs an Faustus abundantem dei misericordiam precatus commendo ipsi anni felicis auspicia [...], 9,1): "Voller größter Hoffnung, für die ich auf Unterstützung hoffe, erlaube ich mir einen Brief zu schreiben [...]. Lässt sich Freundschaft etwa nur an Wohltaten der Bildung <sc. an Briefen, die hohe Bildung zeigen> erkennen und muss man glauben, dass es nicht recht sei, wenn Wünsche eines Ungebildeten vorgebracht werden? Wünsche, die nicht durch Blendwerk der Bildung verhüllt sind, werden leichter deutlich [...] « $(\$ 1) .{ }^{853}$ Bei einer zweiten Lektüre des Briefes weiß man, welche desideria Ennodius im

$851(370,4)$ inter Ciceronis gladios et Demosthenis enituit et utriusque propositi acumina quasi natus in ipsa artium pace collegit. nemo dissonantiam Atticae perfectionis metuat et Romanae, nec praecipua gentium bona in societatem dubitet convenire. [...].

$852(370,7)[\ldots]$ deprecans, ut domum, quam in Mediolanensi civitate et abundantia vestra et neglectus propemodum iam reliquit, mihi quo vultis genere concedatis. iustum est enim ut parentes vestri habeant, quod de patrimonii mole descendit. $[\ldots]$

853 (370,1) Optimae spei plenus, cui fautum cupio, ad curam officii epistularis adspiro. [...] numquid solius doctrinae beneficiis amor agnoscitur nec fas esse credendum est prodire in medium desideria rusticantis? simplicius innotescunt vota nullo peritiae velata praestigio. 
Sinn hat und dass sich die vota nicht, jedenfalls nicht nur, auf die Amtszeit des Boethius beziehen. - Auch die über den Brief in verschiedenen Zusammenhängen verstreuten Begriffe aus dem Wortfeld "Besitz«/»besitzen« dürften gezielt in Hinsicht auf die konkrete Bitte gewählt sein: familiae vestrae bona $(\$ 2)$, avidus maximarum rerum possessor in Bezug auf Bildungsgüter $(\$ 4)$, tibi utrumque in peculio est, Latiaris scientia et vena purpurarum (\$6).

Ennodius zeigt so einen Aspekt seiner rhetorica versutia: seine Fähigkeiten im doppeldeutigen Formulieren; er flicht Andeutungen auf seine große Bitte von Anfang an ein, aber zunächst so, dass man sie aufgrund des Kontextes und der Erwartung in der Situation anders verstehen muss (cf. den Beginn des Briefs an Pomerius, oben 189).

Diese Doppeldeutigkeit auf den zweiten Blick widerspricht außerdem offensichtlich auch den Aussagen über die rhetorischen Fähigkeiten des Verfassers: »[...] und muss man glauben, dass es nicht recht sei, wenn Wünsche eines Ungebildeten vorgebracht werden? Wünsche, die nicht durch Blendwerk der Bildung verhüllt sind, werden leichter deutlich.« $\mathrm{Da}$ die Wünsche aber doch zunächst kunstvoll verhüllt sind, stellt sich die Frage, inwieweit man den folgenden Behauptungen des Lobredners über sich selbst vertrauen kann: "Bei mir ist also der Mund so wie das Herz; ich kann nicht Bitteres im Herzen gegen schmeichelnde Worte tauschen. Ein anständiger Lobredner ist derjenige, dem beim Verfassen von Freundlichkeiten die Seele die Worte diktiert [...]«(\$1f.). ${ }^{854}$

Der Brief hat nicht den erwünschten Erfolg gehabt, denn die Bitte um das Haus erwähnt Ennodius gegenüber Boethius noch mehrfach $(408 ; 415,2$ und $5 ; 418,1$; später wendet er sich mit derselben Bitte an Faustus, der sie ihm dann zusammen mit Liberius erfüllt (siehe oben 26).

Nicht ohne doppelten Boden ist auch das Schreiben (461), mit dem Ennodius auf den guten Ausgang der >Begegnung zwischen Theoderich und Caesarius von Arles (i.J. 513) bzw. auf den Brief des Caesarius mit der entsprechenden Nachricht reagiert und das ebenfalls lobende Passagen enthält. Es handelt sich auch hier nicht um einen >harmlosen` Glückwunsch zum guten Verlauf: Ennodius zeigt, dass er besser informiert ist, als Caesarius vermutet, und dass er - als geübter Panegyriker - nicht zögert, die Geschehnisse in gutem Licht darzustellen, d.h. nicht so, wie sie wirklich waren, sondern so, wie sie gewesen sein könnten.

Über die Begegnung des Bischofs Caesarius von Arles mit Theoderich berichtet auch die Vita des Caesarius. Die genauen Umstände sind nicht überliefert, doch es steht immerhin fest, dass Caesarius unter Arrest stand, gezwungenermaßen Arles verlassen und vor Theoderich treten musste, um sich zu verteidigen. Nachdem die

$854(\$ 2)$ ergo nos hoc sumus ore quod pectore; non amara praecordiorum delenificis possumus mutare sermonibus. pudens laudator est, cui in concinnatione blandimenti dicenda mens suggerit. 
Vita von der Einrichtung eines Nonnenklosters, dem Caesarius' Schwester vorstand, berichtet hat, fährt sie fort: "[...] Aus diesem Grund und wegen des Eifers in dieser Sache ließ der Teufel wiederum eine Anklage gegen den Diener Christi ergehen und ließ den Bischof aus Arles entfernen und unter Bewachung bis nach Ravenna in Italien bringen " (Vita 1,36). ${ }^{855}$ Nach dem überaus günstigen Verlauf der Begegnung mit Theoderich, den die Vita ausmalt (Vita 1,36), reiste Caesarius weiter nach Rom (Vita 1,42); dort trug er Papst Symmachus mehrere Bitten vor, und dieser verlieh ihm das Pallium als Zeichen seiner Stellung als vicarius, als Zeichen der Metropolitanstellung des Bischofssitzes Arles, was das Ende des langwierigen Streits um die Vorrangstellung zwischen Arles und Vienne bedeutete.

Ennodius beginnt mit einer knappen Zusammenfassung des Briefs, den er von Caesarius erhalten hat; die Nachricht von Caesarius habe seiner Erwartung entsprochen: "Ihr habt in Eurem Brief mitgeteilt, was ich erwartet hatte. Denn durch den ehrenvollen Brief, den Ihr mir gesandt habt, habe ich erfahren, was der himmlische Herrscher unseren Herrn, den König, Euch gegenüber zu tun zwang “ $(\$ 1){ }^{856}$ Dann führt Ennodius aus, es überrasche ihn nicht, dass die Begegnung mit Theoderich so gut verlaufen sei: "Wer wüsste nicht, dass dem edelsten Bischof im Dienste Christi die weltliche Herrschaft unterworfen ist und dass die Macht, die Angeklagte bedroht, von der ihr entgegentretenden Unschuld besiegt wird? Wann hätte der Purpur des Herrschers je das arme Gewand eines Mönchs oder das Pallium missachtet? [... $]$ « $(\$ 2) .{ }^{857}$ Angesichts von Ennodius' offensichtlicher steter Sorgfalt beim Formulieren als auch angesichts des langen Streits um die Metropolitanstellung zwischen Arles und Vienne ist die Erwähnung des Pallium hier sicherlich kein Zufall. ${ }^{858}$ Hier dürfte Ennodius auf den weiteren Verlauf der Reise des Caesarius anspielen, denn das Pallium wurde ihm erst später in Rom verliehen. Zwar hat Ennodius eingangs deutlich betont, dass er durch Caesarius' Brief über die Begegnung mit Theoderich informiert worden sei ( $\$$ litteris indicasti; promulgatione conloquii). Nun aber gibt er zu verste-

855 (Caesarii vita 1,36) [...] Pro ista denique causa proque hoc studio proculdubio contra servum Christi diabolus [...] iterum accusatione confecta extrahi ab Arelate antistitem fecit, et in Italia sub custodia Ravennam usque perduci [...]; ed. G. Morin, Sancti Caesarii Arelatensis opera varia, Vol. II, 1942, 296-345. - Über mögliche Gründe der Anklage und insgesamt zu Caesarius' Aufenthalt in Italien siehe: M.-J. DelaGe, Le Séjour de Césaire d'Arles en Italie, in: Studia Patristica 23, ed. E. A. Livingstone, Leuven 1989, 103-110; Ennodius wird nur ganz kurz erwähnt als Quelle, die den Bericht der Vita stütze. - KLINGshirn (1994, 123-132) erwähnt den Brief des Ennodius nur kurz (125).

856 (461,1) Quod spe praeceperam, litteris indicastis. nam venerandi promulgatione conloquii, quid caelestis imperator domnum regem circa vos facere conpulisset, agnovi. [...]

$857(461,2)$ qui hominum nobilissimo in Christi servitute pontifici terrenas dominationes nesciat esse subiectas et minacem reis potentiam innocentiae obiectione superari? quando principalis purpura aut cilicia despexit aut pallium? [...].

858 Auch Vogel nimmt an (gegen Thiel), dass Ennodius hier auf die Verleihung des Privilegs anspielt (praef. XXV). 
hen, dass er nicht auf Informationen von Caesarius warten muss, um informiert zu sein - er weiß bereits vom weiteren erfolgreichen Verlauf der Reise.

Die lobenden Worte über Caesarius beginnen nicht mit individuellem, sondern mit stypischem « bzw. stopischem « Lob, dass Caesarius so vorbildhaft lebe, wie man es von einem Bischof erwarte: "Du übertriffst die anderen wie die Größe der Sonne im Vergleich mit den kleineren Sternen; wer Dich mit den inneren Augen betrachtet, wird belehrt. Denn während Du mit Deinem bloßen Antlitz die Reinheit unterstützt, strafst Du die Sünder auch ohne zu reden. Die Guten finden, wo Du auch gehst, was sie an Deiner Lebensweise nachahmen können; den Bösen wird gezeigt, was sie vermeiden müssen $[. .$.$] " (\$ 4) .{ }^{859}$ Speziell auf Caesarius richten sich hingegen die Bemerkungen über seine Fähigkeiten im Vortrag von (fremden) Texten: „Wer würde, wenn Du redest, nicht wünschen, nicht zu lesen, um mehr zu wissen $<$ d.h. jeder, der Caesarius hört, möchte auf Bücher verzichten $>?^{860}$ Indem Du Büchern durch Deinen Vortrag den wahren Glanz verleihst, unterrichtest Du auch Lehrer: wer immer jener größte Autor ist, er verdankt Dir, dass Du ihn durch Deinen Vortrag bereicherst « $(461,5) .{ }^{861}$ Das Lob richtet sich also nicht auf eigene Werke des Caesarius, sondern auf seinen Vortrag, wobei betont wird, dass es sich um fremde Texte handelt. ${ }^{862} \mathrm{Da}-$ mit könnte Ennodius darauf anspielen, dass Caesarius in seinen Predigten reichlich aus Augustin (cf. \$5 quicumque ille scriptorum maximus) und anderen schöpft. Er könnte auch darauf anspielen, dass Caesarius von seiner Gemeinde keine Höchstleistungen im Lesen erwartet, wie sich seinen Predigten entnehmen lässt, vgl. z.B.: "Denn wer dieser Lesung <sc. aus dem Evangelium> aufmerksam folgt, für den kann, auch wenn er die übrigen Schriften nicht lesen kann, dieser eine Text ausreichen, um alles Gute zu tun und alles Böse zu meiden« (Caes. Arel. serm. 158,1) ${ }^{863}$

$859(461,4)$ tu ceteros velut solis magnitudo astris minoribus conparata transgrederis; te qui interioris hominis oculis inspexit instructus est. nam cum et facie ipsa foveas puritatem, delinquentes feriato ore castigas. boni de conversatione tua, quocumque processeris, imitanda inveniunt; malis fugienda demonstrantur. [...]

860 Anders KenNell $(2000,174)$ : "Who would not wish, when you are speaking, to read so as to know more? «

$861(461,5)$ quis non optet te loquente, ut sciat plura, non legere? tu dum libris genium relatione concilias, et magistros informas: tibi debet quicumque ille scriptorum maximus, quod eum dote elocutionis amplificas. [...]

862 Es geht nicht um Inhalt und Sprache, sondern um den Vortrag, was Delage übersehen hat: "Parmi ses contemporains, Ennode, si soucieux de la langue, lui fait des compliments sur la force et la qualité de sa prédication. Les louanges d'Ennode sont sujettes à caution, mais elles laissent au moins supposer que la langue de l'évêque d'Arles ne suscitait de son temps aucune critique, même chez eux qui se piquaient d'être des lettrés" (Delage 1971, 183f.).

863 (Caes. Arel. serm. 158,1) qui enim lectionem istam diligenter adtendit, etiamsi reliquas scripturas legere non potuerit, ad omne opus bonum faciendum et ad omne malum fugiendum ista illi lectio sola sufficere potest. 
Es folgt eine äußerst verblüffende Passage, denn Ennodius kommt nun auf das Verhalten der Einwohner von Arles zu sprechen: »Woher hatten die Transalpiner diese gute Vorahnung, woher hatten meine Verwandten jene unverhoffte Erhabenheit, einen solchen Mann zu schicken? Doch was soll man bei irdischen Dingen nach dem Göttlichen fragen! Hätte also vor Dir der Hochmut des Palastes nicht am Boden liegen können? Hätte derjenige Dir das Gewünschte verweigern können, der sanfter ist als Schafe und den nur Vergehen kämpferisch machen? « $(\$ 6) .{ }^{864}$ Kein Wort von Arrest und Deportation, sondern: die Gallier hätten Caesarius »geschickt «, und seine "Wünsche" seien erfüllt worden. Ennodius stellt das Vorgefallene so dar, als hätten Caesarius' (und Ennodius' ehemalige) Landsleute ihn in weiser Voraussicht und guter Absicht zu Theoderich gesandt. Auch wenn die konkreten Vorwürfe nicht überliefert sind, so ist doch eindeutig, dass in Wirklichkeit Caesarius sich vor Theoderich wegen der ihm vorgeworfenen errata verteidigen musste.

Ennodius bricht das Lob ab mit einem Hinweis auf die einschränkenden Gesetze der Gattung Brief ( $\$ 6)$, und er bittet Caesarius um weitere Briefe $(\$ 7)$. Der Brief endet rätselhaft: "Berichtet mir bitte auch in einem Brief, was bei Euch die Bitte des Rusticus erreicht hat, der, soviel ich höre, seine Ausschweifungen mit dem Wort `Ehefrauen verhüllt und glaubt, dass ein gesetzliches Wort eine kriminelle Sache entschuldigen kann “ $\left(\$_{7}\right){ }^{865}$ Man könnte fast spekulieren, dass Ennodius hier irgendwie auf die Vorwürfe anspielt, gegen die sich Caesarius verteidigen musste; dafür spräche, dass Caesarius sich selbst (bzw. seine Sprache) gern als rusticus bezeichnet ${ }^{866}$ und dass die Vorwürfe wohl im Zusammenhang mit dem von ihm gegründeten Frauenkloster standen.

VoGel (praef. XXV) schließt aus dem Brief, dass Ennodius bei der Niederschrift noch nicht Bischof gewesen sei, da er Caesarius nicht als frater, sondern als dominus $(\$ 4)$ bezeichne (wobei Vogel selbst Caesarius' Stellung als Metropolit erwähnt und damit das Argument entkräftet); zwar sei die "perversa modestia« bei Ennodius üb-

$864(461,6)$ unde haec praerogativa Transalpinis, unde parentibus meis inauspicata sublimitas, ut talem virum miserint? sed cur inter terrena quaeritur res caelestis! potuit ergo ante te quodlibet palatii supercilium non iacere? potuit tibi cupita subtrahere, quem mitiorem ovibus sola faciunt errata pugnacem?

$865(461,7)$ deprecor etiam ut quid apud vos promoverit Rustici subplicatio, qui, quantum audio, fornicationes suas nomine vestit uxorum et vocabulo legis putat excusari posse rem criminis, mihi manifestetis ministerio litterarum.

866 Siehe z.B. (Caes. Arel. serm. 1,1) Si neglegentiarum mearum culpas et rusticitatem vel imperitiam diligens examinator attenderem [...]; (serm. 1,21 a.E.) [...] rusticissima suggestio mea $[\ldots]$; (serm. 86,1) ideo rogo humiliter ut contentae sint eruditae aures verba rustica aequanimiter sustinere. - Siehe dazu: KLINGSHIRN 1994, 146-151. E. Bona, Simplici et pedestri sermone... (sermo 1, \$20): Appunti sullo stile di Cesario di Arles, Università degli studi di Torino, Quaderni del dipartimento di filologia, linguistica e tradizione classica 4, Bologna 1995, 205-238. 
lich, gehe für einen Bischof aber doch zu weit; nach Vogel hätte Ennodius als Bischof dieser neuen Würde irgendwie Ausdruck verliehen. Allerdings ist, wie dargelegt wurde, der Ton des ganzen Briefs durchaus nicht nur bescheiden. Als Argument gegen eine frühe bzw. für eine späte Datierung der Wahl des Ennodius zum Bischof kann dieser Brief wohl nicht herangezogen werden.

\section{Fazit zu c. (Glückwunschschreiben)}

Der Empfehlung des Iulius Victor, ausführlich zu gratulieren und die Freude des Adressaten zu steigern, folgt Ennodius nur selten. Entgegen der communis opinio (cf. oben 285) sucht er fast immer die Möglichkeit, sich nicht an die Konvention zu halten: Er schreibt weder lange Lobreden und Freudenbekundungen wie Sidonius Apollinaris noch kurze wie Symmachus. Manche seiner Glückwunschschreiben hinterlassen einen zwiespältigen Eindruck, indem er zwar lobende Passagen schreibt, diese aber mit Ironie, spöttischen Anspielungen, Hinweisen auf die Macht der Rhetorik oder mit Verdrehungen der Tatsachen oder auch mit deutlichen Bitten durchsetzt. Wenn Ennodius schreibt, bevor der Adressat ihm von seinem Erfolg mitgeteilt hat, nutzt er die Gelegenheit, um über dessen mangelnden Eifer in der Korrespondenz und damit in der Freundschaft zu klagen. Hat der Adressat ihn informiert und dadurch zu einem Glückwunschschreiben raufgefordert‘, schreibt Ennodius Ermahnungen, dass der Adressat auch im hohen Amt nicht arrogant werden, sondern seine Demut zeigen solle, und zwar, indem er seine Freundschaft mit Ennodius bewahre und die Korrespondenz pflege. Es finden sich nur zwei durchgehend freundliche Glückwunschschreiben ohne Klagen und Ermahnungen, von denen das eine in der besonderen Situation entsteht, dass Ennodius den neuen Quaestor für dessen Amtsvorgänger Faustus bittet, der offenbar in eine schwierige Situation geraten ist und Hilfe zu benötigen scheint.

\section{d. Empfehlungsschreiben ${ }^{867}$}

Empfehlungs- und Bittbriefe, wie sie schon bei Cicero und Plinius einen erheblichen Teil der Briefsammlungen ausmachen, haben eine besondere Funktion, denn sie dienen in erster Linie nicht dem Austausch von Informationen oder der Pflege der Freundschaft, sondern sie sollen auf den Adressaten Einfluss nehmen, sich dem

867 Siehe auch die Ausführungen in Teil I zu den Empfehlungen für Parthenius und andere junge Männer, die zum weiteren Studium nach Rom gehen (oben 113f.). 
Empfohlenen gegenüber in bestimmter Weise zu verhalten. ${ }^{868}$ Allerdings wird diese offensichtliche eigentliche Funktion aus taktischen Gründen häufig verdeckt (siehe z.B. oben 217; 220); die Beschreibung der Fähigkeiten und Qualitäten des Empfohlenen nimmt im Laufe der Zeit immer weniger Raum ein und wird zuweilen wie nebensächlich angefügt. ${ }^{869}$ Der Empfehlungsbrief wird mehr zu einer Visitenkarte, die die Bekanntschaft des Empfohlenen mit dem Verfasser bestätigt.

Ennodius verfolgt auch in solchen Briefen ganz unterschiedliche Strategien bzw. nimmt verschiedene Rollen ein: Häufig hält er sich an die Konventionen und gibt sich freundlich, häufig ist er aber auch selbstbewusst und mehr fordernd als bittend, und erstaunlicherweise beginnt er viele Empfehlungen mit Vorwürfen gegen den Adressaten. Eine Taktik wurde bereits oben (262) dargestellt, dass Ennodius nämlich einigen Empfehlungen eine Praefatio voranstellt, um seine Sicherheit darüber auszudrücken, dass der Adressat dem Empfohlenen helfen werde, und er so weniger bittet als fordert, z.B.: »Unter Freunden und Männern in hohen Positionen ist die Absicht, Gutes zu tun, immer vorhanden, und jemand, der Bitten gewöhnlich gewährt, vermindert den Wert des Gewünschten nicht durch Zögern « $(93,1)$; "Nicht ohne Erfolg bittet man, wenn man dem Vater aller <sc. dem Papst $>$ Fremde empfiehlt $[\ldots]$ « $(416,1)$; »Es gehört sich, dass ich Gebührendes erhoffe und dass Ihr $z u$ stimmt $(444,1) .{ }^{870}$

In einer Untersuchung der Empfehlungs- und Bittbriefe des Symmachus, in dessen Briefcorpus diese mit einem Viertel einen auffällig hohen Anteil darstellen, arbeitet RoDA (1986) bestimmte Muster heraus, wie sie sich ähnlich auch bei Ennodius beobachten lassen: In den Empfehlungen des Symmachus wird der Nutzen für alle (in der Regel drei) Beteiligten der Handlung betont: für den Empfohlenen, den Empfehlenden und auch für den Adressaten (Roda 201). Die Vorteile für den Empfohlenen werden gern herabgespielt (ibid. 184): Dieser habe eine Empfehlung gar nicht nötig, und Symmachus schreibe nur, weil es eine gute Gelegenheit sei, dem Adressaten in einem Brief seine Freundschaft zu bekunden (ibid. 183f.), siehe z.B.: "[...] um gleichzeitig Dir die Ehre eines Grußes zu erweisen und ihm eine Empfehlung zukommen zu lassen« (Sy. 5,29). ${ }^{871}$ Die Empfehlung kommt zuweilen wie nebensächlich (praeter-

868 Treffend Matthews $(1974,64)$ zu den Empfehlungsbriefen des Symmachus: "not to inform but to manipulate, to produce results", "accumulation and exercise of patronage."

869 Z.B. $(62,1)[\ldots]$ iungitur quod $[\ldots] ;(87,2)[\ldots]$ additur quod $[\ldots] ;(135,2)[\ldots]$ huc adcessit quod [...]; eingeflochten in die Grußformel im letzten Satz z.B.: $(92,2) ;(321,2)$.

$870(93,1)$ Apud amantes et honore pollentes beneficiorum affectus in promptu est nec ulla preces, cui praestandi mos est, tarditate depretiat. $(416,1)$ Non inefficaciter poscit, qui parenti omnium peregrinos insinuat [...]. (444,1) Et me sperare quod pium est et vos decet adnuere.

871 (Sy. 5,29) $[\ldots]$ ut et tibi salutationis munus exsolverem et illi commendationis aliquid exhiberem. Siehe auch z.B. (Sy. 3,37) [...] ut una via et te excolerem salute dicenda et illius usui commodarem. (Sy. 3,76) Duo mihi grata proveniunt, quotiens a me litterae postulantur, et quod te honore salutationis inpertio, et quod operam commendationis praesto poscentibus. 
ea [...]) hinzu: "Vor kurzem habe ich Dir geschrieben, doch es verdrießt mich nicht, den Dir geschuldeten Gruß zu verdoppeln. Denn die Freundschaft kann im Schreiben kein Maß halten. Außerdem forderte die Bekanntschaft mit den Reisenden, $[\ldots]$ « (Sy. 2,89). ${ }^{872}$

Für den Empfehlenden ergeben sich verschiedene Vorteile: Er kann die Gelegenheit nutzen, Bekanntschaften wieder aufzufrischen (RoDA 185). Außerdem hat der Erfolg der Empfehlung Auswirkungen auf das soziale Prestige des Empfehlenden und auf seine Möglichkeit, auch weiterhin als Empfehlender auftreten zu können (ibid. 185f.). Zu betonen ist, dass Letzteres nicht moderne Deutung ist, sondern von Symmachus ohne Umschweife ausgesprochen wird, z.B.: "Mein Einfluss wird an der Macht Deiner hohen Position gemessen « (Sy. 2,20). ${ }^{873}$ Wenn er Würdige empfiehlt, steigt sein eigenes Ansehen beim Adressaten: "Wer sich für die Besten einsetzt, scheint weniger deren Vorteil zu unterstützen als vielmehr seine eigene Urteilskraft zu empfehlen" (Sy. 2,29) ${ }^{874}$ - Betont werden auch die Vorteile für den Adressaten (RodA 194), die z.B. im Anwachsen von dessen Ruhm bestehen, wenn er dem Empfohlenen hilft (siehe z.B. Sy. 1,77. 1,93).

Diese Beobachtungen zu Symmachus treffen auch auf etliche Empfehlungsschreiben (oder zumindest Elemente darin) des Ennodius zu. Häufig betont er, dass der Empfohlene eigentlich keine Empfehlung brauche. Auf diese Weise äußert er, der mit Lob explizit und auch tatsächlich sparsam und sehr gezielt umgeht, sich in Empfehlungen lobend über die Empfohlenen und bestätigt so seine eigene Aussage, dass er ungern den Gelobten direkt, sondern lieber gegenüber Dritten lobe (siehe oben 268). Allerdings lobt er weniger mit Beschreibungen von deren Fähigkeiten als vielmehr indirekt, nämlich eben mit der Bekräftigung, dass der Empfohlene die Empfehlung gar nicht nötig habe, zumeist in der Form von Sentenzen, z.B.: »Man müht sich mit überflüssigem Aufwand, Wohltaten zu erweisen, wenn man versucht, die Sonne mit Fackeln zu unterstützen. Vollendetes Ansehen braucht keine Ergänzung und einer, den seine Verdienste zum Gipfel der Freundschaft gebracht haben, braucht keine weitere Empfehlung« (59,1); »Als wenn man die Sonne mit Fackeln unterstützen und

(Sy. 7,86$)$ Et mei circa te propositi ratio poposcit, ut scriberem, et v. c. atque ornatissimo Eusebio adstipulatio mea deesse non debuit [...].

872 (Sy. 2,89) Paulo ante litteras dederam, sed debitam tibi salutationem geminare non piguit. namque amor officiorum modum non tenet. praeterea notitia commeantium postulavit, $u$ t commendationi eorum pagina adiecta proficiat; siehe auch: $(S y, 4,36,1)[\ldots]$ auxit praeterea scribendi causam vir spectabilis frater meus Bassus [...].

873 (Sy. 2,20) [...], quia potentia mea de tui honoris viribus aestimatur.

874 (Sy. 2,29) Pro optimis viris quisquis intervenit, non magis illorum videtur iuvare commodum quam suum commendare iudicium. 
das Meer mit einem kleinen Tropfen bereichern wollte, so betreibt man überflüssigen Aufwand, wenn man das empfiehlt, was von sich aus gefällt « $(425,1) .^{875}$

Wenn der Empfohlene den Brief auch eigentlich gar nicht benötige, biete der Brief doch immerhin dem Empfehlenden eine gute Gelegenheit, seiner Pflicht zum Schreiben nachzukommen, z.B.: "[...] also ist dieses mehr eine Schreibübung als ein Gefallen für den Reisenden. Meine Seele freut sich - bei welcher Gelegenheit auch immer -, an Euch zu denken, wenn ich auch dem Genannten durch mein Schreiben nichts nützen kann « $(53,2)$; »Doch ich habe Freude daran, häufig zu schreiben; denn wenn ich auch dem Überbringer nur wenig helfen kann, so erleiden doch meine eigenen Wünsche <sc. dem Adressaten zu schreiben> keine Einbuße« $(91,2){ }^{876}$

Wenn Ennodius hingegen Empfehlungen mit der Begründung einleitet, dass er als Kleriker die Verpflichtung habe, Bittenden zu helfen, ist dies wohl im Gegensatz zu den letzten Beispielen ein Hinweis darauf, dass die Empfohlenen von niedrigem Stand und in schwieriger Lage sind, so dass er ausdrücklich als Diakon für sie eintreten muss: "Ein Brief, mit dem man Unglückliche empfiehlt, entspricht meinen Vorsätzen “ (115,1); "Derjenige, dem seine Vorsätze befehlen, Unglückliche anzuhören, kann es nicht ablehnen « $(145,1)$; "Das Gesetz meiner Vorsätze lehnt es ab, mit Fürbitten geizig zu sein. Denn es kommt zur Last meines Gewissens hinzu, wenn ich einen Bittenden zurückweise« $(280,1) .877$

Zuweilen verweist Ennodius ausdrücklich auf die Unmöglichkeit, die Bitte um einen Empfehlungsbrief abzulehnen: »Überlegt, ob ich dem hohen Herrn den Erfolg seiner völlig gerechtfertigten Bitten <d.h. um dieses Schreiben $>$ hätte verweigern können " $(154,2)$; " [...] doch mein Gehorsam ist perfekt, wenn ich nicht verweigere, was immer der Höchste < gemeint ist hier der Bischof> fordert " $(274,2)$; "weder konnte ich den Bitten eines solchen Mannes meinen Beistand verweigern, noch durfte ich es« $(424,2) .{ }^{878}$ Ennodius betont so die Macht des Empfohlenen über ihn, wo doch tatsächlich der Empfohlene in dieser Situation der Unterlegene bzw. Abhängige ist. Da

$875(59,1)$ Supervacuis ad beneficia laborat inpendiis, qui solem certat facibus adiuvare. gratiae plenitudo adiectione non indiget, nec ulla requirit conmendationis augmenta quem ad amicitiarum cumulum merita pertulerunt. $(425,1)$ Quasi solem facibus adiuvet et mare exiguo umore locupletet, ita superfluis laborat inpendiis qui per se placitura commendat.

$876(53,2)$ ergo ad stili exercitium iunguntur haec, non ad benificium conmeantis. iuvat animum sub quavis occasione vestri meminisse, licet nominato scriptione nil tribuam. $(91,2)$ ego autem gaudeo scriptione multiplici, quia etsi parum tribuam perlatori, nulla proprii desiderii damna sustineo.

877 (115,1) Proposito obsecuntur paginae, quibus commendatio praestatur afflictis; $(145,1)$ [...] non potest adferre obvias manus, cui inperat propositum adflictos audire; $(280,1)$ lex propositi intercessionis refutat avaritiam. nam ad conscientiae meae sarcinam iungitur, si respuam supplicantem.

$878(154,2)$ cogitate si viro optimo negari effectus potuit et pia et iusta poscenti; $(274,2)$ sed perfecta oboedientia est, quicquid summus exigit, non negari; $(424,2)$ nec potui tanti viri precibus deesse nec debui. 
wir über die jeweils Unterstützten nichts wissen, muss ungeklärt bleiben, ob die diese Hinweise wirklich plausibel sind oder mehr bedeuten, als wir ahnen können.

Manchmal verweist auch Ennodius auf das eigennützige Motiv des Adressaten, durch die Unterstützung des Empfohlenen sein Sozialprestige zu steigern; zweimal schreibt er dies an Faustus: "Dieses werdet Ihr, tadellosester Mann, nicht verweigern - nicht zufrieden damit, dass nur Menschen in Italien Eure Güte kennen “ $(150,2)$; "Eurer Hoheit kommt durch den Bittenden Glanz zu, indem wir mit Bitten etwas erflehen, das üblich ist “ $(225,2){ }^{879}$ Ebenfalls zweimal gegenüber Papst Symmachus: "Wenn Eure Hoheit den Überbringer dieses Briefes freundlich aufnimmt, schmückt sie das glänzende Amt des Bischofs, wie es sich gehört" $(416,1) ;(226,4)$, siehe unten 363. - Von der Steigerung seines eigenes Prestiges spricht Ennodius nur selten (in 321,2 , siehe oben 338 ).

Besonders häufig wird der Nutzen für die Freundschaft zwischen Empfehlendem und Adressat betont. Zum einen kann der Adressat dem Empfehlenden einen Gefallen tun und so seine Freundschaft zu ihm zeigen: »Eure Hoheit möge also den Genannten im Gedanken an mich - wenn ich nicht als Unwürdiger bitte - mit doppelter Sympathie geleiten « $(68,2) ;$ [ [...] und ich bitte, dass im Gedanken an mich und zum Zeugnis Eurer Freundschaft diese Bitten erfüllt werden « $(93,2){ }^{880} \mathrm{Zum}$ anderen bezeichnet Ennodius als seinen eigenen Vorteil beim Empfehlen ganz überwiegend die Möglichkeit zur Kontaktpflege, d.h. die gute Gelegenheit, einen Brief zu schreiben und den Empfohlenen als Briefboten verwenden zu können - nicht er erweist dem Empfohlenen einen Gefallen, sondern dieser ihm, z.B.: "So erwies derjenige einen Gefallen, der um einen bat « $(395,1)$; »Es ist die höchste Freude, wenn sich ein Bote anbietet, der wegen seiner eigenen Schwierigkeiten den Wünschen anderer als Diener der Freundschaft einen Dienst erweist “ $(259,1)$; "Die himmlische Vorsehung hat es gut eingerichtet, dass ich in meiner Sorge ersehnte Boten finde, indem man mich um einen Gefallen bittet. Fern sei es von mir, anderen zu verweigern, was ich < doch eigentlich > mir selbst gewähre, und in schmutzigem Geiz das zurückzuhalten, was mich als Gebenden freut “ $(282,1)$; "Ich danke also dem Überbringer dieses Briefs, der anlässlich seiner eigenen problematischen Lage meinen Wünschen schenkte, dass die Sorgen meiner Seele, die keinen Boten hatten, die gewünschte Hilfe bekamen « $(291,2) .^{881}$ Besonders ausführlich formuliert Ennodius diesen Gedanken in einem

$879(150,2)$ quam rem, emendatissimi hominum, non negabitis, non contenti benignitatem vestram solos in Italia positos agnovisse; $(225,2)$ datur culmini vestro per supplicantem genius, dum, quod usus exigit, precibus inploramus; $(416,1)$ praesentium baiolum si corona vestra dignanter excipiat, praeclarum iuxta morem pontificis ornat officium.

$880(68,2)$ nominatum tamen pro mei consideratione magnitudo vestra gemino, si indignus precator non sum, favore comitetur; $(93,2)[\ldots]$ precor, ut consideratione mei in testimonium diligentiae postulatis detur effectus.

$881(395,1)[\ldots]$ sic contulit beneficium qui poscebat. $(259,1)$ Summa gaudiorum est oportunitas perlatoris, qui minister diligentiae per necessitates suas desideriis obsequium praestat alie- 
Schreiben an Apollinaris (41; zu ihm siehe oben 325): „Wunschgemäß dient ein fremdes Problem den eigenen Wünschen, wenn wir zu unserer eigenen Freude den Bitten anderer einen Dienst leisten. Wer würde nicht gegen Bezahlung für sich selbst zu erlangen suchen, was man einem anderen bei dieser Gelegenheit gewährt? Nun schulden mir die Boten dieses Briefs das, was ich <ihnen> schulde, und nicht nur fordern sie mich nicht auf, es zu begleichen, sondern erklären, dass sie mir verpflichtet seien. Es ist nicht Sorglosigkeit, dass ich selten Briefe schreibe, <sondern:> ähnliches - wie ich nun herausgefunden habe - Gutes $<$ d.h. Bitten um Unterstützung $>$ bietet sich nicht häufig « $(\$ 1){ }^{882}$ Als Dank für diesen Gefallen (beneficium) solle der Adressat den Überbringern des Briefs weiterhelfen, da ja auch dieser sich über die Gelegenheit freuen werde, von Ennodius einen Brief zu erhalten: "Mögen also die Boten, wenn ihr mich schätzt, von dieser Wohltat profitieren, die, wie sie von mir das erbeten haben, was ihnen <eigentlich> angeboten werden musste, so zu Euch, wie ich meine, mit dem Brief etwas Erwünschtes bringen. [...]« (\$2)..$^{883}$

Doch in der langen Reihe der Empfehlungsschreiben hält sich Ennodius nicht immer an die Konventionen und die geforderte Freundlichkeit. Zuweilen verstößt er gegen die Konventionen und gestaltet die Topoi in eigentümlicher Weise, wie an einigen auffälligen Beispielen dargestellt werden soll.

\section{d. 1 Zeugnis für das Verhältnis zwischen Empfehlendem und Adressat}

Ennodius spielt mit dem Motiv, dass die Unterstützung des Empfohlenen durch den Adressaten ein Beweis für die Freundschaft zwischen Empfehlendem und Adressat ist, im Brief an Bischof Constantius (153), indem er die Perspektive verändert; in diesem Fall stellt er es so dar, dass der Empfohlene diese Konvention ausnutzen und anhand seiner Bitte testen möchte, wie stark die Freundschaft zwischen Ennodius und dem Adressaten ist: "Vigilius, einer Eurer Subdiakone, möchte erproben, wie stark

nis. (282,1) Bene providentia superna disponit, ut dum a me beneficia postulantur, sic sollicitudo mea votivos inveniat perlatores. facessat negare aliis, quod mihi tribuo, et illud avaritia sordente continere, quod sublevat largientem. $(291,2)$ gratias tamen praesentium perlatori, qui necessitatis suae occasione desideriis meis praestitit, ut inter aestus animorum, quibus baiulus deerat, optatum praeberet officium.

$882(41,1)$ Pro voto militant desideriis propriis necessitates alienae, dum in gaudium nostrum aliquorum precibus exhibemus obsequium. quis non pretio propter se quaereret, quod alteri sub hac occasione praestatur? debent mihi nunc perlatores praesentium debita mea et non solum me ad solutionem non pertrahunt, sed se fatentur obnoxios. non est incuriae quod raro a me scripta prorogantur: similia frequenter, ut nunc repperi, bona se subtrahunt.

$883(41,2)$ inveniant ergo huius benificii fructum, si me diligitis, portitores, qui sicut a me ea, quae erant obferenda, exegerunt, ita ad vos, ut opinor, de scriptionis conmercio optata perducunt. [...]. 
Eure Liebe zu mir ist; er versucht, unsere Freundschaft als günstige Gelegenheit für seinen Aufstieg zu ergreifen, und will am Anwachsen seiner Ehren den Zustand unserer Freundschaft ermessen, auf dass er den Ertrag bekomme, den wir bei der Ernte der Liebe eingebracht haben. Führt ihn, wenn ich es verdiene, zu den Weihen des Diakonats, damit diese Würde des Genannten mir nützt bei der Hoffnung, Größeres zu wünschen « $(\$ 1) .{ }^{884}$ Im letzten Satz bedient Ennodius sich dann einer ähnlichen Technik wie Vigilius, indem er die Erfüllung seiner Bitte durch eine Bekräftigungsformel (sed ne [...] sic) an einen Wunsch für Constantius knüpft: »Doch möge meine Bitte nicht vereitelt und ihr nicht der Erfolg verweigert werden, so wahr ich wünsche, dass Ihr die Euren Qualitäten gewährte Stellung <sc. als Bischof> lange Zeit innehaben möget “ $(\$ 2) .{ }^{885}$

In Empfehlungsschreiben für seinen Neffen Parthenius spricht Ennodius unverblümt nicht von einem Gefallen unter Freunden, sondern von einer ihm zustehenden Vergeltung seiner Verdienste, z.B. gegenüber Faustus: »Ich sende Euch jemanden, an dem gemessen werden kann, wie meine Verdienste beschaffen sind $<$ d.h. wenn ich mich um Euch verdient gemacht habe, werdet Ihr ihn unterstützen >« $(225,3) .{ }^{886}$ Wenn Ennodius sich so darauf bezieht, dass die Erfüllung des Wunsches von ihm selbst abhänge, kann dies bedeuten, dass der Empfohlene keine eigenen Qualitäten aufweisen kann. In einem anderen der vier Empfehlungsschreiben für Parthenius (226), das sich an Papst Symmachus richtet, führt Ennodius dieses Motiv besonders ausführlich aus, wobei er deutlich durchblicken lässt, dass der Empfohlene keine eigenen Verdienste vorzuzeigen hat. Bevor der Name des Empfohlenen fällt, wird am Beispiel Davids gezeigt, dass der Himmel den Nachkommen gewähre, was eigentlich nur einer verdiene: „Groß ist der Glanz eines Gebers, wenn er das, was nur einer verdient, vielen gibt. Man folgt den Grundsätzen der Himmlischen, von denen die Nachkommenschaft erhält, was eine einzige Person begründet hat. So traf wegen David die Vergehen des Israelitischen Volkes keine Strafe, weil dem Volk die Vollkommenheit des Anführers zuhilfe kam, und der Glaube dieses Mannes hat das Volk entweder aus der Verfehlung gerissen oder in der Gunst unterstützt « $(\$ 2) .{ }^{887} \mathrm{Im}$ Vertrauen darauf $\left(\$_{3}\right.$ hac [...] fiducia) komme Parthenius, der Sohn seiner Schwester, zu Symmachus und

$884(153,1)$ Vigilius subdiaconus vester experiri voluit, quanta mihi a vobis caritas redderetur, et ad occasionem profectus sui coniunctionem nostram conatus adducere, statum inter nos amicitiae, dum augetur honoribus, vult metiri, quatenus ad ipsum fructus redeat, quem ex diligentiae messe condidimus. hunc, si mereor, ad diaconii sacramenta perducite, ut dignitas praefati ad spem mihi proficiat maiora poscendi.

$885(153,2)$ sed ne petitionem meam negatus frustretur effectus: sic concessum meritis vestris locum per longa temporum intervalla teneatis.

$886(225,3)$ direxi personam, in qua meritorum meorum status aestimetur.

887 (226,1f.) grandis est pompa praestantis, quotiens quod unus meruit, plurimis repensatur. (\$2) superorum instituta sectantur, per quos generatio recipit, quod persona condiderit. sic 
nach Rom. Diese Einleitung wirft einen Schatten auf den Empfohlenen: Es klingt durch, dass er - wie das von David unterstützte Volk - keine eigenen Verdienste habe. Im Folgenden wird dieser wenig positive Eindruck bestätigt: Ennodius lobt die studia litterarum, weil man zunächst lerne, seine Fehler abzulegen ( $\$ 3$ ante incrementa peritiae vitia dediscuntur, vgl. Sen. epist. 50,7 virtutes discere vitia dediscere <est>). Ennodius bemüht sich weder, das Wort vitia in diesem Empfehlungsschreiben zu vermeiden (vgl. auch delicta, poena, error im biblischen Beispiel), noch ein lobendes Wort für Parthenius zu finden. Vor dem abschließenden Gruß betont er nochmals, dass Symmachus durch seine Unterstützung des Parthenius zeigen könne, wie sehr er Ennodius schätze: "Ihr habt eine ,Geisel`, an der die Qualität meiner Verdienste Euch gegenüber ganz deutlich wird <d.h. daran, wie Parthenius behandelt wird, lässt sich ablesen, wie sehr Ennodius geschätzt wird $>(\$ 4) .{ }^{888}$ Abschließend verweist Ennodius kurz auf den Nutzen für den Adressaten, dessen Prestige sich steigere, wenn er die Bitten erfülle: »[...] und ich bitte, dass der Überbringer dieses Briefs als Euer Diener ein glückliches Schicksal haben und bei Euch zu den 'Fremden ${ }^{889}$ zählen möge; denn was meinen Bitten gewährt wird, das schmückt Euer Amt über seinen <bereits vorhandenen $>$ Schmuck hinaus « $(\$ 4) .{ }^{890}$ - Wie sehr dieses Schreiben für den eigenen Neffen aus dem Rahmen fällt, zeigt ein kurzer Blick auf die drei anderen, erheblich kürzeren, Empfehlungen an Symmachus: Im Schreiben (154) für die Söhne eines Laurentius betont er die Sorge des Vaters ( $\$ 1$ sollicitudine genitali; trepidante diligentia), dem er die Bitte nicht habe abschlagen können $(\$ 2)$; er erinnert Symmachus an dessen versprochene benignitas, für die er jetzt ein testimonium erhoffe $\left(\$_{3}\right)$. Im Schreiben (409) für einen offenbar verwaisten ( $\mathrm{cf}$. $\$ 1$ orbatos) jungen Adligen ( $\$ 1$ ortus nobiliter) spricht er zuversichtlich davon, dass Symmachus in seinem Amt Waisen und Fremden helfe; er bittet darum, pro mei consideratione $(\$ 2)$ seine übliche Hilfe zu verdoppeln. Im Brief (416) für Beatus spricht er mit noch größerer Zuversicht: Der Vater aller helfe den Fremden ( $\$ 1$ peregrinos), und der Adressat helfe auch ungebeten; Beatus benötige keine langen Lobesreden; hier betont er den Nutzen für Symmachus, ähnlich wie am Ende des Briefs für Parthenius: Wenn er Beatus freundlich

Israelitici delicta populi propter David poena non tetigit, dum genti opitulata est praecessoris integritas, et fides hominis aut eripuit de errore populum aut iuvit in gratia.

$888(226,4)$ habetis obsidem, in quo dilucide meritorum apud vos meorum qualitas innotescat. Anders verstanden von KenNell $(2000,45) »[\ldots]$ should regard Parthenius as a sort of hostage for his uncle's good behaviour."

889 Auf das Gebot der christlichen caritas, Fremde aufzunehmen, weist Ennodius Symmachus in zwei weiteren Empfehlungsschreiben hin, siehe oben 113.

$890(226,4)[\ldots]$ precor, ut perlator praesentium famulus vester felici sorte peregrini apud vos nomen excipiat, quia quod adtributum fuerit precibus meis, vestrum supra dotes suas ornat officium; anders Kennell (2000, 45): Ennodius bitte, Parthenius "may acquire a good name among you by a stranger's happy lot, because what will have been bestowed by my prayers, your office embellishes above its own endowments." 
aufnehme, werde seinem Amt Schmuck verliehen. Wenn Ennodius im Schreiben für Parthenius so wie sonst nie (auch nicht gegenüber anderen Adressaten von Empfehlungen) sein eigenes Verdienst betont, dann dürfte sein eigentliches Ziel dabei wohl nicht gewesen sein, den Neffen in ein schlechtes Licht zu rücken; vielleicht sieht er in dieser Empfehlung für einen Verwandten eine gute Gelegenheit, Symmachus an seine Dienste im Kampf gegen Laurentius zu erinnern.

\section{d. 2 Empfehlung nach langem Schweigen}

Symmachus kommt gelegentlich in die Situation, eine Empfehlung an einen Korrespondenten zu schreiben, mit dem der Kontakt abgebrochen war, und er zeigt sich erfreut, ihn bei dieser Gelegenheit wieder auffrischen zu können. Dabei versucht er zunächst, den konkreten Anlass vergessen zu lassen, z.B.: "Wenn Du Dich noch an unsere alte Freundschaft erinnerst und sie nicht durch das Vergessen vermindert wurde, glaube ich, dass Du Dich über meinen Brief freust, den ich im Vertrauen auf unsere gegenseitige Zuneigung schreibe $[\ldots]$ « (Sy. 9,1). ${ }^{891}$ - Häufig wird darauf hingewiesen, dass beide länger nicht geschrieben haben, z.B.: "Das Säumen muss beendet und unser Eifer muss auf das Gespräch miteinander gerichtet werden, damit nicht die Vernachlässigung des Schreibens die Erinnerung an unsere alte Freundschaft verringert; damit Du diese künftig lieber pflegst, nimm hier von mir den Anfang. Hier also mein Brief, der Dir einen Gruß bringt; dass Du Dich darüber gefreut hast, wird sich zeigen, wenn Du mich nachahmst und ebenfalls schreibst." Dann schließt er die Empfehlung an, die er witzig mit dem Gedanken an das lange Schweigen verbindet: »Wenn aber dieser Brief zudem als Ertrag Deinen Schutz für den Überbringer erbitten wird, dann werde ich den Schaden beklagen, der durch mein bisheriges Schweigen entstanden ist. Denn dann wird feststehen, dass ich weiteren Personen hätte helfen können, wenn ich eher begonnen hätte, mich an Dich zu wenden « (Sy. 7,42) ${ }^{892}$ - In einem anderen Fall weist Symmachus darauf hin, dass der Adressat nicht schreibe, bringt aber selbst entschuldigende Gründe für diesen vor: »Ich schreibe Dir mit der Zuversicht, die Du mir gegeben hast. Seit langem bist Du sparsam im Schreiben, doch ich will Deinem Beispiel nicht folgen, da ich ja weiß, dass einem Mann, der sich auf dem Gipfel der Ehren befindet und der sich daher um viele wichtige Dinge kümmern muss, weniger

891 (Sy. 9,1) Si amicitiae veteris memoria perseverat nec ulla oblivione tenuata est, credo, quod litteras meas libenter accipias, quas fiducia mutui amoris emisi [...].

892 (Sy. 7,42) Abrumpenda cessatio est et in affatus mutuos cura tendenda, ne veteris inter nos amicitiae memoriam scribendi neglectus adtenuet; quam ut libentius dehinc foveas, a me sume principium. en tibi litteras salutationem ferentes, quas sensibus tuis voluptati esse testabitur officii aemulatio. quin si etiam portitori fructum patrocinii tui sermo iste quaesiverit, praecedentis silentii mei accusabo dispendia. constabit enim, pluribus me potuisse consulere, si te adloqui ante coepissem. Siehe auch (Sy. 9,35). 
die Absicht fehlt als die Möglichkeit. Denn es ist ja so, dass man es für entschuldbar hält, wenn etwas nicht mit Absicht versäumt wird. Ich bin mir jedoch, wie es meine Art ist, Deiner Freundschaft sicher und verweigere das übliche Schreiben nicht, wobei ich es als höchste Gunst und Ehre ansehen werde, wenn meinem Bekannten, der Dir diesen Brief bringt, ein Ertrag für diesen Dienst an uns <sc. dass er den Brief überbringt $>$ zuteil wird « $\left(\right.$ Sy. 1,26) ${ }^{893}$ - Entsprechend bringt Symmachus einmal einleitend vor, der Adressat könne ihm, Symmachus, sein Schweigen nicht vorwerfen, da er ein aufreibendes Amt bekleidet habe: "Du kannst mir mein langes Schweigen nicht vorwerfen, da Du wusstest, dass ich bis jetzt im Sacer comitatus <=Gefolge des Kaisers > war; da ich diesen neulich verlassen habe, widme ich mich jetzt wieder der Ehrerweisung, meinen Gruß auszusprechen. Eine Antwort wird zeigen, dass Du meinen Brief gern erhalten hast. Inzwischen empfehle ich den Überbringer dieses Briefs $[\ldots]$ « (Sy. 9,8). ${ }^{894}$

Wenn Ennodius in Empfehlungsbriefen darauf hinweist, dass er mit dem Adressaten lange keinen Kontakt mehr hatte, geht er anders vor: Meistens beginnt er mit heftigen Klagen und Vorwürfen wegen der Schreibfaulheit des Adressaten. Eine Ausnahme ist das Empfehlungsschreiben an seine Verwandte Archotamia (291), in dem er sich (wie in etlichen anderen Briefen an Frauen) sehr freundlich gibt und betont, dass es der Zuneigung und Verwandtschaft nicht schade, wenn man länger schweige, dass es aber förderlich sei, wenn man schreibe (siehe oben 218). Abgesehen von dieser Ausnahme erneuert Ennodius seine Kontakte anstatt mit einer captatio benevolentiae mit Klagen und Vorwürfen wegen des fehlenden Eifers in der Korrespondenz. Die Vorwürfe führen explizit oder implizit zu der Aufforderung, fortan eine bessere Gesinnung zu zeigen und die Bitte zu erfüllen. Dies ist sozusagen die komplementäre Methode zur >verpflichtenden ‘ Praefatio, in der Ennodius seine Sicherheit darüber ausdrückt, dass der Empfohlene unterstützt werden wird (siehe oben 357). Auch die direkten Vorwürfe ,verpflichten` den Adressaten zur Gewährung der Bitte: Er soll den Empfohlenen unterstützen, um dadurch das ,Vergehen` in der Korrespondenz wiedergutzumachen.

893 (Sy. 1,26) Utor apud te fiducia, quam dedisti. dudum parcus es litterarum, sed non imitabor exemplum, ut qui noverim, viro in specula honorum locato et ideo varia et magna curanti non tam studium deesse quam copiam. ea quippe natura rerum est, ut quae praeter industriam negleguntur ignoscenda ducamus. ego tamen securus, ut soleo, amoris tui officium sollemne non renuo in summa gratia et honore positurus, si familiari meo, qui has tibi litteras dabit, fructus aliqui pro tanta in nos sedulitate responderit. vale.

894 (Sy. 9,8) Arguere diuturnum silentium meum non potes, qui me in sacro comitatu hactenus fuisse didicisti; unde nuper regressus honorificentiam dicendae salutationis exerceo. vicissitudo testabitur, quod paginam meam libenter acceperis. interea commendo scripta reddentem $[\ldots]$. 
Bischof Stefanus ( 87 ) wird vor der wie zweitrangig behandelten Empfehlung ( $a d-$ ditur quod [...]) zunächst vorgeworfen, lange nicht mehr geschrieben zu haben; Ennodius schreibt es der Macht seiner Freundschaft zu - nicht, wie in solchen Briefen zur Kontaktaufnahme üblich: dass er schreibe, sondern: dass er sogar einem Bischof solche Vorwürfe mache: "Seitdem Eure Verdienste das ihnen zustehende würdevolle Ansehen bekommen haben und ihnen die Ehre erwiesen wurde, die Euer Lebenswandel fordert, habe ich aufgrund meiner Sünden keinen Brief von Eurer Seligkeit erhalten. Es passt nicht zu Euren Vorsätzen und zu Eurem Charakter, Bittende zu vergessen, wie es mit mir geschieht. Eure bischöfliche Autorität möge meine Vermessenheit nicht anklagen. Es kommt selten vor, dass die Liebe bedenkt, welche Rechte sie sich nehmen darf < d.h. aus lauter Liebe wagt er es, einem Bischof solche Vorwürfe zu machen, ohne an seine Position zu denken>. Niemals kann sich derjenige richtig einschätzen, den die Macht der Liebe antreibt « $(\$ 1){ }^{895}$ Als hätte er Stefanus das Vorangehende in jedem Fall geschrieben, fügt er die Empfehlung an: "Hinzu kommt, dass ich es dem Boten dieses Briefs nicht abschlagen konnte, ihn, den Wohlgeborenen, der in bestimmten Angelegenheiten nach Gallien reist, mit Euch, Höchster, durch einen Brief von mir bekanntzumachen. Ich empfehle ihn in aller Demut und bitte, dass dafür gesorgt wird, dass ich durch ihn mit einem Antwortbrief aufgemuntert werde" (\$2). ${ }^{896}$ Der Brief endet mit einem Gruß und der Bitte um unterstützende Gebete. - Die Empfehlung wird als eine Nebensache bzw. Selbstverständlichkeit hingestellt, die expliziten Bitten und Wünsche richten sich auf eine briefliche Antwort ( $\$ 2$ rogo) und auf die Gebete des Stefanus ( $\$ 3$ spero).

Dem römischen Diakon Hormisda wirft Ennodius in einem Empfehlungsbrief (417) zunächst vor, dass er ihn vergessen habe und nicht mehr schreibe, seit er immer höher aufsteige; am Ende spielt er dann deutlich darauf an, dass Hormisda schon zum Nachfolger von Papst Symmachus ausersehen ist: „Wenn Euer versprochenes Wohlwollen mir gegenüber anhielte, würde es durch häufige Briefe bestätigt. Diejenigen, die ein glückliches Gelingen zum Gipfel gebracht hat, beachten Niedrige kaum. Es ist hart, wenn die Hoffnung auf Erfolg die Bande der Freundschaft zerschneidet - sie $<$ die Hoffnung?> darf die Freundschaft nicht benachteiligen, deren Wünschen sie ent-

$895(87,1)$ Postquam meritis vestris dignitas restituta est et honor quem exegit vita conlatus, nulla beatitudinis vestrae pro peccatis meis scripta suscepi. aliena est a proposito vel a moribus vestris circa supplices quae in me servatur oblivio. temeritatem meam pontificalis non accuset auctoritas. vix est ut diligentia quid iuris possit habere respiciat. numquam se metitur quem stimulat caritatis imperium. - Cf. $(155,2)$ numquam in amore vires interrogo, oben 315 .

$896(87,2)$ additur quod perlatori praesentium obvias manus adhibere non potui, nisi ut bene natum hominem Gallias pro certis negotiis expetentem ad coronae vestrae notitiam mei perducerem sermonis officio. quem tota humilitate commendans rogo, ut per eum vicariis relevari procurer alloquiis. 
spricht und gefällt« $(417,1) .{ }^{897}$ Hormisda erhält nun die Gelegenheit zu zeigen, dass seine Freundschaft doch nicht ganz erloschen ist; Ennodius betont, dass es nur recht sei (iustum est), dass Hormisda den Empfohlenen unterstütze: "Wenn Ihr also etwas Freundschaft zu mir bewahrt habt, wenn noch ein Funke der versprochenen Freundschaft lebendig ist, empfehle ich Euch Beatus, einen edlen jungen Mann, der Euch diesen Brief übergibt; es gehört sich, dass Eure Seligkeit im Gedanken an mich für ihn einen Verwandten und eine Heimat darstellt. Sei sein besonderer Beschützer, der Du bald der Beschützer aller sein wirst. Mein Herr und Bruder, ich grüße demütig und bitte Euch, schnell zu schreiben, wie gut es Euch geht« $(417,1 \mathrm{f}.){ }^{898}$

Probinus, der im Rang eines Patricius stand (cf. SсHÄFER 1991, 98f.), hatte Ennodius während seiner schweren Krankheit gesehen. In einem Empfehlungsbrief an ihn (426; er erhält nur diesen Brief) reflektiert Ennodius darüber, wie unterschiedlich Höher- und Niedriggestellte Freundschaften schließen: Während die Untergebenen lieben, könne man von den Höheren nur Worte erwarten - allerdings habe er von Probinus nach seiner Genesung immerhin Worte, d.h. einen Brief, erwartet: "Wenn Eure Hoheit meine Bitte im Gedächtnis bewahren würde, hätte sich das in häufigen Briefen gezeigt; auch würde nicht das Vergessen diejenigen begraben, die Ihr in Ligurien freundlicherweise die Euren nanntet. Doch weil diejenigen, die an Stand und Macht voneinander getrennt sind, auch hinsichtlich des Gesetzes der Freundschaft nicht vergleichbar sind, zeigt Ihr Untergebenen perfekte Freundschaft, wenn sie würdig sind, von Euch angesprochen zu werden; denn Ihr schließt mit diesem Unterschied Freundschaften, dass Ihr Euch nur dazu bringen lasst, <uns > zu beachten, wir $<$ hingegen dazu $>,<$ Euch $>$ zu lieben. Es wäre eine anmaßende Haltung von Niedrigen, mehr als Worte von den Mächtigen zu erwarten. Durch die Macht der Freundschaft habe ich mich zur Klage hinreißen lassen. " Die konkrete Klage folgt: Probinus hätte Ennodius eines Briefs für würdig halten müssen, denn immerhin habe Christus ihn der Rettung aus der schweren Krankheit für würdig gehalten: "Nach meiner Lebensgefahr, die Ihr gesehen hattet, hättet Ihr mich eines Briefs für würdig halten müssen, schon weil mich Wiederauflebenden das gerade geschehene Wunder empfahl. Ich glaube, dass diejenigen, die die Macht unseres Erlösers aus dem Grab geret-

$897(417,1)$ Si dignatio circa me promissa duraret, adsereretur frequentia litterarum. vix respiciunt humiles, quos ad arcem eventus prosper evexerit. grave est, si spes secundarum rerum caritatis nexus incidat: non debet praeiudicare diligentiae, cui secundum vota blanditur.

$898(417,1 \mathrm{f}$.) si tamen aliquid circa me gratiae custoditis, si vivit amoris scintilla polliciti, Beatum commendo nobilissimum adulescentem praesentium portitorem, cui iustum est ut consideratione mei et parentem beatitudo vestra inpendat et patriam. $(\$ 2)$ esto specialis tutor, omnium mox futurus. domine frater, salutationis humilitate depensa rogo, ut sub celeritate quam bene valeatis scriptione signetis. 
tet hat, der Gunst der Guten würdig sind “ (\$1f.). ${ }^{899}$ Nach diesen Vorwürfen folgt die Empfehlung: »Obwohl ich gegen mein Anstandsgefühl verstoße und redselig bin und mir nicht einmal in Bezug auf mich selbst <Eurer Freundschaft> sicher bin, empfehle ich dennoch Verwandte. Der Überbringer dieses Briefs, der Sohn des verehrten Faustinus, lässt aufgrund seines Vaters viel Gutes hoffen. Ich bitte Euch, diesen zu unterstützen, da Ihr gut wisst, in welchem Licht die Sitten seines Vaters strahlen; auBerdem darf niemand, den die Autorität seiner Lebensweise und seiner Abstammung stärkt, zu anderen als zu Euch streben. Mein Herr, ich grüße also ergebenst und bitte, dass ein Brief Euer Wohlergehen melden möge« $(\$ 2 f.){ }^{900}$

Mit einer Bitte endet ein Brief an Agapitus (122), der aber zunächst mit einer paradoxen Wendung zum Schreiben aufgefordert wird (vgl. auch das vorwurfsvolle Glückwunschschreiben an ihn, 18, oben 333). Der Brief beginnt mit einer längeren Periode, in der zunächst auf Agapitus' Wechsel vom Privatmann zum vielbeschäftigten Beamten bei Hofe hingewiesen wird: »Ich dachte, dass, seitdem sich Eure Hoheit für das Allgemeinwohl einsetzt und Ruhm an die Stelle der Muße getreten ist, seitdem Euch die ständige Sorge um Ravenna beschäftigt, wobei Ihr Eure eigene Ruhe vernachlässigt und unsere von Grund auf stärkt, und seitdem aus dem Glanz eines Privatmannes eine Zierde des Reiches wurde, da der Glanz des Hofes sich neues Licht hinzufügte, das einem Privathaus entzogen wurde, und der Herr der Dinge richtig eingeschätzt hat, dass sein Reich weniger prunkvoll war, als er Euch nicht hatte, - da dachte ich, dass [...].« Sehr naheliegend ist nach dieser Beschreibung der Situation des Agapitus nicht, was Ennodius dachte: »[...], dass Ihr mich angesichts der geringen Entfernung mit häufigen Briefen aufmuntern müsstet« $(\$ 1) .{ }^{901}$ Der vielbeschäf-

899 (426,1f.) Si apud eminentiam vestram subplicatio mea recordatione subsisteret, crebra scriptione patuisset, nec quos apud Liguriam vestros dignatione vocabatis, sepeliret oblivio. sed quia loco et opibus divisi nec diligentiae lege conparantur, ideo perfectam subiectis caritatem, si digni sint adlocutione, praestatis hac in amicitiam discretione coeuntes, ut vos cogamini tantum respicere, nos amare. (\$2) erit vilium superba condicio, si plus a potentibus quam verba praestulentur. ad querellam descendi caritatis imperio. debuistis me post periculum, quod videratis, dignum putare conloquio, vel quia recentis mysterii reviviscentem conmendabat adsertio; puto quod digni sint bonorum gratia de sepulcris redemptoris nostri potentia restituti.

900 (426,2f.) ego tamen, quamvis sim prodigus frontis et garrulus, necdum de me fiduciam gerens propinquos insinuo. $\left(\$_{3}\right)$ praesentium portitor domni Faustini filius sufficienter bona pollicetur merita de parente: hunc ut vos foveatis, imploro, quia bene nostis qua sit creator eius morum luce conspicuus, nec debet ad alios festinare nisi ad vos quemcumque vitae auctoritas armat et generis. ergo, domine mi, obsequio salutationis inpenso rogo, ut prosperitatem vestram epistolaris cura manifestet.

$901(122,1)$ credidi, postquam magnitudo vestra bonis est inpensa generalibus et otium migravit in gloriam, postquam Ravennatibus excubiis occupati, dum quietem vestram neglegitis, nostram omni soliditate firmatis et privatus genius ad regni decora transivit, quando no- 
tigte Adressat hätte wahrscheinlich eher erwartet, dass er selbst aufgemuntert werden müsste oder dass Ennodius zumindest verstehen würde, warum er keine Zeit zum Schreiben hat - Agapitus wird die Topoi gekannt und die paradoxe Pointe gewürdigt haben. Ennodius zeigt sich sehr enttäuscht: »Doch die unnützen Überlegungen meiner Hoffnung wurden von meinen Sünden zunichtegemacht. Eure ungetrübt heitere Seele sendet keine Briefe als Beweis der Freundschaft. Es ist hart, wenn ich die Freundschaft nicht verdient habe, härter, wenn ich die, die ich erlangt hatte, vielleicht getrübt habe« $(\$ 2) .{ }^{902}$ Mögliche Entschuldigungen des Agapitus lässt Ennodius nicht gelten: "Doch ich weiß, dass das mit Wolken von Erklärungen, die zur Wahrheit passen, verdeckt werden muss: dass es bei Privatleuten Briefe gebe, so etwas aber von Beschäftigten nicht mit Recht gefordert werden könne. Doch ich weiß, dass ein in der Freundschaft festes Herz ihr das Schuldige nicht verweigert, mit welchen Lasten und Widrigkeiten es auch beschäftigt sein mag “ ( $\$ 2 f.) .{ }^{903}$ Dann verweist er auf den Auftrag des Boten: "Nun will ich nicht übermäßig klagen. Ich leiste ehrerbietig meinen Gruß und bitte Euch, den Antrag, den der Bote dieses Briefs bei Euch abgibt, zum gewünschten Ergebnis zu führen « $(\$ 3) .{ }^{904} \mathrm{Ob}$ es sich bei der suggestio um die im Brief genannte Bitte um eine Antwort oder um ein Anliegen handelte, das der Bote mündlich übermitteln sollte, lässt sich nicht entscheiden.

Mit Klagen beginnt Ennodius Empfehlungsschreiben auch in dem Fall, dass er einräumt, selbst lange nicht geschrieben zu haben: Einen Brief an Apollinaris (151; zu ihm siehe oben 325) füllt er mit entsprechenden Vorwürfen - obwohl er andeutet, dass er selbst auch kein fleißiger Korrespondent war -, um dann in den letzten Satz kurz seine Bitte einzuflechten. Er betont ausführlich die Bedeutung von Korrespondenz für die Freundschaft: „Indem Ihr das Schweigen gegenüber Eurem Freund in die Länge zogt, habt Ihr zur körperlichen Abwesenheit <auch> die Seele hinzugefügt. Indem Ihr Eure Briefe zurückhieltet, wuchs die Entfernung, die bis dahin unbedeutend war, ins Unermessliche. Der Verzicht auf das Schreiben hat dazu geführt,

vam lucem de domesticis abstractam sinibus palatinus sibi fulgor adiecit et angustiorem fuisse regni sui pompam rerum dominus, cum vos non habuit, recte metitus est, pro vicinitate regionum crebris me relevandum esse conloquiis.

$902(122,2)$ sed inefficacibus spei meae inluserunt peccata consiliis. nullas paginas ad diligentiae testimonium mens serena transmittit. grave est si amorem non merui, gravius si quem exegeram forte turbavi.

903 (122,2f.) scio tamen haec congruentibus veritati excusationum nubibus esse claudenda: in privatis inveniri munera litterarum, non recte ab occupatis ista disquiri. (\$3) sed novi firmam in affectione conscientiam inter quaevis pondera et adversa distractam debita sua gratiae non negare.

$904(122,3)$ nunc nolo esse prodigus in querellis. salutationis reverentiam solvens deprecor, ut suggestionem, quam apud vos deposuerit praesentium portitor, ad votivum perducatis effectum. vale 
dass die Vorsorge der alten Zeit <sc. die Erfindung des Briefschreibens, siehe oben 209> der Freundschaft nichts nützt. Freundschaft setzt Schimmel an, wenn man mit Worten geizig ist und ihr keine frische Luft zukommen lassen will. Nicht gepflegt wird eine Freundschaft, wenn sie nicht in Briefen gezeigt wird. Häufiges Schreiben nährt mit lebendiger Nahrung die den Herzen eingepflanzte Freundschaft« $(\$ 1) .{ }^{905}$ Die folgenden Vorwürfe enthalten immerhin ein Lob der Briefe, die Apollinaris früher geschrieben hat: »Bruder, es wäre besser gewesen, wenn Du meine Wünsche zu keiner Zeit erfüllt hättest, als mir <nun> das oft Gewährte vorzuenthalten; denn Herzen, die Du kunstreich gefüttert und mit süßen Speisen auf den Geschmack gebracht hast, können keine Ruhe kennen. Indem Du nämlich eine ganze Weile lang geschrieben hast, ließest $\mathrm{Du}$ mich die Trennung vergessen, da $\mathrm{Du}$ in die angenehmen Briefe Dein verehrungswürdiges Bild einwobst« $(\$ 2) .{ }^{906}$ Die nächsten Sätze scheinen darauf hinzuweisen, dass Ennodius mit seinen Vorwürfen im Glashaus sitzt, d.h. selbst länger nicht geschrieben hat: »Doch nun sehe ich die Hände der Reisenden leer und durchsuche sie mit leeren Händen.«Wenn Ennodius die Reisenden, d.h. die potentiellen Überbringer von Briefen, als nudus inquisitor fragt, könnte dies bedeuten, dass er selbst den Reisenden nichts, also keine Briefe, mitzugeben hat. In diese Richtung weist auch das Folgende: "Doch ich will nicht meinerseits den Fehler begehen, fremde Schuld zu benennen, um nicht einer Tat überführt zu werden, deren Geschehen ich bedauere " $(\$ 2) .{ }^{907}$ Erst in den Abschluss wird der Hinweis auf den eigentlichen Zweck des Briefs eingeflochten: "Tadellosester der Menschen, empfange also die Abhilfe gegen die Sehnsucht, die Getrennten durch die himmlische Gunst gegeben ist, und unterstützt, wenn Ihr mich nicht vergessen habt, die Boten, damit sie die Unbequemlichkeiten von Reisen nicht erfahren, weil die freundschaftliche Empfehlung den Genannten ein Zuhause verschafft. Muntert mich, wenn sie zurückkehren, mit der Nachricht Eures Wohlbefindens auf ( $\left._{3}\right) .{ }^{908}$ Der Adressat bekommt also, wenn er die Empfohlenen unterstützt, die Gelegenheit zu zeigen, dass er Enn-

905 (151,1) Producendo circa amantem vestri silentia ad absentiam corporalem animum transmisistis; retinendo paginas in inmensum crevit quae hactenus divisio nil valebat. res eo rediit per abstinentiam tabellarum, ut veteris aevi providentia conferat nil amori. ranciscit caritas, quam verborum avarus despicit ventilare; sine cultura est diligentia in usum non reducta per paginas. stili frequentia vivaci pabulo insitam pectoribus nutrit amicitiam.

$906(151,2)$ facilius, frater, fuerat desideriis meis te nullo tempore cupita tribuisse quam saepe indulta subtrahere, quia otium corda nesciunt, quae cibis dulcibus pastor artifex inritasti. aliquanto enim tempore continuando scriptionem inmemorem me sequestrationis effeceras, dum effigiem venerabilem placido inserebas adloquio.

907 (151,2) at nunc commeantium vacuas manus nudus inquisitor inspicio. - ego tamen nolo errore meo alienas culpas adserere, ut quod factum doleo admisisse convincar.

908 (151,3) accipe ergo, emendatissime hominum, desideriorum solacia per caelestem gratiam absentibus adtributa et perlatores, si mei estis memores, sublevate, ut nesciant peregrinationis incommoda, dum nominatis patriam commendatio amica contulerit. quibus remeantibus nuntio me vestrae valitudinis sublevate. 
nodius doch nicht vergessen hat, und damit den anfänglichen Vorwurf zu widerlegen bzw. zu entkräften. Da Ennodius wahrscheinlich selbst zuvor nicht geschrieben hat, macht dieser Brief besonders deutlich, dass es seine Absicht ist, möglichst Unerwartetes zu schreiben, und zwar hinsichtlich von Inhalt und Ton.

Auch im Empfehlungsbrief (86) an Laconius verschweigt Ennodius nicht, dass er selbst lange nicht geschrieben habe, und er deutet sogar an, dass er auch jetzt nur wegen des konkreten Anliegens schreibe; dennoch beginnt er zunächst mit Klagen: "Schon lange wird meine Seele von dem Warten, von dem sie gewöhnlich erlöst wurde, gequält. Ihr habt das Schweigen in die Länge gezogen, und Euch hat keine Notwendigkeit gezwungen « $(\$ 1) .{ }^{909}$ Die letzten Worte (nulla necessitate conpulsi) sind doppeldeutig: Hat Laconius nicht geschrieben, „obwohl ihn nichts zum Schweigen gezwungen hat «, d.h. er hat ohne Not bzw. ohne Grund geschwiegen, oder »weil ihn nichts zum Schreiben gezwungen hat «, d.h. hat er geschwiegen, weil er, anders als jetzt Ennodius, keinen konkreten Anlass zum Schreiben hatte? Dann begründet Ennodius, dass er selbst nur deshalb nicht geschrieben habe, weil er ständig einen Brief von Laconius erwartet habe: "Nicht weil ich Eure Nachlässigkeit nachahmte, schrieb auch ich nicht, sondern von Tag zu Tag war ich stumm, weil mich die Hoffnung täuschte, dass ein Brief eintreffen würde. Nun also hat die jetzt genug angewachsene Schweigsamkeit Eurer Hoheit meine Bedenken besiegt. Das Schweigen, das feste Wurzeln geschlagen hat, muss herausgerissen werden « $(\$ 1) .{ }^{910}$ Dann wird der eigentliche Anlass des Schreibens erwähnt: »Zwei Vorteile bringt also mein Brief: Erstens empfehle ich den Boten, einen Mann von guter Geburt, der wegen seiner entlaufenen Sklaven kommt; zweitens schiebe ich das ersehnte Gute <sc. den Brief> nicht auf. Lebe also wohl, mein Herr; erfahre, dass es mir Deinen Wünschen entsprechend gutgeht, und lass mir das Gleiche von Dir berichten, damit sowohl der Bote sich über eine Wohltat freuen kann als auch ich durch eine Antwort aufgemuntert werde« $(\$ 2) .{ }^{911}$

$909(86,1)$ Diu est quod animus meus illa, qua solebat relevari, expectatione torquetur. in longum traxistis silentia, nulla necessitate conpulsi.

$910(86,1)$ non fui huius imitator neglegentiae, ut neque ego scripta prorogarem, sed ad dies conticui superventuri spe inlusus alloquii. nunc tamen vicit deliberationem meam iam matura amplitudinis vestrae taciturnitas. debet evelli silentium, quod duriter in quadam radice convaluit.

$911(86,2)$ geminis ergo prospiciunt scripta nostra conpendiis: et perlatorem, bene natum hominem propter fugaces suos venientem, commendo et desideriorum bona non differo. ergo vale, mi domine, et pro voto tuo circa me geri prospera cognoscens paribus me fac relevari [cf. den Apparat bei VoGEL] sermonibus, quatenus et perlator de beneficio gaudeat et ego sublever de responso. 
Fazit zu d. (Empfehlungsschreiben)

Auch in Empfehlungs- und Bittbriefen zeigt Ennodius die ganze Bandbreite seiner rhetorica versutia. In vielen dieser Briefe erweckt er zunächst den Eindruck, als schreibe er nur um der Kontaktpflege willen. Oft ist er dabei freundlich und drückt aus, wie sehr er sich darüber freue, dass die Empfohlenen ihm zu dieser Möglichkeit zu schreiben verhelfen. Oft gibt er sich aber auch vorwurfsvoll, dass der Adressat so lange geschwiegen habe. Die Klagen über Schreibfaulheit des Adressaten erhalten in den Empfehlungsschreiben eine neue Funktion. Das Ziel ist nicht eigentlich oder zumindest nicht nur, das getadelte Verhalten zu ändern und den Adressaten zum Schreiben zu bringen, sondern ihn zu einer lobenswerten anderen Handlung, der Erfüllung der Bitte zu veranlassen - wobei an dieser ganzen Argumentation wohl eher der ungewöhnliche Ton als der Inhalt an sich überzeugen soll. 


\section{Zusammenfassung: Ars mihi regna dedit}

Im Laufe dieser Untersuchungen haben sich einige Missverständnisse der bisherigen Forschung ausräumen und Vorurteile bzw. übereilt gefällte Urteile widerlegen lassen, so dass das Ennodius-Bild einige überraschende Facetten und grundlegende Aspekte hinzugewinnen konnte. Die Briefe des Ennodius können Interesse wecken zum einen als Dokumente sowohl des enorm hohen sprachlichen Niveaus in einer Korrespondenz zur Zeit des Theoderich als auch des Bewusstseins des Verfassers von der hohen Bedeutung der cultura sermonis und von der Gefährdung dieser sprachlichliterarischen Bildung. Zum anderen sind sie eines der seltenen Beispiele einer sechten ‘, d.h. nicht für die Veröffentlichung überarbeiteten Korrespondenz. Bisher wurde nicht gesehen, dass ihr Verfasser je nach Adressat und Situation in verschiedenen >Rollen bzw. in unterschiedlichen Haltungen und sehr differenziertem Ton spricht, vom frommen und freundlichen Diakon über den strengen und mahnenden Onkel bis hin zum notorisch unzufriedenen, nörgelnden Freund. Diese Unterschiede in Ton und Haltung zu beobachten ist umso faszinierender, als es sich beim Verfasser nicht um einen sweltlichen Epistolographen handelt, der auch in der niveauvollen Korrespondenz seine Zugehörigkeit zur herrschenden Elite demonstriert, sondern um einen Diakon, der seine literarische Betätigung in Spannung zu seinem kirchlichen Amt bzw. zu den im Zusammenhang mit dem Amt gefassten Vorsätzen sieht.

Im I. Teil der Arbeit lag nach einführenden Abschnitten zu den bisher bekannten Details des Lebenslaufs (I.2.a), zu den vielfältigen Werken von neckischem Epithalamium mit nackter Venus auf einer Frühlingswiese und Cupidos Pfeilen bis hin zu christlichen Hymnen (2.b) und zum von Ennodius bewusst erzeugten sermo difficilis et obscurus (2.c) der Schwerpunkt auf der >rhetorisch-literarischen Vergangenheit ‘ des Diakons und dem Einfluss dieser Vergangenheit auf die schriftlichen Äußerungen des Diakons: Die Betrachtung von bisher in der Forschung nicht wahr- bzw. nicht ernstgenommenen Äußerungen in Briefen und "Schulreden« führte zu dem Ergebnis (I.3), dass Ennodius sich in einer früheren Lebensphase intensiv mit den studia liberalia, d.h. mit sprachlicher Bildung, beschäftigt hat und auch als Gelegenheitsdichter bzw. -redner aufgetreten ist. Wahrscheinlich ist auch, dass er seine Kenntnisse und Fähigkeiten in der ein oder anderen Weise im Unterricht weitergegeben hat; entgegen einer älteren, erstaunlicherweise nie gründlich diskutierten Forschungsmeinung lässt sich jedoch zeigen, dass Ennodius zur Zeit des Diakonats nicht in institutionalisierter Weise Lehrer war. Ganz sicher ist aber, dass er aufgrund dieses ,Vorlebens` die Fähigkeiten und Kenntnisse hatte, die sein vielfältiges Werk demon- 
striert, und dass er deshalb auch als Diakon immer noch an der (sprachlichen) Bildung junger Adliger Anteil nahm, zum einen mithilfe der Korrespondenz, in der er seine jungen Adressaten ermahnen und diese ihre sprachlichen Fortschritte zeigen konnten, zum anderen im persönlichen Umgang als patronus/exemplum (I.4.d), was gelegentliche intensivere Unterweisung einzelner in Privatstunden nicht ausschlieBen muss.

Ennodius zeigt sich an einigen Stellen besorgt um den Erhalt der Bildung, und er wird nicht müde zu betonen, dass es nicht ausreiche, als Adliger geboren zu werden, sondern dass sich der Adel erst durch die Bildung zeigen könne (I.4.b); er erkennt deutlich, dass der Adel als Kulturträger sich für den Erhalt der Kultur auch verantwortlich fühlen muss. Vielleicht steht auch sein Bestreben, den Leser durch verschiedene Mittel wie Doppeldeutigkeiten oder den Verzicht auf satzverbindende Partikeln zum Mitdenken geradezu zu zwingen, letztlich auch damit in Zusammenhang: Er zwingt den Adressaten, wenn dieser seine Briefe verstehen will, ebenfalls zu einer gewissen sprachlich-gedanklichen Leistung.

Die sprachliche Bildung spielte für die Karriere der jungen Adligen in der Tat eine wichtige Rolle, doch Ennodius betont in auffälliger Weise ausschließlich andere Vorteile: Er verweist besonders auf die Macht der Rhetorik (I.4.c), Taten und Ereignisse überhaupt dem Gedächtnis zu bewahren und sie nach Wunsch, d.h. besser oder schlechter als tatsächlich darzustellen. Ennodius betont an der Rhetorik zwar einerseits den Nutzen, durch das eigene Reden und Schreiben Macht über Menschen und Dinge auszuüben, aber andererseits auch besonders denjenigen, dass andere in $\mathrm{Ge}-$ genwart und Zukunft über jemanden reden und so dessen Ruhm in ihrer Macht haben. Seine Überzeugung von der Macht des Wortes macht er auch z.B. dann deutlich, wenn er die diplomatischen und rhetorischen Fähigkeiten des Bischofs von Pavia Epiphanius im Umgang mit den weltlichen Herrschern weniger als das Ergebnis der Macht von Glauben und Gebet als vielmehr der Macht des Wortes darstellt. Auch die Dichtung, der Ennodius zuschreibt, alles schöner darzustellen als in der Wirklichkeit, hat eine wichtige Funktion: Der Dichter kann beim Dichten seine Sorgen vergessen.

In etlichen Passagen weist Ennodius darauf hin, dass er sich als Diakon zu silentium und humilitas verpflichtet fühle (I.3.a); von den vielen in schristlichen Tugendkatalogen ‘ genannten Eigenschaften erwähnt er immer wieder diese beiden, die mit seiner literarischen Tätigkeit in Konflikt stehen: Er zeigt an vielen Stellen, dass ihm - als ehemaligem Gelegenheitsredner und -Dichter - das silentium nicht leichtfällt und dass er aufgrund der Erfolge bei seiner früheren Tätigkeit nicht zur humilitas neigt.

Gegenüber wenigen Adressaten, die ihn zu einem certamen litterarum aufgefordert haben, macht er mit dem silentium insoweit ernst, als er unter Verweis auf seine Vorsätze den Briefwechsel mit ihnen entweder ganz oder in der von ihnen gewünschten Form ablehnt. Er begründet dies mit der humilitas, die ihm verbiete, nach 
Lob zu streben. Doch seine Inkonsequenz zeigt sich bereits an der Gestaltung dieser Briefe, die als regelrechte Recusationes die Fähigkeiten des Verfassers beweisen (II.2.b): Zwar gestaltet Ennodius diese wie auch viele andere Briefe inhaltlich (durch mehr oder weniger direkte Tadel für den Adressaten) und stilistisch (durch die obscuritas) so, dass ihm das unter Korrespondenten übliche Lob für mel, lepos, dulcedo, venustas u.ä. serspart bleibt‘, doch umso mehr zeigt er seinen Scharfsinn, seine Fähigkeit zu geistreicher und überraschender Argumentation. Dennoch ist es Ennodius in diesen Recusationes durchaus ernst mit seiner Verweigerung eines certamen litterarum, wie sich in dem Fall zeigt, als ein Adressat seine erste Absage nicht ernstgenommen hat.

Gegenüber vielen anderen Adressaten jedoch spielt er auf seine mit dem Amt verbundenen Vorsätze (propositum) häufig geradezu in einer Weise an, als beträfe sein propositum nicht sein Leben, sondern als handle es sich dabei um einen ebenso geläufigen Epistolartopos wie bei dem propositum amicitiae des Symmachus (II.2.d.2). Diese Spannung zwischen den immer wieder erwähnten Vorsätzen und der Neigung zur 'weltlichen Literatur, wie sie in den Briefen des Bischofs Sidonius Apollinaris als Konflikt zwischen natura und professio nur einmal erwähnt wird (4,12,1 [...] naturae meminens et professionis oblitus), zeigt sich bei Ennodius auf vielen Seiten seines Werkes. Dieser Konflikt ist es auch, der im »Eucharisticum « dargestellt wird (I.1): Denn im Zentrum dieses Textes steht nicht, wie bisher angenommen wurde, die Rückschau auf die Jugend des Verfassers; die dort als Hauptsache berichtete Krise, die aufgrund von fehlender humilitas wegen der Erfolge als Redner und Dichter entsteht und in einer schweren Krankheit, einem Gelöbnis und der Genesung gipfelt, ist die des Diakons. Allerdings hat Ennodius im "Eucharisticum», ebenso wie Augustin in den Confessiones, von denen es in vieler Hinsicht inspiriert ist, den Konflikt zugespitzt und deshalb manche $>$ mildernde $<$ Details verschwiegen.

Der II. Teil widmete sich nach einigen einleitenden Bemerkungen zur äußerst flexiblen 'Gattung Brief، (1.a), zu Realien des Briefwesens (1.b), zur Brieftheorie und Kategorisierung von Briefen (1.c,d) und zu den mit Ennodius zu vergleichenden Epistolographen (1.e), den Charakteristika der Ennodius-Briefe (2.), die im Vergleich mit anderen Epistolographen herausgearbeitet wurden. Besonders wichtig und ergiebig war dabei der Vergleich mit Symmachus, der im Gegensatz zur bisherigen communis opinio keineswegs pauschal als nachgeahmtes /Vorbild ‘ des Ennodius bezeichnet werden kann, sondern vielmehr als ein Vorgänger, an dem sich Ennodius in der Weise orientiert, dass er sich teils von ihm scharf absetzt, teils von ihm formulierte Gedanken weiter zuspitzt, teils bei Symmachus aufscheinende Ausnahmen zum grundlegenden Prinzip macht. Sowohl für Symmachus als auch für Ennodius ist die amicitia ein Grundgedanke der Korrespondenz, aber beide leiten aus der amicitia grundlegend andere eigene Verhaltensweisen und Forderungen an die Korrespondenz bzw. die Korrespondenten ab; beide schreiben de amicitia, Symmachus char- 
mant und voller Nachsicht, Ennodius meistens selbstbewusst, trotzig-fordernd und/ oder klagend. Der Vorschrift des Iulius Victor (p. 106, 5 f. Giomini/Celentano): iurgari numquam oportet, sed epistolae minime, handelt Ennodius gründlich zuwider, so als wolle er Hieronymus recht geben: vera amicitia, quod sentit, dissimulare non debet (Hier. 81,1,2); auch Symmachus formuliert einmal gegen seine Gewohnheit: adcommodatior est enim querellae oratio humana quam gratiae (Sy. 3,20). Dass diese uncharmante Haltung eine Pose ist, die als Spiel mit Tradition und Konvention gewürdigt werden will, wird häufig am Ende deutlich, wenn Ennodius doch noch mit wenigen freundlichen Worten einlenkt.

Zum Vergleich mit anderen Epistolographen bieten sich die sbrieftypischen Themen Freundschaft und Korrespondenz $\mathrm{und}$ die in der Korrespondenz geltenden 'Spielregeln` bzw. `Normen des Verhaltens` an, da es für beides viel Vergleichsmaterial gibt und dies relativ unabhängig vom sonstigen Inhalt der Briefe betrachtet werden kann. Ein Großteil der Ennodius-Briefe dient der `Beziehungspflege` (da konkrete Nachrichten mündlich vom Boten überbracht werden konnten), und die Topoi spielen darin eine unübersehbar wichtige Rolle, wobei er aus den verfügbaren Topoi offensichtlich ganz gezielt einzelne herausgreift: so wählt er z.B. aus den möglichen Gedanken über den Nutzen von Briefen nur den einen, dass Briefe zum Trost für getrennte Freunde erfunden worden seien (II. 2.d.1.2). Sehr häufig präsentiert er ganze Topos- und Sentenzreihen in den Praefationes der Briefe (2.d.1.3), die daher an Vorworte von herrscherlichen Verlautbarungen erinnern, in denen ebenfalls anhand von Sentenzen ein Grundkonsens über bestimmte Verhaltensweisen insinuiert wird; wie in den Kanzleischreiben schließt Ennodius häufig einen Tadel und/oder eine Aufforderung an. Beim Lesen vieler Ennodius-Briefe werden die Zeitgenossen sich daher eher an Kanzleischreiben erinnert gefühlt haben als an die Symmachus-Briefe.

Anders als sein vermeintliches Vorbild Symmachus gibt Ennodius sich keineswegs mit einer "stummen Freundschaft" zufrieden, und anders als dieser übt er sich nicht in Nachsicht, sondern in Klage, Tadel und direkter Aufforderung zum Schreiben (2.d.1.2). Gegen Symmachus' Prinzip der indulgentia setzt Ennodius das der inportunitas; anstatt der Spielregel zu folgen, dass man in Briefen Ärger (z.B. über die Schreibfaulheit des Adressaten) oder unerfreuliche Nachrichten (wie z.B. über Krankheit) verschweigen solle, bringt er seinen Ärger vor, um ihn so zu beenden statt ihn innerlich weiter zu hegen; er spricht auch über seine Krankheiten, da Freunde Freud und Leid teilen sollten bzw. damit die Freunde mit ihren Fürbitten zuhilfe kommen können. Diese 'Spielregel ‘ des Verschweigens, wie Symmachus sie befolgt und als elegans commentum auch ausdrücklich billigt (obwohl auch er zuweilen die damit verbundenen Probleme sieht), bezeichnet Ennodius als "Verstellung" (dissimulatio) und, in wohl idiosynkratischem Wortgebrauch, als urbanitas (»feines Verhalten ") in malam partem. 
Nicht nur hinsichtlich der Verwendung einzelner Brieftopoi und des Umgangs mit bestimmten Konventionen, sondern auch bei der Gestaltung von Briefen zu bestimmten Anlässen wie z.B. Glückwunschschreiben geht Ennodius häufig eigene Wege. Zwar schreibt er zuweilen auch völlig konventionelle Briefe, d.h. solche, in denen er sich an die Normen hält statt mit ihnen zu spielen; es sind dies z.T. Briefe an Personen, die nur einen Brief erhalten oder solche, bei denen es sich um in einiger Entfernung lebende Verwandte handelt. Gegenüber manchen Verwandten hält sich sein Bedauern über die Schwierigkeit, eine Korrespondenz zu führen, auffälligerweise sehr in Grenzen.

Viele seiner Briefe dienen der Kontaktpflege (II.3.b): Ennodius spielt häufig mit den Normen der Korrespondenz, indem er sich z.B. für einen endlich erhaltenen Brief nicht bedankt, sondern herausstellt, dass ihm nun die Trennung umso schmerzlicher bewusst sei. In der Antwort auf eine Bitte dankt er zunächst pathetisch für den Brief, um dann ironisch darauf hinzuweisen, dass er nun, wo er helfen solle, endlich eines Briefes für würdig erachtet werde. Bei der ersten Kontaktaufnahme verweigert er sich der Gepflogenheit, sich selbst zurückzunehmen und den Adressaten ausführlich zu loben. Wenn ihm selbst vorgeworfen wird, nicht geschrieben zu haben, gibt er entweder den Vorwurf entschieden zurück oder formuliert statt einer Entschuldigung, sozusagen als Ersatz, ein Lob auf den Adressaten bzw. auf dessen Brief; überhaupt lobt Ennodius selten deutlich und ausführlich - fast nur in Momenten, wo die Adressaten dies nicht erwarten.

Nur wenige Glückwunschschreiben (II.3.c) sind durchweg fröhlich und freundlich. Zumeist ist der Ton entweder von Tadel (weil der Adressat Ennodius nicht über seinen Erfolg informiert hat) oder ironischer Demut bestimmt, oder er changiert zwischen Lob und Ermahnung (aufgrund des Erfolges nicht arrogant zu werden) oder zwischen guten Wünschen und Klage (weil er vom Adressaten, der geheiratet hat, getrennt ist). Andere Glückwunschschreiben enthalten zwar regelrecht panegyrische Passagen, lassen aber zwischendurch Ironie oder für den Adressaten nicht angenehme Anspielungen durchscheinen.

Auch die Empfehlungsbriefe (II.3.d) entsprechen der Konvention nur zum Teil. An etliche Adressaten schreibt Ennodius offenbar einen Empfehlungsbrief, ohne in ständigem Kontakt mit ihnen zu stehen. Er fällt, nachdem man lange nichts voneinander gehört hat, nicht mit der Tür ins Haus, sondern sucht zunächst einen Anknüpfungspunkt für den erneuerten Kontakt: die Freundschaft, die ihn und den Adressaten verbinde. Doch Ennodius spricht in diesen Fällen über die Freundschaft überwiegend in der Weise, dass er dem Adressaten dessen Schreibfaulheit und Vernachlässigung der Freundschaft vorwirft: So schickt er der Empfehlung häufig eine ausführliche und deutliche Klage über das Abreißen des Briefwechsels voraus, anstatt sich den Adressaten durch freundliche Worte gewogen zu machen.

Dies alles macht deutlich, dass Ennodius den Vorschriften der Brieftheorie und den Vorbildern der Brieftradition nicht immer folgt, sondern lieber damit sspielt<. Es 
geht in diesen Briefen häufig offenbar weniger um den eigentlichen Inhalt, z.B. die Empfehlung, da dieser angesichts der Situation letztlich sowieso feststeht, als das gedanklich-rhetorische Ausnutzen der Situation, um das ingenium zu beweisen.

Bisher war der Forschung entgangen, dass Ennodius je nach Adressat und Situation in ganz verschiedenen $>$ Rollen` spricht. Die Bedeutung des Adressatenbezugs zeigt sich z.B. an seinen Äußerungen über die weltliche und die christliche Bildung: je nach Stand des Betreffenden bezeichnet Ennodius eine bestimmte Reihenfolge und Intensität der weltlichen und christlichen Studien als angemessen (I.4.a). Der Einfluss der Situation auf die Äußerungen zeigt sich in aller Deutlichkeit in einem Brief an den jungen Arator, der nach früheren Aufforderungen zu fleißigen Studien nun zur Aufgabe seiner intensiven Studien zugunsten der Gründung einer Familie ermahnt wird (I.4.d.4). In den Briefen insgesamt zeigt Ennodius eine erhebliche Wandlungsfähigkeit. Wertvoll ist in diesem Zusammenhang die Bemerkung von LuDoLPH $(1997,13)$ zu Plinius, dass sich aus der Lektüre einer Sammlung von Briefen nicht zwangsläufig ein einheitliches `Persönlichkeitsbild` ergeben muss, da der Verfasser nicht nur sich selbst darstellt, sondern sich selbst in seinem Verhältnis zum Adressaten. Aus den Briefen des Ennodius muss sich umso weniger ein einheitliches Bild ergeben, da er seine Briefe nicht selbst in einer Sammlung herausgegeben hat.

Die besondere Überlieferungssituation ist insgesamt zu bedenken: Es darf nicht vergessen werden, dass Ennodius seine Werke offensichtlich nicht selbst so herausgegeben hat, wie sie uns überliefert sind. Einiges, wie die Heiligenviten, den Panegyricus oder die "Paraenesis" (cf. dazu in einem Brief an Beatus: in lucem exire publicam, 405,1), hat er sicher als einzelne Werke herausgegeben; anderes hätte er mit Rücksicht auf seine Karrierehoffnungen vielleicht nie herausgeben wollen, schon gar nicht, nachdem er Bischof geworden war. Wir können nicht wissen, wem Ennodius z.B. seine sehr weltlichen Epigramme zu lesen gab, wer das witzige (vor zentralen Elementen des Christentums nicht haltmachende) Epithalamium für Maximus zu lesen bekam und wer wusste, dass er weiterhin traditionelle Deklamationen z.B. über eine Vestalin, über Thetis oder Dido schrieb. Daher lässt sich auch das spöttische Epigramm auf Boethius (339) nicht als Argument gegen die chronologische Anordnung der Werke verwenden: BARTlett $(2003,61 f$.) hält es für unmöglich, dass Ennodius das Epigramm in dem gleichen Zeitraum verfasst haben soll, als er sich, wie die Briefe zeigen, um gute Beziehungen zu Boethius bzw. um das Haus bemühte. Doch man kann keineswegs davon ausgehen, dass Boethius von dem Epigramm Kenntnis erhalten sollte. Es ist gut möglich, dass Ennodius gerade dann, wenn er sich in Briefen an Personen, zu denen er nicht in bestem Verhältnis stand, um besondere Freundlichkeit bemühen musste, sozusagen als Ausgleich und nur für sich selbst, auf keinen Fall aber für den Betreffenden, ein bissiges Epigramm schrieb. 
Die Besonderheit, dass die überlieferten Werke so vielfältig sind und dass sie chronologisch überliefert sind, hat das Ergebnis der sorgfältigen Bemühungen des Ennodius um seine äußere Selbststilisierung, wie wir sie besonders im »Eucharisticum “, aber auch in einigen Briefen greifen können, gestört. Bei der Bewertung bzw. dem Vergleich mit anderen conversi sollte man bedenken, dass von vielen anderen tatsächlich nur die Werke überliefert sind, die sie selbst herausgegeben haben. Wir wissen nicht, wie ähnliche Werke des Augustinus, die er in den Confessiones erwähnt, ausgesehen haben, etwa das Werk, mit dem er beim theatrici carminis certamen (conf. $4,2,3$ ) die corona agonistica (conf. 4,3,5) errang, oder die dictio, die er als $>$ Bewerbungsschrift، Symmachus vorlegte (conf. 5,13,23). Der Bewertung des Sidonius hingegen ist es oft nicht förderlich gewesen, dass seine vor der Erhebung zum Bischofsamt verfassten Panegyrici erhalten sind. Allerdings hat sich Ennodius durchaus mit Erfolg stilisiert - er wurde nicht nur Bischof, sondern auch als Heiliger verehrt -, doch dank der besonderen Überlieferung können wir sehen, dass er nicht nur eine Seite hatte. In seinen Werken, nicht zuletzt in den Briefen, sehen wir in der Gesamtschau nicht den künftigen Bischof und Heiligen, sondern nur an wenigen Stellen einen demütigen Diakon, überall aber einen Verfasser, der ohne Zögern von sich selbst sagen kann, was er in der "Paraenesis« der Ars Rhetorica in den Mund legt: ars mihi regna dedit $(452,17)$. 


\section{Literatur \\ (abgekürzt zitierte Literatur)}

Suzanne L. АвRAм, Latin Letters and their Commonplaces in Late Antiquity and the Early Middle Ages, Diss. Indiana University 1994.

Michael von ALBRECHT, Geschichte der römischen Literatur, Bern ${ }^{2} 1994$.

Luigi Alfonsı, Ambrogio in Ennodio, 125-129 in: Giuseppe Lazzati (ed.), Ambrosius Episcopus, vol. II, Mailand 1976.

David AMHERDT, Sidoine Apollinaire. Le quatrième livre de la correspondance. Introduction et commentaire, Bern 2001.

Patrick AMOrY, People and Identity in Ostrogothic Italy (489-554), Cambridge 1997.

Edoardo D'ANGelo, Tematiche omosessuali nella letteratura di età Teodericiana:

Il caso Ennodio, S. 645-654 in: Teoderico il Grande e i Goti d'Italia.

Atti del XIII Congresso internazionale di studi sull'Alto Medioevo

(Milano 2-6 nov. 1992), vol. I, Spoleto 1993.

Ders. (ed.), Atti della Seconda Giornata Ennodiana, Neapel 2003.

Otto BARDENHEWER, Geschichte der altkirchlichen Literatur 5 ,

Freiburg im Breisgau 1932.

Richard BartLetT, Aristocracy and Asceticism: The Letters of Ennodius and the

Gallic and Italian Churches, S. 201-216 in: R. W. Mathisen, D. Shanzer (edd.),

Society and Culture in Late Antique Gaul, Aldershot u.a. 2001.

Ders., The Dating of Ennodius' Writings, S. 53-74 in: D'Angelo (ed.), Atti II, 2003.

Conrad Benjamin, Art. "Ennodius«, RE 5, 2 (Stuttgart 1905), Sp. 2629-2633.

Margareta BENNER, The Emperor says. Studies in the Rhetorical Style in Edicts of the Early Empire, Göteborg 1975 (Studia Graeca et Latina Gothoburgensia 33).

Philippe Bruggisser, Gloria novi saeculi. Symmaque et le siècle de Gratien (Epist. 1,13), MH 44, 1987, 134-149.

Ders., Symmaque ou le rituel épistolaire de l'amitié littéraire. Recherches sur le premier livre de la correspondance, Fribourg 1993.

Hans BRUHN, Specimen vocabularii rhetorici ad inferioris aetatis latinitatem pertinens, Diss. Marburg 1911 (Caput II. De affectata modestia, qua in epistulis Symmachus Sidonius Ruricius Ennodius utuntur).

Karl BüCHNER, Art. »M. Tullius Cicero« (Briefe), RE VII A 1, Stuttgart 1939, 1192-1235.

Hans-Peter BüTLER, Die geistige Welt des jüngeren Plinius, Heidelberg 1970. 
Bruno Bureau, Parthenius, et la question de l'authenticité de la Lettre à Parthenius d'Arator, S. 387-398 in: Moussyllanea. Mélanges de linguistique et de littérature anciennes offerts à Claude Moussy, éd. par B. Bureau et Ch. Nicolas, Louvain, Paris 1998.

Mario CARINI, L'Itinerarium Brigantonis castelli di Ennodio: Una nota preliminare, Atene e Roma, n.s. 33, 1988, 158-165 (= Quaderni Catanesi 9, 1987, 313-325).

Ders., Recenti contributi alla critica Ennodiana (1960-1983), Quaderni Catanesi di Studi classici e medievali 9, 1987, 327-342.

Maria CESA, Integrazioni prosopografiche tardo imperiali, Athenaeum 64, Pavia 1986, 236-240.

Dies., Ennodio: Vita del beatissimo Epifanio vescovo della chiesa pavese, Como 1988.

Peter Classen, Kaiserreskript und Königsurkunde. Diplomatische Studien zum Problem der Kontinuität zwischen Altertum und Mittelalter, Thessaloniki 1977.

Silvia Condorelli, L'esametro di Ennodio: alcune osservazioni prosodiche e metriche, S. 75-89 in: D’Angelo (ed.), Atti II, 2003.

Barbara Conring, Hieronymus als Briefschreiber: Ein Beitrag zur spätantiken Epistolographie, Tübingen 2001.

Catherine Conybare, Paulinus Noster: Self and Symbols in the Letters of Paulinus of Nola, Oxford 2000.

Franca Ela Consolino, L'eredità dei classici nella poesia del VI secolo, S. 69-90 in:

G. Mazzoli, F. Gasti (edd.), Prospettive sul tardoantico. Atti del Convegno di Pavia (27-28 nov. 1997), 1999.

Sister Genevieve Marie Cook, The Life of Saint Epiphanius by Ennodius:

A Translation with an Introduction and Commentary, Diss. Washington 1942.

Pierre Courcelle, Trois récits de conversion au VIe siècle, dans la lignée des »Confessions« de Saint Augustin, Historisches Jahrbuch 77, 1958, 451-458.

Paolo Cugusi, Evoluzione e forme dell'epistolografia latina nella tarda repubblica e nei primi due secoli dell'impero, con cenni sull'epistolografia preciceroniana, Rom 1983.

Ders., L'epistolografia. Modelli e tipologie di comunicazione, in: G. Cavallo, P. Fedeli, A. Giardina (edd.), Lo spazio letterario di Roma antica, Vol. II: La circolazione del testo, Rom 1989, 379-419.

Adolf Deissmann, Licht vom Osten: Das Neue Testament und die neuentdeckten Texte der hellenistisch-römischen Welt, Tübingen ${ }^{4} 1923$.

Marie-José Delage, Césaire d'Arles, Sermons au peuple, vol. I, Paris 1971.

Fulvio Delle Donne, Teoderico rex genitus. Il concetto della nobiltà di stirpe nel panegirico di Ennodio, Invigilata Lucernis 20, 1998, 73-84.

Ders., Il ruolo storico e politico di Ennodio, S. 7-19 in: GAsti (ed.), Atti I, 2001.

Alexander Demandt, Die Spätantike (Handbuch der Altertumswissenschaft III.6), München 1989. 
Albrecht Dihle, Art. »Demut «, RAC III, Stuttgart 1957, 735-778.

Johannes Divjak, Art. "Epistulae«, Augustinus-Lexikon, ed. Cornelius Mayer, vol. 2, Basel 1996-2002, 893-1057.

Siegmar DöpP, Art. »Ennodius «, Lexikon der antiken christlichen Literatur, Hrg.

Siegmar Döpp und Wilhelm Geerlings, Freiburg etc., 2. Aufl. 1999, 189-191.

Augustin Duвогs, La latinité d'Ennodius. Contribution a l'étude du latin littéraire

à la fin de l'Empire Romain d'Occident, Paris 1903.

Karl Dziatzko, Art. »Brief«, RE 3,1 (1897), Sp. 836-843.

Wilhelm EnssLin, Theoderich der Große, München 1947, ${ }^{2} 1959$.

W. Evenepoel, The Place of Poetry in Latin Christianity, S. 35-60 in: J. den Boeft,

A. Hilhorst (Hgg.), Early Christian Poetry. A collection of Essays,

Leiden, New York, Köln 1993.

Alexandre FAIVRE, Naissance d'une hiérarchie, les premières étapes du cursus clérical, Paris 1977.

Michael Fertrg, Magnus Felix Ennodius und seine Zeit, 1. Abteilung, Passau 1855.

Heinrich Fichtenau, Arenga. Spätantike und Mittelalter im Spiegel von

Urkundenformeln, Mitteilungen des Instituts für österreichische

Geschichtsforschung, Erg.-Bd. 18, Graz u.a. 1957.

Carla Fini, Le fonti delle dictiones di Ennodio, Acta Antiqua Academiae

Scientiarum Hungaricae 30, 1982-1984, 387-393.

Dies., Il censimento dei codici di Ennodio, Pisa, Rom 2000.

Jacques Fontaine, Art. «Ennodius«, RAC 5, Stuttgart 1962, Sp. 398-421.

Ders., Poésie et liturgie. Sur la symbolique christique des luminaires, de Prudence

à Isidore de Séville, S. 318-346 in: R. Cantalamessa, L. F. Pizzolato (edd.),

Paradoxos politeia. Studi patristici in onore di Giuseppe Lazzati

(Studia patristica Mediolanensia 10), Mailand 1979.

Åke J. FRIDH, Études critiques et syntaxiques sur les Variae de Cassiodore, Göteborg 1950.

Ders., Terminologie et formules dans les Variae de Cassiodore. Etudes sur le déve-

loppement du style administratif aux derniers siècles de l'antiquité,

Stockholm 1956.

Manfred Fuhrmann, Rom in der Spätantike. Porträt einer Epoche,

München und Zürich ${ }^{2} 1995$.

Federico Gamberini, Stylistic Theory and Practice in the Younger Pliny,

Hildesheim etc. 1983.

Antonio GARZYA, L'epistolografia letteraria tardoantica, S. 347-373 in: AA.VV.,

Le trasformazioni della cultura nella tarda antichità (Atti del Convegno

tenuto a Catania, 27 sett. - 2 ott. 1982), Vol. I, Catania 1985.

Fabio Gasti (ed.), Atti della prima Giornata Ennodiana, Pisa 2001.

Ders. (ed.), Atti della terza Giornata Ennodiana, Pisa 2006. 
Jean Gaudemet, L'église dans l'Empire Romain (IVe - Ve siècles), Paris 1958 (mit Korr. 1989).

Stéphane Gionnni, Fonctions culturelles, sociales et politiques de l'amicitia épistolaire dans la correspondance d'Ennode de Pavie jusqu'à la fin de l'année 503, Lalies 21, 2001, 165-181.

Ders., Les élites italiennes, l'autorité pontificale et la romanité au début du VIe s.:

l'engagement d'Ennode de Pavie, S. 37-52 in: D'Angelo (ed.), Atti II, 2003.

Ders., Communication et préciosité: le sermo epistolaire de Sidoine Apollinaire à

Avit de Vienne, S. 515-544 in: Comunicazione e ricezione del documento cristiano in epoca tardoantica (Studia Ephemeridis Augustinianum 90), Rom 2004.

Ders., Ennode de Pavie, Lettres, tome I: livres I et II, Paris 2006.

Joachim Gruber, Art. "Ennodius«, Sp. 1046 f. in: H. Cancik und H. Schneider (edd.), DNP, Bd. 3, Stuttgart und Weimar 1997.

Isabella Gualandri, Furtiva lectio. Studi su Sidonio Apollinare, Mailand 1979. Jill Harries, Sidonius Apollinaris and the Fall of Rome AD 407-485, Oxford 1994. Wilhelm Hartel, Magni Felicis Ennodii Opera, CSEL 6, Wien 1882.

Benedikt Hasenstab, Studien zu Ennodius. Ein Beitrag zur Geschichte der Völkerwanderung, Progr. K. Luitpold-Gymn. München 1890.

Gerd HAverLing, On the »Illogical " vos in Late Latin Epistolography, in: Latin vulgaire, latin tardif IV. Actes du 4e colloque international sur le latin vulgaire et tardif. Caen, 2-5 septembre 1994, Hildesheim etc. 1995, 337-353.

R. Hercher, Epistolographi graeci, Paris 1873 (ND Amsterdam 1965).

Vinko Hinz, Nunc Phalaris doctum protulit ecce caput. Antike Phalarislegende und Nachleben der Phalarisbriefe, München / Leipzig 2001 (BzA 148).

J. B. Hofmann - A. Szantyr, Lateinische Syntax und Stilistik, München 1965.

Richard M. HonIg, Humanitas und Rhetorik in spätrömischen Kaisergesetzen, Göttingen 1960 (Göttinger Rechtswissenschaftliche Studien 30).

Sabine Horstmann, Das Epithalamium in der lateinischen Literatur der Spätantike, München, Leipzig 2004.

Toon Van Houdt, Jan PAPy u.a. (edd.), Self-Presentation and Social Identification.

The Rhetoric and Pragmatics of Letter Writing in Early Modern Times, Leuven 2002 (Supplementa Humanistica Lovaniensia XVIII).

Sabine HüBNER, Der Klerus in der Gesellschaft des spätantiken Kleinasiens,

Stuttgart 2005.

Herbert Hunger, Prooimion. Elemente der byzantinischen Kaiseridee in den Arengen der Urkunden, Wiener Byzantinistische Studien 1, Wien 1964.

Bernhard Jussen, Patenschaft und Adoption im frühen Mittelalter. Künstliche Verwandtschaft als soziale Praxis, Göttingen 1991.

Robert A. KASTER, Guardians of Language: The Grammarian and Society in Late Antiquity, Berkeley, Los Angeles, London 1988. 
Stefanie A. H. Kennell, Ennodius and the Pagan Gods, Athenaeum 80, 1992, 236-242.

Dies., Magnus Felix Ennodius. A Gentleman of the Church, Michigan 2000.

Dies. (2000 a), Ennodius and his Editors, Classica et medievalia 51, 2000, 251-270.

Dies., Style and Substance in the Libellus pro Syndodo, S. 57-67 in: GASTI (ed.), AtTi I, 2001.

Dies., Ennodius the Epistolographer, S. 109-126 in: D’Angelo (ed.), Atti II, 2003.

Hans-Josef KLAUCK, Die antike Briefliteratur und das Neue Testament, Paderborn 1998.

Theodor KlaUSER, Art. "Diakon «, RAC III, Stuttgart 1957, 888-909.

Richard Klein, Symmachus. Eine tragische Gestalt des ausgehenden Heidentums, Darmstadt 1971.

William E. Klingshirn, Charity and Power: Caesarius of Arles and the Ransoming of Captives in Sub-Roman Gaul, JRS 75, 1985, 183-203.

Ders., Caesarius of Arles, The Making of a Christian Community in Late Antique Gaul, Cambridge 1994.

Helga KöHLER, C. Sollius Apollinaris Sidonius: Briefe Buch I (Einleitung, Text, Übersetzung, Kommentar), Heidelberg 1995.

Heikki Koskenniemi, Studien zur Idee und Phraseologie des griechischen Briefes bis 400 n.Chr., Helsinki 1956.

Helmut Krasser, Claros colere viros oder über engagierte Bewunderung. Zum Selbstverständnis des jüngeren Plinius, Philologus 137, 1993, 62-71.

George P. Lawless, OSA, An Augustine Glossary of Monastic Terms, S. 276-294 in: Homo Spiritalis, Festgabe Luc Verheijen OSA, Hrg. von Cornelius Mayer, Würzburg 1987.

Wolfgang D. Lebek: Deklamation und Dichtung in der Dictio Ennodi diaconi quando de Roma rediit, S. 264-299 in: G. W. Most, H. Petersmann, A. M. Ritter (edd.), FS A. Dihle (Philanthropia kai Eusebeia), Göttingen 1993.

H. LeClERCQ, "Lettres «, Dictionnaire d'archéologie chrétienne et de liturgie VIII,2, Paris 1929, 2683-2982.

Stanislas LÉgLise, Saint Ennodius et la haute éducation littéraire dans le monde romain au commencement du VIe siècle, L'Université catholique n.s. 5, 1890, 209-228, 375-397, 568-590.

Ders., Oeuvres complètes de Saint Ennodius 1: Lettres. Texte latin et traduction, Paris 1906.

Godo Lieberg, »Poeta creator«. Studien zu einer Figur der antiken Dichtung, Amsterdam 1982.

Friedrich LOTTER, Severinus von Noricum: Legende und historische Wirklichkeit. Untersuchungen zur Phase des Übergangs von spätantiken zu mittelalterlichen Denk- und Lebensformen, Stuttgart 1976. 
A. Loyen, Sidoine Apollinaire et l'esprit précieux en Gaule aux derniers jours de l'empire, Paris 1943.

Matthias Ludolph, Epistolographie und Selbstdarstellung. Untersuchungen zu den »Paradebriefen« Plinius des Jüngeren, Tübingen 1997.

Bruno Luiselli, La società dell'Italia romano-gotica, S. 49-116 in: Atti del $7^{\circ}$ congresso internazionale di studi sull'alto medioevo, vol. I, Spoleto 1982.

Adolf LumPE, Ennodiana, Byzantinische Forschungen 1, 1966, 200-210.

Ders., Die konziliengeschichtliche Bedeutung des Ennodius, Annuarium Historiae

Conciliorum 1, 1969, 15-36.

Francesco Magani, Ennodio, 3 Bde., Pavia 1886.

Abraham J. Malherbe, Ancient Epistolary Theorists, Atlanta 1988.

Robert Austin Markus, Gregory the Great and his World, Cambridge 1997.

Beatrice Marotta Mannino, La "Vita Antoni« di Ennodio fra tradizione classica e cristiana, Orpheus n.s. 10, 1989, 335-357.

René Martin, Jacques Gaillard, Les genres littéraires à Rome, tome 1+2, Paris 1981.

John Robert Martindale (= PLRE II), The Prosopography of the Later Roman

Empire. Vol. II. A.D. 395-527, Cambridge u.a. 1980.

Ralph W. Mathisen, Epistolography, Literary Circles and Family Ties in Late

Roman Gaul, TAPhA 111, 1981, 95-109.

Ders., Roman Aristocrats in Barbarian Gaul, Austin/Texas 1993.

Ders., Ruricius of Limoges and Friends. A Collection of Letters from Visigothic Gaul, Liverpool 1999.

Ders., The Letters of Ruricius of Limoges and the Passage from Roman to Frankish Gaul, S. 101-115, in: R. W. Mathisen, D. Shanzer (edd.), Society and Culture in Late Antique Gaul, Aldershot u.a. 2001.

J. F. Matthews, The Letters of Symmachus, S. 58-99 in: Latin Literature of the Fourth Century, ed. J. W. Binns, London 1974.

Gregor MAURACH, "Mit neuen Blumen will ich meine Lieder malen «, S. 37-40 in: Frank Neidhart Steigerwald (ed.), FS Martin Gosebruch, München 1984.

Beat Meyer-FlüGEL, Das Bild der ostgotisch-römischen Gesellschaft bei Cassiodor, Bern u.a. 1992.

John Moorhead, Libertas and nomen Romanum in Ostrogothic Italy, Latomus 46, 1987, 161-168.

Ders., Theoderic in Italy, Oxford 1992.

Gabriella Moretri, L’Epistula didascalica di Ennodio fra Marziano Capella e Boezio, S. 69-78 in: Gasti (ed.) Atti I, 2001.

Sigrid Mratschek, Der Briefwechsel des Paulinus von Nola: Kommunikation und soziale Kontakte zwischen christlichen Intellektuellen, Göttingen 2002.

Wolfgang G. Müller, Der Brief als Spiegel der Seele. Zur Geschichte eines Topos der Epistolartheorie von der Antike bis zu Samuel Richardson, A\&A 26, 1980, 138-157 (bes. 138-144). 
Ders., Art. "Brief “, HWRh Bd. 2, Tübingen 1994, Sp. 60-76.

Beat NäF, Das Zeitbewusstsein des Ennodius und der Untergang Roms,

Historia 39, 1990, 100-123.

Ders., Senatorisches Standesbewusstsein in spätrömischer Zeit,

Fribourg 1995.

Leandro Navarra, Le componenti letterarie e concettuali delle "Dictiones"

di Ennodio, Augustinianum 12, 1972, 465-478.

Ders., Ennodio e la »facies « storico-culturale del suo tempo, Cassino 1974.

Ders., Contributo storico di Ennodio, Augustinianum 14, 1974, 315-342.

Ders., A proposito del De navigio suo di Venanzio Fortunato in rapporto alla

Mosella di Ausonio e agli »Itinerari« di Ennodio, Studi storico religiosi 3, 1, 1979, 79-131.

Reinhard M. G. NickisCH, Brief, Stuttgart 1991 (Sammlung Metzler 260).

James J. O’Donnell, Cassiodorus, Berkeley u.a. 1979.

Ders., Liberius the patrician, Traditio 37, 1981, 31-72.

Ellen W. Oliensis, Horace and the Rhetoric of Authority, Cambridge 1998

A. Отто, Die Sprichwörter und sprichwörtlichen Redensarten der Römer,

Leipzig 1890.

Bernhard PABST, Prosimetrum: Tradition und Wandel einer Literaturform zwischen Spätantike und Spätmittelalter, Köln u.a. 1994.

Zoja PAvlovskis, Statius and the Late Latin Epithalamia, CPh 60, 1965, 164-177.

PCBE, siehe Pietri / Pietri 1999.

John Percival, Desperately Seeking Sidonius: the Realities of Life in Fifth-Century

Gaul, Latomus 56, 1997, 279-292.

Hermann Peter, Der Brief in der römischen Litteratur, Abhandlungen der philol.-

hist. Classe der Sächsischen Gesellschaft der Wissenschaften 20, 3, Leipzig 1901,

ND Hildesheim 1965.

Bettina Pferschy, Cassiodors Variae. Individuelle Ausgestaltung eines

spätrömischen Urkundenformulars, Archiv für Diplomatik 32, 1986, 1-127.

Egidio Pietrella, La figura del santo-vescovo nella »Vita Epifani« di Ennodio di

Pavia, Augustinianum 24, 1984, 213-226.

Charles Pietri, Aristocratie et société cléricale dans l'Italie chrétienne au temps

d'Odoacre et de Théodoric, MEFRA 93, 1981, 1, 417-467.

Charles Pietri et Luce Pietri (=PCBE 2.1, 2.2), Prosopographie chrétienne du

bas-empire, 2: Prosopographie de l'Italie chrétienne (313-604), 2 vol.,

Rom 1999 f.

Maria Rosa Pizzino, L'Eucharisticum di Ennodio di Pavia e le Confessiones di

S. Agostino, S. 801-810 in: Scritti in onore di Salvatore Pugliatti 5: Scritti vari

(Pubblicazioni dell'Istituto di scienze giuridiche, economiche, politiche

e sociali dell' Università di Messina 111, Mailand 1978).

PLRE II, siehe MARTINDALE 1980. 
Giovanni Polara, I distici di Ennodio, S. 217-239 in: La poesia cristiana latina in distici elegiaci. Atti del Convegno Internazionale, a cura di G. Catanzaro e F. Santucci, Assisi 1993.

Rosalba A. Rallo Freni, Le concezioni pedagogiche nella paraenesis didascalica di Magno Felice Ennodio, S. 109-126 in: Umanità e Storia. Scritti in onore di Adelchi Attisani, vol. II: Letteratura e Storia, Messina 1971.

Dies., La metafora scribere agros in Magno Felice Ennodio, S. 749-758 in: E. Livrea, G. A. Privitera (edd.), Studi in onore di Anthos Ardizzoni, vol. 2, Rom 1978.

Dies., Atteggiamenti topici nel programma poetico di Magno Felice Ennodio, S. 831-858 in: Scritti in onore di Salvatore Pugliatti 5: Scritti vari (Pubblicazioni dell'Istituto di scienze giuridiche, economiche, politiche e sociali dell' Università di Messina 111, Mailand 1978).

Stéphane Ratri, Evolution et signification de la civilitas au sixième siècle, d'Ennode à Cassiodore, 163-176 in: Stéphane Rat ti (Hrg.), Antiquité et citoyenneté (Actes du Colloque International, Besançon 1999), Paris 2002.

Stefan Rebenich, Hieronymus und sein Kreis. Prosopographische und sozialgeschichtliche Untersuchungen, Stuttgart 1992 (Historia Einzelschriften 72).

Marc Reydellet, La royauté dans la littérature latine de Sidoine Apollinaire à Isidore de Séville, Rom 1981.

Ders., Art. "Ennodio«, Dizionario biografico degli Italiani, Bd. 42, Rom, Istituto dell'Enciclopedia Italiana 1993, 689-695.

Daniele DI RIEnzo, Gli Epigrammi di Magno Felice Ennodio, Neapel 2005.

Ders., Gli studi ennodiani dal 1983 al 2003, Bollettino di Studi Latini 34, 2004, 130-168.

Sergio RoDA, Polifunzionalità della lettera commendaticia: teoria e prassi nell'epistolario Simmachiano, S. 177-202 in: Colloque Genevois sur Symmaque, ed. F. Paschoud etc., Paris 1986.

Christian Rohr, Der Theoderich-Panegyricus des Ennodius, Hannover 1995 (MHG Studien und Texte Bd. 12).

Ders., Zum Theoderich-Panegyricus des Ennodius. Textkritische Überlegungen im Rahmen einer Neuedition und Übersetzung, Hermes 125, 1997, 100-117.

Ders., Nationalrömisches Bildungsgut im Reich der Ostgoten. Zur Rezeption von Q. Aurelius Symmachus bei Ennodius, Römische Historische Mitteilungen $40,1998,29-48$.

Ders., La tradizione culturale tardo-romana nel regno degli Ostrogoti il panegirico di Ennodio a Teoderico, Romanobarbarica 16, 1999, 261-284. Simona RotA, Motivi mitologici e antichità romane in Ennodio, S. 125-134 in: M. Rotili (ed.), Memoria del passato, urgenza del futuro. Il mondo romano fra V e VII secolo. Atti delle VI Giornate di studio sull'età romanobarbarica, Neapel 1999. 
Dies., Ennodio anti-Lucano. I modelli epici del Panegyricus dictus clementissimo regi Theoderico, S. 31-55 in: Gasti (ed.), Atti I, 2001.

Dies. (2001 a), Catone l'Uticense e Teoderico, S. 81-89 in: M. Rotili (ed.), Società multiculturali nei secoli V-IX. Scontri, convivenza, integrazione nel Mediterraneo occidentale. Atti delle VII Giornate di studio sull'età romanobarbarica, Neapel 2001.

Dies., Magno Felice Ennodio, Panegirico del clementissimo re Teoderico (opusc. 1), Biblioteca di Cultura romanobarbarica 6, Rom 2002.

Dies., Antiquum credit adesse chaos. Ein Deutungsversuch der Itineraria des Ennodius, Rh. M. n. F. 147, 2004, 355-389.

Richard H. und Mary A. Rouse, Ennodius in the Middle Ages: Adonics, Pseudo-Isidore, Cistercians, and the Schools, S. 91-113 in: J. R. Sweeney, S. Chodorow (ed.), Popes, Teachers, and Canon Law in the Middle Ages, Ithaca, London 1989.

Philip Rousseau, In Search of Sidonius the Bishop, Historia 25, 1976, 356-377. Giuseppe Scarpat, L'epistolografia, S. 473-512 in: Introduzione allo studio della cultura classica, vol. I: Letteratura, Mailand 1972.

Christoph ScHÄFER, Der weströmische Senat als Träger antiker Kontinuität unter den Ostgotenkönigen (490-540 n.Chr.), St. Katharinen 1991.

Willy Schet ter, Die Thetisdeklamation des Ennodius, S. 395-412 in: Bonner Festgabe für Johannes Straub, Bonn 1977 (= S. 406-424 in: O. ZwierLeiN (Hg.), Kaiserzeit und Spätantike. Kleine Schriften 1957-1992, Stuttgart 1994).

Johannes Schneider, Art. »Brief«, RAC 2, Stuttgart 1954, Sp. 564-585.

Bianca-Jeanette SCHRöDER, Charakteristika der "Dictiones Ethicae« und der »Controversiae« des Ennodius, S. 251-274 in: Dies. und Jens-Peter Schröder (edd.), Studium declamatorium, Untersuchungen zu Schulübungen und Prunkreden von der Antike bis zur Neuzeit, München und Leipzig 2003.

Dies. (2003 a), "Divitias facundiae ... ostentare - Osservazioni sulla lettera 1,6 Hartel / 10 Vogel, S. 127-135 in: D’Angelo (ed.), Atti II, 2003.

Dies., Pernices verborum saltus in una lettera di Ennodio (381 Vogel / epist. 8,5 Hartel), S. 77-92 in: Gasti (ed.), Atti III, 2006. Johannes Schwind, Arator-Studien, Göttingen 1990.

Danuta Shanzer, Ennodius, Boethius, and the Date and Interpretation of Maximianus's Elegia III, RFIC 111, 1983, 183-195.

Dies., Bishops, Letters, Fast, Food, and Feast in Later Roman Gaul, 217-236 in:

R. W. Mathisen, D. Shanzer (edd.), Society and Culture in Late Antique Gaul, Aldershot u.a. 2001.

Jacques Sirmond, Magni Felicis Ennodii Episcopi Ticinensis Opera, Paris 1611. Rev. Bernard Henry Ska hill, The Syntax of the Variae of Cassiodorus,

Washington 1934. 
Matthias SкeB, Paulinus von Nola, Epistulae / Briefe I, Lateinisch-Deutsch, Freiburg u.a. 1998.

Claire Sotinel, Les ambitions d'historien d'Ennode de Pavie: La Vita Epiphani, 585-605 in: La narrativa cristiana antica: codici narrativi, strutture formali, schemi retorici, Rom 1995.

Wilfried Sтroн, Tröstende Musen: Zur literarhistorischen Stellung und Bedeutung von Ovids Exilgedichten, S. 2638-2684 in: ANRW II 31 (4), Berlin, New York 1981.

Karl Friedrich SтroнекеR, Der senatorische Adel im spätantiken Gallien, Tübingen 1948.

Johannes Sundwall, Die zeitliche Folge der Schriften des Ennodius, Öfversigt af Finska Vetenskaps-Societetens Förhandlingar, 60, 1919.

J. Sykutris, Art. »Epistolographie«, RE Suppl. V, Stuttgart 1931, Sp.185-220.

Klaus Thraede, Grundzüge griechisch-römischer Brieftopik, München 1970.

Jacob J. Trahey, De sermone Ennodiano Hieronymi sermone in comparationem adhibito, Diss. Indiana 1904.

Dennis E. Trout, Paulinus of Nola, Life, Letters, and Poems, Berkeley u.a. 1999.

Gianluca VANDONE, Status ecclesiastico e attività letteraria in Ennodio: tra tensione e conciliazione, S. 89-99 in: GASTi (ed.), Atti I, 2001.

Ders., "Appunti su una poetica tardoantica«, Ennodio, carm. 1,7-8 $=26-27 \mathrm{~V}$, Pisa 2004.

Gunhild VIDÉn, The Roman Chancery Tradition. Studies in the Language of Codex Theodosianus and Cassiodorus' Variae, Göteborg 1984.

Friedrich Vogel, Magni Felicis Ennodi Opera, MGH Auct. ant. 7, Berlin 1885.

Ders., Chronologische Untersuchungen zu Ennodius, Neues Archiv der Gesellschaft für ältere deutsche Geschichtskunde $23,1898,51-74$.

Konrad Vössıng, Schule und Bildung im Nordafrika der Römischen Kaiserzeit, Brüssel 1997.

P. G. WALSH, Letters of St. Paulinus of Nola, vol. I, New York 1966.

Otto Wermelinger, Art. »Ennodius«, Theologische Realenzyklopädie, Bd. IX, Berlin / New York 1982, 654-657.

Carolinne White, Christian Friendship in the Fourth Century, Cambridge 1992.

Michael Winterbotrom, Ennodius, Dictio 21, S. 275-287 in: Bianca-Jeanette und Jens-Peter Schröder (edd.), Studium declamatorium. Untersuchungen zu Schulübungen und Prunkreden von der Antike bis zur Neuzeit, München und Leipzig 2003.

Eckhard Wirbelauer, Zwei Päpste in Rom. Der Konflikt zwischen Laurentius und Symmachus (498-514). Studien und Texte. München 1993.

Chaim Wirszubski, Libertas as a Political Idea at Rome during the Late Republic and Early Principate, 1950 (repr. Cambridge 1960). 
Michaela Zelzer, Ambrosius von Mailand und das Erbe der klassischen Tradition, WS 100, 1987, 201-226.

Dies., Symmachus, Ambrosius, Hieronymus und das römische Erbe, Studia Patristica 28 (ed. E. A. Livingstone) 1993, 146-157.

Dies., Der Brief in der Spätantike. Überlegungen zu einem literarischen Genos am Beispiel der Briefsammlung des Sidonius Apollinaris, WS 107/8, 1994/5, 541-551.

Dies., Die Briefliteratur, in: Neues Handbuch der Literaturwissenschaft, Bd. 4: Spätantike, 1997, 321-353.

Adolar Zumkeller, OSA, "Propositum " in seinem spezifisch christlichen und theologischen Verständnis bei Augustinus, S. 295-310 in: Homo Spiritalis, Festgabe für Luc Verheijen OSA, Hrg. Cornelius Mayer, Würzburg 1987. 


\section{Indices}

Personen, Sachen und Begriffe

abundantia sermonis $59-61$

,Adel«, siehe origo

Adeodatus 124, 317, 326

Adressatenbezug 1, 7, 83-87, 130, 133f., $153,156,171,197,202,217,219,286$, 295, 299, 325, 329, 339, 349, 373, 377f.

Adynata 107-109, 300

Agapitus 333f., 339, 346, 368f.

Agnella 201f., 270

Agnellus 219, 227 f., 308-310, 314, 328, 337-339

Alico 305-307

ambiguitas 58

Ambrosius (Bischof von Mailand) 34f., $45,50,64$ f., 102, 160 f., 207

Ambrosius (junger Adliger) 52, 86, 114f., $117,261,368$

amicitia 150-157, 172, 174, 202 ff. passim, $214 \mathrm{ff}$. passim, $265 \mathrm{ff}$. passim, $276 \mathrm{f}$., 285,329

Antonius (Mönch in Lérins) $46 \mathrm{f}$.

Apodemia $200 \mathrm{f}$., $218 \mathrm{f}$.

Apoll 78

Apollinaris 325, 361, 369-371

Apronianus 305, 307f.

Aquileia 25, 103f., 211, 217f., 270-273

Arator $73,75,95,105,116-118,130-134$, 188

Archotamia 218f., 270, 365

Arnulf von Lisieux 3, 53, 59, 63

artifex 246, 290

Asturius 274-276

Auftragswerke 33f., 36-38, 43, 45, 82,
Augustinus 97f., 160, 162, 254f., 279f., 354,379

Augustinus, Confessiones 11f., 21, 162

Aurelianus 335-337, 339

(Ausonius in Symmachus-Briefen) 222, $265,268,317 \mathrm{f}, 331$

Avienus 42, 100, 105, 118, 120, 122-124, $199,203,221,230 f ., 235,238-240,242$, $278,281-283,287-290,320-322,328$, 343f., 347-349

Avitus 211, 230, 270-273

Barbara 115, 200

Beatus 52, 86f., 113, 115, 120, 262, 310-313, $363,367,378$

Benedictio cerei $25,43 \mathrm{f}$.

Bischofsamt 38

Boethius 1, 317, 322f., 347, 350-352, 378

brevitas $60 \mathrm{of}$.

Briefe if., 4, 6f., 41-43, 59, 68-71, $118 \mathrm{ff}$. passim

Anreden 41, $139 \mathrm{f}$.

>Briefstil 61, 245-247

Brieftheorie (antike) 140-142, (Forschung) 143-147

,Brieftopik< 9, 141f., 204 ff., 234 ff., 252 ff., 258 ff., $282,307,376$

, Gattung، $136 \mathrm{ff}$.

an Frauen 197-202, 217-219, 230, 242, 270, 286, 299

von Frauen $199 f$.

Funktion 151-154, 172, 196, 203, $204 \mathrm{ff} ., 214 \mathrm{ff}$.

Kategorisierung von Briefen 143-150 
Performance / L'art du paraître 8 , 152-155, 156, 285, 295, 339, 378f., siehe auch: Adressatenbezug, Rollen des Ich

Realien 29, 138-140, 149, 192, 325 >Spiegel der Seele‘ 8, 151, 153-155, $197,290,292 \mathrm{f}$.

,Spielregeln ' 155f., 169, 210, 213-217, 233-238, 252, 261, 285, 315, 330, 361,377

,Wettstreit ‘ 174-176, 177, 179-181, 185, 195f., 374

Caesarius von Arles 165, 189, 351, 352-356

Camella $85-87,117$

,Carmina minora< 44f.

Cassiodor 1, 90, 92, 94, 96, 98, 102, 130, $155,157,165$ f., 210, 256-259, 262, 280

Christliche Bildung 52, 64, 86f., 100 Chronologie der Werke 5, 17-19, 28f., 31,36

Cicero 174, 205, 207, 220, (223), 235, 240, 255f., 283f., 351

Claudian 108, 122, $192 f$.

Constantius 323-325

Constantius (Bischof) 361

>Controversiaes 47f., 117

conversatio 55

copiosa loquacitas 59

Deklamationen 3of., 47f., 123

Demut / Hochmut siehe: humilitas

Deuterius, Lehrer in Mailand 30, 34, 40, $76,104,112,131,167-169,281,317$

Diakonat $6,10,13,15-17,20 f ., 23-25,39$, 64f., 68-70, 72f., 75, 82, 116, 169, 182, $185,187,193,198,201,278-284,288$

Dichtkunst 13, 17, 20, 31, 40, 78f., 84, 100, (Schöpferkraft:) 106-111, (unnütz:) 132, 173-175

dictiones 32f., 120, 123, $126 \mathrm{f}$.

>Dictiones ethicae`47f., 117

,Dictiones sacraer 36-39, 65
>Dictiones scholasticae` 40f., 71-78, 90

Dominator 314-316, 337

Domnica $218 f$.

Domnina $198 \mathrm{f}$.

Empfehlungsschreiben $113 \mathrm{f}$., 148f., 217, 219, 261f., 28of., 286, 297, 306, 338, $346,356-372,377$

Ennodius

als Dichter 13f., $31 \mathrm{ff}$., 40, 45, $63 \mathrm{ff}$., 78f., 81f., 110f., 335

Familie 15, 22, 337, 377

Haus 26, 266, 269, 314, 351f.

Lebenslauf 1, 21-31

als Lehrer 3of., $63,72-78,111$.

Name 21, 39

als patronus / tutor 111-118, 133, 316

als Redner 63ff., 80, 82, siehe auch: Dictiones

Zeit vor dem Diakonat 1,5, 30f., $63-82,93,134,373 f$.

Epiphanius von Pavia 1, 23f., 38, 46f., 91 Epitaph des E. 1, 21f., 27, 50

Epithalamium 50-52

,Eucharisticum $11-20,64,82,134,375$, 379

Eugenes 104, 178, 225, 292f., 346f.

Euprepia 26, 69, 116, 197, 203, 223, 282, 300

Faustus 22, 25, 40, 42, 81, 100, 106f., 109, $114,120-124,128,224,235,238-240$, 243-245, 266, 269, 282f., 298, 300, 308, 346f., 347-349, 362

Firmina 299

Firminus 233

Florianus (Adressat) 69, 184-189, 220, 233

Florianus (Patensohn des E., Abt) 27, 188 Florus 266

Frauen 115, 197-202, 217-219, 270, 286

Fronto 256 
Fürbitte 42, 198f., 202, 241f., 277, 296, 30of., 324, 326, 349, 366

Gallien 190-193, 218, 335, 337, 355, 366

Gelübde 14-21

Gerichtsverfahren $25,232,298$

Glückwunschschreiben $235,286,323$, 329-356, 377

Grammatica 52, 86f.

Heiligenviten 46f.

Helisea 217f., 219, 271

Helpidius $229 f$.

Herkules und Antaeus 179f.

Hieronymus 35, 16of., 206f, 223, 225, $254,256,268,281,304,306,376$

Hochmut / Demut siehe: humilitas

Homer $192 \mathrm{f}$.

Honoratus 231-233

Hormisda 1, 113, 195f., 228f., 233, 293f., $366 \mathrm{f}$.

humilitas (des Diakons) 13f., 16, 19f., 38, 63-68, 70, 74, 81, 84, 125, 175, 177, 183, $187,233,279,288,374$

Hymnen 50

indulgentia 9, 213-217, 222, 285, 376

inportunitas, inpudentia 9, 224-226, $252,277,285 f$., 376

Iulianus $341-343$

Iulius Victor 56, 61, 140f., 256, 285, 329f., 356,376

Johannes (Brief 15) 119, 121, 268

Johannes (Brief 4 , Schwiegersohn des Olybrius) 121, 233, 305

Johannes (Briefe 55, 141) 248-252

'Kanzleistil ‘ 209f., 256-265, 376

Kontaktaufnahme $267,303 \mathrm{ff}$.

Kontaktpflege 149f., 286 ff. passim, 377

Krankheit 13-18, 20, 27, 167f., 199, 232, $234,236-242,294,367$

Laconius 26of., 371

Landwirtschaft, Natur etc. (Bilder) 85 , 112,127 f., 18 of., 283 latinitas $85,193,195$

Laurentius, Bischof von Mailand 1, 21, 24, 36, 38, 45, 65-67, 116, 123, 130f., 240,273

Lazarus 18, 199,

Lehrer 30, 71-73, 76f., 91f., 94, 112, 114, 116, siehe auch: Deuterius

sLibellus de synodor $45 \mathrm{f}$.

Liberius 26, 91, 103f., 269f., 271, 310, 313f., 316

libertas 90-94

Liguria 124, 228, 251, 272, 333, 367

Lob (für Diakon) 14, 16, 20, 38, 66, 75, 176f., $183,185,197$

Lob (für amici) 265-273

Lob vor Dritten 119, 122, 268f., 307f., 358

Luminosus $113 \mathrm{f}$., 170

Lupicinus 116, 300

Marcellus 316

Marcianus 121f.

Mascator 70, 181-184, 233

Maximus 50-52, 105

Meribaudus 114

Messala 112, 120, 124, 239, 286

mixtura verborum $56-58,61$

modestia $65-67,101,176,184 \mathrm{f} ., 227$, 231-234, 288, 296, 307f., 315f., 326f., 328

obscuritas $53-63$

Olybrius 40, 78-80, 102, 121, 178, 225, 230, 245f., 269, 301-303

Opilio 328

origo $\mathbf{8 8 - 9 2 , 9 5 , 1 0 5 , 1 2 0 , 1 2 2 , 1 3 0}$

Pamfronius 344-346, 349

Panegyrici latini 66, 94, 101

Panegyricus Theoderico 49f., 88f., 9o, 101, $159 f$.

Paradox 49, 168, 243, 297, 299, 321f., 344

,Paraenesis didascalica‘ 52f., 86-88, 96-100, 115, 378f. 
Parthenius 74, 77, 95f., 112-114, 116, 124-129, 165, 362-364

Passivus 230, 233, 326f.

Patenschaft 73

Paulinus von Nola 151, 160, 162, 265

perspicuitas $55 \mathrm{f}$., 61

Petrus 334f., 339

Phaethon $78 \mathrm{f}$.

Plinius-Briefe 153, 163f., 174, 205-207, $223,234,256,262,267,270$

Pomerius 69, 165, 189-195, 337

Porcianus 295f.

Praefatio 17of., 182, 187, 243f., 252-265, $293,299,311,313,338,357,365$

praevius sermo $303 \mathrm{ff}$.

Probinus 114, 224, 367f.

Probus $310 f$.

propositum 20, 24, 64, 70, 79f., 167, 176, 186, 229, 241, 275, 277-282, 297, 318f., $333,337,375$

querellae 204, 213f., 217, 222-224, 226-228, 241, 248, 251, 275, 301, 336, et saepe

Quintilian 3, 53-63

Ravenna 232, 243f., 263, 345, 368

Recusationes 78-80, 177-197, 327, 375

Reisegedichte $\mathbf{4 8 f}$.

Reisen 25, 48f., 299

Rezeption 27f., 46

Rhetorica 52f., 83, 86f., 96-100, 100-106, 246, 266f., 301f., 374, 379

Rollen des >Ich «1, 133, 156, 197 ff., 202, 217-219, 285f., 295f., 303f., 317, 325, 329, 339, 349, 356f., 372f., 378

Rom 39, 46, 49, 87, 92f., 114, 124-126, 199, $228,243 f$., 262, 310, 324, 350

Ruricius von Limoges 62, 165, 175, 190, 227,296

rusticitas 227

Schisma (Symmachus - Laurentius) $25 f ., 43,45,(229), 270$
Schule (in Mailand) 40, 83, 94, 131

Schweigen siehe: silentium

Semipelagianismus $26 \mathrm{f}$.

Senarius 203, 220, 263, 290-292, 345f.

Senator (Bischof) 263

Servilio 22

Sidonius Apollinaris 3, 9, 32, 35, 54, 61f., $93,155,162-165,172-175,196$, 225-227, 234, 254, 265, 267, 279f., 284, 304-306, 329f., 356, 375, 379

silentium (des Diakons) 20, 64-70, 74, 79-81, 84, 175, 177, 183, 185-187, 279, 374

simplicitas, sinceritas 195f., 226-230, 241, $246,279,290,298,312,327,337$

Sklaven $25,68,126,210,241,263,371$

Speciosa 197, 273f., 317-319, 322

Sprache und Stil 53-63

Stefania 121f., 199f.

Stephanus (Abt) 295-298

Stephanus (Bischof) 366

Stephanus (Vater des Marcellus) 314, 316f.

Studia liberalia 21, 52f., 63, 65, 69-72, 82111 passim, 183, 193, 316

Syllepse $60 \mathrm{f}$.

Symmachus (Papst) 24f., 95, 113, 231, 262, $270,281,294,360,362-364,366$

Symmachus (Epistolograph) 9, 67, 152, 156-160, 174, 207-209, 210, $212 \mathrm{ff}$. passim, 234 ff., 245 ff., 304 ff., 311 Symmachus (Adressat des E.) 52, $310 \mathrm{f}$.

Theoderich 1, 49, 88-91, 93, 101, 334, 346, 352f., 355, 368

Titel der Werke 29, 52

Tonsur 13, 17

Überlieferung 5, 28, 378

urbanus, urbanitas $79,155 \mathrm{f}$., $187 \mathrm{f}$., 196, 224, 226-230, 247, 251, 271, 274, 287, 289,376

Vater siehe origo, Vorbilder 
Venus und Cupido 5of. Verlobung 15f., 22, 273

Veröffentlichung der Werke 5, 7, 19, 28, $35,41,55,335,378 \mathrm{f}$.
Verstellung siehe urbanitas

St. Victor 14-17

Vorbilder 89f., 95, 105, 112-116, 118, 121 
Textstellen (Nummerierung nach Vogel)

1: $36,56,65 f ., 81$

2: 39,49 , (v.23:) 56f., 84f., $86 f$.

3: 73f., 76-78, 90, 95

4: 121, 221, 233, 305

6: $26,60,224 f ., 238 f$., $283 f$.

7,3f.: 58

8: 43

9: 60, 10of., $235,282,344,347-349$

10: 106,282

11: 15,68

12: $58,61,233,247$

13: $84,121,178-181,230,294$

14: $43 \mathrm{f}$.

15: 118f., 139, 268

16: 219,323

17: $89,122,220 f ., 225,278,288,347$

18: $330,332,333 f ., 339$

19: $240 f$.

20: 69, 184-189, 233, 254

21: $69,176 f$., 184-189, 220

22,1: 209

23: $89,122,288,294$

24: $167-170,281,318$

25: 239

26: $40,81,107,109$,

27: $40,78-80,174$

28,2: 221

29,2: 220,225

30: $58,219,221,263$

31: $274-276$

32: 221,225

33,1: 281

35: $220,318 f$.

36: $273 f$.

38: 221, 253f., 26 of.

39: 69, 189-195

40: 58,233

41: 361

42: 301-303
43: $38 f$.

44: 123

47: 274,276

48: $102,159,245-247$

49: $24,33,45 f$.

51: 43

52: $220,223,300$

53: $284,346,359$

54,1: 98

55: 245, 248-250

59: 358

63: $252,260,313 f$.

64: 231-233

65: $288,320 f$.

66: $254,263 f$.

68,2: 360

69: 73

69,9: 91

71: $68,295-298$

72: 176

74: 326

75: 266, 281, $321 f$.

77,2: 281

78: 231, 29of.,

79: $295 f$.

80: $46 f$.

80,122: 91

81: 43f.,

82: 325

84: $254,282,300$

85: 73, 75f., 92, 116, 131, 133

86: 371

87: 366

89: 211

91,2: 359

93: 357,360

94: $57,74,90,92,98$,

95: 70, 181-184, 233

98: 36 


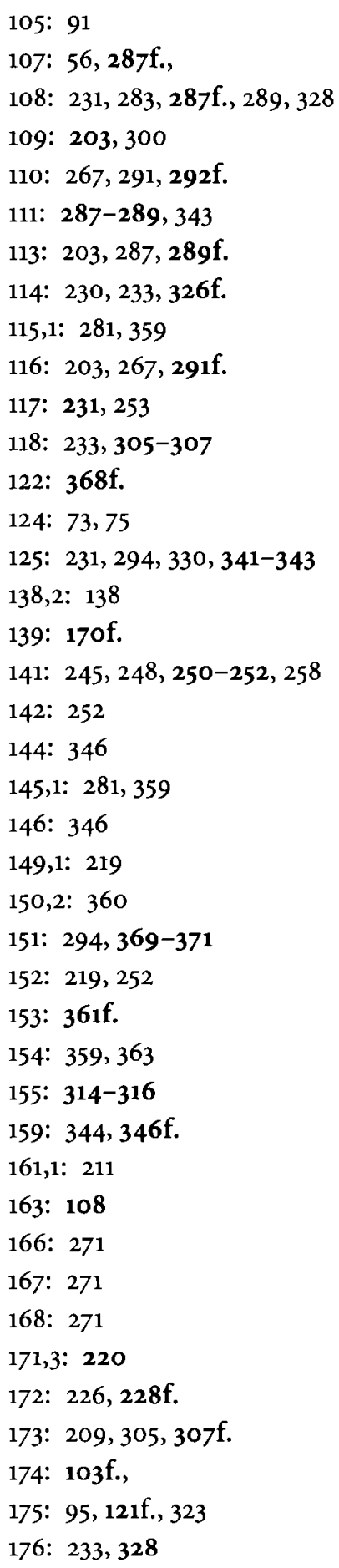

177: $217 f$., 271

178: 211, 271

187: 110

208,v.1: 92

210: 21, 65,

213: 104

214: 37

219: 69,300

224: 330, 332, 334f., 339

225-228: 113

225: 360,362

226: $57,95,360,362 f$.

235,2: 26

236: 22

237: 131

239: 131

240: $46 f$.

242: $58,344-346,349$

243: 131

245: $48 f$.

246: $243 f$.

247: 125

248: 271f.

249: $268,270,272 f$.

251: $209,322,323-325,332$

258: 125

259,1: 360

263: 49f., 90, 92, 101

264: 109

267: 131

268: 226,300

269,1: 241f.,

274,2: 359

277: 37

280,1: 281, 359

282,1: 360

283,1: 211

285: 198, 217 f.

286: 243

290: $126 \mathrm{f}$.

291: 217f., 360, 365 
292,1: 81

293: 26, 254, 300

295,1: 264

296,2: 211

299: 123

301,2: 26

302: 198f.,

303,1: 258

304: 220,225

305: 299f.,

307: 243,346

309: 227f.,

312: 226, $229 f$.

313: $267,300 f$.

314: 123

316: 219

317: 195f., 233

319: 198, 211, 270

320: 95

321: $330,332,337 f ., 339,360$

322: $253,330,332,337,338 f$.

323: 60,240

327: 91

334,2: 278

335,2: 90

336: 27,38

339: 350,378

357: 210, 314, $316 f$.

358: 310-312

360: 57, 268, 310-314

361,2: 310

$363,2: 226$

368: 128

369: $128 f$.

370: $344,347,350-352$

371,1: 21

376: $105,118,243$

377: 120

378: 131

380: 131

387: 105, 131f.,
380: 117

382: 242f.

383,2: 242

384: 177

385: 286f.

387: 118, 139

388: 50-52

389: 266

391: 241

393: 18, 200, 242

394: 18, 198, 199f., 242

395,1: 360

397: 211

398: 313

401: 18,242

402: 18,242

403: 242

404: 242

405: $87,312,378$

407,1: 18

409: $90,113,363$

410: 113

411: $295 f$.

412,3: 335

413: 322f.

416: $113,262,357,360,363$

417: 113, 366f.

420,1: $239 f$.

422: 130-134

423: $48 \mathrm{f}$.

424: 114, 117, 359

425: 114, 117, 261, 359

426: 114, 117, 224, 367f.

427: 293f.

428: 120

430: $117 f$.

431: 84-87, 117

434: 120, 294

438: 11-20

439: $198 \mathrm{f}$.

440,1: 278 
441: 198, 20of., 217f., 278

442,3: 200

443: $308-310$

444,1: 357

446,1: 60

447: 26, 91, 139, 269f.,

448,1: 209

449: 60, 198, 201f., 270

451: $73,86-88$

452: 52f., 87f., 97-100, 115, 174, 378f.
455: $222,227,231,252,330,332,335-337$,

339

456,1: 61

457,4: 61

459: 330,343 f.

460: 124

461: $344,352-356$

463: 344

464: 43

468: $59 f$., 220 
